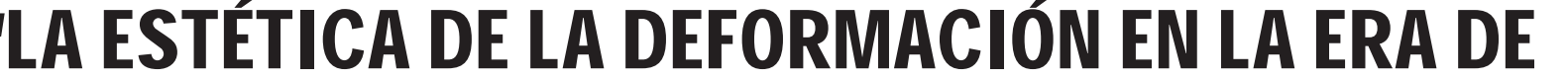

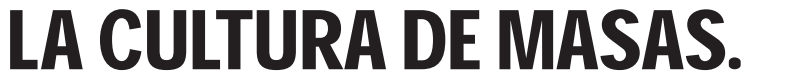

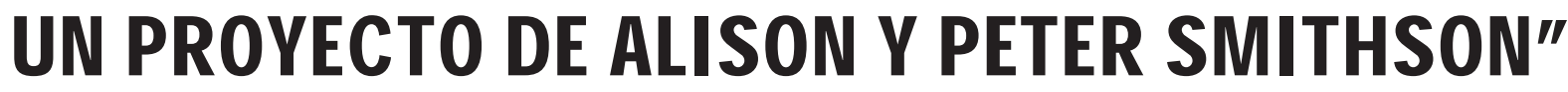

TESIS DOCTORAL

Esteban Herrero Cantalapiedra

año 2016

DIRECTOR DE TESIS

Ginés Garrido Colmenero 



\section{DEDICATORIA}

Quiero mostrar mi agradecimiento a todos los que han arrimado el hombro, algunos desde la más estrecha amistad, Félix Moyano y su maqueta sorpresa, Pepe Coca resolviendo al instante los últimos escollos, Helena Serna consiguiendo imposibles (el Astounding Science Fiction de Marzo del 54), a Álvaro Aparicio, a Mamen Escudero, al colectivo Berlinescas, Virginia, Ruth y José Antonio, a Javier Bustamante.

A los profesores Peter Blundell Jones y Peter Carolin por colaborar desde Inglaterra en mucho más de lo que les pedía.

A Inés Zalduendo de la Loeb Library.

A Matthew Zawadzki, del Archivo de la Universidad de Sheffield.

A Justine Sambrook del Archivo del RIBA

A la familia Voelcker por responder cordialmente a mis correos.

A los miembros de Tribunal de Prelectura, los profesores Rojo, Herreros y Ulargui por dar el pase al esbozo que les presenté. Sin su apoyo con ese gesto la Tesis hubiera encallado para siempre.

A Ana Amo y Pablo Cabrera porque la tesis les ha caído en medio del nacimiento de su hijo Martín.

Especialmente a mi Director Ginés Garrido.

A Federico Herrero por poner en lengua inglesa lo que mandaba a Inglaterra y castellanizar lo que venía de vuelta y ser el intérprete de lujo.

Quiero dedicar el tiempo empleado a Josenia Hervás, y restablecérselo y porque ella sabía mejor que yo que sí se podía. A Olga, la voluntad de hierro de los Herrero. Y a Federico le dedico los conocimientos que he adquirido, que seguro los aprovechará en lo que crea oportuno. 



\section{ÍNDICE}

INTRODUCCIÓN

\section{CAPÍTULO I: LA IMAGEN DE LA DEFORMACIÓN}

1.1. BANHAM Y EL NUEVO BRUTALISMO: IMAGEN O DEFORMACIÓN

1.2. EL NUEVO BRUTALISMO: LA NOTORIEDAD DE LA IMAGEN

1.3. MICHEL TAPIÉ Y EL INFORMALISMO

1.4. DEFORMACIÓN COMO EXPRESIÓN DE UN CAMBIO BIOLÓGICO

1.5. LA VARIEDAD Y LO PARTICULAR

1.6. LA RECTA. INTUICIÓN Y MÉTRICA

1.7. CONCEPTO DE VARIEDAD EN RIEMANN

1.8. CONCEPTO DE ESPECIE Y VARIEDAD. DARWIN Y LA MONSTRUOSIDAD

1.9. EMOCION Y MATERIA: DOS VARIABLES SINCRONIZADAS

1.10. TRANSFORMACIÓN O DEFORMACIÓN. LOS TIPOS ESPACIALES DE CARNAP

\section{CAPÍTULO II: EL ESTIRAMIENTO}

2.1. MÉTODO DINÁMICO. JUSTIFICACIÓN DEL MÉTODO

2.2. LA CONVOCATORIA DEL CONCURSO: EL OBJETO DEL CONCURSO

2.3. DOS FORMAS IRREDUCTIBLES

2.4. LA FORMA REGIDA POR EL PRINCIPIO DE POSICIÓN

2.5. LA FORMA REGIDA POR EL PRINCIPIO DE TRANSICIÓN

2.6. EL PRECEDENTE DE UNWIN. EL CLOSE

2.7. EL CLUSTER

2.8. CÓMO CONSTRUIR TRES CASAS. EL CLUSTER AMERICANO Y EL BRITÁNICO

2.9. PSICOLOGISMO O SOCIOLOGISMO

2.10. CLUSTER, CLOSE Y CAPOGROSSI

2.11. SHEFFIELD EN DOS PROYECTOS RIVALES

\section{CAPÍTULO III: OBJETO Y SUJETO}

3.1. WITTKOWER

3.2. ENDLESS ARCHITECTURE

3.3. PITAGORISMO

3.4. APLICACIÓN DE LA SERIE DEL CUADRADO EN EL ECONOMIST BUILDING

3.5. PANOFSKY

3.6. HACIA LA ABOLICIÓN DEL ESPACIO

CAPÍTULO IV: CONCLUSIONES

CAPÍTULO V: ANEXO DE DIBUJOS

BIBLIOGRAFÍA 


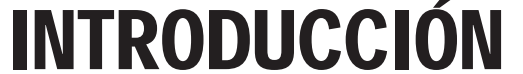

La obra de Alison y Peter Smithson esta conformada desde su inicio precisamente por la particularidad de que en ella intervienen tanto Alison Margaret Gill como Peter Denham Smithson. El proyecto objeto de la Tesis, el concurso de 1953 para la ampliación de la Universidad de Sheffield, se estima tras su examen, que está compuesto de dos partes diferentes y que su unidad lo que provoca es un extraño efecto como imagen.

La dualidad es una agregación binaria que forma una unidad. Me he referido a que Sheffield esta compuesto de dos partes, pero debería haber dicho que está compuesto de dos tensiones, para dejar claro que no es la mera unión de dos formas diferentes como dos extremidades que penden de un mismo cuerpo. Quede claro así, de entrada, que las dos partes son de naturaleza diferente y que es precisamente la naturaleza de cada una de ellas el objeto del que se va ocupar el presente trabajo.

Por otro lado, la dualidad vista en retrospectiva, que es el modo de hacer habitualmente las introducciones, no se planteó como premisa. Surgió como he dicho al examinar el proyecto. Quiero decir con esto, que habrá quien considere que Sheffield (a partir de ahora y para el resto del texto con Sheffield me referiré exclusivamente al proyecto de Alison y Peter Smithson) puede descomponerse de otras maneras, o que incluso, no la considere descompuesta, sino como una unidad inorgánica pura; un mero elemento.

En 1696 Leibniz le dijo a la princesa electora Sofía que en algo tan puntual y homogéneo como una gota de agua, vista al microscopio, resulta haber más de un millón de animales vivos. Habrá por tanto que convencer desde esta Tesis a la princesa o princesas que la gota efectivamente, contrariamente a su apariencia, es en realidad un agregado de formas vivas que tensionan independientemente unas de las otras.

Puedo contabilizar hasta tres planteamientos unitarios.

El primero se refiere a los arquitectos. Alison Margaret Gill y Peter Denham Smithson eran dos arquitectos. Así dicho suena a obviedad. Pero su producción siempre ha sido considerada en el formato de unidad proyectual. Se llega incluso a referirse a ellos, para 
no repetir ni sus nombres, de una forma más puntual todavía como los Smithson. Error en el que yo también habré caído en más de una ocasión a lo largo de estas páginas.

En unas notas que escribí hace años ya, contemplaba en una sus últimas obras conjuntas, antes de que muriera Alison M. Smithson, un tipo de dualidad presente de otra manera. Se trataba de la Hexenhaus, una serie de ampliaciones construidas para Axel Bruchhäuser en una antigua casa de su propiedad, situada en un paraje boscoso. Decía en estas notas, que Peter D. Smithson al aportar él las fotografías sobre el proyecto realizado por su mujer, había de alguna manera transformado la visión de cómo tenía que considerarse la construcción. Exponía que había una transferencia creativa que se podía expresar como un corrimiento entre un primer momento propuesto bajo una formaespacio (el momento correspondiente al proyecto de Alison M.) a otro del tipo materia-tiempo (las fotografías de Peter D.). En tanto la una construía una nueva realidad, el otro simultáneamente operaba sobre la percepción de esta realidad. Este entretejido creativo, esta forma complementaria de operar obligaba a no desechar el documento fotográfico. Las fotografías de Peter D. Smithson, decía, retroceden la construcción a sus componentes en un camino de vuelta. Al contrario que las fotografías que muestran cómo es la construcción o la forma final tras la intervención sobre la casa original de Axel, las fotografías de Peter D. estaban más por deslizarse hacia el lado de la textura que hacia la forma espacial. En un comentario retrospectivo, Peter D. Smithson gustaba en recrearse en los siguientes términos “...árboles y porche desnudos de hojas, árboles y porche modelados por hojas... con nieve, sol, lluvia o viento" ${ }^{1}$. Y esta preocupación por instalarse en el tiempo le llevaba casi a justificar que "el porche se construyó... como si fuese una parte construida del bosque, aunque una de sus ramas no pueda seguir el curso de las estaciones" ${ }^{2}$.

El interés del encuadre de las fotografías vendría a fusionar el material constructivo del proyecto, el entramado de madera del porche, en una formulación de orden superior, donde no habría ánimo de precisar si pertenecían a las carpinterías o a los pies derechos. De esta manera quedaban como esparcidas en el mundo natural de troncos y ramas del bosque, envolviéndose todo en esta nueva unidad superior y arrebatando a la construcción su naturaleza diferenciadora y excluyente, que la tiende a individualizar del entorno. Por tanto, las fotografías tenían la función de deshacer el proceso constructivo llevado a cabo por Alison M. Smithson. Así, entendía yo que operaba conjuntamente la aparente unidad Alison y Peter Smithson; con ciertas tensiones internas.

El segundo planteamiento unitario que he observado se encuentra en el modo que tiene Banham de encarar el proyecto de Sheffield. Se refiere a la imagen perturbadora del proyecto, sin entrar a precisar si la imagen unifica o por el contrario se limita trasladar ya una unidad visual en sí misma. De este segundo sentido, se deduce que, cuando dice que no se trata de un proyecto aconconceptual y que es demostrable que existe una composición, parece dar a entender que la composición afecta por igual a toda la extensión del proyecto. Añade que la composición es topológica, aunque insisto, ello no modifica que el proyecto deba entenderse como un compuesto, sino que parece indicar únicamente que la topología es la guía compositiva del proyecto completo.

1 Marco Vidotto, “Alison + Peter Smithson, p. 204

2 Ibíd. 
$\mathrm{Y}$, en tercer lugar hay otro planteamiento unitario, en este caso, montado sobre la situación de homogeneidad teórica instalada en Gran Bretaña a primeros de los 50 e impuesta desde la obra de Rudolf Wittkower "Los Fundamentos de la Arquitectura en la Edad del Humanismo". Ante la doctrina de la unidad del edifico basada en la observancia ciega del método proporcional resulta difícil mantener la dualidad de Sheffield. La obligación que se traza esta Tesis es remontar a los orígenes las cosas que en ella se tratan, y en este caso, que envuelve al Capítulo III, entrar en las fuentes del principio proporcional. Se descubren así los fundamentos de la proporción aritmética y geométrica en el seno del pitagorismo, sus problemas y su evolución. La postura de los dos arquitectos frente a Wittkower es de admiración, pero también de libertad, como intentaré ir paulatinamente desgranando. Esta libertad suya frente al contexto teórico en que les toca vivir es la que defiende la Tesis.

Por otra parte, las continuas introducciones en debates de orden filosófico requieren una explicación. He procurado no dar absolutamente nada por sabido, problema en el que yo también me he visto envuelto. Las alusiones a Leibniz, Bergson, Riemann, Pitágoras, etc. forman parte de mi propia desconocimiento sobre esta cuestiones al intentar comprender qué hay detrás de la teoría proporcional de Wittkower o del Art Autre de Michel Tapié.

Sobre éste último, por ejemplo, dice él mismo de las obras que integran el Art Autre, que algunos rasgos se puede presentar a la luz de conceptos que extrae de Riemann, matemático del s. XIX, introductor de una nueva geometría. La Tesis descubre en Riemann el concepto de la variedad continua, un conjunto, cuyos elementos pueden recorrer la extensión de la variedad mediante una deformación continua, diluyéndose unos en otros sin cortes entre sí. Los ejemplos del informalismo serían, por tanto, los puntos de la variedad, formas inestables o detenciones aleatorias en este transitar continuo de un mismo objeto. Así, la condición de memorabilidad (el argumento que defiende Banham para Sheffield) viene dada precisamente por el impacto que supone ver cuerpos en estado evolutivo, deformados y sin presentar los contornos de una forma precisa. Bien, la alusión a los cortes en una evolución continua vuelve a surgir al final del Capítulo III, cuando se introduce a Bergson para apoyar el Principio de Transición continua que propugna Leibniz.

Por otro lado el sentido evolutivo que se puede asociar a los elementos de una variedad entra en consonancia con una variedad de estados en evolución en el marco de las especies orgánicas. No sólo como individuo sino también como especie. La coincidencia no sólo es formal, también es temporal entre el descubrimiento de Riemann del concepto de variedad continua y el de Darwin de la evolución de las especies. Ve Darwin, que algunos ejemplares presentan en su cuerpo conformaciones normales de especies diferentes, lo que puede entenderse como una anormalidad o defecto evolutivo, lo que él llama $<<$ monstruosidad $>>$.

Lo peculiar que expone Darwin, es que la monstruosidad puede ser provocada artificialmente por motivos estéticos, como ocurre en determinados animales o plantas ornamentales.

Bien, esto es exactamente lo que descubre la Tesis en el proyecto de Sheffield. 
La unión en un solo proyecto de dos conformaciones de naturaleza diferente, donde una no es la deformación de la otra, sino que son irreductibles entre sí.

El Capítulo II indaga en la naturaleza dual de Sheffield. Y la descubre en la aplicación de dos principios que tienen múltiples derivas, pero interesante en una en particular, referida al espacio. Uno es el Principio de Posición. Bajo él se contempla la situación del concurso dada en su globalidad, en una visión totalizadora que permite buscar y destacar posiciones singulares y tener un control preciso del proyecto desde el inicio. Se dice, que es la opción normal en arquitectura comprender el espacio en su conjunto y que el trazado de ejes y el reparto del espacio obedecen a este principio. Son así vistos la propuesta ganadora del equipo GMW y fundamentalmente el trazado de ejes en Le Corbusier. Una parte de Sheffield es un producto típico de este modo de proceder. Hay un segundo principio que es el Principio de Transición Continua. En los términos expuestos para la variedad de Riemann, sería como si en lugar de ver cuerpos en estados concretos, por deformados que pudieran ser, nos introdujéramos dentro de la propia variedad, acoplándonos al curso de la evolución misma, en un acto de unión interior con la marcha de la evolución. Para ejercer esta acción se toma como punto inicial el extremo del edificio universitario existente, el Firth Court, y se lleva cabo un estiramiento continuo. En esto radica lo que la Tesis distingue como la ampliación, el cuerpo que se enrosca paulatinamente. Para exponer este concepto, la Tesis se apoya en un ejercicio llevado a cabo por Raymond Unwin en Hampstead, el close, o estiramiento lateral del borde de un viario para hacer surgir el espacio útil residencial. A partir del concepto de close, queda derivo en la urbanística americana de principios del s. XX el concepto de cluster, que pasa a ser uno de los argumentos principales de la teoría Alison M. y de Peter D. Smithson en los años 50.

Cotejando lo que da de sí la arquitectura basada en los principios proporcionales con otra arquitectura estancada en el paso del Renacimiento al Barroco como es la arquitectura perspectiva y proyectiva, la arquitectura oblicua, recuperada a la sazón por medio de la intervención en la Tesis de Panofsky, se dirimen aspectos colaterales pero fundamentales de una renovación de los planteamientos: hay planteamientos que se dicen esencialistas y objetivos y otros funcionales y que derivan en subjetivos y relacionales. Sobre estas dos marcos de categorías el propósito que persigue la Tesis es dar cuenta de los dos principios que rigen lo visto en el Capítulo II, el Principio de Posición y el Principio de Transición Continua, responsables ambos, al $50 \%$, de la monstruosidad detectada en Sheffield, que no es negativa, sino, como decía Darwin, la combinación en un solo cuerpo de conformaciones normales en animales de especies diferentes, incluso con fines estéticos.

En definitiva, lo que la Tesis pretende mostrar, es que Sheffield, como una gota de agua vista al microscopio, es un compuesto, no de un millón, pero sí de dos organismos diferentes.

Pero en Sheffield existía ya, y estaba dibujada literalmente esta analogía: hay un doble rostro en una sola cabeza. Todo el trabajo de la Tesis se encamina, o ese es su deseo, a explicar, con toda la claridad y extensión que me ha sido posible, en qué consiste ese doble rostro que estaba ya dibujado en el proyecto desde 1953. 


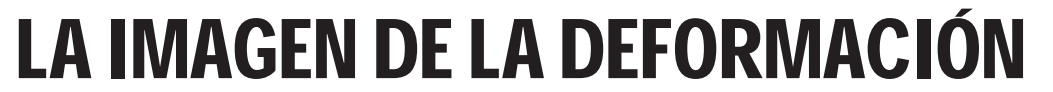

\subsection{BANHAM Y EL NUEVO BRUTALISMO: IMAGEN O DEFORMACIÓN}

En un artículo de 1999, introduje el término deformación para tratar sobre el proyecto de Sheffield. Como estaba en la órbita de Banham, sobre todo en la de su artículo "The New Brutalism"1, el título de mi artículo, "La Imagen de la Deformación" ${ }^{2}$, ofrecía al concepto de imagen, introducido por Banham, el que se introdujera para completarlo, particularmente para el proyecto de Sheffield, la referencia a la deformación. La imagen que nos viene al recuerdo al citar Sheffield, vendría a decir el artículo, no es el objeto en sí, sino una deformación, como si cuando imaginamos una nariz torcida no vemos la nariz sino la torcedura. Esencialmente Sheffield constituía en este artículo una deformación, y este modo de aparecerse como deformación es lo que ofrecía la posibilidad de convertirse en imagen al producir un cierto cambio de estado emocional en el observador.

Si la condición de ser de una imagen es la de estar instalada en la memoria, el motivo por el cual la visión ocular del dibujo de Sheffield alcanzaba el privilegio de ser recordada y elevada al presente como imagen tendría que residir en el hecho de ejercer alguna fractura sobre la conciencia. A esta facultad de provocar un sobresalto es a lo que me refería con deformación.

El modo de proceder de la deformación reside en su inestabilidad formal. Thom lo expresa como una bifurcación receptiva:

"Esas formas inestables son, en el espacio Y que consideramos antes, formas de bifurcación; su punto representativo está situado en el umbral entre dos o varias cuencas de atractores adyacentes sin llegar a decidirse. De ello resulta para el observador un estado de malestar, de angustia; los pintores de la escuela surrealista conocían bien esos efectos que explotaron abundantemente." ${ }^{3}$

Banham aunque parecía sugerirlo, no se refería en ningún momento a la deformación. Había introducido el concepto de Imagen como atributo para definir concretamente Sheffield y distinguirlo así de

1 Reyner Banham, "The New Brutalism", Architectural Review, Diciembre 1955

2 “La Imagen de la Deformación”, Metalocus 03, Año 1/1999

3 René Thom “Estabilidad Estructural y Morfogénesis”, p. 38 
otros edificios brutalistas. Y sugería a su vez para Imagen una definición muy próxima a la de imagen producida por la deformación: imagen que perturba, que afecta a las emociones, que describe el antiarte, que se usa en el sentido de antibelleza, ${ }^{4}$ pero no terminaba por proponer la deformación para resumir con una palabra un concepto que bordeaba en todo momento. La deformación podría resumirse también como un acto de desviación de la norma que, usando palabras de Bataille, es "algo cuya esencia es una alteración que nos llena de zozobra" ${ }^{5}$

\section{EL NUEVO BRUTALISMO LA NOTORIEDAD DE LA IMAGEN}

1.2.

Reyner Banham, para recoger el proyecto de Sheffield, tuvo que retocar las bases del criterio de selección que establecían la pertenencia de un edificio a la corriente brutalista. El primer criterio que estableció proponía las siguientes tres condiciones:

Legibilidad formal del proyecto

Exposición clara de la estructura

Valoración de los materiales por sus cualidades inherentes $<<$ tal como son $>>$.

Confiesa Banham que este criterio quedó establecido conforme a las propiedades que ofrecía el recién acabado edificio de Hunstanton.

Sin embargo con el fin de incorporar Sheffiled en el anterior criterio se sustituyó legibilidad formal del proyecto por $<<$ notoriedad en cuanto imagen>> .

El problema que había observado en la condición de la legibilidad formal del proyecto parecía residir en la cantidad de edificios que se colaban por este filtro sin necesidad de que se consideraran como brutalistas. Por legibilidad formal alude Banham a un estado de coherencia entre la composición espacial de la forma y el entendimiento funcional de esta forma. Digamos un acople entre la forma y la función basado en la inmediata comprensión de ambas partes recíprocamente, y por tanto, no sólo en el sentido de la forma como consecuencia de la función, sino también de la forma como instrumento regulador del funcionamiento del edificio.

Pero, a su vez, el término forma le plantea el problema del formalismo, que le arrincona a seleccionar aquellos edificios cuya disposición de las partes (normalmente en planta) se haga en términos de una composición por medio de formas puras, simétricas y acabadas. La necesidad de potenciar la legibilidad formal para dejar atrás los edificios no propiamente brutalistas que se acogían a este criterio, le lleva a Banham a mover un paso más allá la legibilidad formal y acuña el término imagen. En principio, la legibilidad formal afecta a que el edificio sea una entidad visual inmediatamente aprehensible $y$, en combinación con el funcionamiento, se constituya en un método de validación de éste a través de la experiencia del edificio en su uso real. Ahora bien, el empleo del término imagen conlleva que esa entidad visual, esa forma captada ocularmente, pase a registrarse en la memoria. La memoria está implícita en la facultad de ser de la imagen.

4 Reyner Banham Ibid

5 Georges Bataille, "El Erotismo", p. 17 
Lo dice Ortega de la siguiente manera: "Pero las visiones oculares, al fenecer, dejan en nuestra mente sus <<dobles $>$, que son las imágenes" ${ }^{\prime \prime}$. Bergson por su parte interpone a la imagen el esquema. Podría tratarse el esquema de Bergson como la imagen de Ortega, en cuanto esquema para uno e imagen para el otro tienen una cualidad transformista que las distingue de la visión ocular, precisa y fija y sobre la que "tenemos poco poder". ${ }^{7}$ En cualquier caso, la facultad de la imagen reside en la variación de un estado de conciencia sobre el anterior a modo de salto ejercido por sobresalto. La memorabilidad, que es la cualidad que suma Banham a la legibilidad formal ha de residir por tanto en algún tipo de afectación al espíritu: "La Imagen podría definirse como quod visum perturbat ${ }^{8}$-lo que al ser visto, afecta a las emociones-“

Así pues, la primera condición del criterio del edificio brutalista pasa por que la coherencia del binomio forma-función sea además lo suficientemente intensa en lo visual como para producir en un receptor un cambio de atención al contemplar un edificio, requerimiento que le exige el objeto a la conciencia.

Ciertamente se ha dado un paso adelante al establecer la memorabilidad de la imagen como condición del brutalismo. Sin embargo no se ha deshecho el binomio anterior. Banham necesita introducir el concepto del Informalismo para tratar Sheffield. La cuestión que suscita es, por tanto, si el Informalismo es capaz de producir un impacto visual comparable al formalismo. Si existe, en definitivas cuentas, un segundo tipo de imagen, la imagen del Informalismo.

La cuestión, por tanto, que ha de preocuparnos es saber a qué se refiere el Informalismo.

\subsection{MICHEL TAPIÉ Y EL INFORMALISMO}

El recorrido que establece Banham en el artículo el Nuevo Brutalismo entre la forma y lo informal, o entre sus planteamientos correlativos de legibilidad de la forma y notoriedad como imagen lo plantea en el sentido de adoptar para la arquitectura las claves expuestas por Tapié en su libro Un Art Autre publicado en 1952.

Tapié maneja dos claves que a mi juicio establecen la condición del art autre: la forma trascendente y el devenir en el sentido creador. Es posible que Banham decidiera adoptar la condición de la imagen para establecer un paralelismo al sentido trascendente que propone Tapié para la forma. El sentido de forma trascendente que recorre las páginas de "Un Art Autre" no es propiamente el de la forma congelada que resulta de la visión, sino el sentido de transformismo al que aluden las palabras de Ortega acerca de la vivacidad de la imagen, y que, como señalábamos, correspondería al sentido de esquema (mental) propuesto por Bergson coma antesala de la fijación en la conciencia de la imagen.

La imagen para Ortega como producto de la <<visión interior >>

\footnotetext{
6 Ortega y Gasset “La Idea de Principio en Leibniz", p. 100

7 Ibid, p. 100

8 Reyner Banham, "The New Brutalism"
} 
o sea un registro atenuado del objeto capturado por la visión, tiene, a su juicio, ciertas ventajas e inconvenientes sobre el objeto ofrecido por la visión. La imagen del objeto, pierde detalles en relación al objeto. A cambio gana lo que podemos considerar como un primer acercamiento a la variedad. Esto es, la imagen, las imágenes, "dentro de ciertos límites están a nuestra disposición en todo momento; podemos suscitarlas, podemos modificarlas, descomponiendo sus formas y ayuntándolas a voluntad dentro de esos límites; en suma, transformarlas. La imaginación es el reino del transformismo o metamorfosis..."

En términos similares, decíamos, se refería Bergson al papel que juega el esquema dentro del sistema formado por la representación (en la conciencia) y la imagen: "El esquema mental...se define en función de imágenes, reales o posibles. Consiste en una espera de imágenes, en una actitud intelectual destinada unas veces a preparar la llegada de una cierta imagen precisa, como en el caso de la memoria, otras a organizar un juego más o menos prolongado entre las imágenes capaces de venir a insertarse en él, como en el caso de la imaginación creadora. Es al estado abierto lo que la imagen al estado cerrado. Presenta en términos de devenir, dinámicamente, lo que las imágenes nos dan como completamente hecho, en estado estático. Presente y actuando en el trabajo de evocación de las imágenes, se borra y desaparece tras las imágenes una vez evocadas, pues ha terminado su obra. La imagen de contornos fijos dibuja lo que ha sido." ${ }^{10}$

Lo reseñable en ambos casos, superando las diferencias de definición entre Ortega y Bergson, es precisamente la sensación de ofrecer distintas posibilidades a la visión, interior o exterior, que transmite la imagen y el esquema y que las acercan a la inestabilidad formal citada por Thom. La transformación señalada por Ortega y la capacidad de convocar diferentes imágenes por parte del esquema tienen el mismo sentido de quedar referidas a una variedad, por encima del sentido cerrado, formal, que atribuyen uno y otro al órgano superior, la visión ocular del objeto y la imagen de contornos fijos.

Este es el sentido que me atrevo a atribuir a la forma trascendente de Tapié: la forma informal que abarca una variedad posibles de representaciones. $Y$ el sentido de devenir que adopta Tapié es el sentido que transmite Bergson de estado continuo fluctuante.

\section{DEFORMACIÓN COMO EXPRESIÓN DE UN CAMBIO BIOLOGICO}

La referencia a la metamorfosis como posibilidad plena de conjugar una imagen y la referencia al devenir como fuerza creadora ya están presentes para Goethe bajo el sentido de la transformación entre las especies biológicas. El sentido incipiente de oposición entre la variedad y la forma estable quedaba recogido por Goethe bajo el signo de la deformación:

"Si sólo nos fijamos en lo regulado, llegamos a pensar que necesariamente tiene que ser así, que las cosas se hallan determinadas así desde siempre y son, por tanto, estacionarias. Pero si nos fijamos en las desviaciones, las deformaciones y las formas torcidas y monstruosas,

9 Ortega Y Gasset, Ibid., p. 100

10 Henri Bergson "Memoria y Vida. Textos escogidos por Gilles Deleuze" p. 73 
LÁMINA I.1

LÁMINA 1.2 nos damos cuenta de que, aunque la regla sea fija y eterna, es, al mismo tiempo, una regla viva: de que los seres pueden transformarse hasta lo informe, no por obra de la regla, ciertamente, pero sí dentro de ella y que, en todo caso, no tienen más remedio que reconocer, aunque sea a regañadientes, el imperio inexorable de la ley"11

El catálogo de reproducciones que muestra Tapié en "Un Art Autre" esta lleno de formas biológicas que no se refieren a un ser biológico particular. El elemento expresivo, estético, se alza por encima de las formas que se identifican con individuos concretos para transformarse en simples semejanzas con estos. Estas formas trascendentes son imágenes en el sentido abierto por Ortega. O son la antesala de la imagen, el esquema al que se refiere Bergson. Recuerdan a algunas formas sin llegar a ser ninguna reconocible en concreto. Es la semejanza y no la identidad lo que capta el artista y lo que se empeña en estimular es una asociación entre imágenes.

Hasta el campo de la arquitectura llega el eco del de la semejanza biológica. A Banham se le escapa esta faceta adherida a la imagen. No es sólo que la facultad de la imagen sea la de instalarse en el recuerdo, sino también que acuda a la conciencia por semejanza. Al observar Sheffield, los Smithson asemejan su imagen con la de una serpiente atravesada por una lanza. Al observar el proyecto de la Embajada Británica en Brasilia les recuerda a un cocodrilo curvado sobre el terreno. Esta suerte de asociación con la forma orgánica revela parte del poder de la imagen.

\subsection{LA VARIEDAD Y LO PARTICULAR}

Sin embargo para Tapié, la obra de los artistas tampoco constituye en sí una deformación. Tapié no se instala en los extremos definidos por la forma y la deformada, sino en toda la extensión del recorrido que media entre ambas. La cualidad del Informalismo no es presentarse como una deformación, en el sentido observado por Goethe, como un representante más o menos alejado del ser sujeto a la regla, ni siquiera en el extremo de lo absolutamente informe. Para el Informalismo lo verdaderamente interesante viene a ser la ausencia de jerarquía entre la forma y la deformada. Para el Informalismo tanto un caso como el otro son ejercicios particulares. Es más, es lo informe el caso general y la forma un subproducto particular. En este sentido la forma nítida no se revela más que como un instante particular en la transición continua del devenir. Como en el esquema de Bergson todo un abanico de posibles imágenes están a la espera de ser reclamadas por el esquema. Ninguna tiene más derecho que otra a alzarse sobre una posición de supremacía.

En efecto, dentro del campo de la estética clásica la concepción de la belleza que se manifiesta bajo la simetría, la proporción, y un cierto sentido en el ordenamiento de las partes sería apropiada para un criterio particular basado en algunas relaciones geométricas ya conocidas desde el Renacimiento. Y sin embargo, la certidumbre en este criterio, queda sustituido en el Informalismo por un concepto de belleza, para el cual, de entre todas las "bellezas posibles", esta

11 Goethe: Principes de Philosophie", recogido por Ernst Cassirer "El Problema del Conocimiento. Volumen IV", p. 174 


\section{LÁMINA I.1}

"Un Art Autre: formas que no se refieren a un ser biológico particular..."

Imágenes recogidas en el libro: Michel Tapié, “Un Art Autre“, 1952.

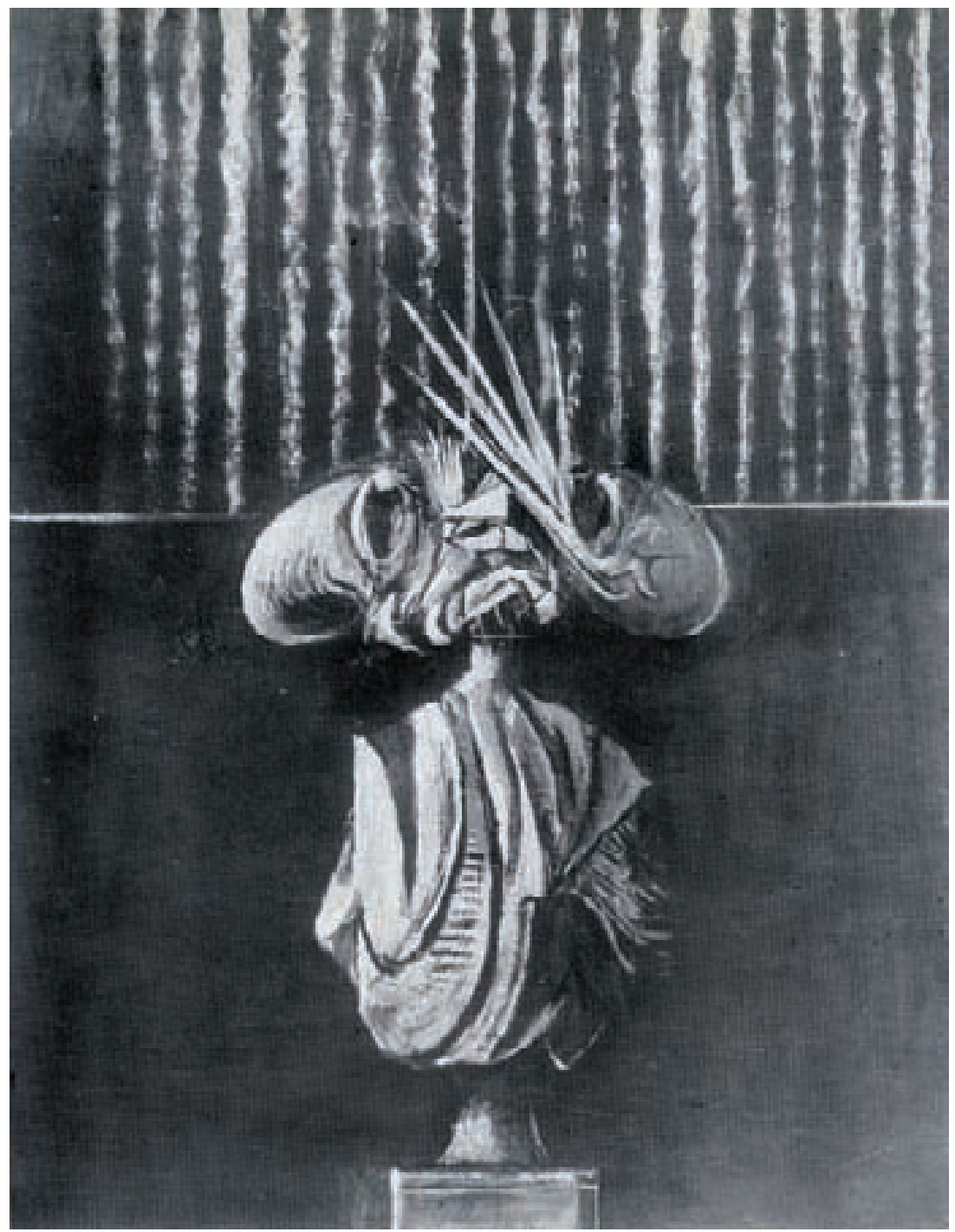

Sutherland, "Head", 1952 


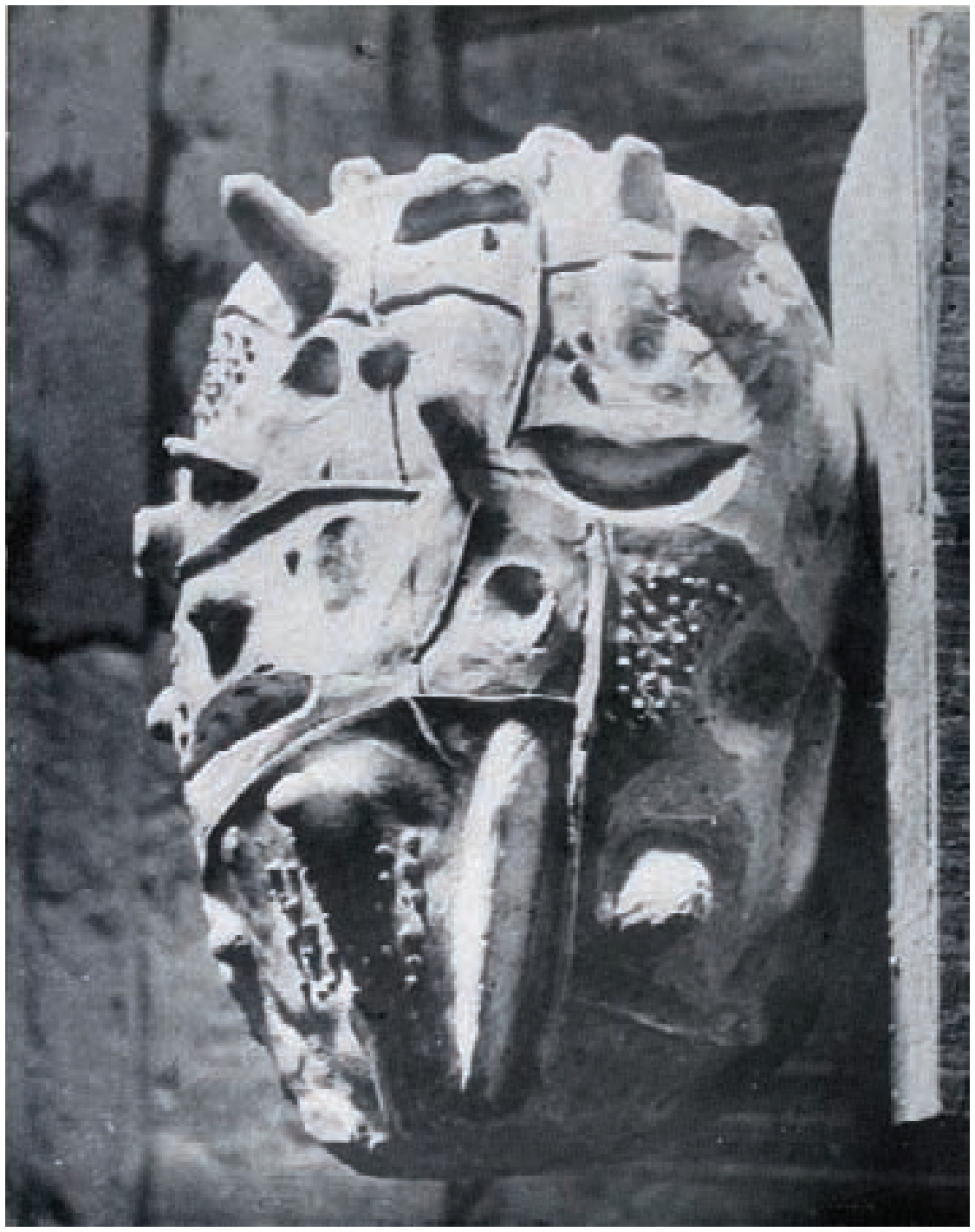

Paolozzi, “Concrete”, 1951 


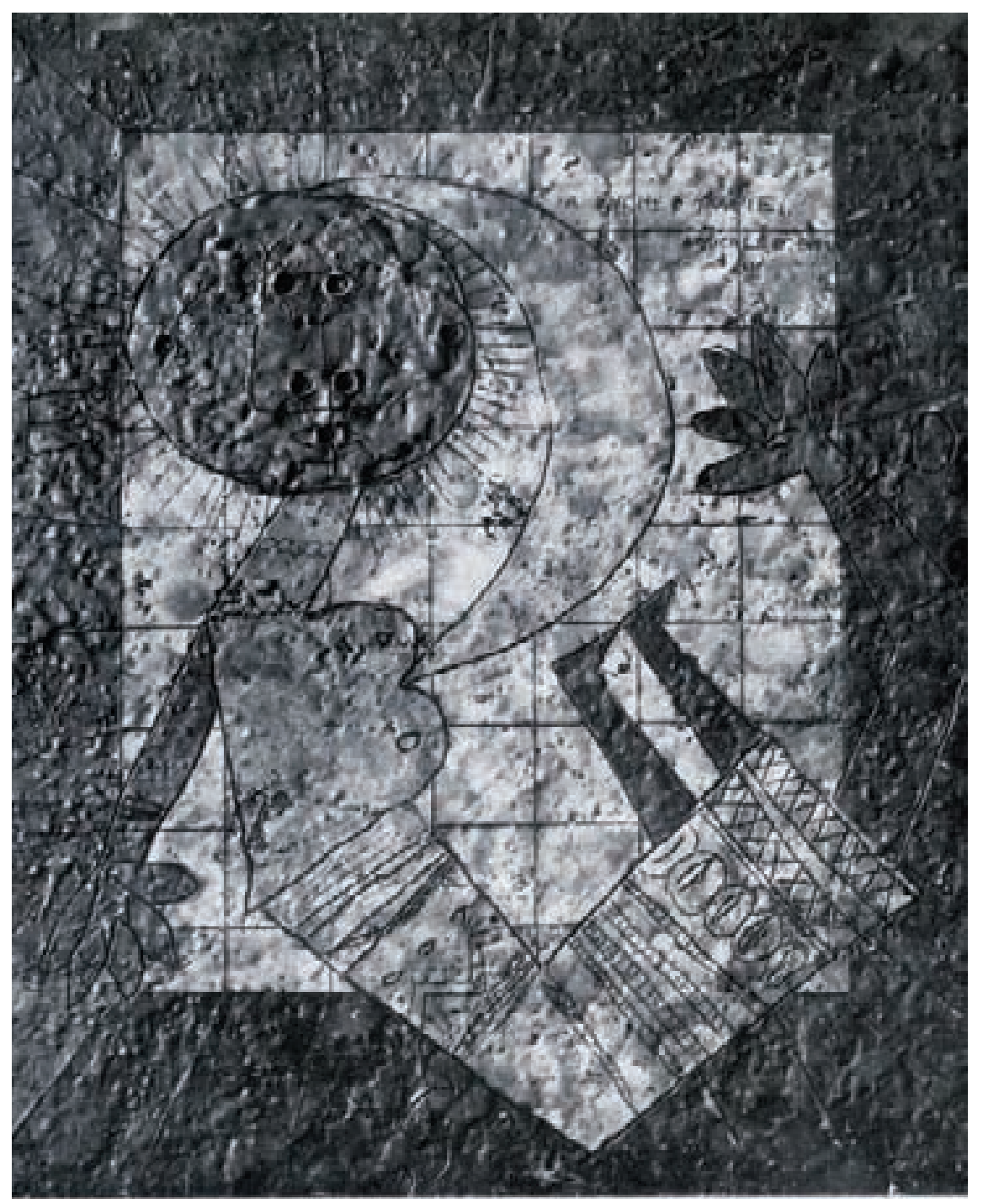

Brauner, "Volupté", 1945 


\section{LÁMINA 1.2}

"Hasta el campo de la arquitectura llega el eco de la semejanza biológica..." Dubuffet y Roland Morand, arquitecto, "Villa Fabala”, 1970.

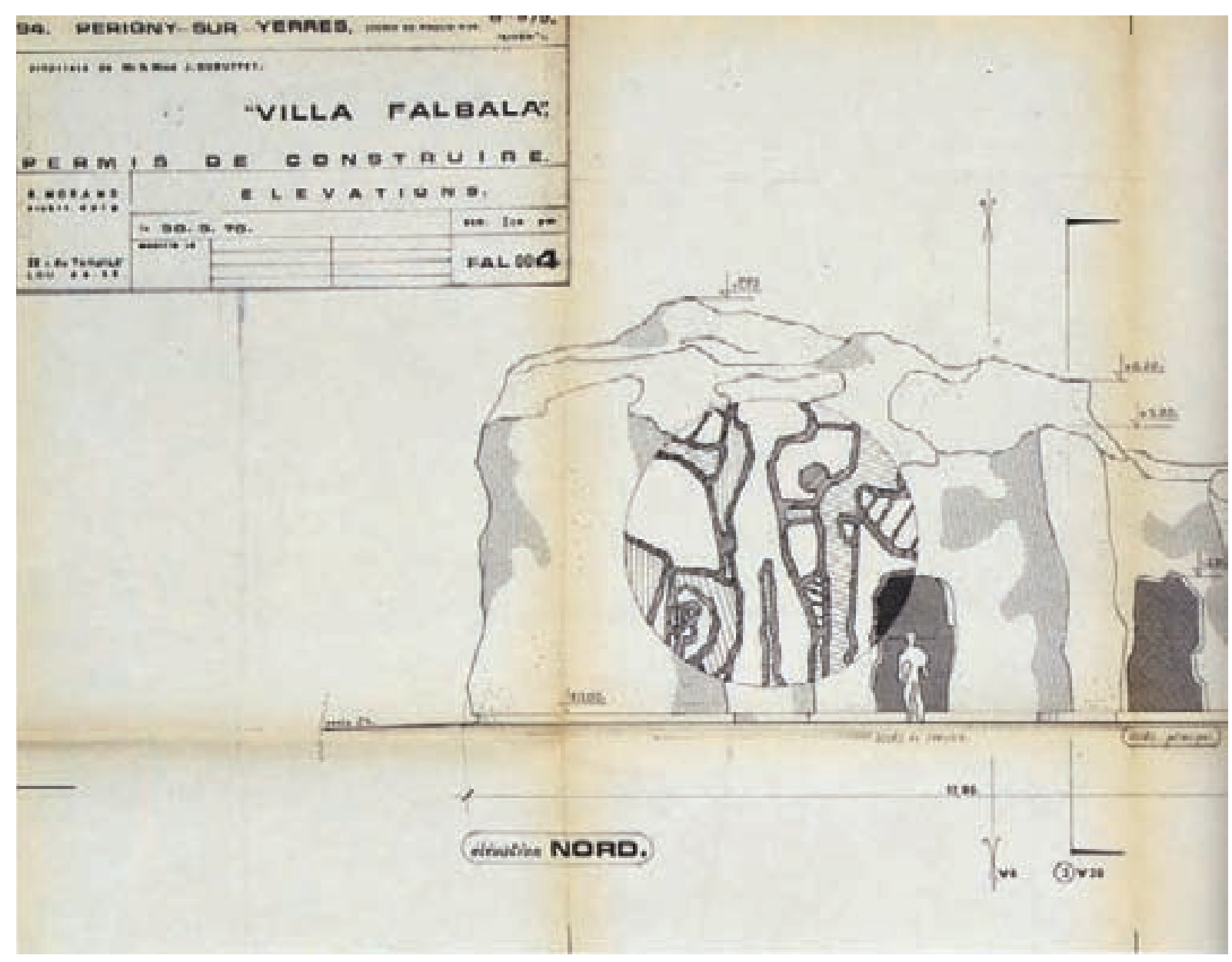




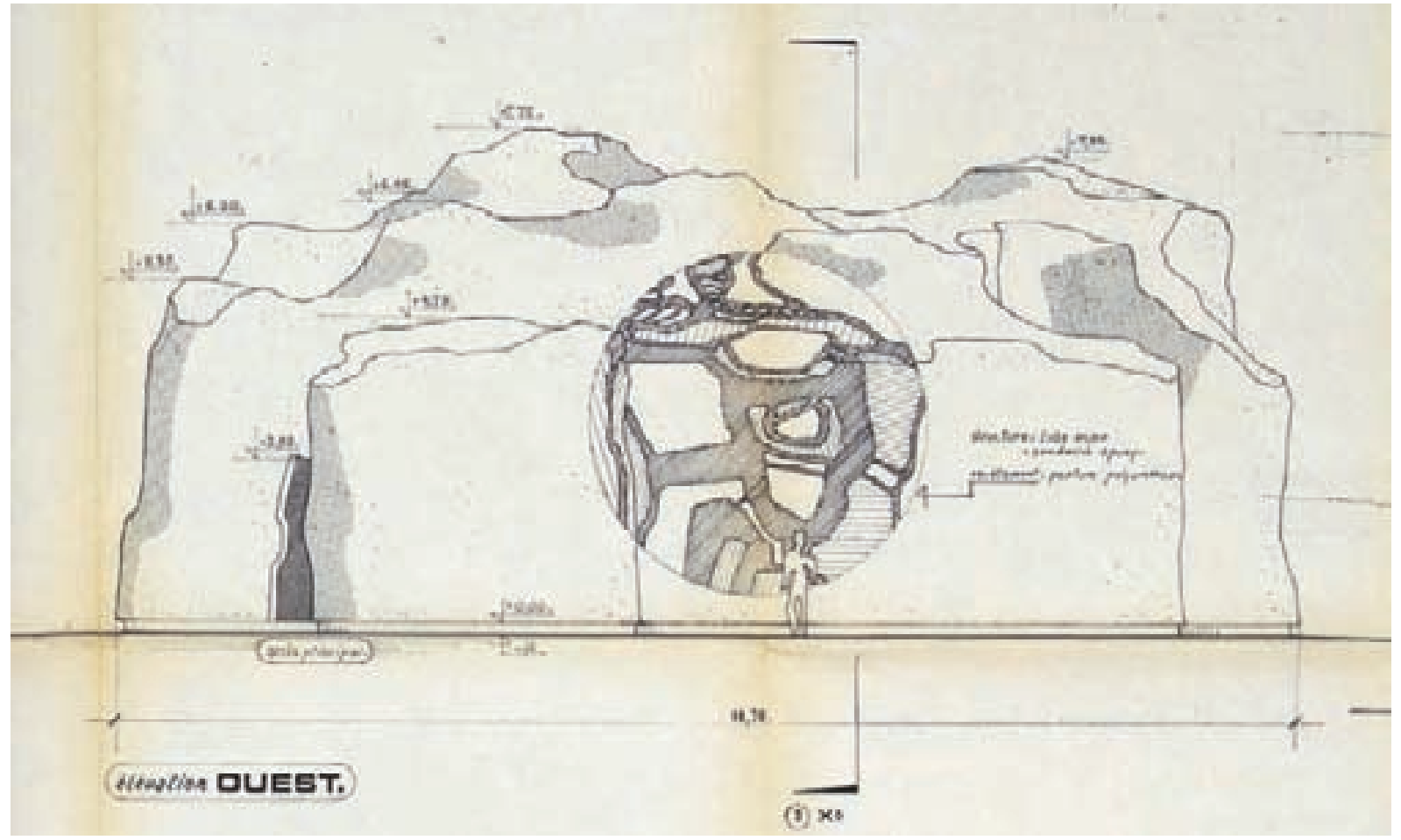



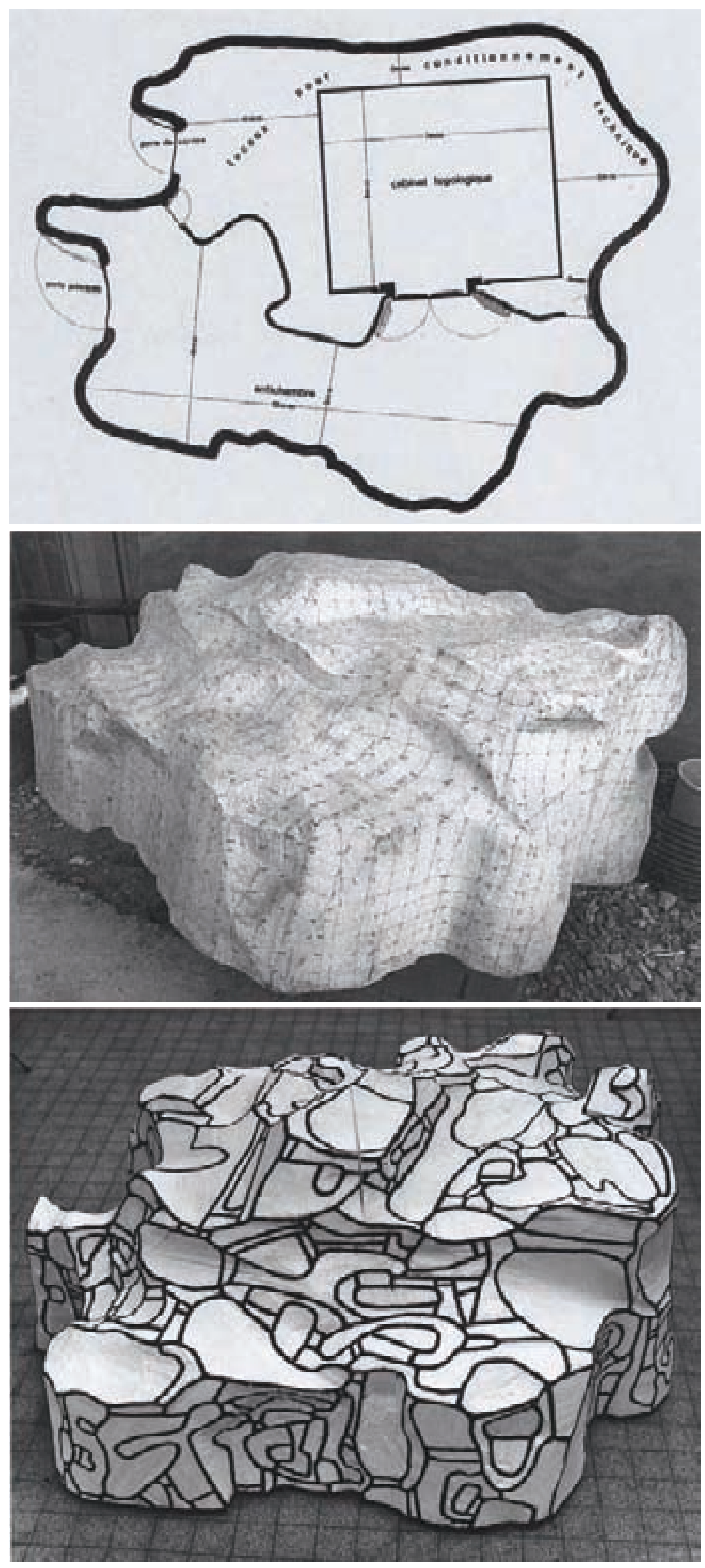
no dejaría de ser más que una en concreto. El coste de expulsar del reino de lo absoluto al criterio clásico de belleza son las llamadas al antiarte o a la antibelleza. La pérdida de esta intuición en la belleza requiere de una reformulación más basta de dicho criterio. El eco de la formulación de Tapié queda plasmado en la definición estética del brutalismo. Dice Banham que "este ascendente dado a la topología... es claramente análoga a la relegación de la "belleza" tomista por la "imagen" brutalista,..."12 Y aclara con la siguiente nota: "Podríamos presentar esta analogía como epistemológicamente rigurosa

-belleza y geometría consideradas hasta hoy como propiedades últimas del cosmos, aparecen ahora como casos especiales, lingüísticamente depurados de conceptos más generales (imagen y topología), a los que, aun siendo primitivos en esencia, sólo se ha llegado tras un inmenso refinamiento-." 13

Bajo un planteamiento de este tipo Banham consigue reunir en una misma definición del brutalismo, dos edificios tan separados formalmente como Hunstanton y Sheffield. Plantea Sheffield como un producto geométrico donde las transformaciones son menos restrictivas que en Hunstanton. Referido al lenguaje geométrico, viene a proponer que el caso de Hunstanton representa a su manera las transformaciones que son propias de la geometría euclídea, esto es, aquellas transformaciones que son invariantes para dicha geometría, mientras que en el caso de Sheffield, el nivel restrictivo de las transformaciones es menor por tratarse de una geometría topológica. De esta manera el brutalismo de Hunstanton es una versión euclídea o si se quiere más particular, incluso se podría decir que métrica, del brutalismo general de Sheffield. Consigue así Banham, finalmente, restablecer una unidad de criterio para el concepto de brutalismo. En definitiva, tanto Hunstanton como Sheffield, son dos versiones del brutalismo, en la que Sheffield abarca como una de sus partes a Hunstanton.

Tanto Tapié como Banham aluden en última instancia al proceso abierto en la geometría desde mediados deI XIX con el advenimiento de los nuevos criterios acerca del entendimiento del espacio, por efecto del "descubrimiento" de las geometrías no euclidianas. En este sentido cabe ver las referencias a Riemann por parte de Tapié:

"Elespíritu geométrico, oesa parte tan particular de lageometría euclidiana, estaba tan instalada en sus necesidades tan restringidas, que estábamos preparados para descartar las generalizaciones de Riemann como fantasías de una sabia sistematización, una proposición del absurdo. Estas visiones opuestas, sin embargo se impusieron como una parte integral de unos conceptos únicos y totalmente disponibles en el dominio no polarizado e ilimitado que se abre para el Informalismo. Le recuerdo que "informal", al contrario de "sin forma", sin contener ninguna de las cualidades negativas o restrictivas, es un término extremadamente general del dominio abstracto de lo inmediato, que incluye cualquier sistema de forma concebible y posible, en el que los clásicos formalismos, que son ciertos modernos no-formalismos, son casos particulares de un minuto"14

12 Reyner Banham "The New Brutalism"

13 Ibid

14 Michel Tapié "The Necessity of an AUTRE Esthetic" 1953 recogido por Francesc Vicens en "Prolégoménes á une Esthétique Autre de Michel Tapié" p. 72 


\subsection{LA RECTA. INTUICIÓN Y METRICA}

Desde el punto de vista de la aceptación de un consenso sobre la forma canónica, cabe ver, en arquitectura, una identificación entre formas geométricas regulares y formas canónicas. $Y$ a este consenso no es ajeno la noción de distancia mínima entre dos puntos como una expresión que define métricamente la forma canónica de un recorrido, como puedan ser la horizontalidad y verticalidad otros tantos atributos de un canon que define una situación de equilibrio.

Dado que Sheffield son estructuras lineales de recorridos, pero no bajo la forma canónica de la menor distancia, es interesante seguir la evolución de la noción de línea recta.

Paralelamente a la definición de magnitud de la recta, como la más corta de entre todas las líneas que tienen los mismos extremos, aportada por Arquímedes, se debe tener en consideración la definición establecida por Euclides en los Elementos. La definición de la recta de Euclides como aquella línea que yace por igual respecto de los puntos que están en ella, se "deja ver intuitivamente" como una relación referida a una constancia de la pendiente. Cabe, por tanto, ver en este doble enfoque, como magnitud por un lado, y como imagen intuitiva por otro, una elección de los parámetros que han de intervenir en la construcción de la noción de línea recta. La noción de Euclides, derivada de la tradición de considerar la recta a partir de las representaciones como un hilo tenso, un rayo de luz etc. "contendría implícitamente una alusión al sentido de la vista, una asimilación del rayo visual al rayo óptico"15

A mi juicio, la dificultad de dar con una definición de recta sin recurrir al modo comparativo de distancia obliga a establecer como lo natural de la recta ese yacer por igual respecto de sus puntos, esto es, no mostrar desviación alguna en su pendiente. $Y$ en este sentido la noción de desviación cabría aplicársela a algún inconveniente que altere o moleste este yacer de un modo recto.

La definición de ángulo que da Euclides como inclinación mutua de dos líneas "que no están en línea recta" viene a resolver la casuística infinita cuando las líneas pierden la rectitud de posición. Si bien se ha hecho notar la innovación que introduce Euclides con la noción de inclinación $<<k$ kisis >> para tratar la relación angular, hay que tener en cuenta la tradición recogida por Aristóteles de ángulo como fractura <<klásis >>. Se recoge, por tanto, que la desviación que produce el ángulo queda afectada por una connotación de desviación y deformación, que, a fuerza de ser contraria a un desarrollo natural, remarca la presencia de obstáculos o fuerzas, condicionantes éstos contrarios a la imagen intuitiva de la rectitud.

Toda esta idea de fuerzas oponentes al desarrollo de la recta son recogidas por Alberti cuando otorga a la recta la condición única de dirigirse en derechura. Una línea recta es aquella que se dirige en derechura de un punto a otro quedando visualizada por la imagen de un eje entre dos puntos, imagen en la que descansa la noción de rayo visual como hilo tenso que enlaza el ojo y un punto del objeto visualizado. Por tanto, de alguna manera, Alberti juzga la recta en función de la posición de dos puntos, entre los que se establece la 
condición de poder ser relacionados mediante un recorrido "derecho". Alberti introduce, una determinada alusión espacial al considerar dos posiciones enlazadas por el rayo visual: la posición del ojo y la del objeto observado. Como se puede hacer notar, la definición de Euclides no conlleva ninguna alusión espacial previa a la de consideración del punto, puesto que la relación de la línea con los puntos es intrínseca a ellos y se establece bajo un mínimo hilo argumental geométrico, la noción de punto, y no entre posiciones o intervalo. La definición de Aberti, sin embargo, establece de alguna manera la idea de un trecho o distancia, que es cubierto al enlazarse entre sí dos puntos separados por un intervalo. La forma más rápida de recorrer el intervalo sería el modo de ser de la rectitud. Parece por tanto que la diferencia entre estas dos concepciones en la definición de recta queda enmarcada en la consideración o no del espacio (del intervalo) como soporte previo de la representación. Mientras que en la raíz euclidiana el concepto de recta es una relación que afecta al modo de disposición de los puntos conforme a ellos mismos, el camino que toma el planteamiento de Arquímedes y que sigue Alberti para establecer los mecanismos de la perspectiva, pasa por establecer como condición para la definición de línea recta la magnitud del espacio que separa los puntos, y por tanto, a nuestros efectos, viene a suponer la existencia de un eje o recorrido. Como veremos, la definición de Euclides, conllevará que en todo momento la condición de yacer por igual tiene que preservarse y contemplarse de alguna manera en el desplegarse la línea. En términos de duración, la propiedad euclidiana lleva consigo la constancia de la pendiente con independencia de la duración. Es como si dijéramos, una observancia que ha de cumplirse para mantener la rectitud indefinidamente. En la definición métrica y perspectiva no hay relación con la duración, ya que su cobertura se agota en el espacio acotado entre los puntos extremos. La transformación proyectiva del método perspectivo hará algo más, identificará en el límite, al considerar los puntos del infinito, la igualdad entre el tramo de circunferencia de radio infinito con la recta: "La recta es un círculo donde el centro está en el infinito". ${ }^{16}$

Otra definición que implica también la existencia de líneas rectas es la definición de las paralelas. Euclides remite a la construcción de las paralelas como un ejercicio de extensión o prolongación indefinida en ambos sentidos, con la condición de que no se encuentren una a otra en ninguno de ellos. Se debe resaltar de nuevo el hecho, por un lado, de que se involucra una determinada manera de construir la rectas paralelas, y que por tanto, el término empleado es el de prolongación. En segundo lugar, como ha sido señalado en las aclaraciones al texto, el término indefinidamente (eis apeiron) "no designa una región o apunta hacia un lugar" sino que es una referencia estrictamente modal. Por otro lado parece ser que la definición de Euclides se desvía de la más usual en su época al no introducir la noción de equidistancia. Cabe verlo, según mi opinión, bajo el supuesto anterior de no tomar en consideración las rectas como ya extendidas a lo largo del espacio y comprobar su paralelismo, sino en términos de generación o construcción, siendo éste preferible al de comprobación, que requiere el uso de instrumentos de medida como la regla. ${ }^{17}$

16 Girard Desargues, "Brouillon Project", recogido en Marie-Anne Privat-Savigny, "Philibert de I'Orme, Girard Desargues, de 'I architecture classique aux enjeux urbanistiques contemporains", p. 52

17 Véase a este respecto en este mismo trabajo las alusiones a Rudolf Carnap y Henri Poincaré 
Esta disertación viene a poner de manifiesto la oposición que se establece entre las dos definiciones de recta, una bajo el modo de generación, que podría asociarse a un planteamiento en términos de duración, previo al espacialismo, y que define simultáneamente al elemento, su forma de construcción y a la generación en el tiempo del espacio; por otro lado, la recta como enlace entre posiciones, donde se supone que el elemento ya es visualizado en su extensión dentro de un entorno o espacio que lo hace sensible.

Esta dificultad que parece deducirse de la definición de recta, deja en manos de Leibniz, de ser una definición básica como elemento geométrico, al introducir la noción de sitio. En efecto, para la definición de un supuesto previo a la definición de recta, Leibniz presenta la noción de sitio, como pares de puntos existentes, enlazados por una variedad de relaciones, no siendo determinante a priori la naturaleza de la relación, sino el hecho de la relación misma. Sin introducir el término variedad, parece que Leibniz abarque toda la serie probable de elementos, rectos, quebrados o curvos para establecer la relación entre dos posiciones. Entendemos que la naturaleza espacial va a estar en función del elemento de relación, y en este sentido, será una recta el modo de relación, cuando el espacio esté definido métricamente y, como veremos, cuando se trate de un espacio absoluto. La novedad es que no va a ser la única manera de definir el sitio entre dos puntos. Se aparta así de nuevo de la idea de espacio métrico, ya que la relación puede establecerse bajo cualquier constructo extenso que enlace los dos puntos. Por ejemplo, tomadas dos parejas de puntos, la relación entre ellos será de congruencia, si el constructo que conecta a dos de ellos puede conectar también a los otros dos. $\mathrm{O}$, en términos de desplazamiento, la congruencia es posible si se puede conservar el constructo entre dos puntos al ser transportados al lugar de los otros dos. En otras palabras, el <<sitio〉> se establece en base a la relación que mantengan entre sí los dos puntos coexistentes, admitiendo para sitio ser un concepto anterior y más general que el de recta.

Así pues, la introducción por parte de Leibniz de un analysis situs supone dar con esa noción más simple y más genérica que la de recta. La recta pasa a ser un concepto derivado, una de las posibilidades de definición del sitio, pero no la única ni a lo mejor la más adecuada en según qué casos, sino, que lo que se abre es toda una variedad de posibles definiciones para el sitio. Se ha hecho hincapié por parte de algunos autores como Echeverría de la menor importancia que va adquiriendo la percepción como fundamento demostrativo de las nociones geométricas que Leibniz va introduciendo al desarrollar su definición de sitio. La primera definición que establece de sitio parece instalada en la premisa platónica de la recta, donde tres puntos de una extensión definen una recta si el punto central obstruye la visión de un extremo desde el extremo opuesto (la línea cuyo medio intercepta o eclipsa ambos extremos). Así pues, para Leibniz en un primer momento, percibir dos puntos de una recta, equivale a percibir todos los puntos de dicha recta. En este sentido, la noción de sitio recto vendría definida desde la percepción simultánea del sitio como alineación.

En un segundo intento, Leibniz busca en la definición métrica de distancia la caracterización matemática de sitio: la distancia mínima entre dos puntos permite caracterizar métricamente el sitio entre ambos. 
Por último, como ya he referido, los esfuerzos de Leibniz por construir una geometría más general que abarque a la recta como un caso especial le lleva a proponer la definición de sitio en base a cualquier tipo de relación que mantengan dos coexistentes, ya sea ésta recta, quebrada o curva. El hecho novedoso es que admite la posibilidad de semejanza entre unas figuras y otras por medio de una mutación continua.

Establecido este último supuesto para la definición del concepto de sitio, el interés reside precisamente en admitir, no sólo a un elemento concreto, la recta, sino a cualquier elemento extenso de ligazón de dos puntos, lo que va a permitir introducir el concepto de variedad y asociado a éste, el de transformación.

\section{CONCEPTO DE VARIEDAD EN RIEMANN}

1.7.

La puerta abierta por Leibniz para un desarrollo del análisis situs, va a ser recogida por Riemann poniendo en crisis la teoría euclidiana. él mismo:

Riemann recoge el método del análisis situs tal como expone

"Con este nombre (analysis situs) empleado por Leibniz, aunque quizá no exactamente en el mismo sentido, puede designarse una parte de la teoría de las magnitudes continuas, en la que las magnitudes no se consideran como existentes con independencia de su posición y medibles unas por otras, sino que desconsiderando plenamente las relaciones métricas, sólo se someten a investigación las relaciones de situación entre puntos y regiones" 18

Cabe ver la idea de deformación continua establecida sobre la recta para una determinada geometría, la de curvatura constante. En el espacio euclídeo la propiedad de la recta de yacer por igual respecto de sus puntos lo era con independencia de la prolongación indefinida de ésta. En una superficie riemanniana de curvatura constante cabría poner en duda tal propiedad: "A la hora de extender las construcciones espaciales hacia lo sumamente grande hay que distinguir ilimitación e infinitud: aquélla pertenece a las relaciones de extensión, ésta a las relaciones métricas...si se presupone independencia de los cuerpos respecto a la posición, o sea, si se le adjudica una medida de curvatura constante, el espacio deberá ser necesariamente finito tan pronto como esa medida de curvatura tenga un valor positivo, por pequeño que sea. Al prolongar las direcciones iniciales que yacen en un elemento de superficie hasta obtener líneas mínimas, obtendríamos una superficie ilimitada con curvatura constante positiva, es decir, una superficie que, en una variedad plana tridimensional, tomaría la forma de una superficie esférica, y por consiguiente finita" ${ }^{19}$ Como se puede intuir, una recta tomada en su acepción de mínima distancia

18 Bernhard Riemann "Teoría de las Funciones Abelianas (1857), recogido en José Ferreirós "Riemanniana Selecta" p.64

19 Bernhard Riemann "Sobre las Hipótesis en que se funda la Geometría (1854) en José Ferreirós “Riemanniana Selecta”, p.15 
sobre una superficie esférica resulta ilimitada pero finita al retornarse sobre sí misma al cabo de una vuelta completa.. Es en este sentido como cabe ver el espacio euclídeo como un caso particular de espacio cuya curvatura fuera cero. Este tipo de planteamientos, cuyo máximo exponente fue poner en duda el postulado de las paralelas para una superficie con curvatura distinta de cero (realmente lo que provocó la crisis era la indemostrabilidad de dicho postulado) llevó al colapso la validez universal del espacio euclídeo.

La tesis de los fundamentos de la geometría llevó a Riemann a plantear para la noción de espacio el concepto de variedad: La fórmula que establece Riemann para dicho concepto es la siguiente:

"Si entre un conjunto de determinaciones distintas de un objeto variable es posible una transición continua de cada una a cualquier otra, entonces la totalidad de las determinaciones constituye una variedad extensa continua; cada una de las determinaciones se llama un punto de la variedad." 20

Dentro del contexto establecido en este trabajo, es interesante observar que el peso del objeto de estudio y de definición deja de recaer en el enlace concreto, sea la recta o la quebrada, para establecer una nueva dimensión que abarca a todas ellas, y donde la nueva definición de sitio puede acoger a la multiplicidad de enlaces, siempre y cuando entre ellos sea posible establecer una transición continua.

Veamos sin embargo en otro contexto científico la dificultad que se abre en el campo clasificatorio el poder establecer los límites para la noción de variedad.

\subsection{CONCEPTO DE ESPECIE $Y$ VARIEDAD. DARWIN $Y$ LA MOSNTRUOSIDAD}

En un intervalo que no llega a la década respecto de la introducción por Riemann del concepto de variedad, Darwin publica El Origen de las Especies (1859). Por especie Darwin reconoce que esta palabra encierra el elemento desconocido de un acto distinto de creación, mientras que por variedad se sobreentiende comunidad de origen: "cuando un naturalista puede unir mediante formas intermedias dos formas cualesquiera, considera una como variedad de la otra, clasificando la más común - o a veces la descrita primero - como especie y a la otra como variedad." ${ }^{21}$ Como han señalado algunos autores, para Darwin, el término especie era arbitrario, ya que una especie no era otra cosa que una variedad bien diferenciada de otras, que la mayor parte de los naturalistas acordaba considerar una especie. La distinción que recoge Darwin entre especie y variedad parece debida a aceptar el consenso entre los naturalistas de determinar a una de las determinaciones o formas como principal dentro del conjunto de la variedad, por el hecho de ser la más abundante en el número de individuos o por ser la primera en haberse clasificado: "si una variedad llegase a florecer de tal modo que excediese en número a la especie madre, aquella se clasificaría como especie y la especie

20 José Ferreirós "Riemanniana Selecta", p.CVI

21 Darwin "El origen de las especies" p. 97 
como variedad..." 22 Por tanto, todo apunta a que la confusión que se establece entre los términos de variedad o especie responde a un interés meramente nominativo, sin otro alcance que el de designar, de alguna manera, al concepto general u objeto variable como lo denominaba Riemann. El problema clasificatorio reside en establecer el límite de la variedad, a partir del cual debe dejar de tratarse de una variedad, o, empleando los términos naturalistas, cuál es el grado de diferencia necesario para asignar a dos formas el rango de especies diferentes.

Lo que para la matemática no suponía problema alguno, dado que, como hemos visto en Leibniz, no habría distinción entre considerar el sitio entre dos puntos a través de cualquier constructo, fuera recto, quebrado o curvo, sí constituye una barrera en la ciencia biológica. Así, el sitio geométrico bien podía quedar definido por un constructo que alternara tramos rectos y curvos sin que esto implicara problema alguno relativo a la combinación de elementos de naturaleza rectilínea o curva.

Sin embargo la combinación en un solo cuerpo de conformaciones normales en animales de especies diferentes queda recogida por Darwin dentro del tipo de las monstruosidades. Además, insiste Darwin, este tipo de conformaciones o anomalías resultan "generalmente perjudiciales o inútiles para la especie." ${ }^{23}$ Lo llamativo de la monstruosidad es su uso en la selección doméstica por la fuerza o impacto visual que produce: "A menudo (el hombre) empezaba su selección por alguna forma medio monstruosa o al menos alguna modificación visible, que hacía que fuera atractiva a la mirada o que se observara con claridad que podía ser útil”24 Resulta por tanto muy interesante para reunir deformación con imagen el hecho de que el propio Darwin reparara en el sentido estético de la monstruosidad como criterio de selección doméstica, aun cuando este individuo tuviera escasas opciones de transmitir su deformación por descendencia.

Téngase en cuenta que el criterio finalista (cuyo fin en este caso es su propia utilidad) usado por Darwin corre en la misma dirección que la definición dada por Aristóteles de monstruosidad. La utilidad procura que en determinadas condiciones (preferentemente artificiales) la monstruosidad llegue a ser una forma viable, siendo, sin embargo, por lo general y sobre todo en su forma natural, algo cuya existencia siempre será en vano al no cumplir por imposibilidad lógica con dos causas finales (a las que tendería cada una de las especies diferentes) un único ser.

Cabría ver en la utilidad (práctica, estética, de la categoría que sea) por tanto, un criterio selectivo superior al de la perfección normativa, o al de incompatibilidad de dos causas finales, ya que de hecho está probada la existencia de dichos seres monstruosos. Dicho de otro modo, la posibilidad de la existencia de estos seres duales, es fruto de su propia utilidad, por paradójico que pudiera ser dicho planteamiento. En un planteamiento que se dirime entre la existencia y la imposibilidad de existencia, para cualquier ser que habite, haya habitado, o habitará, nuestro mundo real, su imposibilidad de existencia habría sido dirimida anteriormente. 
Quiere esto decir que la incompatibilidad finalista de la dualidad que entraña la monstruosidad no es sino el producto de la imaginación en la aplicación de la norma, puesto que cualquier ser dual, si prueba su existencia, no dejará de formar parte del mejor de los mundos posibles. Y aquellos que no cumplan con la existencia, por perfectos que pudieran llegar a ser en sí mismos, serán recluidos en el ámbito de las esencias y sin posibilidad alguna de llegar a sustanciarse, por pertenecer a un mundo que ha reunido o bien, un menor número de esencias, o bien, un mayor nivel de incompatibilidad. entre ellas. Pues bien, esta "trágica elección" de lo que pasará y no pasará a formar parte del mundo no es algo que pueda revertirse; esta enjuiciado desde el origen.

Sin ir más lejos, sobre este mismo texto, como sobre cualquier otro, se ha obrado según este criterio de máxima compatibilidad y por tanto, algunos otros textos similares a éste pero conteniendo otros epígrafes, que por buenos que fueran han dado como resultado un mayor nivel de incompatibilidad en el global de la tesis, no han sobrepasado el umbral de la existencia y continuarán pujando por existir, hasta que, como en algunos casos ocurre, vean la luz otras versiones que no tienen el consentimiento del autor. Pero dentro del nivel teológico dado a los incomposibles, sería un problema de orden politeísta.

LÁMINA 1.3

LÁMINA 1.4
El juego de los incomposibles es ofrecido por el Surrealismo bajo la órbita de los otros mundos posibles que no han alcanzado (ni alcanzarán) a ser el nuestro, dado que el nivel de incompatibilidad es sencillamente mayor que en el que vivimos; pero sí ha logrado hacernos llegar sus imágenes. ${ }^{25}$

Este interesante planteamiento de los incomposible ${ }^{26}$ subraya a favor del criterio darwinista sobre la propia posibilidad de existencia por selección natural o artificial. Se juzga esta posibilidad por el hecho necesario de que resulta ser indispensable su existencia, porque si no fuera así, jamás habría podido llegar a existir. Resumamos por tanto que si bien podemos admitir que la monstruosidad va contra la naturaleza, no va contra ella en su totalidad (realmente todo lo contrario) sino en todo caso contra la suya en particular y siempre con la advertencia de atender a su utilidad.

"Raras veces los filósofos, que todavía parecen estar prendidos de los <<pequeños monstruos〉> que Aristóteles temió pudiesen aparecer en la naturaleza (es decir la combinación de las especies diferentes, dentro de un mismo género), se han detenido en el análisis de este sueño de la razón divina que se desprende de los textos de Leibniz."27

25 En la escalera de los ismos que Tapié maneja para colocar el peldaño del Informalismo, el Surrealismo ofrece, no desde luego su estética, pero sí su mirada hacia los mundos complejos y misteriosos, captados, a su manera, por un Georges Mathieu. Véase Michel Tapié "Un Art Autre"

26 Véase al respecto Javier Echeverría "Leibniz", p. 63 y ss. El paralelismo entre la selección natural de Darwin y la teoría de los incomposibles de Leibniz queda recogida por Echeverría como "un lejano atisbo del cálculo que Leibniz atribuye a Dios" p. 68

27 Javier Echeverría Ezponda, "Leibniz", p. 70 


\section{LÁMINA I.3}

“El juego de los incomposibles es ofrecido por el Surrealismo bajo la órbita de otros mundos posibles..."

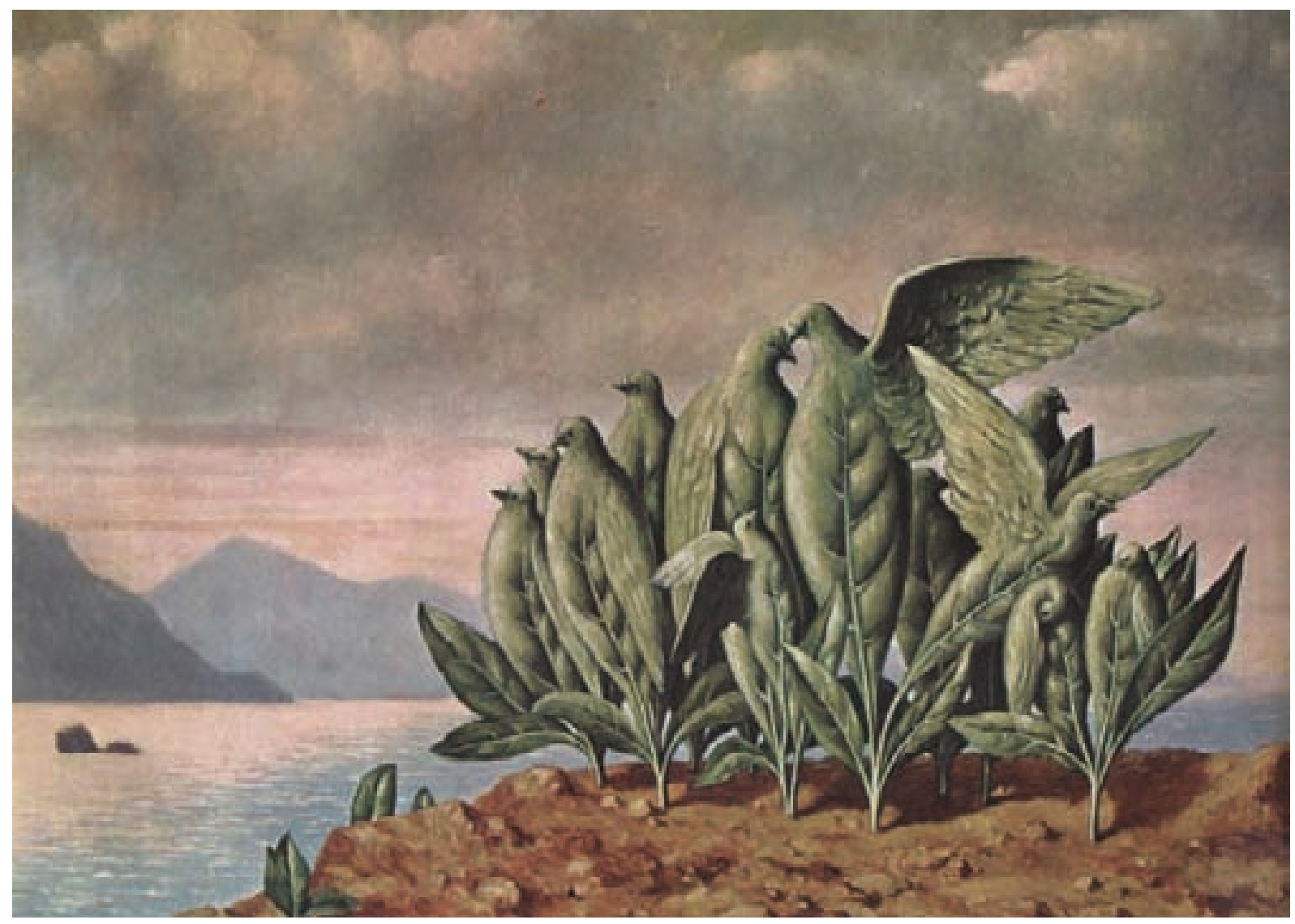

Magritte, “La Isla del Tesoro", 1942 


\section{LÁMINA I.4}

“Raras veces los filósofos se han detenido en el análisis de este sueño de la razón divina..."

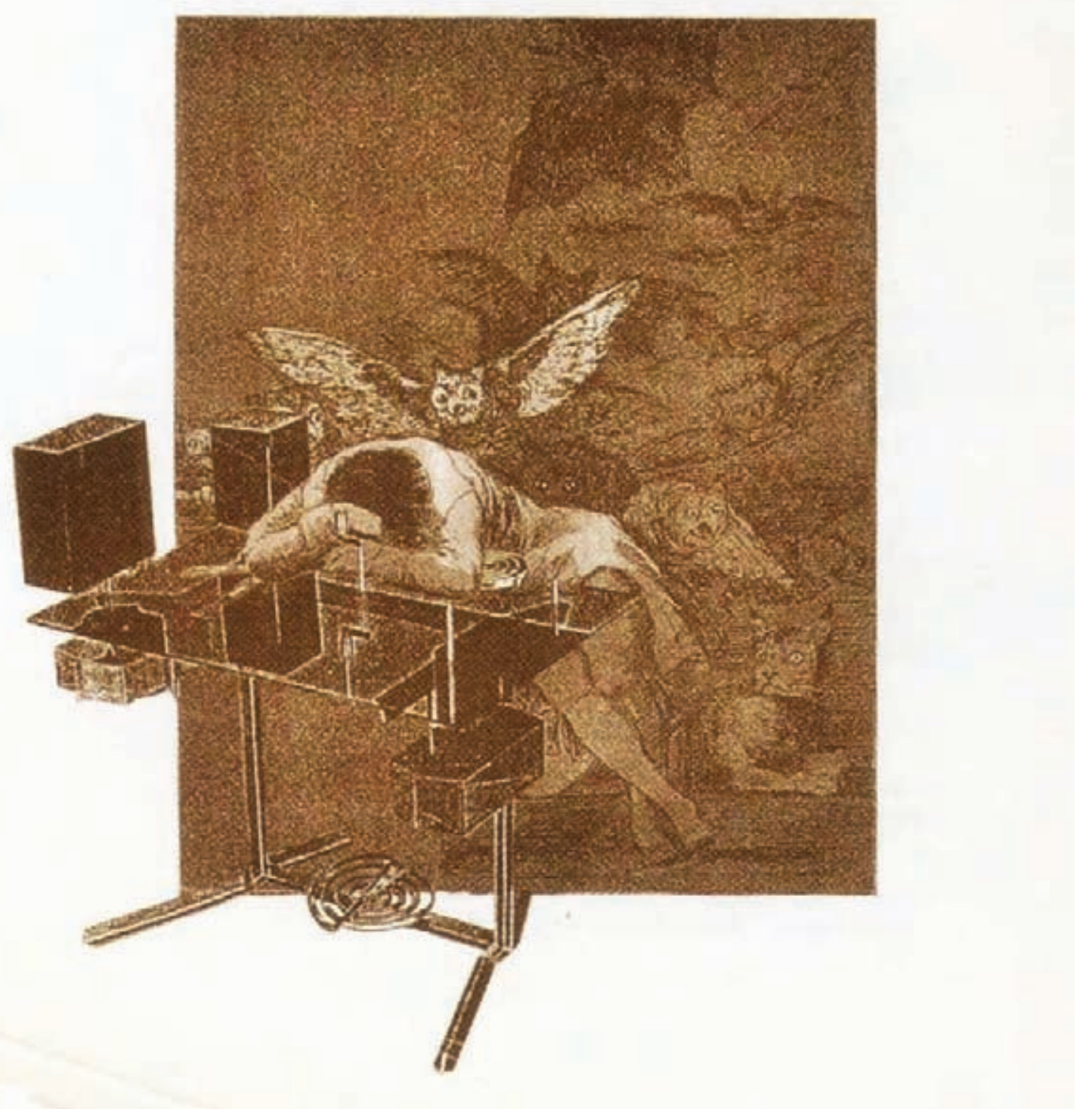

Alison Smithson, "Waterlily \& Fish Desk", 1986 
En un caso diferente como el de las contracciones expresivas del rostro, el propio Darwin se plantea que las deformaciones gestuales del rostro hubieran podido ser objeto del arte. Cuando buscaba métodos útiles para fundamentar una teoría de las emociones, Darwin pensó en lo que la pintura y escultura en principio, podrían ofrecerle. Sin embargo, como él mismo señala, este camino resultó infructuoso: “...esperaba encontrar una gran ayuda de los grandes maestros de la pintura y de la escultura, ya que son grandes observadores. De acuerdo con ello he repasado fotografías y grabados de muchas obras famosas. Sin embargo, y con pocas excepciones, la cosa me ha resultado inútil. La razón es que en las obras de arte la belleza es sin duda el objetivo principal, y los músculos faciales fuertemente contraídos destruyen la belleza." 28

El criterio que Darwin reclama a la historia del arte es el que desdobla emotividad y organización material, fundidos bajo la correspondencia entre un estado anímico y unas contracciones y distensiones de los rasgos faciales, separaciones o acercamientos ente los componentes de la cara. Por la distensión de la materia, por la elasticidad de la piel en su acompañamiento al movimiento muscular, las distancias que transmite la envoltura epidérmica acaban por ser variables. Con estas condiciones, es lógico que el arte, que ha establecido la teoría de las proporciones como condición de la belleza, no le ofrezca a Darwin la información solicitada.

Sin embargo, se puede establecer una distinción por la que se podría extraer el Barroco de una teoría general del arte bajo este criterio. La distinción clásica entre la belleza y la fealdad en virtud de las relaciones armónicas de los rasgos faciales es trastocada en el Barroco al sustituir los tipos aislados antropométricos por una variedad de expresiones que afectan al rostro. De plantear la posibilidad de establecer una correspondencia entre dos variedades continuas, una, la de las emociones, y otra, la de la expresión facial, depende en cierto modo el rasgo distintivo del Barroco en la teoría del arte.

Sin embargo, habremos de ver, que esta correspondencia entre emotividad y materia dista de ser la simple aplicación de una función.

Bajo la distinción entre la mónada y el cuerpo orgánico asociada a ella, formulada por Leibniz en su Monadología, Deleuze establece como el rasgo esencial del Barroco la división del mundo en "dos pisos solamente"29. Estos pisos, a los que se refiere Deleuze, vienen a distribuir dos situaciones que afectan a la mónada: por un lado una interioridad cerrada y por otro una materialidad orgánica. Para Deleuze, la distribución representativa de esta paridad de situaciones en un único ser viviente es organizada a la manera de dos pisos de una misma casa, uno superior cerrado y uno inferior abierto. La relación entre estos dos niveles, el superior y el inferior no es, como pudiera pensarse directa, sino, como el mismo Deleuze explica, por medio de un pliegue. No hay contacto como tal entre lo orgánico (cuerpo compuesto) y el alma (mónada o sustancia simple)

28 Charles Darwin "La Expresión de las Emociones en los Animales y en el Hombre", pp, 46,47

29 Véase Gilles Deleuze "El pliegue. Leibniz y el Barroco", capítulo 3 "¿Qué es el Barroco? 
a la que es asignado el cuerpo, y por tanto, y en virtud del propio plegamiento del pliegue, la relación no puede ser funcional ${ }^{30}$. Pero sí hay simultaneidad o concordancia entre los estados transitorios del alma y los movimientos del cuerpo. En el caso de Darwin, entre la variedad de estados anímicos y la variedad de la expresión muscular de la cara. Esto que Darwin busca, la relación funcional entre el gesto y la emoción, es lo que Leibniz construye como "su" Sistema de Armonía Preestablecida. Este sistema armónico, por el cual el todo reverbera en una simultaneidad y en una concordancia entre los planos materiales y las mónadas hace posible un enlace entre los movimientos primarios del cuerpo y las apeticiones o cambios de estado de las almas. Para entendernos, se trataría de un ajuste calibrado a escala infinitesimal entre el movimiento corporal y la percepción de la mónada. Un símil oportuno, sería el de una programación en una casa domótica que hiciera coincidir nuestra entrada a la vivienda con, por ejemplo, subir las persianas. Las persianas no subirían gracias a un mecanismo oculto que se accionara al empujar la puerta de entrada, sino que, como digo, la sincronía entre las dos acciones, entrar y subir las persianas, seria el fruto de la programación previa del mecanismo de las persianas y la exactitud por nuestra parte de entrar en la casa, de modo que, las dos acciones pudieran verse como perfectamente simultáneas y por tanto engañosamente causales. Dado que para Leibniz, no hay posibilidad en ningún caso de relación directa entre mi naturaleza como persona y la naturaleza de la persiana (o entre cualquier otro objeto o ser viviente, ni incluso con mi propia corporeidad), el acuerdo entre las dos acciones se sustenta en que cada una de las partes funciona como si la otra no existiera, pero vistas ambas al unísono parecen como si se influenciaran mutuamente. A esta programación, que es única y previa y sincronizada para todo ser del mundo, sería a lo que Leibniz pone bajo el sistema de la Armonía preestablecida.

La distinción entre los cambios, movimiento y a petición entre ambas naturalezas del ser se reúne en una única dirección de movimiento, pudiéndose leer en ello la sincronización entre emotividad y rostro, y sin embargo, no por ello, hemos de alcanzar a comprender la causa, oculta por el pliegue. A la escisión entre las causas eficientes de lo orgánico y las causas finales monádicas, entre los movimientos primarios de la materia orgánica y los estados orientados a un fin del alma, es a lo que Deleuze refiere la escisión entre la fachada y el interior de la arquitectura barroca, "la autonomía del interior y la independencia del exterior" ${ }^{31}$, apoyándose en Wölfflin: "El contraste entre el lenguaje exacerbado de la fachada y la paz serena del interior constituye precisamente uno de los efectos más poderosos que el arte barroco ejerce sobre nosotros" 32 .

En otros pasajes, aparte de este extraído del texto de Deleuze, Wölfflin expone con más precisión esta dualidad entre la emoción y la materia, como en el siguiente comentario acerca de las pinturas de los hermanos Carracci en el Palacio Farnese: "El trabajo de los órganos motores es deficiente, el espíritu no domina más que imperfectamente el cuerpo. Los dos elementos, cuerpo y voluntad, se han separado, por decirlo de alguna manera. Es como si estos hombres ya no dominaran su cuerpo, como si no pudieran imponerle completamente su voluntad:

30 Al producir el pliegue dos o más valores en la ordenada para un único valor en la abscisa, la gráfica que adopta el pliegue no puede ser una función.

31 Gilles Deleuze, "El pliegue. Leibniz y el Barroco", p. 43

32 Ibíd.. 
ya no se sabe animar ni dar forma al cuerpo. Estados de disolución..., se vuelven, y cada vez en mayor medida, los ideales exclusivos del arte". ${ }^{33}$ Da la impresión de que Wölfflin se ajusta al sistema leibniziano al interpretar el Barroco. Compárese con el epígrafe de la Monadología: "Según este Sistema (el Sistema de la Armonía preestablecida), los cuerpos actúan como si no hubiese en absoluto Almas, y las Almas actúan como si no hubiese en absoluto cuerpos;...". ${ }^{34} Y$ sin embargo Leibniz no descuida la concordancia entre Alma y cuerpo, aún cuando para ello haya sido precisa la dirección de un agente externo de índole superior, un programador de la Armonía preestablecida, de cuyo tabulación, sin embargo, no tenemos conocimiento preciso, terminando su pasaje: "... y ambos actúan como si el uno influyese en el otro". ${ }^{35}$

En un contexto de la teoría de las emociones, como planteaba Darwin, es lícito pensar que la estructura del conocimiento y del arte del Barroco podría haberle ofrecido argumentos teóricos y ejemplos artísticos. Teóricos y artísticos, dado que el Barroco, como hemos visto, fija su atención en los dos polos del ser, la expresión del alma y del cuerpo. Pero también es cierto que, debido precisamente a la independencia de estos dos planos, en época de Darwin, el Barroco no hubo alcanzado el estatuto de periodo artístico con pleno derecho ${ }^{36}$.

\section{TRANSFORMACION O DEFORMACIÓN. LOS TIPOS ESPACIALES DE CARNAP}

Al abordar esta distinción la dificultad que se le plantea de nuevo al conocimiento es el hecho de no asignar a objeto, o forma alguna, una predominancia sobre las demás que lo constituya en la forma u objeto canónico. Este toque de atención muestra lo instalado que está en nuestra cultura la costumbre o la tradición de juzgar ciertas ideas o formas como perfectas o armoniosas, formas bellas a las que las demás quedan sometidas defectuosamente. A este proceso de desviación de lo común es lo que entenderíamos por deformación o conformación según el sentido de desarrollo, y se encuentra en la base de la ordenación jerárquica.

Todo proyecto arquitectónicamente desarrollado, en un momento dado, ha de resolver la eterna fricción que se da entre el espacio inmaterial del proyecto y el espacio físico del solar que lo ha de contener en el momento de la construcción así como a la materialidad de la construcción en sí misma. ¿Ahora bien, podemos siquiera sospechar que el espacio inmaterial del proyecto es uno y siempre el mismo para cualquier proyecto? Es probable que cada arquitecto, en su forma de proyectar esté implicando un tipo de espacio propio, incluso diferente para cada proyecto, o incluso, que el propio

33 Heinrich Wölfflin "Renacimiento y Barroco", p.87

34 G.W. Leibniz “Monadología” Epígrafe 81, Edición de Julián Velarde, p.130

35 Ibïd

36 Josep Pijoán "Historia del Arte", Editorial Salvat, Tomo VII, p. "El término barroco fue creado y aplicado por los tratadistas neoclásicos del s. XVIII, como sinónimo de <<extravagante y ridículo»>, para designar el arte del s. XVII. Pero un siglo más tarde en 1888, el gran historiador del arte H. Wölfflin en su obra "Renacimiento y Barroco" le confería su actual significado y alcance histórico, como el arte que sucede al Renacimiento y se opone a él." 
proyecto atraviese por varios espacios hasta ponerse en puertas de la construcción. El discurrir del proyecto entre espacios estará sujeto al mantenimiento de ciertos invariantes mientras es sometido a todo tipo de transformaciones que resuelven las circunstancias particulares de la adaptación. Estar en puertas de la construcción supone tomar conciencia del espacio físico. Es la parte correspondiente a la inserción de una métrica propia del proyecto de ejecución. Geométricamente, al espacio del proyecto de ejecución le corresponde su traslación al terreno mediante la conservación de la forma con su correspondiente aumento escalar proporcional, así como el mantenimiento de las medidas angulares. Todo lo que ocurre detrás del proyecto de ejecución, todo lo que le antecede se resuelve tras los filtros de otras transformaciones. Pero en este tramo, la particularidad que reviste la creación arquitectónica reside en el juicio estético de la forma. Esto implica, que normalmente el arquitecto, fija un criterio geométrico dentro de un espacio euclidiano, por el cual el proceso de adaptación ante la entrada sucesiva de datos y condicionantes no interfiere en las relaciones formales y proporcionales adoptadas. Dicho de otra manera, el arquitecto escoge como invariantes aquellos proporcionados por la geometría habitual o euclidiana, por lo menos en las partes esenciales de la forma del edificio: rectitud, paralelismo y proporcionalidad y conservación angular. En un estadio anterior puede darse el caso de no atender sino a cuestiones meramente relacionales, estos es, a la disposición de un orden formal en el que sólo se mantienen la concatenación de funciones dentro de una cierta estructura lógica, en un espacio de ordenación del programa.

Para ver en qué momento y a qué afecta la deformación es necesario considerar qué tipo o tipos de espacios están involucradas en los procesos de deformación.

Ahora bien, ¿por qué referirse a una variedad de espacios? La crisis filosófica abierta por la investigación, a partir de Riemann, de geometrías distintas a la euclidiana condujo hacia un callejón sin salida a la capacidad intuitiva del espacio. A ello contribuyó la posibilidad que tuvo la investigación matemática de manejar espacios n-dimensionales, sin que se tuviera capacidad perceptiva alguna sobre ellos a partir de la tercera dimensión. Rudolf Carnap estableció una síntesis que puede ser de interés en el estudio de la deformación.

Carnap, en 1922, presenta bajo el nombre de El Espacio (der Raum), una ponencia recogida en un texto, en el que da la posibilidad de adjudicar a cada rama de la investigación, como si dijéramos, un tipo espacial distinto, convencido de que no había una unificación posible entre los tipo de espacios manejados por los distintos especialistas: matemáticos, geómetras y físicos. Como señala él mismo, "La presencia de numerosas contradicciones en las diversas opiniones de los científicos más destacados en sus respectivos campos nos sugiere que la "verdad" sobre el espacio puede no encontrarse necesariamente en el compromiso entre éstas, porque esto significaría un rechazo de todas las teorías contradictorias" ${ }^{37}$. Carnap formula tres tipos o formaciones espaciales distintos: el espacio formal (lógico), el espacio percibido (algunas traducciones se refieren a este tipo como espacio intuitivo) y el espacio físico.

Los tres tipos espaciales definidos por Carnap para propósitos

37 Carnap “El Espacio" recogido en Steve Yates “Poéticas del Espacio”, p.121 
distintos de la arquitectura admiten, sin embargo, una interesante proyección sobre el campo del desarrollo de la forma arquitectónica.

Al espacio formal le corresponden lo que él llama partes indeterminadas $u$ objetos relacionados de manera no significativa, números, colores, interpretaciones o personas. No incluye formas espaciales o dimensionales como triángulos o círculos. Esto es, puede incluir cualquier cosa de la que quede excluida su significación espacial. Interesa en el campo del proyecto en cuanto toca al espacio organizativo del programa. Es un terreno donde se establece una secuencia de asociaciones o donde queden determinados uno o varios modos de proceder.

El hecho de proceder mediante el establecimiento de relaciones internas implica algunas consideraciones que quiero destacar:

En primer lugar, en al caso de ampliaciones o proyectos en el ámbito urbano, una fachada, o el cierre de una perspectiva o una plaza la estructura lógica del proyecto, por ejemplo un ritmo de huecos o una altura puede plantearse bajo unas leyes que contradigan la estructura de los edificios presentes en el conjunto considerado.

Pero en segundo lugar, además el arquitecto puede promover errores en la secuencia de las relaciones, forzándola hacia una contradicción. Este procedimiento de deformación me parece interesante en tanto no depende de causas externas y puede llevar a elementos altamente expresivos. La monstruosidad según venía definida por Darwin, como hemos visto, ejemplifica la ruptura de la secuencia al introducir dos sistemas de relaciones en abierta contradicción. Así el surgimiento en un organismo de formas de otra especie distinta sea inducida o natural revela una contradicción en las leyes internas de desarrollo.

El segundo tipo de espacio que propone Carnap es el espacio percibido o intuitivo. Cabe interpretarlo como un espacio de validación de las relaciones establecidas en el espacio formal, al ser sede de las figuras geométricas, y por tanto, cualquier falsedad o veracidad en la secuencia relacional es posible de ser captada intuitivamente o al revés inducir por intuición la constitución de reglas geométricas que serán aprobadas o rechazadas por el filtro de las contradicciones lógicas. Por ejemplo responde a este espacio percibido la inmediatez con que podemos percibir ciertas relaciones entre elementos geométricos como la intersección de dos líneas o la definición platónica de la línea como aquella disposición entre puntos, de tal manera que el central obstaculiza la visión del punto en el extremo. Aunque, como señala él mismo, las normas previstas sobre la percepción han quedado desfasadas.

Sin embargo, arquitectónicamente, la propia condición de representación del edifico en figuras fácilmente reconocibles, contribuyen a hacer del espacio percibido el ámbito normal de las decisiones geométricas del proyecto y por tanto es normalmente por donde comienza el proyecto. Como señala Carnap, dado que la percepción se limita siempre a una zona específica de espacio, solamente pueden extraerse conclusiones sobre sujetos espaciales de tamaño limitado, lo que favorece su uso en la arquitectura al ser el ámbito propio del arquitecto. Podemos considerarlo como un proceso de geometrización en el que las condiciones de adaptación físicas no 
se consideran relevantes.

Como tal, el espacio percibido o intuitivo, no requiere para su uso mayor precisión. Como ha sido señalado, la validez de las propiedades de las figuras es independiente de si son trazadas en una pizarra a mano alzada, o en otra pizarra en algún lugar a kilómetros de distancia, o en un papel con la regla y el compás. Resulta interesante en este sentido lo expuesto por Ortega: "si la geometría de Euclides -como en su forma histórica incuestionablemente acontece- define la igualdad consignándonos a una intuición, sólo poseerán sus teoremas verdad exacta si las cosas de que habla se entienden sólo como aproximadas. Y viceversa: si por línea se entiende exactamente línea, y por igualdad exacta igualdad, entonces la geometría de Euclides es sólo aproximada. La realidad es que tanto da lo uno como lo otro, porque en ambos casos la geometría de Euclides tiene suficiente validez para todos los usos a que se la destine. Y si no vale para algunos, como son las grandes distancias cósmicas o las mínimas subatómicas, no es porque la geometría de Euclides sea exacta o sólo aproximada, sino porque es geometría euclidiana." ${ }^{38}$

Este tipo espacial, ideal o acondicionado, admite la deformación en función de su inexactitud.

La plasmación inmediata de la figura esbozada (suficiente para una intuición de sus propiedades en un espacio de euclideo) en su construcción sin hacer intermediar mecanismos de exactitud, tendría el efecto de dotar de viveza a la propia construcción. La plasmación de la propia inexactitud que no entorpece la captación de la singularidad de la forma planteada estaría favoreciendo a un tipo espontáneo de construcción, sin que por ello tenga que perderse el motivo último del proyecto.

Por tanto, en el ámbito de la deformación la disputa real con la forma prevista va a venir ocasionada por los condicionantes físicos. Hay, como se puede suponer, multitud de ejemplos de deformaciones que se deciden en este marco espacial. Quisiera destacar en un texto de Cannigia, cómo afecta a una estructura de relaciones la acción deformadora debida a la aparición de un obstáculo en su desarrollo:

“... persiste el hecho de que en toda época un recorrido se hace tortuoso si no puede hacerse, o mantenerse recto. El acto de recorrer conforma un recorrido en el que median las exigencias de brevedad y continuidad. Esto implica que, todas las veces que veamos un recorrido no rectilíneo, debemos preguntarnos el por qué, teniendo presente la observación obvia de que si la brevedad impone la rectilinealidad, un recorrido que no obedezca a tal regla debe hacerlo para mantener la continuidad en la superación de un obstáculo interpuesto cualquiera..." 39

Véase por tanto la diferencia en la consideración de la deformación dentro de proceso del proyecto, entre aplicar un falseamiento en la secuencia de relaciones o injertar un orden distinto en la secuencia, como veíamos en el apartado anterior, a aquella

38 Ortega y Gasset Ibid, pp.103, 104

39 Gianfranco Cannigia "Lectura de las preexistencias antiguas en los tejidos medievales" recogido en Gianfranco Cannigia, Carlo Aymonino y Massimo Scolaria "Análisis Urbano" Instituto Universitario de Ciencias de la Construcción, p. 43 
debida al deseo de mantener la congruencia frente a la aparición de condicionantes externos.

El tercer tipo de espacio que define Carnap es el espacio físico. El espacio físico viene determinado por una métrica a partir de una convención por la que se atribuye a determinados contornos de objetos el ser la base de comprobación de la rectitud, y, al intervalo entre dos marcas, ser la base de la medición. La elección del objeto comparativo no hace sino aplazar sin solución la determinación por un procedimiento empírico de la comprobación, porque, como se pregunta Carnap, “¿cómo sabemos que estas líneas comparativas, rayos de luz, el borde recto o el cordel de un péndulo que no está en movimiento son realmente rectos?". Carnap plantea las dudas sobre el grado de certidumbre que se puede tener mediante los objetos de medición en un espacio cuyo interés es la comprobación de hechos científicos. El grado de exactitud no resulta un problema específico en el campo de la arquitectura. Más bien lo que puede plantear es la elección correcta o no en de una métrica adecuada al hecho físico que supone la construcción de un edificio. Por ejemplo, las desavenencias de replanteo en el que se toma como módulo una determinada distancia en función de la unidad de medida métrica y el objeto constructivo que por agregación conforma la dimensión total del edificio, un ladrillo por ejemplo, puede llevar a desacuerdos en el que, o bien la pieza ha de cortarse para ajustarse a la dimensión métrica, o, la dimensión del edificio crecerá o decrecerá producto de la enumeración y no la medida (la determinación del número de piezas enteras es entonces la que determina espacialmente los límites del edificio). El problema que según mi opinión, plantea Carnap para el espacio científico se plantea del mismo modo en la arquitectura entre una fase exenta de medida, propia del espacio percibido, que rige por leyes de otra índole, y el espacio físico. En el artículo "la Fase exenta de medida" puse de manifiesto esta contradicción en el desarrollo del proyecto del Campus del ITT de Mies van der Rohe, entre la elección previa de una modulación basada en una malla de 24 pies de medida y la construcción de los edificios por piezas enteras de ladrillo, lo que produjo un ajuste de toda la modulación $1 / 4$ de pulgada por debajo de la medida inicial de 24 pies.

Pero en el ámbito de la deformación, ésta también puede provocarse artificialmente, al mantenerse un mismo módulo numérico sobre convenciones métricas distintas. Por ejemplo, el mantenimiento de un intervalo bajo la cifra " 3 ", en el que se alternara distintas unidades métricas como pudiera ser 3 metros seguido por 3 pies etc.

Las deformaciones, como puede deducirse, afectan al tamaño de las partes del edifico produciéndose un variación por factor de escala. El caso del Economist Building de Alison y Peter Smithson es un claro ejemplo de cómo un campo métrico particular queda estrechamente vinculado a una parte del edifico, pero no a otras, manteniéndose sin embargo la impresión de identidad formal y constructiva entre todas las partes.

Ciertamente el arquitecto puede parar el desarrollo en alguno de los tres estadios. Si adopta un modo de hacer como el de la arquitectura popular, que fue fuente de inspiración brutalista, podría considerar exclusivamente el tipo de espacio relacional con independencia de cualquier determinación formal, que vendría dada por la pura conveniencia de aprovechar los recursos materiales 
disponibles. Serían éstos en última instancia los que dictaminan sobre la forma. Por tanto el proceso se torna inmediato entre el espacio relacional y el espacio métrico a través de las dimensiones inherentes a la fabricación de los materiales, sin preocupación por la forma resultante. 


\section{II}

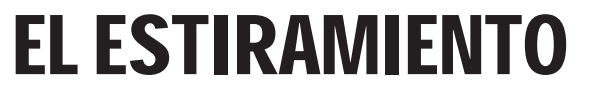

\subsection{METODO DINAMICO. JUSTIFICACIÓN DEL METODO}

Al plantear la inmediatez como un rasgo característico del Brutalismo, me he tomado la libertad, ciertamente, de situarme en la piel del arquitecto brutalista. Apoyándome en la distinción de los tres tipos espaciales de Carnap, he propuesto que un factor desencadenante de la imagen reside en percibir incongruencias como consecuencia de que el arquitecto brutalista se salta uno de los controles formales que ofrece esta triple condición espacial. Veremos ahora otro tipo de "incongruencias" de mucho mayor calado.

Una de las objeciones que se pueden plantear a un método dinámico es que presenta hipótesis que no se pueden comprobar empíricamente. Consiste el método en tomar el proyecto que se nos ofrece a estudio e intentar llegar a él desde aquellas condiciones de partida que podamos restablecer. Puede contarse para ello con información suplementaria disponible, que pasa por requerir del arquitecto que reproduzca el proceso formal, tratar con la documentación de pasos intermedios que pueda haber archivada, y tomar la situación objetiva que motiva el desencadenamiento del proyecto.

El método, que es dinámico en el sentido que supone una acción, la de proyectar para conseguir obtener la forma conocida, es en sí mismo un método comprensivo. Para llevar a cabo esta acción, es necesario entroncarla con un método común de proyectar que es facilitado por el aprendizaje normativo del arquitecto. Quiero decir, que la postura que tomamos como arquitectos nos faculta para abordar este método, algo que un historiador del arte, sin conocimiento práctico en el proyecto de arquitectura, por ejemplo, no podría hacer.

De entre estos tres requeridos, la explicación por parte del autor, la recopilación de los croquis intermedios y la apelación a una situación, el primero puede considerarse tan falsamente concluyente como trivial, dado que la racionalización del proceso creativo a posteriori puede ser objeto de toda simplificación y modificación consciente e inconsciente que el autor recuerde y desee transmitir, ya que es imposible incluir todos los factores psicológicos presentes en la elaboración del proyecto. 
El segundo requerido aporta una documentación objetiva que informa sobre paradas contrastables en el recorrido hacia la forma final que se presenta. El que no haya documentación al respecto y que este hecho sea persistente en la labor del autor, es un indicador que he expuesto como propio del brutalismo, de lo que se desprende una forma más directa de proyectar que otras y un salto sobre uno de los tipos espaciales.

La contribución de la situación objetiva requiere reunir los motivos que desencadenan el proyecto, que en este caso, no son otros que los expuestos en el concurso de ideas convocado. Los condimentos que se pueden introducir, y que atienden a las circunstancias históricas que envuelven el proyecto, no adquieren relevancia en la acción en sí, aunque son elementos explicativos que ayudan a hacer brillar ciertos rasgos del proyecto que pueden ser considerados coherentes con una situación global y que trascienden la situación inmediata hacia una lógica de la situación. Por eso estas circunstancias ambientales (mejor que históricas) serán tratadas independientemente en el tercer capítulo.

Tras exponer cuales son a mi juicio los pasos en los que se asienta el método dinámico abordaré algunas cuestiones relevantes del método comprensivo que permiten encajar al dinámico como una variante con sus singularidades (dado que estamos ante un proceso creativo en el sentido que recoge un momento inspirativo) de aquél, específico para el proyecto de arquitectura.

El método comprensivo es una respuesta en el ámbito de la sociología dado por Max Weber al método científico establecido para las ciencias naturales ${ }^{1}$. Parte de suponer ciertas regularidades en la acción social, definida ésta como una conducta humana con un sentido subjetivo que está referida a la conducta de otros orientándose por ésta en su desarrollo. La relación social o el ámbito en el que se ejercen las acciones es la conducta de varios recíprocamente referida, orientándose por esa reciprocidad. A partir de aquí el método plantea la interpretación de la acción social concreta a través de la comparación de ésta con una acción tipo. La diferencia que estriba entre la interpretación causal de una acción concreta y de una acción tipo, es que en el primer caso, el desarrollo externo de la acción y el motivo son conocidos de un modo certero y al mismo tiempo comprendidos con sentido en su conexión. La interpretación de la acción tipo considera grados en la adecuación de sentido y en la comprobación. A partir de estos grados de adecuación, el método comparativo determina probabilidades tipificadas de que, dadas determinadas situaciones de hecho, transcurren en la forma esperada ciertas acciones sociales que son comprensibles por sus motivos típicos y por el sentido típico mentado por los sujetos de la acción. Como apostilla Dahrendorf ${ }^{2}$, las leyes del mundo social para Weber no tienen un valor incondicional, ya que su propia implantación comprende la posibilidad de que no llegue a producirse lo que sería típicamente comprensible. En este sentido, la interpretación de la acción tipo, descansa sobre probabilidades. En definitiva, el método comprensivo trata de la comprensión de estructuras que hacen regularmente posible un comportamiento

1 Los fundamentos del método comprensivo han sido tomados de: José Félix Tezanos Tortajada, "La explicación sociológica: una introducción a la sociología", pp 148 y ss.

2 Véase Ralf Dahrendorf, "Oportunidades vitales. Notas para una teoría social y política", p.92 
determinado dentro de unos patrones de probabilidad, dada la precariedad de las relaciones entre norma y acción, o entre estructura y comportamiento.

En nuestro caso, es evidente que la relación causal no va encaminada a suponer que para las condiciones de partida, objetivamente conocidas, una acción tipo establece al proyecto ganador como proyecto tipo sobre el que medir la distancia de adecuación del resto de propuestas. No tiene un sentido determinista el presente trabajo ni se entra en considerar lo acertado o equivocado de la decisión de premiar un trabajo en concreto. Lo que viene a cuento de tratar con el método comprensivo es aceptar un estado de leyes y normas en la redacción formal de un proyecto, que nos permita en base a una tipificación asumida por la enseñanza de la arquitectura, plantear un grado de acercamiento al trabajo de otros. Dicho de otro modo se puede considerar una estructura proyectual homogénea en algún grado, que hace comprensible para un arquitecto seguir los pasos de la acción de proyectar dados por otros arquitectos. Y en este exclusivo ámbito, a mi juicio, al reproducir la acción de proyectar este proyecto en concreto de Alison y Peter Smithson se observan ciertas situaciones de hecho que no son deducibles unas de otras (tomado esto como refería Dahrendorf sin un valor incondicional). Expuesto en la forma weberiana al reproducir el proyecto (proceso que se encuadra como acción tipo) conociendo el resultado a obtener (la acción concreta), hay partes que no son comprendidas con sentido en su conexión o no puede ser comprobado como causalmente adecuado dentro del acaecer global que se interpreta como la acción concreta. En pocas palabras, se detectan dos formas o maneras de proyectar que se consideran irreductibles entre sí y que aluden a un entretejido simultáneo de dos acciones de distinta naturaleza que afloran en una figura unitaria. Cabe señalar, como se figuran, que he alcanzado aquí, el punto central del análisis que constituye esta tesis. Sólo aquí podemos comenzar a comprender el significado que, bajo este método dinámico, adquieren dos formas irreductibles entre sí, para retrotraernos al problema que la imagen, en el sentido mentado por Banham, suscita, o que en los términos darwinianos se ofrece como monstruosidad.

Comencemos por ver en qué consiste la convocatoria.

\subsection{LA CONVOCATORIA DEL CONCURSO: EL OBJETO DEL CONCURSO}

LÁMINA II.1
El concurso toma como punto de partida la ampliación de la Universidad de Sheffield. Para ello dispone de unos terrenos cuyo hecho más significativo es que son cruzados por una vía de acceso rápido a la ciudad Ilamada Western Bank. El terreno a un lado de Western Bank es limitado oblicuamente por una calle lateral, la Bollsover Street. Una segunda vía, Winter Street, dispuesta entre Bollsover y Western Bank, secciona de nuevo el área universitaria, formando una cuña de tejido residencial alternado con pequeñas construcciones. Tanta fragmentación, lleva a tomar la decisión de eliminar la Winter Street en el momento de plantear la ampliación. Incluida la cuña residencial que pasa a ser terreno de la Universidad. En 1953, sin embargo, tanto la calle como los adosados estaban todavía en pie. Al lado oeste de la Winter Street, y lindando al sur con Western Bank y al norte con Bolsover Street, queda englobado un terreno abierto y arbolado, una 
gran pradera de césped, el Weston Park. Enfrente del parque, al otro lado de Western Bank, los terrenos universitarios, de menor tamaño, se diluyen en una zona residencial de unifamiliares. Western Bank, además de cortar el terreno, baja con fuerte pendiente hacia el centro de Sheffield.

Estos terrenos habían sido utilizados por la Universidad de Sheffield desde 1908 al concluirse las obras del primer edificio, el Firth Court (1903-1905), llevado a cabo por el arquitecto Edward Gibbs ${ }^{3}$. El edificio se ubicó envuelto por el Weston Park y la calle Western Bank. Desde 1908 hasta la fecha del concurso en 1953 la Universidad no había dejado de transformarse mediante construcciones exentas, como talleres y además por ampliaciones sucesivas del Firth Court , al que se añadió por el propio Gibbs en 1909 la biblioteca Edgar Allen, edificio exento pero comunicado con el cuerpo principal. ${ }^{4} \mathrm{La}$ última ampliación del Firth Court, que modificó la forma inicial en $C^{5}$ hacia un desarrollo asimétrico en forma de J se llevó a cabo en 1941 , fecha relativamente cercana a la convocatoria. Contrariamente a la sensación de homogeneidad y simetría que transmite la planta original del Firth Court, la fachada a Western Bank la resolvió Gibbs volumétricamente como un edificio independiente a la manera de un pabellón representativo. Este cuerpo acoge el acceso principal centrado en fachada con la escalera en el eje. La planta superior alberga el gran volumen del Aula Magna que ocupa por completo el alzado a Western Bank. La articulación con el resto del edificio se resuelve con la torre octogonal de la escalera secundaria y con una pieza rectangular adyacente a ésta, a la manera de una Torre del Homenaje, que albergaba, en su última planta, la Escuela de Arquitectura original. En el ángulo posterior y al final del edificio original repite Gibbs el motivo de la caja de escaleras octogonal. Otra decisión interesante de Gibbs, en esa misma dirección, consiste en articular exteriormente los alzados al parque agrupando partes del edificio en unidades individualizadas mediante gabletes sin que esto comprometa la distribución interior continua mediante un corredor central. El resultado es un edificio fuertemente articulado por medio de torreones de escaleras en esquinas y motivos repetidos en fachada, al cual le infunde Gibbs un aire de fortaleza que envuelve una zona claustral interior, el llamado Quadrangle. Estos rasgos del edificio de Gibbs, el Firth Court con la Biblioteca, son desde luego rasgos que pasarán a formar parte, y de forma nada velada, de la propuesta de los Smithson, y que en cierto modo la distingue de otras. Veremos en su momento en qué consiste, a mi juicio, la importancia que para la ampliación supone esta imponente masa.

Al otro lado del Western Bank, se alzaba desde 1936 un discreto edificio dedicado a las actividades estudiantiles, el Students Union.

3 Edward Mitchel Gibbs, 1847 - 1935. Vésase al respecto, Peter Blundell Jones, "University of Sheffield School of Architecture", p. 8, Ruth Harman y John Minnis "Sheffield. Pevsner architectural guides", p. 78, y Helen Mathers, "Steel City Scholars. The Centenary History of the University of Sheffield", p. 46

4 Dado que la biblioteca ocupaba parte de los terrenos públicos del parque Weston Park, La Universidad necesitó el permiso municipal para construir en dichos terrenos. Véase Helen Mathers, "Steel City Scholars. The Centenary History of the University of Sheffield", pp. 44 y 45

5 La planta original contemplaba el cuarto ala que cerraba el edificio, pero en 1913 se desestimó tal idea. Ibíd., p. 46. Sólo subsiste la escalera de enlace con este proyectado cuarto ala, y que en, según algunos dibujos, no debió construirse en inicio. 
LÁMINA 11.8

LÁMINA II.9
Para la fecha del concurso, además de estar previsto limpiar el patio interior del Firth Court de las construcciones temporales de los talleres, y suprimirse una vía interior, la Winter Street y para ganar espacio hasta la Bollsover Street, estaba en marcha la construcción de la Facultad de Química, emplazada cerca de la confluencia en ángulo agudo de las dos calles, y que, por tanto, habría de convertirse en el límite más al este de la ampliación, además de imposibilitar el poder resaltar adecuadamente la universidad mediante un edificio en una esquina importante en el contexto urbano.

El asunto que se planteaba con el concurso era crear la ordenación de un nuevo campus universitario por medio de unas pautas claras de desarrollo dirigidas a mostrar un criterio para el futuro que vertebrara las ampliaciones venideras. Además de la confección de este Plan Director, el concurso premiaba al equipo ganador con las construcción de dos edificios, uno para el la Administración y Artes, y otro para la nueva Biblioteca, cuya posición en el terreno quedaba determinada en las cláusulas del concurso. Otras determinaciones eran la necesaria conservación del edificio señero de Gibbs y sus ampliaciones, y el Students Union, de manera que el terreno al otro lado de Western Bank quedaba incorporado como terreno universitario en pleno derecho, con la dificultad intrínseca y residual de cómo cruzar la calle principal.

Como se ve, en 1953 , el terreno era una mezcolanza de usos, edificaciones y viarios, que forzaban a usar la imaginación para contemplar el problema limpio y libre de tanta fragmentación. Era literalmente imposible recorrer a pie los terrenos destinados a la ampliación, por lo que el ejercicio debía resolverse casi íntegramente como una actuación "en abstracto". En cierto modo, para aquellos que visitaran los terrenos, sólo el viario debió ofrecerles alguna pista clara para enfocar el asunto. De hecho, la mayoría de concursantes se dejó enredar por la disposición de la Winter Street, a la que, salvaguardando su posición, convirtieron en eje peatonal. Alison y Peter Smithson tomaron sin embargo Western Bank como motivo principal.

\subsection{DOS FORMAS IRREDUCTIBLES}

A partir de los datos de concurso, cómo se llega hasta la forma final es lo que se pretende estudiar al enfrentarse con los problemas compositivos y espaciales desde este punto cero de las condiciones del concurso.

La visión del proyecto nos presenta dos partes diferenciadas. Intentar hacerlas surgir introduciéndonos en una secuencia de toma de decisiones indica que no es posible un encadenamiento lógico de construcción de una a partir de la otra. Que en definitiva, hay dos formas irreductibles entre sí.

Si se observa el proyecto en planta, se puede distinguir dos partes bien precisas:

Por un lado un eje recto que parte del Students Union y termina en el edificio de la Biblioteca y por otro, la parte que engloba el grueso de los edificios universitarios y que se enrosca terminado nuevamente en la biblioteca. Estos dos sistemas lineales, además de 


\section{LÁMINA II.1}

"(La Universidad) dispone de unos terrenos cuyo hecho más significativo es que son cruzados por una vía de acceso rápido llamada Wester Bank..."

1. Plano del entorno de los terrenos de la Universidad de Sheffield en 1952. Se distinguen en negro en el centro del plano los principales edificios universitarios: Firth Court, la Biblioteca Adgar Allen, Students Union y la Facultad de Química y el eje este-oeste que forma Western Bank. La ciudad de Sheffield se localiza, pendiente abajo, hacia el este. Un plano en detalle de éste sería el facilitado como documentación del concurso. (Fuente: Tatjiana Schneider, "This building should have some sort of distinctive shape", p. 21)

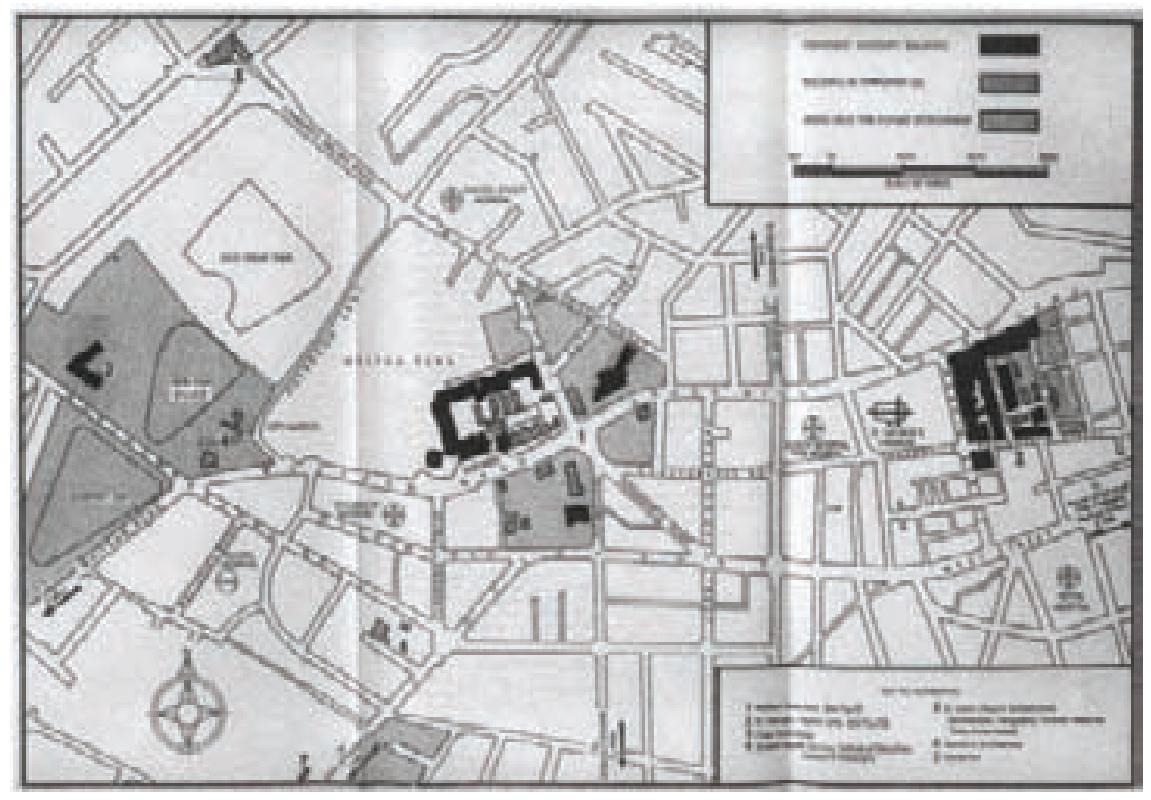


2. Owe Arup \& Partners, „Paso subterráneo bajo Western Bank“, 1969.

En 1966 se estimaban en unos 10.000 cruces diarios la afluencia entre los dos terrenos de la Universidad separados por la calle Western Bank. Tras algunos disturbios a consecuencia de un accidente, la Universidad, con la ayuda económica municipal, decidió en 1966 unir ambos terrenos mediante un puente. (Fuente, Helen Mathers : "Steel City Scholars" pp. 236 y 238)
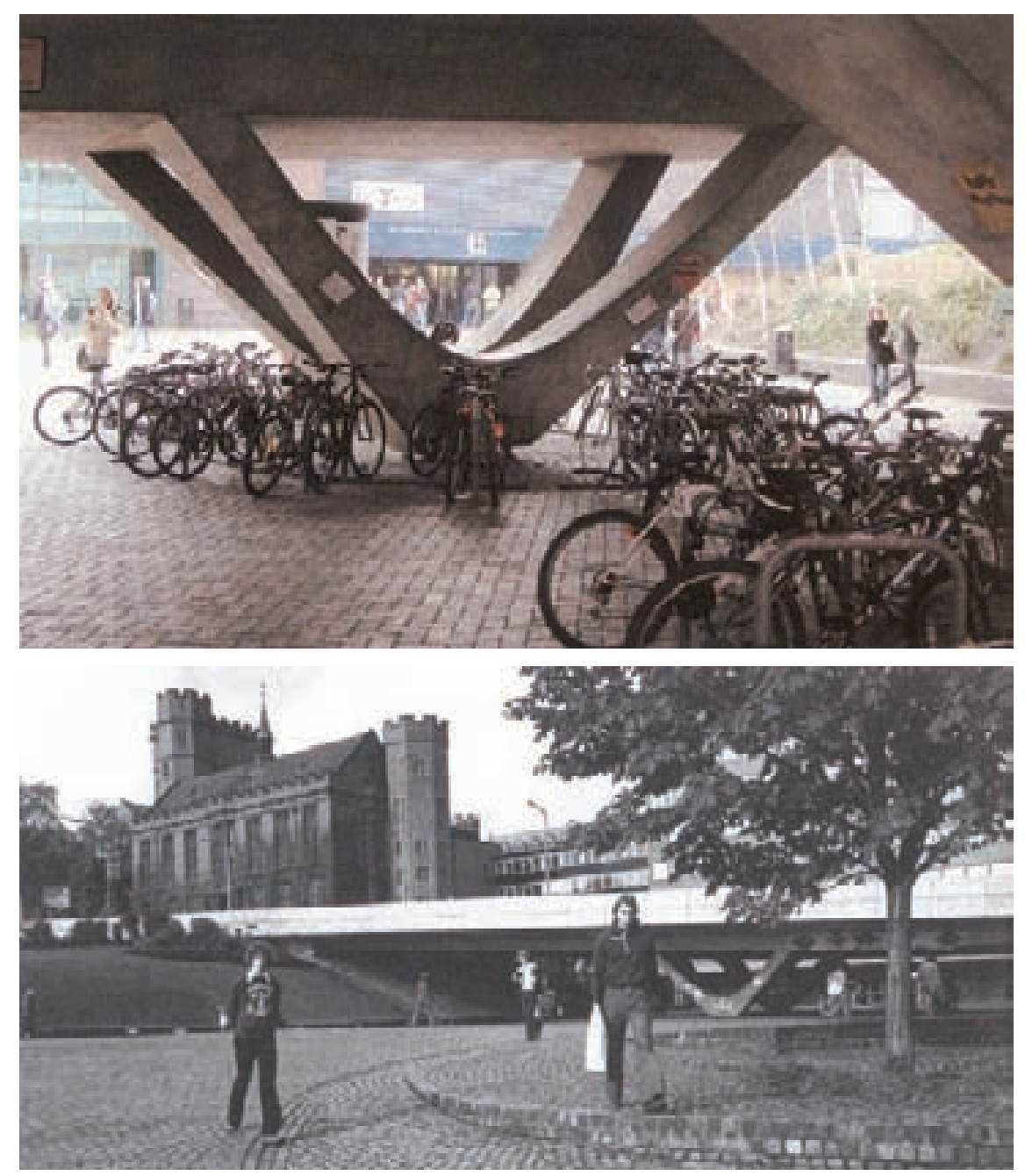


\section{LÁMINA II.2}

“Estos terrenos habían sido utilizados por la Universidad de Sheffield desde 1909, al concluir las obras del primer edificio, el Firth Court (1903 - 1905) llevado a cabo por el arquitecto Edward Gibbs..." Edward Gibbs, "Firth Court", 1903 - 1905.

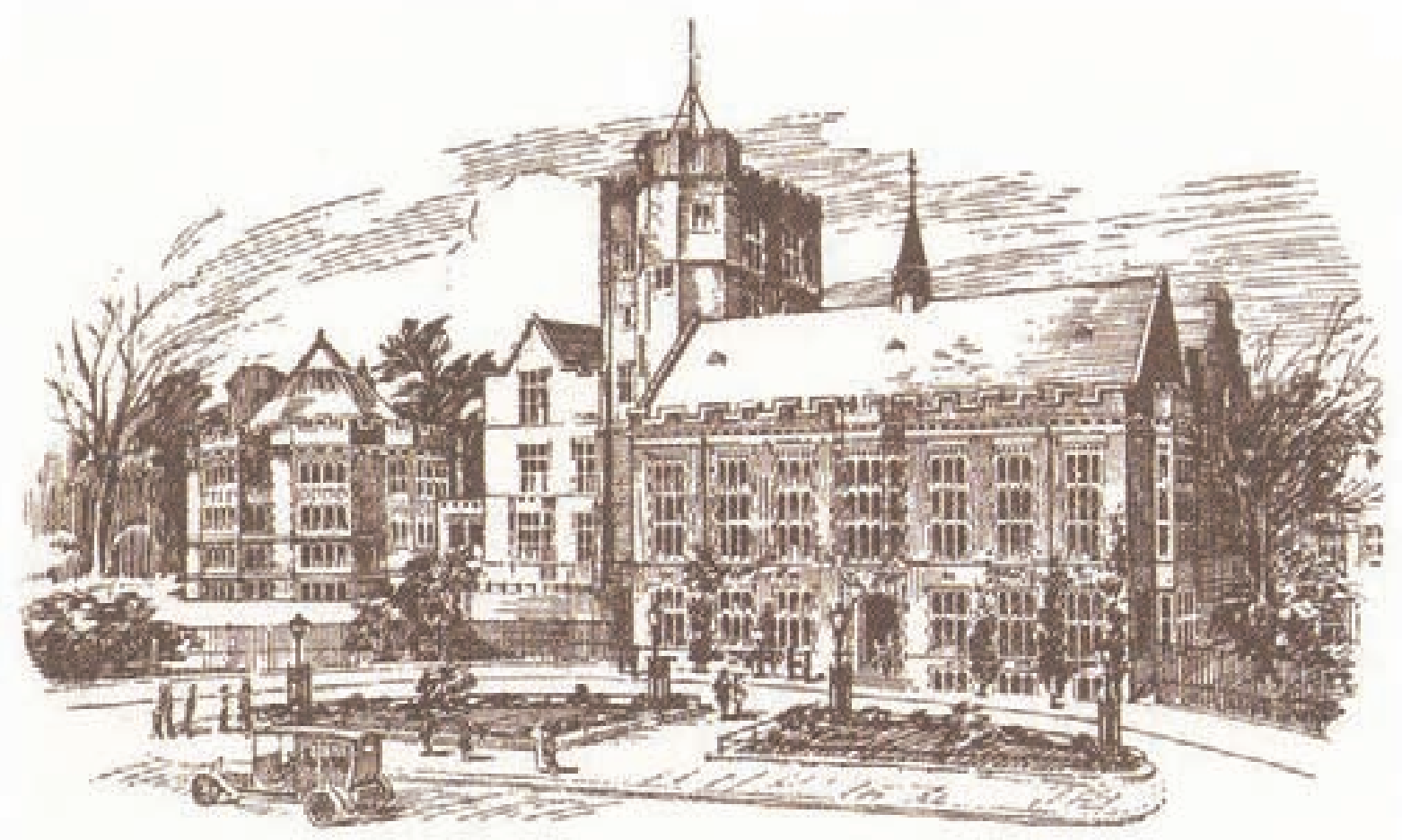

Vista del Firth Court desde Western Bank hacia 1905. A su izquierda el proyecto de la Biblioteca de 1909 (lado oeste del edificio principal). 


\section{LÁMINA II.3}

"(Firth Court) al que se añadió por el propio Gibbs en 1909 la biblioteca Edgar Allen..." Edward Gibbs, "Biblioteca Edgar Allen”, 1909.
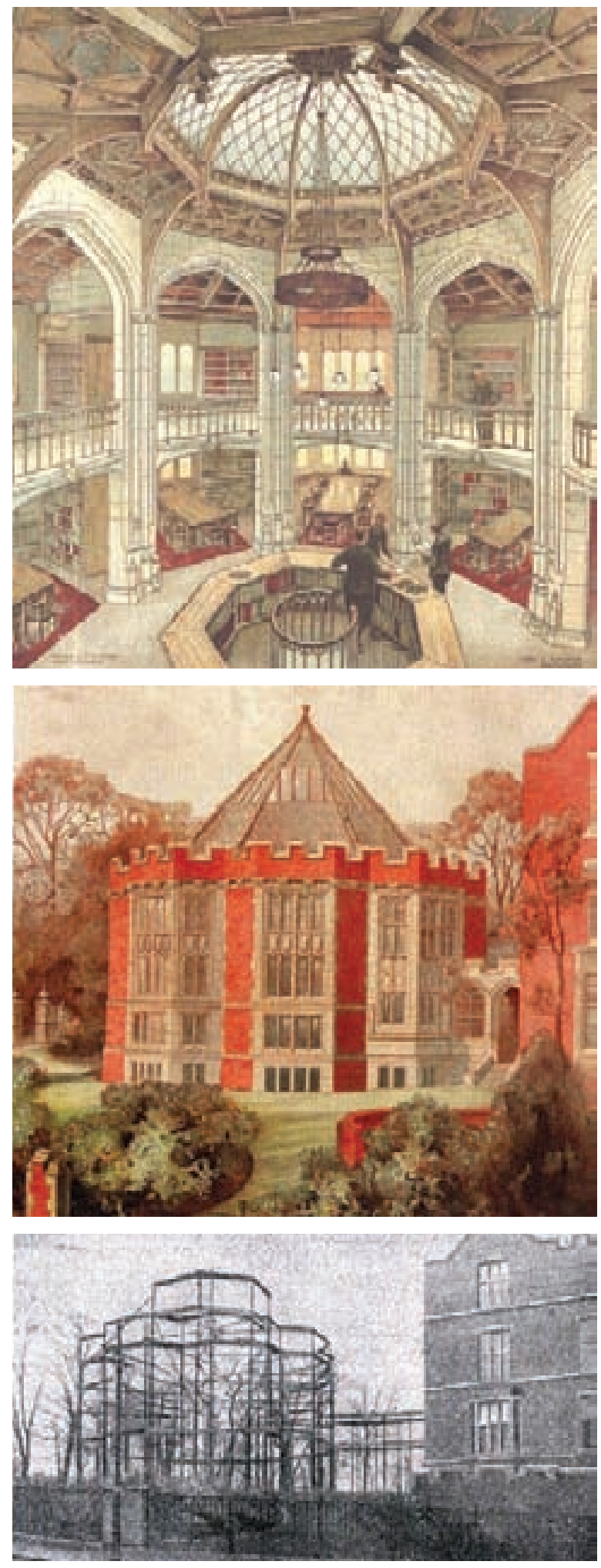


\section{LÁMINA II.4}

"Contrariamente a la sensación de homogeneidad y simetría que transmite la planta original del Firth Court, la fachada a Western Bank la resolvió Gibbs volumétricamente como un edificio independiente a la manera de pabellón representativo..."

Edward Gibbs, "Firth Court", 1903 - 1905.

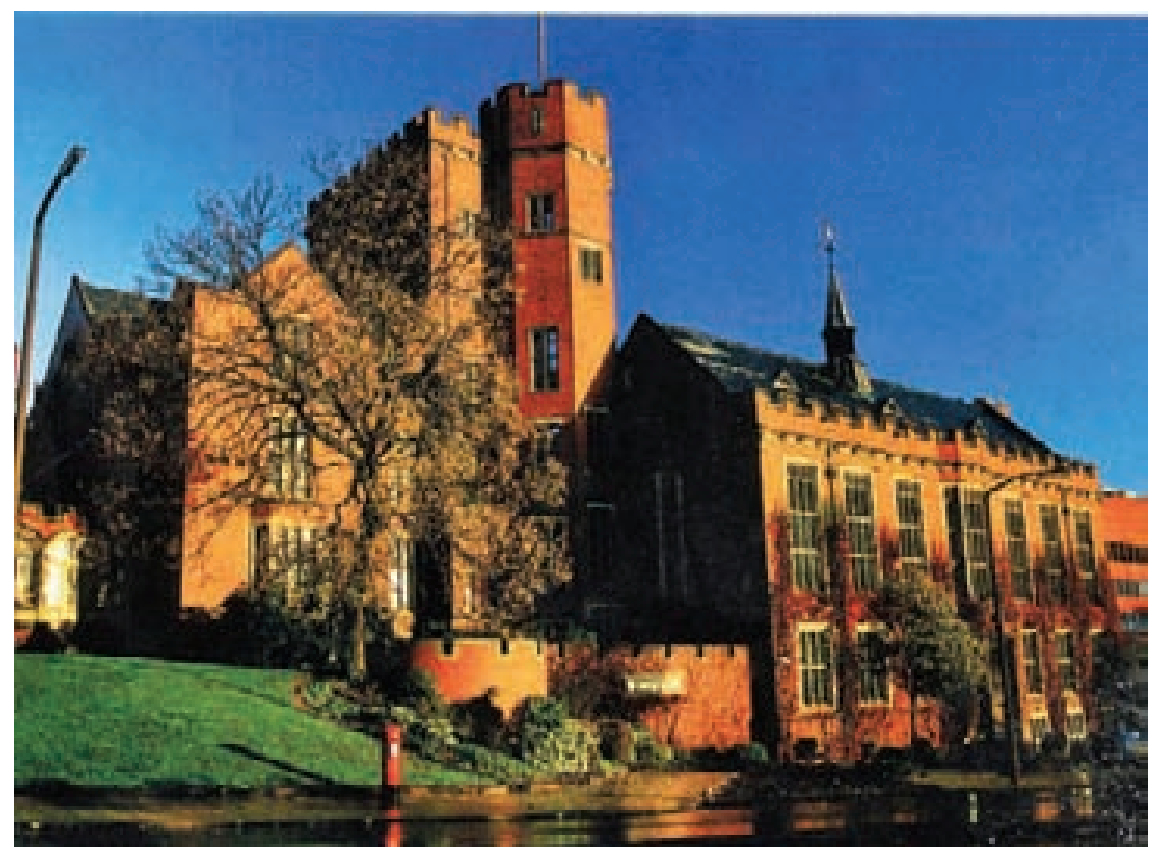

Vista del Firth Court desde Western Bank. A la derecha el cuerpo de entrada, en el eje una de las torres de escaleras y la torre donde se ubicaba la Escuela de Arquitectura original. Fotografía Matthew Bullen.

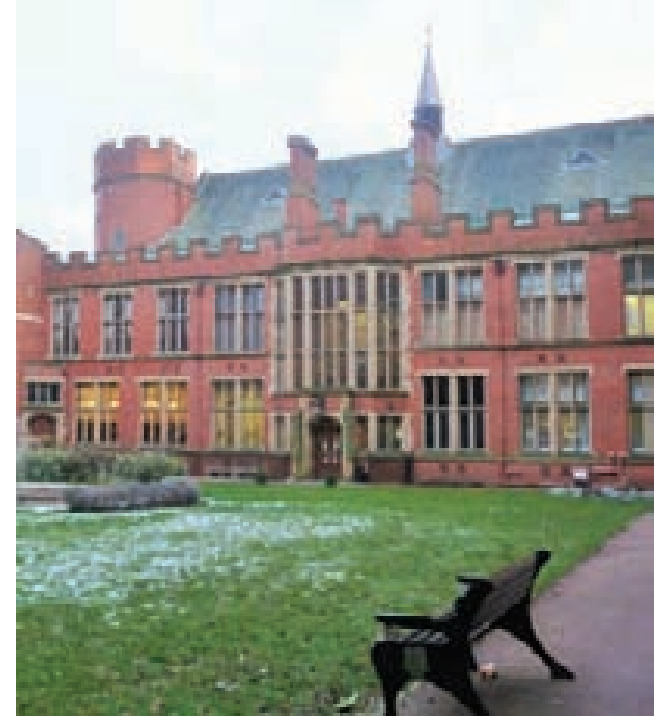

Vista del cuerpo de entrada desde patio o claustro interior (Quadrangle). A la izquierda un cuerpo octogonal similar a las cajas de escaleras, pero que incluye dependencias de servicio y cuya construcción es posterior (a la fecha del concurso sólo constaba del nivel de planta baja). Febrero 2015. Fotografía Álvaro Aparicio Serna.

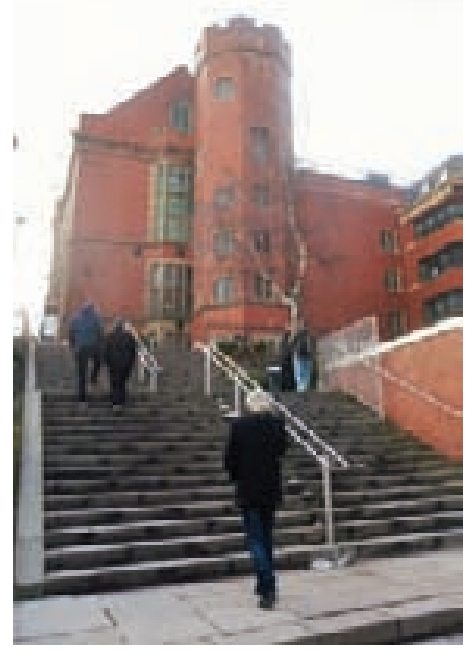

Vista de la fachada este del pabellón de entrada con el cuerpo octogonal anterior. Nótese la diferencia de cota entre el exterior y la zona claustral, y la fuerte pendiente de la calle Western Bank. Febrero 2015. Fotografía Federico Herrero Hervás. 


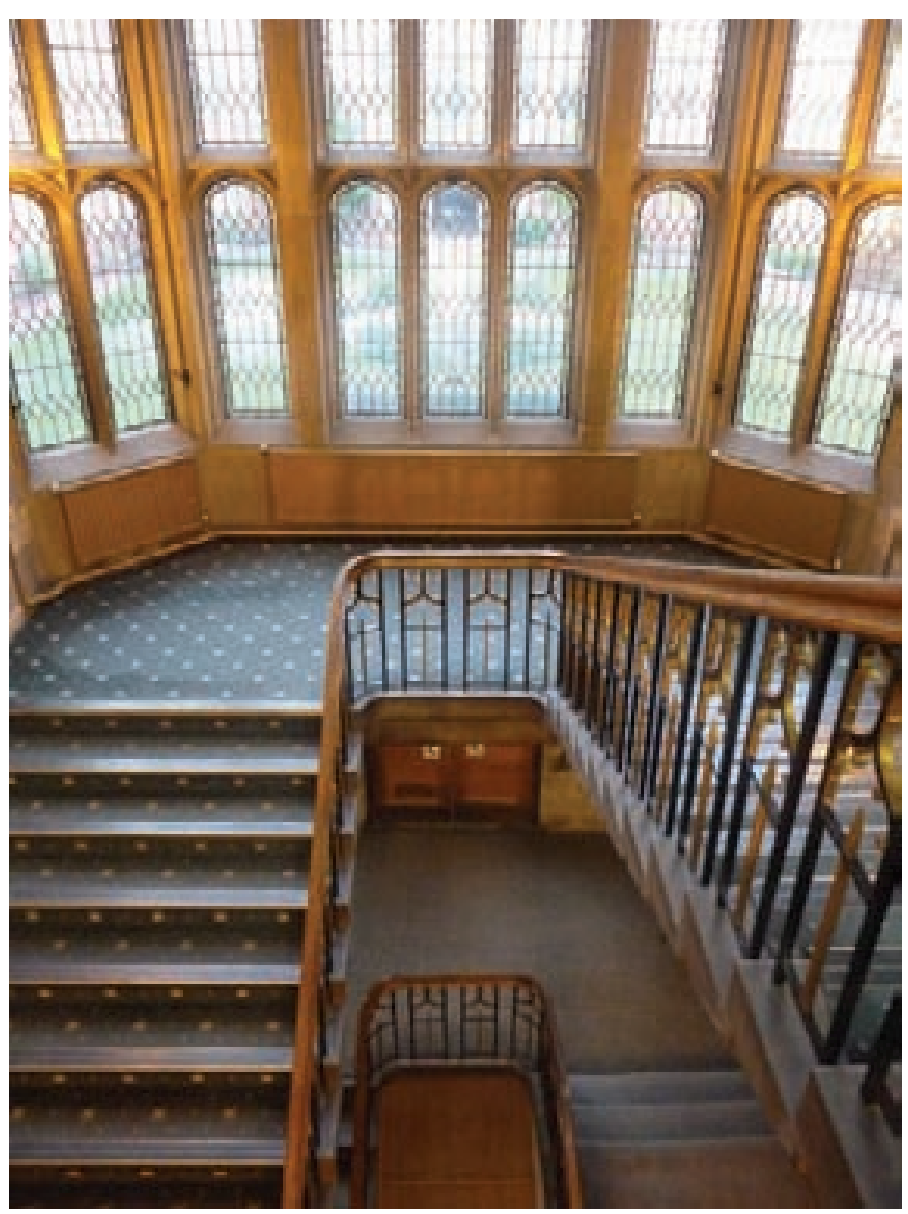

La escalera principal. Febrero 2015. Fotografía Josenia Hervás.

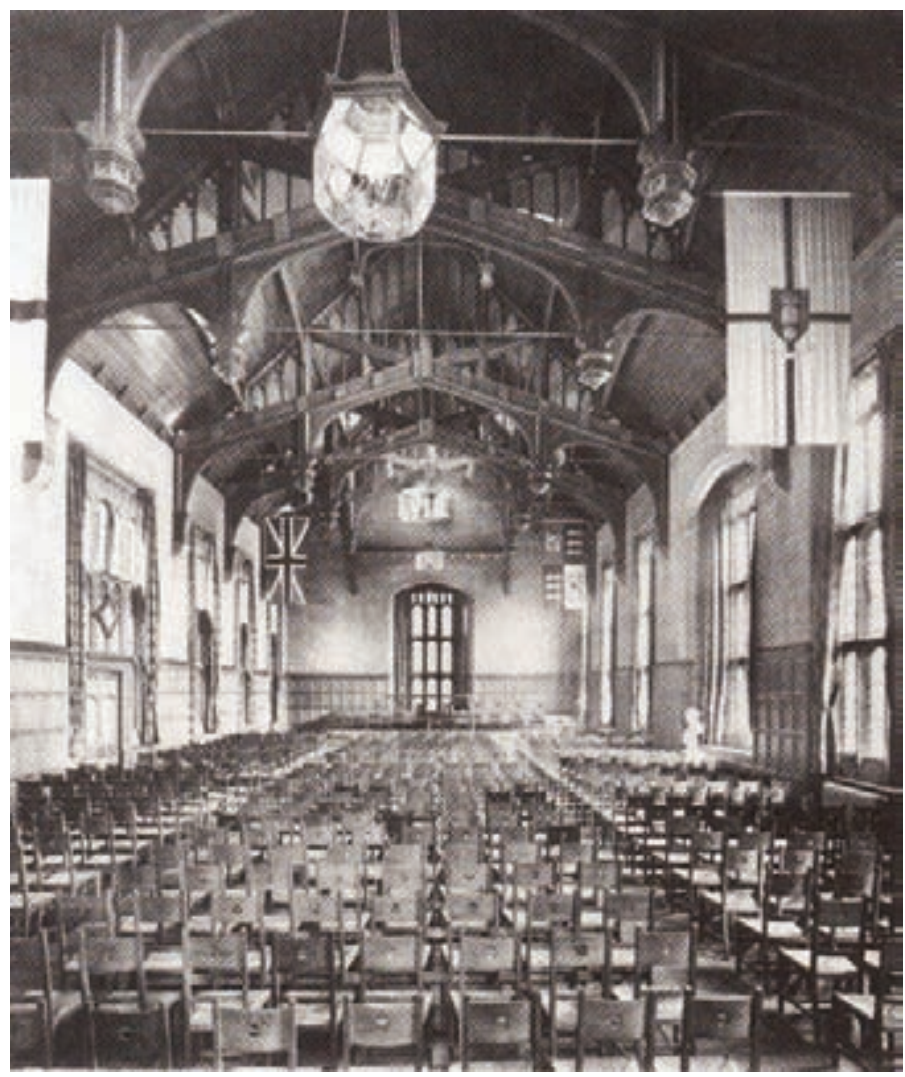

El Aula Magna, el Firth Hall. 


\section{LÁMINA II.5}

“Otra decisión interesante de Gibbs,..., consiste en articular exteriormente los alzados al parque agrupando partes del edificio en unidades individualizadas mediante gabletes..." Edward Gibbs, "Firth Court", 1903 - 1905.

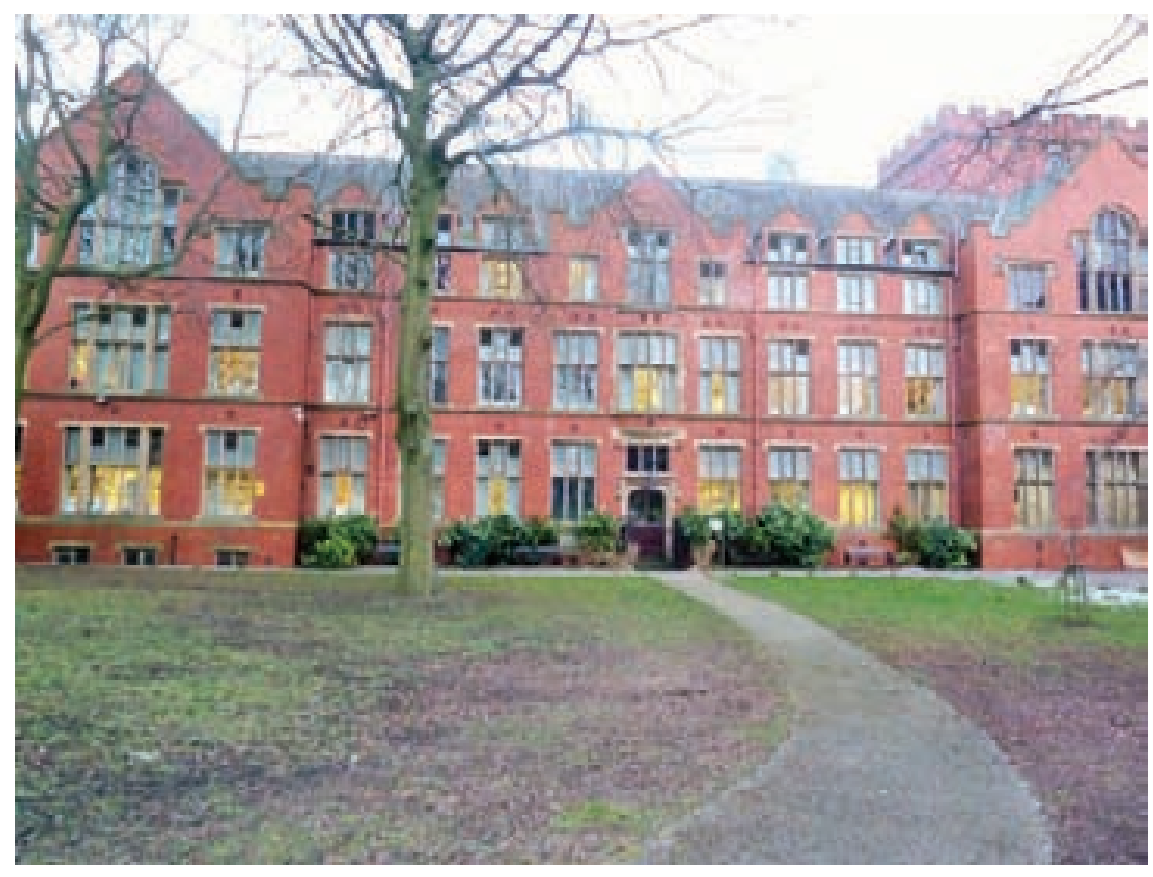

Vista del ala oeste del Firth Court desde Weston Park, Febrero 2015. Fotografía Álvaro Aparicio Serna. 


\section{LÁMINA II.6}

“...al cual infunde Gibbs un aire de fortaleza que envuelve una zona claustral interior, el llamado Quadrangle..."

Edward Gibbs, "Firth Court", $1903-1905$

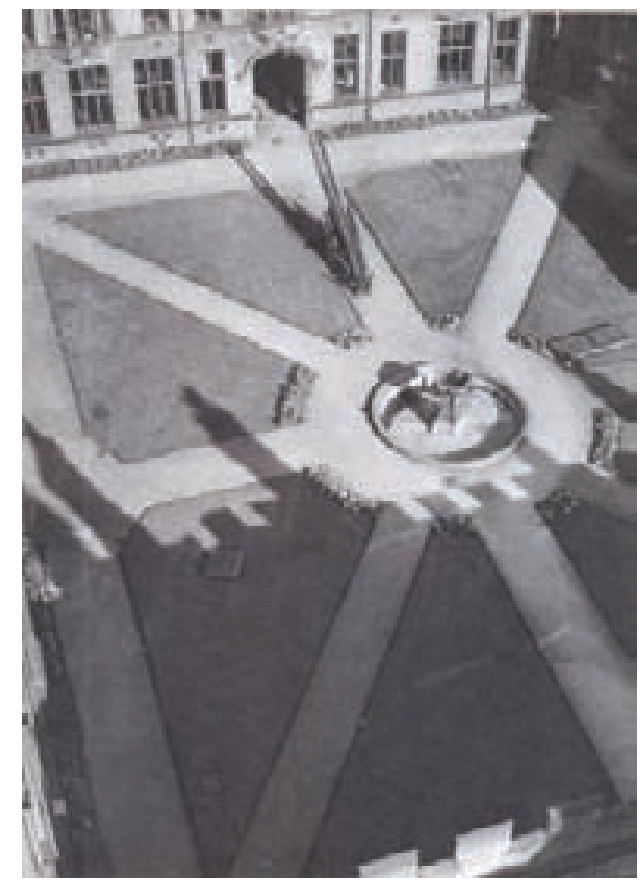

Vista del Quadrangle con el trazado original.

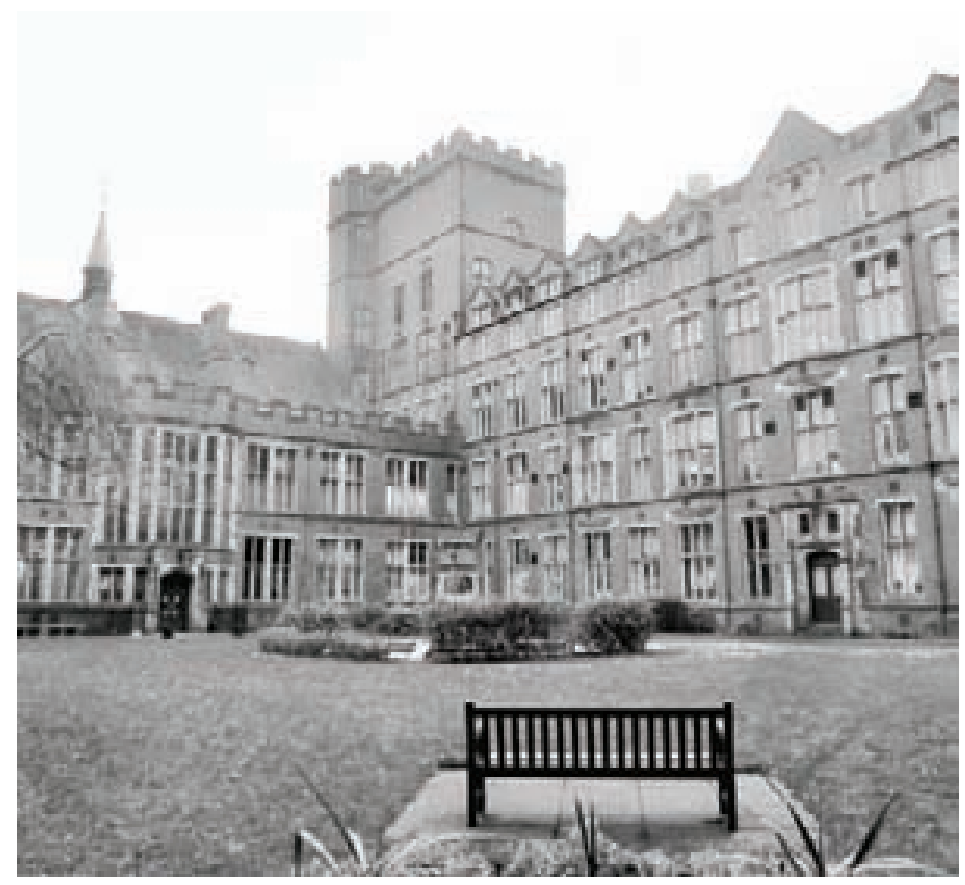

Vista del patio claustral, a la izquierda la parte posterior del cuerpo de entrada, y en el ángulo la articulación entre la escalera octogonal y el cuerpo de la Escuela de Arquitectura original a modo de Torre del Homenaje. Febrero de 2015. Fotografía Álvaro Aparicio Serna. 


\section{LÁMINA II.7}

"Al otro lado del Western Bank, se alzaba desde 1936 un discreto edificio dedicado a las actividades estudiantiles, el Students Union..."

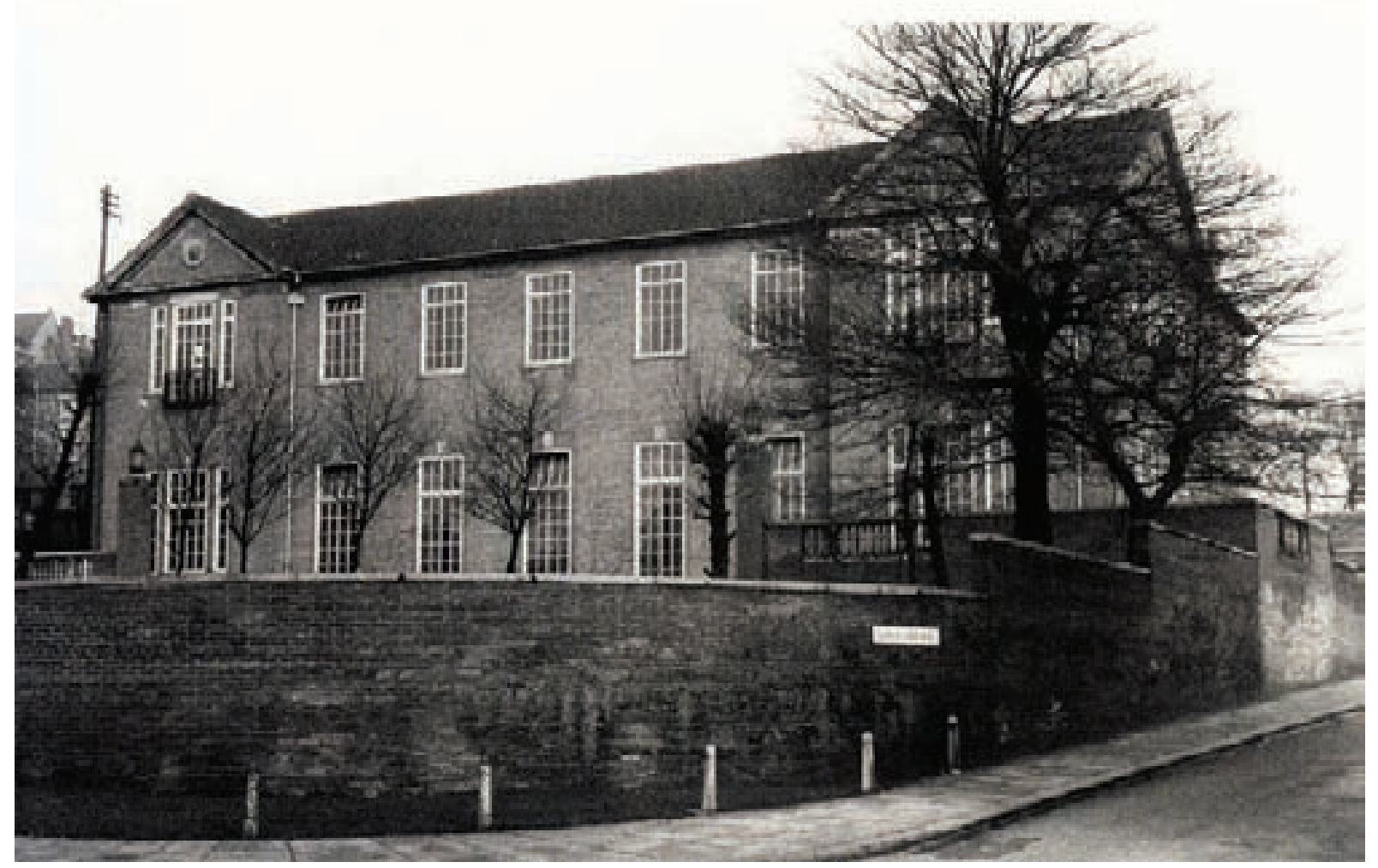




\section{LÁMINA II.8}

"Para la fecha del concurso... estaba en marcha la construcción de la facultad de Química, emplazada cerca de la confluencia en ángulo agudo de las dos calles (Western Bank y Bolsover Street)..."

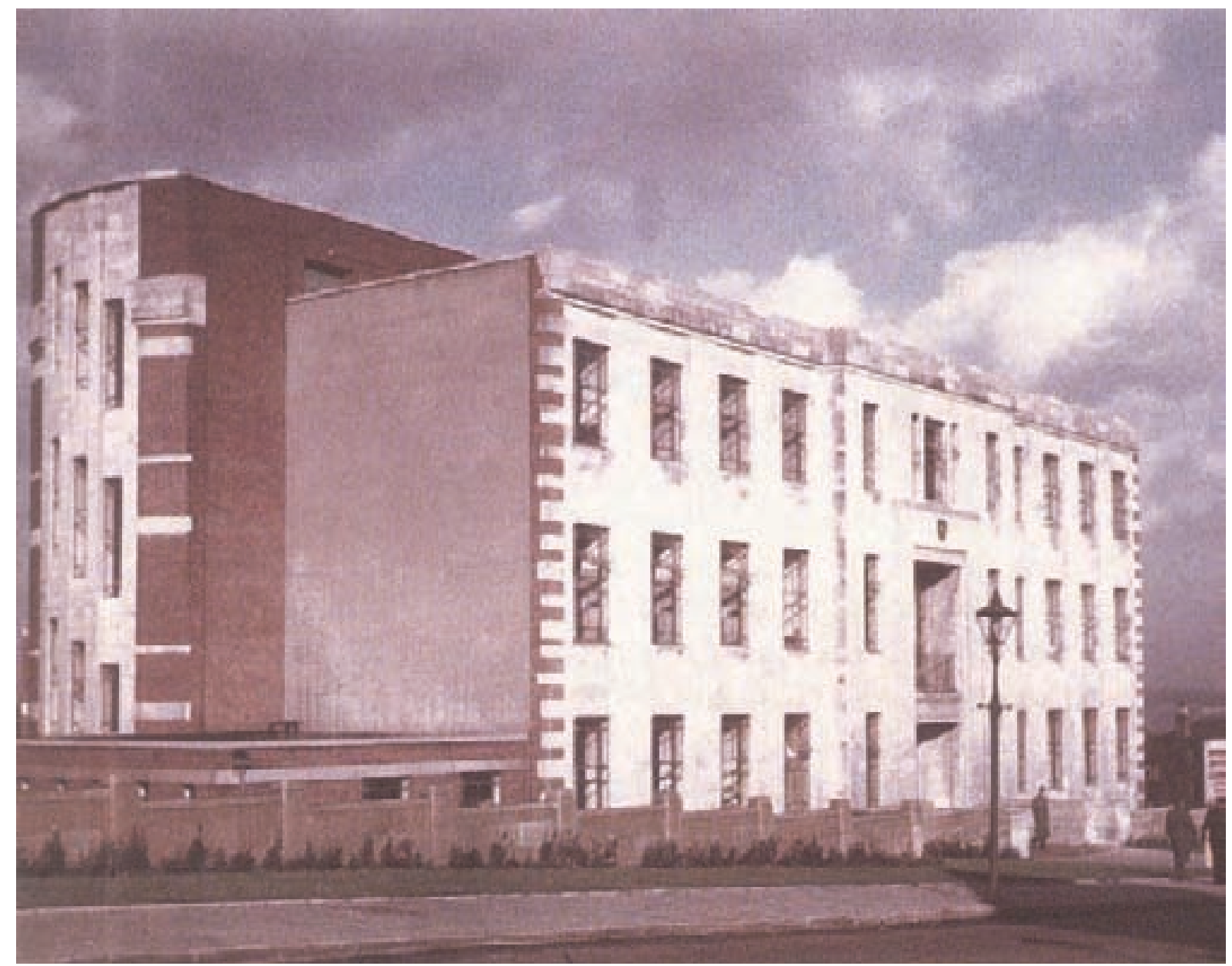




\section{LÁMINA II.9}

“...en 1953, el terreno era una mezcolanza de usos, edificaciones y viarios, que forzaban a usar la imaginación para contemplar el problema limpio y libre de tanta fragmentación..."

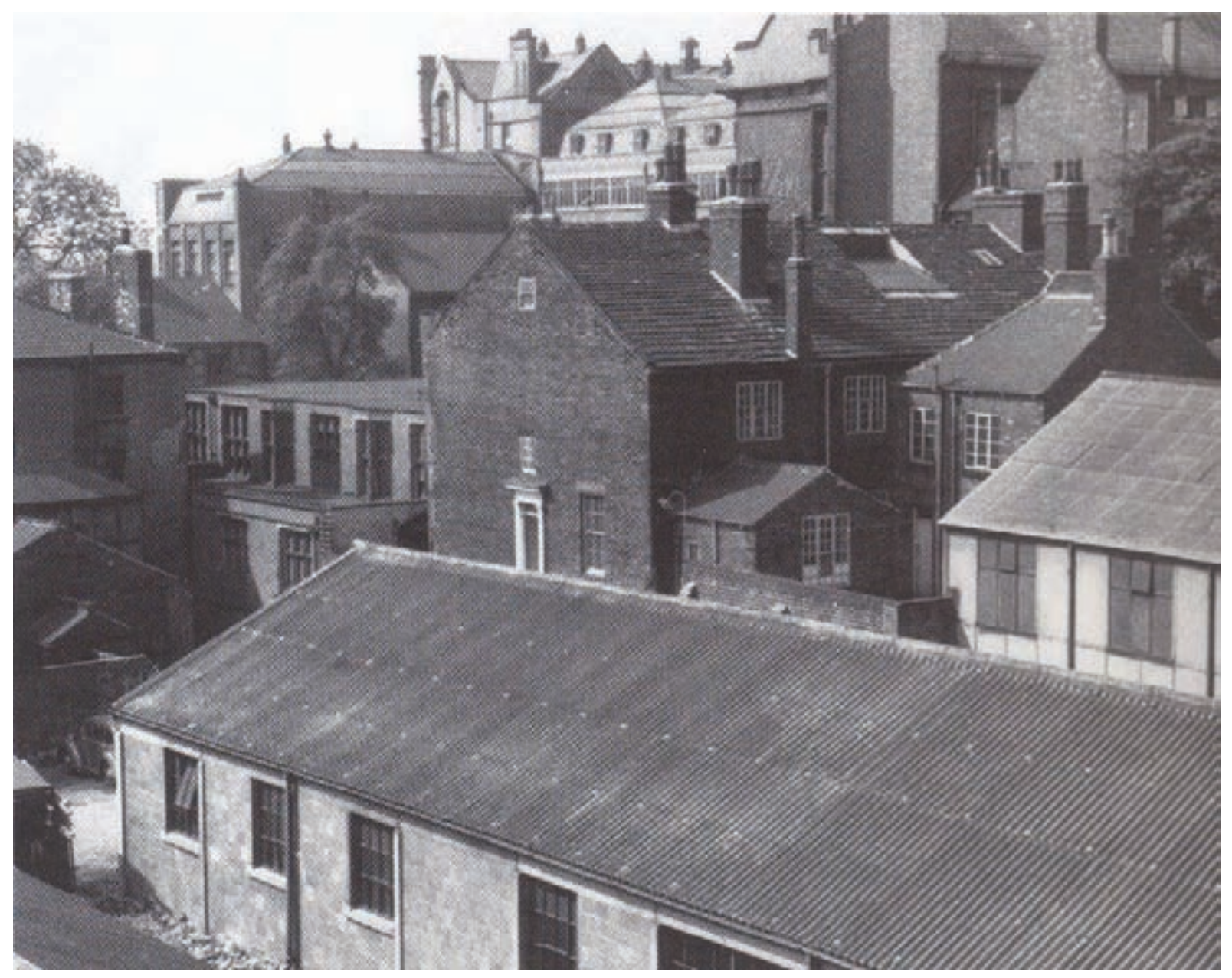

Interior del patio formado por la extensión del Firth Court. Arriba a la derecha se reconoce el lateral del pabellón de entrada con el Aula Magna (Firth Hall). 


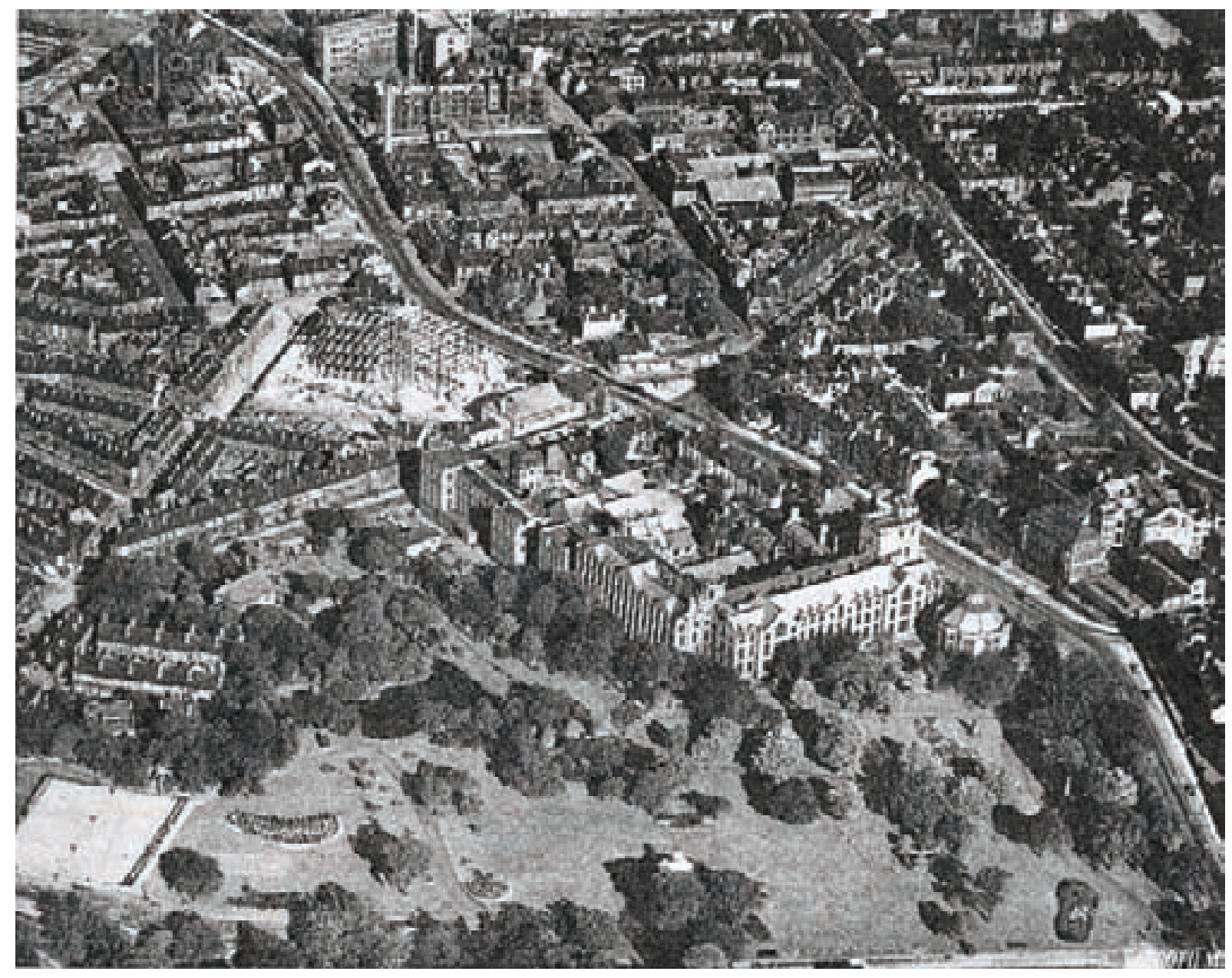

Fotografía aérea del terreno del concurso, disponible en el número del 23 de Abril de 1953, p. 487, de la revista "ARCHITECT and Building News". Obsérvese la ampliación de la Facultad de Química en construcción, el trazado todavía existente de la Winter Street y la manzana triangular de viviendas entre Bolsover Sreet y Winter Street. 


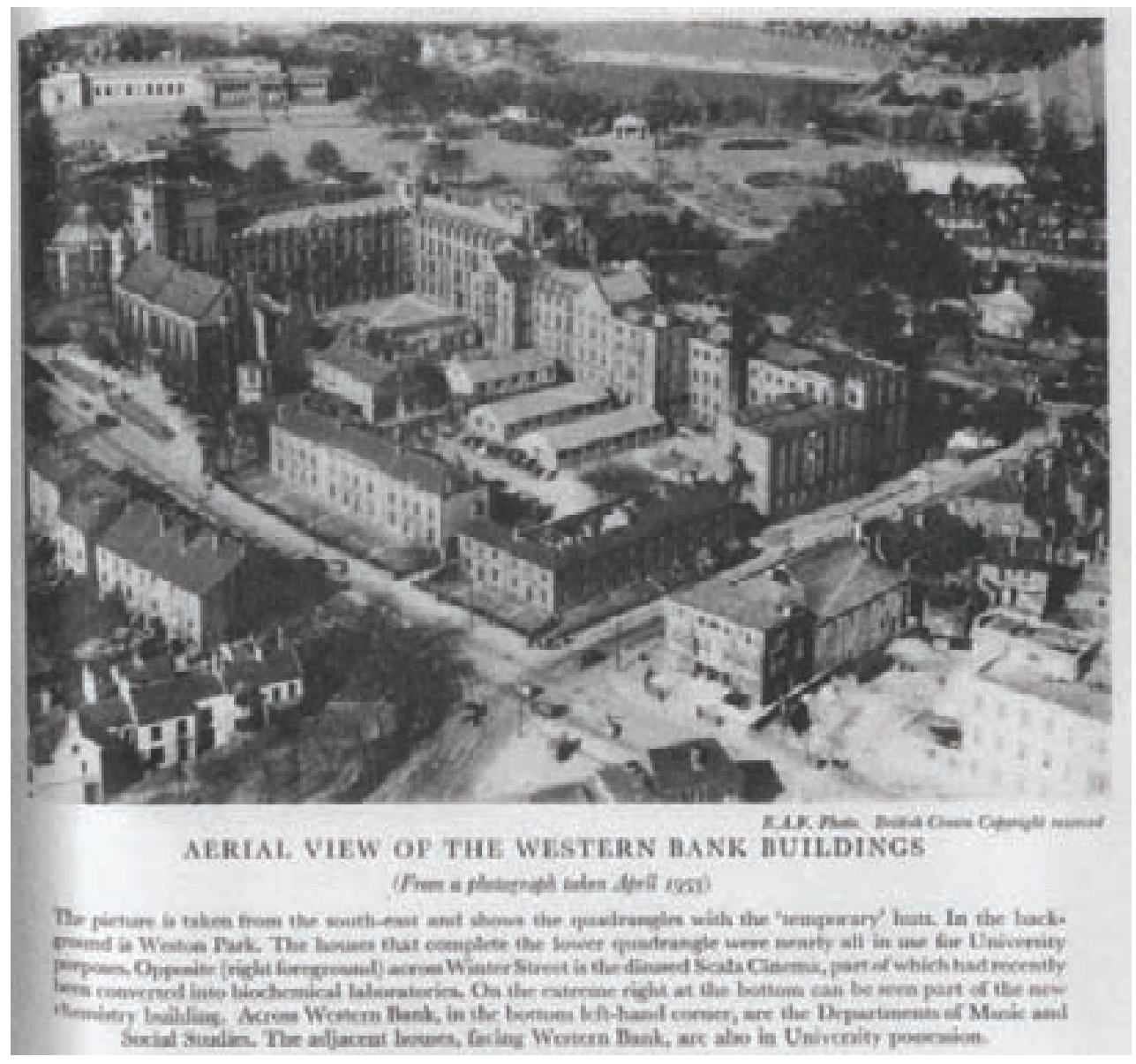

Fotografía aérea de Abril de 1953. No pudo estar disponible en la Documentación ofrecida a los concursantes dado que el periodo de consultas quedó cerrado en Marzo. Obsérvese en el ángulo inferior derecho el edificio de Química ya terminado y la colmatación del patio del Firth Court con las construcciones temporales de los laboratorios de Física y Química (existentes hasta 1962). Fuente: Tatjana Schneider, "This Building should have some sort of distinctive Shape", p. 34.

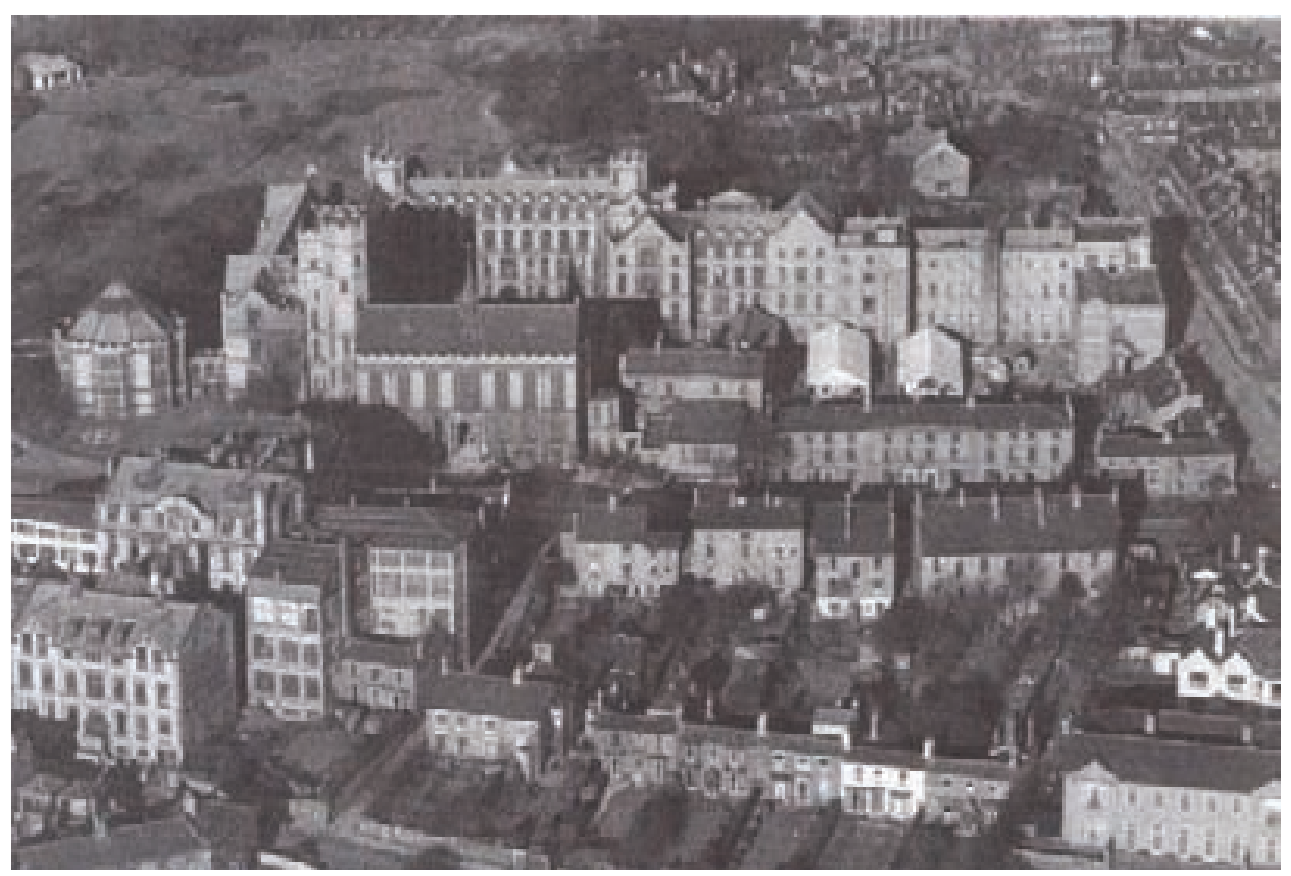

Fotografía aérea del Firth Court a mediados de los 50. En el ángulo inferior derecho el Students Union. 
tener al edificio bibliotecario como elemento común, se intersectan en el nivel de concourse. Pero aunque coexisten y se apoyan mutuamente para procurar una ramificación de los recorridos, no me ha sido posible deducir del eje lineal la posición ni desarrollo del edificio enroscado. Son, como si dijéramos, dos edificios de naturaleza diferente cuya relación espacial no deja de ser ficticia; una adherencia en varios puntos, compartiendo un mismo cuerpo edificado y atravesándose mutuamente. Aunque a primera vista pudieran parecer de la misma familia, y uno de ellos, la deformación por giros sucesivos del otro, tal planteamiento no me ha sido confirmado al tratar de plantear la génesis del proyecto. Siguiendo el símil que planteaban los Smithson de una serpiente atravesada por una lanza, resulta obvio que la naturaleza de la serpiente y la de la lanza son distintas, aunque formalmente tengan relación por tratarse de estructuras lineales. Algunos cuerpos semiindependientes como el aulario están vinculados compositivamente al eje y no al edificio enroscado.

Hay además un tercer edificio que juega en la caso del proyecto de los Smithson un papel muy destacado: es el edificio Firth Court.

La relación entre los tres edificios es distinta. Por un lado, el eje lineal atraviesa el Firth Court. Por otro lado el edificio enroscado se conecta al extremo de éste y se puede considerar que lo prolonga.

\subsection{LA FORMA REGIDA POR EL PRINCIPIO DE POSICIÓN}

Esta doble y distinta relación del Firth Court con los edificios propuestos por los Smithson me lleva a proponer la siguiente hipótesis sobre los tipos de acción llevada a cabo al proponer el diseño de Sheffield:

Por un lado, se puede plantear el eje lineal bajo el Principio de Posición, y por otro lado, el edificio enroscado, la ampliación propiamente dicha, bajo el Principio de Transición.

Los Principios de Posición y de Transición toman su razón de ser de la investigación en el cálculo infinitesimal en el siglo XVII. Planteados en nuestro contexto, estos principios desbordan seguramente la aplicación original que se proponen. Pero denuncian algunas conductas intelectuales que no quiero pasar por alto y que considero pertinentes. Por un lado, denuncian directamente a la simplificación que se esconde en Descartes bajo el apoyo insistente en las ideas claras y distintas encerrándolas bajo la presunción de ser evidentes y simples. Aunque el ejercicio que supone la transición continua para casos simplificados complica la sencillez de una fórmula general, revela sin embargo un mayor alcance; no se detiene en el cálculo, sino que busca el análisis, no le basta la tendencia sino que quiere hallar el cambio de la tendencia. Denuncia por ello el razonamiento estático que se instala en la ecuación de la igualdad exacta y le plantea la desigualdad cuyo error es menor que cualquier cantidad dada, trastocando la jerarquía entre igualdad y desigualdad: la igualdad será entonces una desigualdad con un valor residual menor que cualquier cantidad considerada. Se deshace del tope a la razón que le plantea el querer presentir inmediata o actualmente la infinitud del espacio y prefiere obrar al contrario, a través de la estricta capacidad de agregación ilimitada de la fracción semejante. De modo que, revertido el planteamiento, no 
hay por qué comenzar con una proposición que parta del espacio, sino del orden, casi valdría decir, que poniendo un pie delante de otro, en un sentido, siempre hacia el infinito, o en el otro, siempre hacia el infinitesimal, y no creo que haya que suponer mucho más: "el autor agrega que en el pretendido conocimiento de lo infinito, el espíritu ve solamente que las longitudes pueden ser puestas unas a continuación de otras y repetidas tantas veces como se quiera. Muy bien; pero este autor podría considerar que ya es conocer el infinito el conocer que esta repetición siempre se puede hacer" ${ }^{\prime \prime}$. Brunschvicg nos hace ver en el cálculo infinitesimal cómo la propia naturaleza de la razón impide que se detenga jamás y es por ello que cualquier presunción que suponga haber alcanzado la cima del conocimiento o del método no es sino eso, una presunción. Como iremos viendo, la forma de plantear la dificultad de Sheffield, el proyecto de Alison y Peter Smithson para el concurso de Sheffield, en este trabajo, parte de captar, a su vez, la dificultad de una época por poner en duda ciertas certidumbres. En este sentido, al exponer los Principios de Posición y de Transición no hago más que presentar por anticipado la conclusión. La certidumbre de la posición y la incertidumbre de la transición continua, tomarán otras caras, otros nombres, pero el pequeño proceso dialéctico del que nos ocuparemos, será siempre el mismo, la dificultad de hacer entrar el infinito. Y dará lugar a unas concepciones más metafóricas o a otras que surjan de supuestos más hilvanados: "La imagen es un punto de parada, un reposo en el movimiento de la imaginación. Nunca envuelve al infinito; el infinito no puede ser logrado por medio de la imaginación que permanece en reposo, pues siempre se reposa sobre un límite...El infinito no es una imagen estática" ${ }^{7}$ y frente a esta, la otra: "El problema del infinito en una figura no se corresponde con la actividad o el reposo de una facultad, sino más bien con el espacio en el cual se está situado y se da lugar la figura geométrica..." ${ }^{8}$

El Principio de Posición, principio básicamente espacialista, parte del supuesto de que el Todo equivale a las partes. Este principio trata, como explica Brunschvicg ${ }^{9}$ de la ciencia de lo finito, mientras que el segundo, el Principio de Transición se argumenta contra el anterior, y es propuesto por Leibniz en la crítica al procedimiento cartesiano y trata de lo infinito. El segundo principio reprocha al primero que parta de los supuestos de extensión y magnitud, y que reclame a la los cuerpos, la imagen de su masa extensa. Esquiva el problema que plantea la intuición del infinito a través de la consideración de la desigualdad dinámica.

El Principio de Posición ofrece una visión global del espacio pudiéndose actuar simultáneamente en cualquier posición de éste. Permite establecer un eje de coordenadas extendido sobre el espacio, estando cada punto determinado por su posición. Ofrece una composición armónica de las partes en relación al todo, que pueden ajustar su posición libremente ya que la percepción del espacio es unitaria.

El proyecto ganador del concurso, firmado por el equipo de

6 Leibniz, "Carta a Remond", recogido en Brunschvicg, "Las etapas de la filosofía matemática", p. 241

7 André Darbon, "Une Doctrine del Infiniti", recogido en Echeverría Ezponda "La Intuición en Matemáticas. Las Figuras y el Lugar", p. 198

8 Echeverría Ezponda Ibíd

9 Leon Brunschvicg, "Las Etapas de la Filosofía Matemática”, p. 242 
arquitectos Gollins, Melvin, Ward \& Partners es un ejemplo claro de composición bajo este Principio. Los volúmenes se distribuyen por el terreno de forma controlada, formando barreras, espacios abiertos de relación, cierres perspectivos etc. con un control total sobre las decisiones espaciales. En la mayoría de proyectos de arquitectura se maneja este principio por la conveniencia que ofrece este control espacial simultáneo sobre el conjunto, otorgando el poder de controlar la relación entre las partes. La intuición sobre la forma total está en todo momento disponible.

En el proyecto de los Smithson, una idea básica es crear un eje de circulación peatonal elevado entre dos partes bien definidas posicionalmente: el Students Union y la nueva Biblioteca. El eje se traza recto con objeto de establecer una relación de mínima distancia para un recorrido cuyos extremos están perfectamente determinados. El eje de circulación es inapelable y no duda en atravesar el Firth Court en lugar de salvarlo por deformación. En el conjunto del proyecto, en su resultado final, este eje organiza todas las partes del proyecto, pero de un modo peculiar. El eje es una fuerza compositiva monumental. Engarza todas las partes del proyecto en una unidad de nuevo cuño. Es irreprochable esta facultad que tiene el eje. Ahora bien, atraviesa los cuerpos como si ya existieran. El Firth Court es realmente preexistente, pero ¿̇y la ampliación? ¿Estaba la ampliación ya sobre el papel cuando se toma la decisión de proponer un eje para devolverle al espacio el mando de la organización del proyecto? ¿Es el eje el responsable del plan?

Todo hace pensar que el eje que parte del Students Union tiene en la Biblioteca el elemento culminante. Si hubieran ganado el concurso habrían levantado poco más que el Edificio de las Artes y la Administración, el proyecto hubiera quedado dominado por el eje que recorre la posición entre el acceso y la Biblioteca, y el concurso habría quedado resuelto a la manera cómo Le Corbusier desarrolla algunas ordenaciones secuenciales bajo un eje lineal a las órdenes de un plan. Para Amberes en 1933, y es un ejemplo muy claro del eje que se va a plantear en Sheffield, Le Corbusier propone la espiral del "zigurat" al final de un eje que comienza ascendiendo. Esta misma secuencia queda recogida en Sheffield 20 años más tarde. Pero lo que deseo hacer resaltar es que el eje funciona tras el estudio de las posiciones principales en el terreno, por dónde se accede y dónde se sitúa el elemento dominante y qué acontecimientos subdividen el recorrido. A su vez, en el caso del ejemplo de Amberes, la ubicación de este eje se complementa con otro homólogo dedicado a zona deportiva, de tal manera que encuentra acomodo entre ambos, con sencillez y nítidamente, la zona residencial en forma de cuña. Toda la urbanización de la lengua de terreno envuelta por el meandro adquiere una estructura geométrica global y unitaria, y, en este sentido la ordenación final lo que revela es un cálculo previo de las posiciones y direcciones principales del terreno en su globalidad. Deducir de un proyecto como éste algo diferente a una organización por partes subordinadas supondría dotar a estas de una autonomía compositiva de la que carecen.

No hay que bajar a los años treinta para encontrar ejemplos de

LÁMINA II.11 control sobre el territorio mediante la disposición de un eje de enlace entre posiciones distantes entre sí. Hacia 1950, un contemporáneo y compañero de estudios de Peter Smithson en la Universidad de Durham como Gordon Ryder propone, como encargado del equipo 
creado para la ocasión por Lubetkin, un sistema de ejes en el Plan Director del área minera de Peterlee. Ryder pone en relación zonas separadas del territorio eligiendo algunas posiciones clave que son enlazadas mediante un eje lineal. La idea es armar geométricamente una gran porción de territorio mediante un completo control espacial, estudiando la ubicación de los elementos principales. Tres bloques lineales que forman una $Y$ espacial, y un elemento dotacional, a cuya posición dominante le corresponde establecer el nexo con otras áreas alejadas, se articulan por medio de un eje conector. Esto da idea del tratamiento unitario de todo el espacio intervenido aceptando que el espacio puede y debe ser considerado como un elemento dado y cuya consistencia como agregado de partes relacionables entre sí de diversos modos no se pone en duda. Deducimos de ello como resultado una acotación clara de la extensión que coincide o se solapa con la propia intervención y los límites, por lejanos que parezcan, o queden fuera de área tratada, son partes integradas a este espacio por medio del establecimiento de los ejes, sean éstos visuales, o físicos (viarios) como es el caso presentado. El espacio, en fin, no toma del eje su fuerza generatriz, más bien al contrario, es el eje el resultado de haber adoptado previamente como partes sobresalientes dos lugares del espacio.

La doctrina presente en el proyecto de Alison y Peter Smithson para la nueva planta de la Catedral de Coventry parte del mismo supuesto del Principio de Posición. No muy lejano del proyecto de Peterlee, ni en el tiempo, 1951, ni en las intenciones, cosa por otra parte nada extraña, dado que Alison Smithson tuvo a Gordón Ryder de profesor en la Universidad de Durham ${ }^{10}$, el proyecto de Coventry aspira a poner en relación por medio de un eje a la propia catedral con el centro de la ciudad, y como tal se señala en el plano de situación indicando dos puntos singulares en el recorrido, y, se remarca mediante un puente que, penetrando los restos de la torre, termina en una de las capillas laterales. Como señalan los autores en la memoria, "el eje que une el centro de la ciudad con la antigua torre pasa a ser el elemento dominante y la base sobre la que se construyen las armonías geométricas de la catedral”11. Este eje, materializado en un puente al salvar el foso que rodea la torre, y con una suave pendiente ascendente hacia la capilla elevada del interior, inclinación que acompaña la cubierta de la catedral en su movimiento, presenta los rasgos característicos que luego se desarrollarán plenamente en Sheffield: esto es, el cruce con un segundo eje normal a éste, la elevación respecto al nivel del terreno, la penetración en una estructura existente y la inclinación ascendente hacia el objetivo final. Adquieren estos acontecimientos, desarrollados en un pequeño intervalo de extensión, la categoría de predicados de lo que ha de consistir un eje. Digamos, que se enlazan sucesivamente estos acontecimientos como los términos que se cuelgan a la definición de lo que ha de ser todo eje que se precie: linealidad, rectitud, elevación, facultad de penetrar otros cuerpos, ascensión y finalmente culminación en un lugar singularmente escogido.

Todo lo que un eje es o simboliza, su concepto, se recoge en estos predicados. Le Corbusier define el eje como la línea de conducta

10 Véase Rutter Carroll, "Ryder and Yeats", pp. 1 y 2.

11 Alison Smithson y Peter Smithson, "Concurso para la Catedral de Coventry" recogido en Marco Vidotto, "Alison + Peter Smithson. Obras y Proyectos", p.30 
hacia un objetivo ${ }^{12}$, y de nuevo nos hayamos ante predicados como la rectitud, la elevación, la firmeza para atravesar los vaivenes y la culminación. Es ésta última, sin duda, la condición primera del eje, la definición de un objetivo, establecer un límite preciso. Obsérvese que la diferencia con la doctrina del infinito expuesta por Leibniz, radica en que no basta con proponer la acción de añadir una longitud tras otra y suponer que la acción se puede repetir indefinidamente, sino, todo lo contrario, pensar que esta acción se va a llevar a cabo un número limitado de veces, y elucidar cual va a ser el número real que marque el límite de la sucesión. Y es así, que el infinito es un tipo de planteamiento que repugna a Le Corbusier: "En arquitectura es preciso que el eje tenga un objetivo. En la Escuela se ha olvidado esto y los ejes se cruzan en estrellas, todos hacia el infinito, lo indefinido, lo desconocido, la nada, el sin fin. El eje de la Escuela es una fórmula, un truco". ${ }^{13}$

No estamos tratando aquí, por tanto, de un eje barroco sino de un eje regido por el Principio de Posición.

Veamos cómo se forjan los arquitectos ganadores del concurso de Sheffield la idea del eje. He nombrado antes al equipo ganador, GMW, formado en Londres en 1947, por Frank Gollins (nacido en 1910), James Melvin (1912) y Edmund Fisher Ward (1912). Antes o

LÁMINA II.13

LÁMINA II.14 durante el concurso habían ya presentado un proyecto de College de Tecnología y Comercio para la Universidad de Sheffield en asociación con la Oficina Técnica municipal, y por tanto, el concurso no debió de resultarles del todo ajeno ${ }^{14}$. Para el concurso de Sheffield, GMW, plantea, como otros concursantes (todos de los que tengo información gráfica excepto el de los Smithson), una ordenación de bloques entorno al trazado de la Winter Street, que, recordemos corta en dirección norte sur el área de la Universidad, dejando una zona residual en cuña al este, ocupada por el nuevo edificio de Química. GMW propone, en paralelo a la Winter Street una peatonalización del área al este de la calle a modo de plaza rectangular a la que se abren al oeste la Biblioteca y al este la torre de las Artes. Este emparejamiento de los edificios principales mediante la plataforma peatonal da a entender que el centro del campus, de la vida social universitaria, se va disponer en esta plaza. De Western Bank nace el acceso al campus tras cruzar por debajo el bloque lineal de la Administración y la Facultad de Química, aprovechando el desnivel del terreno con fuerte pendiente este - oeste. Al sur de Western Bank, en paralelo al bloque anterior, se localiza la pastilla de uno de los dos edificios destinados a Medicina. El resto de edificios se distribuyen más o menos camuflados entre las construcciones existentes, aunque cabe resaltar, situados a un lado y al otro de la plaza peatonal, la Escuela de Arquitectura (un cuerpo de una planta con iluminación cenital), entre la ampliación posterior del Firth Court y el bloque lineal propuesto, y enfrente el Edificio de Calderas, semienterrado. La solución, por tanto, plantea una dirección principal de desarrollo norte sur que funciona como un eje que polariza el resto de las posiciones. El eje, necesita como requisito una secuencia de objetos o acontecimientos enlazados. En este caso, desde el Students Union parte el desarrollo lineal, que recorre por debajo el cuerpo del edificio destinado a servicios universitarios y comedor, cruza bajo la Facultad de Medicina, atraviesa a nivel Western Bank, y cobra pleno

12 Le Corbusier "Hacia una arquitectura", p.151

13 Ibíd.

14 Véase "Architectural Design", Mayo 1953, p. 148 
sentido al traspasar la zona de pilares que sustentan la Facultad de Física hasta llegar a los puntos álgidos del recorrido, la Biblioteca y la Torre de las Artes, que sin embargo no aciertan a rematar el eje, que termina "desinflado" en Bolsover Street. Se ha interpretado, con frecuencia, la deuda que la relación entre el cuerpo bajo de la Biblioteca y la Torre de las Artes, ha establecido con la Lever House de SOM y con el Seagram Building de Mies van der Rohe. Respecto a este segundo, cabe hacer notar la reinterpretación que se produce en el proyecto de GMW de la posición lateral del Seagram Building con el eje de Park Avenue. En el caso del proyecto de GMW para Sheffield esta primera solución lateralizada, además de dar por válida esta asociación con el Seagram, responde también a una composición "abstracta" en la que intervienen las figuras y posiciones de los diferentes rectángulos que forman la biblioteca, la Torre y el bloque lineal de la Administración y el Departamento de Física, bordeando tres de las cuatro costados de la plataforma peatonal, en una relación que combina equilibrio y dinamismo, ciertamente a la manera ya ensayada por Mies en el Campus del ITT.

La solución final del proyecto, con la nueva ubicación de la Torre de las Artes en el extremo norte (que aloja definitivamente la Escuela de Arquitectura), centrada sobre el eje, es más coherente con la naturaleza del propio eje y de la torre. En esta nueva posición, la Torre de las Artes, con sus 20 plantas y siendo el edificio más alto de Sheffield, se beneficia del eje, dado que ordena incuestionablemente su acceso axial, acorde a la magnitud y pureza volumétrica del edificio. En tanto que éste encuentra en ella el remate en un punto álgido apropiado. Digamos con simplicidad que GMW han llevado el proyecto finalmente del lado de Le Corbusier.

\section{LA FORMA REGIDA POR EL PRINCIPIO DE TRANSICIÓN}

El Principio de Transición fue propuesto por Leibniz para trascender el concepto de ecuación cartesiano. No es por tanto un principio intuitivamente espacial sino formal. Sin embargo tiene un gran alcance. Se entiende bien con el siguiente ejemplo de Belaval: "La idea de número no nos ofrece más que un ejemplo aproximado, en primer lugar porque la definición euclídea de la unidad numérica (Einsheit) sólo tiene sentido a partir de la idea de todo y de unidad metafísica (Einheit). Además también porque, al ser la idea una expresión, existen varias expresiones de una misma esencia divina: La intuición que tenemos del 1 ya no es la misma si lo pensamos como unidad supuesta simple o según la igualdad $1=1 / 2+1 / 4+1 / 8+\ldots$ El primer pensamiento se refiere, o parecerse referirse, al contenido de la idea, y, por tanto, parece justificar la regla cartesiana de la evidencia, el segundo pensamiento concierne a una génesis, su evidencia es la de una operación lógica distinta." ${ }^{15}$

Para Echeverría, ahondando la explicación de Belaval: "Lo que Leibniz va a criticar en Descartes es precisamente la idea de que sólo existe una intuición de la unidad propia a la aritmética, que sería la unidad simple y se expresaría en el número 1...Leibniz...la va a ampliar a la metafísica... Leibniz sustituye las figuras como forma de expresión 


\section{LÁMINA II.10}

"El concurso habría quedado resuelto a la manera cómo Le Corbusier desarrolla algunas ordenaciones bajo un eje lineal a las órdenes de un plan..."

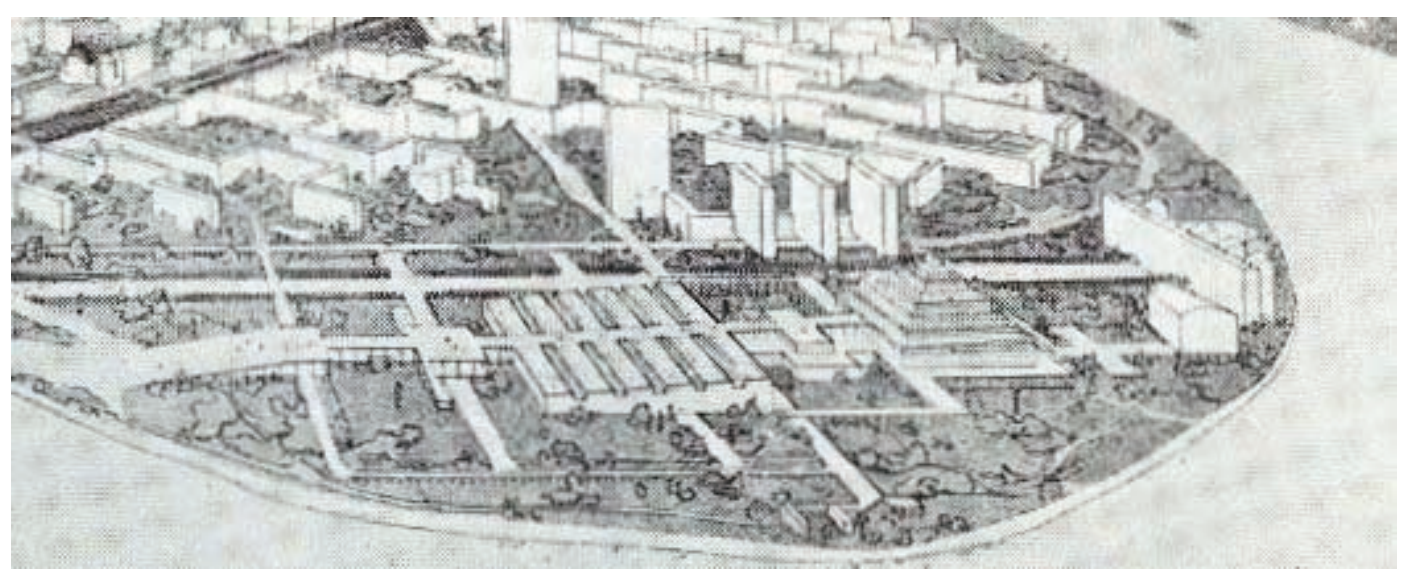

Le Corbusier, "Urbanización de la Rivera izquierda del Escalda, Amberes”, 1933, imagen parcial.

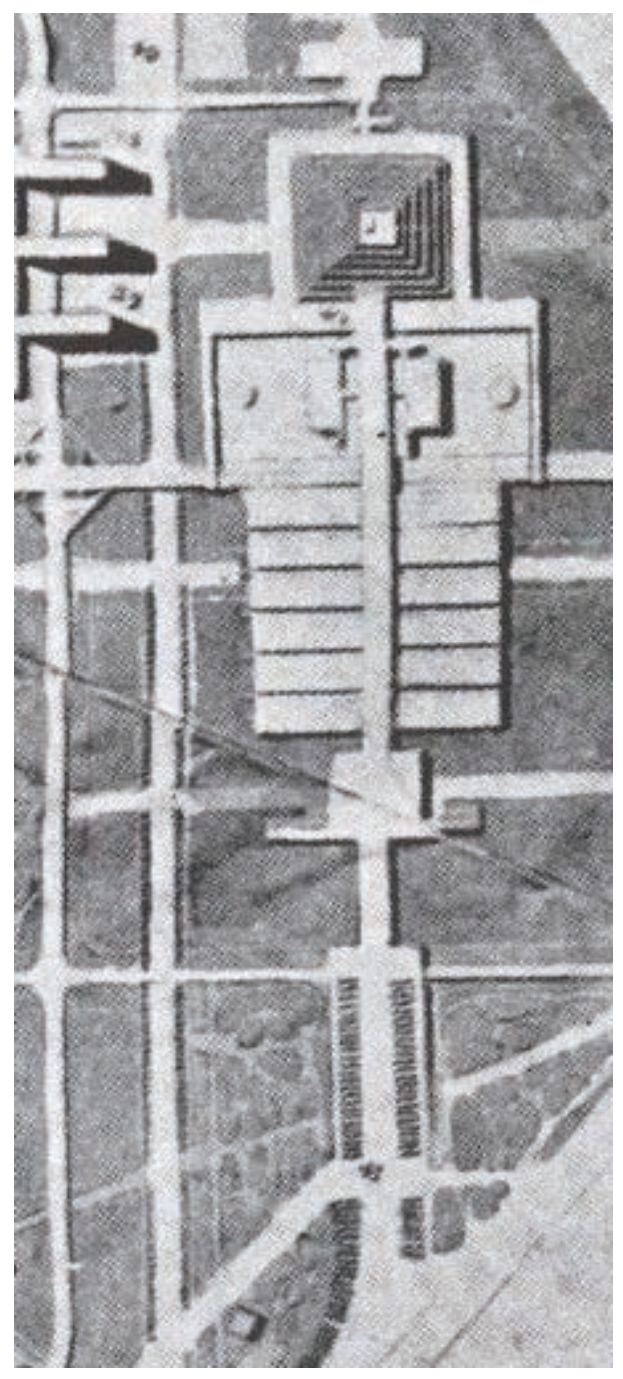




\section{LÁMINA II.11}

“Hacia 1950, un contemporáneo y compañero de estudios de Peter Smithson en la Universidad de Durham como Gordon Ryder propone... un sistema de ejes en el Plan Director del área minera de Peterlee ..."

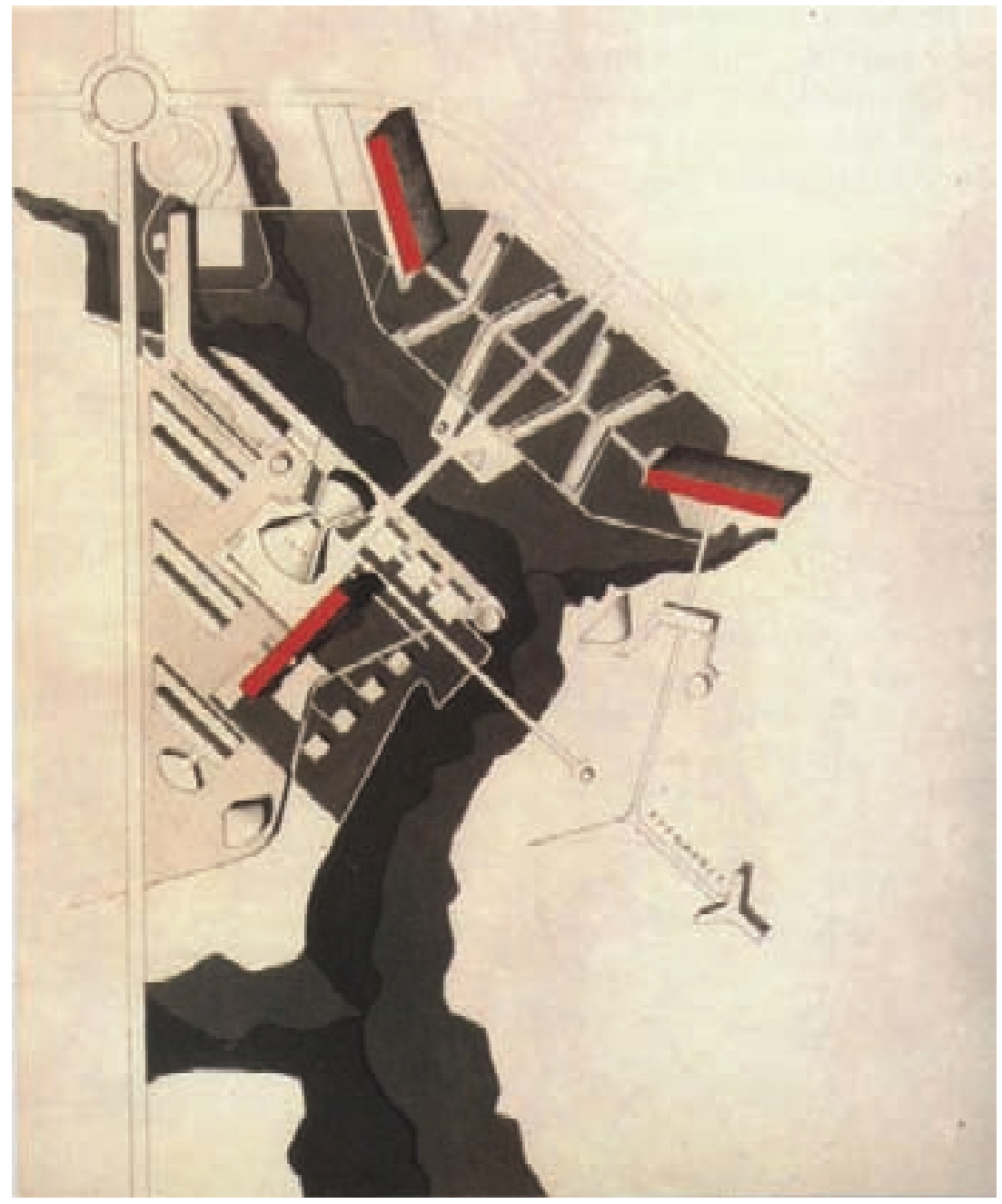

Gordon Ryder (como arquitecto principal del grupo liderado por Bertold Lubetkin): "Plan Director de Peterlee" hacia 1950. 


\section{LÁMINA II.12}

“No muy lejano del proyecto de Peterlee,... dado que Alison Smithson tuvo a Gordon Ryder de profesor en la Universidad de Durham, el proyecto de Coventry aspira a poner en relación por medio de un eje a la propia catedral con el centro de la ciudad... "

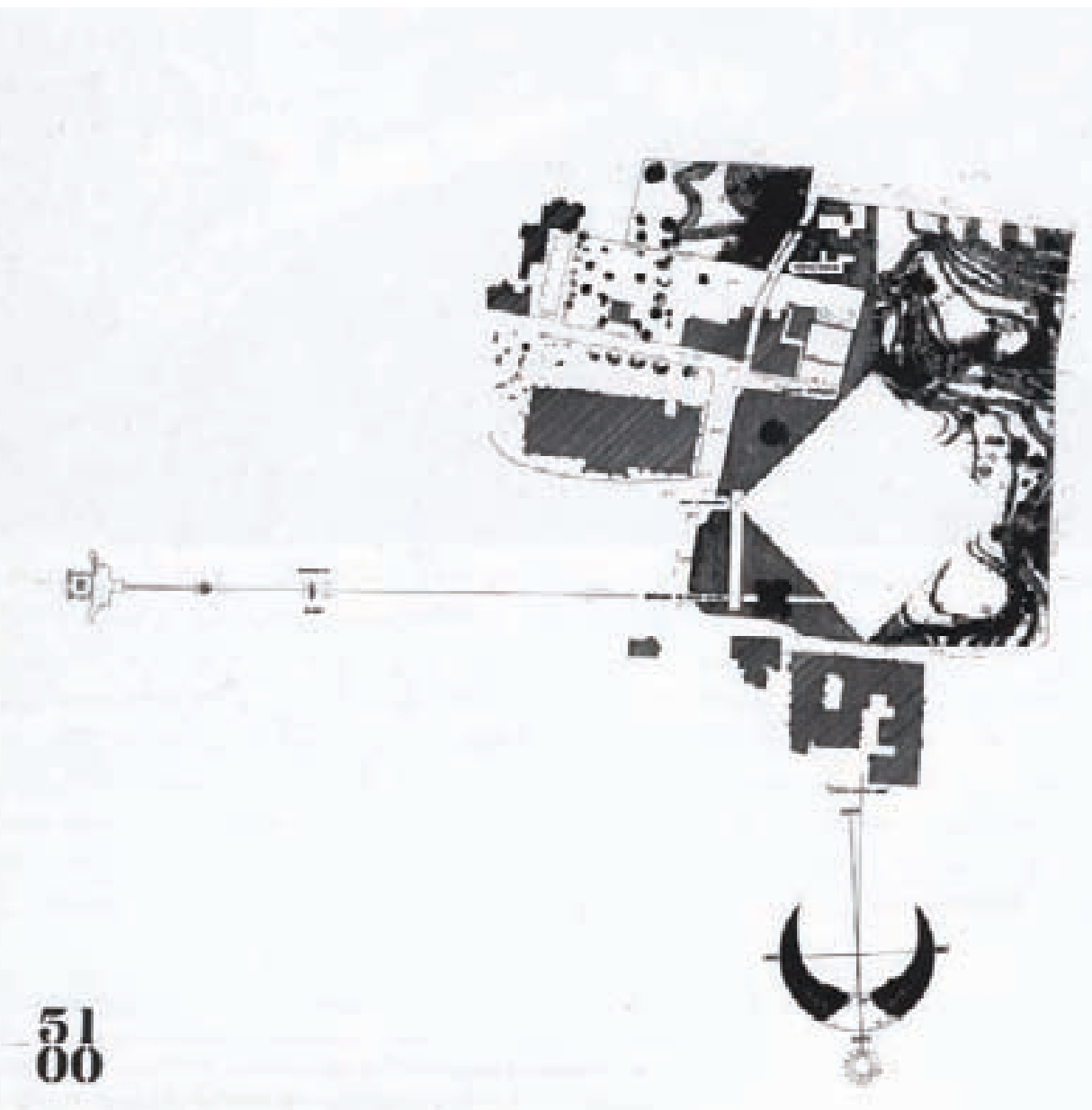

Site plan. Air. 


\section{LÁMINA II.13}

"Antes o durante el concurso (GMW) habían presentado un proyecto de College de Tecnología y Comercio para la Universidad de Sheffield en asociación con la Oficina Técnica Municipal, y por tanto, el concurso no debió de resultarles del todo ajeno..."

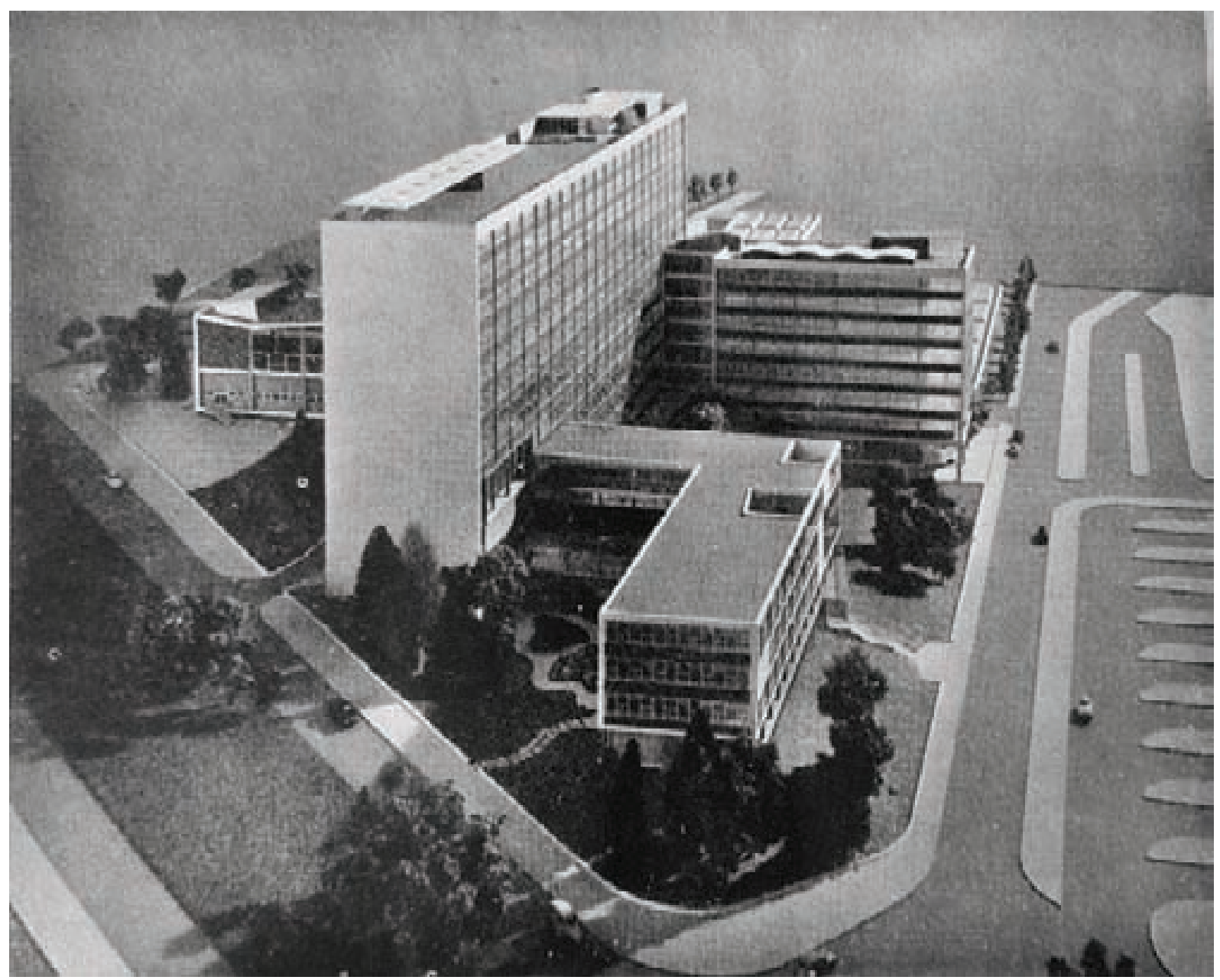

Gollins, Melvin y Ward (GMW): “Facultad de Tecnología y Comercio”, Sheffield.

Fuente Architectural Design, Mayo 1953, p. 148 


\title{
LÁMINA II.14
}

“...desde el Students Union parte el desarrollo lineal, que recorre por debajo el cuerpo destinado a servicios universitarios y comedor, cruza bajo la Facultad de Medicina, atraviesa a nivel Western Bank, y cobra pleno sentido al traspasar la zona de pilares que sustentan a Facultad de Física hasta llegar a los puntos álgidos del recorrido, la Biblioteca y la Torre de las Artes, que sin embargo no aciertan a rematar

\author{
el eje..."
}

Gollins, Melvin y Ward (GMW): “Concurso de Ampliación de la Universidad de Sheffield", 1er. Premio.

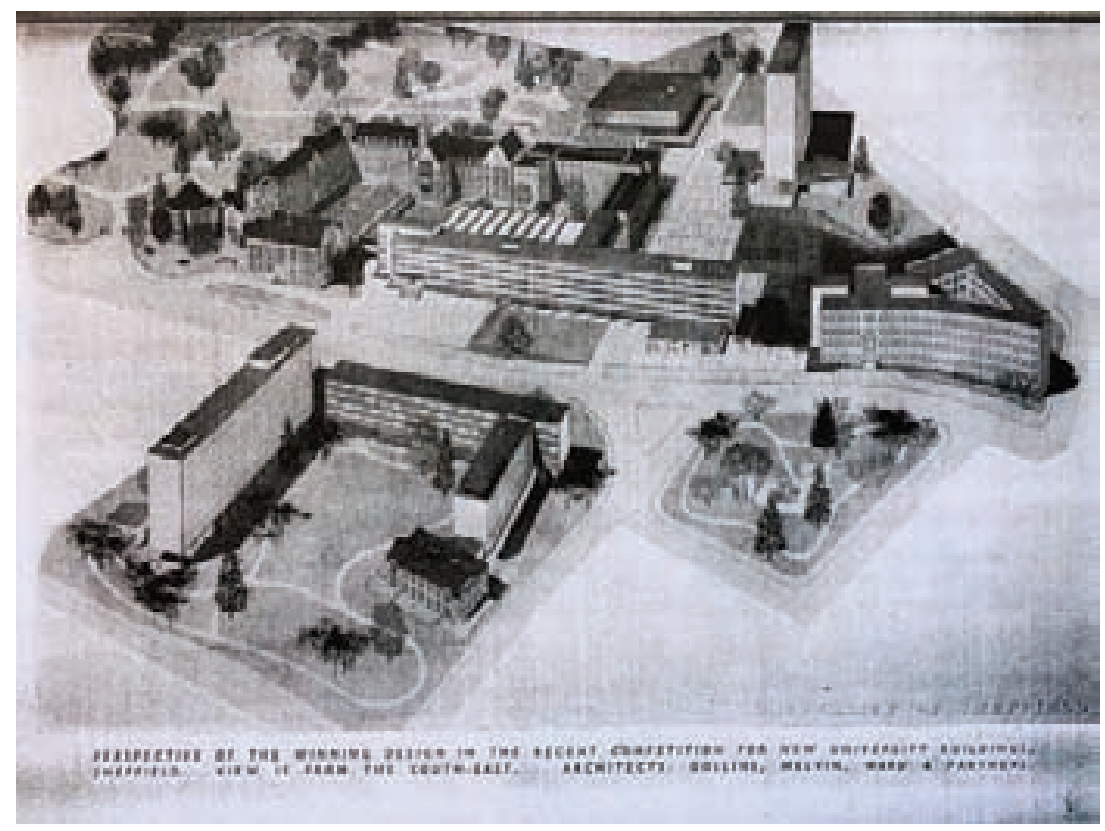

Perspectiva de Concurso. Fuente "The Architect and Building News", 31 Diciembre, 1953.

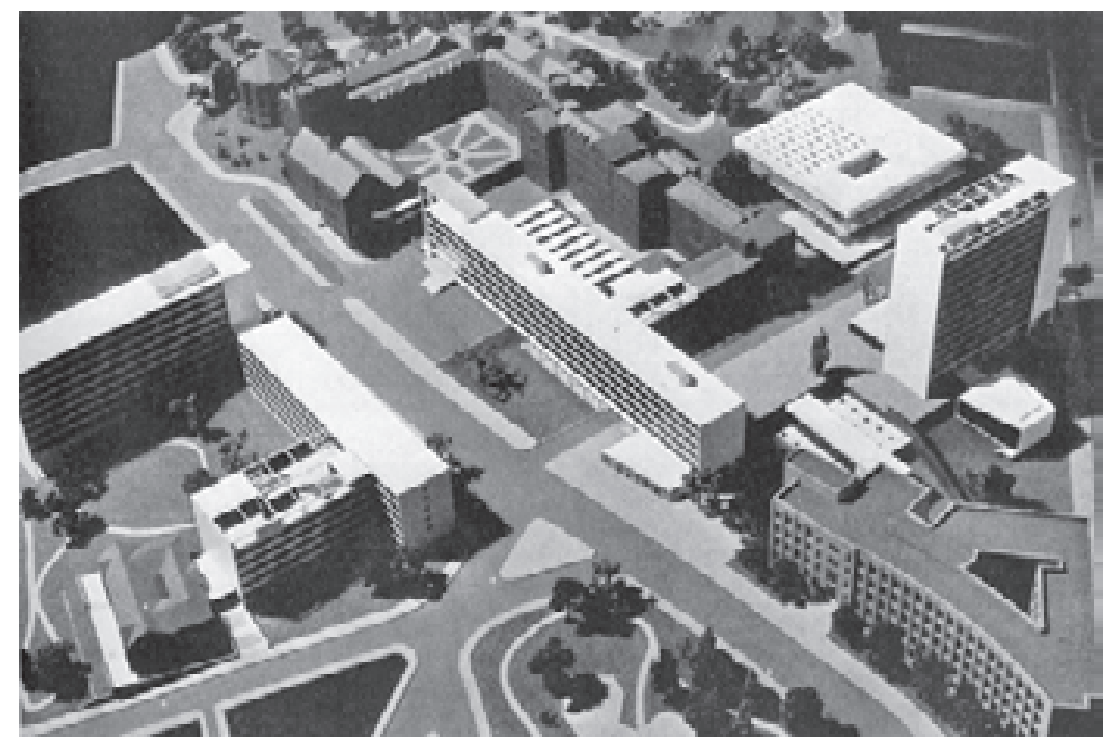

Maqueta de presentación en la Royal Academy. Fuente "Architectural Design", Mayo 1954, p. 163 


\section{LÁMINA II.15}

"La solución final del proyecto, con la nueva ubicación de la Torre de las Artes en el extremo norte, centrada sobre el eje, es más coherente con la naturaleza del propio eje y de la torre..."

Gollins, Melvin y Ward (GMW): “Concurso de Ampliación de la Universidad de Sheffield", desarrollo del proyecto.

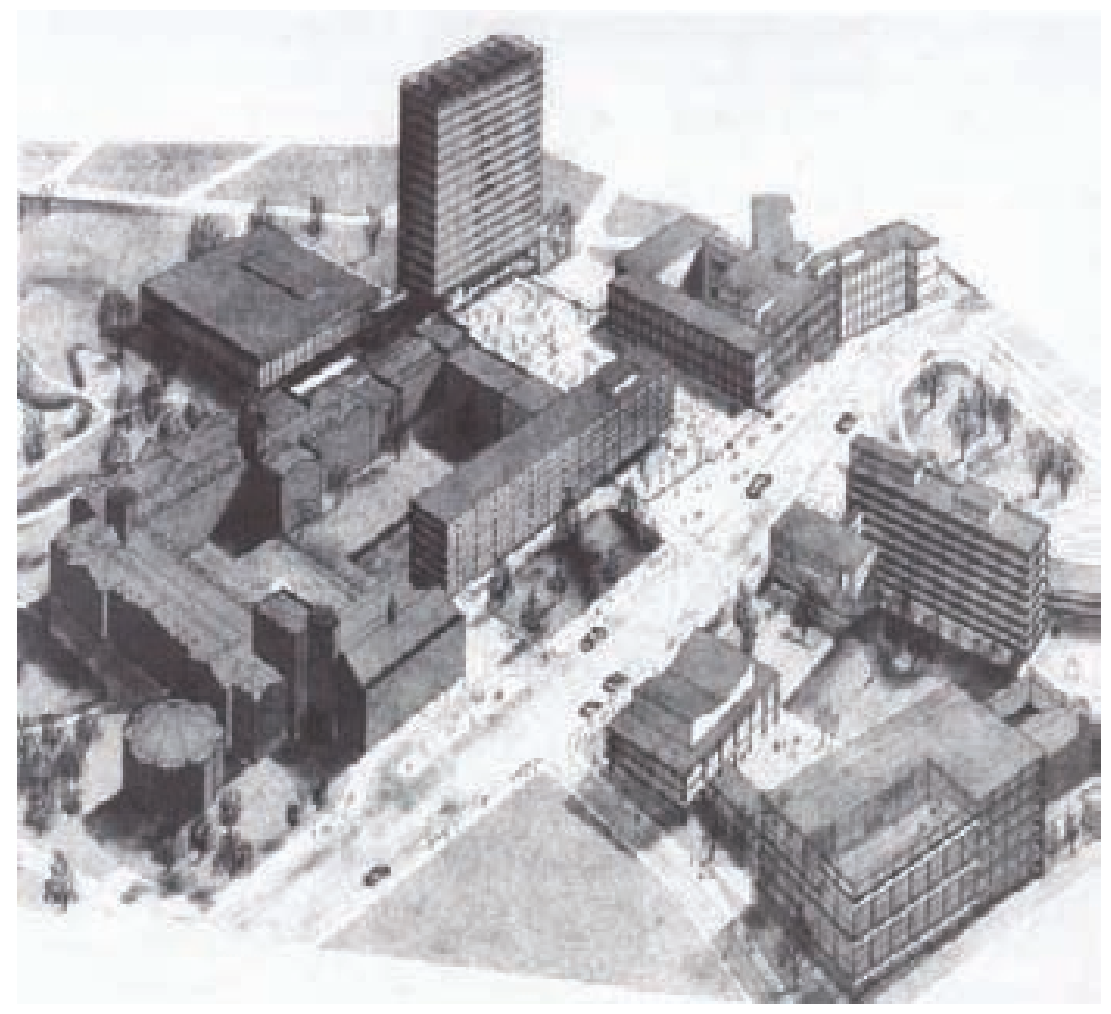

Perspectiva de 1957 de la versión definitiva. Fuente: Helen Mathers "Steel City Scholars. The Centenary History of the University of Sheffield", p. 172

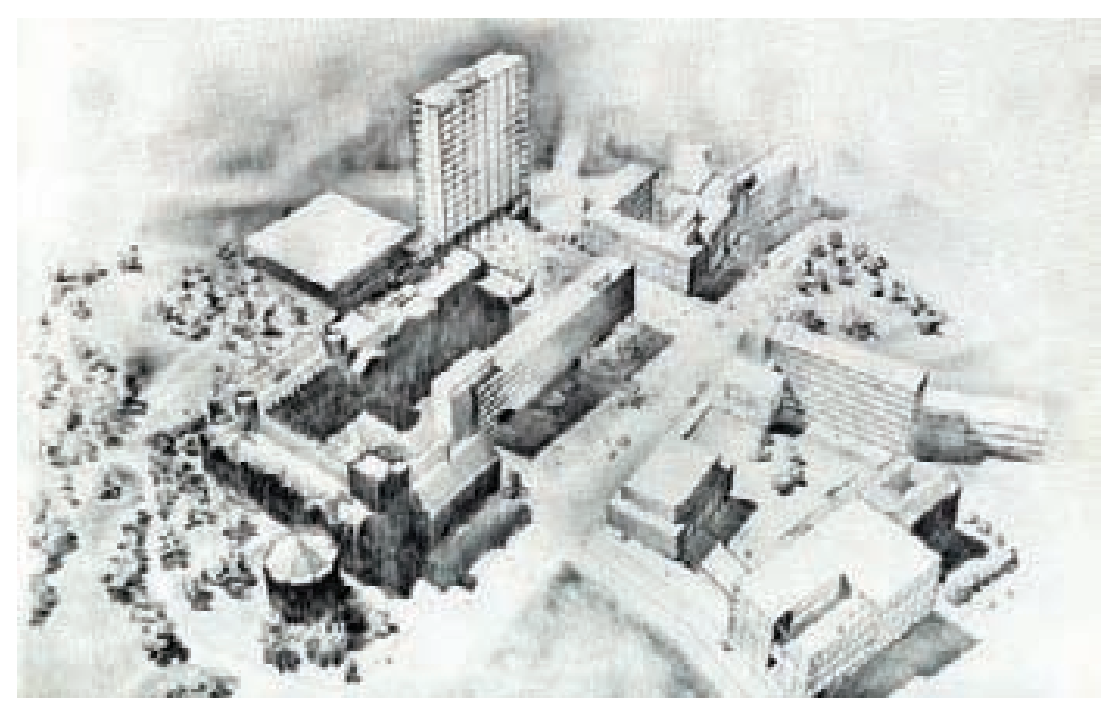

Variante de la perspectiva anterior. Fuente: "Architectural Review", Octubre 1957, p. 249 


\section{LÁMINA II.16}

“En esta nueva posición, la Torre de las Artes,..., se beneficia del eje,...en tanto que éste encuentra en ella el remate en un punto álgido apropiado..."

Gollins, Melvin y Ward (GMW): "Concurso de Ampliación de la Universidad de Sheffield", comparación en planta de la solución de concurso y la definitiva.

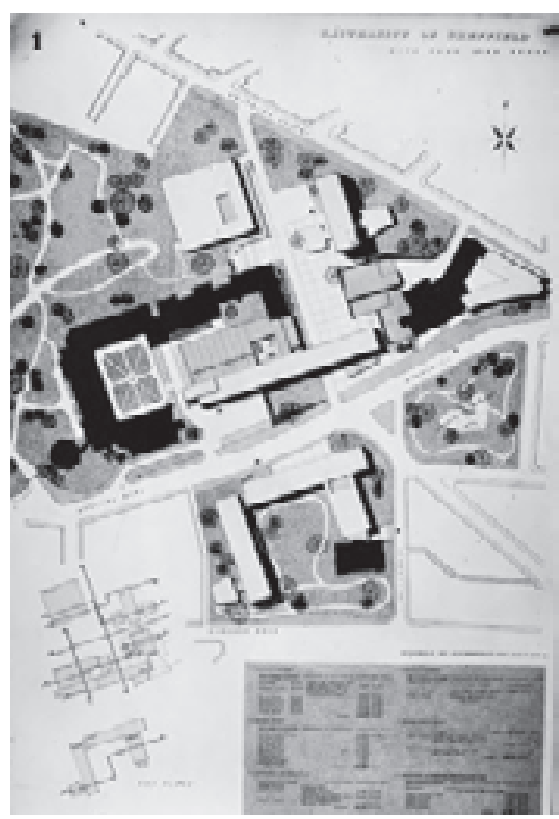

Ordenación en planta de 1953.

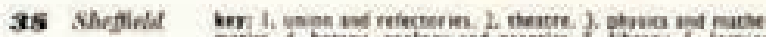

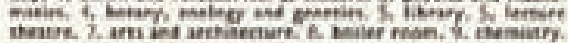

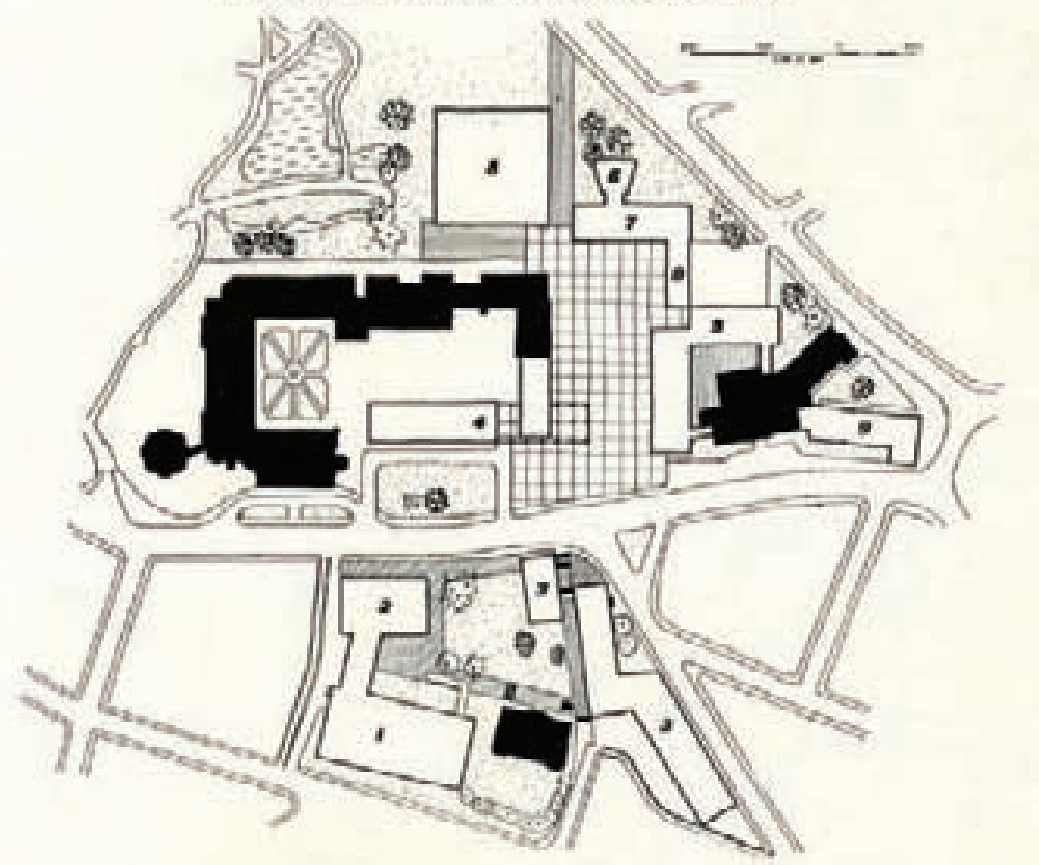

Ordenación definitiva de 1957. Fuente: “Architectural Review”, Octubre 1957, p. 249 
Traspasado al tipo de espacio formal, la serie numérica queda definida en un extremo por la igualdad y abierto a la indeterminación por el otro extremo. Mientras, como hemos visto en el Principio de Posición, la condición del espacio es ser absoluto y definitivo, unitario en sí, lo que abre el Principio de Transición es que un entendimiento del espacio sólo es accesible por medio de múltiples visiones parciales que dependen dinámicamente de la posición que adopta el punto de vista. Para Hocquenghem y Shérer el punto de vista es "finito en lo que descubre y afirma, y a la vez infinito en su dinámica (el posible cambio de vista, su fuga hacia delante)"17 . De esta segunda interpretación parte una reconsideración de la perspectiva, que concuerda en esencia con la expresión de infinita divisibilidad de la unidad en una sucesión de términos. De aquí, como veremos más adelante, que la perspectiva admita en potencia una sucesión indefinida de puntos de vista que se suman entre sí, destruyendo la regla de la evidencia cartesiana de la intuición unitaria del espacio como naturaleza extensa, lo que . Hocquenghem y Shérer consideran bajo la teoría de las mónadas como "esta pluralidad primordial de la unicidad" ${ }^{18}$. Como consecuencia no hay una única forma de encarar el espacio; hay otra, que se resume bajo la puesta en duda de la existencia del espacio mismo. No es el espacio el objeto directo de Leibniz, sino la ordenación, el acto razonable de colocar en orden, del conglomerado de lo infinitamente compuesto hasta su invisibilidad "la multiplicidad de las mónadas... absorbe en ellas la realidad de la objetividad espacial"19 . Y en sentido inverso, partiendo de lo minúsculo, de la concentración de fuerzas monádicas, es donde el espacio encuentra el principio mismo de su despliegue. Citan Hocquenghem y Shérer a Michel Serres: "La metafísica de Leibniz... no es una lógica pura, sino una pasión interna de existir, de salir, de estar fuera" 20 Es la otra intuición sobre el espacio, la de atender a su surgimiento, de la que ahora nos ocupamos.

En el Principio de Transición el espacio no se ofrece a una única mirada inmediata, sino que se revela en la duración. No interesa cristalizar la duración por medio de la ley de recurrencia ni del término general de la sucesión, sino contemplar frente a frente el despliegue mismo, o la subdivisión de la materia paso a paso hasta el infinitesimal y nuevamente, siempre compuesta, "como la más pequeña partícula de polvo contiene un mundo con infinidad de criaturas" ${ }^{21}$. Cuando se invoca a lo infinito el problema se plantea al fin en los nuevos términos distintos a los del finito. Los nuevos términos obligan a bajar al nivel donde se genera el espacio, que en este trabajo adoptará la forma de un punto de aplicación de la fuerza de estiramiento.

Acorde con la conjugación de ambos principios, en Sheffield coexisten dos naturalezas distintas de tomar el espacio que se vuelven, a mi modo de ver irreductibles una a otra. Ver el edificio enroscado

16 Javier Echeverría Ezponda Ibid, p. 337

17 Guy Hocquenhem y René Schérer, "El Alma Atómica. Para una estética de las era nuclear", p. 70

18 Ibíd., p. 71

19 Ibíd.

20 Ibíd., p. 72

21 G.W. Leibniz, "Carta a la Princesa electora Sofía" en G.W. Leibniz "Filosofía para Princesas", p. 70 
plenamente desarrollado, la ampliación, es hacer uso de una visión unitaria del espacio. Responde a una visión descriptiva pero no nos dice nada en cuanto a su génesis.

La alternativa que ofrece el Principio de Transición es, como en la serie numérica, una acción de estiramiento. El espacio en la serie esta definido desde la propia secuencia de la iteración. En Sheffield se adopta una secuencia rítmica estructural que se va distendiendo a partir de un extremo del Firth Court, ejerciendo sobre éste una acción de estiramiento por la que se genera a su vez el espacio. El espacio de la ampliación, de la serpiente ${ }^{22}$, sólo parece surgir bajo la acción de estiramiento que ejerce el avance de la estructura. Comparativamente se puede asociar a la acción constructiva de un encofrado deslizante. La ley de composición de este edificio es intrínseca a él mismo y por este motivo obra con total independencia del eje entre el Students Union y la Biblioteca.

Si consiente en llamarse un segundo eje, lo será a costa de inclinar en exceso la definición de eje dada anteriormente, dado que no contempla como objetivo una posición fija. En efecto, nada impide suponer que la metáfora ante la que nos sitúa la espiral ofrece una reducción logarítmica cuyo final tenderá a cero en una aproximación al $90 \%$, al 99\%, al 99,9\%, al 99,99\%, al 99,999\%... indefinidamente.

Pero tampoco contempla la facultad del atravesar cuerpos, facultad que también define al eje. Mientras que el eje responde a una verdad geométrica y nada le impide concebirlo sin perder la continuidad antes y después de chocar contra el ala del Firth Court, o sea atravesarlo, la ampliación pierde la dirección como consecuencia de entrar en el espacio de la Facultad de Química, Esta deformación en la dirección se ejerce sobre la dirección del vector de estiramiento. Naturalmente ocurre de nuevo con la posición de la Bolsover Street, que le confiere otro cambio de dirección. Por último, la atracción de la posición de la biblioteca determina el movimiento en espiral enroscándose en sí misma. ¿Qué línea de conducta podría estimar Le Corbusier que ésta? Aquella sin un objetivo, y por tanto indefinida en su peor acepción.

A partir de las contradicciones que presenta la ampliación ésta se resiste a ser tratada como un segundo eje. De donde podemos distinguir un eje de otro que no lo es, en función de su espacialidad o materialidad. El primer eje responde a un criterio espacialista y el segundo a uno corpóreo, de agregados, donde la materia tiene un peso específico. $Y$ respecto al primero, en tanto relacional, no es sino algo ideal, un orden entre dos posiciones, que si cambiaran de lugar arrastrarían consigo al eje. Supuestas ésta inmóviles el eje no es sino la traza. Por su elevación, el eje no dejaría ni la huella sobre lo único

22 Ya he comentado el símil que establecen Alison y Peter Smithson entre la forma de la ampliación y la serpiente. El texto es el siguiente: "Los nuevos edificios forman una especie de serpiente con una astilla atravesando su cuello, la rizada biblioteca sería su cola, y el Aula Magna su cabeza", en Alison y Peter Smithson, "De la Construction Orientée" memoria redactada como contribución al libro dirigido por Gyorgy Kepes, "La Structure dans les Arts et dans les Sciences", p.112. El texto fue redactado en 1962 pero no apareció publicado hasta 1965 cuando vio la luz al libro de Kepes. Además, según se recoge en la revista "arena. The Architectural Association Journal", Febrero 1966 , p. 211, debió haber algún problema debido a cambios tipográficos efectuados en la edición del libro que no se correspondían con las intenciones de los autores. 
inmóvil, el terreno. El segundo sin embargo recibe el tratamiento de un cuerpo, y, por tanto, le cuelgan las propiedades de la materia, por un lado, ser impenetrable y no penetrar, sino chocar y variar de rumbo, su divisibilidad siempre posible y su peso sujeto a la atracción. En este sentido, como pura materia, la forma le viene de solicitaciones exteriores o si se quiere, sus acontecimientos no le son intrínsecos tal como definen al eje, y esto plantea que pueda ser definida, con propiedad, como una estructura abierta. En tanto no se trata ya de algo ideal o puramente espacial, sino de un cuerpo, está determinado en sus propiedades por la existencia. $Y$ en este punto se revela el hecho dual de este proyecto. Para un cuerpo, la asunción de tales o cuales masas hacen que su trayectoria y la posibilidad de describir una figura rectilínea o quebrada estén influenciadas por la propia estructura del campo en el que está inmerso. Para un espacio, que responde sólo ante solicitaciones geométricas, tal aspecto le es indiferente.

En Sheffield se dan la mano un planteamiento finito y otro infinito de la arquitectura. Uno hunde sus raíces en la tradición del espacio y lo traslada hacia una composición por ejes. El otro surge de la aplicación de fuerzas a un espacio que, comprimido en un punto en el extremo del Firth Court, contiene el principio de virtualidad, el deseo de existir, el conato de salir fuera. Nace del estiramiento de la materia y depende de la acción. La presencia simultánea de las dos figuran que se dan en estos espacios revela el carácter dual que marca la imagen de Sheffield, su monstruosidad, su belleza y su poder perturbador.

Con el resultado diseccionado sobre la mesa veamos que la dualidad converge en el proyecto de Alison y Peter Smithson porque consiguieron reunir en ellos las fuerzas que se debatían a finales de los cuarenta y primeros cincuenta.

Pero antes de que el debate estuviera siquiera en el horizonte, presentaré de qué manera la obra de Unwin en Hampstead basaba la producción del espacio residencial a partir del estiramiento de los bordes las vías de circulación, acción topológica sin la cual no se hubiera podido llevar a cabo esta urbanización.

\section{EL PRECEDENTE DE UNWIN. EL CLOSE}

La idea de una generación del espacio por estiramiento en contraste con la intuición inmediata y simultánea del espacio tiene, según mi opinión, un precedente en la teoría del site planning esbozada y desarrollada por Raymond Unwin.

Unwin distingue dos formas de planeamiento: el site planning y el Town planning. La escala del Town planning es la escala urbana, y su interés radica en armar la conveniencia general de la ciudad. La escala del site planning por el contrario es de detalle, y su primera consideración pasa por la disposición de las edificaciones y la urbanización del terreno en aras de sacarle el mayor partido.

La aplicación del site planning la llevó a cabo junto a Barry Parker en la urbanización de la ciudad jardín de Hampstead en 1909, el año que echaba a andar la Universidad de Sheffield. El problema que detecta Unwin es la definición de un ancho de vía mínimo de entre 12 y $15 \mathrm{~m}$. para todas las vías de circulación sea cual sea su posición y su finalidad, y, como expone él mismo son tan absolutamente inadecuadas para las vías principales de la ciudad como excesivas para 
dotar de acceso a una pocas viviendas.

Al afrontar la urbanización de Hampstead consiguió la aprobación de una ley parlamentaria que permitiera una mayor flexibilidad sobre el ancho de las vías. Concretamente nos interesa la siguiente aprobación:

"Otra cláusula permitía a la sociedad (la sociedad Hampstead Garden Suburb) construir vías cuya longitud no superara los $150 \mathrm{~m}$. con una anchura de $6 \mathrm{~m}$. (repárese que la mitad del ancho de vía estándar), siempre y cuando las casas a ambos lados de la calle distaran entre sí más de 15 m... En el plano de Hampstead Garden Suburb se ve cómo estas vías más estrechas de lo normal se utilizaron ampliamente y dieron lugar a la formación de muchos grupos de casas alrededor de zonas verdes, campos de tenis y plazas que no se hubieran podido obtener sin las atribuciones contenidas por esta Ley. ... y aunque se reserven $6 \mathrm{~m}$. por vía, en muchos casos resulta suficiente construir una calzada de 4 m." 23

Gracias a esta iniciativa, como refiere él mismo:

"Muchas de estas organizaciones (de viviendas) fueron posibles gracias a unos poderes especiales obtenidos por el Hampstead Garden Suburb, que le permitieron bajo ciertas condiciones utilizar calzadas ligeras para el tráfico rodado con el fin de acceder a grupos de casas en lugar de las vías ordinariamente requeridas por las ordenanzas de la edificación." ${ }^{24}$

La pretensión de Unwin, su acierto al planificar atendiendo a criterios de entorno próximo para mejorar la situación de la vivienda, fue conseguir reducir el ancho mínimo de vía obligado hasta entonces por la ley, para formar grupos de casas servidas desde un ramal secundario. Como señalan Cambi, Di Cristina y Steiner:

"La manzana especulativa rectangular cede su sitio a manzanas más grandes, edificadas en gran parte en su interior, donde penetran calles sin salida. Un núcleo de casas individuales con espacios abiertos comunes y una calle de servicio sin salida forman "el close", el módulo de proyectación urbanística adoptado en el suburbio de Hampstead..." 25

\section{LÁMINA II.18}

El conseguir una reducción del ancho de vía, permitía a Unwin disponer de una vía secundaria estirando uno de los bordes de la vía principal, deformando por estiramiento la calzada lateralmente hasta crear un fondo de saco alrededor del cual se disponían las viviendas formando un close. Este procedimiento por estiramiento lateral del borde de una banda es una operación de la misma naturaleza espacial que las vistas en el caso de Sheffield. Es en efecto una aplicación del Principio de Transición para generar un espacio a partir del estiramiento, cuyo punto de aplicación, en este caso, no es sobre un extremo de la estructura lineal sino sobre un borde de la misma. Como señala Unwin,

"En todos los casos el terreno se desarrolla desde una vía a la que los edificios quieren naturalmente dar el frente..." 26

23 Raymond Unwin p. 239

24 Ibid p. 241

25 Cambi - Di Cristina - Steiner "Tipologías Residenciales en Hilera”, p. 9

26 Unwin, Ibid p. 260 


\section{LÁMINA II.17}

“La aplicación del site planning la llevó (Unwin) a cabo junto a Barry Parker en la urbanización de la ciudad jardín de Hampstead en 1909, el año que echaba a andar la Universidad de Sheffield..."

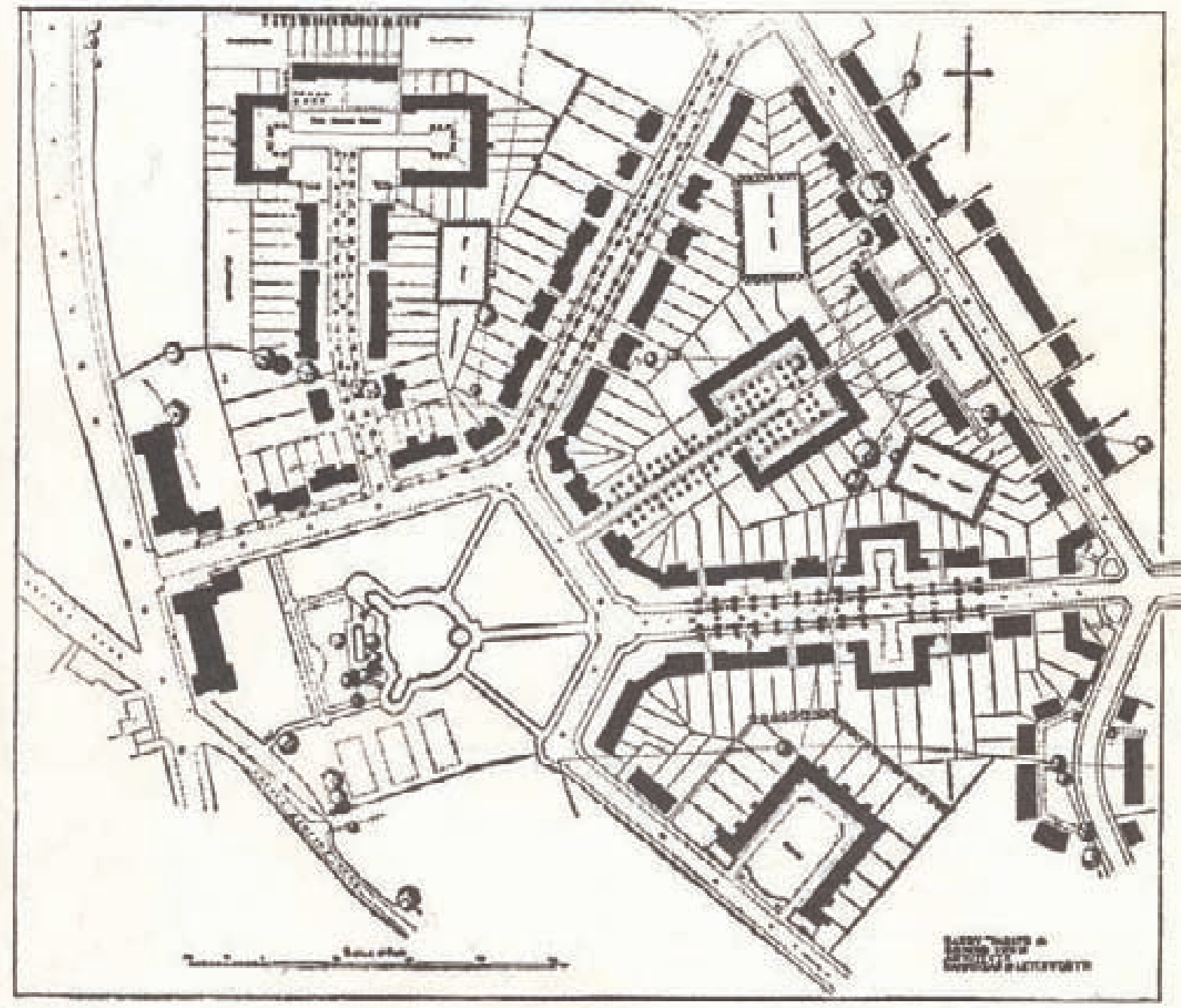

Raymond Unwin y Barry Parker: "Hampstead Garden Suburb”, 1909. 


\section{LÁMINA II.18}

“El conseguir una reducción del ancho de vía, permitía a Unwin disponer de una vía secundaria estirando uno de los bordes de la vía principal, deformando por estiramiento la calzada lateralmente hasta crear un fondo de saco alrededor del cual se disponían las viviendas formando un close..."

Raymond Unwin y Barry Parker: “Hampstead Garden Suburb”, 1909.

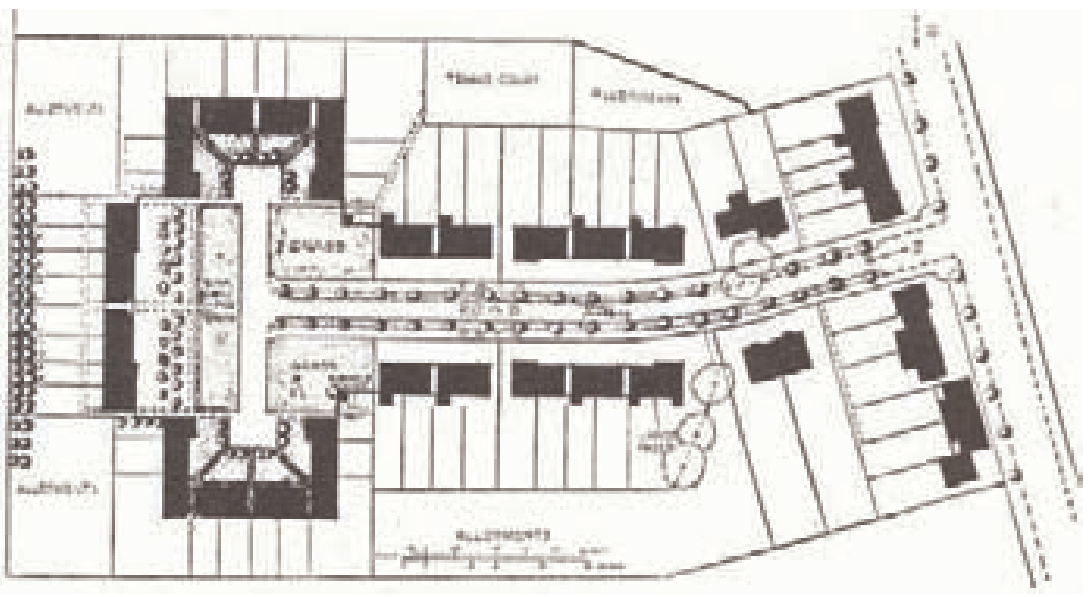

El close de Asmuns Place.

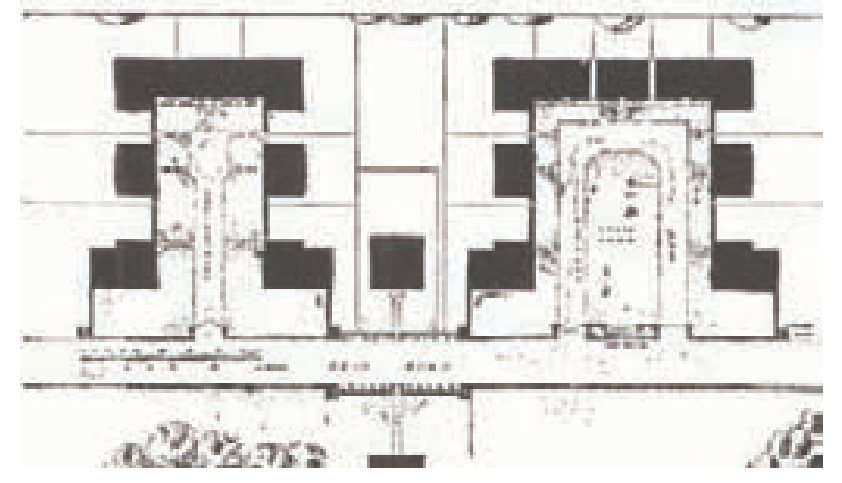

Dos tipos de close, de una vía con ensanchamiento de giro, y de dos vías con jardín central.

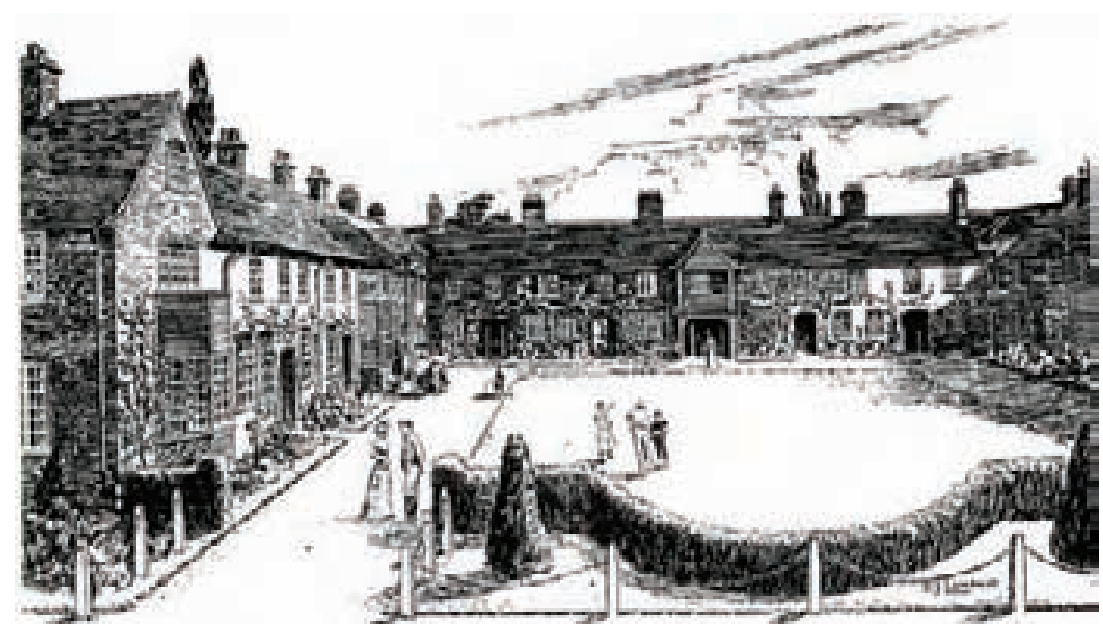

Vista del segundo tipo, Litchfield Square. 
En Estados Unidos, la adaptación del modelo de Unwin adquiere los rasgos de una organización sistematizada bajo una nueva unidad, la supermanzana (superblock). El principio es el mismo que el empleado en Hampstead, a partir de fondos de saco que generan el tejido residencial. La diferencia estriba en que la vía principal sometida a los estiramientos encierra, por medio de cruces con otras de similar envergadura, un área considerable, que es establecida como la nueva unidad de referencia. Los ejemplos ofrecidos primero por Herbert Emmerich y luego desarrollados por Clarence Stein y Henry Wright, contienen en cada supermanzana un elevado número de estructuras tipo close formando un agregado al cual se le va a dotar de un nuevo significado, distinto del bloque aislado y de la ciudad jardín sin límites precisos. Lo que identifica a este agregado como un nuevo concepto de unidad urbana se puede calificar en el aspecto físico, como una doble envoltura. Por un lado, facilitando que sea una unidad perceptible, aspecto que se consigue mediante el trazado de las vías principales envolventes. Y segundo, mediante una nueva acción de envolvimiento, cercar un espacio común interior, limitado por las estructuras de los close. La creación de este espacio común interno habrá de adoptar diferentes formas, según sea regular o irregular en su trazado, abierto al exterior o construido, pero siempre caracteriza este nuevo modelo y dotará de sentido específico a un nuevo término, el cluster. El cluster puede ser considerado, por tanto, una agrupación de estructuras close con un doble envolvimiento y cuyo sentido puede resumirse en dotar de cohesión al agregado. Este factor de cohesión, a cuya consecución trabajan los dos niveles de envolvimiento permiten referirse a él como unidad de referencia para un desarrollo urbano. Es a este factor de cohesión, que se pude definir como identidad, al que nos interesa calificar como cualidad del cluster. En síntesis, la identidad es la cualidad del cluster.

La identidad: básicamente se establece una sensación de identidad del habitante con el cluster por medio de una gradación entre los niveles de privacidad del espacio. Comenzando con la casa, y la parcela individual, el habitante distingue además otros niveles sobre los que ejerce un cierto derecho de uso, como son el espacio del close, a un nivel que podemos interpretar como de calle semiprivada, y en un ámbito superior, sobre la banda de zonas comunes que se extiende en el interior del cluster, sobre la cual ejercen su uso y disfrute todos los moradores del cluster. El siguiente nivel, es el formado por la agrupación de clusters, dotado de un centro económico, religioso, cultural y de ocio, del que participa la comunidad entera. Digamos, que todos estos niveles de intensidad tanto en los diferentes grados de privacidad como de uso y disfrute que se ejercen sobre el cluster, responden a la clasificación dada a los llamados elementos de asociación: la casa, la calle, el barrio y la ciudad.

En segundo lugar, que el envolvimiento sea dado por vías de circulación y no mediante fosos o murallas, responde al segundo requisito que es el de la movilidad, tanto física como social.

Bien, estas son las ideas básicas que plantean los urbanistas americanos y que son recogidas por Alison y Peter Smithson en textos como "An Urban Project, Golden Lane Housing" (1953) o "The Built World: Urban Reidentification" (1955) o "Cluster City" (1957). Pero nuestro interés no se centra en las ideas que dirigen el tipo de 
comunidad definida por el cluster, sino en la identidad entendida como cualidad, o incluso en la cualidad misma. Lo que queremos ver es que rige bajo la denominación de unidad, o cómo se relaciona con el Principio de Transición.

Este agrupamiento, el cluster, lo que ofrece es una continuidad en el paso de escalas desde la agrupación de varios clusters pasando a la trama del close para la unidad vecinal y más abajo, al nivel de la vivienda particular con la parcela propia. Quiero decir con esto, que la nueva unidad formulada por la doctrina del cluster ha de ser contemplada, a nuestros efectos, bajo la óptica de un tipo de continuidad, que se enlaza solidariamente a la divisibilidad indefinida de la agrupación. Así, en cada porción del total, siempre es posible repetir una nueva subdivisión en la que nos volvemos a encontrar con esta cualidad cohesiva que gobierna sobre la pluralidad del agregado. Esta cualidad que se distribuye a cualquier nivel de la estructura del cluster es, como hemos dicho, la identidad entre el habitante y el lugar. Es el sentido de la identidad, en definitiva, lo que se ofrece de garantía de que tratamos con una unidad de nuevo cuño y no con un simple agregado. En este sentido, en cada punto de la estructura física, lo que se ha de concebir como inmediatamente apreciable, como la blancura en determinados cuerpos, es la identidad, como cualidad propia del cluster. La identidad aflora ya total e igual a sí misma, y, ni en más ni menos cantidad, sea cual sea la parte donde detengamos nuestro disección del cluster. La identidad, en resumen, no es algo que dependa de la extensión, pero al mismo tiempo que no es algo físico expresa lo físico de forma unitaria, de forma comparable a como la vida expresa la materia orgánica desde el rebaño hasta la célula.

Que la cualidad del cluster no dependa de la extensión queda plenamente recogido en los escritos de Alison y Peter Smithson en relación al cluster: "Debemos prever para cada lugar un tipo de estructura capaz de crecer pero de continuar siendo clara y fácilmente comprensible en cada etapa de desarrollo. La palabra cluster resume el espíritu de una estructura de este tipo."27 $\mathrm{O}$ en esta otra expresada en el contexto del CIAM IX: "El objetivo del urbanismo es la comprensibilidad, es decir la claridad de organización. La comunidad es por definición algo comprensible. Y la comprensibilidad, por tanto, debería ser también característica de las partes." 28

La consideración del cluster como un ejercicio de generación espacial bajo la cualidad de la identidad le hace particularmente interesante en este apartado del Principio de Transición, dado que el tipo de relación establecida entre el todo y las partes no se refiere a un modo geométrico sino a un juego de envolvimientos. Como veremos más adelante un tipo geométrico que conviene al cluster en la vertiente ofrecida por los Smithson será el derivado de la geometría proyectiva, cuyas propiedades invariantes pueden ser útiles ante los cambos de dimensión y crecimiento del cluster.

Mostraremos los ejemplos ya citados que contribuyeron

27 Alison y Peter Smithson, "Cluster City. A New Shape for the Community", en "The Architectural Review", Volumen 122, № 730, Noviembre 1957, p.336

28 Alison y Peter Smithson, "Ponencia en el Congreso CIAM IX", celebrado en Aix en Provence entre el 19 y el 26 de Julio de 1953. Recogido en el texto "Manual del Team X" p. 19. Es importante hacer resaltar la fecha de asistencia al Congreso dado que esta dentro del periodo de elaboración de las propuestas para el concurso de Sheffield. 
a sintetizar la teoría del cluster, y, que validan, en mi opinión, la asignación al Principio de Transición.

En primer lugar los ejemplos ofrecidos por Herbert Emmerich, con la primera consideración a las supermanzanas de finales de los años veinte. Todo lo expuesto anteriormente toma en los ejemplos de Emmerich su más acabado sentido.

Por otro lado el desarrollo dado en la Urbanización de Radburn (1928) por Clarence Stein y Henry Wright, cuya particularidad es combinar dos estiramientos, uno para la vía en fondo de saco y otro para una vía peatonal. El avance de este modelo radica en la elección de la orientación del frente principal de la vivienda sobre la vía peatonal en lugar de sobre la calzada, lo que ofrecía la posibilidad de abrir los salones de las viviendas a amplios espacios ajardinados entre los close de viviendas.

El otro desarrollo que merece reseñar es el modelo en lazo propuesto por Victor Gruen para Forth Worth en 1956, donde los estiramientos se producen por los bordes interiores del lazo. El objetivo que persigue Gruen es generar un espacio por embolsamiento mediante una vía de circulación continua. A partir de esta acción, el estiramiento de los bordes hacia el interior del embolsamiento reconfigura el close en líneas de rodadura de aparcamiento de vehículos, promoviendo el desarrollo de espacios públicos completamente peatonales en el área interior del recinto.

\section{COMO CONSTRUIR TRES CASAS. EL CLUSTER AMERICANO Y EL BRITANICO}

Más allá de resultar una anécdota curiosa, la explicación de lo que significa constituir en unidad un agregado de edificios, lleva a formular a los Smithson y a Victor Gruen exactamente el mismo problema: cómo plantear la correcta ubicación de tres casas. Tiene su interés detenerse en estos dos ejemplos.

Victor Gruen pone un ejemplo en el que tres hermanos con sus respectivas familias compran un terreno, un lugar idílico en su origen, bien comunicado, situado en el encuentro entre una tranquila calle y una autopista que enlaza con la ciudad cercana. Cada familia decide independientemente construirse una vivienda unifamiliar con su parcela privada. Contratan, nos cuenta Gruen, a tres arquitectos que diseñan libremente las viviendas según las directrices que les marcan los propietarios. En el cuento Gruen esquematiza a sus personajes, sustituyendo su carga sicológica por el establecimiento de roles o patrones de interactuación social tan definidos que sus comportamientos resultan fácilmente predecibles: "estos tres hermanos eran muy similares en la mayoría de los aspectos: en sus ganancias -incluso en la elección de esposas. Y por este motivo no sorprendió a nadie que las instrucciones que dieron a los arquitectos fueran prácticamente idénticas" y que aún así, "fue bastante sorprendente para ellos darse cuenta de que los tres planes eran prácticamente idénticos". El meollo del asunto viene cuando descubren que tras su terreno se empiezan a levantar más casas y lo que en principio consideraron unas condiciones idílicas empiezan a tornarse un motivo de enfrentamiento entre los hermanos y sus familias por el 
reparto de las parcelas, las molestias que se ocasionarán a sí mismos por la proximidad de sus viviendas o lo pequeño que resulta el jardín. "Es realmente esto todo lo que vamos a recibir por venir a este lugar de ensueño?, se pregunta uno de los hermanos. "Creo que tenemos más silencio y privacidad en nuestros apartamentos de la ciudad. Tiene que haber una solución mucho mejor". Es en este momento cuando interviene la doctrina del cluster de manos de un nuevo arquitecto, al que van a visitar las tres familias, pues dicen de él que es un auténtico mago en estos asuntos. Tras replantear las viviendas, concentrando su superficie ahora en dos plantas, eliminar los jardines frontales, sacarles un garaje común con un taller "ya que los tres hermanos disfrutaban del bricolaje", unificarles los jardincitos traseros en un jardín privado y orientar las casas en torno a la tranquila calle original, les convence: "tendréis la misma superficie útil que antes, el triple de jardín y muchos más dinero para los muebles y otros gastos". Pero, topan con la normativa municipal que exige retranquear la construcción. Nos encontramos aquí con el mismo problema que tuvo que afrontar Unwin para desarrollar Hampstead. Hemos visto ya, que para llevar a cabo el proyecto de urbanización, Unwin necesitó de la aprobación de una cláusula especial que permitiera un nuevo ancho de vía, más estrecho que el definido por el planeamiento. Es interesante observar cómo Gruen reproduce en este cuento la tesitura real que afectó a la puesta en marcha de la ciudad jardín de Hampstead. Y, dado que en el suburbio londinense debió prevalecer un espíritu de justa admiración por las bondades de la nueva doctrina, así ha ocurrir lo mismo en el cuento: "la vida puede ser más rica y feliz gracias a la cooperación y al entendimiento. Se puede ganar un espacio en el jardín trasero si quieren moverse hacia delante. Si compartimos la tierra con nuestros hermanos podemos conseguir más de la vida".

El ejemplo empleado por Alison y Peter Smithson encara el mismo problema de cómo resolver la inserción de tres casas. Pero ni el lenguaje utilizado es el mismo, (en el caso que vamos a ver a continuación se trata de un texto similar a un manifiesto) ni se solapa con una doctrina sociológica paralela como puede entreverse en el texto de Victor Gruen. En este sentido, conviene aclarar antes de entrar en el ejemplo de los Smithson, aunque sea un tema tangencial al que nos ocupa, la diferencia que se abre entre el cluster americano y la teoría británica.

El origen del cluster americano, tal como lo hemos presentado a partir de Emmerich es paralelo en el tiempo a la doctrina del funcionalismo americano en sociología (a partir de los años treinta). A diferencia de otros modelos que observan la estructura social, el funcionalismo hace descansar el estudio de la sociedad sobre la base de la estratificación social y no sobre la estructura de clases. Esto tiene una importante consecuencia dado que frente a la división en un número muy limitado de clases sociales (normalmente tres), el enfoque funcionalista presenta un desarrollo de la sociedad más fluido. Si observamos el tipo de crítica que se repite en este trabajo, podemos apreciar también como se repite su contenido. Éste pasa siempre por considerar el modelo precedente incompleto por su excesiva simplificación. Tanto si nos situamos en el binomio Descartes - Leibniz, como Le Corbusier - Smithsons, o en este caso, Marx - Weber, la postura de los que ocupan el primer término es homogénea en tanto sus productos teóricos son considerados la unidad de medida universal en sus respectivos campos. Bien, en esta situación, lo que discuten los segundos es precisamente el valor de universalidad de los primeros. 


\section{LÁMINA II.19}

“... los ejemplos ofrecidos por Emmerich, con la primera consideración a las supermanzanas de finales de los años veinte..."

Herbert Emmerich:

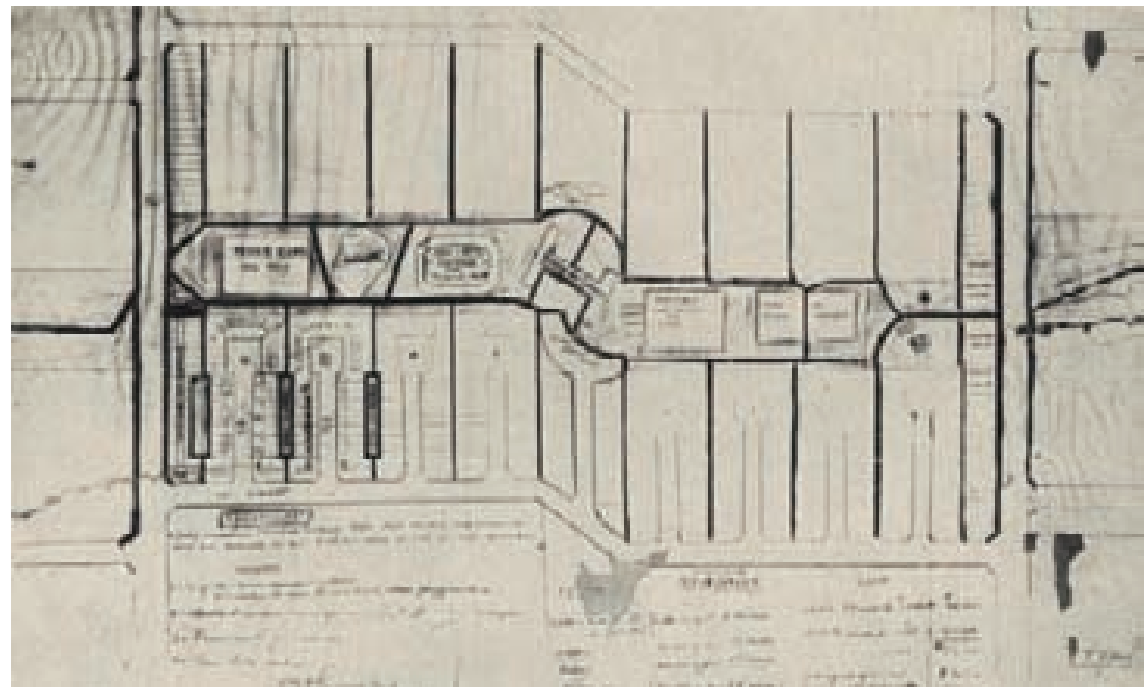

Esquema de supermanzana, Diciembre 1927. Obsérvese en el ángulo inferior izda. de la supermanzana el desarrollo de los close.

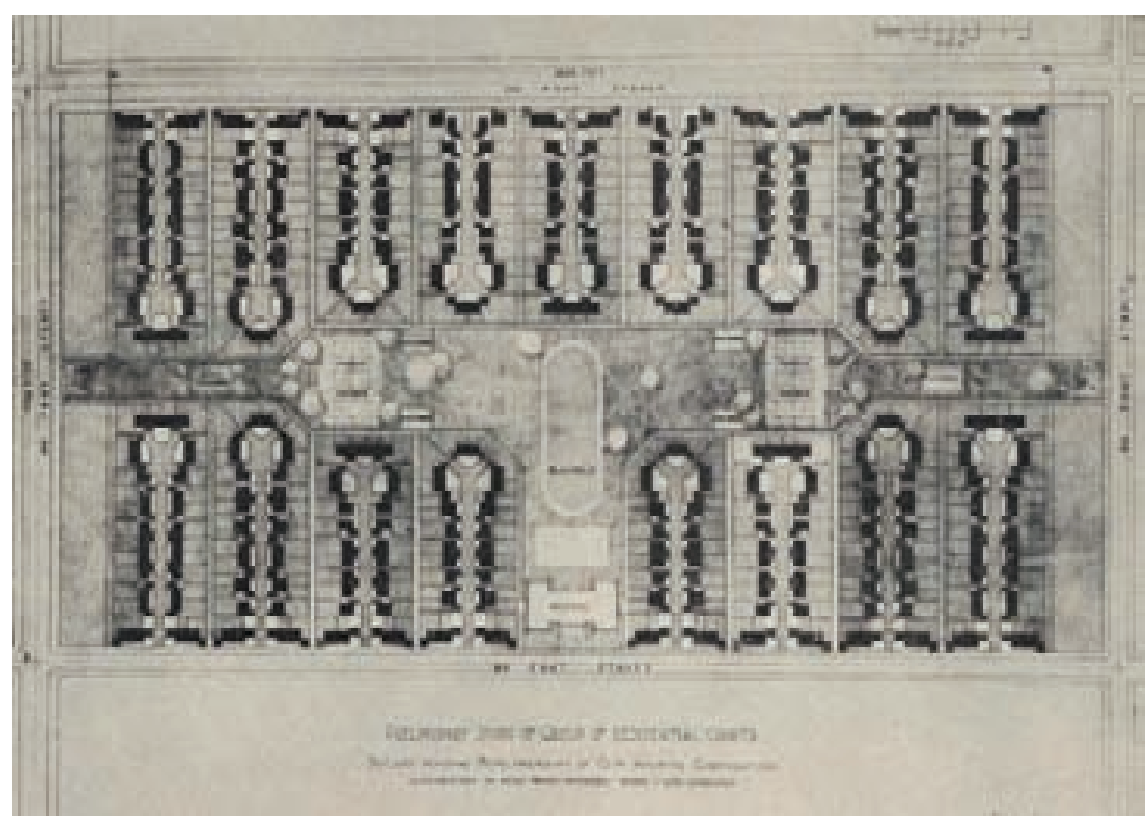

Esquema de supermanzana, Enero 1928. Es considerada por Clarence Stein la base del Plan de Radburn. (Clarence Stein, "Toward New Town for America" 1951, pie de foto Plate 4). 


\section{LÁMINA II.20}

“El avance de este modelo radica en la elección de la orientación del frente principal de la vivienda sobre la vía peatonal en lugar de sobre la calzada..."

Clarence Stein y Henry Wright: "Radburn", 1928.

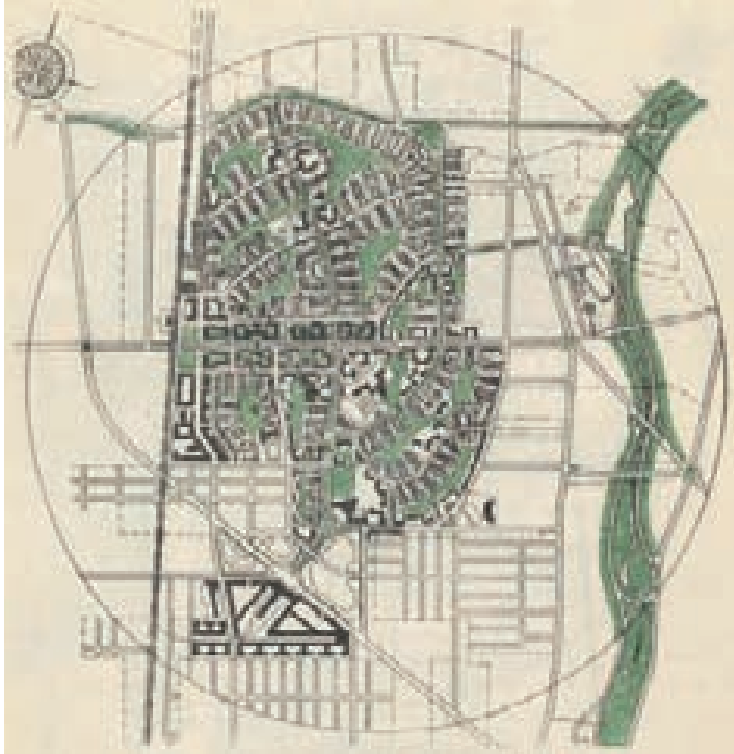

Plano de la estructura completa de la ciudad.

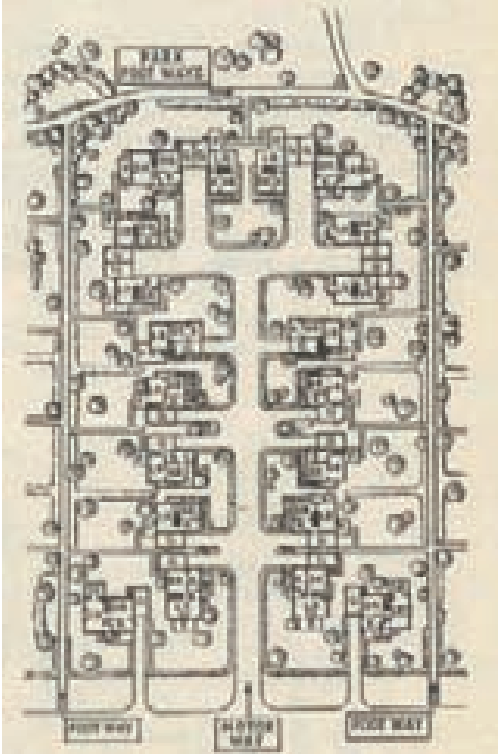

Distrito residencial. Nótese la forma celular que aporta la estructura de caminos peatonales.



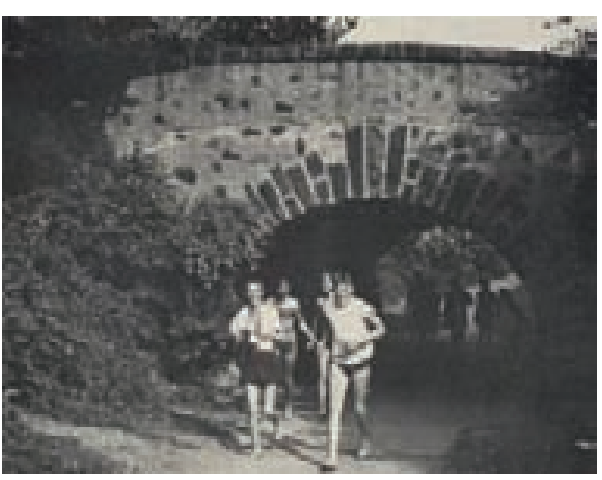

Separación del tránsito rodado del camino peatonal con cruces a distinto nivel.

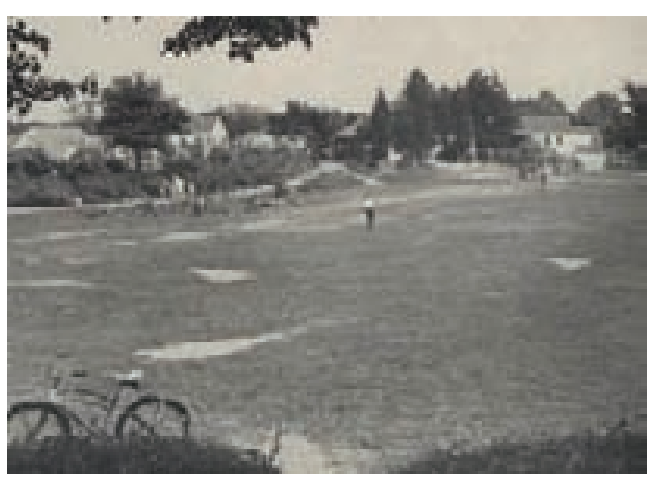

La lengua central de terreno comunitario. 


\section{LÁMINA II.21}

"El objetivo que persigue Gruen es generar un espacio por embolsamiento mediante una vía de circulación continua. A partir de esta acción, el estiramiento de los bordes hacia el interior del embolsamiento reconfigura el close en líneas de rodadura de aparcamiento de vehículos..."

Victor Gruen: "Fort Worth", 1956.

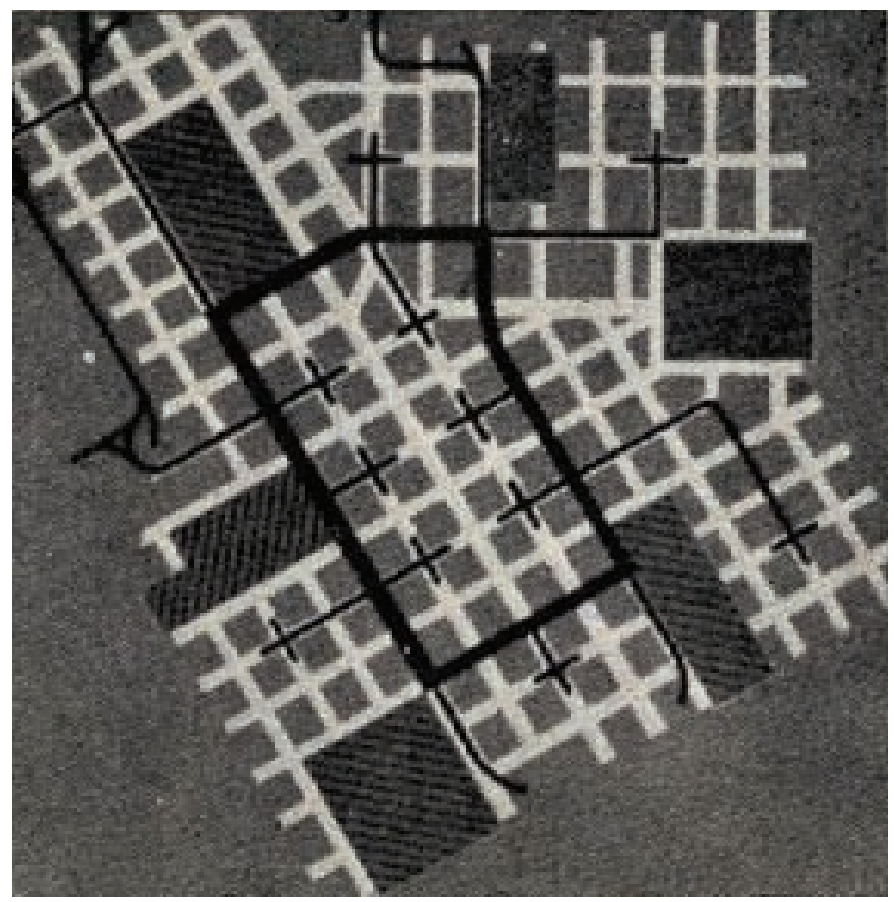

Plano de la doble red de tránsito rodado y peatonal. Se crean seis aparcamientos perimetrales que resuelven la peatonalización del recinto.

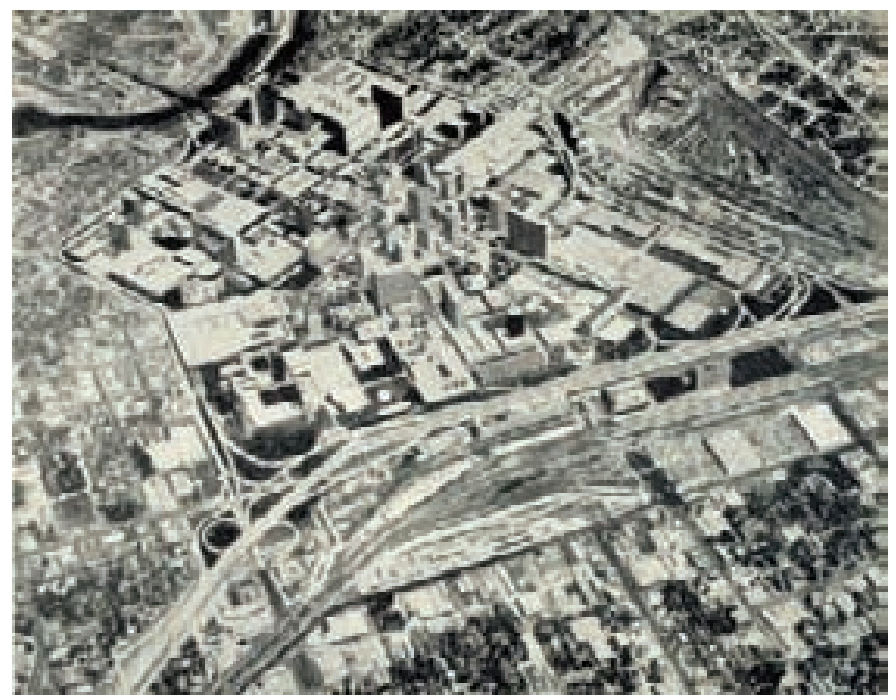

Maqueta del conjunto. La creación de un lazo mediante vías perimetrales es la primera operación para generar un espacio por embolsamiento. Esta técnica es usada para la regeneración del área encerrada sin perder su conectividad. Del mismo modo es la operación "New ways for London" presentado por Alison y Peter Smithson en el XI Congreso CIAM en Otterlo (1959) como modelo de intervención y regeneración de un área del Soho. 
Victor Gruen: "Fort Worth", 1956.

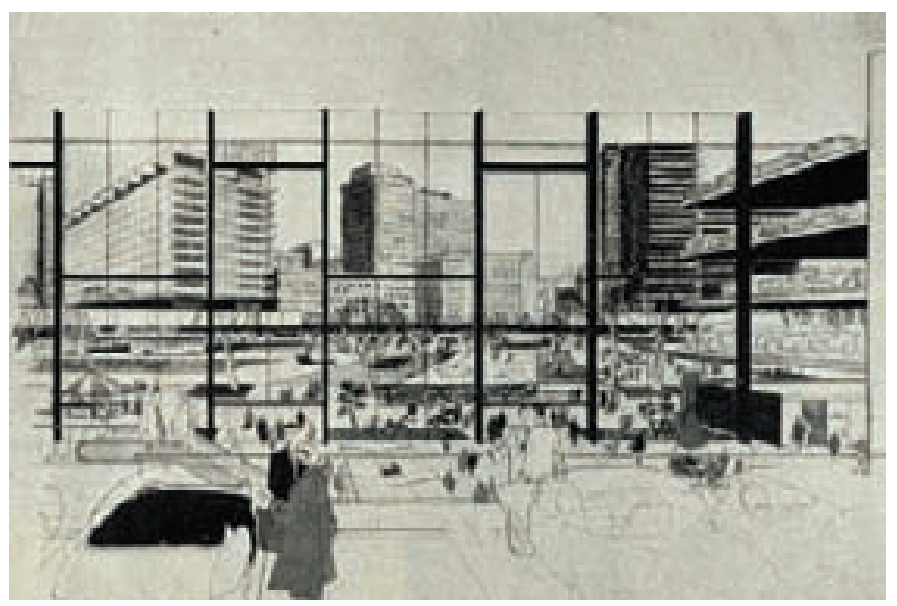

Vista de la zona interior de servicios terciarios desde uno de los close de aparcamientos.

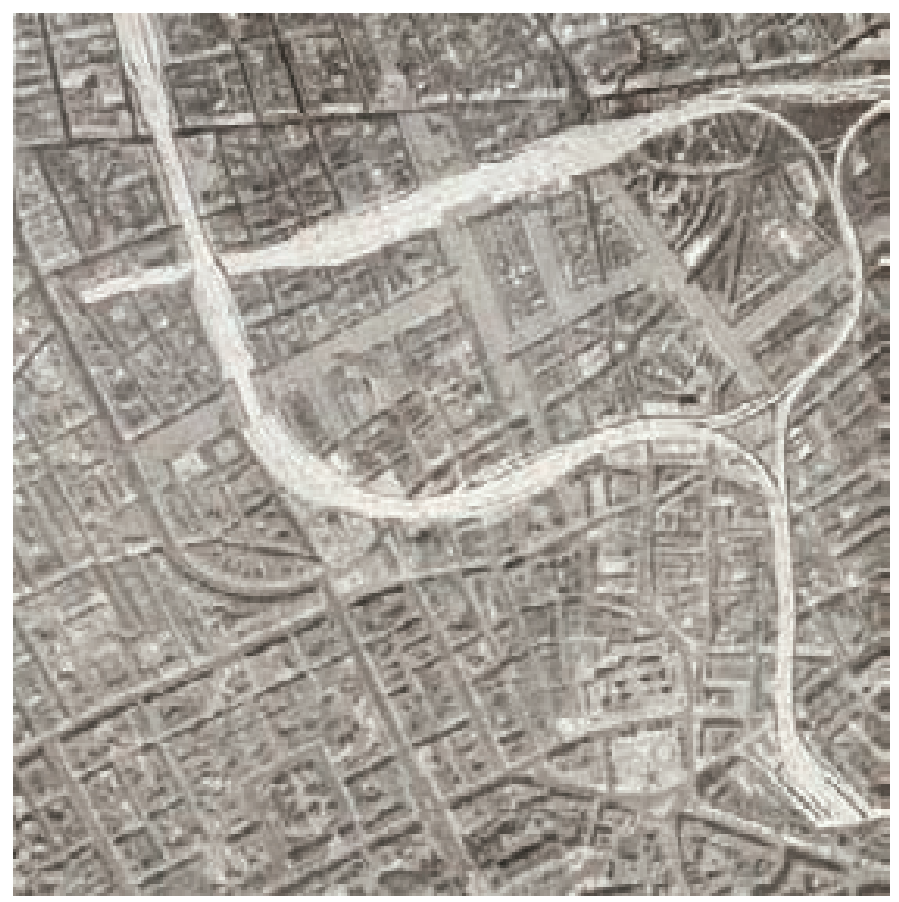

Alison y Peter Smithson: "New ways for London (London Road Study)", 1959. Obsérvese la estructura continúa de circulación mixta, peatonal y de tráfico rodado (route building), que se engarza con el sistema perimetral de autopistas urbanas. 
$Y$ en este contexto, los nuevos enfoques no son sustitutivos (en tanto que lo que encuentran y donde basan sus objeciones es que se dan casos no contemplados por estos modelos, y la crítica la apuntan, por tanto, a una limitación del alcance efectivo de los modelos universales) sino que son acumulativos, es decir, recogen más variables y aportan mayor complejidad. En el caso de la crítica de Weber al marxismo la aportación de éste conlleva no sólo contemplar el factor económico, sino introducir otros nuevos como el prestigio y el estatus. El resultado es una multidimensionalidad cuya consecuencia directa es la creación de un nuevo modelo de graduación continua, que, en el caso del análisis social, pasa por contemplar una multiplicación de estratos en lugar de un número limitado de clases. Este enfoque weberiano de la estratificación es el que será recogido en la doctrina funcionalista americana, bajo Kingsley Davies y Wilbert Moore y fundamentalmente por el conocido Talcott Parsons. Dos ramificaciones interesantes del principio de análisis funcionalista son la movilidad (que veremos bajo el planteamiento arquitectónico dado por los Smithsons a este tema), y la subjetividad. Esta segunda rama, que es tan constante como el tipo de crítica anterior, y que vemos en la oposición al espacio absoluto cartesiano, es parejo en el tratamiento sociológico. Frente al modelo externo - objetivo de pertenencia a la clase social, el modelo de estatus se contempla desde el punto de vista subjetivo, derivado de la reciprocidad que mantienen entre sí sujeto y sociedad, interacción por la que se ordena su posición social en un determinado nivel. Esto es, los nuevos mecanismos de distribución social, el estatus o el prestigio son otorgado por los demás ( y para determinados contextos, o en función de determinadas circunstancias), de tal modo que es el enjuiciamiento en el desarrollo de los roles individuales lo que finalmente se evalúa y lo que asigna las posiciones de los individuos. De ahí que el sistema de estratificación sea visto bajo un parámetro gradual y no absoluto como el de la clase social. En este sentido el funcionalismo adquiere pleno sentido bajo el concepto de función social como veremos y es tratado por Victor Gruen en el texto anterior y en el concepto de cluster.

Por último, cabe admitir en esta síntesis comparativa otro concepto que aparece repetido en este trabajo, que es de distancia, y que admite ser, en la teoría sociológica, un reflejo de la distinción dada entre el espacio absoluto y el relacional bajo los conceptos de longitud y distancia. En este sentido el sistema bajo la forma de una estratificación por estatus o prestigio es señalado como una estructura de distancias, y es más acorde que el término longitud que puede convenir a la división en clases. Como es fácil de ver, un modelo economicista consiente en fijar una unidad de renta como parámetro de medición y adscripción a las clases. La evaluación del prestigio bajo parámetros objetivos conlleva problemas irresolubles (determinar una relación convincente entre una ordenación ocupacional y el prestigio asociado ${ }^{29}$ ) que imposibilitan tomar una unidad de longitud homologable a la distancia entre un estrato y otro: "Pero si el médico gana de cincuenta a cien veces más que el basurero, ¿̇podemos decir que el médico es de cincuenta a cien veces más importante que el

29 Normalmente se ha derivado la medición del prestigio trasladándolo hacia la medición del prestigio ocupacional. Como han señalado diversos autores se han confeccionado escalas de hasta 425 niveles ocupacionales. Con todo, la cuestión afecta a si esta medición en base a ordenaciones ocupacionales esta sustentada realmente en el status o prestigio más que en factores económicos. Véase al respecto, Harold R. Kerbo, "Estratificación Social y Desigualdad. El conflicto de clase en perspectiva histórica, comparada y global”, pp. 126 y 127. 
basurero?" ${ }^{30}$ En otro orden de cosas esta distinción entre longitud y distancia afecta también la distinción dada por Lewin entre longitud euclidiana y distancia hodológica, que, como veremos, reviste con un nuevo contenido la distinción que se puede establecer entre el eje y la ampliación.

En definitiva, lo que la tesis funcionalista propone es tomar a la sociedad como un continuum de posiciones de ordenación de los estratos sociales. En este sentido, el cluster no hace sino recoger esa continuidad estructural y plasmarla físicamente en una ordenación escalonada y cohesionada por la identidad. De tal modo, como hemos subrayado, se puede establecer una estratificación en el escalonamiento entre la casa, la parcela, el close, el cluster y la agrupación de clusters como elementos que pautan la estructura territorial. Puede decirse que la estructura fundamental del close y de las relaciones entre los close es esencialmente la estructura del cluster ${ }^{31}$. En todo el engranaje del modelo del cluster, el hecho básico recae sobre un sistema de cesión de espacios privados que van adquiriendo una nueva categoría de semiprivacidad compartida. Esto es por un lado lo que se extrae del texto de Gruen y donde radica la bonanza de la nueva ordenación en la que "todos ganan", digamos, cooperando y entendiéndose entre sí mediante cesiones parciales de sus respectivas parcelas. Este sentido cooperativo, que emana, no de ellos mismos (no son los hermanos ni sus familias los que promueven en primera instancia ceder parte de sus terrenos), sino que les es inducido de arriba a bajo (lo que les hace ver el arquitecto es el beneficio conjunto que como grupo familiar adquieren) es el elemento dinamizador de la sociedad en la tesis funcionalista, y a la vez la garantía de su cohesión ${ }^{32}$. En efecto, el enfoque funcionalista parte de considerar como bien supremo a satisfacer, las necesidades propias a la sociedad (o comunidad) como conjunto, entendida ésta en su acepción cultural, como un conjunto de creencias y valores compartidos, sustanciados en sus instituciones, lo que ordena para su provecho una distribución funcional, ocupacional valdría decir, de sus miembros, que se ajusta y regula en sí misma en virtud de sus necesidades actuales, promoviendo o discriminando tales o cuales ocupaciones. Digamos que las miras puestas en las motivaciones vienen cursadas por el beneficio social en su conjunto, y en tal o cual momento, a lo cual la sociedad revierte en forma de recompensas en un reparto de estatus (con las implicaciones no sólo económicas, sino de prestigio y estima, parejas a tales estratos). De tal modo, podemos decir, siguiendo a Parsons, que lo que opta por favorecer el sistema social es a sí mismo por encima de los intereses personales. Para Talcott Parsons la riqueza y los ingresos

30 Harold R. Kerbo "Estratificación Social y Desigualdad. El conflicto de clase en perspectiva histórica, comparada y global”, p. 116

31 Como señalan algunos autores para el caso de Radburn "lo que más sorprende ...(es) el hecho de que en Radburn la tipología no es más que la consecuencia arquitectónica de las soluciones urbanísticas; no existe ruptura entre ambas escalas". Giorgio Ciucci, Francesco dal Co, Mario Manieri-Elia y Manfredo Tafuri "La Ciudad Americana, de al Guerra Civil al New Deal”, p.272

32 Garantía de cohesión que, a veces se vuelve en contra de los instigadores de ese sistema cooperativo, como relata Clarence Stein en el caso de la operación Sunnyside: "el aspecto más irónico de todo ello es que fue precisamente la sociedad (CHC, City Housing Corporation) quien había promovido y favorecido las asociaciones cívicas que habían acostumbrado a sus habitantes a organizarse y actuar colectivamente" En Giorgio Ciucci, Francesco dal Co, Mario Manieri-Elia y Manfredo Tafuri "La Ciudad Americana, de al Guerra Civil al New Deal", p.271 
altos eran valores comparativamente secundarios frente al prestigio social de acuerdo a los criterios axiológicos dominantes promovidos institucionalmente, y que se entienden como un deseo de favorecer el interés de la institución social (en el caso del ejemplo el familiar) por encima de los privados. La doctrina del cluster, que prima toda acción que tenga por objeto el mantenimiento y desarrollo de la estructura del cluster está basado en un respeto a las reglas de convivencia generadas por la micro sociedad que lo forma, en donde el equilibrio en la edificación y distribución de espacios públicos y privados, hacen ver que el acento se pone en el orden urbano como metáfora del orden social. Una situación sin altibajos en la calidad ni tamaño de las edificaciones privadas parecen promover que la desigualdad de estatus no motiva un deseo de ostentación en lo económico. De este modo lo que se observa es una sumisión a las reglas o normas promovidas desde el cluster que trabajan siempre en beneficio propio o en aras de su propia conservación como institución de referencia, constituyendo el elemento invariable y reconocible por sus habitantes, el que establece y pauta las relaciones entre éstos, las obras que pueden o no hacer, y donde la población es el elemento variable, que se reemplaza a sí misma, y, de ahí, que la conectividad, la relación con la autopista, y a través de ella con la ciudad, adquiera el rango del otro factor dominante del cluster. ${ }^{33}$

Veamos a continuación el texto de los Smithson: "Tomemos, por ejemplo, el problema de construir tres casas en una calle existente; las casas ubicadas a cada lado de la calle constituyen, junto con la calle misma, un hecho urbano definido; las tres casas nuevas no deben limitarse a contrastar con este viejo hecho (o adaptarse a éste) sino que deben proporcionar una indicación, un signo, de una nueva estructura comunitaria. Pero esto no podrá lograrse si el arquitecto no ha concebido de manera más o menos completa una idea general o ideal acerca de la dirección hacia la cual está encaminada su obra." ${ }^{34} \mathrm{~A}$ partir de aquí, el ejemplo se esconde un buen trecho del artículo para reaparecer del siguiente modo: "De acuerdo con esta descripción, el problema de construir las tres casas en una calle existente se resuelve encontrando el modo en que (aún respondiendo a la vieja idea de calle) se rompa con la vieja fachada y se construya en profundidad, proporcionado una sugerencia, un signo de la nueva estructura comunitaria." ${ }^{35}$

Los Smithson sostienen que la idea debe ser la base de la acción proyectual. Y esta idea debe constituir una forma de continuum, ante la cual, el arquitecto debe responder siempre, sea cual sea la circunstancia que se le ponga por delante. En este sentido, cabe entender que no se aporte ningún ejemplo gráfico que responda exactamente a la pregunta de cómo construir tres casas en una calle existente y que nos remitan al concepto de cluster. Pero sí exponen que debe hacerse en profundidad, estirando un borde del vial. Dan por buena, por tanto, a la acción definida por Unwin en los close, dado que presentan además una solución de urbanización por close (Close Houses). Aluden con las imágenes que acompañan el texto a dos 
operaciones que permiten vislumbrar cómo sería la distribución en profundidad que indican. Están las viviendas Jaoul de Le Corbusier, insertas fuera de la ordenación a calle y conectadas con ésta mediante una rampa de garaje. Es fácil de ver la relación buscada con el close, resuelto en esta caso como un garaje que hace las veces de una plazoleta de giro (un fondo de saco) subterránea y que vincula la posición de las dos casas. Pero me resulta más interesante destacar el segundo ejemplo que atañe a la ordenación de un centro cívico en Fort Worth por parte de Victor Gruen. La organización que presenta Fort Worth es del mismo orden que Radburn, y podemos concluir de ello una secuencia de etapas que enlazan las distintas doctrinas del cluster.

\subsection{PSICOLOGISMO O SOCIOLOGISMO}

El modelo close, que depende exclusivamente de la acción de estiramiento adquiere en la teoría de los Smithson un desarrollo propio, que se puede interpretar como una variante de las casas unifamiliares en hilera ${ }^{36}$, a las cuales se las incorpora o son servidas por un corredor central. El cluster smithsoniano, sin embargo, pierde parte del carácter orgánico de las propuestas americanas. Sin querer desmentir a los que apoyan una vertiente sociológica en la teoría de los Smithson, en el cluster propuesto por ellos no hay un sentido cooperativo claro de la estructura comunitaria. Incluso, en aquellos casos, como el complejo del Economist, en que se puede hablar de una cesión de un espacio comunitario, éste es el resultado residual de una operación formal dirigida a separar los edificios, extrayendo de éstos los usos que se repiten y son susceptibles de centralizarse ${ }^{37}$. Admitiendo que cada edificio cede parte de su área de recepción para resolverla en una única pieza a modo de lobby exterior o plaza, o que unifica en su subsuelo los servicios repetidos de aparcamiento y cocinas, lo que se resuelve es un problema limitado al ámbito de la arquitectura. La idea de la colectivización del espacio, por emplear el término que ellos usan, no difiere en nada de un planteamiento que sopesa el ahorro económico que conlleva prefabricar las partes que se repiten en un edificio.

En este sentido cabe admitir un enfoque netamente arquitectónico del problema donde el componente sociológico no esta definido como tal. La resolución del problema de las tres casas es pues una cuestión que da respuesta desde la arquitectura a problemas planteados visualmente para advertir los signos de una nueva estructura comunitaria, donde hay que entender por estructura comunitaria no a una comunidad de seres humanos sino a un grupo orgánico de edificios.

Mi argumento contra un exceso de contenido sociológico en el planteamiento que algunos autores dan a la obra de los Smithson no ha de ser interpretada erróneamente. No es mi intención, por supuesto, eliminar la resultante sociológica de un planteamiento como el llevado acabo por los Smithson, pero cabe distinguir entre la aplicación de un planteamiento psicológico y uno sociológico. En efecto, cabe advertir siempre que la evaluación social se da por elevación de un componente

36 Conviene apreciar en este contexto las casas en hilera como una tipología extraída del repertorio de tipologías básicas del Movimiento Moderno.

37 Véase Alison y Peter Smithson, "The Pavilion and the Route"en "Architectural Design", Volumen 35, Marzo 1965 pp. 144 y 145 
primario psicológico, en el que se ven afectados las pasiones, temores y demás derivados de la naturaleza humana. El modo de enfrentarse del hombre al medio natural encuentra en la arquitectura el material mediador indispensable para neutralizar los aspectos negativos de la naturaleza. La teoría del umbral, por ejemplo, por la cual se revaloriza el espacio de mediación entre el exterior y el interior no viene afectado en nada por un componente social, sino que es de orden psicológico, de adecuación entre dos realidades climatológicamente opuestas. Se puede añadir que el móvil de los caminos cubiertos del close va encaminado en el mismo sentido. La sensación primaria de protección o de dominio del medio natural o frente al ambiente artificial resulta la clave de algunos proyectos, y siguen a determinados planteamientos: "El cllima inglés no se caracteriza por su intensidad sino por su inestabilidad. La casa, por tanto, debería ser capaz de captar todo lo que pueda conseguir del buen tiempo...Tal actitud respecto a la protección y al cambio deberá guiar la forma de todo plan de distribución" ${ }^{\prime 38}$. La insistencia en un origen psicológico de las normas que rigen la arquitectura sólo puede significar que el planteamiento sociológico es el resultante de un proceso en que los requisitos psicológicos han quedado resueltos en el estadio previo. De hecho, si se observa el modelo de cluster propuesto por Alison y Peter Smithson no hay un salto cualitativo entre el close y el cluster, y éste sólo puede ser visto como un agregado de estructuras close, sin que de la combinación de estos se extraiga que se transformen en otra especie distinta. La identidad ente el habitante y el cluster se extrae exclusivamente de la identidad manifiesta con la unidad primaria, la casa y la calle. La identidad con el todo es una iteración de las identidades individuales y en este sentido sólo se haya, como si dijéramos, presente a ese nivel.

Si hemos de intentar establecer una reducción en la forma de interpretar el cluster por parte de los arquitectos británicos, es más conveniente efectuar la reducción de la sociología en función de la psicología que a la inversa. Este sentido psicologista es apreciable en las nuevas interpretaciones que dan a la obra de Alison y Peter Smithson los autores holandeses y que muestran un giro frente a la raíz sociológica dada en épocas anteriores. Me refiero a las revisiones dadas por autores como Max Risseleda o Dirk van den Heuvel, entre otros, y que tiene como fin presentar la obra fundamentalmente residencial de los arquitectos como exponentes de una teoría de lo cotidiano.

Si bien, en mi opinión, la postura sociológica de los Smithson (como la defendida por Joseph Maria Montaner) no corresponde con precisión a ninguna corriente contrastable formulada desde la sociología, por lo menos del modo como parece implicado el cluster americano con teoría funcionalista, la teoría de lo cotidiano se encaja mejor en el cuerpo teórico de los Smithson, aunque, según mi opinión, a costa de banalizarlo hasta lo insustancial, dada la propia irrelevancia de los argumentos. No voy a extenderme en esta asunto, pues a día de hoy, dada la inmensa influencia ejercida por estos autores (en lo cual no 
es indiferente la monopolización editorial que sobre tema tienen ${ }^{39}$ ) es imposible no toparse con la cotidianeidad en cualquier texto que recoja a los Smithson, y simplemente me basta con registrar un párrafo para sondear la profundidad del enfoque: "En un planteamiento posterior, la casa como contenedora no sólo fue una envoltura para el uso cotidiano y un marco abierto al arte de la habitación... sino también un lugar que registraba estas pautas de uso diario junto con los cambios que tiene lugar a lo largo del día y estación tras estación. Prestó nueva forma y definición a lo cotidiano estableciendo una nueva relación entre los distintos aspectos del proceso de habitación - situándolos no en un sistema o en un orden, sino en una constelación dinámica que se construye mediante la colección de objetos y la casa. Los ocupantes y sus (inter)acciones continúan desarrollando esa constelación incluso más lejos, añadiendo sus propios <<estratos〉> a la arquitectura, en términos a la vez de uso y de significado." ${ }^{40}$

\subsection{CLUSTER, CLOSE Y CAPOGROSSI}

Aunque el planteamiento sociológico del cluster pueda parecer incompleto, lo cierto es que la formalización del cluster dota de estructura a la agrupación de casas y edificios y en mí opinión a partir de un punto crítico que señala el momento en que el espacio empieza a desplegarse cuando se comienza a estirar el close. Por ello el planteamiento que expongo rehuye los temas sociológicos y psicológicos para centrarse en asuntos puramente espaciales o geométricos exclusivos de la acción de proyecto de arquitectura y que toman la acción también en el sentido literal. Esta acción literal de estiramiento, que la hemos expuesto como dejándola caer del Principio de Transición formulado por Leibniz tiene algunas connotaciones comunes con el ejercicio de la action painting. Ha sido señalada por los propios Smithson su deuda con la obra de Pollock y no voy a insistir en ello. Pero no quiero pasar por alto el elemento formal que plantea la adopción del cluster. Dado que nuestros arquitectos se refieren a la posibilidad que les ofrece el cluster de crear nuevas imágenes ${ }^{41}, y$ en este sentido han sido estudiados algunos esquemas en relación a la obra gráfica de Nigel Henderson y Eduardo Paolozzi ${ }^{42}$, propongo sumar a estas "imágenes", a modo de curiosidad, la obra de otro contemporáneo, afín al Art Autre y como tal presente en la selección de Michel Tapié, como es la de Giuseppe Capogrossi. Parece que la

\section{LÁMINA II.23} pintura de Capogrossi, que refleja "racimos y cremalleras", constituye un paralelo formal de algunos dibujos debidos a los Smithson sobre los modelos del close y del cluster. Cabe en este sentido destacar la

39 Max Risseleda y Dirk van den Heuvel, "Team 10 1953-81, in search of a Utopia of the present", Max Risseleda y Dirk van den Heuvel, "Alison y Peter Smithson - from the House of the Future to a house of today", Max Risseleda, "Alison \& Peter Smithson. A Critical Anthology", Dirk van den Heuvel, "Alison and Peter Smithson, A Brutalist Story, involving the house, the city and the everyday (plus a couple of others things)"

40 Dirk van den Heuvel, "Recogiendo, dando la vuelta y poniendo al lado de..." en Dirk van den Heuvel y Max Risseleda "Alison y Peter Smithson. De la Casa del Futuro a la casa de hoy", p.37

41 "El concepto de cluster nos da la posibilidad de crear nuevas imágenes...", en Alison y Peter Smithson "Cluster City. A New Shape for the Community", en "The Architectural Review", Volumen 122, № 730, Noviembre 1957, p.336

42 Me refiero al interesante texto de Manuel de Prada, "Entre el Arte y la Naturaleza. Notas sobre Topología y el Origen del Brutalismo" 
exposición que el Institute of Contemporary Arts (ICA) dedicó a dicho pintor en 1957 y que recogía la producción de Capogrossi desde 1953. Tampoco es indiferente la alusión por parte de Giulio Carlo Argan a la dureé de Bergson para describir la obra de Capogrossi. ${ }^{43}$

\section{SHEFFIELD EN DOS PROYECTOS RIVALES}

De vuelta al concurso de Sheffield, dentro del apartado que versa sobre el Principio de Transición o Ley de Continuidad, es necesario considerar también bajo este Principio el proyecto presentado por el equipo formado por Colin St. John Wilson y Peter Carter. Ya he señalado que, por lo menos según la documentación de que dispongo, la mayoría hace uso del Principio de Posición, de forma más o menos similar, y con mayor o menor calidad, a la representada por la propuesta ganadora de GMW. Sin embargo, el proyecto de Wilson - Carter en este sentido abandona, en mi opinión, esta distribución por posiciones destacadas del espacio, y concentra todo el esfuerzo en producir una elongación del Firth Court, de manera equivalente a lo que he denominado "la ampliación" en el proyecto de Alison y Peter Smithson. Aunque la propuesta de Wilson y Carter ofrece patrones de giro por ángulos rectos la idea que rige el desenvolvimiento espacial permite observar el mismo procedimiento de desarrollo por estiramiento para generar un elemento continuo.

La circunstancia anómala del parecido entre dos soluciones que se destacan del resto permite suponer la existencia de ciertas y no veladas influencias y rivalidades mutuas entre gentes que orbitan alrededor de Reyner Banham y Eduardo Paolozzi ${ }^{44}$. Cabe añadir que de las anotaciones realizadas por otro participante al concurso como James Stirling, se extrae la superioridad de las propuestas de estos dos equipos frente a la de los demás, a las que añade Stirling la suya propia, y la de un tercer arquitecto como John Voelcker. ${ }^{45}$ Desconozco

43 Véase Giulio Carlo Argan, "Capogrossi", p.43

44 Es interesante a este respecto destacar la relación como coleccionista que St. John Wilson mantiene con Eduardo Paolozzi. Un ejemplo significativo es el referente a uno de los ejemplares de la escultura "Study for a larger form in Concrete", adquirida por St John Wilson. Se da la circunstancia de que otra copia de este objeto es el que quedó recogido en el libro de Michel Tapié "Un Art Autre". Véase al respecto, Judith Collins, “Paolozzi", pp. 71 y 72.

Respecto a su relación de amistad con Reyner Banham: “Conocí a Peter Reyner Banham y a Mary Bnaham en 1950. Vivían al lado de mi alojamiento de estudiante en Oppidans Road, cerca de Primrose Hill...Una noche Peter Carter y yo nos quedamos sin tinta china mientras dibujábamos el proyecto para el concurso de la Catedral de Coventry, se me ocurrió que podría ver si los vecinos de la lado tenían una botella de sobra. No hubo suerte con la tinta pero empezó una amistad de los más genial...Eso quería decir que tenía acceso a muchas revistas de arquitectura, y la sala de los Banham se convirtió en una especie de salón, que pronto sería el semillero del Independent Group..." Colin St. John Wilson, "Testimonios retrospectivos" en "El Independent Group: la postguerra británica y la estética de la abundancia", p. 195.

45 Véase al respecto James Stirling "The Black Notebook", recogido en Mark Crinson, "James Stirling. Early Unpublished Writings on Architecture", p. 21 
LÁMINA II.25

el proyecto de Voelcker ${ }^{46}$, pero el de Stirling es fácil adscribirlo a una distribución de los edificios bajo el Principio de Posición. Por tanto, de momento, sólo esta pareja de proyectos constituyen ejemplos claros del Principio de Transición, con la salvedad, que ya he analizado, de que en el caso de Alison y Peter Smithson confluyen los dos modos de operar con el espacio. Es esta especialísima nota, la que presta a su proyecto, y esa es mi tesis, esa dualidad tan "monstruosa" a efectos darwinianos, gracias a la cual consigue la distinción de la memorabilidad. En pocos casos como en este, un pequeño detalle en un plano, el doble rostro de la escultura "The Great Head", puede simbolizar mejor una idea. ${ }^{47}$ Como imagen sin posibilidad de existencia, ella no nos da sino la clave de la dificultad de componer con dos métodos y hacerlos compatibles.

Veremos en el siguiente capítulo las dos fuerzas que iluminan el debate arquitectónico en Inglaterra en el cambio de década entre los cuarenta y los cincuenta, que eran las de lo finito y lo infinito y que como dije al principio de este capítulo ayudan a hacer brillar ciertos rasgos del proyecto que pueden ser considerados coherentes con una situación global.

46 Respecto al proyecto de John Voelcker parece ser que no hay rastro de él. Puesto en contacto con la familia de Voelcker por mediación del Profesor Peter Carolin, antiguo colaborador del arquitecto, la familia me comunicó no tener noticia de tal proyecto. Por otra parte, en los números monográficos dedicados a su obra tampoco se menciona dicho proyecto.

47 Me refiero al minúsculo apunte de una escultura Ilamada "The Great Head" inserto en el plano de situación del concurso de Sheffield en la esquina entre las calles Bolsover Street y Western Bank. Las facciones de la cabeza presentan un doble rostro masculino y femenino. 


\section{LÁMINA II.22}

"Aluden con las imágenes que acompañan al texto ("Cluster City") a dos operaciones que permiten vislumbrar cómo sería la distribución en profundidad que indican..."

Alison y Peter Smithson: "Cluster City. A New Shape for the Community", en "The Architectural Review", Noviembre 1957.

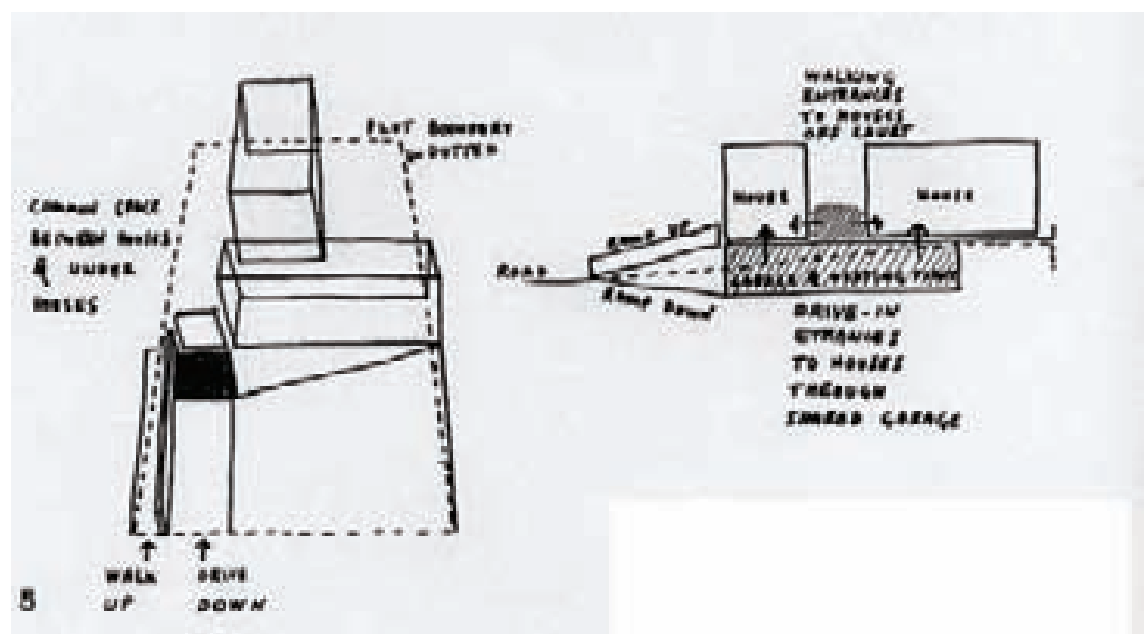

Le Corbusier, "Maisons Jaoul", 1951-55. Esquema de Alison y Peter Smithson para mostrar la doble conexión peatonal y rodada de las viviendas con la calle. El fondo de saco de Unwin es transformado en aparcamiento subterráneo.

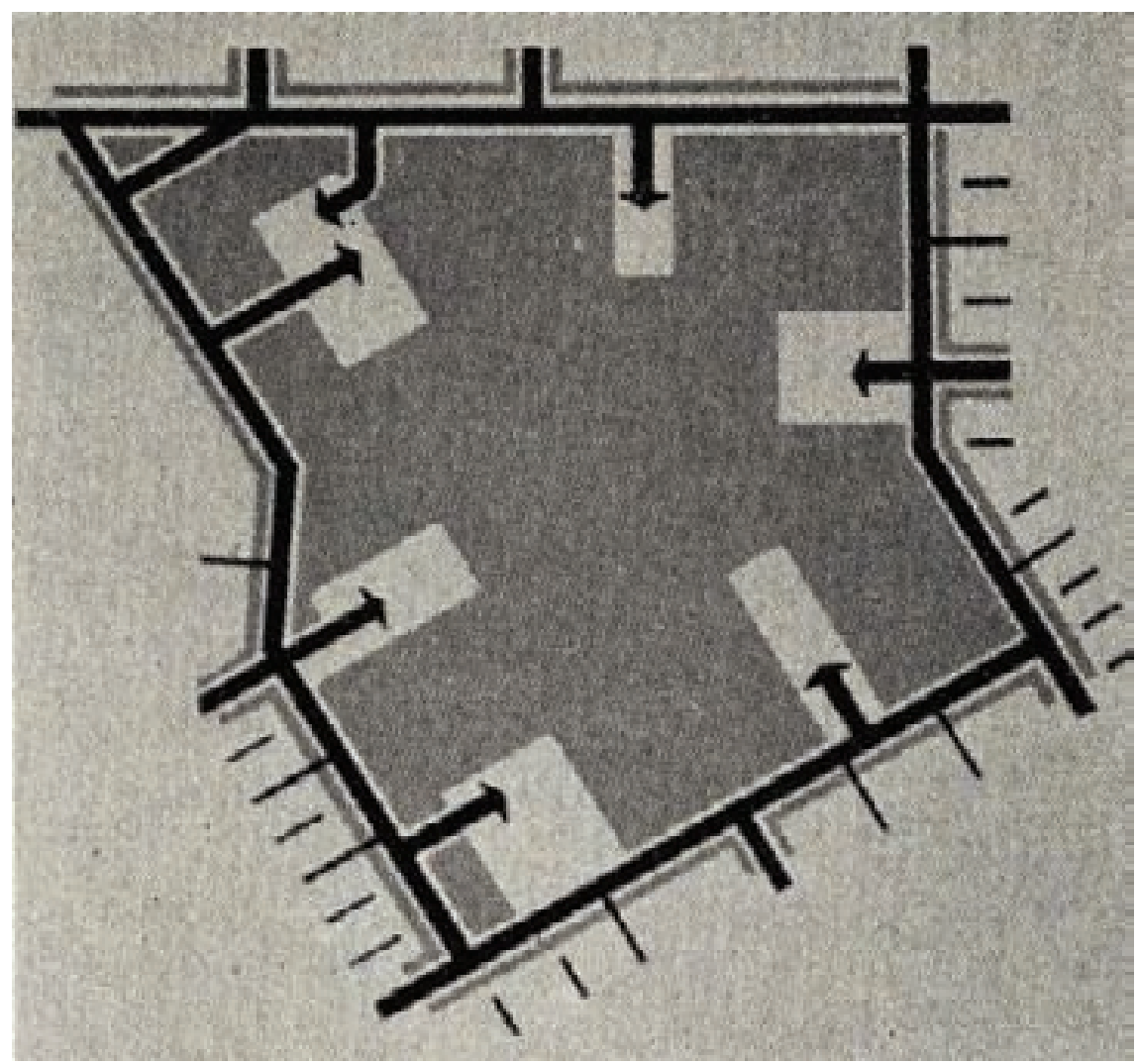

Victor Gruen, "Fort Worth", 1956. Esquema que muestra la posición de los edificios de aparcamiento. Es de resaltar en ambos casos el papel fundamental que adquieren la centralización de los aparcamientos dentro de la evolución del close. 


\section{LÁMINA II.23}

"Parece que la pintura de Capogrossi, que refleja "racimos y cremalleras", constituye un paralelo formal de algunos dibujos debidos a los Smithson sobre los modelos del close y del cluster ..."
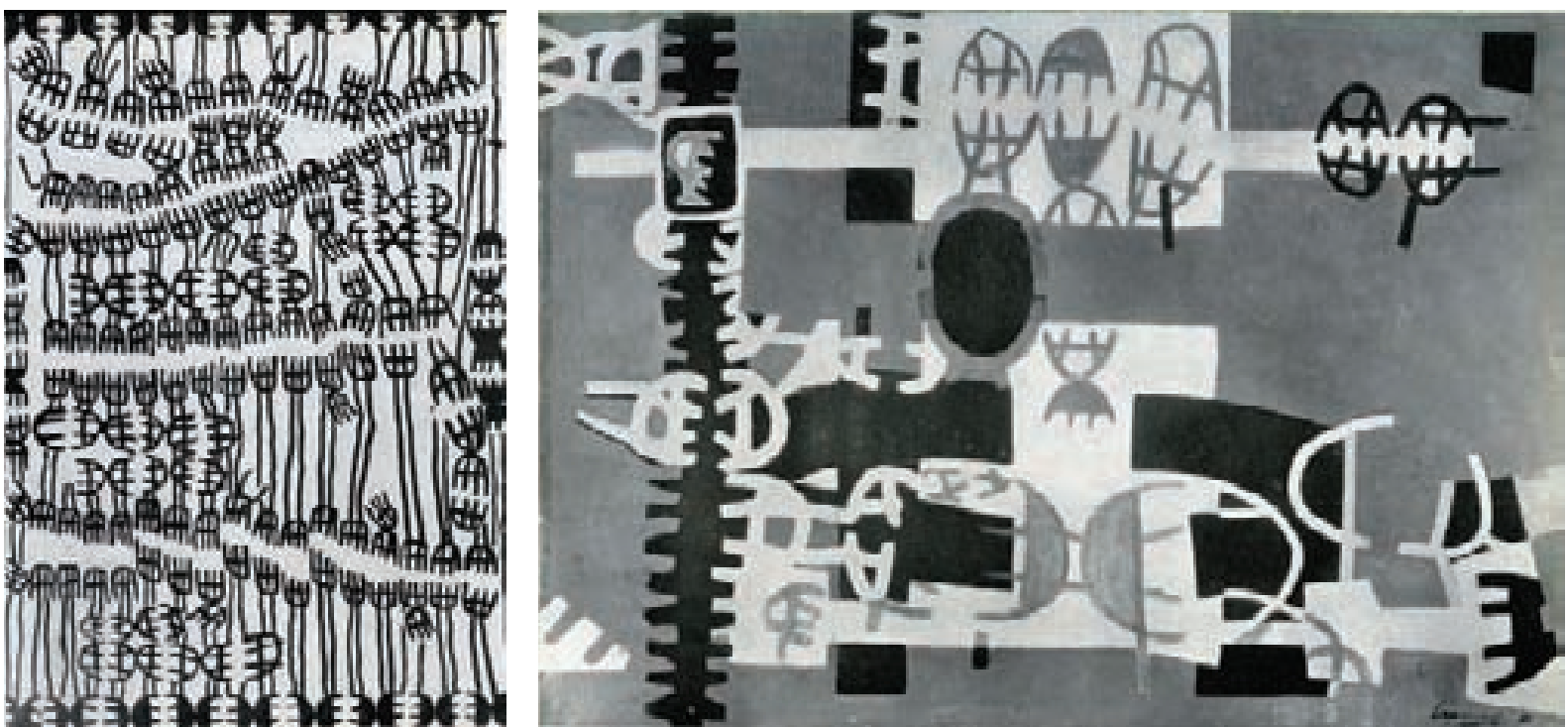

Dos reproducciones de Capogrossi recogidas en el libro de Michel Tapié “Un Art Autre”, 1952.

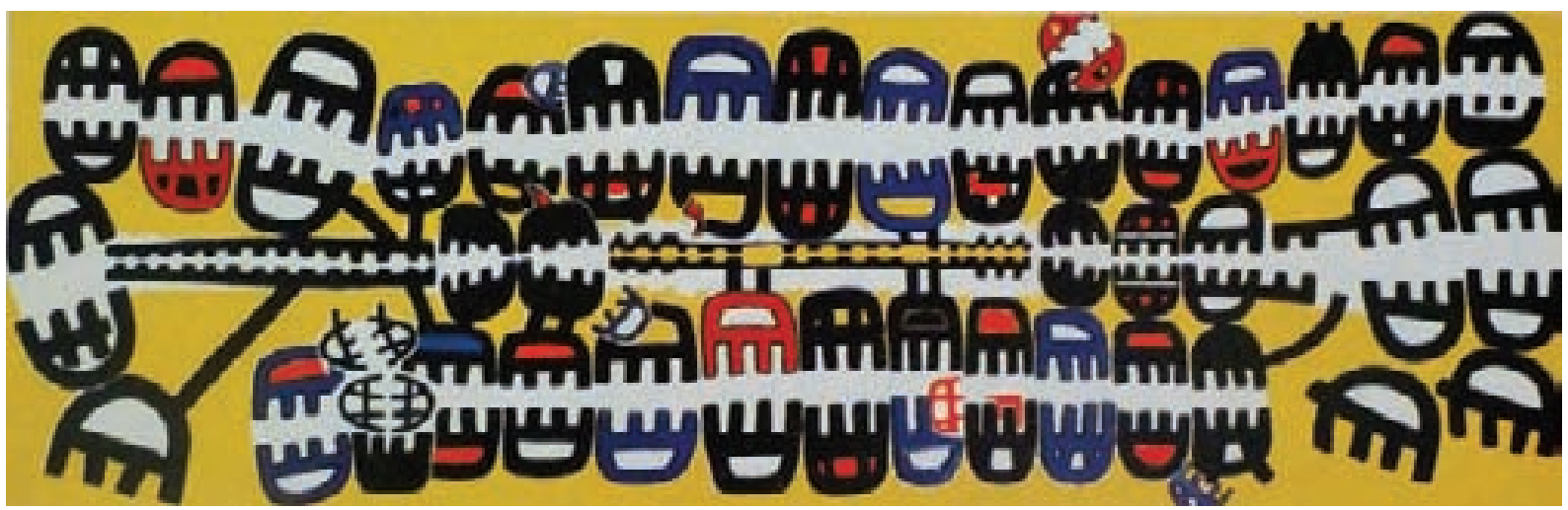

Capogrossi, "Superficie 28”, 1952.

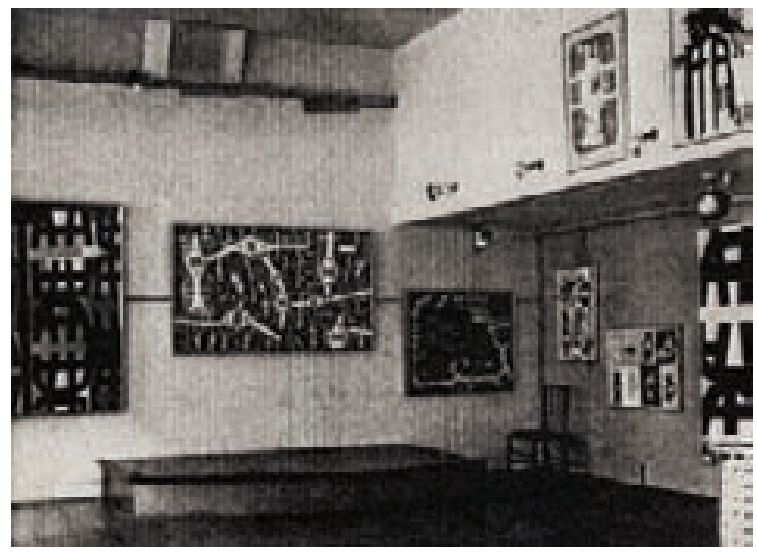

Exposición en el Institute of Contemporay Arts (ICA):

“Capogrossi. Paintings 1953-1957", entre el 30 de mayo y el 22 de Junio de 1957. 


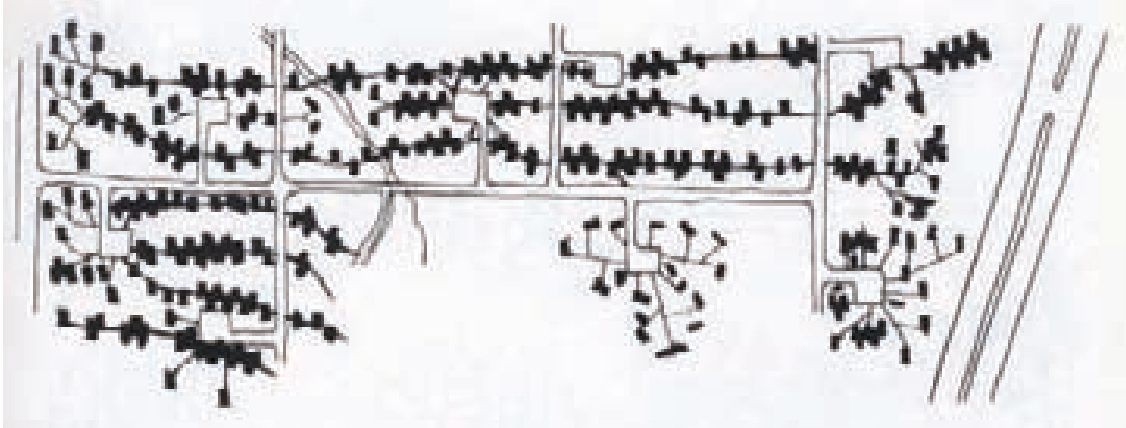

Alison y Peter Smithson, "Town: Close Houses", 1955. Diagrama de cluster.
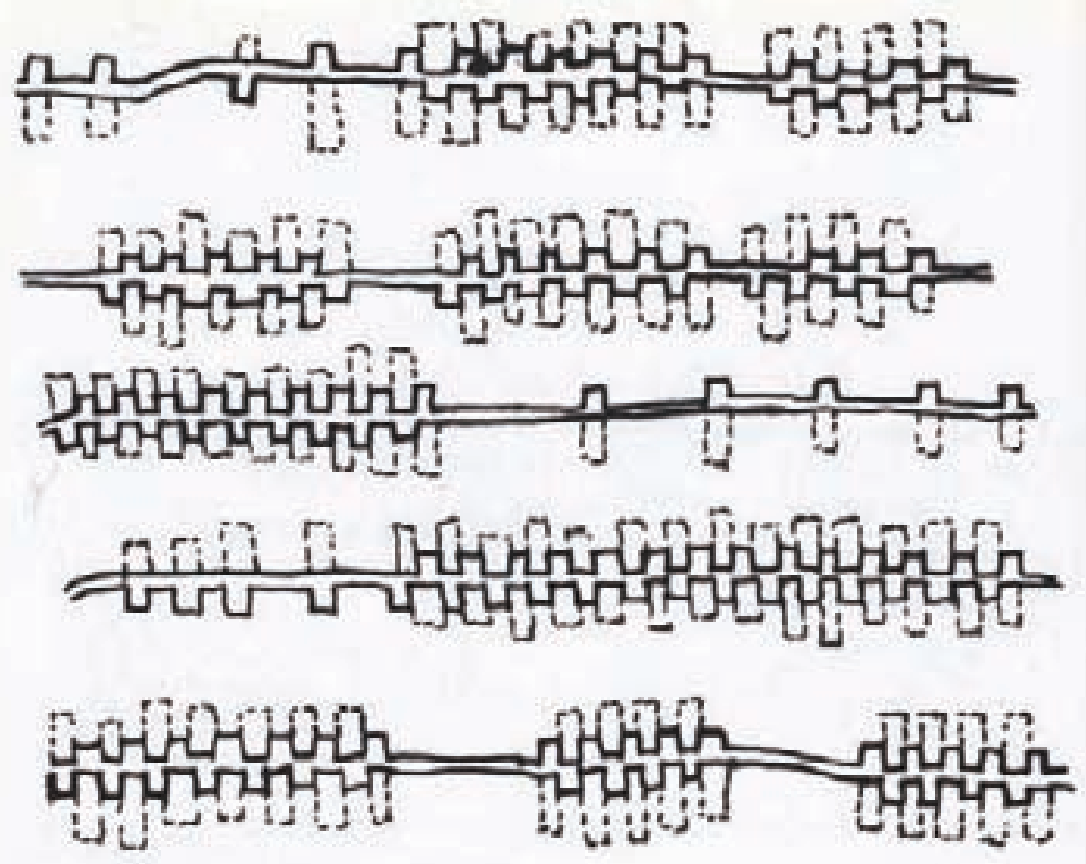

Alison y Peter Smithson, "Town: Close Houses", 1955. Diagrama de calles con las close houses.

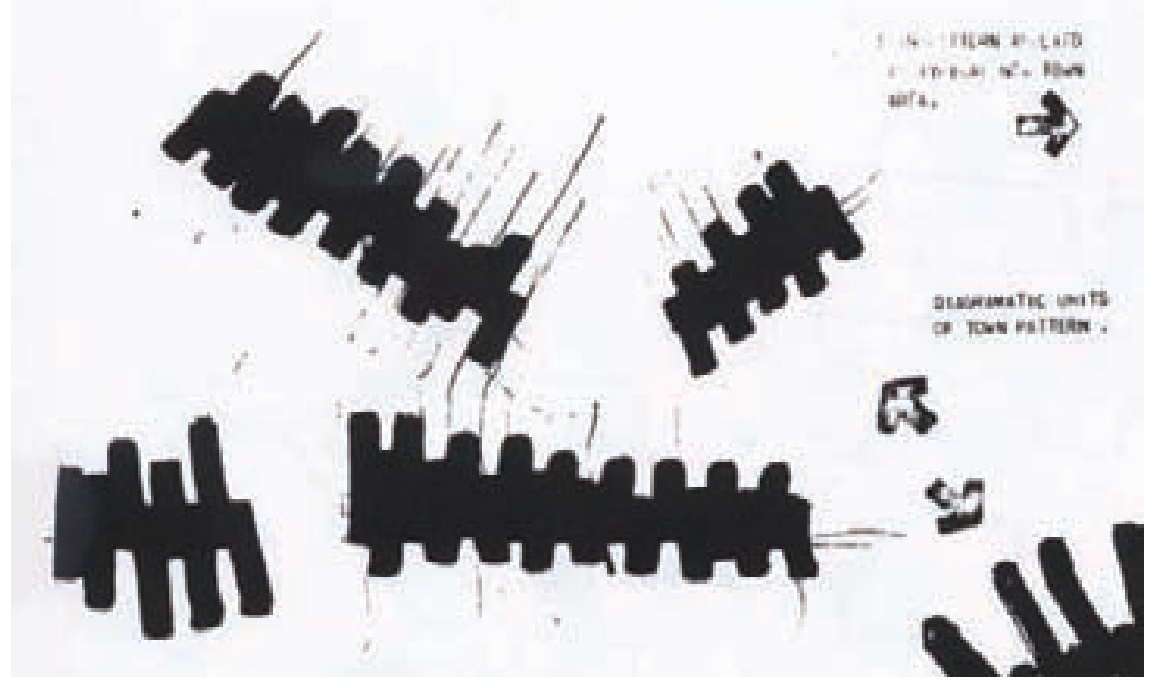

Alison y Peter Smithson, "Town: Close Houses", 1955. Modo de desarrollo de las close houses. 


\section{LÁMINA II.24}

"La circunstancia anómala del parecido entre dos soluciones que se destacan del resto permite suponer la existencia de ciertas y no veladas influencias y rivalidades mutuas entre gentes que orbitan alrededor de Reyner Banham y Eduardo Paolozzi ..."

Colin St. John Wilson y Peter Carter, "Sheffield University Competition", 1953.

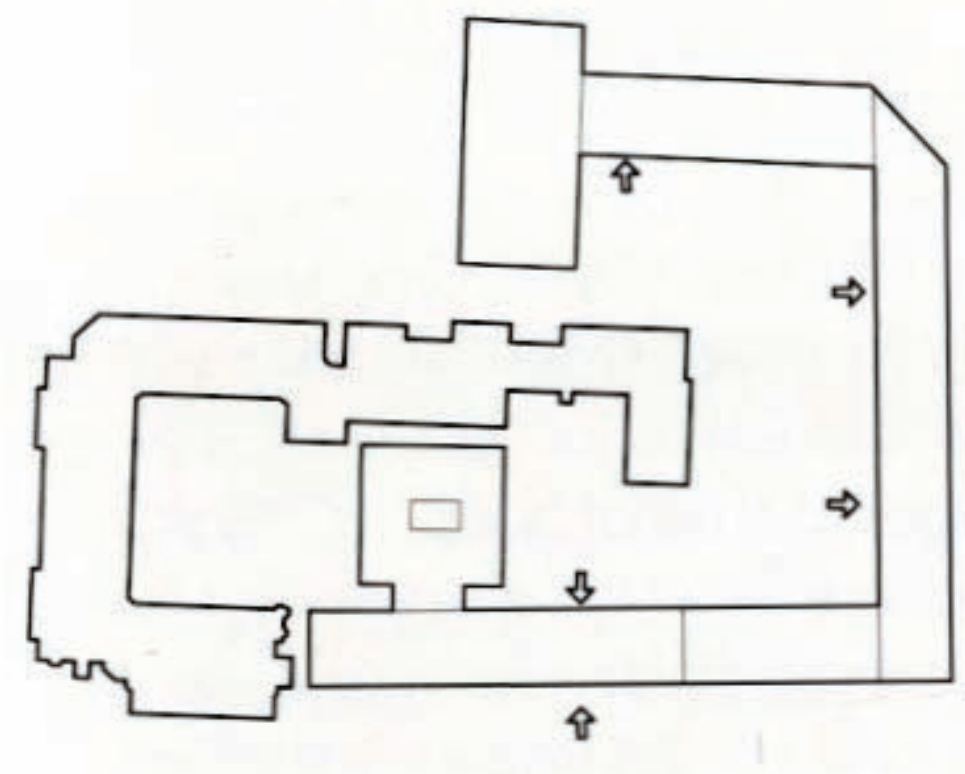

Esquema de planta.

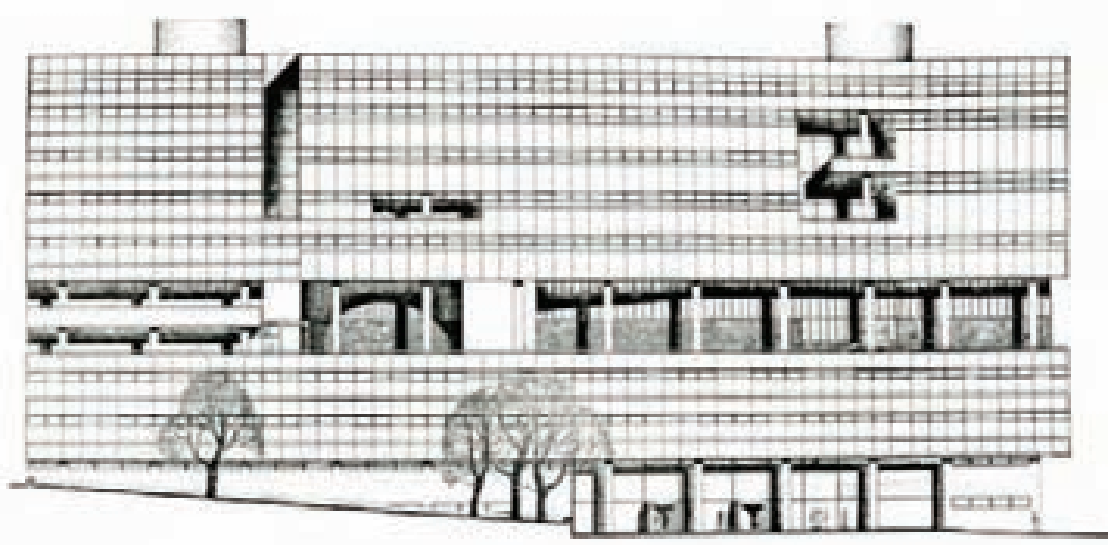

Alzado. Extraído de James Stirling: “The Black Notebook”, 1953-1956. 


\section{LÁMINA II.25}

“...con la salvedad... de que en el caso de Alison y Peter Smithson confluyen los dos modos de operar con el espacio. Es esta especialísima nota, la que presta a su proyecto, y esa es mi tesis, esa dualidad tan "monstruosa" a efectos darwinianos, gracias a la cual consigue la distinción de la memorabilidad. En pocos casos como en este, un pequeño detalle en un plano, el doble rostro de la escultura "The Great Head", puede simbolizar mejor una idea. Como imagen sin posibilidad de existencia, ella no nos da sino la clave de las dificultades de componer con dos métodos y hacerlos compatibles..."

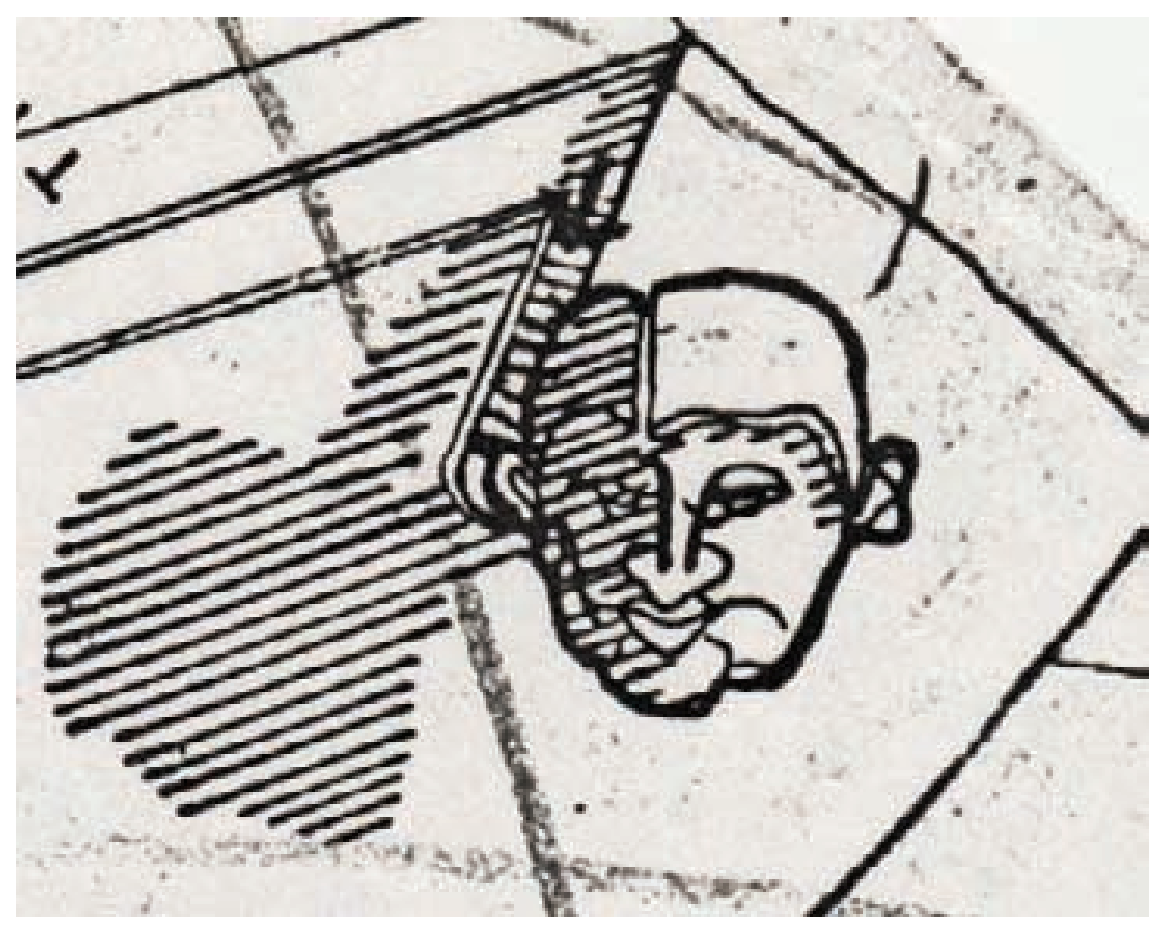

Alison Smithson, Peter Smithson "The Great Head", "Concurso de Ampliación de la Universidad de Sheffield", "Plano 00 ·Site Plan", 1953, detalle. 


\section{III}

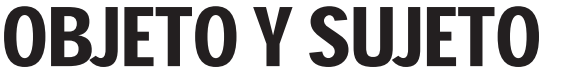

\subsection{WITTKOWER}

Hubo pocos libros de arquitectura fundamentales en la juventud de Alison y Peter Smithson". Dos de ellos fueron "Hacia una Arquitectura" (1923) y "Los Fundamentos de la Arquitectura en la Edad del Humanismo" (1949). Tanto el manifiesto de Le Corbusier como el ensayo de Wittkower dirigen sus páginas a celebrar el carácter espiritual de la arquitectura. La armonía de la proporción en la arquitectura es el reflejo de la armonía del mundo.

La noción común de la armonía descansa en una norma: las leyes matemáticas rigen el cosmos y son susceptibles, por tanto, de ser captadas intelectualmente. El sistema del mundo forma una estructura y en la relación y posición de las partes y el todo se advierten unas reglas inequívocas, por las cuales, es posible para el hombre construir un sistema universal.

Admitiendo que los textos se cruzan en este punto, en admitir la existencia de una estructura universal, cabe situar dicho punto donde la visión de Le Corbusier corta con la situación histórica planteada por Wittkower. El plano de Wittkower se tiende sobre el Renacimiento, en la edad de Humanismo, mientras que la visión de Le Corbusier no se encuentra, sin embargo, con el Renacimiento, sino mucho más atrás, topa con el templo dórico. Para hallar ese punto de encuentro entre ambos es necesario retrotraer los fundamentos de la arquitectura renacentista. El interés del libro de Wittkower no se halla en ese sentido en la arquitectura del Renacimiento como estilo, sino en las leyes que rigen su sistema. El punto de vista de Wittkower, aquello que dicta su investigación, es demostrar, a través de Alberti, Francesco Giorgi y otros, que la teoría de la arquitectura renacentista se apoya sobre las bases firmes de la ciencia griega, en la juventud de la ciencia griega, en la época del dórico.

El paso de una apreciación sensible, la de la musicalidad de ciertas relaciones de las cuerdas del instrumento musical, la lira tetracorde, al campo de lo científico, al campo de un saber demostrativo,

1 Peter Smithson señala únicamente tres libros, uno de los cuales era "Vers une Architecture". Véase Peter Smithson "Fortifications" en ILA\&UD Annual Report 19981999, p. 52 
se produce dentro de la escuela pitagórica. No voy a insistir mucho en ello, y me ceñiré a lo expuesto por Abel Rey. Para éste, "la música por sus relaciones con la acústica se nos presentaba como el dominio ideal en el que podríamos precisamente captar ese tránsito de lo cualitativo a lo cuantitativo: tránsito de lo concreto a lo abstracto, de las apreciaciones singulares, es decir sensibles, estéticas, aún siendo colectivas, a lo universal de una técnica en la que hemos creído ver el avance hacia la ciencia y la formación de ésta". ${ }^{2}$ Y la relación entre las longitudes de las cuerdas con los intervalos matemáticos, 4/3, 3/2, 2, "son las cifras... que se enlazaban en la serie de la tetráchtys 1, 2, 3, 4: la relación 1 a 2 expresa la relación más sencilla, la de la octava, y las relaciones de 2 a 3 y de 3 a 4 , la quinta y la cuarta". ${ }^{3}$

El paso de una apreciación sensible a una formalización matemática, según Rey, fue dado a través de la figuración del número: "con la idealización abstracta que facilitaban las especulaciones sobre la serie de los números y de sus relaciones (progresión y proporción), que es en lo que consiste toda la aritmética pitagórica primitiva, con el reconocimiento del carácter augusto de la década o del tetráchtys, suma de los cuatro primeros números, 1, 2, 3, 4, se debió finalmente percibir el posible papel de estos cuatro primeros números en las determinaciones de los tres acordes del tetracorde (cuarta, quinta, octava) y sus características de construcción". ${ }^{4}$

El encuentro, por tanto, entre unas manifestaciones musicales, especialmente agradables al oído, con una serie, progresión o relación numérica, especialmente agradable al intelecto, tuvo su lugar de origen, como señala Rey, dentro de la Magna Grecia: "se deduce, al parecer, que la teoría matemática de la música que tuvo su nacimiento en los finales del siglo VI dentro de la secta pitagórica y por tanto en el país dórico, no pudo producirse sino allí, mutuamente adoptado a la música dórica...y en efecto esta emparentado,..., con los cánones de la arquitectura dórica". ${ }^{5}$

El desplazamiento del Renacimiento hacia la antigüedad clásica, lo basa Wittkower, en la prolongación de los preceptos pitagóricos de la aritmogeometría hasta su renacer en los s. XV y XVI: "Los artistas del Renacimiento no pretendían traducir la música en términos arquitectónicos, sino que consideraban los intervalos consonantes de la escala musical como pruebas visibles de la belleza de las relaciones proporcionales entre los pequeños números enteros: 1:2:3:4"6 emparejando la teoría renacentista con la vertiente mística de la matemática pitagórica. Como señala Wittkower "no era una mera especulación teórica, sino el testimonio de una solemne creencia en la estructura matemática y armónica de toda la creación. Y tenía su reflejo práctico en un nuevo estatuto liberal de las artes: "Frente a <<estas artes〉> liberales (el cuarteto de las <<artes〉> matemáticas: la aritmética, la geometría, la astronomía, y la música), la pintura, la escultura y la arquitectura se consideraban ocupaciones manuales. Para elevarlas desde el nivel mecánico al nivel de las artes liberales, hubo que dotarlas de una base teórica, es decir de una fundamentación

2 Abel Rey, "La juventud de la Ciencia Griega", p. 333

3 Ibíd., p. 334

4 Ibíd., p. 335

5 Ibíd.,. pp. 340, 341

6 Rudolf Wittkower "Los fundamentos de la Arquitectura en la Edad del Humanismo", p. 159 
matemática".7

Bajo la operación llevada a cabo por Wittkower en "Los Fundamentos de la Arquitectura en la Edad del Humanismo" queda establecida una doble validación de la arquitectura del Renacimiento. Se crea un marco histórico donde se recogen y se insertan los preceptos de la teoría pitagórica, y , esta es la novedad, se adjudica por medio de éstos un cuerpo teórico doctrinario a la arquitectura como arte liberal. En "Los Fundamentos de la Arquitectura en la Edad del Humanismo" el Renacimiento adquiere una nueva consistencia que es aportada por la relación con la ciencia y filosofía griegas, a través de Platón y de Pitágoras.

Por medio de este enlace es posible, entroncar y hacerlo concomitante con el desarrollo dado por Le Corbusier en los años veinte. Digamos, que la admiración del templo dórico en "Hacia una Arquitectura", y la arquitectura del Renacimiento, en "Los Fundamentos de la Arquitectura en la Edad del Humanismo", encuentran su punto de intersección en el sustrato de la ciencia griega. En apoyo de esta tesis, los paralelismos establecidos por Colin Rowe en 1947 de las villas Stein y Savoye de Le Corbusier con las villas palladianas Foscari y Rotonda en "Las matemáticas de la vivienda ideal".8

Lo que permite a Rowe justificar su propio artículo es el método que en él lleva a cabo. No son las descripciones de los acontecimientos que se dan cita en las plantas o en las fachadas de los dos objetos principales de su comparación, a Villa Malcontenta y la Villa Stein. En este sentido hay suficiente disparidad como para hacer de ellos elementos incomparables. El tema que aborda Rowe es demostrar que estos edificios son comparables a través de sus figuras. Como este método no deja de ser un método establecido ya por la ciencia griega, digamos que lo que se alcanza en "Las matemáticas de la vivienda ideal" es una perfecta unidad de criterio, cuyo fundamento es matemático y griego por partida doble. En este sentido Rowe no se aparta del método empleado por Apolonio para comparar dos cónicas entre sí. Dado que el problema que afecta al análisis comparativo de los edificios es una acumulación de factores (constructivos, materiales, estilísticos, funcionales etc.) el procedimiento que persigue Rowe es el recurso a la instanciación de éstos en las figuras que los representen. Al igual que ocurre en los edificios, las cónicas, nos dice Echeverría acerca del procedimiento de Apolonio, carecían de identidad geométrica: "Se sabía cómo construirlas, se conocían algunas de sus propiedades y también su utilidad para bordar problemas como el de la duplicación del cubo o el de la trisección del ángulo; pero todo ello no les proporcionaba identidad geométrica". Paralelamente, Rowe no trata de instalarse en la técnicas de construcción estructural, muros de carga o pilares, que los diferencian del todo, sino que dirige su análisis a establecer la identidad geométrica de las dos villas. Para ello, reduce ambas a una secuencia, que es el único argumento eficazmente comparativo: La Villa Foscari se transcribe como $2: 2: 1 \frac{1}{2}$, la Villa Stein queda como $1 / 2: 1 \frac{1}{2}: 1 \frac{1}{2}: 1 \frac{1}{2}: 1 / 2$. Para Apolonio dos elipses son comparables no por superposición de sus trazos, sino por reducción

7 lbïd

8 La relación entre Rowe y Wittkower proviene del trabajo de tesis doctoral de Rowe llevada a cabo en la London University, cuya dirección estaba a cargo de este último. Véase al respecto Anthony Vidler, "Historias de un Presente Inmediato", capítulo "Movimiento Moderno Manierista: Colin Rowe" p. 79 y ss. 
a su triángulo característico: "Llamaremos figura de la sección construida sobre el eje o sobre un diámetro al rectángulo delimitado por este eje o este diámetro y el lado recto correspondiente". Quiere esto decir, que a partir de datos de su eje y de puntos de su trazado es posible establecer para la elipse (y para las cónicas en general) una nueva figura que se va a erigir en su representante geométrico, siendo esta figura un rectángulo, una figura para la cual ya no se plantean problemas teóricos.

Del mismo modo se opera con ambos procedimientos: no se comparan ya los trazados o planos directamente entre sí. El trazado efectivo de las villas o de las cónicas es irrelevante en este contexto. Lo que entra en la argumentación son, en un caso, relaciones de proporción entre números y número de elementos que intervienen en la secuencia, y en las cónicas, los criterios de igualdad entre rectángulos, figuras ya sobradamente conocidas. Por tanto, el paso decisivo que apunta Rowe, y el que le permite saltar por encima de tantas desemejanzas "que parece grotesco compararlos" ${ }^{\text {, }}$, es proponer un sistema numérico proporcional que evalúe secuencias rítmicas y que ejerce la misma función que el rectángulo característico, esto es, limitar la comparación a un hecho objetivo de base matemática, e incluso, como hemos visto, de fundamento griego.

Bien, este es el argumento matemático con el que Rowe se considera en deuda con Wittkower. Lo que había podido demostrar Wittkower, por encima de que fueran tales o cuales los números implicados en las relaciones, era que se consideraban transmisores de una armonía universal, y, en consecuencia, su uso estaba sancionado por la práctica de la arquitectura durante el Renacimiento. Ahora bien, en el siglo XX no había tal creencia en un acuerdo común similar. Como indica Wittkower, "...me sorprendió el efecto electrizante que produjo en los estudiantes, y el debate que acto seguido mantuvimos puso de manifiesto que el problema de la proporción les interesaba especialmente. Al parecer en los cinco años que llevaban estudiando no habían oído una palabra sobre la proporción, bajo el pretexto de que se trataba de algo intuitivo, un sentido de orden que se tenía o no se tenía, pero que no se podía enseñar... muchos jóvenes artistas y arquitectos han sido alumnos míos, y una y otra vez me he encontrado con que ésta (la proporción) era la cuestión que más les preocupaba". Rowe aprecia lo solitario de la aventura de Le Corbusier: "La posición teórica sobre la que descansaba el punto de vista de Palladio desintegróse en el siglo XVIII al convertirse la proporción en una cuestión de sensibilidad individual y de inspiración privada; y Le Corbusier, a pesar del apoyo que encuentra en las matemáticas, ya no puede gozar por su situación histórica de aquella incuestionable posición". Y es la lucha en Le Corbusier por restituir unos trazados reguladores contra el espíritu de los tiempos: "-Con vuestros trazados reguladores mataréis la imaginación, entronizaréis la receta (se espeta Le Corbusier a sí mismo en un diálogo imaginario) -Pero todas la épocas precedentes han empleado ese instrumento necesario.-iEso no es cierto, son invenciones suyas, es usted un maniático!. -Pero el pasado nos ha legado pruebas, documentos iconográficos, estelas, losas, piedras grabadas, pergaminos, manuscritos, dibujos..."10 
El problema en sí podía considerarse un asunto menor e incluso anacrónico si no fuera porque para los "jóvenes" arquitectos los textos se alinearon entre sí. Resulta que "Hacia una arquitectura" y "Los Fundamentos de la Arquitectura en la Edad del Humanismo" podían interpretarse como complementarios, y a esto contribuyó la aparición de El Modulor hacia 1950. Y la crítica a uno de ellos de algún modo implicaba al otro. De hecho se podía ver entre líneas la resistencia por parte de la crítica británica corporativa a aceptar las tesis de Wittkower como una defensa de la tradición insular ante las tentativas de orden corbuserianas. Butler, encargado de la sección de crítica de libros de la revista del órgano colegial RIBA Journal en el número de Diciembre de 1951, manifiesta ciertas dudas sobre el texto de Wittkower. Por un lado: "debo confesar -dice Butler- que encuentro algunas citas de Francesco Giorgi ininteligibles, y ciertamente aburridas las explicaciones de Alberti sobre las razones proporcionales, a pesar de que, para ellos, la analogía entre la proporción musical y visual era algo más que especulaciones teoréticas, e incluso, como aparece testificado, se trate de una solemne convicción en la estructura armónica y matemática de la creación"11. Pero además, señala Butler, Wittkower apunta directamente a Inglaterra como causante de la pérdida de en la confianza en estos sistemas proporcionales: “... como el autor nos cuenta, y es triste descubrirlo, fue en Inglaterra donde la estructura completa de la estética clásica fue derrocada desde su base..." ${ }^{12}$. Finalmente Butler muestra por medio de Ruskin ("se debe dejar a la inspiración del artista que invente proporciones maravillosas") y Guadet (las proporciones "son pura quimera") que estos sistemas no tienen en este momento otra validez que la simple utilidad para "nuestros" jóvenes arquitectos de "atraerlos momentáneamente fuera de la experimentación sin gobierno de la ingeniería"13 si hubieran sido convenientemente simplificados.

En la misma revista, en Febrero del año siguiente, 1952, aparecieron por parte de los "jóvenes" arquitectos las defensas al libro de Wittkower. Primero Alison y Peter Smithson (se transcribe entera su carta):

"Estimado Sr., se puede percibir que su crítico encuentra el libro del Dr. Wittkower difícil, opaco y nada gratificante (provechoso). Comienza con un insulto nada sutil al Dr. Wittkower, incluyendo algunas citas bastante irrelevantes y termina con la afirmación: "La conversión de la tesis histórica en una exposición más simplificada de las teorías principales, que contenga diagramas claros, que puedan atraer temporalmente a nuestros jóvenes arquitectos fuera de la experimentación sin gobierno de la ingeniería".

11 A.S.G. Butler, RIBA Journal, Sección "Book Reviews", "Architectural principles in the age of humanism", pp. 59 y 60

12 “Comenzó Hogarth en 1753; le siguió Hume, que en su ensayo Of the Standard of Taste, exclamó "La belleza no es una cualidad de las cosas en sí mismas, más bien existe en la mente que las contempla". También Burke hizo trizas la concepción clásica de la proporción; y Lord Kames, en 1761, lanzó un ataque frontal contra la traslación de las consonancias musicales en la arquitectura. Finalmente Richard Payne Knight, en 1805, encontró una prueba pseudo lógica que indicaba que la armonía musical y la proporción espacial no tenían absolutamente nada en común". A.S.G. Butler, ibíd., p. 60

13 lbíd. 
El Dr. Wittkower es considerado por los jóvenes arquitectos como el único historiador del arte en Inglaterra capaz de describir y analizar edificios en términos espaciales y plásticos y no en términos de origen y fechas; y este no es un fenómenos insular, como mostró el Dr. Giedion en una lectura a comienzos de año en el I.C.A., al indicar que en seminarios celebrados en Zurich y en el M.I.T. durante 1950, los libros más discutidos del año fueron El Modulor y Los Fundamentos de la Arquitectura en la Edad del Humanismo y ambos tratan sobre la proporción. Además el Dr. Wittkower fue el único representante de este país invitado al reciente Congreso Internacional sobre Proporción celebrado en Milán, donde matemáticos, artistas y arquitectos, se reunieron para tratar sobre esta cuestión de vital importancia.

Parece extraño que la obra sobre arquitectura más importante editada en Inglaterra desde la guerra (en 1949) haya sido recogida en una revista profesional casi tres años después de su publicación y por alguien totalmente ignorante sobre el estado de la profesión y aparentemente más que deseoso de alienar a una de las pocas personas de fuera de la profesión que ve los edificios como obras de arte y no como posible trampolín literario de su propia erudición. Atentamente. Alison y Peter Smithson (Arquitectos)"14

Acompañando a la carta de los Smithson se publica otra de John Voelcker en los siguientes términos (se transcribe igualmente en su totalidad):

"Estimado Sr., Mr. Butler termina del siguiente modo su artículo sobre "Los Fundamentos de la Arquitectura en la Edad del Humanismo" del Dr. Wittkower "... su tesis histórica... puede atraer a nuestros jóvenes arquitectos fuera de la experimentación sin gobierno de la ingeniería". El Dr. Wittkower cierra su libro: "El tema (la proporción) ha adquirido otra vez actualidad entre los jóvenes arquitectos contemporáneos, y probablemente ellos nos ofrecerán nuevas e inesperadas soluciones para este antiguo problema".

Los Fundamentos de la Arquitectura en la Edad del Humanismo es uno de esos raros libros que no sólo examina una situación histórica particular sino que aporta el material necesario para convertirse en una fuerza activa en la situación presente. Así pues, no puedo estar de acuerdo con Mr. Butler cuando dice que requiere de un aprendizaje muy especializado. La estética clásica, que en este país ha sido tratada en los libros por igual para escolares y para arquitectos, sólo hoy empieza a verse desde su perspectiva histórica -como un ingrediente esencial de la tradición europea, que la hereda.

La reacción comienza con Hogarth en su Análisis de la Belleza (1753) y aún se mantiene firme. Sugiero que es por esta razón, que Mr. Butler considera casi aburridas las explicaciones sobre las proporciones de Alberti. Para muchos de nuestra (joven) generación esta aplicación aritmética ilumina por un instante la inmediata, y especulo, que eterna cuestión de la coherencia y compenetración de nuestras acciones, y más específicamente de nuestros edificios.

En los últimos años la afinidad con este problema ha sido directamente expresada por la joven generación. En PLAN Magazine, 
la revista de la Architectural Students Association, han sido publicados dos artículos que tratan esta cuestión. En 1950, Le Corbusier publica sus investigaciones sobre la proporción (Le Modulor), ésta es una obra rica en pensamiento filosófico y en sus significados técnicos inmediatos. Con poco menos que palabras vacías han sido en este país valoradas sus profundas tesis. En 1951, se celebraron una exposición titulada Studi Sulle Proportioni y un congreso De Divina Proportioni como parte de la Trienal de Milán. Asistieron arquitectos, artistas, matemáticos e historiadores del arte de Europa y América. Este evento fue ampliamente recogido por la prensa europea, incluso por los diarios franceses e italianos, mientras que prácticamente pasó desapercibido para la prensa, especializada o no, de este país.

Quisiera acabar anotando un párrafo de la contribución hecha por el Dr. Wittkower a este congreso: "Este examen puramente histórico (de los sistemas proporcionales) puede, creo, indicarnos una dirección relativa a nuestros problemas actuales, una época de la geometría no euclidiana y de la cuarta dimensión. Nuestra idea del tiempo y del espacio es, necesariamente diferente de la de los siglos anteriores y no existe atajos para una nueva comprensión de la proporción. Las discusiones habidas en el congreso nos ayudarán, a lo mejor, a ver nuestros problemas en el nuevo contexto" - Atentamente. John Voelcker (Estudiante) $)^{15}$

Confieso entender más la postura "oficial" británica, que la vehemencia en la defensa, encendida, de los Smithson y John Voelcker. El asunto presenta tantos pliegues que resulta difícil tomarlo en su conjunto.

En "Hacia una Arquitectura", Le Corbusier se dirige fundamentalmente al sentido de la vista, a la percepción de los volúmenes bajo el componente de la emoción plástica. En su disquisición con el trabajo de los ingenieros se advierte el lugar que ocupa la plasticidad de la arquitectura, y el papel relevante de la proporción. Pero por eso mismo, cuesta ver en ello, una independencia de ésta, el poder "despegar" la proporción del cuerpo de la arquitectura, conferir a la proporción su propia naturaleza como principio dominante. Aún en sus declaraciones más solidarias con el principio proporcional, como por ejemplo "La arquitectura es el arte por excelencia, que llega al estado de grandeza platónica, orden matemático, especulación, percepción de la armonía mediante las relaciones conmovedoras"16 resulta dependiente en último término de una teoría que coloca en primer lugar la percepción directa de los volúmenes. Allí donde halla una contradicción entre la razón intelectual y la percepción sensible, esta se decanta inevitablemente del lado de la visión. Ejemplo de ello, son las desviaciones que hacen del Partenón el ejemplo perfecto del templo dórico. Le Corbusier recoge que se "han aplicado las deformaciones más sabias, llevando a las molduras una adaptación impecable a las leyes de la óptica". ${ }^{17}$

En "Los Fundamentos de la Arquitectura en la Edad del Humanismo" el mensaje que transmite Wittkower pasa por aceptar que la arquitectura del Renacimiento haya sus fundamentos fuera de

15 John Voelcker, RIBA Journal, Sección "Correspondence", "Architectural Principles In The Edge Of Humanism", pp. 140 y 141

16 Le Corbusier, "Hacia una Arquitectura" pp. 86, 87

17 Ibíd.. nota a pie de foto, p. 170 
sí misma, dado que, como dice se trata de un arte liberal. Su convicción reside en la alusión a la filosofía neoplatónica cuya expresión científica es el resultado de adoptar un sistema armónico que tiene en el número su expresión más clara del cosmos.

Se podría llegar a reunir las dos vertientes, la perceptiva y la intelectiva de esta situación siguiendo a Saint Simon, "nada mejor que las siguientes palabras para mostrar fielmente la oposición que existe entre ellos (el antiguo y el por venir sistema social): en el antiguo sistema, la sociedad está gobernada esencialmente por hombres; en el nuevo, no está gobernada más que por principios". ${ }^{18}$

Tomados juntos ambos textos, lo que puede aportar Wittkower a "Hacia una Arquitectura" y donde podía ser útil (siguiendo en esto a Butler) a la generación de los Smithson, era mostrando que para la práctica de la arquitectura convenía regirse por unos principios.

Si hemos de atender a los principios, el asunto de cómo queda enlazada la matemática con la teoría arquitectónica en el planteamiento de Wittkower era algo indefendible ya en los siglos XV y XVI a poco que se profundizara en la evolución de la ciencia en el propio Renacimiento: "Aquí reside la nítida línea divisoria que separa el concepto kepleriano de la armonía de la concepción neoplatónica y neopitagórica del universo con la que en un principio parece entremezclarse y confundirse. Esta separación no puede establecerla la matemática en cuanto tal, sin ninguna determinación y caracterización lógica más definida, pues... se humillaba la matemática al servicio de la mística y de la magia. El intento de reducir la realidad a relaciones numéricas puras conduce simplemente a juegos alegóricos, si no se pone desde el primer momento al servicio de la rigurosa analogía causal de los fenómenos de la naturaleza, si no se enseña a entender y emplear la matemática como condición para el conocimiento empírico de la ley." ${ }^{19}$

Si se pretende estar a salvo de los principios, que constituían un blanco fácil, podría uno retirarse a una posición más segura, y, llegar a compartir que la conjunción de Wittkower con Le Corbusier dota de peso específico al texto de éste último acerca de que "trazado regulador es un seguro contra la arbitrariedad" 20 .

Cualquier ataque que por tanto pudiera dirigirse hacia los principios renacentistas (aburridos y anacrónicos) ${ }^{21}$ hallarían en esta expresión "un seguro contra la arbitrariedad", la manifestación más convincente de que más allá de una doctrina (muy especializada), podríamos convenir en que el sistema proporcional junto con los trazados reguladores son un método. Como método, entonces, habría que juzgarlo desligado de la validez o falsedad de los principios, y en vista de sus consecuencias prácticas, considerarlo como fructífero o estéril.

En sus consecuencias prácticas el método puso en pie la estética neopalladiana. Atributos que parecían olvidados como la simetría

\footnotetext{
18 Henri de Saint Simon "Gobierno y Administración" en "Socialismo premarxista" p. 38

19 Ernst Cassirer "El Problema del Conocimiento", Tomo I, p. 315

20 Ibïd., p. XXX

21 En el sentido de Butler
} 
se unieron a los productos derivados del sistema proporcional, cuyo rasgo fundamental era el carácter de finitud y de volumen limitado aplicados a los edificios. Es en este sentido en el que prospera la estética neopalladiana, profundizando en la imagen directa del edificio. Así resulta que el concepto de memorabilidad se instala, según Rowe, que es quien parece introducir el término, en la belleza clásica de la simetría y el equilibrio, persiguiendo un acuerdo entre las partes y el todo propio de modo palladiano de composición: "Palladio buscaba un plano de claridad meridiana y la organización lúcida de elementos convencionales siguiendo una simetría que fuese una forma de orden memorable..." Es razonable, por tanto, estimar las consecuencias del método, en función de sus rasgos característicos como la simetría y el orden basado en las magnitudes y atender a sus aciertos o errores estéticos en función del modelo tomado como referencia.

En cuanto al grado de aceptación, seguimiento, y duración en la aplicación del método proporcional, lo que se puede distinguir como la fecundidad del método, podemos hacernos una idea a través de lo que se recoge en algunos textos. Tomando como datos, algunos debates y declaraciones en revistas de la época, de la exposición hecha por Anthony Vidler ${ }^{22}$ se infiere un momento álgido, en fecha muy temprana, hacia 1948, y su declive absoluto en 1957.

Banham sitúa en fecha excesivamente temprana, 1951, el abandono por parte de los Smithson de la composición neopalladiana, a partir, nos cuenta, de que finalizaran el concurso para la Catedral de Coventry, si bien, como hemos visto, en 1952 seguían respaldando el texto de Wittkower. ${ }^{23}$

A finales de 1953, con motivo de la exposición "Parallel of Life and Art", la conferencia impartida por Peter Smithson en la sede de la Architectural Association llevó el título "We are not here to talk about

22 La publicación reciente (2008) de libro de Anthony Vidler, "Historias del Presente Inmediato", permiten enfocar el neopalladianismo desde cierta perspectiva (vése pp. 87 y 88 ) . Lo más interesante, sin embargo, se encuentra más adelante, p. 98 , donde se deja ver, lo que parece ser una operación dirigida a preparar de forma conveniente la doctrina del Movimiento Moderno continental para su inserción en el contexto británico asunto en el que se habría implicado consciente o inconscientemente la Tesis de Wittkower: "Sin embargo, este llamamiento (lanzado por The Architectural Review) también tenía un lado estético dirigido al movimiento moderno supuestamente dogmático de los años de preguerra: (cita Vidler a Richards, Pevsner, Lancaster y Hastings, responsables, a la sazón de la revista, en un editorial de The Architectural Review de Enero de 1947) "El objetivo obvio a corto plazo debe consistir en recuperar algo del alcance y de la riqueza que descartaba el Acto Revolucionario". Esta tarea (continua Vidler) requería un "nuevo humanismo" para la arquitectura y al buscar un "contacto más directo con las aspiraciones humanas", la arquitectura "se convierte cada vez más en un vehículo para las aspiraciones de la humanidad". Un programa de este tipo suponía descartar muchas de las doctrinas del movimiento moderno que, a la luz de la experiencia, se habían convertido en "características negativas"..."

23 "Habíamos estado en Italia para contemplar las iglesias de planta central y cuando leímos el libro de Wittkower, encontramos que en él se respondía a muchas de nuestras dificultades. Había estado trabajando en su tesis probablemente durante treinta años. Supimos que era uno de nuestros maestros." Alison y Peter Smithson en conversaciones con Jeremy Baker el 4 de Julio 1965 y 4 de Enero 1966, recogidas en "Arena. The Architectural Association Journal", Febrero de 1966, p.182. Probablemente hagan referencia a su viaje por Francia e Italia en el invierno de finales de 1950, Ibíd. p. 181 
Simmetry and Proportions". ${ }^{24}$

Para Jencks, por otra parte, se puede hablar de una "vitalidad del movimiento", por lo menos antes de que surgiera el Nuevo Brutalismo . ${ }^{25}$

Pero es en Estados Unidos donde el método pareció ser más fecundo. Banham, en un balance de los años 50, aportaba lo siguiente: "Pero, en un sentido más amplio, esta época de la historia de la arquitectura moderna ha dejado algo detrás. Marca el comienzo de una arraigada fe en los trazados modulares numéricos como instrumentos beneficiosos a la arquitectura; una fe que se ha institucionalizado en la Modular Society, donde, sin embargo, se intenta fundamentar la misma en algo más sólido que en las vagas sensaciones producidas por la entrega al "lore" operativo...Lo que es nuevo en esta situación es el hecho de que este interés por la historia no ha aparecido en países cuya gran arquitectura reside en el pasado y a los que el futuro no ofrece nada sino en países como los Estados Unidos..."26

Un asunto fundamental dentro de lo controvertido del método proporcional, radica en la influencia que pudo ejercer sobre el Nuevo Brutalismo. Y en mi opinión y por lo menos en lo que respecta a Alison y Peter Smithson, resulta ligero establecer una relación estrecha entre en "Los Fundamentos de la Arquitectura en la Edad del Humanismo" y la teoría del Nuevo Brutalismo. O por lo menos, la relación entre el Brutalismo y la composición neopalladiana no es tan evidente como algunos pretenden hacen creer: "éramos fans de Palladio, pero uno siempre tiene que luchar contra la mística de la dimensión -cualquier cosa que parezca que va a cerrarse sobre ti - como alguno de esos galimatías que uno encuentra en FLW"27

Theo Crosby, por ejemplo, al presentar el manifiesto publicado por los Smithson en Architectural Design, en Enero de 1955, acerca de las dos corrientes usadas en Hunstanton, una que proviene del Profesor Wittkower "ciertas lecciones sobre el empleo formal de la proporción" 28 y otra de los japoneses respecto al uso sensual de los materiales, pone en bandeja, como si dijéramos, la respuesta de los Smithson:

"Lo que resulta novedoso entre los Movimientos (tendencias) en el Nuevo Brutalismo, es que encuentra sus más profundas afinidades no en un estilo arquitectónico del pasado, sino en las formas de las

24 Véase "arena, The Architectural Association Journal", Volumen 81, Número 899, Febrero de 1966

25 Charles Jencks, "Movimientos Modernos en la Arquitectura", "Los Nuevos Palladianos", p.250

26 Reyner Banham, "Balance 1960, la Tradición y la Tecnología”, en Arquitectura no 26, Febrero 1961, p. 7

27 Peter Smithson, "Systems of Proportions", discurso dado en el RIBA el 18 de Junio de 1957, oponiéndose a debatir sobre "Sistemas de proporción, como hacen más fácil un buen diseño y más difícil uno malo". Recogido en "Arena, the Architectural Association Journal", Febrero 1966

28 Theo Crosby, presentación del artículo "The New Brutalism", en "Architectural Design", Volumen XXV, Enero 1955, Editorial, p. 1 
LÁMINA III.2 moradas de los campesinos..." ${ }^{29}$, y, "se ha discutido que la Escuela de Hunstanton, la cual probablemente debe tanto a la arquitectura japonesa como a Mies,...para los japoneses FORM, sólo era una parte de su concepción general de la vida, una suerte de expresión reverencial del mundo natural y, partiendo de ahí, de los materiales usados en el mundo de la construcción". ${ }^{30}$

En cualquier caso, huyen de hacer mención alguna a una posible estructura palladiana.

Según Risselada, en la llamada Casa del Soho (1952), que según sus autores, de haber sido construida hubiera significado el primer exponente de edificio neobrutalista, es posible ver que "(los Smithson) todavía preferían el orden clásico, matemático, que se podía encontrar en los Architectural Principles in the Age of Humanism (1949) de Wittkower". ${ }^{31}$

Transcribo íntegra, a modo de réplica, una bellísima carta enviada por Kenneth Scott recogida en la revista "The Architectural Review" en Abril de 1954, donde define "sus emociones" ante la Casa del Soho de una manera que nadie más a logrado transmitir, y donde las alusiones a cualquier rasgo del método proporcional brillan por su ausencia.

\section{Kenneth Scott:}

"La profesión asume una gran deuda con el Editor de Architectural Design por haber tenido el coraje de publicar en el número de diciembre el proyecto de los Smithson de una casa en el SOHO. En primer lugar, hasta donde yo tengo conocimiento, los Smithson han dispuesto de espacio para expresar su nueva teoría. ¿Es ésta, me pregunto, un presagio?. ¿Es así, como se va a atisbar en el futuro la arquitectura inglesa?

Alguien ha dicho que los Smithson construyen más bien cuevas que casas. La idea proviene de la sensación que uno tiene dentro de sus edificios, de estar en contacto con la verdadera naturaleza, de la cual el edificio forma parte. Esta sensación es característica de todos sus edificios, aunque es particularmente aparente en el más reciente de todos. Es una sensación muy diferente a la cualidad indefinible, accidental de la escuela romántica, que incorpora imitaciones de efectos naturales. Por el contrario, las casas de los Smithson, enfatizan la sensación íntima de refugio. Uno se encuentra en un espacio que representa a todo el espacio, orientado uno mismo hacia la materia en la cual se yergue la casa y por la que es construida. Cada parte de la casa parece estar en equilibrio con la brutalidad esencial del hombre.

Un sentimiento parecido de intimidad puede encontrarse en la casa del SOHO, uno de los mayores logros poéticos de los artistas. Tan solo el plano revela que el tema principal de la estructura es la tensión recíproca entre dentro y fuera. Los muros parecen estar colocados según líneas de una energía en potencia. Son concentraciones de materia sólida, emitiendo rayos de fuerza conforme a la naturaleza

29 Alison y Peter Smithson, "The New Brutalism", en "Architectural Design", Volumen XXV, Enero 1955, Editorial, p. 1

30 Ibíd.

31 Dirk van den Heuvel y Max Risselada "De la Casa del Futuro a la casa de hoy", p.197 
de cada material; éstos parecen extender su poder en el interior del perímetro del armazón de la casa, determinando la positiva unidad del interior. El espacio interior, sin topes definitivos ni áreas encerradas tangibles, toma la identidad de un vacío y de una unidad definitiva en la manera cómo están situadas las masas de los muros, la unión de peso y energía creando espacios concentrados con una gran riqueza expresiva. Todo lo que en el interior queda reunido en un golpe de vista está coordinado: aire, luz, vidrio, los planos horizontales, tensos, dinámicos de suelos y techos, crea de una sola vez una sensación de espacio definitiva e infinita. Dentro, cualquier cosa contribuye al equilibrio del espacio, equilibrio encarnado en grandes y pequeños volúmenes, restableciendo una sensación de íntima brutalidad, al tiempo que participa en la naturaleza circundante. Naturaleza que por sí misma contribuye al efecto arquitectónico; de hecho, juega un papel importante, junto con la arquitectura, en la formación del impacto emocional total sin precedentes creado por los Smithson. Los artistas han dado unidad a su obra creando un efecto directo, instantáneo, mediante una estricta rectangularidad. Nada más habría podido dominar la turbulencia de este entorno. Los artistas buscan identificary sumergir su obra en este entorno, seleccionando lo más desafiante del sitio en un acto de prueba de su genio, mediante el cual va a parecer siempre posible dominar la brutalidad, reintegrándola en la creación de una nueva materia geometrizada. ${ }^{\prime 32}$

\section{ENDLESS ARCHITECTURE}

Una conferencia pronunciada en la Architectural Association en Junio de 1951 por parte de Richard Llewelyn Davies nos permite plantear una primera disputa con los defensores de la forma y los sistemas proporcionales renacentistas, $y$, abrir el debate sobre la consideración compositiva del edificio como entidad cerrada.

El tema que aborda Llewelyn Davies trata de un infinito metafísico. Más allá de los límites propios a la realidad física del edificio, ciertos detalles constructivos o geométricos permiten a Llewelyn Davies proponer una nueva forma de ver la arquitectura moderna. Se refiere a la endless architecture, y que podrá caer bajo la acepción de lo infinito. Bajo este acorde se distingue de la arquitectura infinita barroca, en que no se ocupa de la extensión. Por otra parte, trata de un infinito que podría plantearse como un infinito actual. Con todos los matices que se quieran, la arquitectura del infinito actual participa del mismo sentido que otorga la perspectiva al infinito del punto de fuga en la pintura ${ }^{33}$.

El ejemplo paradigmático de una endless architecture para Llewelyn Davies es el tratamiento de la esquina del Alumni Memorial

LÁMINA III.3

32 Kenneth Scott, en "The Architectural Review", Abril 1954, p. 274

33 La captura del infinito, tal como lo acuña Benévolo, indica la manera como la arquitectura barroca se representa la noción del infinito actual: "Entre finales del siglo XVI y finales del siglo XVIII cambia la idea del mundo, y cambia el sentido de la palabra <<infinito>>: de límite del mundo, metafísico o religioso, pasa a ser una parte del mundo, explorable a través de la investigación y virtualmente traspasable"(1). Según el autor: "De este modo, el punto de fuga, de referencia estructural, pasa a ser una meta accesible en teoría, que puede explorarse y casi alcanzarse con los medios disponibles"(2) (Leonardo Benévolo, "La Captura del infinito", (1), p. 9, y (2), p. 36 
Hall de Mies van der Rohe. La repetición de la estructura en fachada entra en contradicción con el establecimiento de un final para la serie (agregación indefinida de un mismo motivo modular), motivo por el cual, el encuentro entre dos fachadas concurrentes se resuelve sin un corte nítido de ambos planos. A partir de este conocido motivo de esquina dado por Mies ${ }^{34}$, las implicaciones para Llewelyn Davies son de sumo interés en el contexto que abrimos en el capítulo anterior. Señala Llewelyn Davies a propósito de las fachadas del Alumni Memorial Hall: “Esta es una concepción fundamentalmente diferente de la concepción del muro como algo finito en si mismo, proporcionado según una relación intrínseca entre sus dimensiones de longitud y altura". ${ }^{35} \mathrm{Y}$ señala asimismo que esta solución mediante ángulos que se repliegan de la esquina "está en abierta contradicción con la esquina enfatizada y almohadillada del Renacimiento"36

Es obvio que esta interpretación de la arquitectura de Mies, (además de los ejemplos de Wright y Neutra propuestos por el mismo autor) en 1951 colisiona frontalmente con el propósito de los defensores de los sistemas proporcionales.

Pero la ramificación resultante de enfatizar una lectura del edificio como una composición cerrada o por el contrario como una sucesión de elementos seriados, resulta más interesante si se atiende a quién dirige Llewelyn Davies su atención para probar la amplitud de su teoría de la endless architecture. Entre los ejemplos de la arquitectura infinita citados cabe incluir también algunos edificios de Le Corbusier. Pero no puede obviar el hecho, según lo visto en "Hacia una Arquitectura", de que es Le Corbusier el principal introductor de los sistemas proporcionales en la arquitectura moderna. Es por ello que Llewelyn Davies asume que la "infinitud es sólo un aspecto del diseño, sólo uno entre muchos" 37 , y que, "de hecho he mostrado que en algunos aspectos de mis comentarios hay elementos de una mercada infinitud, así como elementos de un carácter opuesto". ${ }^{38}$

LÁMINA III.4

La manera como Llewelyn Davies sortea el problema que le plantea Le Corbusier, ilustra un nuevo aspecto de la infinitud. Para Llewelyn Davies la infinitud se halla en Le Corbusier de dos maneras relacionadas entre sí a través del número y la progresión. Intrínsecamente, la infinitud es consecuencia del empleo de diagonales proporcionales entre la longitud y la altura del alzado, que los hacen irreductibles uno a otro por medio de cocientes de números naturales.

Por otro lado, emplea determinadas figuras, como la espiral,

34 Véase al respecto también Charles Jencks, "El Lenguaje de la Arquitectura Posmoderna", pp. 15, 16 y 17. Señala Jencks en un pie de foto de la esquina del Alumni Memorial Hall: "Para Leslie Martín la esquina era visualmente un punto y aparte y Llevelyn Davies decía que parecía <<infinita〉> por el retranqueo conseguido con dos perfiles I y el perfil L"

35 Richard Llewelyn Davies, "Endless Architecture", Architectural Association Journal no 67,1951, p. 108

36 lbíd.

37 Ibíd., p. 112

38 Ibíd.. 


\section{LÁMINA III.1}

“Como método, entonces, habría que juzgarlo desligado de la validez o falsedad de los principios, y en vista de sus consecuencias prácticas, considerarlo como fructífero o estéril"

Presento una colección de proyectos de arquitectos cercanos a los Smithson. Júzguense en ellos la aplicación del método proporcional, por ejemplo en la frontalidad. A continuación, proyectos, cuya organización presenta rasgos en común con Sheffield.

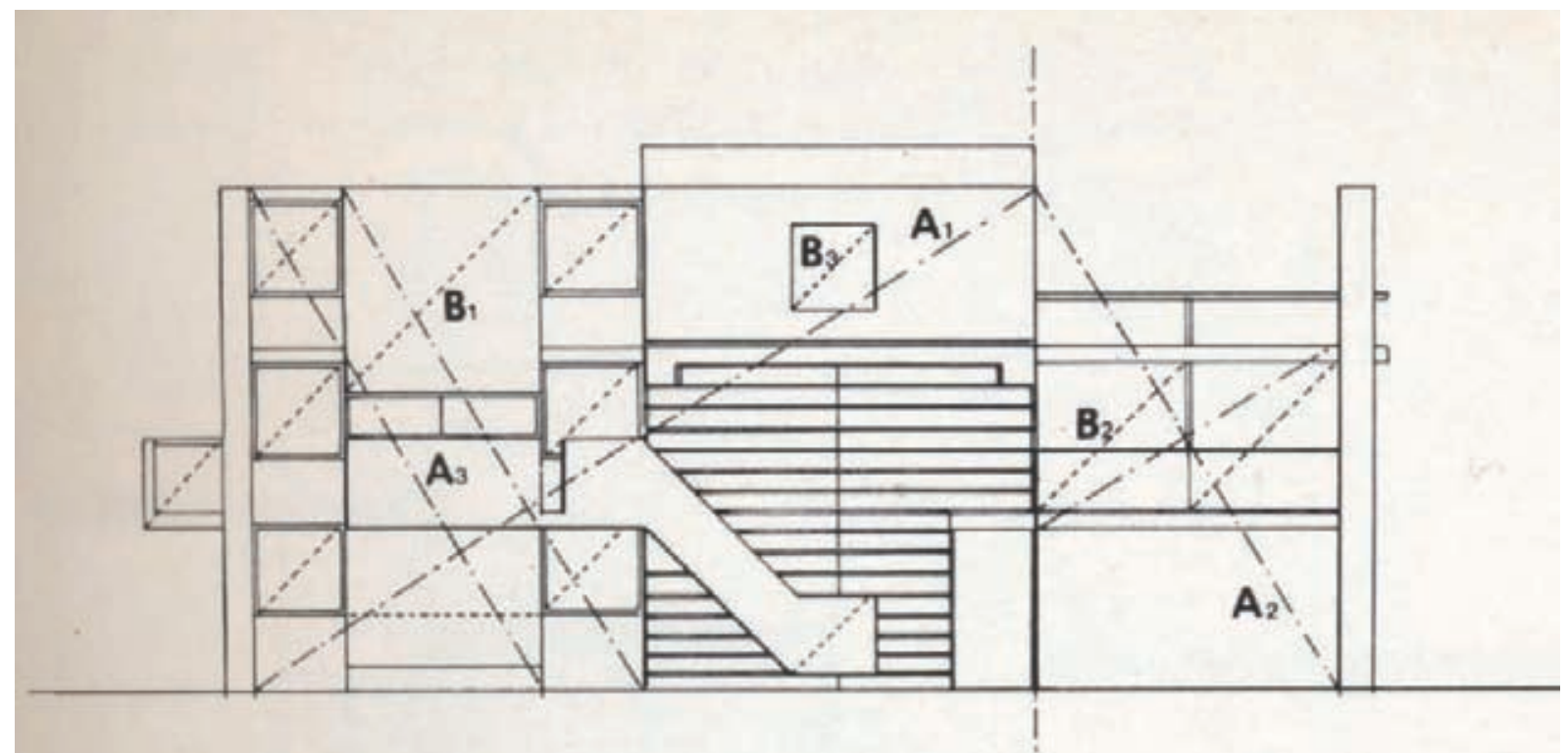

James Stirling „Casa con muro transversal y núcleo. Core and Crosswall“, 1951.

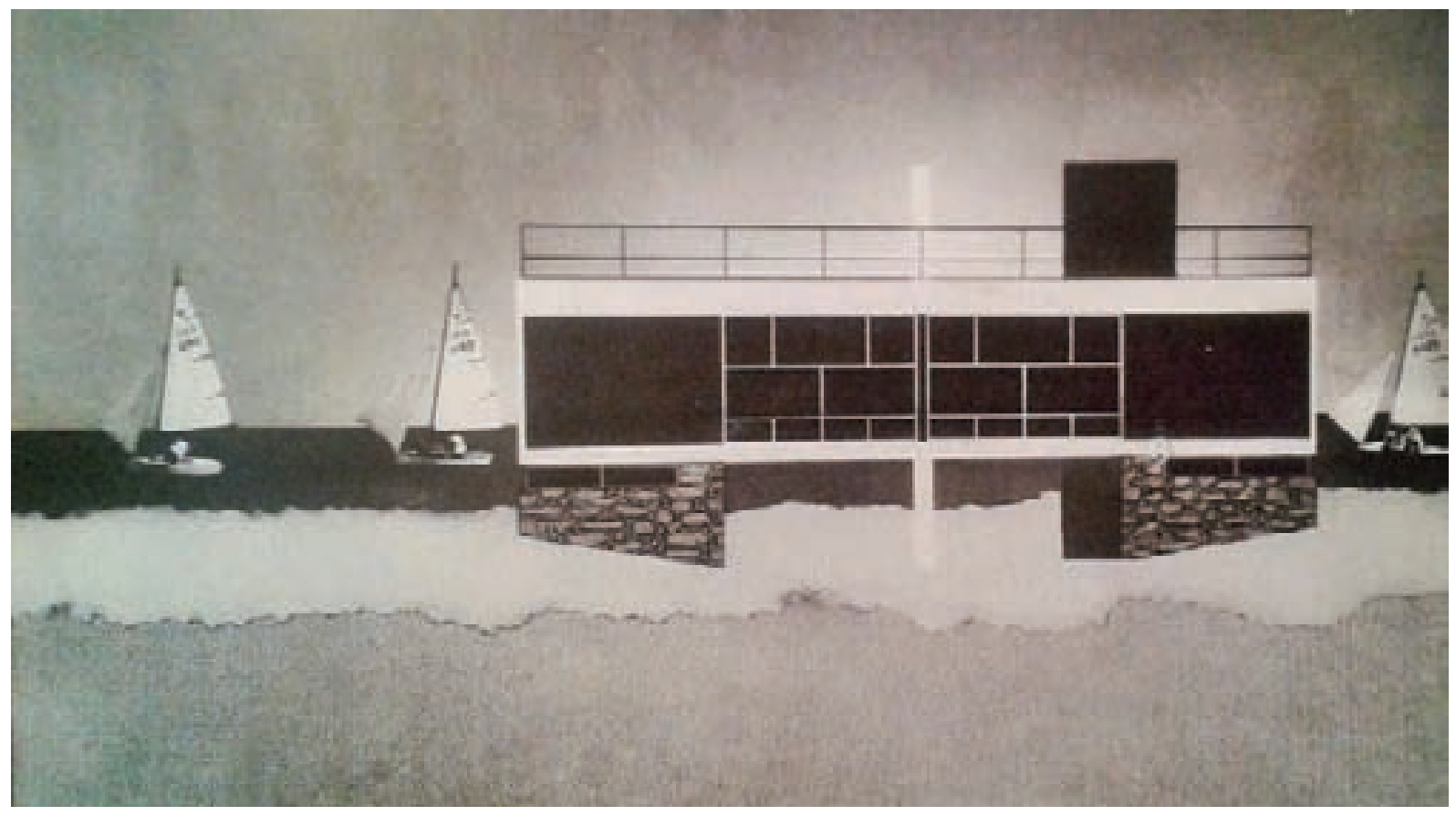

Gordon Ryder, "Sailing Club", 1952 


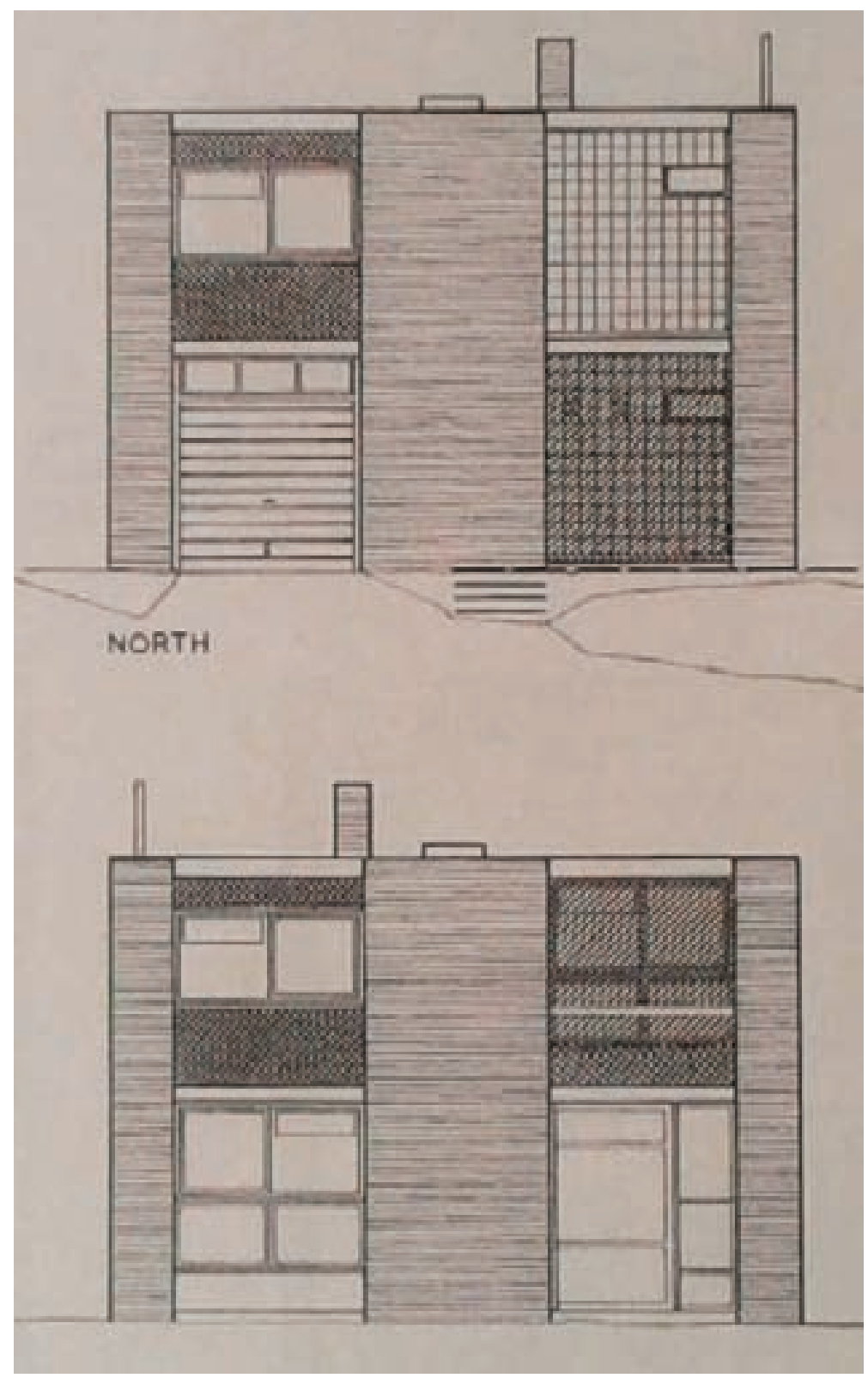

John Voelcker, "House at Highgate", 1953. Fue publicada en 1954 (Architectural Design, Abril 1954, p. 96), "bajo el título más que provocativo de Nuevo Formalismo". Peter Carolin, "John Voelcker, Team 10 founder member: a view from the practice", en arq architectural research quaterly, Volumen 16, № 4, 2012, p. 369 


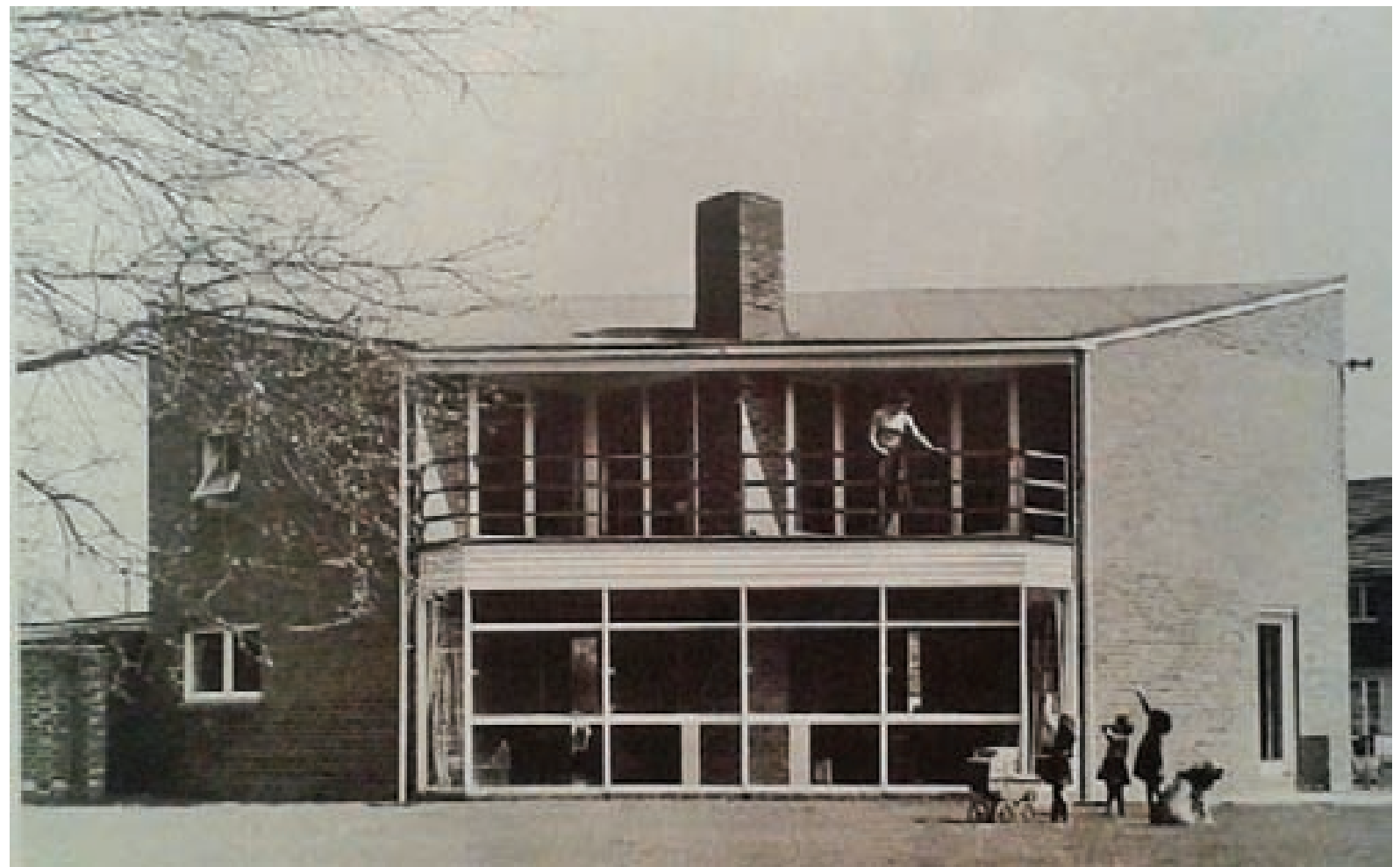

Gordon Ryder y Jack Lynn, "Walker House”, 1952

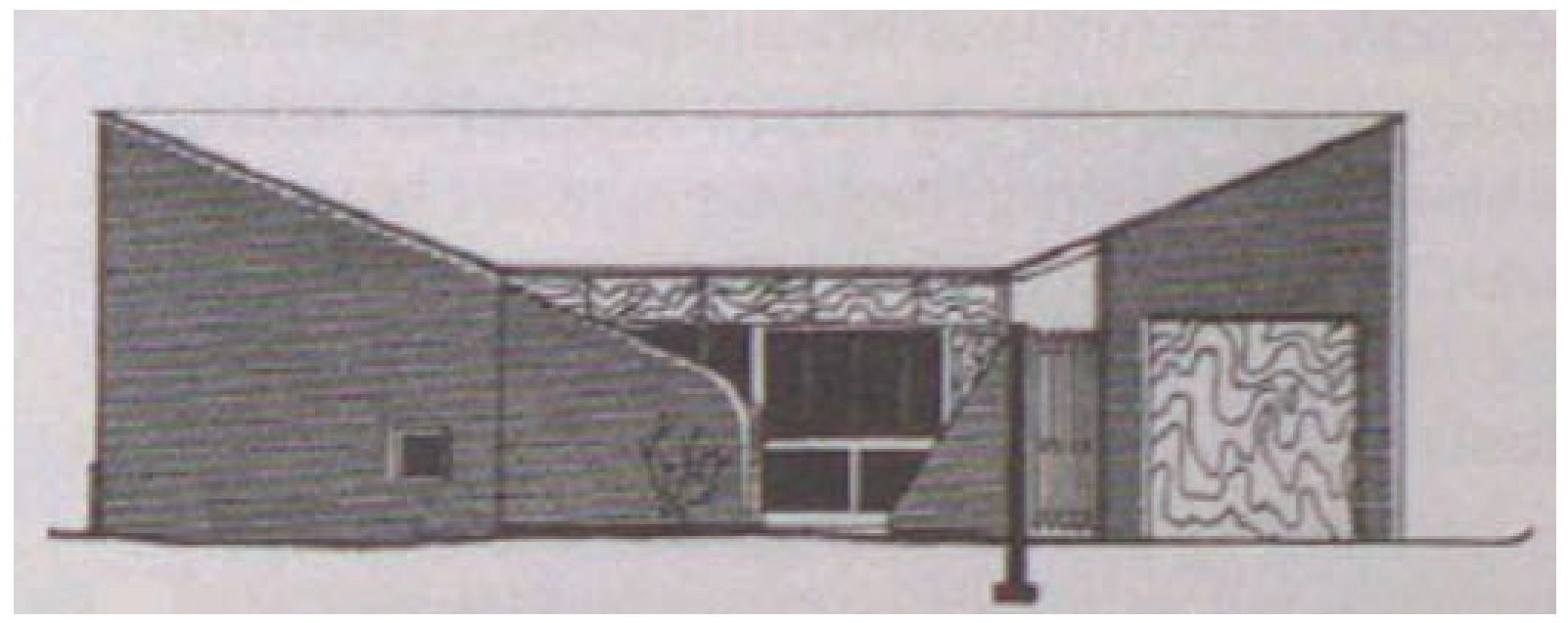

John Voelcker, "Lyttelton House", 1959 


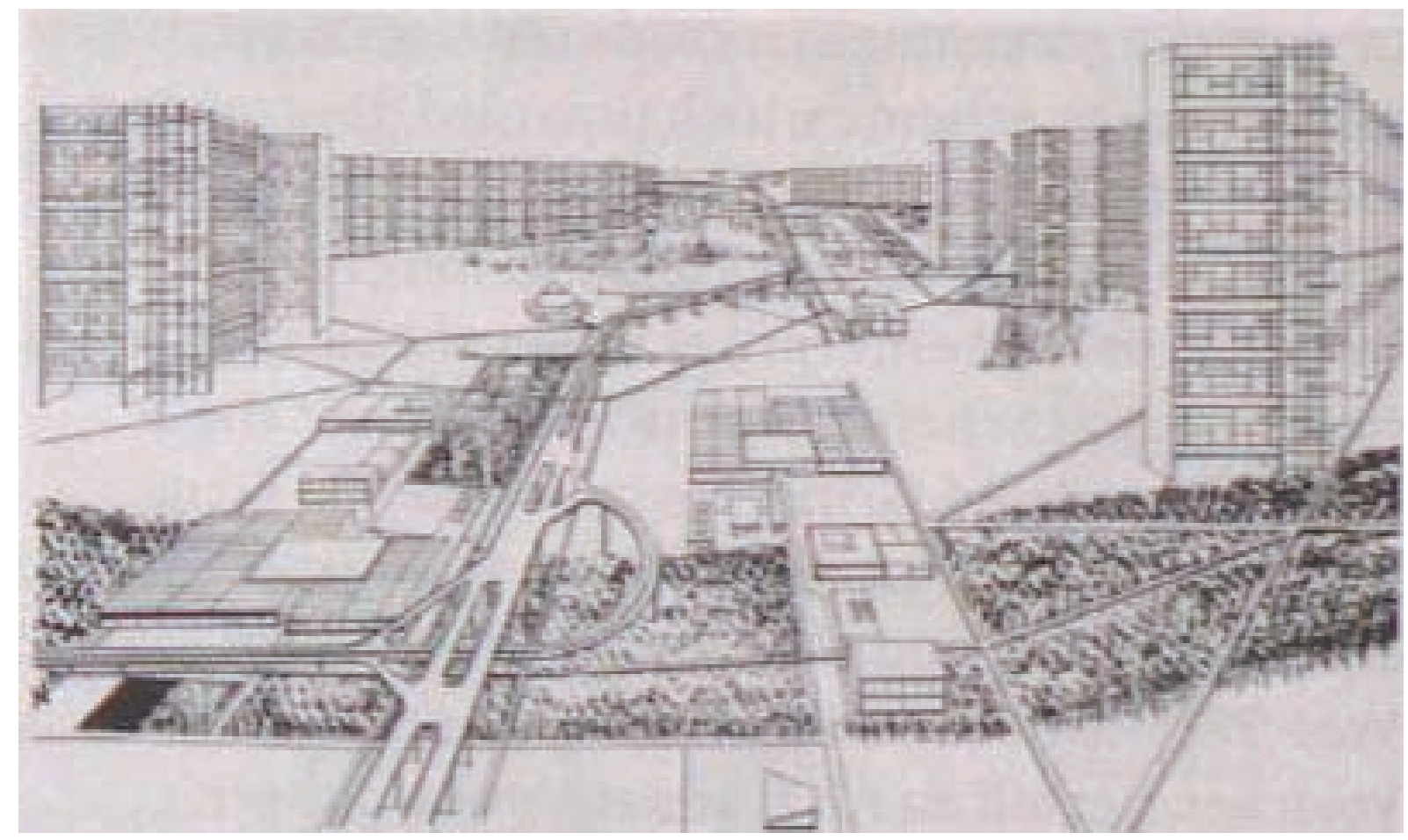

John Voelcker, Pat Crooke y Andrew Derbyshire, "The Zone Grid", 1951-1952. Proyecto (Tesis) Fin de Carrera. Sorprende lo temprano de la fecha, que antecede incluso a Golden Lane de los Smithson. Este proyecto compartido estuvo bajo la supervisión de Arthur Korn, Ernö Goldfinger y Ronald Jenkins. Éste último (miembro de Ove Arup and Partners) estuvo implicado en el desarrollo de Park Hill, y en las estructuras de Hunstanton School, de los Smithson, probablemente desde mediados de 1950.

Jack Lynn y Ivor Smith, "Park Hill“, Sheffield, 1953-1955, proyecto. 19571960, construcción. Fotografía Josenia Hervás, Febrero 2015

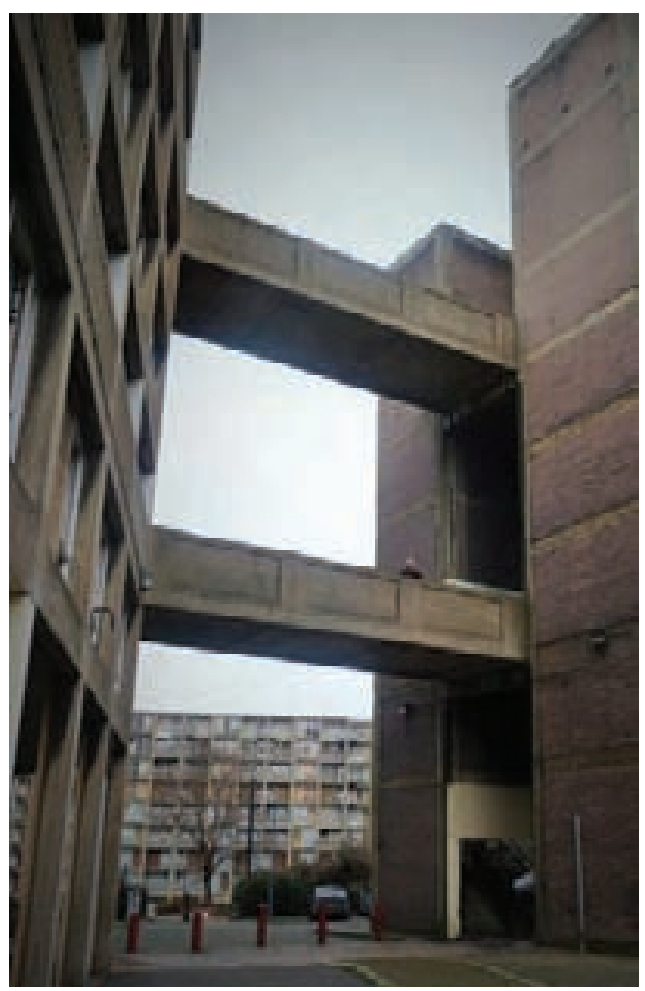




\section{LÁMINA III.2}

“...la llamada Casa del Soho (1952), que según sus autores, de haber sido construida hubiera significado el primer exponente de edificio neobrutalista..."
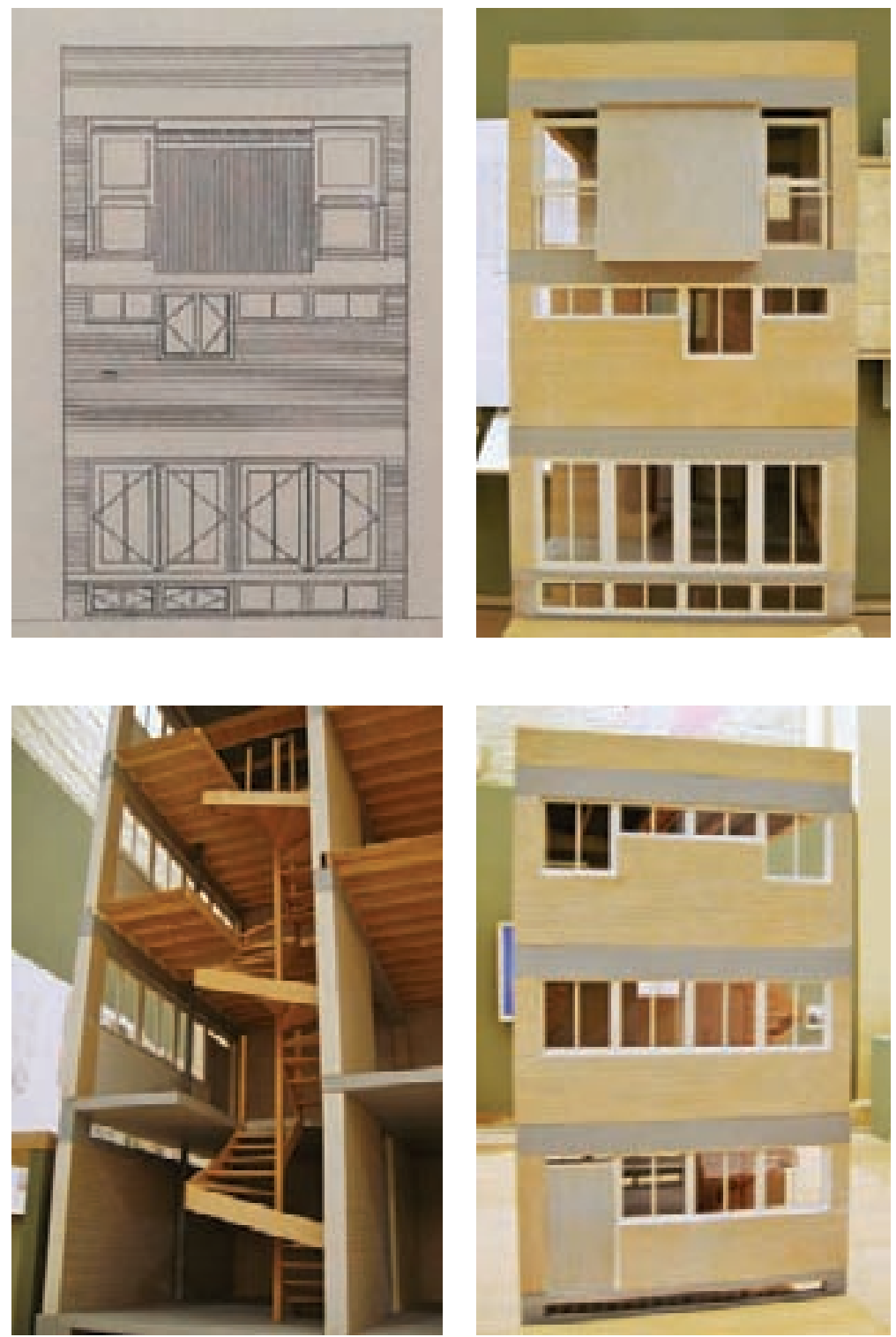

Alison Smithson, Peter Smithson „House at Colville Place (Soho)”, 1952. 


\section{LÁMINA III.3}

"El ejemplo paradigmático de una endless architecture para Llewelyn Davies es el tratamiento de la esquina del Alumni Memorial Hall de Mies van der Rohe..."

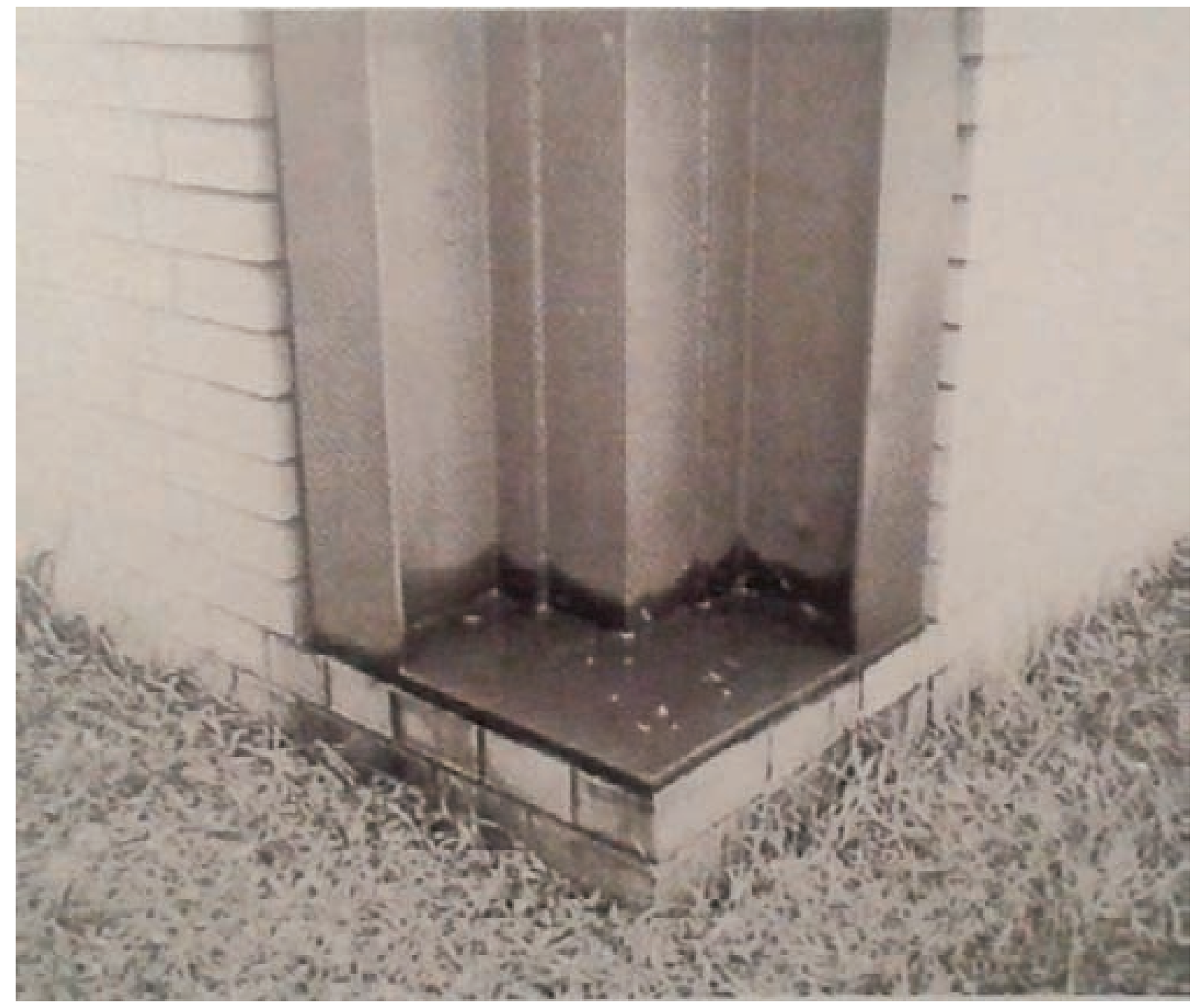

Mies van der Rohe "Alumni Memorial Hall“,1945-1946, detalle. 


\section{LÁMINA III.4}

"La manera como Llewelyn Davies sortea el problema que le plantea Le Corbusier, ilustra un nuevo concepto de infinitud..."

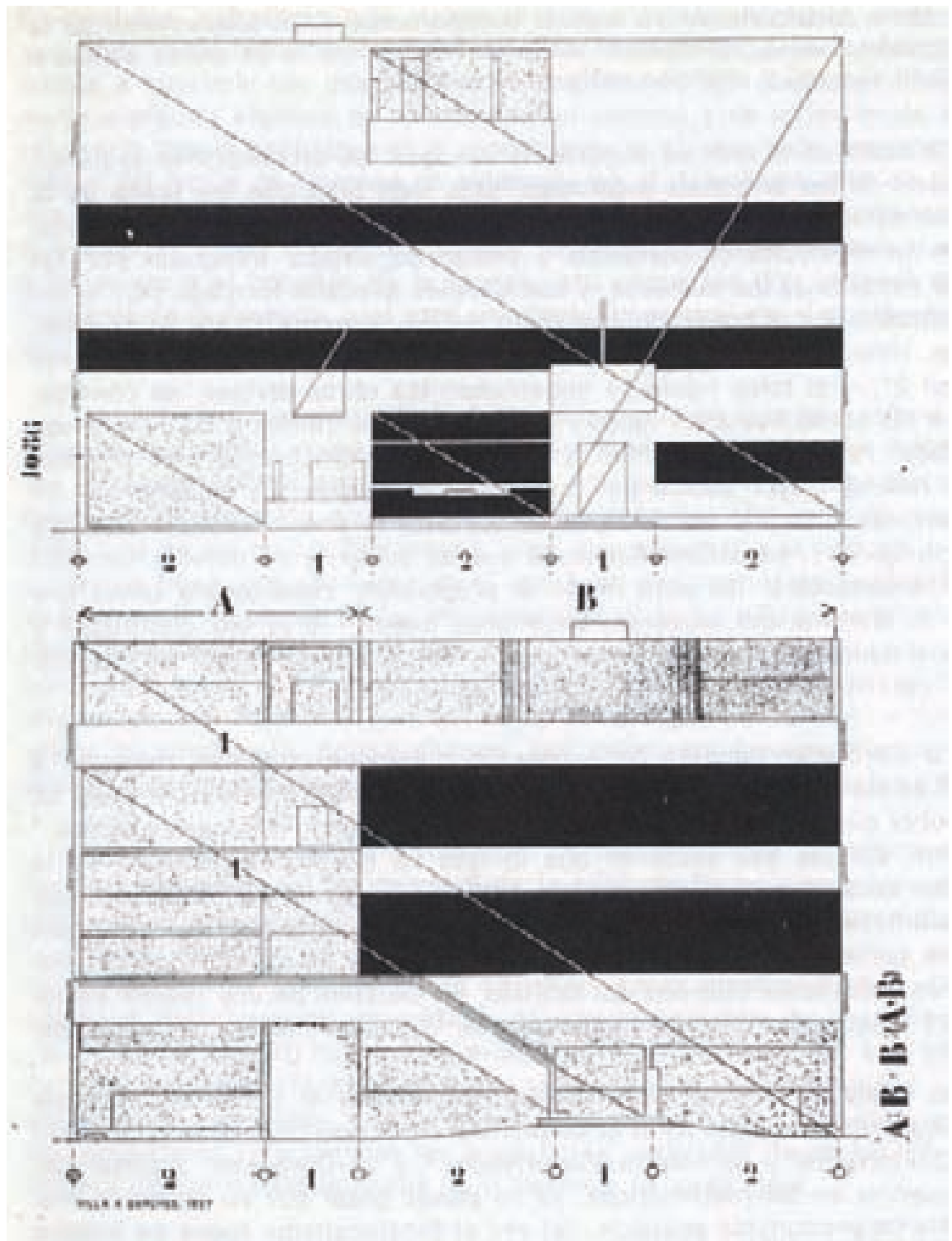

Le Corbusier, "Villa Stein", Garches, 1927. “Progresión armónica de diagonales", Llewelyn Davies, "Endless Architecture", Architectural Association Journal, no 67, 1951, p.111 


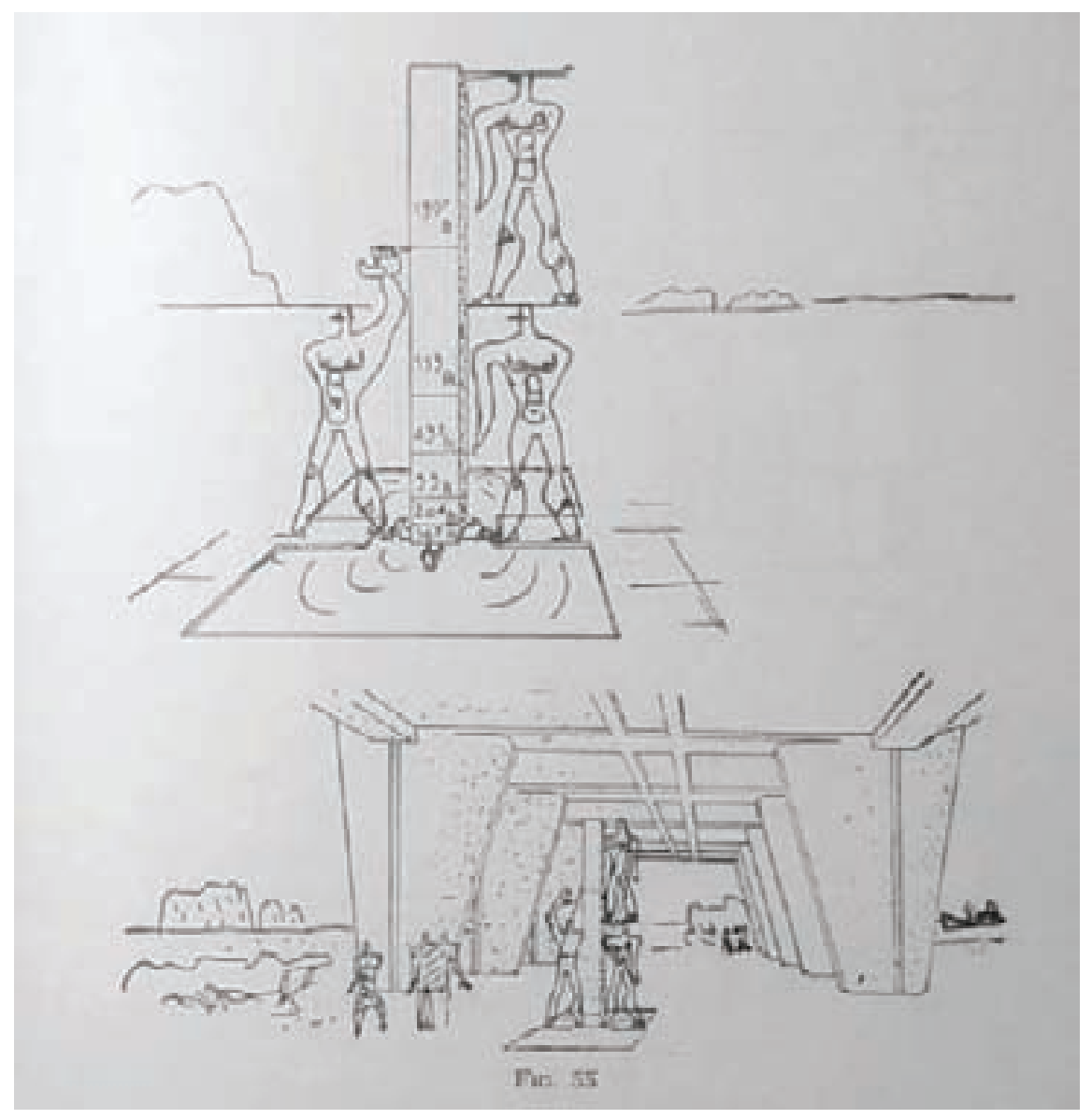

Le Corbusier, "Unidad de Habitación de Marsella", 1947-1952, Modulor

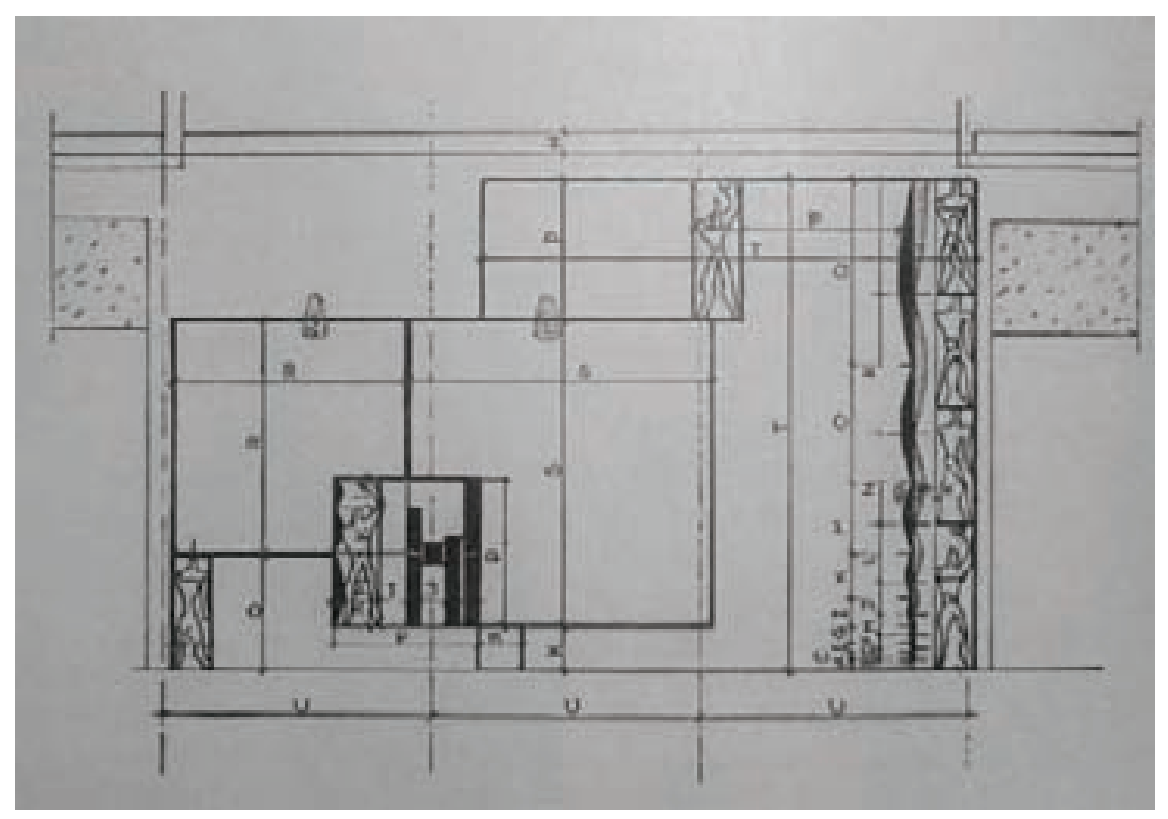

Le Corbusier, “Unidad de Habitación de Marsella”, 1947-1952, Fachada este del vestíbulo. 
que en su naturaleza queda implicada la propia infinitud. ${ }^{39}$

Tal como lo plantea Llewelyn Davies es posible conjugar en un solo edificio dos métodos abiertamente opuestos, uno limitante y otro expansivo, siendo ambos de naturaleza irracional. Con esto parece ofrecer una salida al problema derivado de encasillamiento en los principios proporcionales discutidos por los partidarios de las tesis de Wittkower. Nuevamente es la figura de Le Corbusier la que sirve tanto al problema como a su solución. Así lo ofrece Llewelyn Davies al valorar el sistema del Modulor: "Pienso que Le Corbusier se halla concernido con el que es probablemente el más difícil de todos los problemas -la unión entre una arquitectura infinita y repetitiva y los viejos principios de la composición finita. Sus estudios sobre la proporción, que han culminado en un sistema geométrico que ha denominado el "Modular" (sic), sistema basado en las series infinitas, las series de Fibonacci, representa su solución... Por tanto, Le Corbusier espera cerrar la brecha entre el edificio infinito y el diseño tradicional a través de proporciones complejas como método habitual". ${ }^{40}$

A tenor de lo expuesto en endless architecture cabe ver en los deseos de Llewelyn Davies un intento por introducir otros principios activos, cuyo potencial, sin embargo, no parece que llegue a vislumbrar. Sobre el Alumni Memorial Hall es cierto que la esquina evita la línea que ofrecen dos planos al cortarse. Pero, por la misma razón, es una recreación mediante perfiles de una articulación clásica de la esquina, con columnas en ángulo. Sea desaparición o articulación, no es seguro que el detalle de la esquina, por su propia localización marginal, llegue a comprometer la idea global del edificio como una caja cerrada.

Respecto al intento de mediar con la corriente en pos de una composición tradicional o finita, el acuerdo deja sus argumentos como residuales. Admite como punto de partida Llewelyn Davies que el edificio es una unidad bien definida y delimitada. Que la relación entre los elementos se haga por medio de diagonales o la magnitud irracional, es algo que al geómetra (y al arquitecto) no le produce mayor desasosiego. Podía constituir un serio problema en caso de diagonales físicas de módulos cuadrados, en donde entonces, la cuestión de la inconmensurabilidad se hace patente en longitudes diferentes e irreductibles aritméticamente entre el lado y la diagonal. Este es un tema por ejemplo, que surge con fuerza en la arquitectura inmediatamente posterior, donde se introduce con decisión la solución del chaflán de esquina. En este sentido, bien cabría contrastar los dos modelos de infinitud para esquinas: el presentado mediante un diseño que evoca geométricamente la anulación de la recta de corte de dos planos, y otro, que evoca aritméticamente (y produce constructivamente y por tanto plantea problemas dimensionales de prefabricación) la inconmensurabilidad entre el módulo de esquina y el de fachada.

Cabe advertir, por tanto, unos argumentos muy prudentes

39 La sección áurea que es el método empleado por Le Corbusier proporciona los lados del rectángulo áureo según una relación irracional entre ellos ( 1 y $1+\sqrt{ } 5 / 2)$ y donde a partir de la sucesión de cuadrantes se obtiene la espiral logarítmica. A su vez el límite de la sucesión de los cocientes de la serie de Fibonacci es el número áureo. La serie de Fibonacci obtiene cada término como la suma de los dos anteriores a partir del segundo término.

40 Ibíd. 
por parte de Llewelyn Davies a la hora de proponer una endless architecture. La introducción de las series infinitas de Fibonacci como sistema proporcional basada en la sección áurea no hacen sino consolidar una arquitectura fuertemente geométrica como es la de Le Corbusier. En este sentido el argumento que Wittkower observa en los arquitectos del Renacimiento resulta más convincente ante lo que significa lo inconmensurable: "Resulta obvio que las proporciones irracionales habrían situado a los artistas del Renacimiento ante un dilema irresoluble, ya que la actitud renacentista respecto a la proporción se basaba en una nueva interpretación matemática y orgánica de la naturaleza, en la que todas las cosas se relacionaban entre sí mediante números (es decir, aritmética frente a geometría)"41, lo que le lleva a concluir: "No creo que sea ir demasiado lejos considerar la conmensurabilidad de las medidas como el punto nodal del arte del Renacimiento". ${ }^{2}$

Las nuevas aportaciones de Wittkower ${ }^{43} \sin$ embargo pueden verse a la luz de lo formulado por Llewelyn Davies pero en contra de admitir la conjugación de lo finito y lo infinito. Lo abierto por éste último solo puede entrar en un callejón sin salida. Tal como lo expone el propio Wittkower es conceptualmente imposible combinar un método aritmético con uno geométrico: "Digamos que los artistas del Renacimiento eran muy conscientes de las propiedades peculiares y excepcionales de la Sección Áurea...Pero mientras la Sección Áurea jugó un papel importante en la geometría medieval, es preciso acabar de una vez con el viejo mito, constantemente repetido, de su papel predominante en el arte del Renacimiento" El problema es que "es imposible conciliar sus propiedades irracionales con una <<anotación fidedigna y conmensurable de las dimensiones $>>$ ", aspecto por el cual, "cuando encontramos la Sección Áurea en el arte renacentista podemos decir con certeza que no fue puesta deliberadamente allí" ${ }^{44}$.

En "Form and Mathematics"45 Ruth Olitsky y John Voelcker vuelven sobre el tópico entre Palladio y Le Corbusier. Básicamente el planteamiento intenta dar de nuevo salida a la contradicción que supone comparar matemáticamente el método aritmético del primero con el geométrico del segundo. Los arquitectos buscan una conciliación, aún sabiendo ya de antemano, como había advertido Wittkower, que tal extremo es conceptualmente imposible, derivando el problema hacia a un estrato común, el de la simbología del hombre con el Universo en la construcción de un Cosmos: "El Modulor, gracias a su profunda

41 Rudolf Wittkower, "Los Fundamentos de la Arquitectura en la Edad del Humanismo", Apéndice IV, Parte IV: "Las proporciones renacentistas y la conmensurabilidad", p. 215. Según versa en el encabezamiento de este apéndice el texto parece derivarse del siguiente ensayo <<Algunas observaciones sobre las proporciones medievales y renacentistas > datado en 1951. Hago hincapié en la concordancia del año 1951 para valorar conjuntamente la aportación de Llewelyn Davies y Wittkower al abordar el irracional. Podría sospecharse que Llewelyn Davies usa el argumento de Wittkower para plantear el irracional como una pequeña revolución en el seno de la tradición neopalladiana defendida por los jóvenes arquitectos.

42 Ibíd.

43 Me refiero al texto enviado a Architects'Year Book no V en 1953.

44 Rudolf Wittkower, "Sistemas de Proporciones" en "Architects'Year Book, V" 1953, recogido en la edición "Rudolf Wittkower. Sobre la Arquitectura en la Edad del Humanismo" p. 537

45 Ruth Olitsky y John Voecker, "Form and Mathematics", en Architectural Design, Octubre 1954, pp. 306 y 307. 
afinidad con la tradición clásica o ya sea sólo porque ha captado la imaginación de los arquitectos, aporta un símbolo cosmológico...Este símbolo contiene su propia representación numérica en la forma de dos series matemáticas en estrecha relación. El enigma del presente radica en el hecho de que no hay un lenguaje formal generalmente aceptado ni compartido. Hay que volver a invocar a la tradición ya que sólo a través del lenguaje de la forma puede el símbolo llegar a ser simbólico, tal como lo usan las matemáticas, y los arquitectos pueden volver a hacer del Universo físico, o cuanto menos de una pequeña porción de él, un lugar inteligible donde vivir".

No me cabe duda de la buena voluntad de John Voelcker, y sin embargo no deja de errar, como todos los defensores a ultranza de Le Corbusier, al intentar formalizar una relación que la revolución científica del s. XVII hizo que se "desestime toda consideración basada sobre conceptos axiológicos, como son los de perfección, armonía, sentido y finalidad...(y) el divorcio del mundo del valor y del mundo de los hechos". ${ }^{46}$ Resulta sorprendente advertir como la insistencia en representar un orden estaba dando por hecho la existencia de ese orden. Puede decirse al respecto, que el diagrama de Feynman se instauró en física cuántica cuando la representación atómica mediante un esquema que repetía la distribución planetaria del sistema solar estaba condicionando la propia forma de entender el comportamiento del átomo. ${ }^{47}$

Como ya he indicado, la tesis de Llewelyn Davies aisladamente no aporta suficientes argumentos que permitan deducir de ella una ruptura con los modos tradicionales de composición (se deduce de ello la manera geométrica empleada por Le Corbusier, no la aritmética). Sin embargo la alusión al método de las series si se toman como fuerza activa y envuelto con el argumento de lo infinitesimal y no de la sección áurea podría proveer las bases de una composición más propiamente "infinita".

Cabe ver en esta ramificación de una endless architecture un acercamiento a lo propuesto por los Smithson en Sheffield. Para ello será necesario recuperar la senda de la visión moderna aparcada desde los intentos de recuperación de los sistemas armónicos pitagóricos.

Pero antes, visto el problema que suscita la revisión de la matemática pitagórica, y el embrollo entre los métodos aritmético y geométrico conviene detenerse por un momento en ella.

46 Alexandre Koyré, "Del mundo cerrado al universo infinito", p. 6. El interés de recurrir a las palabras de Koyré, radica fundamentalmente en su fecha, 1953, y por tanto son oportunas su introducción en este debate. (Si bien el libro es publicado en 1957 , como señala el autor, debe su origen a una conferencia dada en Diciembre de 1953)

47 El diagrama de Feynman que aparece en 1949 consiste en una representación esquemática de los acontecimientos, no en representaciones gráficas de los objetos. Considérese como el deseo de dar unidad de sentido al mundo físico lleva a Born en 1923 a escribir "Es evidente que la idea de que las leyes del macrocosmos reflejan en pequeño el mundo terrestre ejerce una gran atracción mágica sobre la mente humana; de hecho, está enraizada en la superstición de que el destino del hombre puede leerse en las estrellas". Ese mismo año los físicos se vieron obligados a abandonar la imagen del átomo como sistema solar. Véase al respecto, Arthur I. Miller, "Einstein y Picasso. El espacio, el tiempo y los estragos de la belleza", pp. 303 y ss. 


\subsection{PITAGORISMO}

En principio la Matemática pitagórica nos interesa en este trabajo por haber influenciado el método proporcional llevado a cabo en el Renacimiento. Sin embargo, dado que excede el ámbito particular del uso de las medias proporcionales, e ilustra aspectos valorativos del número, volvemos a encontrar determinados temas que son recurrentes en la labor emprendida en estas páginas.

Entre los temas que introduce la Matemática pitagórica quiero destacar uno en concreto. Es su evolución ante el desafío que le imponen dos frentes de desestabilización. Uno es la diezmediación de número par y otro, la diagonal de cuadrado o el irracional $\mathbf{V} 2$.

La raíz del pensamiento pitagórico se produce por oposición de los contrarios. En este sentido se puede atender a un producto intelectual diferente del monismo jónico, del que sin embargo, como veremos traslada uno de los principios fundamentales. Por un lado hay un acuerdo en denominar la ciencia jónica como preferentemente de raíz sensorial. Es posible que la raíz del pensamiento jónico, que halla en dos elementos perceptibles como el agua y el aire, el origen del cosmos, advierta en éstos su intrínseca carencia de forma o su facultad de transformación. Si una cualidad de éstos sería su propia ilimitación, es con Anaximandro, como lo llimitado en sí mismo y no como predicado, adquiere el rango de origen, de principio originario. Señala Jaeger ${ }^{48}$ que Anaximandro habla del apeiron como que no es elemento alguno determinado, pero que "todo lo incluye y todo lo gobierna". Hay pues, un salto hacia la abstracción en la consideración del apeiron, que desborda por elevación la presencia en el mundo físico, para constituirse un principio intelectivo. Señala Jaeger también, que el apeiron responde a una interpretación que lo identifica con una divinidad, de tal forma que "la salida de las cosas del apeiron es una separación de contrarios" ${ }^{\prime 9}$. Fíjense que el pitagorismo aborda la preñez de los contrarios pero bajo el signo opuesto, el de lo Limitado, La Unidad. Dice Abel Rey refiriéndose al pitagorismo que, "la unidad, impar por excelencia,... recibe algunas veces el nombre de par-impar... Hay, pues, en la unidad, par" ${ }^{\prime 50}$. Antes de entrar en las cuestiones que aquí se implican, es necesario dejar claro que el pitagorismo obliga a situarnos del lado de lo Limitado. Podemos establecer en este punto importantísimo todas las secuelas que busquemos en nuestro tema. El fundamento pitagórico va a estar siempre en lo Limitado: "para los pitagóricos la posibilidad de hacer ciencia está exclusivamente del lado de lo limitado y finito, de lo que tiene forma y contornos precisos" ${ }^{\prime 51}$.

¿No cabría ver en esto, para llevarlo a nuestro terreno, las dos ramificaciones que Llewelyn Davies establecia para la endless architecture? La Unidad contiene el Par (lo Limitado contiene a lo llimitado). Aunque no sepamos con claridad todavía que fundamento contiene esta expresión, va, por lo pronto, en sentido contrario, a decir que de lo llimitado surge lo definido, que es tanto como decir que lo

\footnotetext{
48 Véase Werner Jaeger, "Paideia”, p. 158

49 Ibíd.

50 Abel Rey, "La Juventud de la Ciencia Griega", p.199

51 Javier Echeverría, "La Intuición en Matemáticas. Las Figuras y el Lugar", p. 46
} 
amorfo contenga "en potencia"52 "la perfección de la forma circular (o) la nitidez geométrica de los contornos" ${ }^{\prime 53}$. ¿No es en la primera expresión donde podemos encontrar la introducción del infinito de las series logarítmicas de Le Corbusier? ¿ No es la Unidad de Habitación de Le Corbusier una Unidad que contiene al Par?

El sentido que Anaximandro da a su criatura, el apeiron, se resuelve en el plano lógico. Lo indefinido infinito no puede ser un elemento físico, el agua o el aire, pues la propia infinitud de uno, destruiría al otro y haría que dejara de existir al instante ${ }^{54}$. No admite tampoco algo anterior a él, porque lo infinito no tiene principio, ya que eso significaría que tiene un límite ${ }^{55}$.

El apeiron por tanto es la máxima expresión de lo inclusivo. Nada queda excluido de él, y es en este sentido como adquiere el rango de lo infinito absoluto y principio de todo. Hay a mi juicio una posible interpretación del apeiron que lo empareja con el infinito absoluto de Cantor, según lo apunta Russell. Russell viene a proponer que para zafarse de determinadas paradojas como las que propondrán los eleatas a los pitagóricos, la consideración del infinito debe hacerse a partir de la igualdad cardinal para los conjuntos de infinitos elementos. Así, para plantear una escapatoria al dilema lanzado por Zenón de Elea entre Aquiles y la Tortuga, estima Russell, que la obstrucción al razonamiento viene de suponer válido el axioma de que el todo contiene más elementos que la parte. Esto, cierto para conjuntos de números finitos, no lo es para números infinitos. Basta, dice él, con ordenar el conjunto para establecer unas correspondencias, directa e inversa, entre cada elemento de los dos conjuntos infinitos. Como ejemplo propone Russell el conjunto de números naturales que contiene como una parte el conjunto de los pares. Si es posible, como es el caso, asociar a cada número su pareja par, multiplicándolo por dos, se verá en seguida que la parte de los pares contiene tantos números como el total de números naturales pares e impares.

Mediante un razonamiento de esta índole resuelve la paradoja de Aquiles y la Tortuga, al dar como erróneo el argumento de Zenón, la parte que recorre la tortuga (menor que el recorrido completo de Aquiles dado que dispone de una ventaja) contiene un número menor de lugares que el recorrido total, o al contrario, que Aquiles habría estado en más lugares que la Tortuga, lo cual le impediría alcanzarla.

52 El emparejamiento entre el apeiron y el caos es tan profundo como que ambos suponen el mismo estado original de plasticidad infinita. Como señala Rey, al apeiron hace laico al cosmos ("La juventud de la Ciencia Griega", p. 39). "Por naturaleza y por esencia, el caos es lo que no se puede definir ni encerrar, aprisionar en el rigor de las palabras. Pues no es nada determinado. Sólo es concebible como oposición que le distingue de todos los seres, sus descendientes. No es ni la noche, ni la nube, ni el aire, ni el agua... mejor dicho, es todo en potencia", Albert Rivaud, "Le problème du devenir et la notion de la matière dans la philosophie grecque depuis les origines jusqu'a Théophraste", citado por Abel Rey, Ibíd.

53 Abel Rey, Ibíd.

54 “Los elementos están en mutua oposición -el aire es frío, el agua húmeda y el fuego caliente- $y$ por eso si uno de ellos fuera infinito, los otros dejarían de existir al instante". Aristóteles, "Física, III", citado por Abel Rey, Ibíd., p. 49

55 "Todo es principio o procede de un principio; pero lo infinito no tiene principio, ya que eso significaría que tiene límite. Además, es ingendrado e indestructible y en esto se parece a un principio; en efecto, lo que nace debe necesariamente tener fin y hay un término a toda destrucción". Aristóteles "Física I", citado por Abel Rey, Ibíd., p. 58 
Admite sin embargo Russell, y este es el punto en el que se despliega en todo su poder el concepto de apeiron, lo que Cantor define como infinito absoluto. Dice Russell: "Existe un número superior a todos los números infinitos, que es el de todas las cosas juntas, de todo tipo y especie. Es obvio que no puede haber un número superior a éste porque se ha eliminado todo, no queda nada que sumar. Cantor, tiene una prueba de que no hay ningún número superior a éste..." ${ }^{56}$ (Incluyo este exposición un tanto engorrosa de la relación equivalente entre el todo y las partes, porque será un argumento que reaparecerá en el siguiente capítulo, como demostración, para Bergson de lo contrario, el todo es mayor que las partes, si uno se instala en un devenir).

Bien, el ejercicio que van a hacer los pitagóricos con el apeiron de Anaximandro es a mi modo de ver rebajarlo de intensidad y de rango. En ellos el principio supremo es la Unidad. Retoman ${ }^{57}$ el apeiron pero bajo su contrario, el poras, en la Tabla de Opuestos siguiente:

$\begin{array}{ll}\text { Limitado (poras) } & \text { Ilimitado (apeiron) } \\ \text { impar } & \text { Par } \\ \text { Unidad } & \text { Pluralidad } \\ \text { Derecha } & \text { Izquierda } \\ \text { Masculino } & \text { Femenino } \\ \text { Reposo } & \text { Movimiento } \\ \text { Recto } & \text { Curvo } \\ \text { Luz } & \text { Oscuridad } \\ \text { Bueno } & \text { Malo } \\ \text { Cuadrado } & \text { Oblongo }\end{array}$

Vemos que si en Anaximandro el apeiron contenía en su plenitud los principios opuestos, incluido el modo de determinación de lo limitado, (el mundo y además la infinitud, los infinitos mundos), los pitagóricos dan a entender, al ponerlo al mismo nivel que el poras, que su principio parte de otras premisas y tiene otras consecuencias.

La Unidad viene marcada por un sentido de perfección y de principio. Aspira, según Cornford, a constituirse en lo divino al quedar asignada al principio de belleza y bondad ${ }^{58}$. Distinguiéndose de este principio, pero en consecuencia en cualquier caso, está la unidad aritmética. Hay cierta confusión en la separación de estos dos conceptos y en la propia definición de la Unidad. La Unidad como principio, puede ser vista como la unificación en un solo cuerpo de los contrarios desplegados en la tabla anterior. Recibe la Unidad a veces el nombre de par-impar, dado que en el ejercicio de limitar y definir se envuelve ya de lo ilimitado e indefinido. Teofrasto, para Cornford, sitúa la Unidad al mismo nivel seminal que el Indefinido. La Unidad no es omniabarcante, sino que comparte posición jerárquica con su opuesto. La dificultad de establecer un único principio adquiere los

56 Bertrand Russell, "Las Matemáticas y los Metafísicos” aparecido en 1901, y recopilado en "Misticismo y Lógica", p. 128.

57 Retoman o más bien se podría decir que trasladan de lugar geográfico el apeiron. Una generación más joven es Pitágoras que Anaximandro (finales del s. VII el segundo y últimos del s. VI el primero), desarrollando aquél su actividad, a partir de su expulsión de Samos (en la Jonia), en el sur de Italia (Metaponto), que, como señala Rey, está en el "extremo opuesto del mundo griego". Se considera, por tanto, como un factor de renovación, la ligazón de la escuela pitagórica a un nuevo entorno geográfico como es el constituido por las colonias de la Magna Grecia.

58 Francis Macdonald Cornford, "Platón y Parménides", pp. 39 y 40. 
rasgos propios que se observan cuando se busca la fuente general de todo en una sola noción y del hecho de que las demás cosas sean pasen a ser casos particulares de ésta. Apunto en este sentido hacia lo visto en el caso de la geometría riemanniana sobre la geometría euclídea. Parece un hecho repetido si observamos el apeiron o la metageometría, que por su mayor plasticidad formal, es más frecuente que tenga el principio de ilimitación e indefinición la propiedad de acoger como un caso específico lo limitado, que al contrario. Así, por tanto, parece el pitagorismo necesitar del emparejamiento de los opuestos, sin una noción que les anteceda. Las palabras de Teofrasto acusan este sentido: "ahora bien, (Platón y los pitagóricos) en la medida que hacen una suerte de oposición entre el Uno y la diada indefinida, de la que depende todo lo que es indefinido y desordenado y, por así decir, toda la deformación, es absolutamente imposible para ellos que la naturaleza pudiera existir sin la diada indefinida; dicen que es igual de importante o incluso que predomina sobre el otro principio; por lo cual consideran a los dos principios como contrarios entre si" ${ }^{\prime \prime 5}$.

Vemos ya en la tabla de las perfecciones e imperfecciones que cualidades aprensibles del apeiron, como la deformación o lo amorfo pasan por ser un constitutivo de la naturaleza. Es a esta notable imperfección que uno observa primero en la multiplicidad de la naturaleza y luego en su variedad de formas, deformaciones unas de otras, a la que debemos el funcionamiento de una "acción limitadora" necesaria para constituir los términos a la izquierda de la Tabla de Opuestos. Se plantea por tanto la limitación no sólo como principio constituyente del mundo, sino además, y es importante, en un sentido regulador, como prueba de contraste, para establecer la clasificación de las cosas y colocarlas a uno $u$ otro lado de la tabla. En este sentido el órgano regulador no va a ser otro que el número. Todas las cosas son números, expresión máxima de la ciencia pitagórica, encuentra aquí un sentido ético como clasificador ${ }^{60}$ moral de las cosas.

Es desde este punto de vista, como el número sin ser principio si es regulador cualitativo tanto de la deformación como de la forma y en su facultad está abarcar cualquier fenómeno natural o moral: "la diversidad de los números representa la esencia cualitativa de cosas completamente heterogéneas: el cielo, el matrimonio, la justicia, el

59 Teofrasto, "Metafísica", recogido en Cornford, Ibíd., p. 40

60 Ha sido señalado por Jaeger, las profundas implicaciones entre la ciencia de la naturaleza y la justicia. Lo que formula la ciencia griega de la naturaleza cae bajo el sentido intuitivo de la justa compensación entre opuestos. Defiende Jaeger en este sentido, que "el conocimiento de esta norma del acaecer tiene un sentido inmediatamente religioso. No es una simple descripción de los hechos, sino la justificación de la naturaleza del mundo. El mundo se revela...como una comunidad de las cosas sujetas a orden y a justicia" Jaeger, op. cit, p. 159. El sentido ético que introduzco, no esta afectado por la distinción entre derecho y moral, dado que el sentido normativo dictado por la diké (término que referido a la justicia) parece abarcar todos los ámbitos, desde la moral individual hasta la legalidad del cosmos. Parece por tanto, que lo que se espera del comportamiento del mundo no haría sino validar este sentido intuitivo de justicia aplicable tanto a los hombres como a los fenómenos y que los funde en un único sistema regulador. A este propósito indica Jaeger la anticipación de un punto de vista teórico sobre la naturaleza, que es coincidente con un sentido práctico del comportamiento humano, pero no con el teórico. Habría pues una transmisión, según Jaeger, desde una legalidad cósmica hacia el sentido espiritual del hombre, que desemboca en el descubrimiento de "las leyes interiores del alma". Jaeger, Ibíd., p. 152. 
kairos (la oportunidad), etcétera" ${ }^{61}$. Evidentemente no sólo conceptos de tanta elevación, sino también formas tan tangibles como el caballo ${ }^{62}$ tiene su número asignado.

En cualquier caso acompañaría desde el primer pitagorismo, el más vinculado a su fundador, la unión de la belleza y la armonía a un sentido ético-místico. $Y$ es en este primer momento donde se citan ya el descubrimiento de la relación del número de vibraciones con la longitud de las cuerdas de la lira, con el descubrimiento de la legalidad de la naturaleza y con el orden de la vida humana. No cabe a mi juicio, plantear en la esfera del pitagorismo la discusión que se hará, en el ámbito que nos ocupamos, entre una ética o una estética ${ }^{63}$.

Bien. ¿cómo definir entonces la Unidad? La Unidad juega en mi opinión dos papeles: como principio de limitación, tal como hemos visto en simetría con el apeiron, y como unidad aritmética o principio del número. En este segundo sentido, la unidad puede considerarse como un conversor cualitativo del número que le desequilibra hacia un lado u otro de la tabla de contrarios: "la unidad participa de la naturaleza de ambos (es a la vez par e impar), puesto que cuando lo sumamos a un número par, lo convierte en impar, y cuando lo sumamos a un número impar, lo convierte en par; de ahí que la unidad reciba el nombre de par-impar" ${ }^{\prime \prime 4}$. Ahora bien, para entender en toda su amplitud la cualificación que adquiere la naturaleza del par o del impar, para entender el significado pitagórico de par o impar, hay que precisar que el número no se suma aritméticamente, sino figurativamente, esto es, por medio de figuras. Para las operaciones de contabilidad o meramente prácticas para sus comercios con las colonias, los griegos disponían de los símbolos alfabéticos y numéricos apropiados a tal efecto. La ciencia pitagórica usa otro sistema numérico de tipo geométrico. Este sistema es el número figurado. Se opera, digamos, no mediante signos, sino, a través de figuras que acuñan el valor numérico.

El sentido físico y visual del número le es dado por la unidad aritmética. Los números tienen extensión, ocupan un espacio y adoptan una figura a través de la ordenación de las unidades. No ocupa lo mismo ni se dispone de la misma manera el dos que el tres. La unidad aislada como tal por la ciencia pitagórica es el punto extenso.

"Definen (los pitagóricos) el punto como la unidad que tiene posición, y la unidad, como un punto sin posición" 65 . Pongamos un ejemplo conocido: la justicia es el número diez, contiene diez unidades. A su vez, la justicia o ya, su representante, la década o

61 Werner Jaeger, "Paideia", p. 161.

62 Eurito pasa por ser el que formuló esta asignación. De puro ramplona ha adquirido fama.

63 En respuesta al artículo "The New Brutalism", Architectural Design, Volumen XXVII, Abril 1957, pp. 111 y 112, Alison y Peter Smithson distinguen con nitidez la ética de la estética: "Hasta ahora, el Brutalismo ha sido analizado estilísticamente, cuando en realidad su esencia es ética". Alison y Peter Smithson "The New Brutalism, (respuesta a la críticas de la página anterior)" Ibíd., p. 113. ¿Ética o estética? La ambigüedad la deja Banham para su libro de 1965.

64 Aristóteles citado por Cornford, p. 43.

65 Aristóteles, "Metafísica, XII", en Abel Rey, op. cit. p.200. Veamos al avanzar este trabajo que este tipo de cuestiones no son en absoluto irrelevantes. 
número diez, es observable a través de diez puntos, no distribuidos de cualquier manera. La visualización del número diez es bajo una figura plana triangular: la primera fila la ocupa un punto, la segunda dos, la tercera tres y la cuarta cuatro, siendo la suma de $1+2+3+4=10$. El poder simbólico de la década excede al que pudiera conferirle su propio valor numérico (diez, los dedos de las dos manos conocido desde antiguo como instrumento contable). El espíritu, sensibilizado en los griegos por el orden geométrico más que por el valor absoluto del número, queda atrapado en la imagen de la llamada tetractys, sugestionado por sus atributos de perfección. El descubrimiento de la escala musical a través de la armonía de los acordes de la cuarta, la quinta y la octava, encuentra en las razones entre las filas de la tetractys su correspondencia geométrica: la razón entre las filas cuarta y tercera, 4:3, es la cuarta, la razón entre las filas tercera y segunda, $3: 2$, es la quinta, y por último, la razón entre la segunda y primera filas es la octava, 2:1. Queda transferido el valor desde lo intangible del sonido a la emoción plática de la figura y nuevamente reflejado hacia un valor abstracto como es la justicia. La figura, un triángulo equilátero de cuatro puntos por lado, representación de la década y cuyas razones internas entre las filas son las que ofrecen los cuatro primeros números naturales permite sopesar algo del alcance del número figurado. El alcance en toda su dimensión vendrá ofrecido, como veremos más adelante, por el tipo de operación que resulta de la aplicación del gnomón y por la cualificación del número a partir de la división de su figura en dos.

La naturaleza de la unidad aritmética es por tanto extensa. ¿Cómo de extensa? Suponemos que ante la presión eleata, lo suficiente para ser generadora de todas las cosas y a la vez lo mínimo posible. Los puntos unidades con extensión eluden la complicación lógica de tener que basar la correspondencia entre los números y la realidad mediante construcciones puramente abstractas, dado que de un punto matemático inextenso no se podría deducir la extensión física de las cosas. Podemos sentir en la matemática pitagórica algunos rasgos propios de la física, que desaparecerán según aumente su autonomía y deje de ser una ciencia de principios y causas para serlo de los elementos. A diferencia del punto euclídeo, puramente matemático, que no tiene dimensión, el punto pitagórico como unidad formativa o representativa del fenómeno físico, conserva un quantum de extensión: "los pitagóricos construyen todo el cielo con números, pero no con números mónadas (números como puros conceptos), ya que suponen que las unidades tienen una magnitud"66. En segundo lugar, en virtud de la representación física del punto, la unidad adquiere una posición y es comienzo del número. Se intuye aquí, como hemos visto en el caso de la tetractys, que el número se sostiene de las aportaciones de la aritmética y la geometría.

La unidad aritmética es en definitiva un punto extenso con posición, finito e indivisible. Considerado con otras unidades el conjunto ordenado de puntos en el espacio conforma una figura y un número.

Una de la aplicaciones fundamentales del número figurado y por la cual se extraen las afecciones del número son las series de 
números cuadrados y oblongos (rectangulares). Para el incremento de una figura en una serie se utiliza el gnomón.

La particularidad que distingue la serie de los cuadrados de la serie de los oblongos reside en la forma resultante: para los números cuadrados la forma resultante es invariante, el cuadrado, mientras que en los oblongos difiere, por la variación de proporción entre los lados. ¿Cómo se interpreta en este sentido el gnomón? El gnomón es la figura que cuando es añadida a un cuadrado aumenta su tamaño pero no su forma. El gnomón de la serie de los cuadrados es la unidad con dos brazos iguales en escuadra y es, a su vez, la sucesión de los impares, 3 , 5,7 , etc. De esta manera, al añadir al 1 el gnomón 3 da el cuadrado de 2 (4); al añadir el gnomón 5 al 4, da el cuadrado de 3 (9), al añadir el gnomón 7 al 9 da el cuadrado de lado 4 (16) etc. En cambio, el gnomón de los oblongos es siempre par: al 2 se añade el gnomón 4 , y da el 6, al 6, el gnomón 6, da el 12, al 12 el gnomón 8, da el 20, etc. Visto como número figurado el seis es dos filas de puntos de base 3 y altura 2 . El 12 , tres filas de base 4 y altura 3 etc. La relación entre unidades de los lados de cada rectángulo es la siguiente: $3 / 2,4 / 3,5 / 4,6 / 5 \ldots$ Cada una de las relaciones es diferente de la anterior. Por otro lado, en un número cuadrado figurado, como es inmediato de ver en la figuración, la relación entre las unidades de los lados es siempre la misma.

Bien, a partir de esta propiedad formal los pitagóricos asocian lo mismo como lo "uno" y lo diferente como lo "otro" ${ }^{67}$. El cuadrado y el rectángulo son expuestos como contrarios en la Tabla de Oposiciones en el último casillero. Está claro que esta clasificación la tiene que hacer la matemática pitagórica sobre la dualidad de lo "uno" y lo "otro"68 hasta remontarse a sus principios respectivos del poras y del apeiron.

La implicación del rectángulo con la diada se articula a través del concepto de lo "otro", creado por medio del término chôris, que incorpora varias acepciones como "aparte", "separadamente", pero también "diferentemente". Surgen de la misma raíz chôrion, el "rectángulo", y, chôra el "intervalo". El chôra, objeto en sí mismo sin figura, en tanto que es el vano de extensión indefinida que queda entre dos puntos, es la causa de que el par o diada caiga en el lado derecho de la Tabla de los términos opuestos. Veamos cómo se forma la idea del chôra:

"Cuando se divide al Impar en dos partes iguales, queda una unidad en el medio; cuando se divide, en cambio, al Par de la misma manera, sólo queda una chôra vacía sin dueño y sin número, manifestando el carácter deficiente e incompleto del Par ${ }^{\prime \prime 69}$. También en este pasaje se insiste en el carácter indeterminado del intervalo: "En la subdivisión de los números, el Par, dividido por el procedimiento y de la manera que sean, deja, por así decirlo, en su interior una chôra, pero si efectuamos la misma subdivisión con el Impar, siempre deja en medio un término medio." ${ }^{\prime \prime 0}$

67 "Nos cuenta (Nicómaco) que los antiguos, Pitágoras y sus sucesores, descubrieron "lo otro u otredad" en el "dos" y lo "mismo o mismisidad" en el uno". Cornford, op cit. p. 45

68 Como señala Rey hay cuadrados pares (el 4, o el 16, por ejemplo). Por tanto la distinción no es sobre lo par del número sino por algunas cualidades de la figura y el gnomón asociado. Véase Abel Rey, op cit. p. 213.

69 Posidonio, recogido por Abel Rey, Ibíd. p. 287

70 Plutarco, recogico por Abel Rey, Ibíd. pp. 287, 288 
La primera impresión que nos transmiten estos pasajes nos demuestra con claridad palmaria la distinción entre "lo mismo" y "lo otro". Cualquier punto, sea donde sea que esté dibujado, sea cual sea el material que lo sustente es siempre uno y el mismo. Y esta propiedad no es aplicable al intervalo. No se puede fijar una dimensión, digamos que estandarizada, para el intervalo, ni se puede transportar ni producir físicamente mediante una varilla o un palo. Así, siendo un componente siempre variable, esta preso de la deformación misma, sin llegar por su naturaleza a concretarse en número. El intervalo, el chôra va a ser siempre "lo otro", al efectuar la división del Par.

Tenemos aquí dos de las más importantes acepciones manejadas en esta tesis, la deformación y lo "otro", la "otredad" lo "autre", unificadas en la teoría del número pitagórico y ambas situadas bajo la misma afección de lo indefinido e ilimitado, del apeiron. Cada rectángulo es "otra cosa" respecto al anterior y al posterior en un sentido que trasciende a la figura geométrica y que se dirige directamente a las cosas significadas. Las cosas cuyo número sea oblongo son otras y distintas, lo que nos sitúa frente a la pluralidad ilimitada e irreconciliable con la unidad.

En cuanto al chôra la situación es la misma que se manifiesta en el rectángulo, su propia variabilidad o si se prefiere su fluidez: en suma lógica a las afecciones indicadas, Aristóteles apunta una más referida a esto último: "Pitágoras Ilamaba a la materia "lo otro" al ser algo que siempre fluye y continuamente deviene en otra cosa"71.

Vemos, como de alguna manera, todos los apelativos que califican el proyecto de Sheffield, incluido el de flujo van encontrando posición del lado derecho de la Tabla de Opuestos, y, por tanto, separándoles de las bases positivas que los pitagóricos asocian al poras, al principio de lo definido y limitado. Así la parte que hemos definido como la ampliación, responde a este concepto de "lo otro", mientras que el eje puede ser entendido en este contexto como una compensación o un reequilibrio en el sentido dado por Jaeger (véase nota 13), en base a su carácter limitado y definido.

Bien, en segundo lugar el chôra nos introduce de lleno en el segundo problema que afecta al modo proporcional palladiano y renacentista en general, por el cual la razón huye de introducir los segmentos continuos de proporción y en concreto aquellos como la $\sqrt{2}$, irracionales, y se decanta por el empleo de relaciones entre números enteros.

La manera como el chôra es indeterminado, no es sólo por su intrínseca variabilidad o aformalismo. Es algo que atañe al proceso de subdivisión infinitesimal. Hemos adelantado que la unidad se caracteriza por ser finita e indivisible. Tiene en este sentido una consideración atómica. El método de la división del Par descubre la falta de límite para la división continua del intervalo. Toda parte del intervalo es de nuevo un intervalo, lo que obstruye cualquier intento de retener para éste un cierto número o una cierta limitación que haga de tope a la secuencia de partición. Este problema, que probablemente no estaba contemplado en la formulación de Anaximandro sobre el apeiron, al entrar en contacto con un razonamiento como el pitagórico, que se construye mediante el principio de limitación, deriva en el 
colapso lógico y, en mi opinión, sobre tal dificultad se apoya la base de la separación de contrarios.

Propone el pitagorismo una nueva formulación de la unidad en la que no se hace intervenir el chôra. Toma por unidad un cuadrado de lado la unidad, el cual encaja con otro sin intervalo entre ambos. Ciertamente el campo (una de las acepciones del chôra ${ }^{72}$ ) se hace denso en figuras, se evacua por presión el vano entre posiciones y de este modo admite ser numerado. La unidad rellena todo el plano y aparentemente desaparece, de forma natural, la indeterminación dada por el chôra. Y sin embargo, como es fácil aventurar, no hace sino elevar a tangible el problema de la indeterminación. Ya no se trata de la variabilidad en la extensión entre posiciones de unidades, sino en una figura, la diagonal, limitada geométricamente pero irreductible aritméticamente al segmento unidad del lado del cuadrado. El avance respecto al intervalo informe es estrictamente geométrico: ahora la indeterminación, esta firmemente trazada y limitada entre las dos esquinas opuestas del cuadrado, pero su razón respecto a la unidad se torna inconmensurable. Es la $\sqrt{2}$, número de infinitos dígitos decimales no periódicos.

Hacia el final del pitagorismo se tomará por fin como nueva unidad el segmento continuo. Como indica Echeverría, a diferencia con el chôra, el segmento "es el intervalo con figura, al cual se supone compuesto de puntos", mientras que el chôra era "el intervalo sin figura". La deriva de la decisión de un cambio en la sustanciación de la unidad abrirá dos vías, la de la Academia y la de Eudoxio. Me remito en este tema, que no vamos a abordar porque excede el periodo pitagórico que estamos tratando, a lo expuesto por Echeverría en su Tesis Doctoral, que es suficientemente claro: "Dos ciencias se distinguen entonces y se desarrollarán simultáneamente: una propiamente aritmética, incluso bajo su forma de una aritmo-geometría, tiene por objeto el número; la otra, nacida de la meditación del irracional y que da sus primeros pasos en la sombra, tendrá por objeto el espacio, y no ya contado en campos iguales y numerados, sino continuo y libre del número..."73 Sobre el texto de Michel, Echeverría, de su puño y letra, añade: "Ciencia del discontinuo, ciencia del continuo. No sólo se distinguen, sino que se oponen, reservándose cada una su dominio propio. Una, la ciencia del número, no quiere conocer el espacio más que como una colección de puntos (unidades con dimensión), excluyendo así toda magnitud irracional; otra poniendo en el mismo plano lo racional y lo irracional, niega en primer lugar al número la preeminencia que le correspondía, y a continuación, llega a excluir el número eliminándolo de una geometría que, independiente de toda medida ya no considera más que propiedades específicas de las formas" ${ }^{\prime 74}$.

Bien, visto en perspectiva, se puede admitir una bifurcación de la raíz de la aritmo-geometría pitagórica en dos troncos, cada uno con su objeto de interés, surgido del problema de la mezcla de lo continuo

72 "En el fondo el intervalo en todas sus significaciones posibles podría estar bastante bien dado por nuestra expresión "el campo", es decir, allí donde se desarrollan las determinaciones, y del cual no se puede decir nada más que por ellas y con ellas", Abel Rey, "La maturité de la pensée scientifique grecque" pp. 248 y 249 , recogido en Javier Echeverría, "La Intuición en Matemáticas. La Figura y el Lugar", pp. 167 y 168, nota 8.

73 Paul Henri Michel, "De Phytagore á Euclide", recogido en Javier Echeverría Ibíd. pp. 69 y 70

74 Javier Echeverría, Ibíd. 
y lo discreto. En este sentido, las consecuencias se aprecian, tal como acertadamente ha puesto de manifiesto Wittkower, en una radical distinción en el Renacimiento de los métodos proporcionales. Resultan obvios así los problemas que elude la arquitectura renacentista al promulgar la defensa del sistema pitagórico de proporción por medios exclusivamente aritméticos. Ahora bien, los métodos proporcionales corbuserianos son estrictamente geométricos. El llamamiento a un orden neopalladiano, montado sobre una base pitagórica, en un ambiente definido por el trazado geométrico de raíz corbuseriana, defendido por los seguidores de Wittkower y Le Corbusier, sólo cabe admitirlo bajo el esfuerzo de desligar lo sensible de la figura del conocimiento racional de ésta. La fórmula en este sentido es admitir un nuevo concepto de unidad o principio de limitación, establecido en este caso en la distinción entre lugar geométrico y lugar mecánico, tal como se plantea en el ámbito platónico. Sin entrar en detalle, el lugar geométrico alude al un tipo de conocimiento eidético de la figura, y de otra manera sería su construcción mecánica. Sólo salvando como ideal la figura geométrica frente a la construcción mecánica de ésta, es posible llegar a evitar el problema del continuo: "Sucede por accidente a la línea el admitir mitades hasta el infinito, pero su esencia es otra, así como su ser" ${ }^{\prime 75}$.

En la tesis de Echeverría, que ve en la figura, en el segmento, la función de la antigua unidad pitagórica, la divisibilidad continua sólo es un problema que afecta a la representación de la figura, el segmento continuo en este caso, pero en ningún caso, a la idea de ésta, cuya fuero sería comparable al de la unidad como punto extenso pero indivisible (elemento de contradicción pitagórica en sus propios términos y que articulará en torno a él el problema del infinito como veremos más adelante).

Para terminar con la disyuntiva de Le Corbusier, la inclusión, como decía Llewelyn Davies, de lo ilimitado (la series del Modulor) en el seno de una figura finita y proporcionada, sólo cabe verlo como una construcción mecánica encaminado a construir una figura unitaria en sí misma, una unidad en el sentido en sentido platónico, de la que vemos, porque así se nos muestra, a través de la exposición del Modulor e incluso de su bajorrelieve, simultáneamente su eidos y su figura característica. No hay en el platonismo de Le Corbusier, problema alguno de contradicción, como tampoco en Palladio, aunque bajo consideraciones distintas de lo que por unidad se entendía y estaba así regulado.

En la Tesis, sin embargo, para la Universidad de Sheffield hemos tomado el camino del número, no el geométrico. En este sentido hemos expuesto el método de Leibniz de Transición Continua que se acomodaba dentro del problema del infinitesimal. En apoyo de esta tesis, presentaremos un ejercicio puro de pitagorismo, y en concreto sobre la serie del número cuadrado, tal como hemos visto bajo la aplicación del gnomón. Cabe verlo como una interesante variante del palladianismo, en tanto comparte sus mismos principios $y$, en este sentido, animo a contemplarlo así, como un producto específico del ambiente de discusión matemática y neopalladiana desarrollado en los cincuenta, y del cual constituye, por otra parte, su última y más estentórea palabra. Se trata del complejo de edificios del Economist Building. 


\subsection{APLICACIÓN DE LA SERIE DEL CUADRADO EN EL ECONOMIST BUILDING}

La teoría que contempla la arquitectura moderna no toma como objeto propio la estructura numérica de los edificios. No me refiero a su carácter simbólico, sino estrictamente clasificatorio. La tradición del modo de clasificación del templo griego se venía estableciendo desde Vitruvio según la posición y número de columnas que le rodean. La sistematización de Vitruvio probablemente coloree la arquitectura templaria griega de consideraciones helenísticas que se entremezclen con la propia tradición de la época clásica y no corresponda enteramente con el modo de operar del arquitecto dórico o jónico. En cualquier caso, la sistematización que ofrece sobre la clasificación de los templos se basa en el número de columnas situadas en el frente y laterales del templo. A partir de Vitruvio se establecen los siguientes tipos:

El templo períptero o hexástilo cuya notación sería $6 \times 11$, el pseudodíptero y el díptero, de 8x15, el hípetro o decástilo, a cuya definición sólo le alcanza el número frontal de columnas, 10. Decía que la sistematización vitruviana actúa en aras de fijar ciertos tipos (e incluso también probablemente ciertos tópicos) frente a un contingente ciertamente heterodoxo y alegre de templos griegos.

La variación de casos reales en el caso concreto del templo dórico abarca un número mayor de relaciones entre las columnas del frente y del lateral.

Así, sólo para el hexástilo la variedad de templos encontrados queda reflejada en notación siguiente: 6x10,6x11, 6x12, 6x13, 6x14, $6 \times 15,6 \times 16$ y $6 \times 17^{76}$. Como se puede apreciar, el caso de $6 \times 11$, sería uno entre varios, y probablemente esta proporción estaría encaminada a sentar un cierto canon por encima de otras proporciones.

Pero de este ejemplo, lo interesante son dos cosas.

Primero la propia notación o clasificación del templo según el número de columnas, lo que enseguida pone sobre aviso de la proximidad con el número figurado a partir del número de unidades de las caras del cuadrado o del rectángulo.

En segundo lugar la disociación entre el aspecto cualitativo y cuantitativo del número y en definitiva sobre la diferencia entre la magnitud discreta aritmética y continua geométrica. Se puede comprobar por las dimensiones del estilóbato que se levantaron templos de 6x12 más grandes que la mayoría de los templos de 6x13 y que varios de $6 \times 14$.

Otra consideración que apunta en esta dirección esta relacionada con la proporción del lado largo para un invariante en el número de columnas del frente. En los templos de $6 \times 17$ se observa que se comprime la distancia del intercolumnio lateral, de manera que se fuerza a disponer un número mayor de columnas que el que por dimensión les hubiera correspondido de haber mantenido el reparto

76 Véase esta clasificación y en general, lo referente a este epígrafe, en Esteban Herrero "La Fase Exenta de Medida", Revista Europea de Investigación en Arquitectura. REIA, número 3, 2015, pp. 26-39 
fijado para el frente. En el caso más extremo, el templo D de Selinunte, se ha forzado hasta el límite de imponer 17 columnas cuando por envergadura no le hubiera permitido pasar del tipo 6x14. Resulta interesante ver bajo el chôra el intervalo entre dos columnas como algo cuya naturaleza es indefinida.

En conclusión, puede observarse una planificación del templo en virtud del número de columnas, que antecede o contradice a la propia dimensión física del templo. Quiero decir, parece que el objetivo del arquitecto griego pasa por fijar una limitación aritmética para establecer el tipo de templo que se va a levantar, sin que esto contradiga que se puedan establecer proporciones parciales de raíz geométrica. El primera acto sería por tanto establecer un número de columnas y este número no vendría dado por la capacidad espacial del lugar sino por otras cuestiones. En cualquier caso, con esto no haríamos sino trazar un puente entre arquitectura griega y la matemática pitagórica, y en todo caso, insistiría en la influencia que aquella mantiene con la segunda. ${ }^{77}$

Salvando la distancia de los requerimientos técnicos y plásticos de la arquitectura, el hecho es que el plano del templo, con su distribución en el espacio de los tambores de las columnas y la variabilidad del intercolumnio, pudo ejercer de modelo figurado a la artimo-geometría. Para ello requeriría ver en la sección del tambor del fuste un ejemplo para el tratamiento de la unidad que el pitagorismo primitivo situó en el punto extenso. El hecho de que del diámetro de la columna se derive el módulo por el que se asignan las dimensiones totales del orden, no dejaría de estrechar la relación con la idea de la unidad como principio del número, sin ser ella misma número, de la misma manera que el tambor no es el capitel aunque su medida exprese la de éste.

Por tanto, resulta prudente, asociar a la columna el principio de determinación de la planta del edificio. Es en este sentido, a lo que me refería más arriba de cómo la teoría había perdido de vista una clasificación de la arquitectura en base numérica. Así, por ejemplo, cualquier arquitecto no tendría impedimento en identificar el Partenón como templo bajo la notación $8 \times 17$, y probablemente le costaría más hacer lo mismo con los edificios columnarios del s. XX como la Villa Savoye, de $5 \times 5$.

La obra americana de Mies van der Rohe se presta mejor que la obra de Le Corbusier a una clasificación de este tipo, especialmente en los edificios en altura dada la uniformidad que presentan entre sí. Agrupándolos según la notación axb en función del número de pilares en planta, obtenemos la siguiente clasificación:

77 Sostiene a este particular Abel Rey que "La Arquitectura y la medida del cielo, la Astronomía, fueron, pese al papel que desempeñó la Geometría práctica y pese al sentido etimológico, el medio técnico en donde tuvo nacimiento la Geometría matemática", Abel Rey op cit. p.177. Abel Rey parece indicar aspectos técnicos como la curvatura del éntasis, de trazado hiperbólico, que sería tratadas en principio como curvas mecánicas antes de su consideración como lugares geométricos por Apolonio. Considero la distribución columnaria sobre el plano del templo como acto de delimitación por el cual se otorga un número al templo, como antecedente práctico del estudio del número figurado por parte de la ciencia pitagórica. 
Tipo I: $4 \times 6$

860-880 Lake Shore Drive (1948-51)

$(64.10 \times 106.10)$

900-910 Lake Shore Drive (1953-56)

Commonwealth Promenade (1953-56)

$(67 \times 109)$

Seagram Building (1954-58)

$(87.7 \times 143.10)$

Westmount Square (oficinas) (1965-68)

$(83.6 \times 136)$

Tipo II: $4 \times 7$

Westmount Square (apartamentos) (1965-68)

$(67.6 \times 162)$

Tipo III: $4 \times 8$

Toronto Dominion Center (Trust Tower) (1963-69)

Tipo IV: $4 \times 9$

Commonwealth Promenade (1953-56)

Toronto Dominion Center (Bank Tower) (1963-69)

$(124.3 \times 244.3)$

Tipo V: 4X11

900-910 Lake Shore Drive (1953-56)

Lafayette Park (1955-56)

Tipo VI: 5x9

Chicago Federal Center (Federal Office) (1959-73)

$(116.4 \times 228.4)$

Tipo VII: $5 \times 14$

Chicago Federal Center (U.S. Courthouse)(1959-64) (116.4 x 368.4)

Como se aprecia, la mayoría de los edificios en altura son tetrástilos, fundamentalmente con la proporción $4 \times 6$. También se aprecia una indiferencia respecto al uso, compaginándose el tipo oficina con el residencial para cualquier proporción (excepto los tipos VI y VII exclusivamente terciarios). En la tabla de medidas (en pies y pulgadas) se ve una dimensión homogénea en el tipo residencial, sea cual sea la proporción estructural. En las oficinas, la variación del módulo es mayor, y se aprecia un módulo relativamente pequeño en el Seagram frente a otro comparativamente bastante mayor en el Toronto Dominion Center. Como en el caso del templo griego, la notación no corresponde con la dimensión real, como sucede entre los apartamentos Commonwealth Promenade de $4 \times 9$ y el Toronto Dominion Center (Trust Tower) de $4 \times 8$ pero de mayor envergadura que el anterior, dado a que se elige por norma para el tipo residencial un módulo dimensional menor que el de las oficinas. En definitiva, la estructura más utilizada por Mies es la resuelta en la proporción 4 a 6, y además, con insistencia en el reparto de 4 columnas y tres huecos, como ocurre para el frente de la Torre de Oficinas en Londres (1967, no ejecutada) donde se ensancha el intercolumnio central para evitar introducir una quinta columna.

Bien, esto es lo que se puede extraer de una clasificación bajo una notación obtenida por un sistema del tipo del número figurado. Como se ve, aporta notables clasificaciones que permiten extraer conclusiones acerca del tipo estructural más usado por el arquitecto. Este mismo método lo vamos a aplicar sobre el Economist Building.

\section{LÁMINA III.5}

El Economist Building (1959-1964) es un pequeño cluster que engloba varios edificios sobre una infraestructura común, en un planteamiento muy similar al desarrollado en el capítulo anterior. 
Los tres edificios principales mantienen fuertes vínculos materiales y estructurales, pero también posee cada uno algún tipo de particularidad que los distingue entre sí. Cada edificio cumple una función determinada que los da nombre: el banco, la torre de oficinas y la torre de apartamentos. Contando el número de pilares por cara, sin entrar en considerar las particularidades, podemos obtener la siguiente identificación: el banco, 5, las oficinas, 6 y la torre de apartamentos 7 . Bajo el supuesto de que esta estructura perimetral es convertida en número figurado, y por tanto se añaden los pilares de esquina y que la sección del pilar es el punto extenso, obtenemos una figura densa en puntos que nos permite pasar de la estructura física a una progresión de números cuadrados, que corrige la identificación anterior y la deja como sigue: $7 \times 7$ para el banco, $8 \times 8$ para las oficinas y $9 \times 9$ para los apartamentos. Como he señalado en otra parte, la progresión sobre la figura cuadrada a través del gnomón es uno de los descubrimientos atribuidos a la primera época del pitagorismo. En concreto, la serie de números cuadrados representa la sucesión de números impares $(2 n-1)$ representada por el gnomón con vértice en la unidad y brazos iguales. De esta forma se puede leer la sucesión $7 \times 7,8 \times 8$ y $9 \times 9$ como consecutiva al sumar números impares consecutivos a los números cuadrados resultantes: el 15 y el 17 sobre el cuadrado de 7 y de 8.

Este mecanismo crea un vínculo al crecimiento de la figura, por el cual, como veíamos, obteníamos una cualificación para la progresión de cuadrados que se atribuía al término "lo mismo". Cada vez que hacemos crecer la figura volvemos a obtener "lo mismo", aún cuando su magnitud sea diferente, dado que la relación entre los lados es lo "uno", el 1, la unidad aritmética indivisible. Pero también obliga posicionalmente a cumplir un cierto orden. El orden va del menor al mayor sumando, pero no se cumple mezclando las figuras. Las figuras representantes de los tres edificios del Economist (los cuadrados $7 \times 7$, $8 \times 8$ y $9 \times 9$ ) cumplen estos requisitos. El crecimiento es consecutivo y la disposición en el espacio real de los edificios es la ordenada por la serie del menor al mayor: la posición del edificio intermedio, de 8x8, actúa como enlace entre extremos. Repasando el plano de situación tenemos en primer lugar el banco (7x7), tras él la torre de oficinas $(8 \times 8)$ y posteriormente se encuentra la torre de apartamentos $(9 \times 9)$.

Y, en virtud de la inclusión del chôra no hay por qué contemplar restricciones en el vano entre las unidades, o arquitectónicamente, en la distancia del intercolumnio. Veamos el sentido paradójico que ofrece el principio de indeterminación.

El módulo que se establece como base para el desarrollo del proyecto, es de 10 pies y 6 pulgadas, pero en la torre de apartamentos el módulo aplicado es exactamente la mitad: 5 pies y 3 pulgadas, de forma que esta torre mide menos que los otros edificios, aunque cuantitativamente sea el mayor. Como en el templo griego, de un valor mayor no se deduce una mayor dimensión métrica. No es como se ha dicho, la mitad de la torre de oficinas, ya que el número figurado de los apartamentos es mayor que el de las oficinas, pero sí su módulo. Nos encontramos en la misma situación que con el templo, cuyo valor de $6 \times 13$, no garantizaba mayor envergadura espacial que un templo de $6 \times 12$. Este hecho revela un encaramiento por parte de los Smithson con el problema de la indeterminación del intervalo, al cual no sólo no rehuyen sino que se acomodan en él, usándolo para insertar un edificio según una ley de crecimiento que garantiza por esta ley la unidad del conjunto. Sino es por la indeterminación el edificio físicamente no 
cabría en el solar o para hacerlo entrar hubieran tenido que renunciar a la unidad del conjunto. La jugada, por tanto se revela en la máxima potencia del pensamiento pitagórico. La paradoja resulta en este caso económica, puesto que aún siendo métricamente menor que el edificio de oficinas, el consumo de material sí responde a la magnitud que como número figurado contiene.

Otro rasgo que nos coloca ante el uso de la indeterminación por parte de los Smithson es el chaflán de esquina en los edificios. Como queriendo adoptar una posición ante el debate abierto por Wittkower, deciden aplicar el argumento más doloroso al pitagorismo, la $\sqrt{2}$, en el seno mismo de un ejercicio pitagórico perfecto. Pero en este caso no logran eludir el efecto ambiguo que produce. La crítica no lo pasó por alto y tuvo que buscar justificaciones funcionales como el soleamiento, o las vistas cruzadas como asideros para no dejarse turbar por la impresión de desacuerdo que mantienen entre sí el lado del módulo y su diagonal. Así aparece el siguiente comentario: "Visto desde la distancia, mirando hacia arriba o hacia debajo de la calle parecen integradas las costillas verticales de forma clara dentro de la perspectiva de la calle, pero los chaflanes de esquina del edificio dan la impresión de poca altura (menor fuerza ascensional) y muestran una tendencia a desentonar dentro del flujo. Las proporciones cambian abruptamente debido a que el mayor desarrollo del tramo de la diagonal arroja una dimensión diferente de la fachada. Se puede argumentar que estas esquinas atrapan e invitan a una desviación desde la calle, pero en su declaración simple y desnuda de proporción -como en el resto de divisiones del bloque- carece de la escala humana del detalle de la subdivisión, la cual proporciona el episodio animado que tiene el resto de la calle... Es característico del esquema el achaflanamiento de las esquinas de todos los bloques... funcionan mejor cuando el módulo es relativamente pequeño y la diferencia entre la diagonal y el módulo no es tan grande como para frustrar el movimiento de un alzado al siguiente." ${ }^{78}$

También Gordon Cullen se refirió a la diagonal: "Las particulares esquinas achaflanadas de los edificios permiten cierta flexibilidad en el proyecto, ya que siendo la dimensión del ángulo ambigua, es relativamente fluida en oposición a lo inevitable del módulo... También reduce el volumen aparente de los edificios y abre la posibilidad de que existan vistas cruzadas entre los mismos." 79

Dentro del marco de las operaciones que se pueden llevar a cabo con la figura en la matemática pitagórica está aquella que trata sobre el modo de generar el número cuadrado a partir de la composición de números triangulares. Este mecanismo nos va a permitir dar con algunas propiedades del edifico más complicado del

LÁMINA III.6

Economist, el banco. Puede verse en la portada de Baumeister de qué manera la acumulación de diagonales en este edificio están a punto de echar a perder la unidad al conjunto.

Para el banco, los Smithson presentan una primera solución,(en forma de pera), que luego deciden regularizar en la forma simétrica

78 Artículo Offices and Shops en "The Architects'Journal", 16 de Diciembre de 1964, p. 1452.

79 Gordon Cullen, "Ios Edificios del Economist", artículo recogido en "Alison y Peter Smithson: Ideas y realizaciones", Cuadernos summa-nueva visión, no 14, Noviembre 1968, p. 21. 
final. Tanto para un caso como el otro su figura característica es el cuadrado $7 \times 7$. Veamos cómo se crea el cuadrado $7 \times 7$ y cómo su génesis contempla las dos versiones. particular:

Transcribo a continuación lo expuesto por Abel Rey sobre el

"Plutarco atribuye finalmente a los antiguos pitagóricos esta proposición: agregando la unidad al producto por 8 de un número triangular, se obtiene un número cuadrado". ${ }^{80}$

Continúa Abel Rey poniendo como ejemplo de la demostración el número 7x7: "Sea el número triangular 6 . Tenemos $6 \times 8+1=49$. El cuadrado dividido en 49 pequeños cuadrados... puede servir para demostrar la proposición... El cuadrado 49 se subdivide, en efecto, en 4 rectángulos iguales, cada uno de 12 cuadrados pequeños que dejan un pequeño cuadrado en medio. Cada uno de estos rectángulos es, según la observación pitagórica, el doble de un triángulo de 6 pequeños cuadrados en superficie y con lados 4 y 3 , y las diagonales que separan los triángulos forman un cuadrado que comprende por consecuencia 4 de tales triángulos ( $4 \times 6=24$ pequeños cuadrados) más el cuadrado del medio". ${ }^{81}$

Geométricamente se puede apreciar el efecto de la rotación de los rectángulos alrededor de la unidad central y cómo vale de trama para marcar las singularidades de las dos versiones del banco. También da cuenta de la creación de la serie por medio de la unidad hasta alzarse en el primer número cuadrado.

Pero permite apreciar también algunos rasgos puramente cuantitativos. Por ejemplo la primera versión en forma de pera distribuye asimétricamente el área equivalente a tres rectángulos más la unidad. Esto significa que los cortes sobre la figura del cuadrado contando las pérdidas de los chaflanes equivalen agrupados a un rectángulo de $4 \times 3=12$ unidades, o que su desaprovechamiento es de 12 unidades frente a las 49 iniciales.

En el caso de la figura simétrica el cómputo de las áreas y contabilizando nuevamente los chaflanes da una pérdida de medio rectángulo, equivalente al área del triángulo de 6 unidades.

Esto probablemente puede que no sea más que un juego, pero da idea del alcance que puede tener el número figurado. Podría ser que no viéramos en ello más que una forma intuitiva de producir una serie modular que de unidad al conjunto. Sin embargo, comparado con el complejo Westmount Square levantado por Mies van der Rohe (del cual hemos ofrecido los números de las torres de oficinas y apartamentos), que contempla el mismo programa, habremos de admitir para el Economist, y no sólo a nivel de interpretación, sino en el propio planteamiento de los arquitectos, un conocimiento de ciertas propiedades de la aritmo-geometría y de los elementos de manipulación que ofrece la matemática pitagórica para el desarrollo unitario de un complejo sin recurrir a la identidad de las figuras, que no se observan en otros proyectos, como en el citado de Mies, por ejemplo. Esta nota cobra un sentido específico en el marco del neopalladianismo 
abierto por Wittkower y Colin Rowe una década antes. Me atrevo a sugerir en vista de ello, que el Economist es una proclamación lanzada al corazón mismo del ambiente británico, del mismo modo que lo era la Universidad de Sheffield, aunque con un planteamiento opuesto. Hay en el Economist, a mi juicio, un ejercicio radical, mucho más consecuente e instruido que en los edificios que abanderan el palladianismo y que emplean diagonales en los trazados reguladores para obtener el principio de limitación y proporción del objeto. No pretendan encontrar en el Economist un ejercicio de palladianismo, sino sobre el palladianismo. El palladianismo del Economist está en el eidos de sus figuras, las construcciones características, las que se usan para analizar las formas dados a la percepción sensible y que actúan en representación de éstas. Resulta así que el Economist es más palladiano en esencia, porque se remonta para su creación al mismo manantial que abastecía a Palladio, la ciencia pitagórica.

Pero no cabe contemplar en los Smithson una renuncia a lo conquistado para Sheffield. El Economist también tiene sus trampas. Los irracionales nos muestran esta otra cara de los Smithson, la de lo indeterminado, la de "lo otro". Al fin y al cabo, de nuevo, se nos muestran bajo el doble rostro.

\subsection{PANOFSKY}

Me surge la duda de por qué tuvieron tanto éxito la tesis de Wittkower sobre la arquitectura del Renacimiento y por qué no la tuvo el librito de Panofsky "La Perspectiva como Forma Simbólica"82, que en definitiva aborda la forma por excelencia del Renacimiento, la que fue capaz de definir a una época, la perspectiva, habiendo compartido ambos autores en sus inicios una biografía similar. Probablemente el ambiente de los cincuenta era reacio a los trucos visuales a partir de las deformaciones perspectivas de los maestros del Renacimiento y del Barroco, ávidos como estaban los jóvenes arquitectos de sentar las bases de una nueva arquitectura. Pero la cuestión, seguramente no debe desecharse a la primera.

Giedion, en "Espacio, Tiempo y Arquitectura" publicado en 1941, aborda la perspectiva en las mismas claves que abrió Panofsky, pero para mostrar la obsolescencia de tal estructura. La tesis de Panofsky presenta la perspectiva bajo la superación del pitagorismo sin nombrarlo directamente. Toma como base del carácter científico del método perspectivo la asunción del espacio euclídeo. $Y$ es en este punto donde Giedion concentra su critica a la perspectiva: "El espacio tridimensional del Renacimiento es el espacio de la geometría euclidiana. Pero en torno al 1830 fue creada una nueva geometría que difería de la de Euclides por su empleo de más de tres dimensiones. Tales geometrías han continuado evolucionando, hasta alcanzar una fase en la cual los matemáticos se ocupan de figuras que no pueden ser concebidas por medio de la imaginación" ${ }^{83}$

Giedion se refiere a Gauss, Lobatchevsky, Bolyai (hijo), y sobre

82 Erwin Panofsky, "La Perspectiva como Forma Simbólica". La edición original en alemán es de 1927, y hasta 1991 no hubo edición en lengua inglesa, lo que da idea de lo poco receptivo del ambiente en el tema de la perspectiva.

83 Sigfried Giedion, "Espacio, Tiempo y Arquitectura", p. 454 


\section{LÁMINA III.5}

“El Economist Building (1959-1964) es un pequeño cluster que engloba varios edificios sobre una infraestructura común..."

Alison Smithson, Peter Smithson "Economist Building", 1959-1964

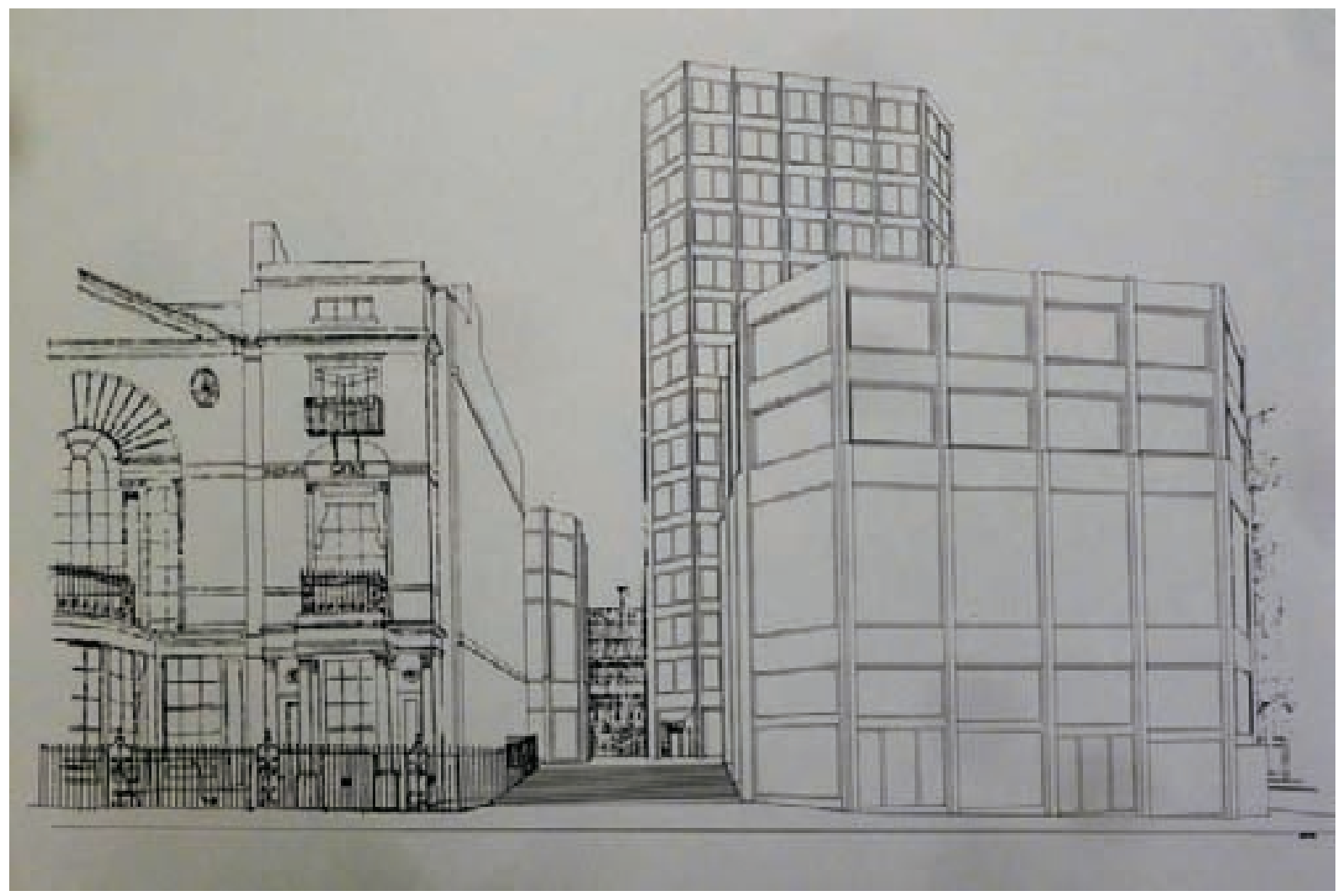

Ronald T. Simpson, "Vista perspectiva desde St. James Street", Original 1959. Fuente: Archivo Alison \& Peter Smithson Archive, Loeb Library, Harvard. Según consta en la ficha el dibujo original es modificado en 1980 para mostrar la puerta de acceso en la cara norte de la Torre de Oficinas. 


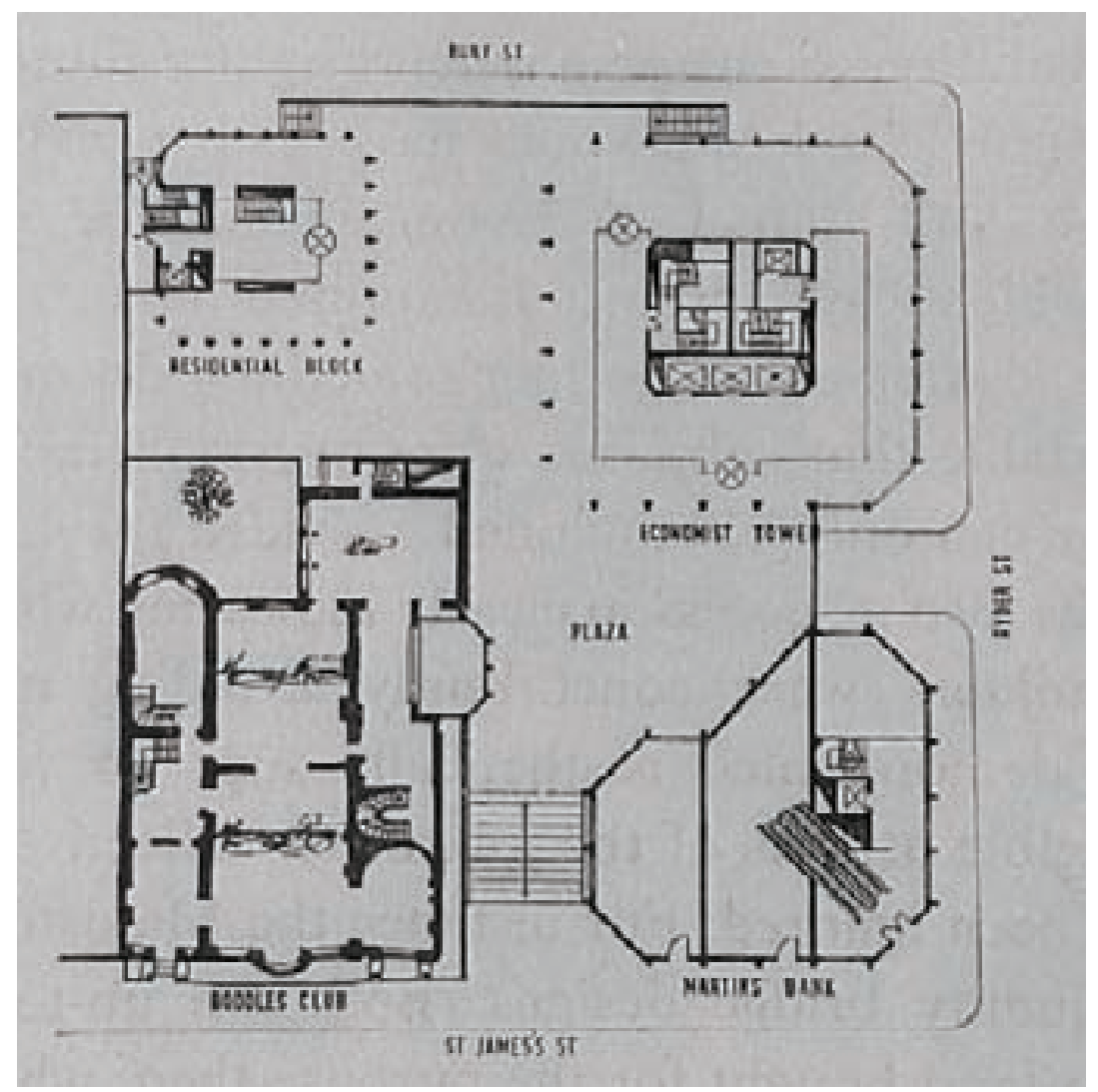

Alison Smithson, Peter Smithson "Economist Building", 1959-1964. Planta 10 solución. Fuente: "The Architectural Review", Diciembre 1961, p. 229. Obsérvese la forma de "pera" inicial del Edificio del Banco.

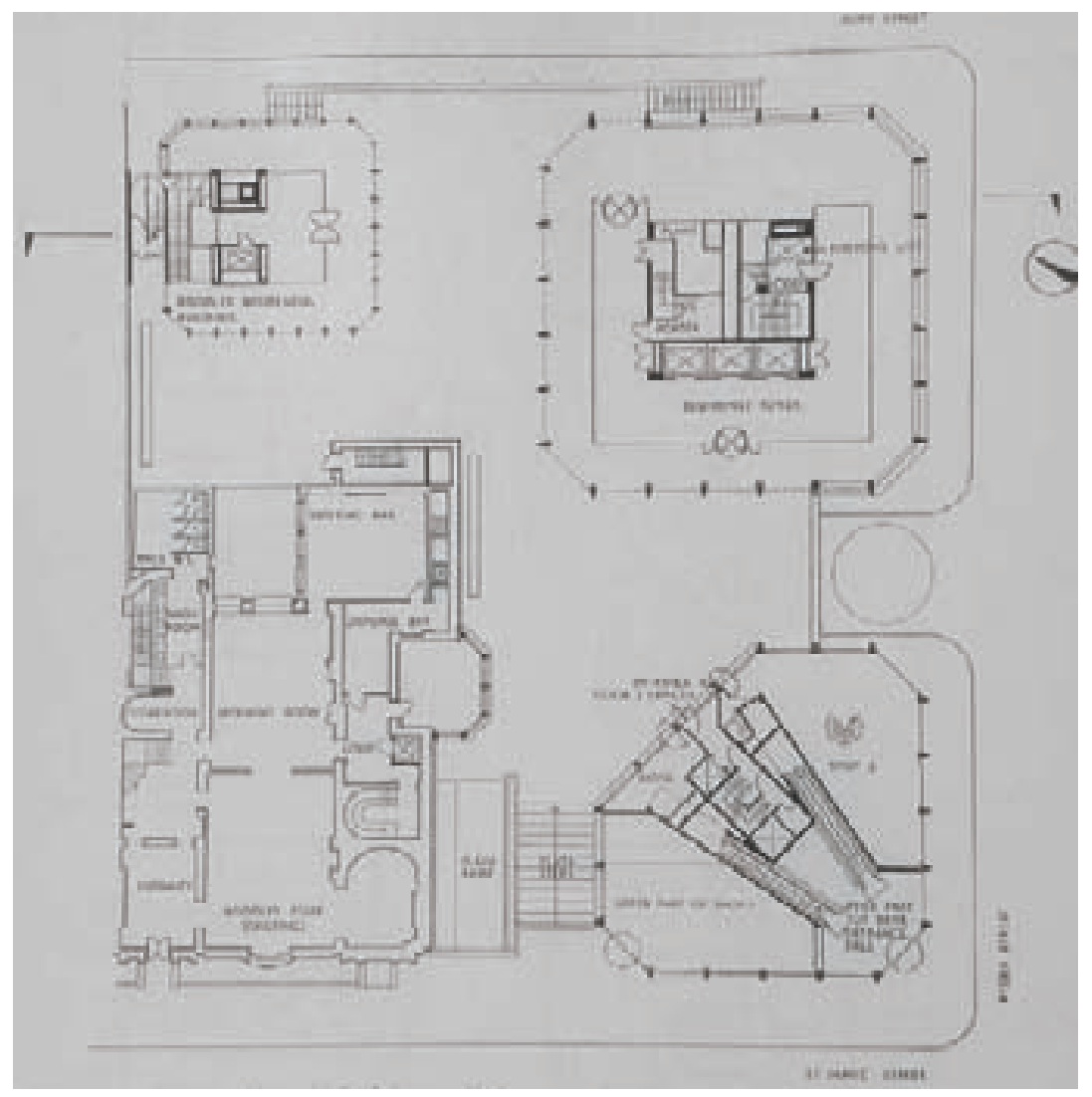

Alison Smithson, Peter Smithson “Economist Building”, 1959-1964. Planta solución definitiva. Fuente: "The Architects'Journal Information Library", 16 Diciembre 1964, p. 1450 


\section{LÁMINA III.6}

“Puede verse en la portada de Baumeister de qué manera la acumulación de diagonales en este edificio (el banco) están a punto de echar a perder la unidad del conjunto..."

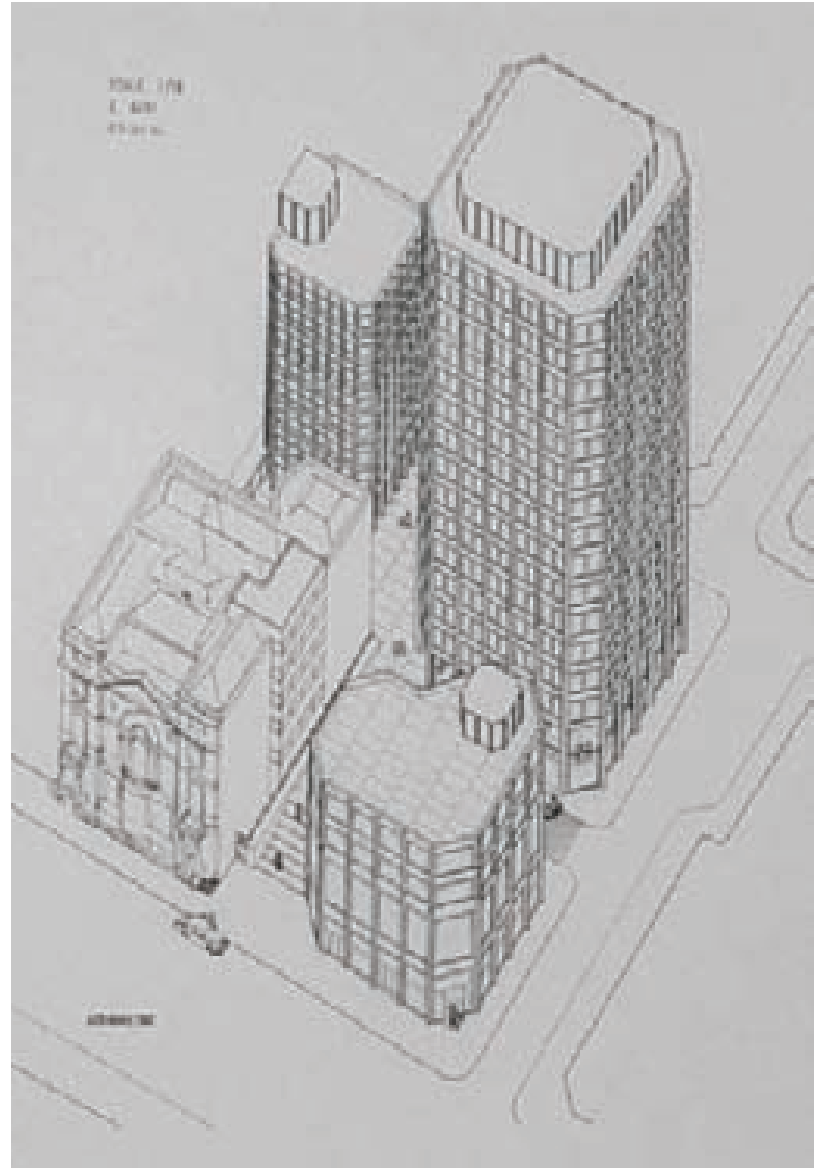

Alison Smithson, Peter Smithson "Economist Building", 1959-1964. Primera solución. Axonométrica

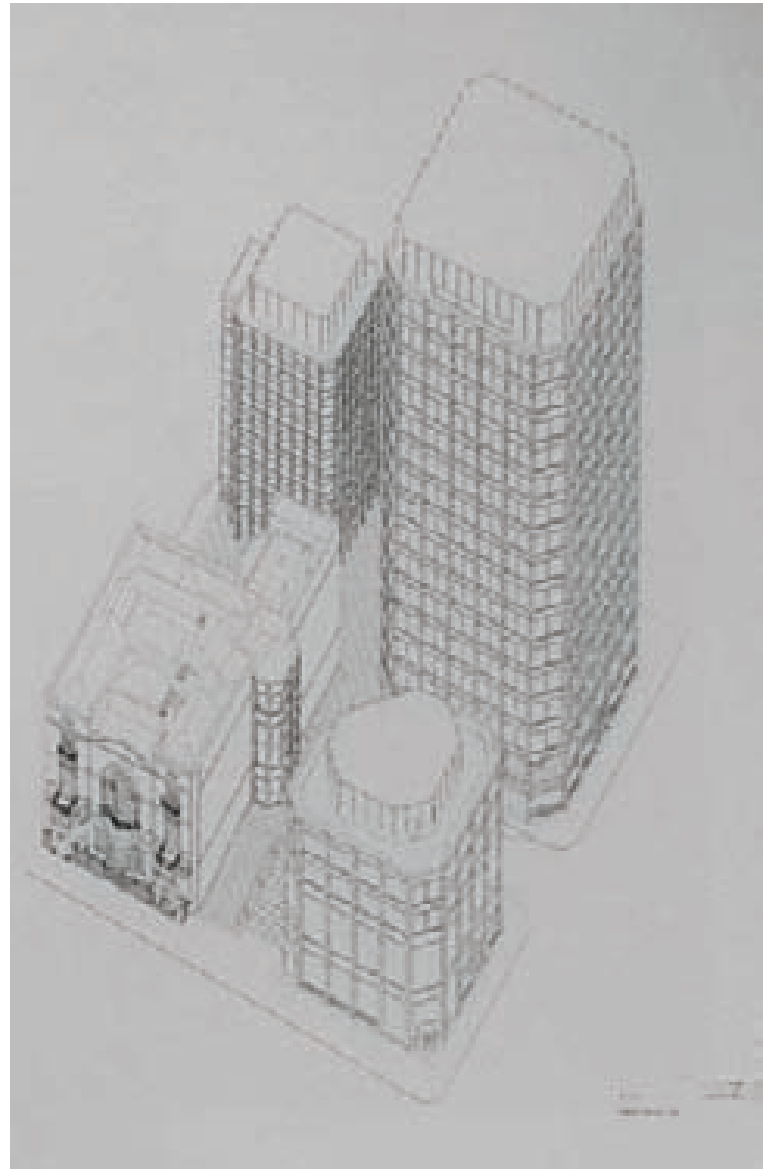

Alison Smithson, Peter Smithson "Economist Building", 1959-1964. Solución definitiva. Axonométrica 


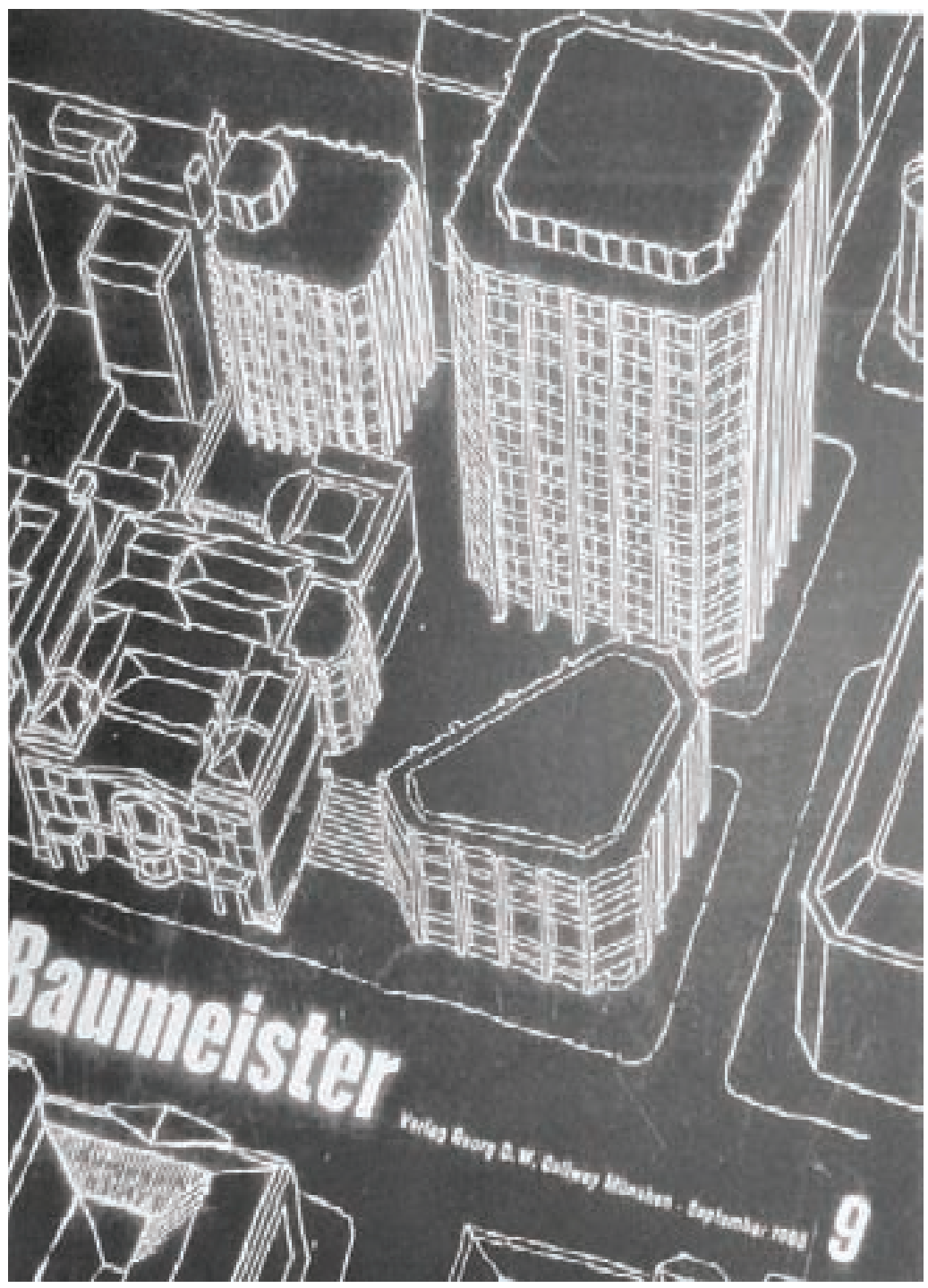

Alison Smithson, Peter Smithson "Economist Building", 1959-1964. Revista "Baumeister", no 9, Septiembre 1965, Portada. Obsérvese que el trazado del Edificio del Banco es una interpretación errónea, que no corresponde a ninguna de las dos soluciones. En este sentido, se interpreta que la operación de cortes diagonales de la primera solución provoca la dificultad de retener su verdadera figura. 


\section{LÁMINA III.7}

"Sin embargo, comparado con el complejo Westmount Square levantado por Mies van der Rohe, que contempla el mismo programa, habremos de admitir para el Economist, y no sólo a nivel de interpretación, sino en el propio planteamiento de los arquitectos, un conocimiento de ciertas propiedades de la aritmo-geometría..."

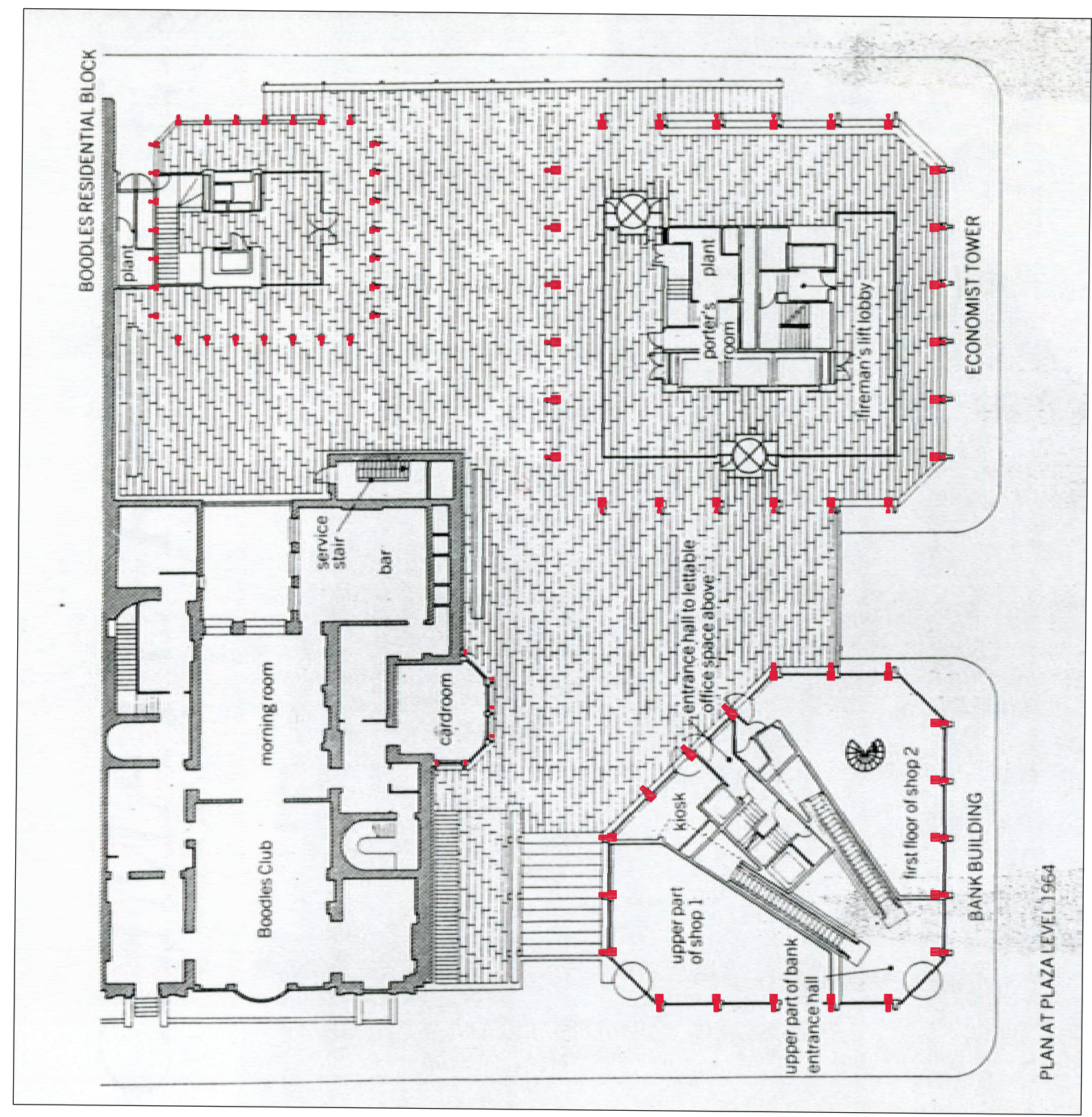

Alison Smithson, Peter Smithson “Economist Building”, 1959-1964.

Planta retocada por el autor para resaltar la estructura de pilares. 


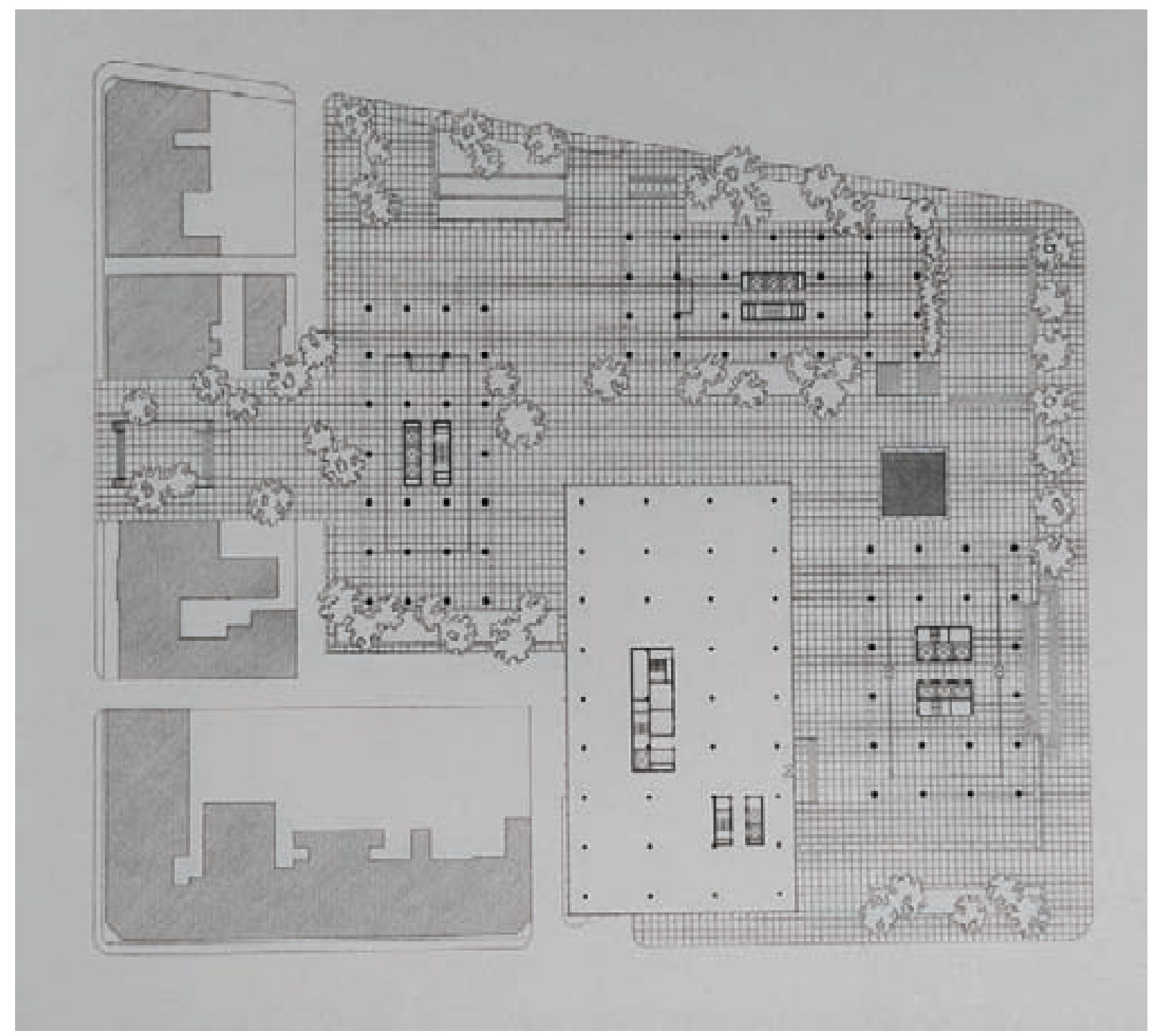

Mies van der Rohe "Westmount Square”, 1965-1968. 
todo a Riemann, para luego pasar a la topología. Pero a mi juicio, podemos acomodarnos un poco antes en el tiempo, para ver una disputa interesante entre Newton, Descartes y Leibniz, que, espero, nos oriente en la complejidad del método espacial que hemos columbrado en Sheffield.

\section{Empecemos por Panofsky.}

Para Panofsky, el descubrimiento de la perspectiva como método científico del Renacimiento, completamente desligado de los métodos de la óptica griega, pasa por desvincular del todo el espacio geométrico o espacio del conocimiento puro, del espacio de la percepción sensible. La manera de hacer del lienzo una estructura matemática integral requiere, como condición previa, eliminar del espacio visual toda acción que, partiendo del sujeto, tienda a ejercer sobre los objetos y fenómenos de la visión lazos afectivos o psicológicos propios de éste. Este es el requerimiento de espacio absoluto que defiende Panofsky como condición para el surgimiento de la perspectiva.

Vemos de entrada cómo el espacio, que en el pitagorismo estaba del lado del apeiron y participaba de lleno en las contradicciones de lo "otro", cobra aquí, con el espacio euclídeo, plena legalidad. Habíamos visto también, la llegada de la ciencia del continuo por medio del cambio de unidad del punto extenso por el segmento continuo. Tenemos aquí una renuncia más al pitagorismo, la renuncia a la afección o al tratamiento subjetivo que se mostraba en la Tabla de Opuestos. Este punto es interesante: los aspectos místicos de la ciencia pitagórica, aquellos que son consecuencia de una interpretación mágica de los poderes del número, y por los cuales quedaban jerarquizados en su mayor o menos perfección, se vuelven irrelevantes ante la nivelación axiológica que ejerce la estructura perspectiva sobre el espacio, las figuras, y en general, todo aquello que pudiera constituirse contrario a la objetivación.

Se ve claramente esta actitud en un pequeño pasaje de Galileo: "A decir verdad, en todos estos argumentos, yo no me siento obligado a conceder sino que lo que tiene principio, medio y fin, pueda y deba llamarse perfecto. Pero que, además, por el hecho de que $<<$ principio, medio y fin > son 3 , el número 3 sea perfecto y tenga que tener la facultad de conferir perfección a quien lo tenga, no siento que haya nada que me mueva a concederlo. $Y$ no entiendo ni creo que, v. g., para las piernas el número 3 sea más perfecto que el 4 o el 2; ni sé que el número 4 implique alguna imperfección para los elementos, y que sería más perfecto que fueran 3. Mejor es, por tanto, dejar esas vaguedades a los retóricos y que pruebe lo que pretende con demostraciones necesarias, que es lo que debe hacerse en las ciencias demostrativas." ${ }^{84}$

Algunas de las limitaciones que obligaban a tratar con determinados números enteros en la teoría de las proporciones caen también gracias a la ciencia perspectiva. Por ejemplo, quedaba establecida la relación entre los números 6,8 y 12 para llevar a cabo la relación armónica, al darse entre ellos la propiedad $(8-6) / 6=(12-8)$ / 12. Señalaba Wittkower al respecto: "tres términos están en relación

84 Galileo Galilei, "Diálogo sobre los dos máximos sistemas del mundo Ptolemaico y Copernicano", comentario puesto en boca de Filippo Salviati, p. 10. 
"armónica" cuando la distancia entre cada extremo y la media, dividida por el extremo respectivo es equivalente (es decir $(b-a) / a=$

$=(\mathrm{c}-\mathrm{b}) / \mathrm{c}) .{ }^{185}$ En definitiva, el modo armónico no permite partir de cualquier segmento con independencia de su medida, sino que obliga a comenzar por las magnitudes expresadas por la terna de los números anteriores. Por ejemplo, como expone Wittkower, Palladio ajusta la proporción entre los lados y la altura de una habitación a la relación $6 / 8$ / 12, y se "ciñe estrictamente a la vertiente práctica del métier, sin referirse en lo más mínimo a lo que verdaderamente significan estas proporciones... Estos tres tipos de proporciones (además de la armónica, la aritmética y la geométrica) se atribuyen tradicionalmente a Pitágoras, y sin ellos no puede imaginarse ninguna teoría racional de la proporción". ${ }^{86}$ Sin embargo, la demostración de las propiedades de dos triángulos proyectivos, expuesta por Desargues, permite deducir geométricamente la posición del punto interior para establecer la relación armónica entre los intervalos para cualquier longitud. ${ }^{87}$

Con esto no pretendo sino subrayar o enfatizar las dos posiciones tomadas por Wittkower y Panofsky ${ }^{88}$ en torno a una misma época (y considero, como se hace normalmente, la geometría proyectiva de Desargues una consolidación matemática de los expuesto por los pintores y arquitectos del s. XV y XVI). ${ }^{89}$

Por tanto, se puede establecer una diferencia substancial entre la consideración del Renacimiento bajo la óptica de Wittkower y la de Panofsky. Si el objeto que se encumbra de la posición del primero es

85 Rudolf Wittkower "Los Fundamentos de la Arquitectura en la Edad del Humanismo", p. 153

86 Ibíd. p. 152

87 Girard Desargues "Le Brouillon project", 1639. Véase al respecto, Clémence Ronze-Daviron, "Les travaux scientifiques de Girard Desargues" en Marie-Anne Privat-Savigny, "Philibert de I'Orme, Girard Desargues, de I'architecture classique aux enjeux urbanistiques contemporains", pp. 51 y 52 . Téngase en cuenta que la distancia temporal entre la muerte de Palladio, 1580 y el "Le Brouillon project" es sólo de 59 años.

88 La presencia de Wittkower y la ausencia de Panofsky, que declinó la invitación, en el Congreso De Divina Proportione, celebrado en Milán entre el 27 y el 29 de Septiembre de 1951, adquiere relevancia en este contexto. La ausencia de Panofsky de un congreso tan alabado por Voelcker y Smithsons, me refuerza a mantener mi tentativa de enfrentamiento entre las posturas de estos dos historiadores. Sobre el Congreso y su participación, véase el artículo de Daniele Pisan, " $\mathrm{L}^{\prime}<<$ armonia di una civiltá macchinista >: un binario morto >. II convengo De Divina Proportione alla IX Triennale di Milano del 1951", en la revista "Engramma", no 70, Marzo 2009.

89 La diferencia que se establece entre perspectividad y proyectividad alude al desplazamiento del vértice del haz proyectivo. Por tanto, cabe ver en el desarrollo potencial del método de la perspectiva hacia el método proyectivo la superación de la necesidad de establecer un único punto de vista, paliando en gran medida la disonancia entre la objetividad del espacio de referencia y la subjetividad debida a la elección del punto único, que era, como era de esperar, el argumento principal de los ataques a la perspectiva en el ámbito de la pintura. Mediante la secuencia de proyecciones y secciones de la proyectividad, queda salvado el segundo escollo que incidía en el método perspectivo, su estatismo. Por último, aquello que la perspectiva de los siglos XIV y XV estaba manejando, pero probablemente sin tener plena conciencia de ello, que era asociar el punto de corte del rayo céntrico con el plano del lienzo, punto de inclinación del haz de rectas perpendiculares al plano, con la noción de infinito, adquiere en el s. XVII, en la obra de Desargues, su incorporación definitiva. Véase a este respecto, Panofsky, "La Perspectiva como Forma Simbólica", p. 54 
el empleo de los trazados reguladores y una suerte de querencia por lo Limitado y lo Definido, cuyo origen, lejano, está en la división de valores de la ciencia pitagórica transportados hasta el Renacimiento, el objeto de interés del libro de Panofsky, por incierto que pueda ser para los arquitectos, es seguro que, en este terreno, cae del lado opuesto: "mediante esta peculiar transposición de la objetividad artística en el campo fenoménico, la concepción perspectiva impide el acceso del arte religioso al reino de lo mágico,..., y al reino de lo simbólico dogmático...le impide, como algo absolutamente nuevo, el acceso al reino de lo visonario..."

La cuestión que nos ocupa es, si en la objetivación del espacio que defiende Panofsky, no hay cabida al empleo místico del número, ¿qué sería entonces aquello que vendría sustituirlo? No está clara la respuesta a este interrogante. La "Perspectiva como Forma Simbólica" no trata de arquitectura, y los edificios, la iglesias de planta central y las villas de Palladio, han adquirido una consistencia nueva bajo la mirada de Wittkower, extrayendo sus fundamentos y presentándolos como principios comprensibles, constituyendo un cuerpo de leyes que se pueden desarrollar con tal de que la investigación arquitectónica se vuelque sobre ellos y tome como ejemplo la postura mantenida por Le Corbusier. $Y$ esto es en efecto lo que aconteció durante los primeros cincuenta.

Por tanto, del lado contrario sólo cabe conjeturar el sentido que podía tener una construcción perspectiva para la arquitectura, dado que, por otra parte, el espacio euclídeo ya estaba plenamente consolidado como espacio de referencia de la arquitectura moderna.

En este sentido hay que destacar la función de la geometría proyectiva en dos ámbitos tremendamente prácticos: la estereotomía y la arquitectura militar.

En lo referente a la estereotomía se citan la teoría proyectiva con un método que servía entre otras cosas, para actualizar antiguas estructuras. Es interesante considerar a este respecto un ejemplo, aunque anterior en el tiempo a Desargues, sin embargo suficientemente ilustrativo de una operación de renovación mediante la estereotomía. Es el caso de una intervención de Philibert l'Orme en una antigua fortaleza. Señala Jean Marie Pérouse de Montclos: "Los artificios estereométricos más diversos permiten completar el castillo que en origen comprendía los baluartes A y B. La estereotomía es presentada de esta manera por Delorme como el medio para pasar del viejo mundo gótico a un nuevo mundo $<<$ regular $>>^{\prime \prime 1}$. La idea que rige en este caso el uso de la estereotomía es aportar a una estructura existente el grado de compleción necesario para dotarla de los rasgos simétricos o regulares propiamente modernos. "En efecto, el castillo está lleno de artificios estereométricos, trompas, (...), compartimentos en esquina, compartimentos en ángulo entre una cortina y el camino de ronda. De este modo el tratado aparece tanto como una astucia para hacer nuevo lo viejo, como la piedra angular que permite la mutación de la Edad Media caduca en el Renacimiento"

90 Erwin Panofsky, "La Perspectiva como Forma Simbólica”, pp. 55 y 56

91 Jean-Marie Pérouse de Montclos "L’Architecture a la Française. XVle, XVIIe, XVIII siécles", p.93

92 Ibíd. 
LÁMINA III.8

LÁMINA III.9
No creo necesario, insistir, en este sentido, en lo cercano de la propuesta de l'Orme, duplicando volúmenes e insertando elementos de conexión puntuales para transformar un antiguo edificio en una estructura completa en sí misma, con lo ejercido en Sheffield por los Smithson sobre la fábrica del antiguo Firth Court. Tanto en una caso como en otro se producen los estiramientos adecuados $y$, por qué no, estereométricos, si la palabra es conveniente, para, de alguna manera, sentir que se modifican simultáneamente lo existente con la ampliación, agrupados, entonces, en una nueva unidad que trasciende el significado por separado de ambos.

Ahora bien, si esto no deja de ser una caso práctico de sensibilidad personal de un arquitecto, la estereotomía admite una generalización nueva al quedar envuelta por la teoría geométrica de Desargues. Es sabido que Desargues elevó, en su condición de arquitecto, la práctica del corte de la piedra a casos ejemplares de aplicación de transformaciones proyectivas, fundamentalmente de las cónicas. Pero, en este sentido, no es en su condición de geometría descriptiva como enseñanza reglada que nos interesa incluir la geometría proyectiva, sino la propia figura de Desargues como introductor de determinadas transformaciones entre figuras, traspasando así el alcance que se tenía de la geometría euclídea ${ }^{93}$.

En la geometría euclídea, "una transformación del plano en la cual se conservan invariables las distancias se llama una congruencia. En una congruencia el plano se comporta por así decirlo como un cuerpo sólido; cada figura se transforma en una congruente; las rectas en rectas y los círculos en círculos" ${ }^{\prime 4}$.

Por el contrario, para un espacio proyectivo: "si... acordásemos caracterizar la identidad de cada figura geométrica por sus propiedades, resultaría que dos figuras transformables entre sí por cualquier movimiento del grupo principal serían idénticas. En relación a un determinado grupo, el proyectivo, figuras visualmente diferentes, como la elipse, la parábola y la hipérbola, son una misma figura" ${ }^{\prime 5}$

Es fácil imaginar un mundo de transformaciones posibles no contempladas en la geometría euclídea, ni en la anterior pitagórica. Una variación en la corriente de la teoría proporcional hacia la teoría de la perspectiva hubiera significado, por ejemplo una revalorización de determinadas propuestas englobadas bajo la Arquitectura Oblicua. En ésta se podían contemplar como una mejora proporcional determinadas deformaciones vetadas para la práctica convencional y en donde, por determinación de posición respecto al punto de vista, algunas figuras admitían su transformación sin por ello perder su identidad. Tal es el caso de las deformaciones en las secciones de los tambores de las columnas, que pasaban de circulares a elípticas en función de su posición dentro del conjunto de la fábrica y con respecto a la posición más favorable para situar al espectador. En este sentido, en lugar de una categorización esencialista de los elementos de la arquitectura, siempre formas idénticas a sí mismas, estaríamos hablando de familias o grupos de formas.

93 Señala en este sentido el autor anterior, que "el mismo Delorme se contentó con decir que su geometría viene de Euclides..." Ibíd. p. 184

94 Hans Freudenthal, "Las Matemáticas en la vida cotidiana", p. 222

95 Javier Echeverría, "La identidad de las Figuras Geométricas" en "Theoría. Revista de Teoría, Historia y Fundamentos de la Ciencia”, Año I, № I, 1985, p. 215 
Esto plantea una interesante cuestión. Como hemos expresado en el párrafo anterior, dependiendo de la geometría elegida, así será lo que el grupo de transformación permita hacer con la figura. Por continuar con el ejemplo de la sección del tambor de la columna, resulta que para una geometría como la euclidea, la figura que puede utilizarse para el tambor, un círculo, siempre ha de ser un círculo, dado, que por desplazamiento de posición, en esta geometría han de considerarse congruentes sólo aquellas figuras que coincidan punto por punto cuando son superpuestas. Pero para el grupo de transformaciones de la geometría proyectiva la sección del tambor es una cónica. Pero es más, si en lugar del grupo de transformación proyectivo, estuviéramos en la geometría topológica, la familia de formas que pudieran constituir la sección del tambor de la columna sería cualquier curva cerrada, o un cuadrado o un rectángulo.

En segundo lugar el marco categorial por el que la esencia de la sección de tambor haya de ser exclusivamente un círculo queda subsumido dentro de un marco más general. Sólo será un círculo en función de determinada posición. Consideremos este pasaje de Cassirer: "No estamos obligados a probar la unidad substancial del hombre. Ya no se considera como una substancia simple que existe en sí misma y ha de ser conocida por sí misma. Su unidad se concibe como unidad funcional". A partir de tomar en consideración la geometría proyectiva, lo que va a poner en cuestión la Arquitectura Oblicua es precisamente que la esencia del tambor de la columna tenga que ser un círculo. El criterio de unidad substancial va a ser reemplazado por el de unidad funcional. Me interesa dejar claro que en el cambio de categorías hay una inversión de los valores. La sección de la columna será aquella entre las cónicas más adecuada a los factores que entren en juego, y entre ellos, el más sobresaliente, será la posición fijada para la observación del conjunto. No diremos que las columnas son de sección circular, sino que para una determinada posición de la columna y desde un determinado punto de vista tal columna es de sección circular. A partir de ahí, lo que habrá serán grados de circularidad o de excentricidad, que serán los parámetros comparativos de una columna con otras. La unidad de la columna vendrá dada en los términos de un conjunto de figuras posibles para el tipo de geometría considerado ${ }^{96}$.

En un marco de categorías como el de la historia del arte, la columna y la pilastra parecen corresponder a entidades de todo punto

96 En ningún autor encontramos una defensa más vehemente de las posibilidades de la Arquitectura Oblicua como en Juan de Caramuel Lobkowitz (1606-1682). Un contemporáneo como Tosca sigue atrapado en la certidumbre de asociar la columna a la circularidad: "el obispo Caramuel en el Tratado seis de su Arquitectura establece como cosa muy cierta e indubitable que las plantas de las columnas que en la arquitectura recta eran redondas en la oblicua han de degenerar en elípticas... pero no veo razón alguna que nos obligue ha admitir la sobredicha transformación de las columnas"(1). En otro pasaje insiste Tosca en lo mismo: "no hay necesidad de transformar la columna circular en elíptica porque al cuerpo circular es de la misma suerte adaptable la fábrica oblicua que la recta"(2). (1) y (2), Tomás Vicente Tosca, “Compendio matemático..." recogido en Francisco José León Tello y Ma Virginia Sanz Sanz, "Estética y Teoría de la Arquitectura en los Tratados Españoles del Siglo XVIII", p. 469 (1) y pp. 469 y 470 (2). Ahondando en el sentido plenamente discursivo de la teoría elaborada por Caramuel, es significativa la crítica lanzada contra él por Guarino Guarini, tachándola de "excesivo rigor intelectual y falta de experiencia constructiva". Véase Antonio Bonet Correa, epígrafe II-10, en Dora Wiebenson, "Los Tratados de Arquitectura: de Alberti a Ledoux", p. 108 
diferentes, y con precisión son tratados como objetos diferentes. Al tratar el problema del muro para saber en qué casos corresponde emplear la columna o la pilastra, la distinción emplaza a la columna a la categoría de ornamento y a la pilastra al de sustentación y por tanto, el problema se plantea en términos geométricos en la elección del círculo o del rectángulo. Considerando ahora una inversión de los términos, la circularidad y la rectangularidad en lugar de referirnos a ellas como propiedades, serán funciones en espera de concreción, que se aplican sobre argumentos que serán ornamentales o sustentantes. No diremos que las categorías ornamentales o sustentantes se definen por sus formas circulares (columnas) o rectangulares (pilastras), sino que tales o cuales aplicaciones en casos concretos de la ornamentación o la sustentación son mediante columnas o pilastras. Se desaloja así cualquier tentativa de definición conceptual que se quiera adjudicar a éstas y aquellas, quedando emplazada su valoración al cruce de casos concretos. El problema conceptual que parece traspasar Wittkower a Alberti, en lo que define como un proceso de maduración del lenguaje de éste al abandonar progresivamente un tratamiento clásico de la columna adosada al muro y sustituirlo por un empleo lógico de la pilastra, puede auscultarse de este otro modo, si nos atenemos a que Alberti no define la pilastra sino como columnae rectangulae, dado que es en el término <<columna > donde recae la categoría de belleza o sustentación, siendo lo rectangular o circular de su sección sus diferencias específicas. En los casos extremos a los que se refiere Wittkower de las fachadas de San Francesco de Rímini o de San Andrea de Mantua tanto la columna como la pilastra en un caso y otro asumen los mismos roles ornamentales, y seguramente será tan nula su función estructural tanto en un caso como en el otro. Que convenga una u otra habrá de ser entendido en la manera y grado que satisfagan ambas funciones su argumento ornamental.

Generalizando al contexto de los principios proporcionales, el sentido que toma la aplicación de una lógica proposicional, en lugar del marco categorial aristotélico o esencialista, constituye el reverso de la teoría jerárquica de la buena proporción. En lugar de intemporalizar los atributos de buena proporción como algo exigible al conjunto del edificio, bajo este marco perspectivo y aplicando las oportunas transformaciones, la buena o mala proporción, será analizada bajo criterios de proximidad o lejanía al espectador, y sobre partes individualizadas del conjunto. En efecto, la buena proporción no sería un atributo, predicado o propiedad de la belleza del edificio que entre en su definición, sino una función que toma sus valores de partes o elementos muy concretos del edificio, y cuyo objetivo sería resaltar el conjunto, pero desde tal o cual momento, situación o posición que adoptara el espectador.

Se entenderá fácilmente la diferencia entre considerar

\author{
LÁMINA III.11
}

un trazado regulador para el ámbito del plano euclideo que bajo una perspectiva. Desde los orígenes de la arquitectura perspectiva renacentista la buena proporción conllevaba deformaciones proporcionales requeridas para la correcta visualización de determinadas piezas de singular importancia, que contradecían en buena medida la buena proporción obtenida por el método del trazado regulador general. Incluso en fábricas que uno imagina sometidas a los más férreos controles proporcionales como en el Tempieto di S. Pietro in Montorio de Bramante, como nos muestra Arnaldo Bruschi, "el edificio está todo él <<deformado>> perspectivamente en función del observador; la proporción $<<$ musical $>>$ albertiana pierde todos 
sus valores metafísicos al pasar de la bidimensionalidad del papel y de la superficie muraria a la tridimensionalidad perspectiva ofrecida por la implantación curvilínea de Bramante, que deviene en servicial instrumento de control de una imagen" ${ }^{\prime 27}$.

Ejemplos todavía más significativos de deformaciones aplicadas a proporciones vienen de la mano del barroco. Dentro del marco de las oportunidades que ofrece la ciencia perspectiva, la galería o columnata del Palacio Spada de Borromini muestra de que manera la alteración de la proporción, con la reducción progresiva del tamaño de las columnas, entablamentos, intercolumnios, inclinación del nivel de capiteles y frisos, disminución de los arcos fajones, inclinación y disminución de la bóveda de cañón, hacen de cada elemento de la arquitectura un parámetro insaturado, que precisa de las coordenadas de su posición en el conjunto para alcanzar su valor como objeto de construcción. No constituyen por tanto objetos en sí, sino formas en espera de concreción. En el caso del Palacio Spada, la buena proporción sólo puede alcanzarse tras analizar la posición más ventajosa del espectador, con el fin de que, a través de la contemplación de la galería, la sensación de estrechez del espacio real queda compensada. Como señala Argan, "la perspectiva de Borromini, aunque desarrollada en el filo de la más rigurosa lógica geométrica, tiende a contraer, o directamente a anular, el espacio...sustituye el espacio real por el fantástico" ${ }^{\prime 98}$.

El ámbito de desarrollo propio de la Arquitectura Oblicua son los corredores y las escaleras, donde se produce el contraste entre la inclinación del suelo y la vertical, con ejemplos como la Scala Regia o los corredores laterales de San Pedro de Bernini. Este tipo de ejercicios marcadamente perspectivos sobrepasa en intención la mera direccionalidad de los ejes para hacerlos partícipes de las deformaciones a que les someten las inclinaciones y cambios de plano ${ }^{99}$. Hay una proliferación de éstos en el Barroco. No vamos a tratar más. Donde quiero llamar la atención es en las posibilidades que entraña seguir uno $u$ otro camino en la actualización de un periodo como el Renacimiento, donde parecen disputarse dos septentriones la teoría y práctica de la arquitectura. Un norte, efectivo, reglado, el de Wittkower, y otro, posible, indefinido, el de Panofsky. Posibilidades no resueltas en Sheffield, pero sí apuntadas, de una inclinación o escalonamiento de los bloques que conforman la ampliación y el eje. Posibilidades que remiten a Sheffield a una arquitectura fundamentalmente de corredores. Posibilidades que hacen resurgir en casos concretos la Arquitectura Oblicua, como el Pabellón del Grupo 2 presentado a la exposición This is Tomorrow, y que obran con total discrecionalidad frente las reglas estrictas de la proporción y que son incluso obras llevadas a cabo por sus propios defensores, como es el caso de John Voelcker (en colaboración con Hamilton y McHale) ${ }^{100}$.

97 Arnaldo Bruschi, "Bramante", p. 206

98 Giulio Carlo Argan, "Borromini”, p. 93

99 "La arquitectura oblicua edifica sus fábricas sobre suelos inclinados o en pasadizos y puertas que corren en viaje o en templos redondos o elípticos", Tomás Vicente Tosca, "Compendio matemático..." recogido en Francisco José León Tello y Mạ Virginia Sanz Sanz, op. cit. p. 469

100 Exposición This is Tomorrow, en la Whitechapel Gallery de Londres, entre el 9 de Agosto y el 9 de Septiembre de 1956. Véase al respecto los números de Septiembre y Noviembre de Architectural Review y de Septiembre y Octubre de Architectural Design de 1956. 
Pero, efectivamente en los primeros cincuenta, sólo uno de los caminos es el dominante. Habrá que esperar a los sesenta, con la teoría de la complejidad y contradicción de Venturi y la teoría del tipo de Rossi, cuando se reoriente el sentido del objeto de arquitectura.

Pero donde se ven mejor las cosas del espacio es a veces en textos de fuera de la profesión. Athusser, en un ensayo sobre Maquiavelo ${ }^{101}$, distingue dos tipos de espacio, que bajo nuestra mirada, ya enfocada o deformada hacia estos temas, se readaptan convenientemente a nuestro contexto. Sin entrar a considerar la cuestión qué ocupa a Althusser, éste distingue un espacio de la teoría y un espacio de la práctica. Dice del espacio de la teoría que no tiene sujeto, mientras que el segundo, "no tiene sentido más que por su sujeto, posible o necesario"102. Pero acto seguido, elimina la noción de sujeto, y lo recambia por contextura, fuerzas opuestas y entremezcladas y lo que es significativo, sólo tiene sentido si deja o procura un lugar vacío. De tal manera, que termina por distinguir un espacio del otro por medio de la existencia de ese lugar vacío. Si uno aventura a poner en paralelo esta doble noción de espacio, con el marco funcional que hemos venido proponiendo para la arquitectura perspectiva, habremos de convenir, que el espacio de la práctica es la expresión espacial de la noción de función insaturada que arrastramos. Mientras que, por otra parte, el espacio de la teoría, espacio objetual, es un espacio lleno o saturado. Esta cualidad nos permite encajar en este segundo tipo el modelo de edificio que adoptan los seguidores de Wittkower. El edificio objeto, que debe a alguna de sus longitudes el descubrimiento de todas las demás, cuyo rasgo principal esta en que su comprensión viene formulada por sus propia legalidad interna que es la que dirime sus límites de altura, anchura y profundidad y por algunas razones externas invariantes que dan medida a las partes y a los elementos, sin variación entre unos edificios y otros, toma su definición bajo un marco de proposiciones teóricas, que no necesitan de mayor validación, dado que se resuelven en su mismo plano lógico ideal. Pero por otra parte, el espacio euclideo, base del espacio perspectivo, también resulta ser un espacio de la pura teoría. En este contexto renacentista, también, cómo no, el de Maquiavelo, es como si Althusser, sobre la misma dualidad en la que estamos trabajando, decidiera esbozar la teoría pura como un apéndice del Neoplatonismo. En su continuidad y homogeneidad, en su invarianza no hay sede de fuerzas ni tensiones ni deja huecos en él. Es un espacio dado a la pura intelección. Y de este espacio euclídeo, nace, o como si dijéramos, se expulsa el espacio perspectivo. Espacio, tomémoslo así, que nace carente de concreción. Para Althusser, el espacio de la práctica (política) que surge del análisis del espacio teórico (teoría de la política), se vuelve diferente en tanto su modalidad es la de "<<estar a la orden del día >>...modificado... por la existencia de este lugar vacío, de este sitio por llenar, que debe ocupar el <<sujeto >> de la práctica política, Príncipe o partido" ${ }^{103}$. Se distinguen dos partes en el espacio de la práctica, su parte invariante, que en el caso que toca Athusser es la coyuntura de la Italia del XVI, su lengua común, su pobreza, su fraccionamiento etc., y un hueco que precisa ser llenado por un sujeto, o por una categoría. Se comprende que el espacio de la práctica es un espacio que necesita de validarse en el momento que adquiera un contenido a diferencia del espacio de la teoría, que como hemos

101 Louis Althusser, "Maquiavelo y nosotros"

102 Ibíd., p. 57

103 Ibíd., p. 58 
dicho, esta exento de este trámite. La arquitectura perspectiva toma del espacio euclídeo el análisis, debe a él su facultad de ser científico, pero precisa para completarse de la elección de una posición, de un sujeto posicional, o una categoría, para poder desarrollar su contenido. Más adelante precisa Althusser, que el espacio de la práctica no tiene un solo vacío sino que éste es doble, uno, el que ocupa el Príncipe invocado y otro, que abre para alojar su propio punto de vista, como dice Althusser, un lugar para introducir su texto, "El Principe", "tomado como texto activo o manifiesto, literatura ideológica y política que se posiciona y toma partido" ${ }^{104}$. ¿No nos habíamos encontrado antes la misma dualidad de posiciones que ofrecían la práctica proyectiva de la Arquitectura Oblicua? Una posición para la columna, que admitíamos no era sino un grupo de cónicas posibles para la geometría proyectiva, que necesitaba de dos concreciones, una su posición en el conjunto y otra proveniente del punto de vista más favorable del espectador. ¿No hay en Althusser una utilización, y no como él mismo dice, de un espacio topológico, sino perspectivo? ¿No resulta de la posición de Maquiavelo el punto de vista elegido, y el Príncipe, no se concreta en un sujeto-forma en el instante que se posiciona en las coordenadas del lugar vacío? E inversamente, tras Althusser, ¿no conviene al método proporcional el papel sublimado de la pura teoría, el espacio homogeneizado y a la perspectiva el papel de la práctica, el espacio completado y singularizado por la ocasión, la coyuntura, el lugar o la conveniencia?

Otra rama de una arquitectura perspectiva es el trazado militar de las fortificaciones. El interés de Alison y Peter Smithson por asuntos relacionados con el territorio y la imagen de las líneas defensivas o por amurallar recintos es inusitado entre los arquitectos, a excepción, en todo caso, de Ralph Erskine.

Alison y Peter Smithson dejaron algunos artículos sobre el tema, y de lo expuesto en ellos, además de asuntos concernientes a los sistemas defensivos griego y romano, habría que destacar la figura de Francesco di Giorgio.

En un artículo redactado para el ILA\&UD"105, "Three generations"106 (1981) Peter Smithson establece una concordancia entre tres generaciones de arquitectos del s. XV con otras tres del s. XX. Los arquitectos del XV representativos son Brunelleschi (1377-1446), Alberti (1404-1472) y Francesco de Giorgio (1439-1501). Cada uno de ellos perteneciente a una generación. Peter Smithon tenía realmente interés en que fuera Francesco di Giorgio y no otro el que se erigiera como representante de la Tercera Generación de arquitectos del Quattrocento ${ }^{107}$, para hacerlo concordar con la suya propia.

104 Ibíd., p. 60

105 ILA\&UD, International Laboratory of Architecture and Urban Design, fundado y dirigido por Giancarlo De Carlo, con sede en Urbino entre 1976-81 y 1992-93.

106 Peter Smithson, "Three Generations”, en ILA\&UD Annual Report 1980, Urbino, 1981

107 Según relata Beatriz Colomina, antecedía al articulo una conferencia dada por Peter Smithson en Harvard en 1976. Para el cartel anunciador, que se preparó por un estudiante basado en el tema que le expuso Smithson telefónicamente, aquél eligió como obra de la Tercera Generación San Pedro de Roma dado por las trazas de Bramante. A pesar, como dice Colomina, que Bramante había nacido sólo cinco años después de di Giorgio, Peter Smithson mandó sustituirle por éste, aludiendo que Bramante pertenecía a una Cuarta Generación. Beatriz Colomina, "Couplings" en "Oase", no 51, 1991, p. 28 
La teoría de Francesco de Giorgio sobre las iglesias de planta centralizada había sido recogida ya por Wittkower en "Los Fundamentos de la Arquitectura en la Edad de Humanismo" y por tanto su figura no era desconocida para los Smithson en los cincuenta. Sin embargo, Wittkower ya tenía algún problema con el método proporcional de di Giorgio para encajarlo del lado de la proporción aritmética y pitagórica: "Allí donde Francesco de Giorgio sugiere el empleo de un esquema medieval, inconmensurable y geométrico para el diseño de una iglesia"108, aunque, según aprecia, "en realidad dicho esquema le conduce a un módulo racional"109. En cualquier caso, lo que no recogían las páginas de "Los Fundamentos de la Arquitectura en la Edad de Humanismo", eran alusiones a la arquitectura militar de di Giorgio. Sí se destacaba esta faceta en "Espacio, Tiempo y Arquitectura", donde Giedion decía de él que "era famoso como ingeniero militar"110. Incluso llegaba a proponer que "los bastiones en cuña que colocaban a los defensores en condición de enfilar de flanco la formación de tropas atacantes que de cualquier parte se aproximen, se suponen inventados por Francesco di Giorgio"111. Por tanto, la faceta como arquitecto militar de di Giorgio, era cuando menos tanto o más conocida que como tratadista, arquitecto eclesiástico, o inventor de ciudades ideales.

El artículo "Three generations" incluye tanto obra eclesial como militar. Y por ello es importante resaltar que, al unificar generacionalmente la obra de di Giorgio con la de los Smithson, en este artículo se puede advertir en algo concreto la desviación que ambas dos Terceras Generaciones mantienen ante los postulados de Alberti, usados como proa contra los argumentos de Wittkower. Reflejan este sentido las palabras de Peter Smithson cuando escribe que "Giancarlo De Carlo siempre dice que vemos (los Smithson) en la arquitectura de di Giorgio una "deformación tipológica: por ejemplo, la proporción ideal de la esquemática sección de San Bernardino no es seguida en el edificio real. Pero, la realidad es al mismo tiempo "perfecta", y ha descendido sin interrupción de la geometría ideal de los fundadores de la segunda generación -esto es, de Alberti. Pero ha habido un cambioel manejo de las mismas formas por parte de di Giorgio es menos estricto, más adaptado al terreno y las construcciones existentes; aún retienen las resonancias de aquellas viejas geometrías puestas en acción"112.

Esto supone considerar un distanciamiento de di Giorgio frente a Alberti, o en términos más amplios de una generación con otra, en tanto que su arquitectura, más allá de incluir coyunturas preexistentes y topográficas, vendría a establecer por derecho propio un espacio de la práctica distinto del espacio de la teoría albertiano -como hemos expuesto anteriormente-, y al que se le podría exigir la misma coherencia o perfección que al otro, dado que no hay tomarlo como sucedáneo que se limita a poner en práctica la doctrina del espacio teórico, sino que constituye en sí mismo una alternativa a

108 Rudolf Wittkower, "Los Fundamentos de la Arquitectura en la Edad del Humanismo", p. 202

109 Ibíd.

110 Sigfried Giedion, "Espacio, Tiempo y Arquitectura”, p. 53

111 Ibíd., p. 45, nota a pie de ilustración no 6

112 Peter Smithson, "Three Generations", en ILA\&UD Annual Report 1980, Urbino, 1981, recogido en "Oase", no 51, 1991, p. 89 
éste. Aquí es donde parece rozar el argumento de Wittkower, y, sobre todo, donde se encuadra por alusiones, a su vez, la posición de los Smithson. Adquiere así el audaz ejercicio doblemente comparativo efectuado por Peter Smithson, una lectura bifocal, no sólo porque los Smithson se distancian efectivamente de su generación anterior, la de los Prouvé, Sert o Eames, y de la primera del Movimiento Moderno, Le Corbusier, Gropius, o Mies, sino porque lo hacen también, al asociarse a di Giorgio, y esto es lo que más me interesa, de la figura de Alberti y la teoría proporcional, que se habían colado, alcanzado una segunda existencia en su época.

Pero, y esto también es relevante, la arquitectura eclesial de di Giorgio no es substancialmente distinta de la arquitectura militar. Esta observación la hace Peter Smithson en otro artículo para el ILA\&UD, llamativamente titulado "Fortifications": "Con él (Francesco di Giorgio) el lenguaje tanto de la arquitectura sacra como de la militar es más o menos el mismo"113.

Por eso la arquitectura militar y religiosa son como apéndices de un mismo modo de concebir la arquitectura; lo dicho sobre una hay que validarla para la otra. Pero la arquitectura militar antecede estéticamente a la religiosa. Según Peter Smithson: "la estética de las bombas de rebote entra con Francesco di Giorgio"114

Otra estética y otra geometría entran a través de la arquitectura militar. Y la cuestión que buscamos, ¿cuál es la estética o la geometría de las bombas de rebote?

Según parece este tipo de bombas se utilizaba al cargar los cañones con poca pólvora, "generando una bala que salta y rebota destruyendo imprevistamente cuanto encuentra $<<$ sin permitir sosiego alguno a los defensores $>>^{\prime 115}$

Parece ser también que es invento de 1688 y de Vauban. No es esta una cuestión que debamos aquí resolver. Lo que interesa a nuestros efectos, es dirimir que diferencia de planteamiento y consecuencias hay entre una arquitectura que busca dentro de sí su sistema y, por decirlo de otra manera, constituye un sistema cerrado y otra que lo extrae de la interacción constante con cosas que se hallan fuera, y que es, por tanto un sistema abierto, que se reajusta permanentemente. El ejemplo de Vauban, quizá nos lleve mejor a interpretar esta diferencia.

Vauban ${ }^{116}$, en su doble condición de ingeniero militar, en calidad de Director general de fortificaciones y militar activo, primero como Brigadier de Infantería y más tarde ya como Mariscal de Francia,

113 Peter Smithson, "Fortifications", en ILA\&UD Annual Report 1998-99, Venecia, 1999, p. 56

114 Ibíd.

115 Ramón Gutiérrez y Cristina Esteras, “Territorio y Fortificación. Vauban, Fernández de Medrano, Ignacio Sala y Félix Prósperi. Influencia en España y América", p. 7

116 Sebastián Le Prestre, Marqués de Vauban (1633-1707) “Mariscal de Francia, y Director general de fortificaciones de aquel reino, compuso un Tratado del Ataque, y Defensa de las Plazas... dividido en dos partes, que la primera contiene el Ataque de las Plazas, y la segunda su Defensa..." Ignacio Sala, "Prólogo al Lector", en "Tratado de la Defensa de las Plazas que escribió Mr. De Vauban..." 1793, incluido en Ramón Gutiérrez y Cristina Esteras, "Territorio y Fortificación. Vauban, Fernández de Medrano, Ignacio Sala y Félix Prósperi. Influencia en España y América”, p. 268 
juega el doble papel de pertenecer al ejército atacante pero también, de ser defensor de plazas fuertes. En este sentido su peso histórico como renovador de los sistemas de fortificación lo debe a los propios adelantos que él mismo introduce en las técnicas de sitio y ataque. Es este proceso constante de compensación, en el que tan pronto está en un lado como en el otro de la batalla, lo que hace de la arquitectura militar de Vauban un ejercicio fluido en el que se suceden hasta tres sistemas que mejoran las maneras de contener o repeler una situación de agresión.

Observar esta interacción constante es lo que me interesa destacar. Señalan Ramón Gutiérrez y Cristina Esteras que "lo más notable fue que el propio Vauban colocó en crisis su (primer) sistema al desarrollar nuevas y brillantes técnicas de ataque... (y) fue así como los adelantos en el ataque planteados por Vauban exigieron una renovación profunda del sistema de defensa"117. Valga como sucinta muestra de esta readaptación constante, por ejemplo, de lado atacante, los sistemas de aproximación mediante trincheras autónomas en zigzag "que permiten acceder a las cortinas"118 y el replanteamiento de las defensas que "pronto comenzaron a desarrollar estrategias de cavar galerías de <<contraminas >>"119. O, el perfeccionamiento de la artillería mediante "el estudio de las potencialidades del fuego enfilado y las innovaciones del efecto de rebote"120 que desarrollan la defensa en profundidad del tercer sistema de Vauban, a través del "sistema de recinto externo y el de recinto de seguridad interno que es también abaluartado aunque con flancos más pequeños y con las torres y casamatas en los salientes"121.

Además de la fluidez que supone el ejercicio de readaptación constante en el estudio de la fortificación, el trazado y construcción de la fortificación obedece a leyes y a reglas que vienen desde fuera. Los parámetros de trazados cambian las proporciones aritméticas de los números enteros por proporciones angulares dictadas siempre por la regla de que "no debe existir ningún lugar del recinto de una fortificación que no pueda ser visto y defendido con fusiles"122, añadiendo que "el alcance de los fusiles es de 120 a 140 ó 150 toesas". Como es natural el resultado de aplicar una geometría angular variable a una construcción ofrece edificios que parecen deformaciones topológicas o "estados fluidos" de sus congéneres civiles, los palacios.

A este respecto, un criterio de idoneidad debido a la regularidad o irregularidad del trazado resulta irrelevante, como aprecia Vauban: "Una plaza es regular cuando sus líneas y ángulos respectivos son iguales entre sí y se encuentran a la misma distancia. De lo contrario, la plaza es irregular. No puede sin embargo considerarse peor, si todas

117 Ibíd., p. 6

118 Ibíd., pp. 14 y 15. Como señalan los autores:"La eficacia de Vauban en los sitios y el desarrollo de sus sistemas de avance de trincheras cambió la misma psicología del militar que de a poco dejó de considerar deshonroso el tomar la pala y cavar trincheras y galerías subterráneas en lugar de atacar a pecho descubierto", Ibíd.

119 Ibíd., p. 15

120 Ibíd.

121 Ibíd., p. 9

122 Mr. De Vauban, "El Verdadero Método para Fortificar", "Libro I", 1702, incluido en Ramón Gutiérrez y Cristina Esteras, "Territorio y Fortificación. Vauban, Fernández de Medrano, Ignacio Sala y Félix Prósperi. Influencia en España y América”, p. 164 
sus partes están protegidas con fusiles"123.

El tratado de fortificar de Vauban es el ejercicio de diseño completo de un sistema de fortificación, que contiene un sin fin de piezas y partes que adoptan nombres diferentes pero que remiten siempre a la figura compuesta por flanco, cortina y cara, verdadera unidad del sistema defensivo. Flanco, cortina y cara resuelven modificando su escala o complejizándose al desdoblarse, como en un fractal, todas las situaciones defensivas. La misma unidad funcional, que orientaba la adjudicación, dentro de la familia de las cónicas, de la circularidad o excentricidad para el tambor de la columna al introducir el argumento posicional en la Arquitectura Oblicua, es el criterio que gobierna el diseño de la fortificación. En efecto, la misma estructura $<<$ flanco, cortina y cara $>>$, con sus diferencias angulares y de tamaño, producto de introducir los valores de posición, y que engloba a su vez el análisis de toda una serie de situaciones variables, como la defensa activa o la protección de los soldados en caso de repliegue de la guarnición, permite aplicar a los sistemas de Vauban el criterio de no definición substancial de la estructura $<<f l a n c o$, cortina y cara $>$. Esto es, la forma no se toma aisladamente, sino que se establece en relación a los factores que intervienen en tal o cual posición, y como he expuesto, además deben estudiarse complementados en dos tipos de solicitación opuestas, como son la contención y el repliegue. Por tanto, más que una definición de la unidad, lo que tendería a eliminar toda la tensión inherente al cumplimiento de su delicada función, y que por tanto la cosificaría, impidiendo su evolución ante las nuevas técnicas de sitio y ataque, lo que cabe aplicar es un marco proposicional o relacional. Su forma, por tanto, no retiene más que los mínimos enlaces a priori entre los tres elementos <<flanco, cortina y cara $>$, siendo su ajuste angular definitivo pospuesto al momento de establecer la combinación con los otros términos o elementos defensivos, introducidos como los argumentos de la función. Introdúzcase este tipo de marco categorial en la distinción entre el espacio de la teoría y el de la práctica, que hemos expuesto anteriormente.

Podría esgrimirse su finalidad meramente funcional como una prueba suficiente para desalojar a la fortificación del marco de un planteamiento estético como el que rige en el trazado de la planta eclesial, de las villas o de los palacios renacentistas y barrocos. Podría pensarse que sus objetivos son otros, y que, por tanto, no ha lugar a tal inclusión dentro de los patrones elevados que rigen a la arquitectura. Pero no es así. El tratado militar renacentista está impregnado en los mismos valores eternos que guían a la arquitectura civil. Todavía en pleno siglo XVII en un puñado de tratados "Ios aspectos mágicos y naturalistas de la geometría fueron formulados como simples reminiscencias de las antiguas nociones del Renacimiento"124. Puede verse este aspecto en múltiples ejemplos. Citaré tres de ellos. L'Avertimenti e Regole de P.A. Barca (1620), "que recomienda la utilización de fortificaciones cuadradas, pentagonales o hexagonales ya que estas figuras eran los símbolos de la relación entre el cuerpo humano y el cosmos"125. O Jean Errard de Bar-le-Duc, en su tratado "La Fortification Démonstrée et Réduit en Art (1594), "que recomienda que el personal responsable de la fortificación o de la defensa de una ciudad no esté compuesto solamente de soldados experimentados,

123 lbíd., p. 165

124 Alberto Pérez Gómez, "L’Architecture et la Crise de la Science Moderne", p. 212

125 Ibíd. 
sino además de buenos geómetras.... así se comprende que el buen uso de la proporción puede preservar de gastos inútiles"126 (en relación al empleo del ángulo recto que propone Errard, véase la nota a pié de página no 76). O el tratado de Gabrielo Busca, L'Archittetura Militare, que cree en los rituales fundacionales heredados de la vieja tradición, considerándolos eficaces y necesarios en la fortificación: "estas ceremonias conducen a un trazado de caminos ortogonales, dividiendo la ciudad en cuatro partes, que corresponden a las partes del cielo, imitando así el orden cósmico" 127.

Por tanto, cabe ver en el tratado de Vauban un planteamiento tan distintivo, como el que anima a la arquitectura perspectiva respecto de la arquitectura proporcional. Vauban "estima que el arte de la fortificación no consiste en la aplicación de reglas o de sistemas geométricos conceptuales, sino que derivan de la experiencia y el buen sentido. La necesidad es que la realidad empírica y la inteligencia práctica pueden equilibrar las reglas geométricas"128.

Para comprobar esto, basta con ver en el tratado de Vauban, que la definición de los elementos no es autónoma, sino que está referida a los ángulos que forman entre sí, a su vez éstos en función del barrido y alcance de los fusiles y de la protección de los fusileros. Sólo para el trazado del baluarte, la conjunción de dos flancos y dos caras y su conexión con las cortinas, tenemos el ángulo de espalda, el ángulo de gola, el ángulo flanqueado, el ángulo del flanco, y el ángulo de tenaza. A su vez, la medida de las cortinas es función del alcance del fusil y su consideración depende de si entran o no como elementos activos de la defensa, en cuyo caso se considera una longitud del flanco rasante, que se ajusta por medio de la amplitud del ángulo entre la rasante y la fijante. En fin, toda una serie ajustes recíprocos obtenidos por el método de rasantes o tangencias a las caras, cuyas trazas "desaparecen una vez terminada la fortificación"129.

Con la referencia a la Arquitectura Oblicua y a la Fortificación he querido demostrar, no sólo la sustitución de un marco místico como el pitagórico por uno galileano o llamar la atención sobre las limitaciones interpretadas desde "Los Fundamentos de la Arquitectura en la Edad Humanismo". Ese era el objetivo de abrir las puertas a una arquitectura perspectiva o proyectiva, que genéricamente denomino "Panofsky", sin que bajo este término genérico haya que hacer coincidir estrictamente lo expuesto en estas páginas con lo esgrimido

\section{LÁMINA III.16}

por este historiador. La idea, como cabe suponer, era enfrentar, en el ámbito de la arquitectura, dos modelos que coexisten en una época de transición científica como es el paso del Renacimiento al Barroco, dado que los años cincuenta, vienen marcados en su inicio, por la recuperación del Renacimiento, pero sólo de una parte de él. ¿Qué hemos obtenido al provocar este enfrentamiento entre Wittkower y Panofsky?

126 Ibíd., p. 213

127 Ibíd.

128 Ibíd., p. 216

129 Mr. De Vauban, op. cit. p. 166. Como es natural, el grado de adecuación de relaciones angulares se mide en función de la eficacia. Sí resulta significativo que Vauban desapruebe el empleo de ángulos rectos: "Jean Errard propone un flanco perpendicular a la cara para cubrir su artillería, sin necesidad de orejones. Sin embargo la cubre tanto que es inutilizable y el foso está poco defendido. Marolois, Chevalier de Ville y algunos otros construyen sus flancos perpendiculares a la cortina. Cometen el mismo error en cuanto a la defensa del foso". Ibíd., pp. 171y 172 


\section{LÁMINA III.8}

“Lo cercano de la propuesta de l'Orme, duplicando volúmenes e insertando elementos de conexión puntuales para transformar un antiguo edificio en una estructura completa en sí misma, con lo ejercido en Sheffield por los Smithson sobre la fábrica del antiguo Firth Court..."

Philibert l'Orme "Regularización de una antigua fortaleza"

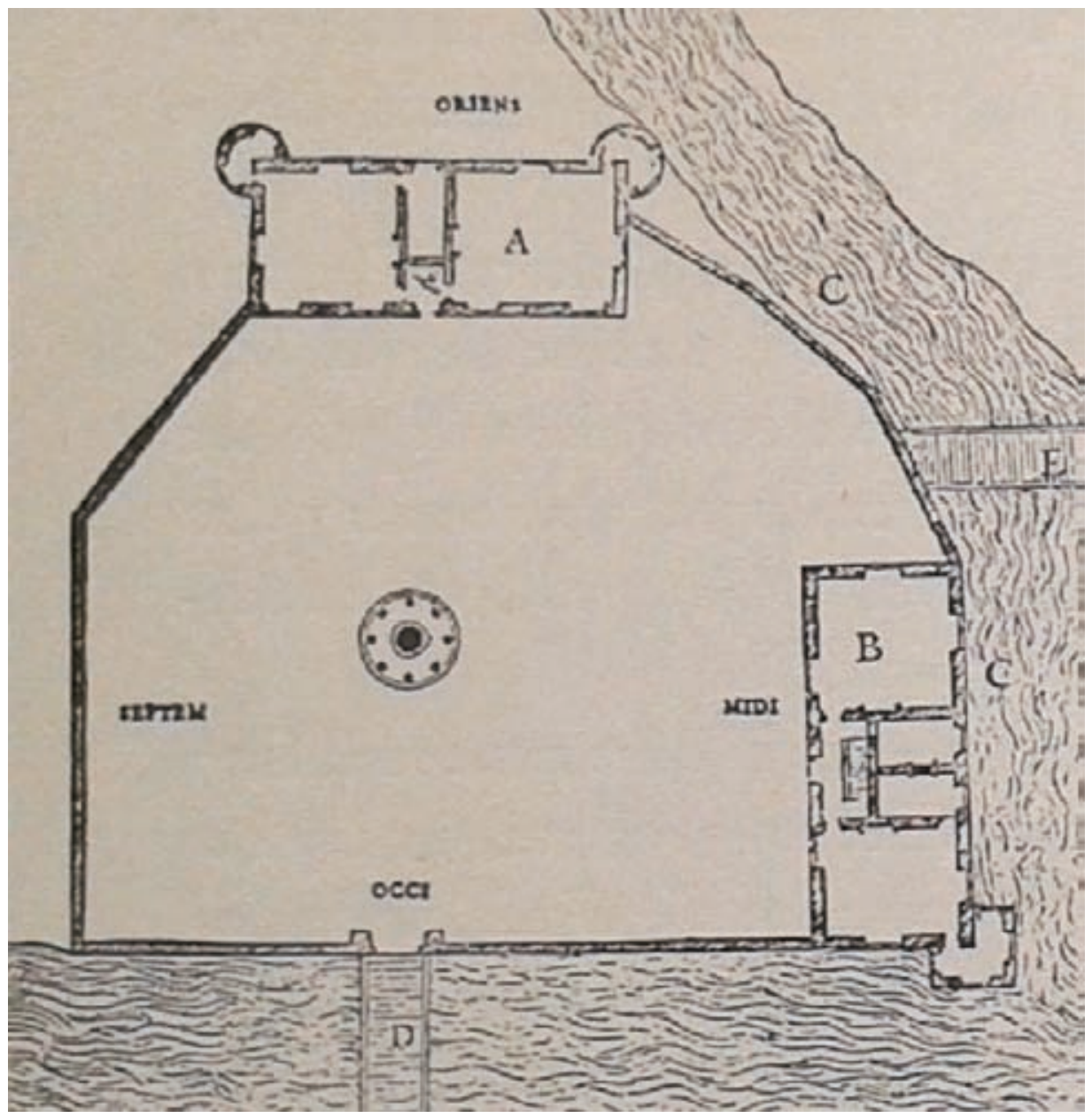

Estado original 


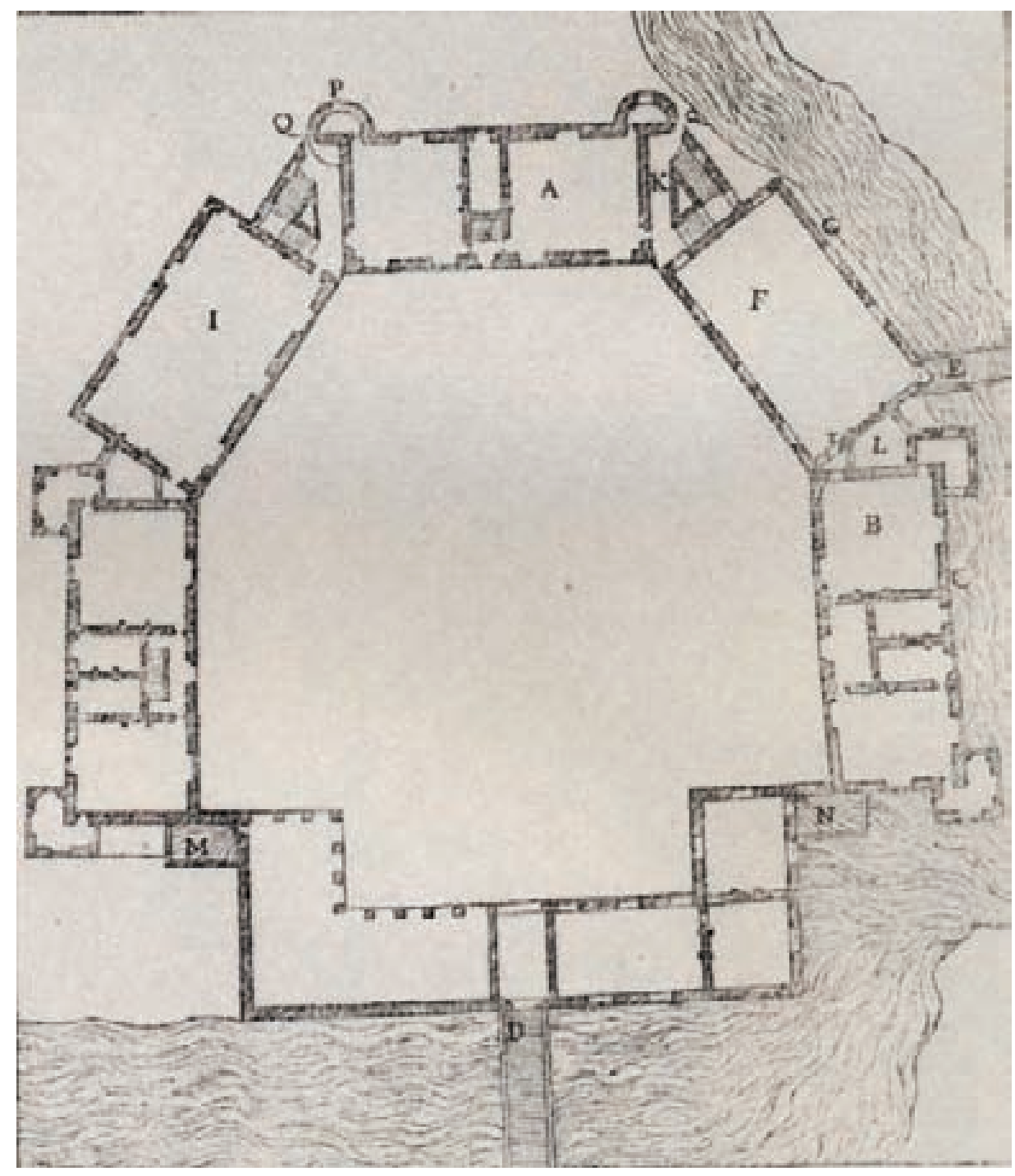

Es interesante comparar el ejercicio de l'Orme simultáneamente con Sheffield y el Economist para valorar la conectividad y continuidad del conjunto, que empareja la propuesta de l'Orme con Sheffield, pero no con el Economist. En el sentido de una operación similar, siendo el Economist un ejercicio de renovación de un conjunto en el que interviene también el Boodles Club, la compleción del agregado de piezas se realiza enfatizando posiciones singulares mediante la ocupación de las cuatro esquinas. Por otra parte, la conectividad en l'Orme se resuelve mediante la articulación interpuesta para el giro, manteniendo íntegros los bloques rectangulares. En Sheffield, es el propio rectángulo el que se deforma para recibir el giro. 


\section{LÁMINA III.9}

“Desargues elevó, en su condición de arquitecto, la práctica del corte de la piedra a casos ejemplares de aplicación de transformaciones proyectivas..."

Girard Desargues "La Pratique pour la coupe des pierres en l'architecture". Fuente, J. Dhombres y J.

Sakarovitch,“Desargues en son Temps”
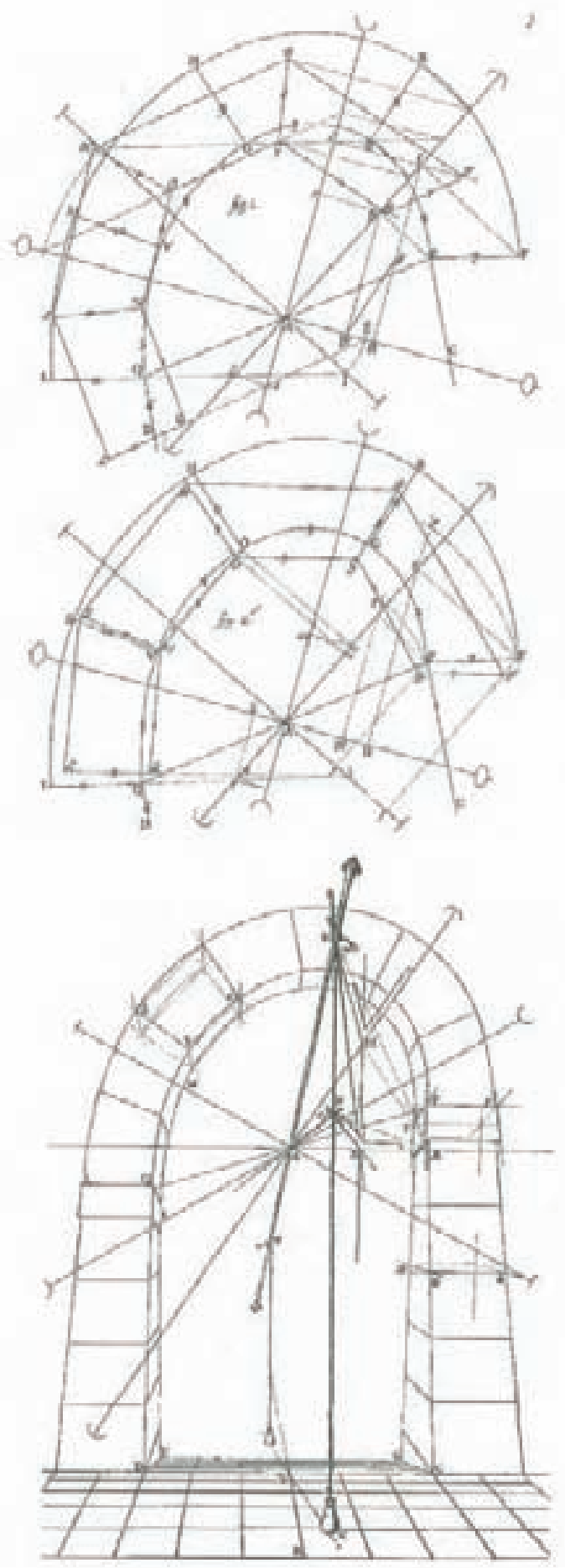

Planchas relativas a la resolución de una bóveda oblicua. 


\section{LÁMINA III.10}

"A partir de tomar en consideración la geometría proyectiva, lo que va a poner en cuestión la arquitectura oblicua es precisamente que la esencia del tambor de la columna tenga que ser un círculo..." Juan de Caramuel Lobkowitz "Arquitectura civil Recta y Oblicua...", 1678
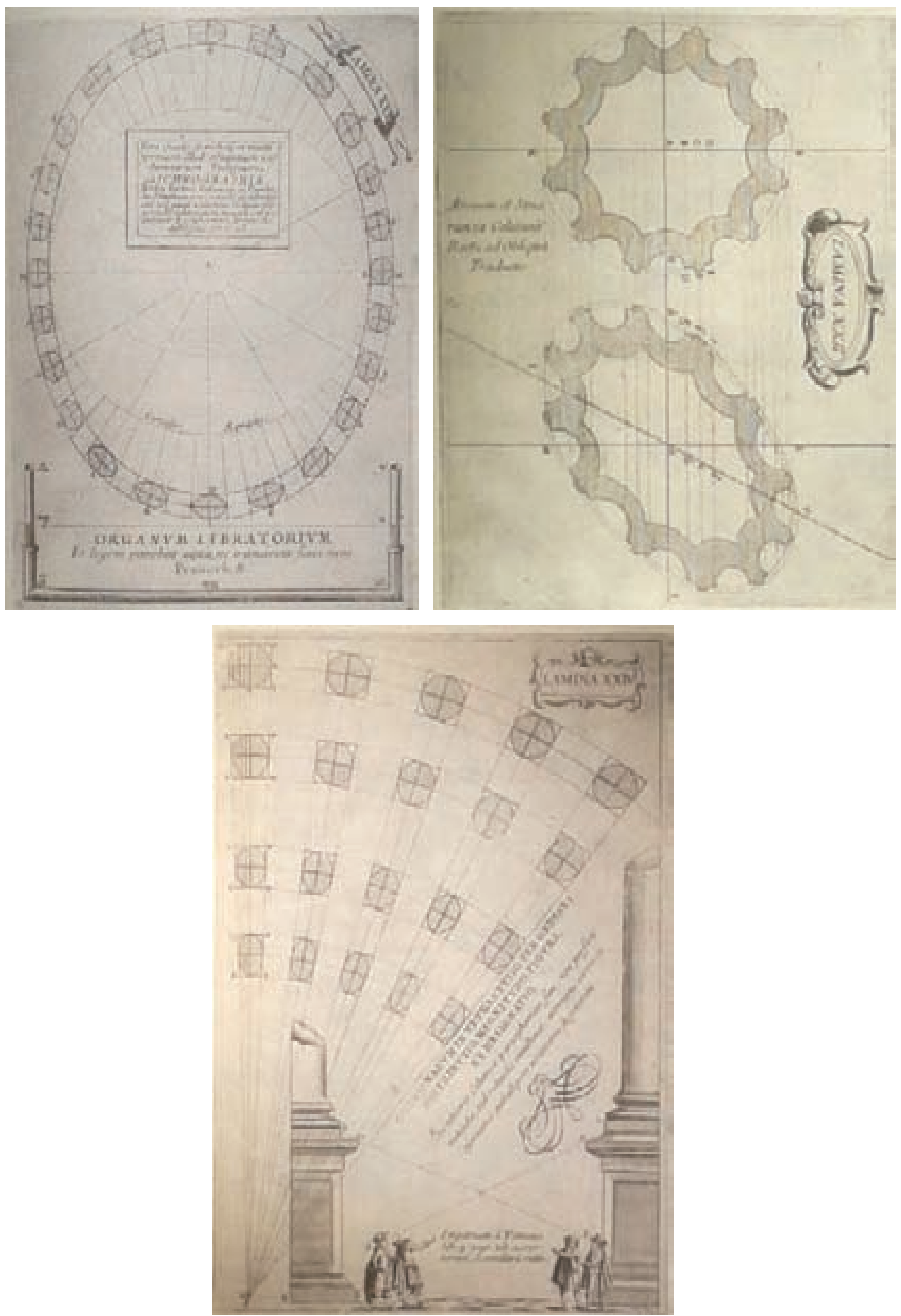


\section{LÁMINA III.11}

“... la buena proporción conllevaba deformaciones proporcionales requeridas para la correcta visualización de determinadas piezas de singular importancia..."

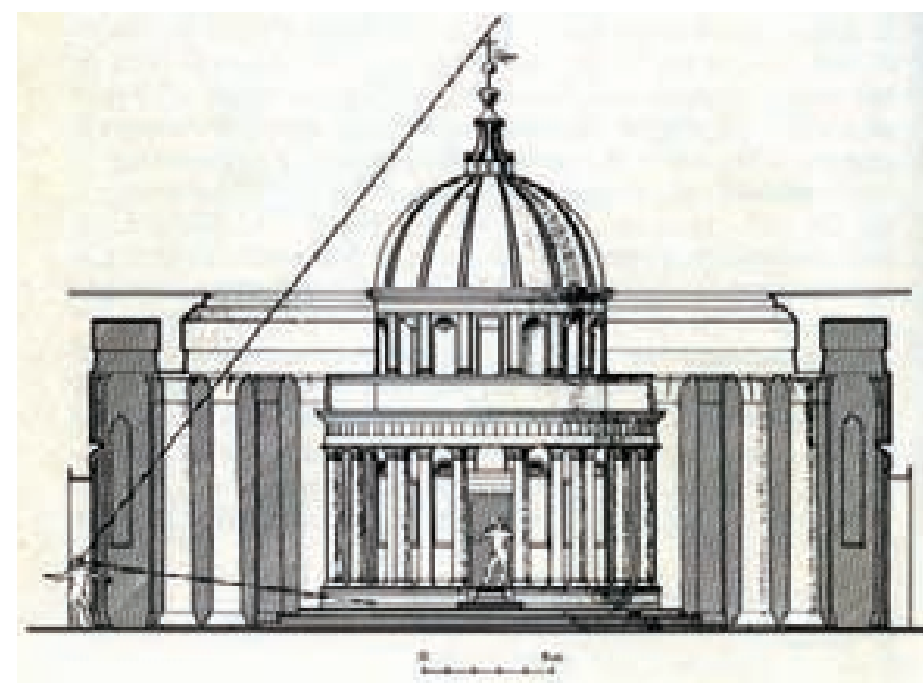

Lorenzo Sirigati, “La pratica di prospettiva”, 1596, Tempieto di San Pietro in Montorio
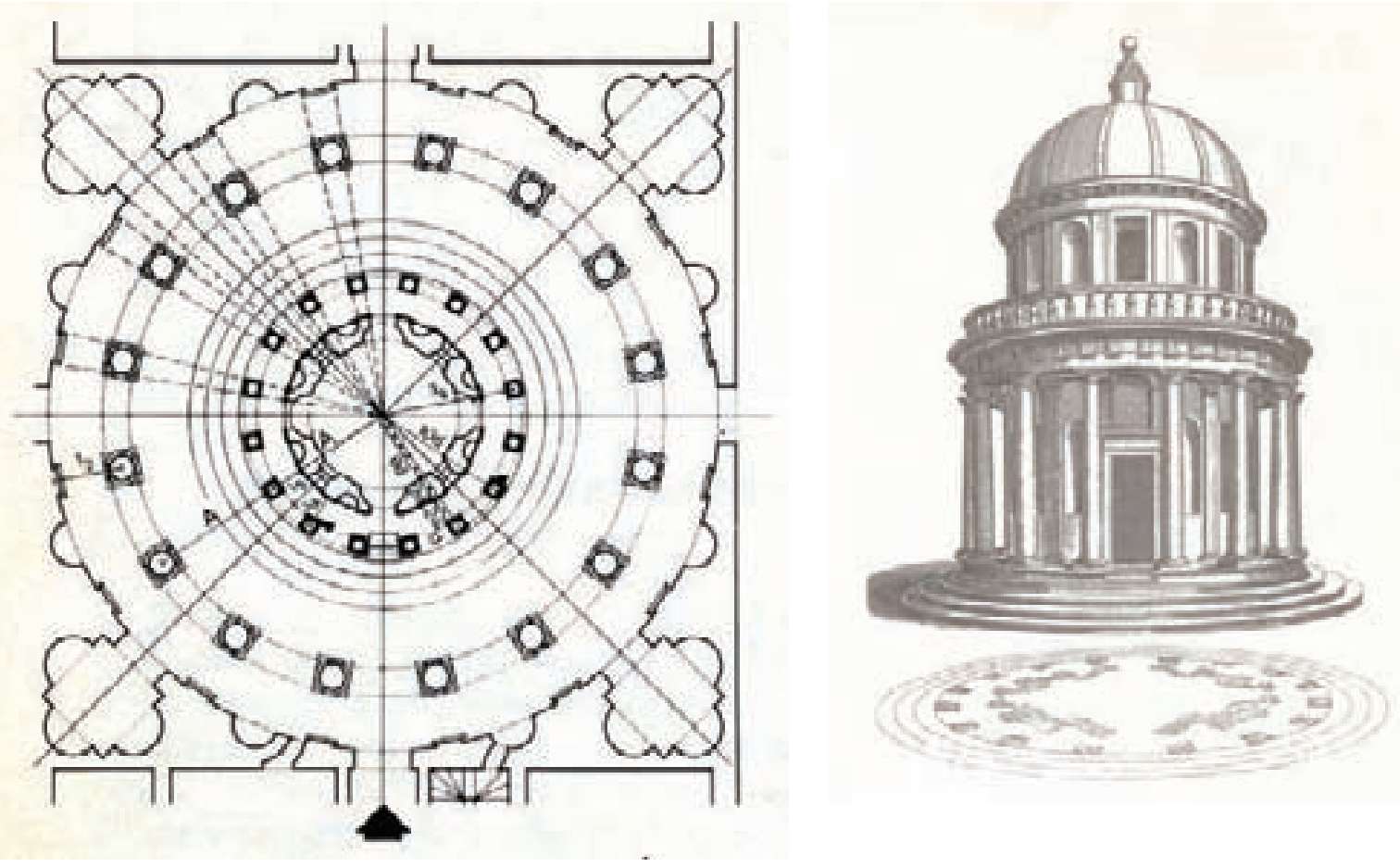

Donato Bramante "Tempieto di San Pietro in Montorio", 1502-1510.

Compárese la circularidad de las columnas con el ejemplo de Caramuel. En Bramante no hay lugar todavía para una excentricidad en el tambor de las columnas, dado que si bien se toma un lugar privilegiado para el punto de vista del espectador (Lotz indica una posición clave ya que "la versión original de la planta proponía que el edificio estuviera rodeado por una logia circular, y el visitante que entrase en el patio habría visto el propio edificio entre dos columnas y el arquitrabe (¿o el arco?) de la logia de cerramiento". Wolfgang Lotz, "La Arquitectura del Renacimiento en Italia", p.13) la centralidad del edificio neutraliza cualquier factor de posición independiente de su centro, manteniendo a las partes del edificio vinculadas a él, dominando el edificio su propia integridad formal, en lugar de derivarla a la posición del espectador. Puede decirse que el espectador y la columnata se hallan en un exterior pero irradiado desde el centro y dependiente de él. Si bien, como señala Bruschi, hay una réplica para deformar algunas dimensiones que se ajustan a la perspectiva desde el punto de vista exterior. 


\section{LÁMINA III.12}

"El ámbito de desarrollo propio de la Arquitectura Oblicua son los corredores y las escaleras, donde se produce el contraste entre la inclinación del suelo y la vertical, con ejemplos como la Scala Regia o los corredores laterales de San Pedro de Bernini..."

Presentamos ejemplos de escalonamientos de primeros de los 50, como el edificio Semiramis, de George Candilis y Schadrach Woods o ejercicios perspectivos como el Pabellón del Grupo 2 para la exposición This is Tomorrow, que muestran un leve resurgir de las formas de la Arquitectura Oblicua.

Véase conjuntamente con el método de resolver Desargues la "descente biaise", la bóveda oblicua para cubrir corredores inclinados o escaleras.

Gian Lorenzo Bernini “Scala Regia” Perspectiva

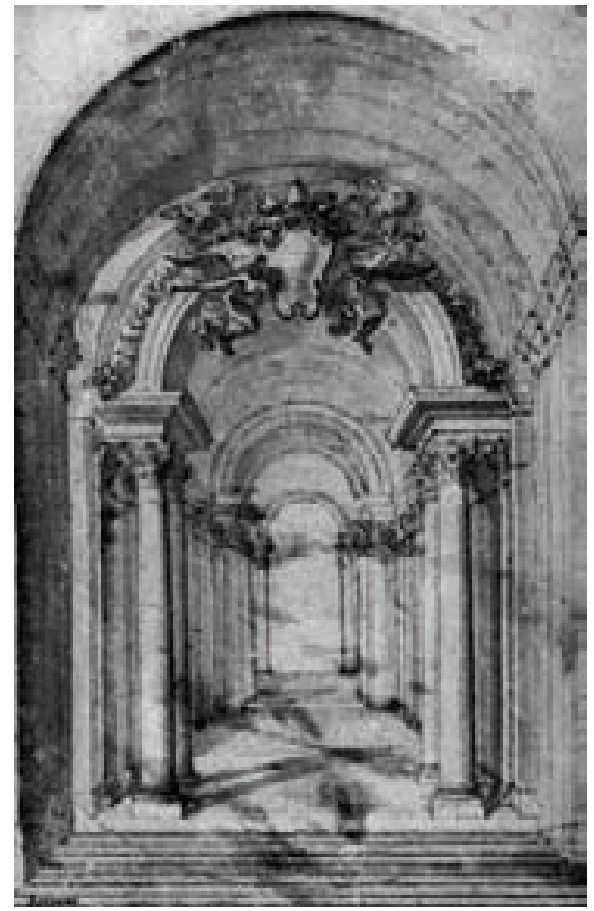

Gian Lorenzo Bernini “Scala Regia” Planta

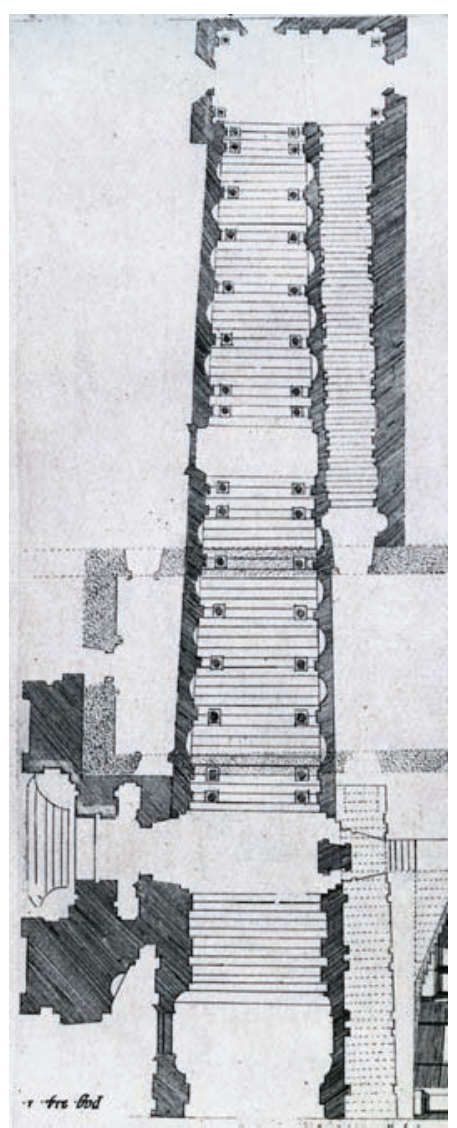



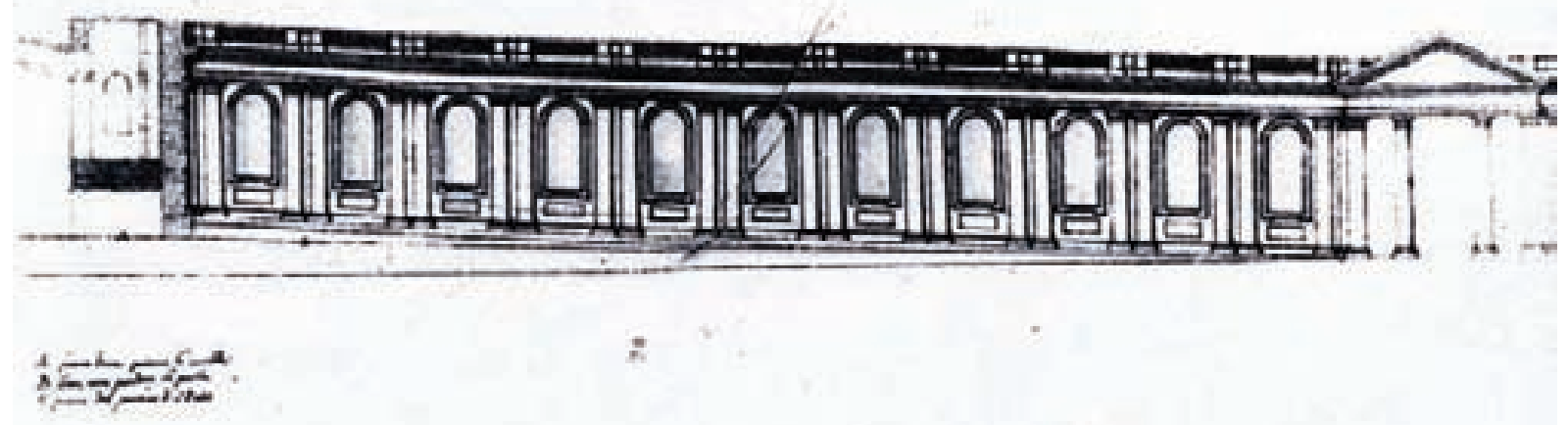

;

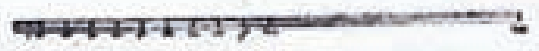

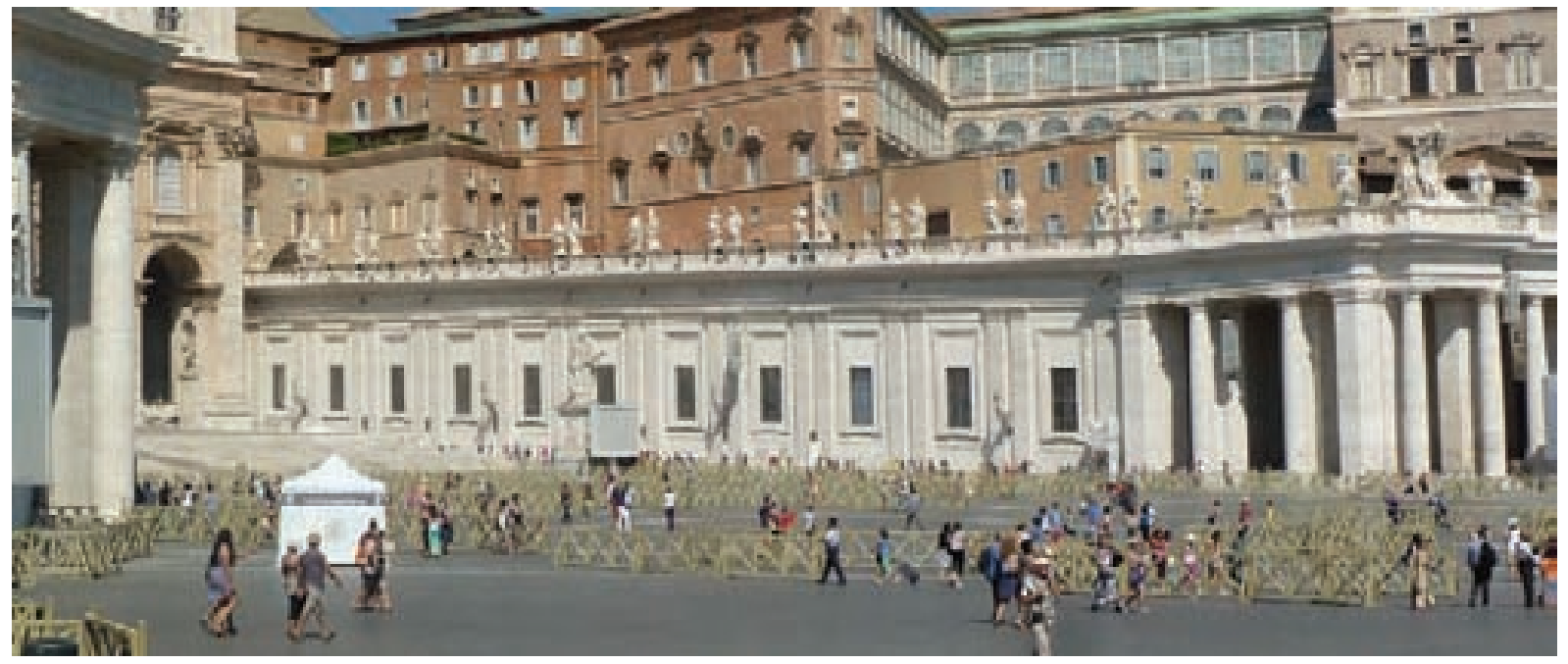

Gian Lorenzo Bernini “Corredores laterales" Foto del autor 
John McHale, "Poster" Fuente Architectural Design, Septiembre 1956, p. 304
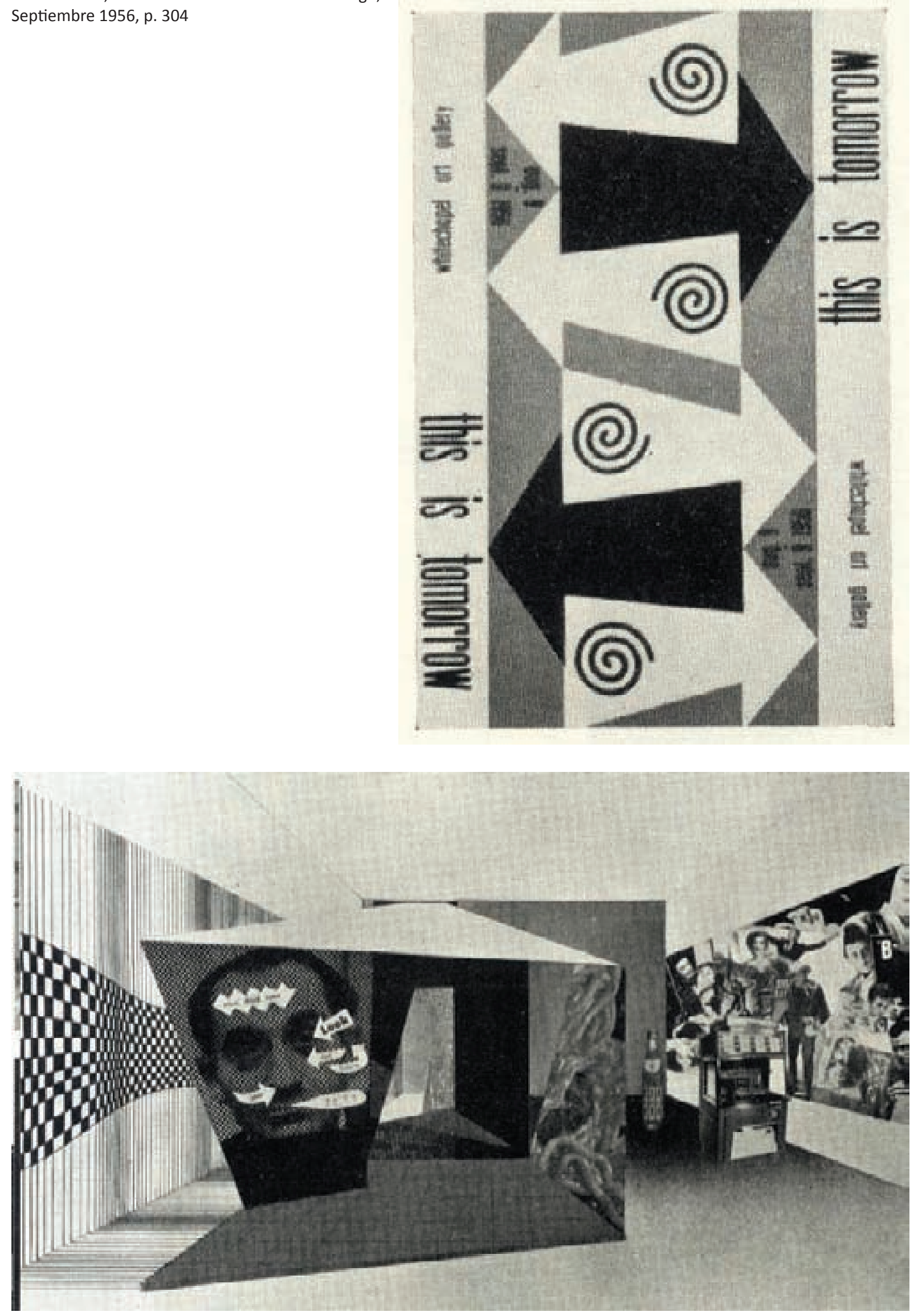

Richard Hamilton, “Fotomontaje para el catálogo de la exposición”, Fuente Architectural Design, Septiembre 1956, p. 303 

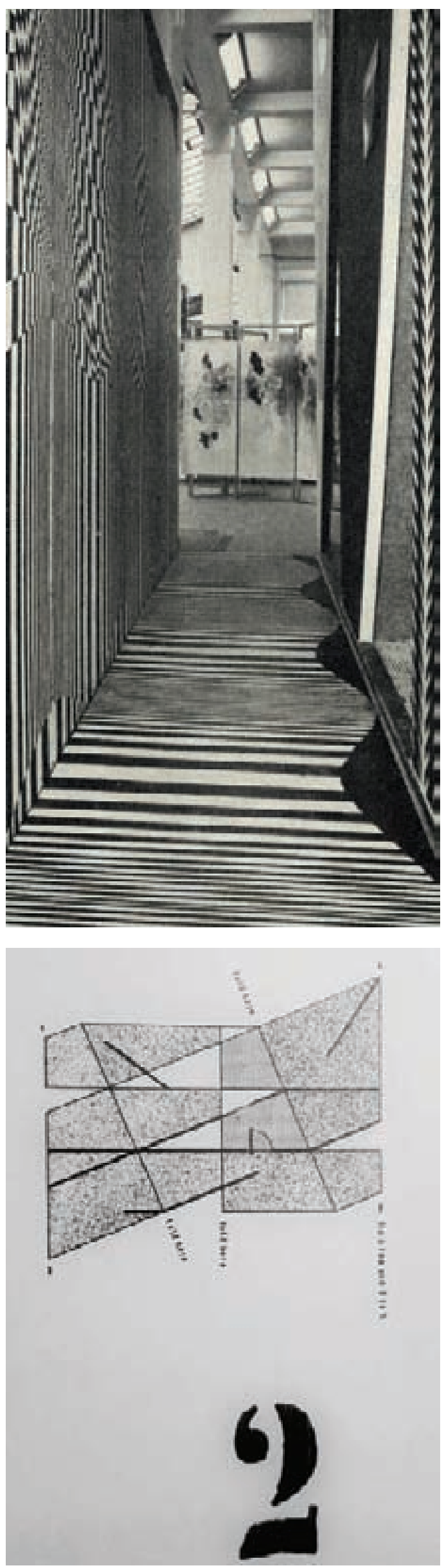

John Voelcker, Richard Hamilton y John McHale, "Pabellón Grupo 2", Exposición This is Tomorrow, 1956, Perspectiva, Fuente Architectural Design, Octubre 1956, p. 334

John Voelcker, Richard Hamilton y John McHale, "Pabellón Grupo 2", Exposición This is Tomorrow, 1956, Planta 


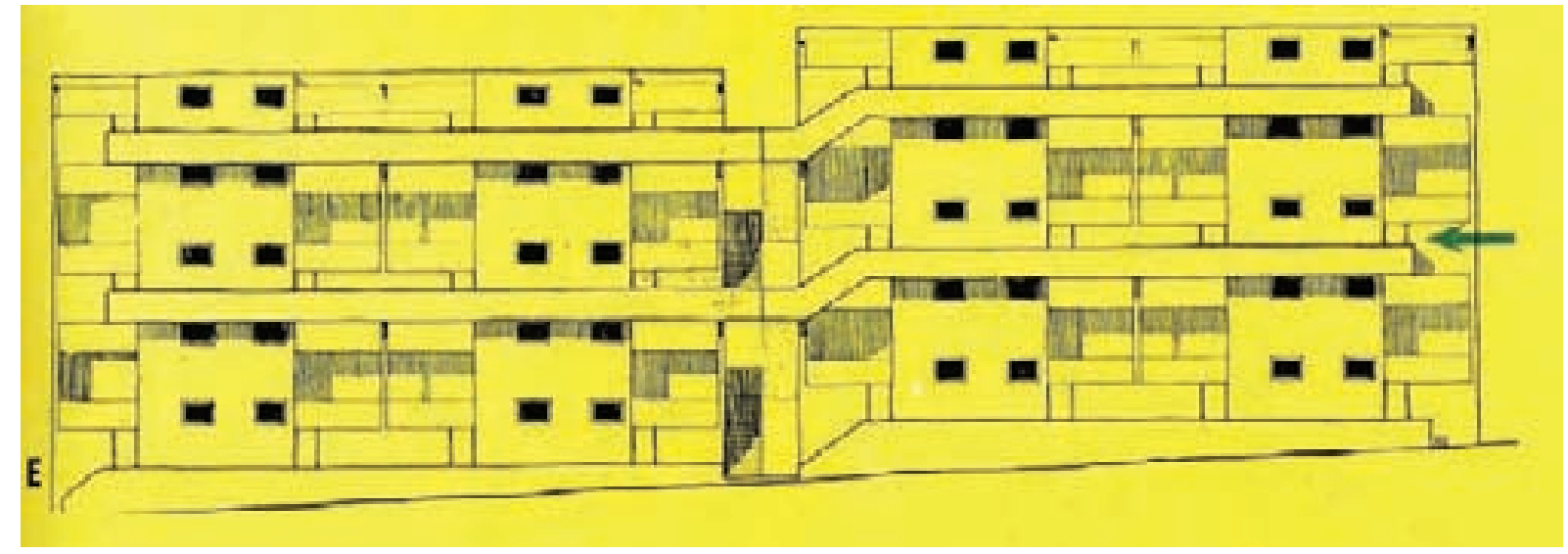

George Candilis y Schadrach Woods, “Edificio Semiramis”, 1953. Alzado. Fuente I'architecture d'aujourd'hui, Diciembre 1954, p. 55

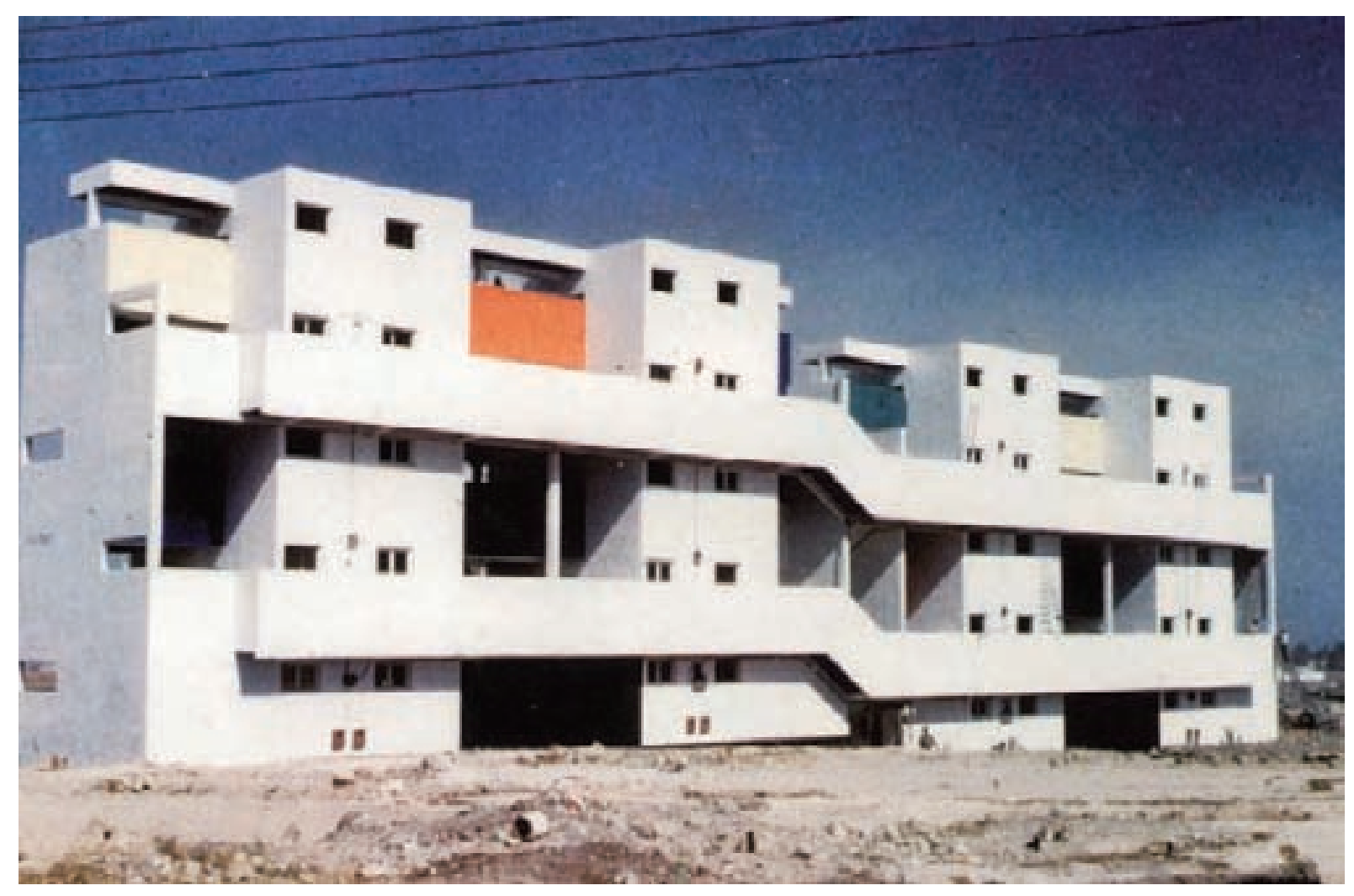

George Candilis y Schadrach Woods, "Edificio Semiramis", 1953. Fotografía, Fuente, Tom Avermaete, "Another Modern. The Post-War Architecture and Urbanism of Candilis-Josic-Woods, p. 160 
Véase conjuntamente con el método de resolver Desargues la "descente biaise", la bóveda oblicua para cubrir corredores inclinados o escaleras.

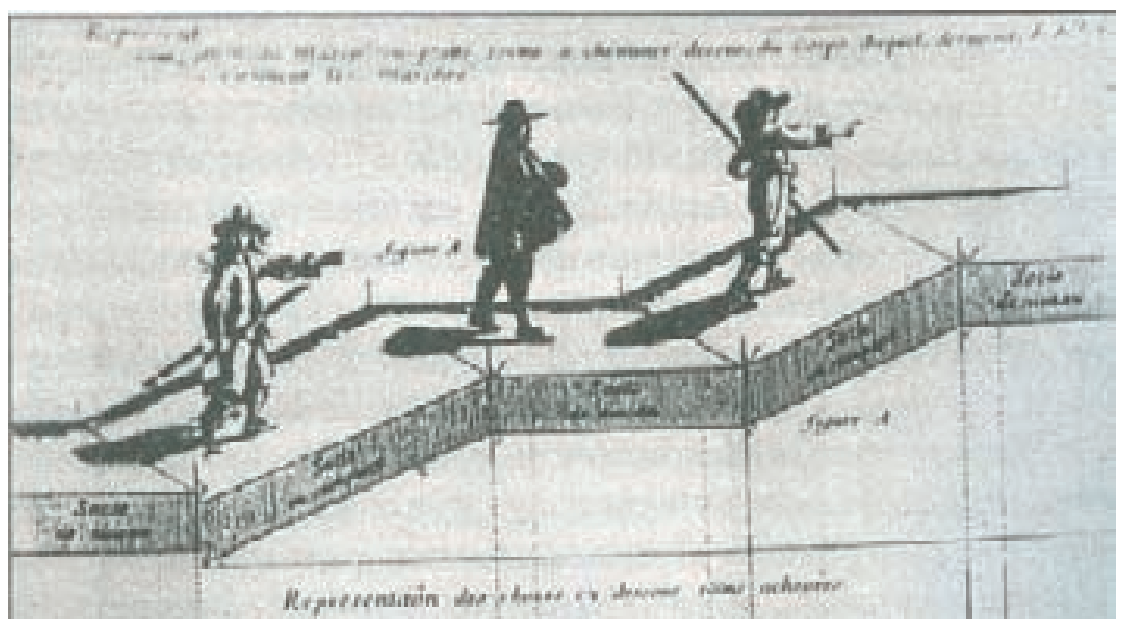

Girard Desargues, "Trazados de tramos inclinados escalonados"
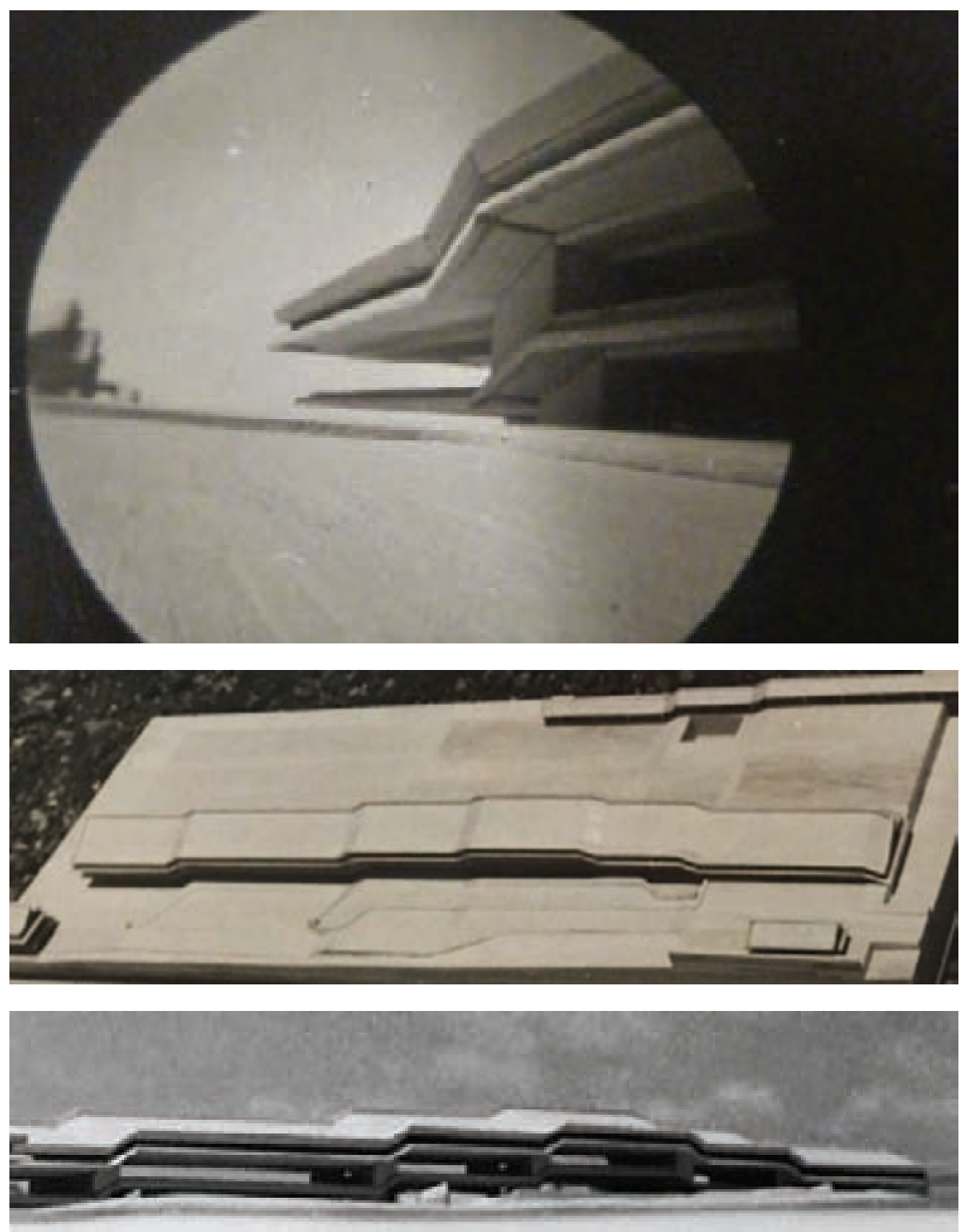

Alison y Peter Smithson, "Embajada de Gran Bretaña en Brasilia" 1965,Fuente Archivo Alison \& Peter Smithson, Loeb Library, Harvard, maquetas 


\section{LÁMINA III.13}

"El interés de Alison y Peter Smithson por asuntos relacionados con el territorio y la imagen de las líneas defensivas o por amurallar recintos es inusitado entre los arquitectos..."

Peter Smithson "Bailey Bridge". Puente desmontable del tipo que encontró Peter Smithson en la Armada. Fuente, Peter Carolin, arq, Volumen 2, no 32, Verano 1997

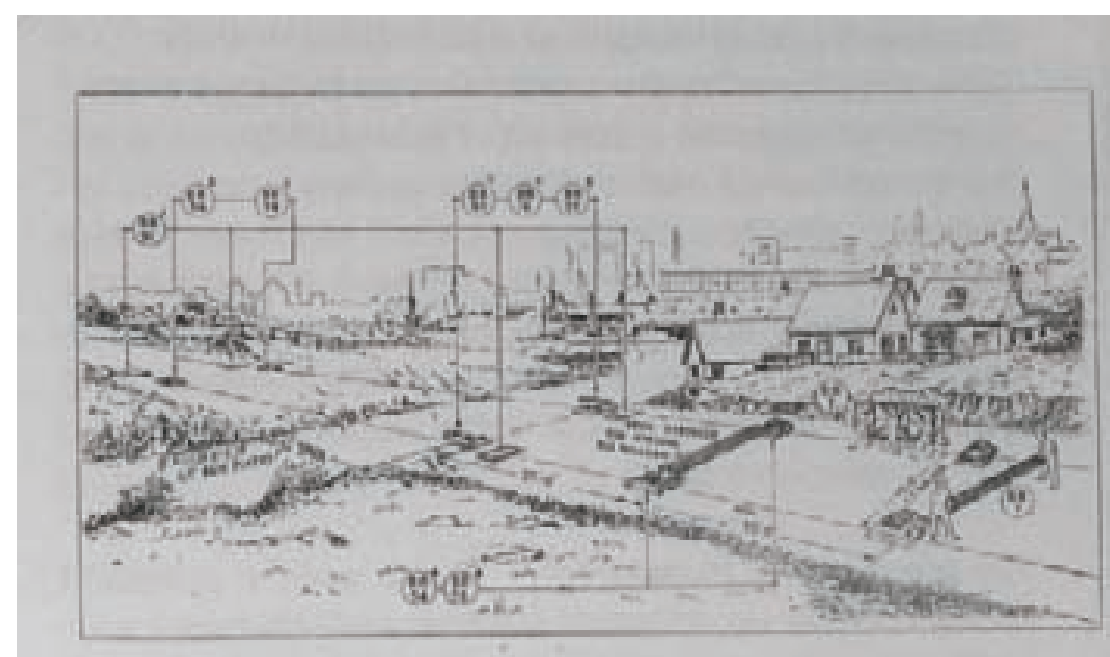

$2 a$

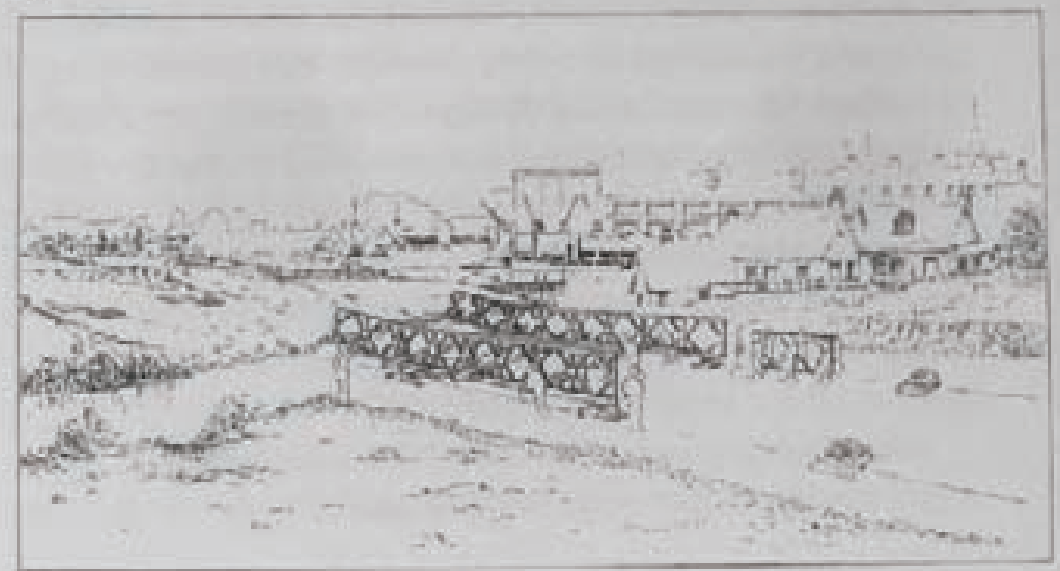

$2 b$

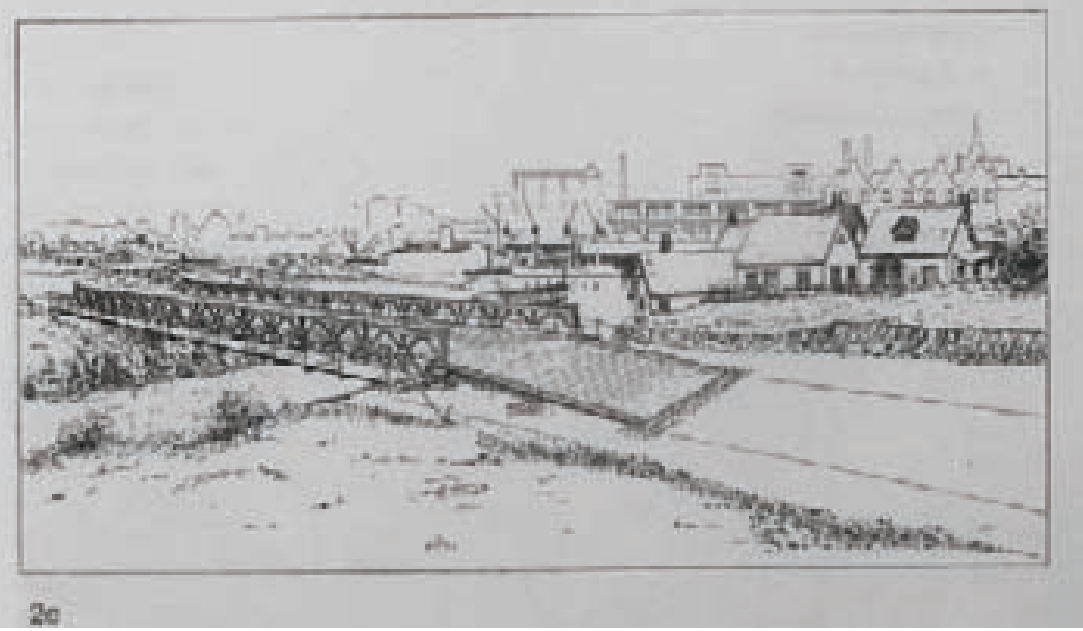




\section{LÁMINA III.14}

“... sino porque lo hacen también, al asociarse a di Giorgio, y esto es lo que más me interesa, de la figura de Alberti y la teoría proporcional, que se habían colado, alcanzando una segunda existencia en su época..."

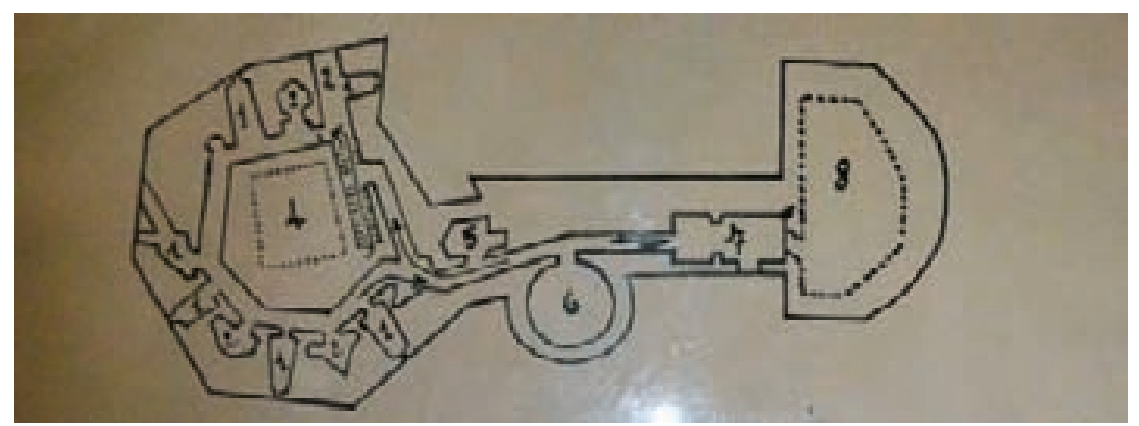

Francesco di Giorgio Martini “Fortaleza de Mondavio". Plano del conjunto

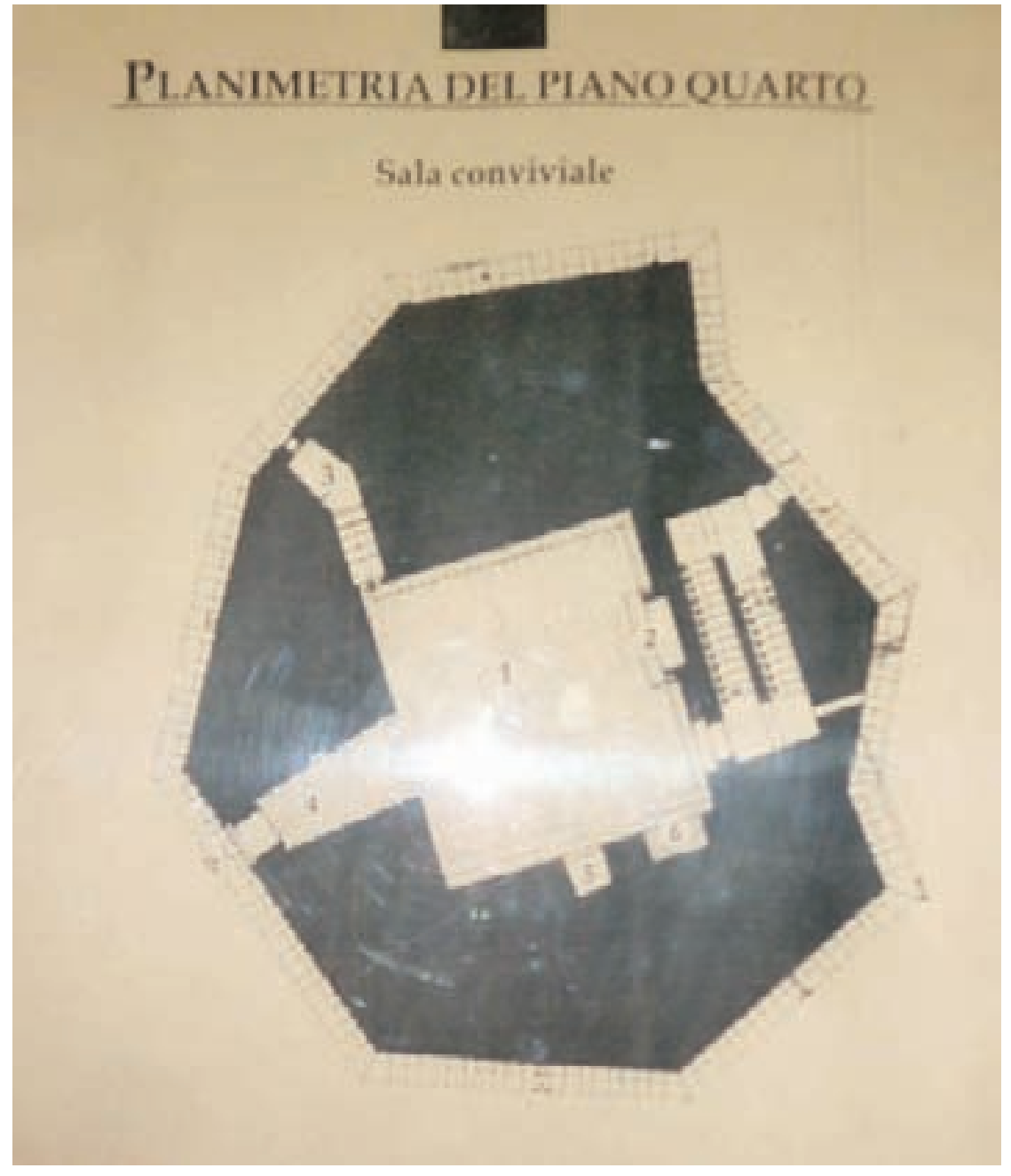

Francesco di Giorgio Martini “Fortaleza de Mondavio". Planta del nivel 4으 

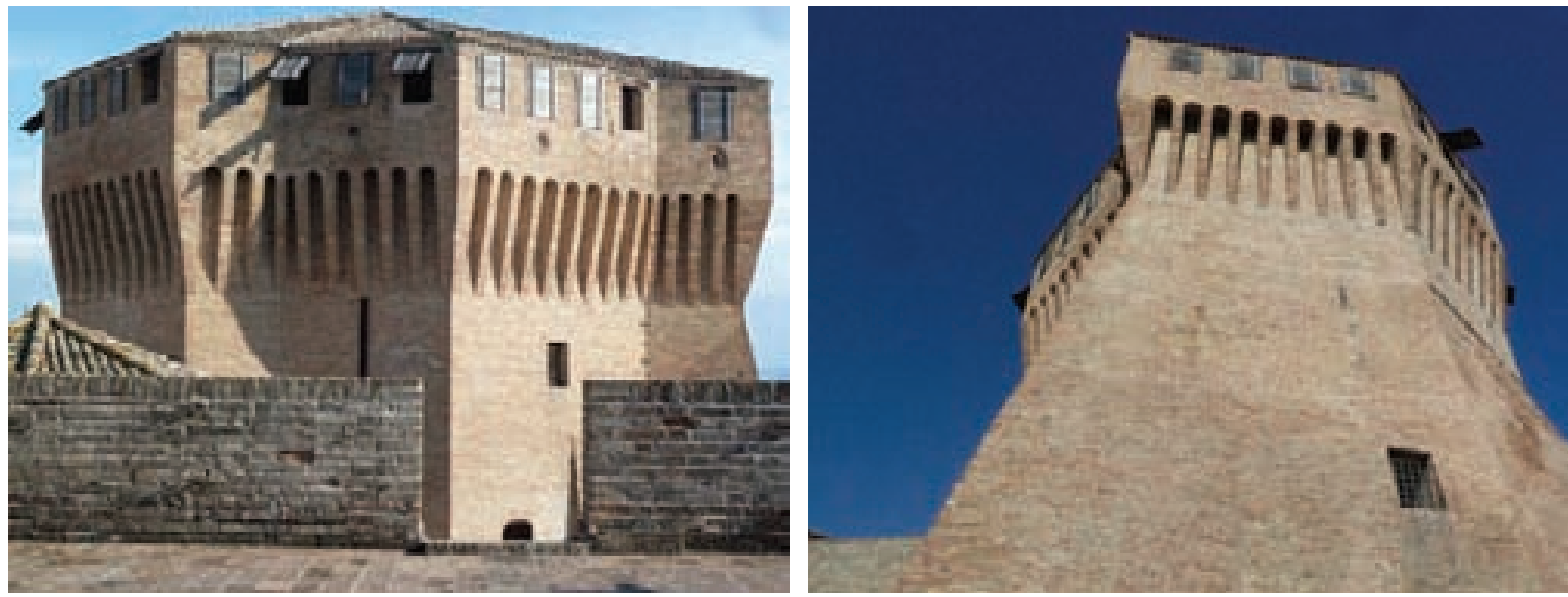

Francesco di Giorgio Martini “Fortaleza de Mondavio”. Fotografías del autor

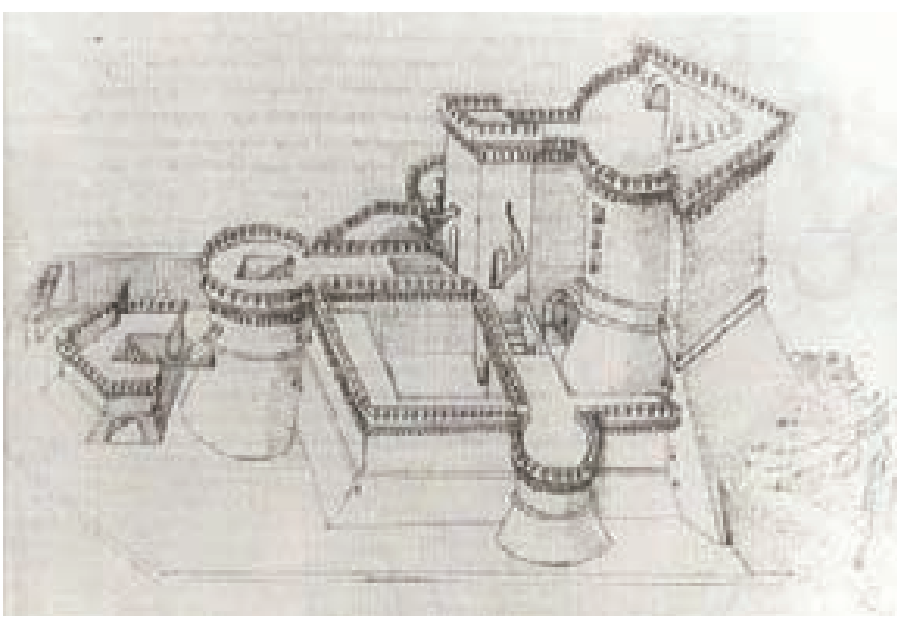

Francesco di Giorgio Martini "Diseño de Fortaleza".

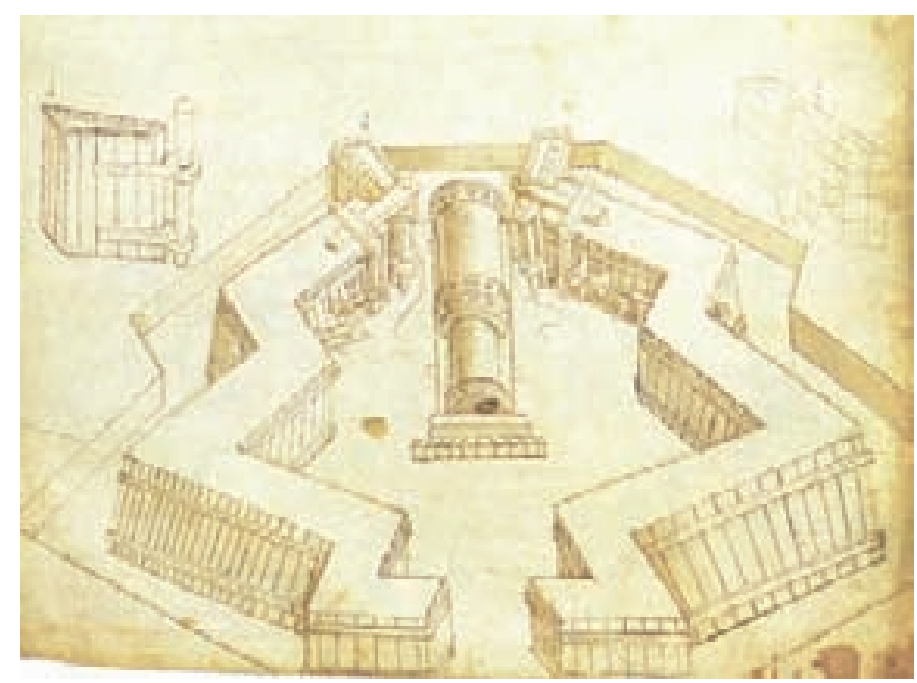

Francesco di Giorgio Martini "Amurallamiento". 


\section{LÁMINA III.15}

"Su forma, por tanto, no retiene más que los mínimos enlaces a priori entre los tres elementos $<<$ flanco, cortina y cara >>, siendo su ajuste angular definitivo pospuesto al momento de establecer la combinación con los otros términos o elementos defensivos, introducidos como los argumentos de la función..."

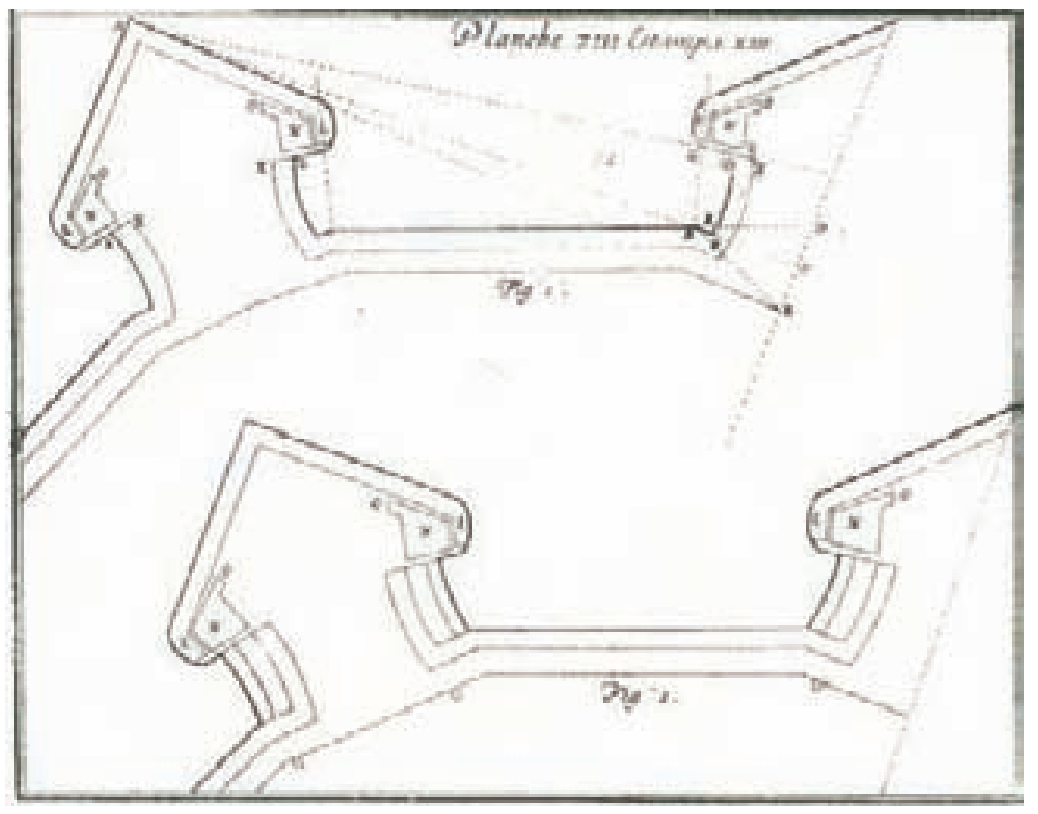

Vauban, "Fortificación". Trazado de la rasante y la fijante y los ángulos del flanco

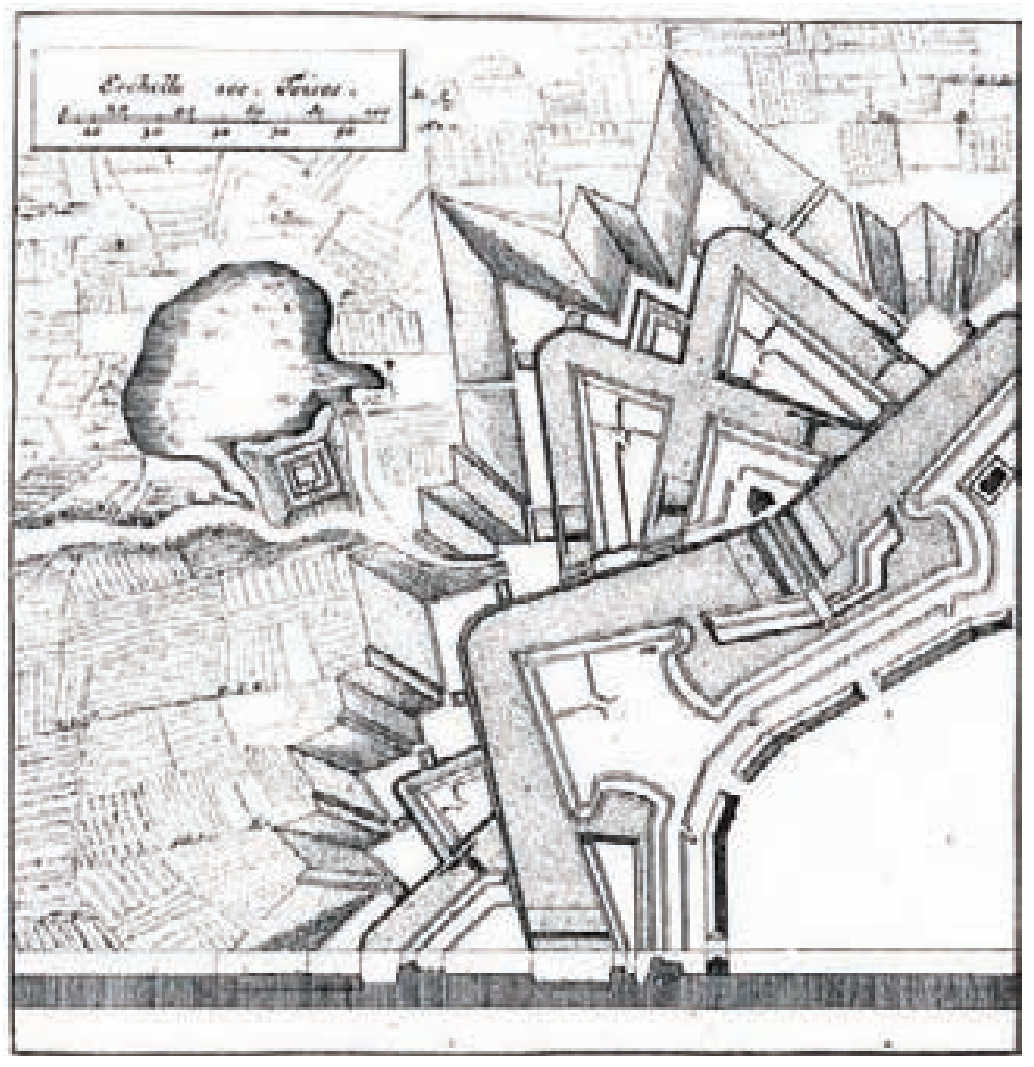

Vauban, "Fortificación", Trazado eliminadas las huellas de los ángulos 


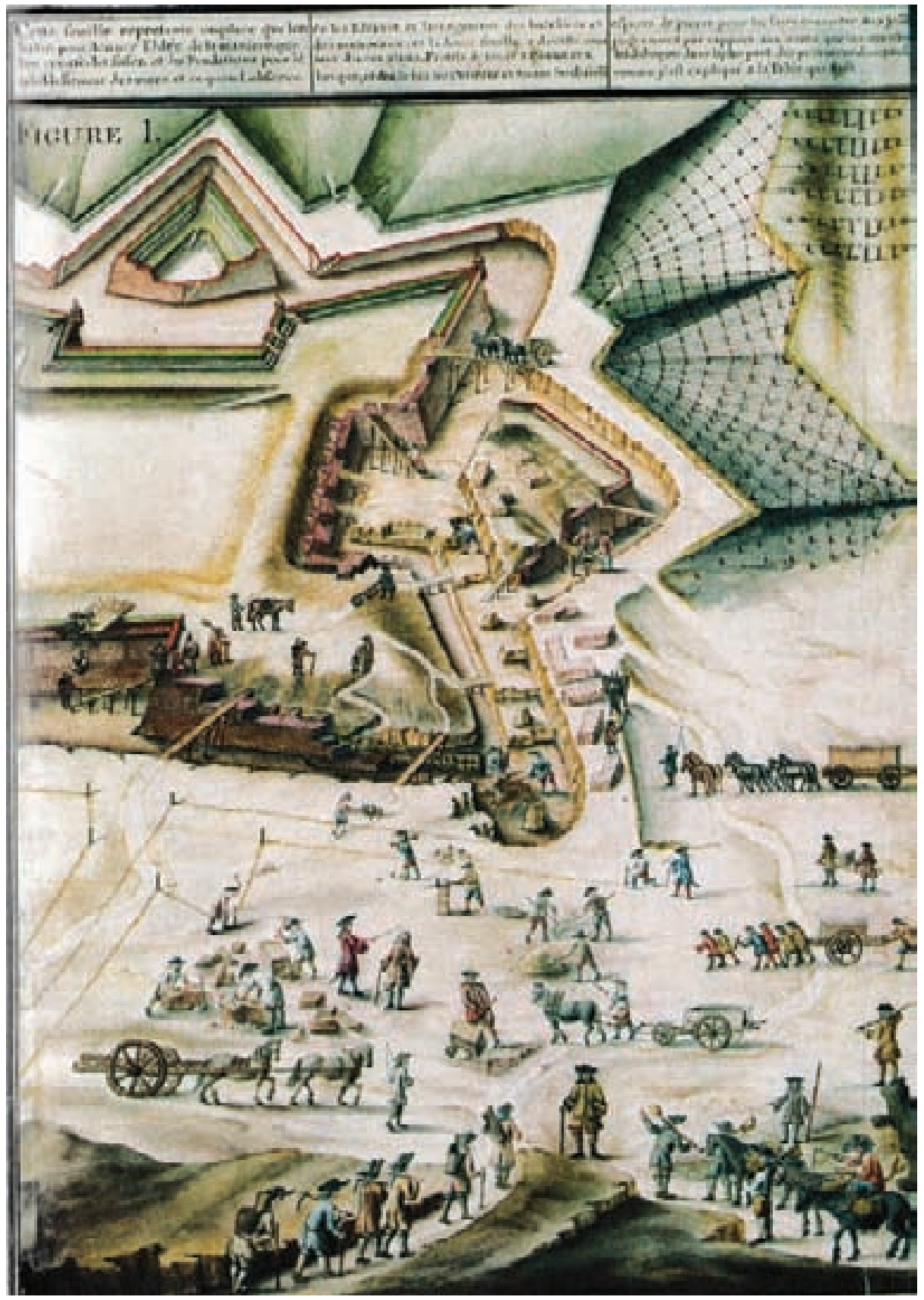

Vauban, "Fortificación”. En construcción. 


\section{LÁMINA III.16}

"La idea, como cabe suponer, era enfrentar, en el ámbito de la arquitectura, dos modelos que coexisten en una época de transición científica como es el paso del Renacimiento al Borroco..."

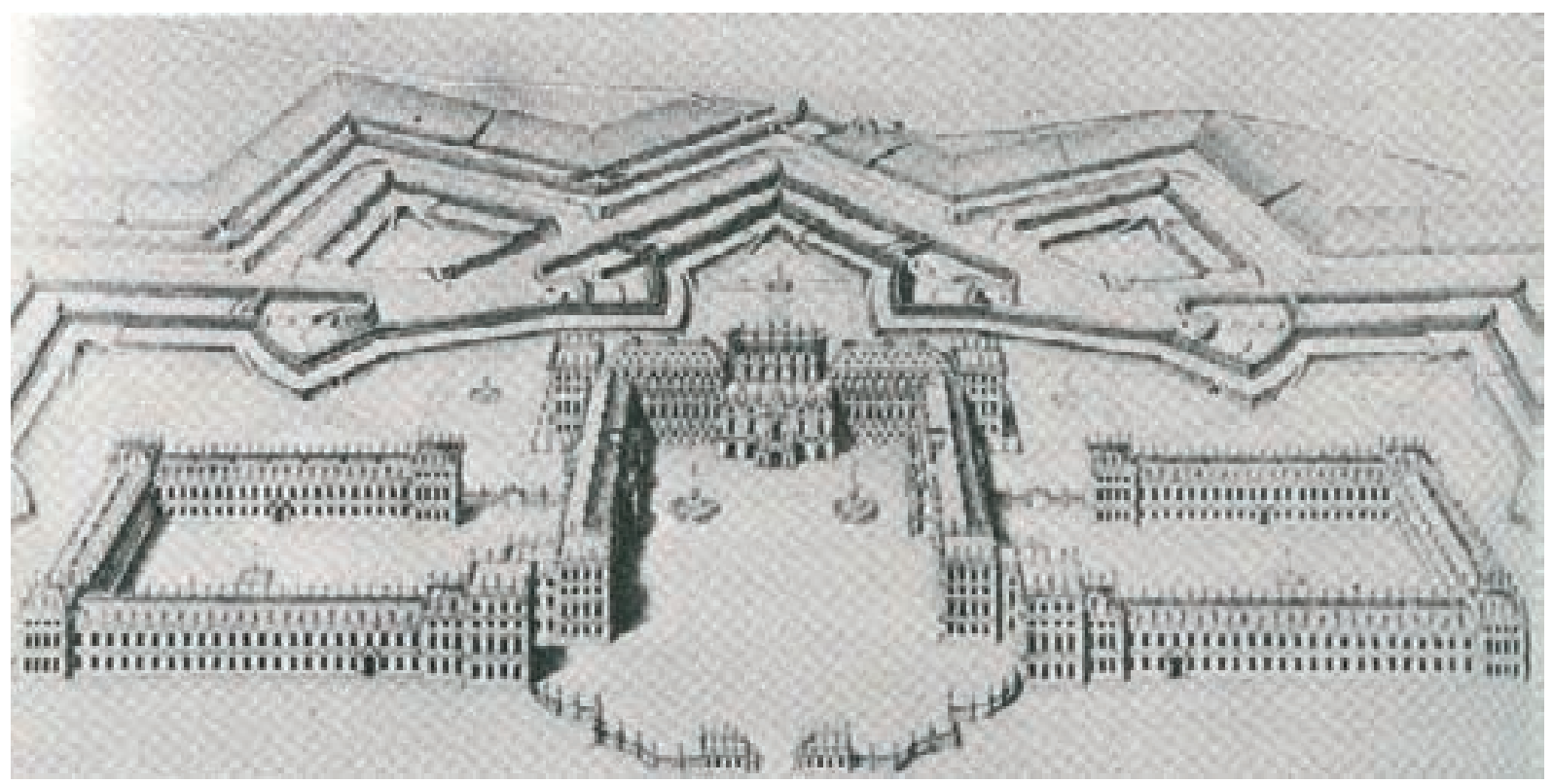

Palacio de Mannheim, hacia 1720

Incluso en el seno mismo del Barroco, como es este ejemplo, la fortificación, como una transformación topológica del palacio, destruye casi por entero la geometría para abrirse a la fluidez del Principio del Continuo. 


\subsection{HACIA LA ABOLICIÓN DEL ESPACIO}

Con el empleo de la perspectiva hemos trasladado fundamentalmente la consideración del objeto hacia una consideración de posiciones. A cada posición le corresponde ahora un objeto diferente dentro de una variedad de transformaciones posibles. Ciertamente el grado de diferencia viene dado por la limitación de la transformación perspectiva. Hemos tocado aún así dos casos excepcionales. Por un lado la serie del número cuadrado, dictaminada también por el principio de posición al establecer el orden creciente de la serie, aspecto éste que se cumplía en el conjunto del Economist. $Y$ un caso curioso que escapa a las transformaciones perspectivas que es la columnae rectangulae, contradictoria en sus propios términos si nos atenemos a buscar la definición del objeto, pero "idénticas" o por lo menos en algún grado en orden al contenido de la función ornato o sustentante. La ciencia militar, por otro lado, cuando transforma su objeto, de ser una representación del orden divino para constituirlo en parte de una ciencia defensiva, es la máxima expresión de una teoría posicional del espacio y del empleo de la técnica perspectiva, al tomar como límites de la figura del bastión el barrido de los fusiles en la defensa cercana y de las líneas de rasantes respecto a las posiciones de la artillería atacante. $Y$ en este sentido su ineficacia resulta llamativa ante el bombardeo vertical y de rebote, dado que la trayectoria en un caso y el rebote aleatorio en el otro, no pueden ser recluidos entre las trazas de los haces de rectas proyectivas y por tanto resultan imprevisibles. Resumiendo, en todos los casos tenemos un despliegue previo del espacio para establecer un Principio de Posición.

Bajo este Principio de Posición hemos renunciado a definir sustancialmente el objeto. No nos hemos dejado envolver por la disputa de la proporción para definir los límites estéticos del edificio, y por supuesto también renunciamos a la polémica entre Blondel y Perrault, que en esencia parecía adoptar el artículo de Butler al criticar el libro de Wittkower en la sección de libros del RIBA Journal y que encendió a Volecker y a los Smithson.

Digamos, por tanto, que hemos trasladado el problema de hallar la esencia del edificio bajo el concepto de forma, por el de una pluralidad de formas posibles de ese objeto que se definen por la ley de la relación entre la posición del espectador y la del objeto. Apuntábamos también, que el estricto cumplimiento de la ley de relación precisaba de un sustrato espacial plenamente geométrico.

La perspectiva como estructura espacial matemática es la tesis de Panofsky, que toma en su apoyo, la distinción dada por Cassirer entre el espacio del conocimiento puro o espacio geométrico y el espacio de la percepción sensible. La manera de hacer del lienzo una estructura matemática integral parte, como condición previa, de eliminar del espacio sensible toda acción que, partiendo del sujeto, tienda a ejercer sobre los objetos y fenómenos de la visión lazos afectivos o psicológicos propios de éste. Según ve Cassirer, no hay ni puede haber transición en la secuencia de pensamiento, que transporte de uno a otro, sino que se requiere de "una negación de lo que aparece inmediatamente dado en la intuición sensible, a fin de llegar al "espacio intelectivo" de la matemática pura"130. La consecuencia no es una abstracción del marco 
físico, sino su construcción bajo un único criterio: hacer del espacio una nueva estructura asentada en tres rasgos fundamentales: "continuidad, infinitud y completa uniformidad"131. El marco físico queda, como si dijéramos, desposeído de todo contenido de conciencia, entre los cuales están la propia limitación de la visión fisiológica, y cualquier afección del sujeto. La auténtica revolución, y esta es básicamente la tesis que presenta Panofsky, está en la construcción de un espacio continuo, homogéneo e infinito del marco físico, de tal modo que puede decirse con propiedad, que la perspectiva reside "en la objetivación del subjetivismo"132.

Cabe ver en ello, una traslación de la substancia del objeto hacia la substanciación del espacio. Consecuentemente el Principio de Posición estará dado bajo las coordenadas del cartesianismo. El cartesianismo procede básicamente a medir, lo cual no es sino la aplicación de un orden de selección de los atributos del objeto que puedan ser medidos, y de un criterio de medición, refiriendo tanto las medidas como las unidades de medición a un sistema de referencia común. Cabe añadir que la medición es un instrumento o criterio conforme a una regla del pensamiento, y por tanto la dimensión no entra en cuestiones ontológicas del ser, $y$, en este sentido toma distancias prudenciales, en tanto concepto o artificio intelectivo (categoría pura del espíritu), respecto al laberinto de la esencia del objeto. Por otro lado, no aborda más que los elementos que encajen dentro de este concepto de orden y medida, descartando aquello que no sea mensurable. Por último, la dimensión no abarca sólo la longitud, anchura o profundidad sino cualesquiera otros elementos, como el peso o la velocidad que definan unívocamente una magnitud. Por tanto, insisto, aborda al ser en aquellos aspectos que admitan ser mensurables y no otras cualidades. Las nociones de claridad y distinción que han de regir a las ideas cartesianas no admiten aquellas complicaciones que contradigan la evidencia. El éxito del método descansa tanto en la reminiscencia, sobre la base de un conocimiento intuitivo de lo que es conocido y no es deducido, y en un conocimiento de lo desconocido, por comparación con lo conocido intuitivamente. De esta forma acotar con claridad y distinción el problema es parte ya de su resolución, y aquello que no entre a formar parte de las ideas claras y distintas, queda fuera de él.

En definitiva lo que hay en Descartes es una traslación del concepto general de magnitud al espacio. Todos los problemas relacionados con la comparación de magnitudes quedan referidos, por fin, a un sistema de coordenadas. Lo que de él se obtiene son relaciones de posición. Cualquier determinación mensurable del objeto, una longitud, por ejemplo, queda referida a la posición de sus puntos inicial y final, cuya marca o posición en el sistema de coordenadas, elegido a voluntad, y conforme a las distancias respecto a las líneas de abscisas y ordenadas, otorga la longitud del objeto, al quedar ésta expresada algebraicamente por medio de la ecuación.

El problema fundamental que va a plantearse sobre el espacio cartesiano es la limitación dimensional. De varias maneras: por un lado en lo que respecta al objeto de análisis, limitado al modo y razón según el cual sea considerado como mensurable. Por otro lado, en lo que respecta al espacio, limitado a ser sede de figuras representables

131 Ibíd.

132 Erwin Panofsky, "La Perspectiva como Forma Simbólica". 
en un número limitado de dimensiones. Y en tercer lugar al transmitir al espacio el concepto de sustancia. La segunda limitación no tiene aplicación en el campo del objeto arquitectónico, y por tanto el Principio de Posición rige privilegiadamente en el dominio de la arquitectura.

El primero es la piedra angular de la critica al sistema perspectivo en el campo de la pintura moderna: el color no parece ser uno de lo modos o razones según el cual el objeto sea mensurable. A partir de ahí la declaración de Cézanne, si bien está referida a la limitación del espacio euclídeo según Borchers, alcanza con más razón al espacio cartesiano: "Para el pintor no existe ni línea, ni círculo, sino únicamente contraste de colores"133. Como señala Borchers nadie verá claramente estas figuras estereométricas (los sólidos geométricos) en una tela de Cézanne. Los podrá ver en las telas de los pintores del primer Renacimiento y de los perspectógrafos...." ${ }^{134}$.

El tercer punto queda entreverado con la ausencia o no de contenido para la posición. La tesis de Panofsky, avalada por Cassirer, plantea el espacio de la geometría pura del siguiente modo: "en última instancia, la homogeneidad del espacio geométrico se funda en que todos sus elementos, los "puntos" que se unen en él, no son sino simples determinaciones de posición que carecen de todo contenido propio e independiente al margen de esta relación, de esta "posición" en que se encuentran los unos con respecto a los otros." ${ }^{135}$ Quiere esto decir, que el punto pierde todo contenido emotivo o psicológico que pueda quedar agregado a él en un espacio real al sustanciarse en el espacio homogéneo, o dicho de otra manera, adquiere la cualidad sustantiva del espacio geométrico, que es la homogeneidad. Cassirer se refiere al espacio mitológico y ahí, la posición sí mantiene sus contenidos propios: "el espacio visual y el espacio táctil coinciden en que, en contraste con el espacio métrico de la geometría euclidiana son "anisótropos" e "inhomogéneos": las direcciones fundamentales de la organización: adelante-atrás, arriba-abajo, izquierda-derecha, en ambos espacios fisiológicos no son equivalentes"136.

Cassirer y Panofsky toman las posiciones en el marco psicofisiológico desde el punto de vista del sujeto (cultural), pero como posiciones externas a él, o que son señaladas en referencia al espacio. La arquitectura oblicua puede convenir a un modelo de espacio geométrico, donde las posiciones adquieren un contenido relevante: en un espacio defensivo delante o detrás, izquierda y derecha no son intercambiables. En cierto modo un espacio defensivo no es desde luego isótropo.

Pero vamos a plantear la posición desde el punto de vista del punto con contenido mental, dado que constituye la base a la critica de Leibniz de la existencia del espacio y nuestro objetivo, por fuerza, tendrá que ser coincidente, si queremos operar un cambio de Principio de Posición a Principio de Transición. La cuestión radica en el lado contrario en trasvasar al espacio cualquier ámbito de determinación, vaciando de contenido al objeto. Lo que se cuestiona es a fin de cuentas, cuál es el grado de atribuciones que se da al espacio.

133 Juan Borches, "La Medición como Substrato del Fenómeno Arquitectural", en "Hogar y Arquitectura", Marzo-Abril, 1970, p. 36

134 Ibíd.

135 Ernst Cassirer, op. cit. p. 116

136 Ibíd., p. 117 y Panofsky, op. cit. pp. 10 y 11 
Veámoslo con ejemplos aportados del lado de los defensores de una teoría espacialista ${ }^{137}$.

Dice Clarke, "Y aquí es evidente el absurdo de suponer que el espacio no es algo real, sino que es meramente el orden de los cuerpos, puesto que, conforme a esta idea, si la Tierra, el Sol y la Luna hubieran sido colocados donde están ahora sitiadas las estrellas fijas más lejanas, supuesto de antemano que estuvieran en el mismo orden y distancia en que lo están ahora unos con otros, no habría sido ...la misma cosa en realidad; pero se seguirá también que además habrían estado entonces en el mismo lugar que están ahora, lo cual es una contradicción manifiesta"138. Otro ejemplo: "no es imposible para Dios el hacer dos gotas de agua exactamente iguales. $Y$ si las hiciera así, jamás llegarían a ser, sin embargo, una y la misma gota de agua, pese a ser iguales. El lugar de una no sería el de la otra, aunque fuera completamente indiferente cuál fuera colocada en cada lugar"139. En conclusión "dos lugares, aunque exactamente iguales, no son el mismo lugar"140. Nadie, desde luego, tendría problemas en admitir esto, si bien implícitamente, se está dotando de realidad al espacio, y en consecuencia, de la capacidad de intervenir en la definición del objeto que ocupa un lugar.

Podría pensarse que el cartesianismo escapa de dar tal atribución al espacio al no distinguir en principio unos lugares de otros. Tampoco es así, desde el momento en que son las dimensiones espaciales las que fijan las partes en que puede descomponerse el objeto. El espacio cartesiano estima sobre el objeto la forma en que éste es mensurable y en consecuencia establece su modo de aprehenderlo y descomponerlo. El cuerpo es representable en una figura, y no en sus propiedades esenciales: "para conocer cualquier cuerpo, se establece la figura, y se determina la dimensión que le corresponde, a partir de lo cual el cuerpo es visto como si estuviese incluido en el espacio correspondiente, y sólo después el cuerpo o su figura, es descompuesto en sus partes o proyecciones sobre los ejes, y estudiado analíticamente, según el orden de sus partes, heredado del orden existente en el espacio, y que éste transmite a toda representación, a cuanto esté en él" ${ }^{141}$. Véase, incluso sólo en el tratamiento de la figura, la diferenciación que establece espacialmente la geometría cartesiana: "Si en la geometría proyectiva... que parte de la consideración de la figura en tanto unidad dada, que se sostiene por sí, y al cual su referencia al espacio es accidental, podríamos señalar la incidencia que dicha concepción de la figura tenía sobre la concepción misma del espacio; en la geometría analítica cartesiana se produce el efecto inverso: aquí es el espacio el que constituye por sí mismo, el que expresa la unidad del todo, y toda figura siempre está como inmersa en el espacio que la engloba, en un todo del cual es parte y determinada es sus propiedades por dicha relación con el espacio global"142.

137 Los ejemplos son parte de la correspondencia entre Clarke (Samuel Clarke, portavoz dela teorías del espacio absoluto de Newton) y Leibniz.

138 Clarke, "Tercera Respuesta”, epígrafe 2, Ibíd., p. 73

139 Clarke, "Cuarta Respuesta”, epígrafes 3 y 4, Ibíd., p. 90

140 Clarke, "Cuarta Respuesta”, epígrafes 13, Ibíd., p. 92

141 Javier Echeverría, "La Intuición en Matemáticas. Las Figuras y el Lugar”, pp. 285

y 286

142 Ibíd., p. 277 
Del lado contrario se defiende la irrealidad del espacio. Para poder mantener las cualidades esenciales del objeto se parte del concepto de los indiscernibles, por el cual no pueden existir dos objetos exactamente iguales ${ }^{143}$. Esta es una facultad de los objetos, no una cualidad derivada de su posición en el espacio. Lo que hace que un objeto sea discernible de cualquier otro no es su forma ni su extensión, argumentos espaciales, sino su facultad de percepción, facultad que le confiere ser sujeto de percepción ${ }^{144}$. Veamos que este va ser un rasgo fundamental en nuestro tema. Ejemplos de este lado no faltan tampoco.

Dice Leibniz, primero con respecto a si existen los indiscernibles: "No hay dos individuos indiscernibles. Un caballero de alcurnia amigo mío, hablando en presencia de Mme. la Electora en el jardín de Herrenhausen, creyó que encontraría fácilmente dos hojas enteramente iguales. Mme. la Electora le desafió, y en vano corrió a buscarlas durante largo rato. Dos gotas de agua o de leche, miradas por el microscopio, serán discernibles"145. Ahora respecto de la facultad del espacio de poder ejercer distinciones "El espacio, según M. Newton, está íntimamente presenta al cuerpo contenido en él, y que es conmensurable por él. ¿'Resulta de todo esto que el espacio percibe lo que pasa en el cuerpo y que va a recordar una vez el cuerpo haya salido?"146. O, ¿sería el espacio capaz de alterar un orden, si fuera tal su carta de naturaleza que ejerciera por sí mismo el orden? "Del mismo modo que el espíritu se puede figurar un orden consistente en líneas genealógicas cuyas magnitudes no consistirían más que en el número de generaciones y donde cada persona tendría su sitio. Y si se

143 El principio de los indiscernibles, está en relación con la monadología, según la cual, los cuerpos, están "animados" por sus mónadas o almas. Esto es válido para cualquier tipo de materia, orgánica o inorgánica, ya que esta última, al ser compuesta, contiene a su vez un sinfín de partículas orgánicas ("y aunque la tierra y el aire interpuestos entre las plantas del jardín o el agua interpuesta entre los peces del estanque no son planta ni pez, contienen, sin embargo, todavía plantas y peces, si bien de una sutilidad la mayoría de las veces imperceptible para nosotros" Leibniz, "Monadología" epígrafe 68"). Planteada la hipótesis de materia inorgánica simple responde Leibniz: "Pero se oponen a esta consecuencia porque (dicen) los cuerpos sensibles son compuestos, a la vez sostienen que hay insensibles que son simples. Yo respondo que no estoy de acuerdo. No hay en mi opinión nada simple más que las verdaderas mónadas, que no tienen partes ni extensión. Los cuerpos simples y los perfectamente similares son una continuación de la falsa hipótesis del vacío y de los átomos, o de una filosofía perezosa, que no penetra suficientemente en al análisis de las cosas y se imagina poder llegar a los primeros elementos corporales de la naturaleza porque eso satisfaría a nuestra imaginación." Leibniz, "Respuesta Cuarta" (a Clarke), epígrafe 24 en "La Polémica Leibniz - Clarke", p. 105

144 Este es el punto esencial de la Monadología: "el estado transitorio que envuelve y representa una multitud en la unidad o en la sustancia simple no es otra cosa que lo que llamamos Percepción, que debemos distinguir de apercepción o consciencia..." ("Monadología" epígrafe 14"). Es la percepción, la indisoluble relación entre percepción y mónada, el rasgo que otorga la individualidad esencial, dado que "cada alma representa exactamente el universo entero" (Leibniz, "Carta a la princesa electora Sofía" recopiladas en "Filosofía para Princesas", p. 70) y "en esta reunión admirable consiste la naturaleza del sentir, y ello hace también que cada alma sea como un mundo aparte, representándose al mundo a su manera y según su punto de vista" (Ibíd.)

145 Leibniz, "Réplica al tercer escrito inglés", epígrafe 4, "La Polémica Leibniz Clarke", p. 78

146 Leibniz, "Segunda Carta", epígrafe 4, ibíd., p. 58 
añadiera la ficción de la metempsícosis y se hicieran volver las mismas almas humanas, las personas podrían cambiar de sitio en dichas líneas, Aquel que ha sido padre o abuelo, podría volverse hijo o nieto, etc., $y$, sin embargo, esos sitios, líneas y espacios genealógicos, aunque expresaran verdades reales, no serían más que cosas ideales" ${ }^{147}$.

También la presunción que se adjudica a sí mismo el espacio cartesiano, que, por su distinción y claridad, se considera el único modo de ver y conocer los cuerpos, dado que su orden es el orden de las cosas, el orden del $\operatorname{cosmos}^{148}$, admite su réplica por parte de Leibniz: "He objetado además que si el espacio es una propiedad y si el espacio infinito es la inmensidad de Dios, el espacio finito será la extensión o la mensurabilidad de alguna cosa finita. Así, el espacio ocupado por un cuerpo será la extensión de ese cuerpo, cosa absurda, puesto que un cuerpo puede cambiar de espacio, pero no puede dejar su extensión" ${ }^{\prime 149}$.

En definitiva, hemos pasado de una expresión del tipo $<<$ dos lugares, aunque exactamente iguales, no son el mismo lugar $>>$, a que esta expresión carezca de aplicación, dado que se ha efectuado el trasvase de sentido contrario, del espacio al sujeto (y de objeto de percepción a sujeto de percepción). De manera gráfica, el sujeto ya no se deja sus vestidos en el lugar que ocupaba, cuando cambie de lugar y otro venga a situarse en é $1^{150}$.

Para una situación invariable, estática o inmóvil, no hay objeción en atribuir a las posiciones las afecciones de los sujetos. En tanto toda la situación no experimente cambio de ningún tipo, el espacio resulta de todas las posiciones tomadas juntas. En este sentido el Principio de Posición, sólo puede referirse a una situación sin cambio o modificación. El todo equivale a las partes, es aplicable

147 Leibniz "Respuesta Cuarta", epígrafe 47, Ibíd., p. 113

148 El espacio cartesiano en su condición de cosmos matemático, de universalidad, por dos motivos: Puesto que todos los cuerpos tienen extensión. Y segundo, puesto que la extensión de los cuerpos tiene su representación más simple en el espacio cartesiano por medio de figuras.

149 Leibniz, "Respuesta Cuarta”, epígrafe 37, Ibíd., p. 110. Aunque en este caso cambiar de espacio pueda suponer cambiar de posición, admite también una consideración a un cambio de espacio cartesiano. Señala Echeverría: “aún cuando no se renuncie a la idea de estudiar una figura según su ecuación, dicha ecuación no estará referida a un sistema de coordenadas cartesiano, o incluso ni siquiera se pensará a la figura inmersa en $\mathrm{R}$ (espacio métrico definido por la recta Real). Todo esto va a confluir hacia una teoría de espacios abstractos... La elaboración de una noción básica del lugar en el cartesianismo... es lo que ha llevado a la constitución de la topología general,... y la de la recta real. Con ello se supera incluso la teoría de espacios abstractos, pues resulta que la concepción de la figura no cambia sólo en función de los cambios de espacio, lo que también cambia es la concepción del lugar... Ya no se trata de que podamos considerar espacios diferentes a $\mathrm{R}$, sino sobre todo que podamos considerar a $\mathrm{R}$ según topologías diferentes, según ordenaciones de sus puntos y de sus partes muy diversas. Todo lo cual modifica por completo las propiedades atribuibles a una parte de R, lo que se puede ver en una imagen visible". (Javier Echeverría, op. cit. pp. 296 y 297)

150 "Si el espacio es propiedad o afección de una sustancia que está en el espacio, el mismo espacio será unas veces la afección de un cuerpo; otras la de otro cuerpo... pero he ahí una extraña propiedad o afección que pasa de sujeto a sujeto, Los sujetos dejarán de ser así sus accidentes como un vestido con el fin de que otros sujetos se puedan revestir. Después de eso ¿cómo se distinguirán los accidentes y las sustancias? Leibniz Ibíd., p. 110 
en tanto se tome el espacio como extensión sin cambio. En el espacio cartesiano la elección de un punto singular para situar en él el origen de coordenadas supone la fijación de una posición al que queda referido todo el espacio. Este hecho de por sí plantea un problema de arbitrariedad al hacer recaer en un punto del espacio cartesiano, homogéneo, infinito y continuo, la singularidad de ser el referente de todo el espacio y no hacerlo recaer en otro o de modificarlo. El espacio absoluto de Newton se distingue del espacio relativo, en tanto "permanece constante igual e inmóvil, por virtud de su naturaleza y sin relación alguna con ningún objeto exterior" ${ }^{151}$. ¿Cómo se representa este espacio absoluto? "Imaginemos que todos los cuerpos han sido destruidos y reducidos a la nada, y daremos el nombre de espacio absoluto a lo que queda en pie y de lo que ha desaparecido, a la par con los cuerpos mismos, toda relación de situación y de distancia entre ellos...Todos sus atributos son, dicho en otras palabras, privativos o negativos; no parece significar, por tanto, más que la simple nada"152 Además de la inmovilidad, el espacio absoluto contempla el vacío. Pero precisamente en cuanto pierde el sustento, como hemos dicho, del contenido que le aporta al lugar la presencia del sujeto, el espacio pierde con él toda posibilidad de absorber la afección. Rota la relación espacio-sujeto, por incomparecencia de éste (espacio vacío) o por cambio de la situación y movimiento de los sujetos, en el espacio habría de recaer la sustancia, aspecto que se torna irresoluble en su contradicción en cuanto permitiera su ocupación y dejara de ser vacio, o se volviera a detener.

¿Qué consecuencia tiene esto? La misma dificultad de considerar el espacio bajo el cambio o movimiento que bajo el vacío. En relación al movimiento, que es el tema que va a abordar el Principio de Transición, la consecuencia es la dificultad de conciliar una noción de espacio con una situación de variabilidad o de cambio; en definitiva con una situación de flujo. Retener la noción de espacio pasa por la necesidad de suponer que existe algo inmóvil donde se pueda representar el movimiento. Expone Leibniz: "Subrayo, en fin, que las huellas que los móviles dejan algunas veces en los inmóviles sobre los que ejercen su movimiento han dado a la imaginación de los hombres la ocasión de formarse esta idea, como si quedara aún alguna huella pese a que allí no hay ninguna cosa inmóvil... Y es esta analogía lo que hace que se imaginen sitios, huellas, espacios, aunque esas cosas sólo consistan en la verdad de las relaciones y jamás en alguna realidad absoluta"153.

Por fin, el espacio (cartesiano y absoluto) queda, (y con él el Principio de Posición), desmontado, cuando menos como realidad substancial en una situación de cambio o movimiento. Ciertamente, carece de sentido ante este nuevo panorama a-espacial volver a la situación del problema proporcional de Wittkower. Pero también, lo que hemos venido englobando bajo la posición de Panofsky, cede ante la nueva situación de cambio. No obstante es del texto de Panofsky de donde cuelga el ramal para cambiar de escenario: "En Leibniz, el perspectivismo, filosóficamente exacerbado, destruye la estabilidad de la representación de la cual surgió"154.

151 Ernst Cassirer, "El Problema del Conocimiento", Tomo III, p. 396

152 Berkeley, "Principles of human knowledge", citado en Cassirer, íbid, p. 398

153 Leibniz, "Respuesta Cuarta", epígrafe 47, Ibíd., p. 114

154 Guy Hocquenghem, René Scherer, "El Alma Atómica. Para una estética de la era nuclear", p. 71 
"En el fondo, la ilusión proviene del hecho de que el movimiento, una vez efectuado, ha dejado a lo largo de su trayecto una trayectoria inmóvil sobre la que se pueden contar tantas inmovilidades como se quiera"155. Se verá aquí, punto por punto, el mismo problema y la misma reserva hacia la consideración del espacio más allá de proveer de ilusiones para explicar el movimiento. Se trata en este caso de Henri Bergson, pero la postura se mantiene en vigor doscientos años después. Tenemos el mismo problema, el espacio nos da una idea del movimiento, pero nos coloca fuera de éste, y nos fuerza a interpolar partes discretas en un movimiento continuo para restituirlo al conocimiento.

Disuelta la condición de inmovilidad, desaparece consigo la imagen de la trayectoria, la ilusión del espacio como algo fijo al que se traslada por puntos las secciones dadas del movimiento. Este es el trabajo que se llevó a cabo en el espacio cartesiano. La aplicación del movimiento al espacio se realiza determinando la dimensión que le corresponde al movimiento del punto. En un movimiento plano, la figura del movimiento, su trayecto, es descompuesto en partes o proyecciones sobre los dos ejes. Luego se estudiará analíticamente, según el orden transmitido por la descomposición en partes, dictadas por el orden del espacio cartesiano. Así se expresa en el Principio de Posición, tratando al todo a partir de sus partes y reencajando a unas hasta completar al otro. La consideración dinámica de la igualdad como una serie indefinida, nos aporta en modo analítico del otro punto de vista. Ya lo vimos al situar la unidad bajo la serie $1 / 2+1 / 4+$ $1 / 8+\ldots=1$ : "lejos de presuponer una división actual del segmento 1 , y considerar una suma de partes, se aplica una operación inexplicable en las categorías cartesianas, el paso al límite. Los puntos suspensivos indican esas partes <<tan numerosas como se quiera $>>$, que no es otra cosa que una designación al infinito syncategoremático, al cual puesto que no es un todo, no se podrá aplicar la igualdad estática definida por el que hemos llamado principio de posición: el todo es igual a la suma de las partes" ${ }^{\prime 156}$.

Esta inigualdad entre el todo y las partes se revela además de otras formas bajo el Principio de Transición.

Bergson, difusor contemporáneo del principio de transición, llevó en "La Evolución Creadora" (1907) la bandera del método continuo. Dejó una ilustrativa analogía del Principio de Posición con el mecanismo del cinematógrafo, hasta denominar al pensamiento científico, anclado para él en la descomposición del tiempo y el espacio en partes o intervalos, bajo ese calificativo ${ }^{157}$. Es claro que

155 Henry Bergson, "La Evolución creadora”, p. 311

156 Belaval, recogido en Camino Cañón Loyes "La Matemática, creación y descubrimiento", p. 127

157 Para Bergson el conocimiento mecánico ejercido al estudiar una situación en movimiento, un movimiento individualizado propio de esa situación, es descomponerlo en partes para volver a reconstituirlo en un movimiento abstracto y uniforme, el cual se contrasta con un movimiento tipo. Indica con ello Bergson, que la ciencia, en lugar de aplicar el estudio al movimiento mismo, inserta un paso intermedio, de descomposición y recomposición: "Y tal es también el artificio de nuestro conocimiento. En lugar de apegarnos al devenir interior de las cosas, nos situamos fuera de ellas para recomponer su devenir artificialmente... se resumiría diciendo que el mecanismo de nuestro conocimiento usual es de naturaleza cinematográfica". Henri Bergson, "La Evolución Creadora”, pp. 307 y 308 
el resultado de aplicar este método se basa en la equivalencia entre las partes y el todo, dado que lo que se estudia no es el movimiento en sí, sino uno genérico y abstracto, descompuesto según cortes transversales efectuados desde posiciones intermedias de su evolución y recompuesto basado en aquél.

Sin embargo, en un conocimiento instalado en el proceso de evolución del movimiento mismo, las partes no concuerdan con el todo, se gana o, hay más, en el todo que en la agregación de las partes. Supuesta la división de un proceso en estados intermedios, principio y final, la reunión de estas partes es menor que si entramos en el proceso mismo desde su estado de origen hasta su punto final. Es lo que llama $<<$ Transición $>>$, y en términos de Leibniz, $<<$ Principio de Transición >>. Expone Bergson: "Habría que abstraerse completamente de él (del conocimiento cinematográfico), para disipar de una vez los absurdos teóricos que la cuestión del movimiento suscita. Todo es oscuridad, todo es contradicción cuando se pretende fabricar una transición mediante estados. La oscuridad se disipa, la contradicción cae desde el momento en que uno se ubica a lo largo de la transición, para distinguir en ella estados practicando allí cortes transversales a través del pensamiento. Es que en la transición hay más que la serie de estados, es decir de los cortes posibles, más en el movimiento que la serie de posiciones, es decir de las detenciones posibles" ${ }^{158}$. Podemos pensar que hay más información, más en la evolución de la forma en el devenir que en formas realizadas una tras otra. Hay más, porque se "podrá extraer de los términos del primer tipo los del segundo, pero no (se) podrá extraer del segundo el primero"159. Pero también hay más en el Todo bajo la transición, no sólo información de la transformación sino la encadenación de los opuestos en un solo arco: "En la Matemática de lo finito, con el Principio de Posición como rector, una transformación puede hacer semejante dos elementos al modo de la curva a la recta. La curva y la recta constituyen un par de elementos $<<$ homogéneos >>. Sin embargo, en la Matemática de lo infinito, el Principio de Continuidad permite relacionar pares de elementos que aparecen más bien como una especie de contradictorios: tiempo/ instante, espacio/punto, desigualdad/igualdad"160.

Sostienen por tanto, Leibniz y Bergson, que hay aumento en el todo frente a la agregación de partes. Este aumento viene del acto mismo de generación. Hay más en el todo desde el momento que acepta la indeterminación creadora. Instalarse en la indeterminación, nos trae de nuevo el apeiron, las cualidades negativas de la Tabla de Opuestos. Hay más en lo cae que del lado del apeiron que del poras, en el rectángulo que en el cuadrado, más en lo "otro" que en lo "mismo", más podríamos añadir en lo oblicuo que en lo recto. Pero esto no serían sino cualidades, visiones desde una posición del proceso. La indeterminación no se aplica a la forma sino al cambio en general. Hay que tener precaución con categorizar bajo la forma de la figura. En Sheffield no se ha hecho la distinción sobre la forma de la ampliación, sino sobre lo irreconciliable de ésta al eje. Fíjense que no hemos designado la ampliación bajo ningún término específico. No la he

158 Ibíd., p. 315

159 Ibíd., p. 317

160 Camino Cañón Loyes, op. cit. p. 126. El Principio de Transición “permite considerar el reposo como un movimiento infinitamente pequeño y la coincidencia como una distancia infinitamente pequeña, y la igualdad como la última de las desigualdades, etc." Leibniz, Carta a Varignon, recogido en Camino Cañón Loyes, Ibíd. 
Ilamado ni la $<<$ herradura $>>$, ni la $<<$ serpiente $>$, términos empleados por los Smithson. No la he marcado con un nombre, me he limitado a nombrarla pero no designarla. No he hecho referencia a la forma. Es un problema que se desliza por el Principio de Transición y nos extrae de él inadvertidamente. "Por último, hago notar que los rastros (traces) que los móviles dejan alguna vez en los inmóviles sobre los cuales ejercen su movimiento, han proporcionado a los hombres la ocasión de formarse esta idea, como si todavía quedase algún rastro cuando ya no hay nada inmóvil, pero esto no es sino ideal, y lleva consigo únicamente que si hubiera allá algo inmóvil se le podría designar"161. Ese algo inmóvil y que por tanto admite una designación es el espacio. Al colocar una designación o un símbolo damos de nuevo con el espacio, se nos cuela el espacio. "Por el mero hecho de designarlo, de poner en su lugar la designación, el símbolo que le representa, ya está expresando la esencia propia al lugar... se está representando la suposición misma de que el lugar permanece fijo"162.

Otros falsos asideros del lenguaje aplicado al cambio, que sin embargo son del lado de lo estable: "la vista estable tomada sobre la inestabilidad de las cosas: la cualidad que es un momento del devenir, la forma que es un momento de la evolución, la esencia que es la forma media por encima y por debajo de la cual las otras formas se escalonan como alteraciones de aquella, por último el designio inspirador del acto que se cumple"163. Tres cosas cumple la Arquitectura Oblicua: es inesencial, aformal en tanto responde no a una forma sino a una variedad, no cualitativa por depender del argumento introducido en la función. Se diferencia del Principio de Transición por el designio. La forma de entre la variedad le viene otorgada desde que corresponde su lugar a una posición en el conjunto. En el Principio de Transición no hay forma prefijada para un estado evolutivo, es evolución creadora.

Partíamos de Panofsky (y Cassirer) en la consideración del espacio geométrico puro, como aquél espacio en el que la posición carece de contenido psicofisiológico. Por Leibniz, la posición espacial absorbe el contenido o la afección del sujeto que ocupa su posición en tanto se trate de una situación intemporal o sin cambio. En esta situación, en el plano relacional, que como si dijéramos, es una trama de conexiones impuesta al plano del espacio geométrico, las relaciones se articulan por medio de la distancia, a la que podemos añadir que tiene un contenido afectivo. Se distingue de este modo la $<<$ distancia >> de la $<<$ longitud $>$. Esta distinción atrae sobre sí dos conceptos más, lo actual y lo virtual. La distancia actual deviene longitud, pero su naturaleza es virtual, admite una tendencia de variación. La longitud, por el contrario es siempre actual referida a la métrica del espacio. Adaptando lo expuesto más arriba, se podrá extraer de los términos de la distancia los de longitud, pero no se podrá extraer del análisis de la longitud la distancia. La distancia podemos incorporarla en la topología de Riemann como una variedad, el conjunto de determinaciones distintas de una situación variable donde es posible una transición continua de una distancia a cualquier otra. Cada una de las determinaciones posibles se entiende sería una longitud métrica.

161 Leibniz, "Respuesta Cuarta", epígrafe 47, en la traducción presentada por Echeverría. Javier Echeverría, op. cit. pp. 378 y 379

162 Javier Echeverría, Ibíd., p. 393

163 Henri Bergson, op. cit. p. 316 
La distancia como variedad continua, según Bertrand Russell recae en el concepto de espacio relacional que distingue del espacio absoluto. Dos puntos A y B guardan entre sí una distancia que es simplemente una relación entre los dos y una longitud actual, o cierta porción de espacio, que se extiende entre y $\mathrm{B}$. Si adoptamos la teoría del espacio relacional, "los términos A y B, cuya distancia es espacial, deben ser a su vez, ellos mismos no espaciales, pues no son relaciones. $\mathrm{Si}$ adoptamos la segunda, es decir, la distancia actual que media entre dos puntos, comprobamos que ésta es divisible en un número indefinido de puntos, cada uno de ellos igual a los puntos terminales A y B".

Digamos que esta distinción nos lleva a admitir o recomponer la idea de espacio, bajo la condición de no ser actual, sino una virtualidad. El espacio relacional definido por una variedad de distancias o posiciones virtuales entre sujetos no espaciales (no definidos a través de la posición) es dependiente de las relaciones o afecciones de los sujetos. En cada corte transversal aplicado a la propia evolución del espacio relacional, o dicho de otro modo, en todo estado que detengamos la evolución de la virtualidad y la hagamos actual, los sujetos devendrá objetos espaciales, acto de lo que se extrae la división en partes del espacio métrico. Para entendernos, aunque sea burdamente, el lenguaje coloquial tiene expresiones del tipo "ponte en mi lugar" para denominar situaciones del tipo "qué harías tú en mi lugar", que suponen una variación de una situación dada. Es de suponer que la posición concreta del primero, pierde el punto de vista de éste cuando le cede la posición al segundo, y el consejo estriba precisamente en el modo de encarar la situación desde dos afecciones subjetivas diferentes. Y ciertamente para cada una de las situaciones se establece una medición distinta entre el sujeto y el motivo de consejo, que puede ser interpretada bajo un espacio métrico. Por otra parte, cada sujeto deviene espacial en el momento o instante de encarar el asunto.

Trátese, por tanto, el espacio relacional como un espacio en evolución en el que se pueden designar momentos concretos como en el ejemplo anterior. Con este ejemplo he querido poner de manifiesto el carácter subjetivo del espacio relacional, que incorpora dos estados subjetivos, la conciencia y la percepción.

No vamos sino a esbozar la teoría del punto de Leibniz, para distinguir entre el punto matemático y el punto metafísico (dejamos al margen el punto físico). El punto matemático, siguiendo la distinción anterior de Russell es un punto espacial, es punto de referencia de longitudes o extremidad de la línea. El punto metafísico, es el centro de percepción y de conciencia, y, esto es importante para el principio del movimiento o del cambio, dado que es la sede de la fuerza o virtualidad. Como es lógico pensar, el punto metafísico no es espacial y podemos suponer que es la unidad del espacio relacional, si tal cosa cabe atribuir a este espacio. En una teoría como la topología psicológica de Kurt Lewin, cabría añadir que actúa sobre este punto una fuerza de repulsión o de atracción como principios de movimiento. No es el caso, dado que no es posible en Leibniz suponer la teoría de campo de fuerzas.

No se puede hablar de relación entre los dos tipos de puntos, dado que técnicamente sólo tiene sustancia real el punto metafísico. El punto matemático es el modo del punto metafísico en el espacio 
geométrico y se dice que el punto metafísico "se proyecta" en el punto matemático. Vemos por tanto que se mantienen los dos planos, el real y el del espacio o ideal. Para secciones dadas en la duración, el punto matemático es, o se puede asociar, al punto cartesiano. A su vez, el punto matemático constituye también el punto de vista del punto metafísico. Esto adquiere un sentido preciso si hacemos la siguiente deformación: en la estructura geométrica de los ejes cartesianos el haz de rectas paralelas lo hacemos confluyente en un punto, lo convertimos en una estructura fugada, en un lienzo con una estructura perspectiva al modo del lienzo del pintor. Digamos entonces, que el punto matemático está en un espacio perspectivo. ¿Que consecuencia observamos de esto? El desdoblamiento del punto en Leibniz reúne la doble modalidad del espacio geométrico y perspectivo con la transición continua. A partir de conjugar la idea del punto metafísico como unidad substancial, de la unión de la multiplicidad en un punto, versión metafísica del concepto matemático de unidad que engloba la serie indefinida, con la concordancia de las rectas paralelas en un punto del infinito, el intento es hacer de la perspectiva una ciencia geométrica del continuo con lo que suma esta ciencia, la representación del infinito en la propia estructura del plano, el acceso al infinito actual, lo que incorpora del Brouillon Project de Desargues. A través de estos cortes en la duración, por el que nos asomamos al espacio en intervalos, atisbamos ya la estructura direccional y dinámica marcada por la inflexión de las paralelas en el punto de fuga, y podemos decir que el punto de vista "fuga hacia delante"164.

Tomando el punto metafísico como un contenido mental, sin posición asignable, veremos que participan dos fuerzas o causas de movimiento sobre él, la apetición y la percepción. La apetición podría convenir a un conato o ímpetu, que contiene el principio de fuerza y acción. La naturaleza de esta fuerza puede asimilarse a una fuerza o empuje vital y en este sentido es por definición continua.

La percepción es el modo donde se juega la continuidad. En la percepción entra en juego la memoria que incorporan las percepciones precedentes y a su vez preparan las futuras. La continuidad de la variabilidad del movimiento recae en la continuidad de las percepciones. Del mismo modo que el reposo era una forma de movimiento imperceptible, que garantiza el principio de continuidad, la percepción no puede surgir más que de otra percepción. Es realmente en este punto donde su cobra sentido el principio de continuidad o de transición: "Y lo mismo que todo estado presente de una sustancia simple es naturalmente una consecuencia de un estado precedente, así también el presente está grávido del futuro"165.

En este sentido podemos concluir que se trata de un estiramiento del pasado sobre el presente que impulsa hacia adelante el movimiento. No se alcanzan posiciones más o menos singulares a saltos. Incluso distinguir una percepción de otra sería dotar de una numeración a la sucesión de percepciones y siempre cabría intercalar otra en medio. Realmente podemos convenir que es una percepción indefinida que va "revistiendo distintas cualidades": (cuando) la conciencia realiza una discriminación cualitativa sin ninguna intención de contar las cualidades o incluso de hacer de ellas varias; entonces 
hay multiplicidad sin cantidad. Otras veces, por el contrario, se trata de una multiplicidad de términos que se cuentan, o que se concibe como capaz de contarse; entonces se piensa en la posibilidad de exteriorizar unos por relación a los otros; se los desarrolla en el espacio"166.

Tan continuo es en Sheffield el eje como la ampliación. La diferencia estriba en el método. El desarrollo por estiramiento lo que hace es colocar al arquitecto mentalmente fuera del espacio y situarlo en la propia duración de la acción de estiramiento, que dura mientras se trabaje conscientemente en ello. Los cambios de dirección no son sino choques contra los objetos, los edificios, la calle existente. No hay intencionalidad en los cambios de dirección, sólo colisiones, como "cuando el sabio Tales, abstraído por la observación de un fenómeno celeste, cae en un pozo"167. 


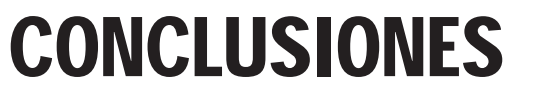

En relación al título.

Cuando empecé coloqué Sheffield en el lado de la cultura de masas. La evolución de la Tesis ha hecho que perdiera su capacidad de decidir sobre el transcurso de ésta. No obstante, cuando he situado el centro de discusión entre las posturas de Wittkower y de Panofsky en el marco de las categorías esencialista y funcionalista, en relación a si predomina el sentimiento desde el objeto o el sentimiento desde el sujeto, no pensaba que tuviera una consecuencia en el tema de la cultura de masas, y sin embargo, antes de pasarlo por alto, citaré una consideración a este respecto: "el objeto ya no se define por su forma esencial, sino que alcanza una funcionalidad pura, como declinando una familia de curvas enmarcadas por parámetros, inseparable de una serie de declinaciones posibles o de una superficie de curvatura variable que él mismo describe... Como muestra Bernard Cache es una concepción muy moderna del objeto tecnológico: ni siquiera remite a los orígenes de la era industrial, cuando la idea de lo estándar aún conservaba un especto de esencia e imponía una ley de constancia $(<<$ el objeto producido por las masas y para las masas $>>))^{\prime 1}$. Este es un texto de Deleuze que recoge las implicaciones del estudio de la variabilidad de las tangentes asociadas al movimiento de un punto en las curvas en la construcción del cálculo infinitesimal de Leibniz y que enlazan con la geometría proyectiva de Desargues

Conforme a lo expuesto en el Capítulo III, a partir de que queda establecida una variabilidad formal para un grupo de transformación diferente del euclídeo, como era el caso del proyectivo en la arquitectura oblicua, la idea de una estandarización queda a cargo del método proporcional, cuyo fin, efectivamente, es dotar de relaciones dimensionales preferentes y cuya aplicación, como es el caso del Modulor, es proveer un alto nivel de estandarización en los componentes. En el caso de Sheffield, la sustitución de los componentes del cerramiento por otros con una modulación distinta, como indican la axonométricas de 1953 y 1978, indican el poco peso que se otorga a la permanencia de estos elementos. Una dinámica de cambios, según lo expuesto por Cache, aleja la perspectiva de la cultura de masas de lo expuesto en este trabajo, por lo menos en cuestión de estandarización. 
Mucho más interés tiene el segundo título, la estética de la deformación. En este punto, la conclusión, es de una superación de la deformación al imponerse el modelo de los dos principios, el de Posición y el de Transición. La deformación sugiere una visión estática o bien una multiplicidad de visiones estáticas por conciencias discontinuas que entran aleatoriamente sobre un proceso en evolución. Pondré un ejemplo sobre la obra de Francis Bacon, dado que Sören Thurell relaciona a este pintor con nuestros arquitectos ${ }^{2}$. Dice Milan Kundera al observar algunos trípticos de Bacon: "Miro los retratos de Bacon y me sorprendo que, pese a su $<<$ distorsión $\gg$, se parezcan todos a su modelo. Pero ¿cómo puede parecerse una imagen a un modelo del que es, conscientemente, programáticamente, una distorsión? Sin embargo, se le parece; lo prueban las fotos de las personas retratadas; e incluso si no conociera esas fotos es evidente que en todos los ciclos, en todos los trípticos, las diferentes deformaciones del rostro se parecen, que se reconoce en ellas a una única y misma persona. Si bien <<en distorsión >>, esos retratos son fieles..." ${ }^{3}$ Bien, probablemente la forma de trabajar de Bacon fuera a partir de ir estirando o aplicando una fuerza deformante sobre el retrato, ciertamente lo desconozco ${ }^{4}$. Lo que me interesa resaltar es la mirada de Kundera. El toma los retratos de los trípticos como vistas deformadas de un objeto variable, que es la persona retratada, dado que según nos comunica tras ellos se reconoce a una única y misma persona. Si recordamos la definición de variedad continua de Riemann, y lo que llama los quanta o puntos de la variedad, habremos de convenir que las deformaciones de las que habla Kundera, los retratos de Bacon, son esos puntos de la variedad. Decía Riemann: Si entre un conjunto de determinaciones distintas de un objeto variable es posible una transición continua de cada una a cualquier otra, entonces la totalidad de aquellas constituye una variedad extensa: cada una de ellas se llama punto de la variedad"5. Considerando ahora, no ya a la persona sino su emulsión en la pintura, la serie infinita de retratos posibles que pudiera hacer Bacon, constituiría la variedad continua. Si supusiéramos que Bacon comienza cada nuevo retrato exactamente donde dejo el anterior para transformarlo y así sucesivamente tendríamos una concepción continua de la variedad de retratos. Pero Kundera, en lugar de asistir al hipotético proceso creativo, al que sólo tiene acceso Bacon, se sitúa en una exterioridad al mismo, en la que solo ve deformaciones. A esta visión establecida desde posiciones exteriores a la variedad, o que la toma en momentos diferentes para estudiar su evolución puntualmente, se oponía la consideración del movimiento de Bergson: "suponer que el móvil está en un punto del trayecto es cortar, a través de un golpe de cincel dado en ese punto, el trayecto en dos...Es distinguir dos actos sucesivos ahí donde en hipótesis, no hay más que uno. Finalmente es transportar al curso mismo de la flecha todo lo que puede decirse del intervalo que ella ha recorrido, es decir, admitir a priori este absurdo de que el movimiento coincide con la inmovilidad" ${ }^{\prime \prime}$. Kundera, por tanto y como no puede ser de otro modo, sólo asiste a la suplantación del movimiento efectuada por la inmovilidad con apariencia deformada.

2 Véase Sören Thurell “Alison \& Peter Smithson”, Arquitectura no 292, Julio 1992

3 Milan Kundera, "Presentación" en "Bacon. Retratos y Autorretratos", p. 11

4 "Yo hago marcas. Es lo que llama marcas al azar. Ven que es realmente una especie de limpieza. Toma una brocha o un trapo y limpia una parte del cuadro". Gilles Deleuze, "Pintura. El Concepto de Diagrama”, p. 43

5 José Ferreirós, "Bernhard Riemann. Riemanniana Selecta”, p. CVI

6 Henri Bergson, "La Evolución Creadora", p. 311 
La postura que se ha defendido desde la Tesis ha sido precisamente la contraria a Kundera. Suponer una acción de estiramiento y seguir el curso de esta acción. Determinar cual era el origen o punto donde se aplica el estiramiento, e ignorar cualquier espacialidad, hasta llegar a reconocer que los cambios de dirección eran por colisiones o barreras al proceso, lo que Leibniz designa como fuerza derivativa. Por otra parte se ha considerado el estiramiento como un elástico en cuya punta se aplica el vector de fuerza del acto creativo "como un punto elástico que sin cesura se va distendiendo a lo largo del espacio"7.

Ciertamente en este punto ha habido una variación desde la primera hipótesis que consistía en tratar el proyecto como una imagen de la deformación. Lo irreductible, a mi juicio, en el proceso compositivo entre las dos partes, tras intentar recrear el proyecto desde cero y descubrir que no había posibilidad de deducir ni descubrir una forma desde la otra, me llevó a moverme del lado de la existencia en Sheffield

LÁMINA IV.1

de dos principios opuestos. Una imagen del frontón de la puerta de Santa Maria in Trivio de Giacomo del Duca ayudará a entender el problema que generó la coexistencia de dos formas incompatibles en origen y yuxtapuestas una contra otra. Por tanto, en lo referente al título, la conclusión es que ambos han quedado superados por la dinámica de la propia Tesis.

La idea de que el proyecto de Sheffield es un organismo complejo en el que coexisten dos formaciones irreductibles a un único origen común a ambas cobra existencia en el propio transcurso de la Tesis. Un texto localizado en el Archivo de Alison \& Peter Smithson apunta en la misma dirección acerca de la necesidad de considerar una dualidad. Se trata de un texto retrospectivo, escrito en 1979, para la exposición "ALISON e PETER SMITHSON. DUE PROGETTI"8. Apoyándose en la conjunción entre "alta densidad" y ."el sueño de Virgilio", un par de conceptos complementarios presentes desde 1954 para explicar este proyecto, el texto los presenta como dos naturalezas diferentes, una perteneciente al ámbito de la factible y otra al de la ensoñación: "En algunas notas del 21 de Enero de 1954 - tomadas con motivo de una conferencia en la Architectural Association - Peter Smithson tenía escrito, "Alta Densidad y Sueño de Virgilio". Cómo estas dos naturalezas, lo factible y la ensoñación, se sostiene y se traba una en otra, nos ha intrigado constantemente" ${ }^{\prime \prime}$.

La Tesis ha trasladado las ideas de lo factible y la ensoñación al campo de lo espacial y lo temporal. Lo factible, la parte práctica, la manera de resolver la distribución de la afluencia de estudiantes por medio de una concentración espacial, y luego, de otro lado, la ensoñación, la virtualidad, la modificación, como un proceso temporal.

A estas dos naturalezas, desde las páginas de la Tesis, se las ha asociado dos modos de operar en el proyecto. Uno, bajo el Principio de Posición, que toma una vista actual del espacio para ordenar sus

7 Xavier Zubiri “Cinco Lecciones de Filosofía”, p. 172

8 Exposición que reúne el proyecto de la Universidad de Sheffield y el proyecto del Churchill College, celebrada en la Cooperativa Libraria Editrice Architettura (C.L.E:A.R.), en Roma, entre el 28 de Mayo y el 30 de Junio de 1979. El texto original está fechado el 14 de Febrero de 1979.

9 "Sheffield University and Churchill College: 1953 and 1959", 2o folio. El 1을 esta firmado por P.D.S. en fecha 14 de Febrero de 1979. 


\section{LÁMINA IV.1}

“...una imagen del frontón de la puerta de Santa Maria in Trivio de Giacomo del Duca ayudará a entender el problema que generó la coexistencia de dos formas incompatibles en origen y yuxtapuestas una contra otra"

Giacomo del Duca "Puerta de Santa Maria in Trivio", 1573-1575
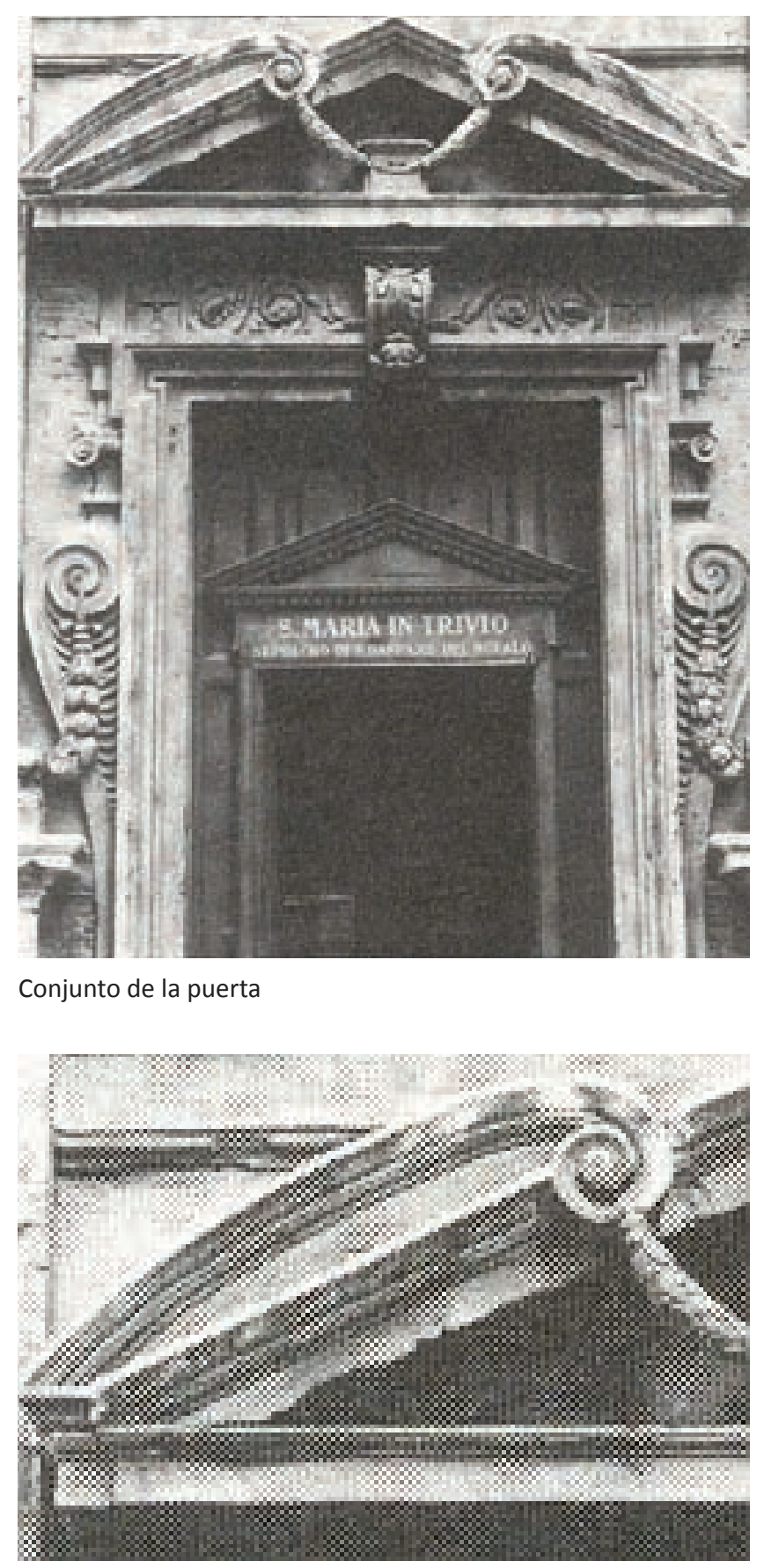

Detalle del frontón 
posiciones singulares y construir un eje de ordenación del conjunto. El otro, el Principio de Transición Continua, que es acción pura, toma el extremo del Firth Court para producir un estiramiento del espacio contenido en éste. Las facultades se alojan en este espacio que surge nuevo, que existía pero como potencia contenida en el viejo edificio; pura virtualidad opuesta al estado actual: simboliza el crecimiento y el cambio.

En este mismo texto retrospectivo se indica la presencia del eje: "Eje simbólico entre la Biblioteca y el Union (el edificio comunitario de las actividades estudiantiles)"10. Para nosotros, el eje, es una línea norte sur que ata los extremos del recinto universitario y que ordena el espacio. Una aplicación del Principio de Posición.

La otra parte recibe el nombre de "continuum". En un extracto del informe original Alison y Peter Smithson se refieren a él como el "continuum"”: El "continuum" contiene la Administración, Artes, Física, Química, Medicina, y termina en la Biblioteca / Escuela de Arquitectura"11. El reparto del espacio es intuitivo sin escoger puntos concretos: "los departamentos con necesidad de grandes espacios (Las facultades de Química y Medicina) han sido localizadas en el desarrollo este del continuum, y aquellos que requieran espacios relativamente pequeños (Artes, Administración y Física) están en la parte oeste del continuo"12. Denota meramente un reparto de actividades en función del espacio resultante obtenido de trazar el continuum.

Como ocurre con la crítica de Leibniz al espacio cartesiano, los ejes no pueden dar solución a problemas relativos al estudio del movimiento, del flujo, y del cambio, y necesitan otro sistema o principio de orden superior para resolver sus peculiaridades; es el Principio de Transición Continua o de Continuidad. En este sentido, la Tesis promueve el Principio de Continuidad para estudiar el continuum.

En esto radica por tanto el sentido dual que ofrece la Tesis para interpretar Sheffield y que deja el titulo dado originalmente en estado de complementación.

Un texto de Greg Lynn ${ }^{13}$ aporta un término que concide básicamente con lo expuesto en estas páginas para la parte que hemos denominado ampliación y que coincide con lo que Alison y Peter Smithson Ilaman el continuum. Greg Lynn utiliza el término "forma animada". Según Lynn es necesario cambiar de un espacio pasivo de coordenadas estáticas, como el espacio cartesiano, a uno activo de interacciones, lo que implica salir de una pureza autónoma. En este punto coincide con la crítica vertida desde nuestra posición a la limitación que ejerce el marco esencialista promulgado desde los principios proporcionales. Denuncia Lynn que esta pureza autónoma ha llevado a los arquitectos a rechazar el principio de fuerza virtual,

10 Ibíd.

11 Alison y Peter Smithson, "Extracts from the Original Report", contenido en un texto de 1959.

12 Ibíd.

13 Greg Lynn, "Animated Form" en "Injertos no 11", Universidad Internacional Menéndez Pelayo, editado por CIRCO, con motivo del Seminario "Injertos": pensamiento periférico. Una crítica. / IV Bienal de Arquitectura Española. Santander, Julio 1997. Para la Tesis se ha seguido una versión ampliada y traducida, en una distribución digital de nombre Spanish Theory. 
junto con la variación diferencial que implica. Reclama por tanto al arquitecto del espacio, que lo concebido como un contexto de fuerza y moción, más que como un vacío neutral. Y termina por enunciar las maneras en que se manifiesta la operación de estatismo que ha llevado a promover unos componentes específicos y no otros a la forma de proyectar: verticalidad (como posición de jerarquía cultural al promover edificios perdurables), utilidad, tipología, procesión, verticalidad (en función de un modelo estrictamente gravitatorio).

Explica éste último en unos términos que ayudan a encajar algunos de los argumentos defendidos en la Tesis: "En el modelo complejo y estable de la gravedad, la moción se transforma en un principio de orden...Estas ideas se vuelven muy aparentes en los 2 modelos de gravedad, presentados por René Descartes y Gottfried Wilhelm Leibniz. Descartes aisló y redujo elementos... a sus identidades constitutivas, para crear una ecuación estable... Leibniz, de otro lado, examinó componentes dentro de su campo contextual de influencias, dentro de un continuo temporal en desarrollo. Al retener el rol creativo-estructural de tiempo y fuerza, determinó que una posición en el espacio sólo puede ser calculada continuamente como un flujo vectorial..." ${ }^{14}$

Coincidimos en la crítica al modelo estático, pero nos separa su consideración del espacio. Como he señalado repetidamente, en este trabajo, el Principio de Transición niega rotundamente cualquier consideración previa del espacio, incluidos aquellos como campo de fuerzas o atractores, estableciéndose únicamente como un continuo temporal en desarrollo, debido a la fuerza activa, y cuyas variaciones son debidas a colisiones o barreras al desarrollo, mutándose la fuerza activa en fuerza derivativa (engendrada por la energía derivada de la colisión de los cuerpos entre sí) ${ }^{15}$. Véase en este punto lo expuesto en estas páginas por Cannigia: un recorrido que no obedezca a su rectitud debe hacerlo para mantener la continuidad en la superación de un obstáculo interpuesto cualquiera. Plantear el espacio como una realidad fenoménica que informa el desarrollo de la forma supone un reconocimiento de sus propiedades que lleva a Lynn a proponer un espacio topológico, que hemos descartado por lo anteriormente expuesto.

Sin embargo, el término "forma animada", puede ser útil en nuestro trabajo al implicar algunas referencias que nos son pertinentes: "Esta relación entre fuerza y objeto que almacena esa fuerza en su forma nos recuerda a una declaración de Henri Bergson... (Bergson argumentaba que la materia no puede ser separada del proceso histórico de su actualización)... Este rechazo a la visión de forma, tiempo y moción discretos...se basaría en ese "vitalismo anorgánico" que recorre las obras de Leibniz, Bergson, y Gilles Deleuze..."16

Termina Lynn por definir vitalismo anorgánico como una teoría donde "los organismos son vistos como entidades de órganos vivientes que han sido fusionados... No se puede descubrir o deducir una estructura esencial en dicho conjunto..." ${ }^{17}$. 
LÁMINA IV.2
Bien, en definitiva, concuerda con lo deducido en esta Tesis por otras vías, que nos llevó a promover el concepto de monstruosidad elaborado por Darwin a partir de la combinación en un solo cuerpo de conformaciones normales en animales de especies diferentes. El término anorgánico que promueve Lynn sugiere una mejor aplicación al proyecto de Sheffield, en tanto contempla una transferencia recíproca de habilidades de un organismo a otro: "Un cuerpo es el conjunto fusionado de un ecosistema que opera con un alto nivel de continuidad y estabilidad... es una lógica de diferenciación, intercambio y conjunto, dentro de un ambiente de influencias.." En el caso de Sheffield es obvio que ambas partes ponen al servicio común el nivel de concourse, creando un anillo continuo elevado de circulación.

Pero por otra parte, la visión de Lynn nos sitúa en un nivel de intencionalidad que no hemos querido abordar en esta Tesis, replegándonos al estado de generación de las partes, que nos ha permitido distinguirlas con precisión. La Tesis se ha situado en el corazón mismo de la dinámica del proyecto y de la consideración del espacio bajo criterios objetivos y subjetivos, con posiciones enlazadas mediante longitudes, o sujetos móviles que establecen sus distancias mediante relaciones no espaciales. Y en este sentido, la conclusión, dejando al margen cualquier argumento valorativo, es que cada parte responde a un principio de proyectar diferente y que ambas, en su proceso generativo hacia el nivel de las formas, son irreductibles entre sí.

La unión en una sola entidad requiere ver previamente esta doble naturaleza con precisión. Así, la conclusión podría venir dada por simultaneidad de dos concepciones del proyecto excluyentes entre sí, reunificadas tras la actualización de ambos procesos. De ésta incompatibilidad primordial a la que tenemos acceso mediante la visión unificada que nos enseñan Alison y Peter Smithson, se desprende la perturbación que remueve la imagen y que la hace entrar en el reino de lo memorable. La estética de la monstruosidad o de los incomposibles, sería el tercer componente que vendría sumarse al titulo y que los comprende a todos. 


\section{LÁMINA IV.2}

“...el concepto de monstruosidad elaborado por Darwin a partir de la combinación en un solo cuerpo de conformaciones normales en animales de especies diferentes..."

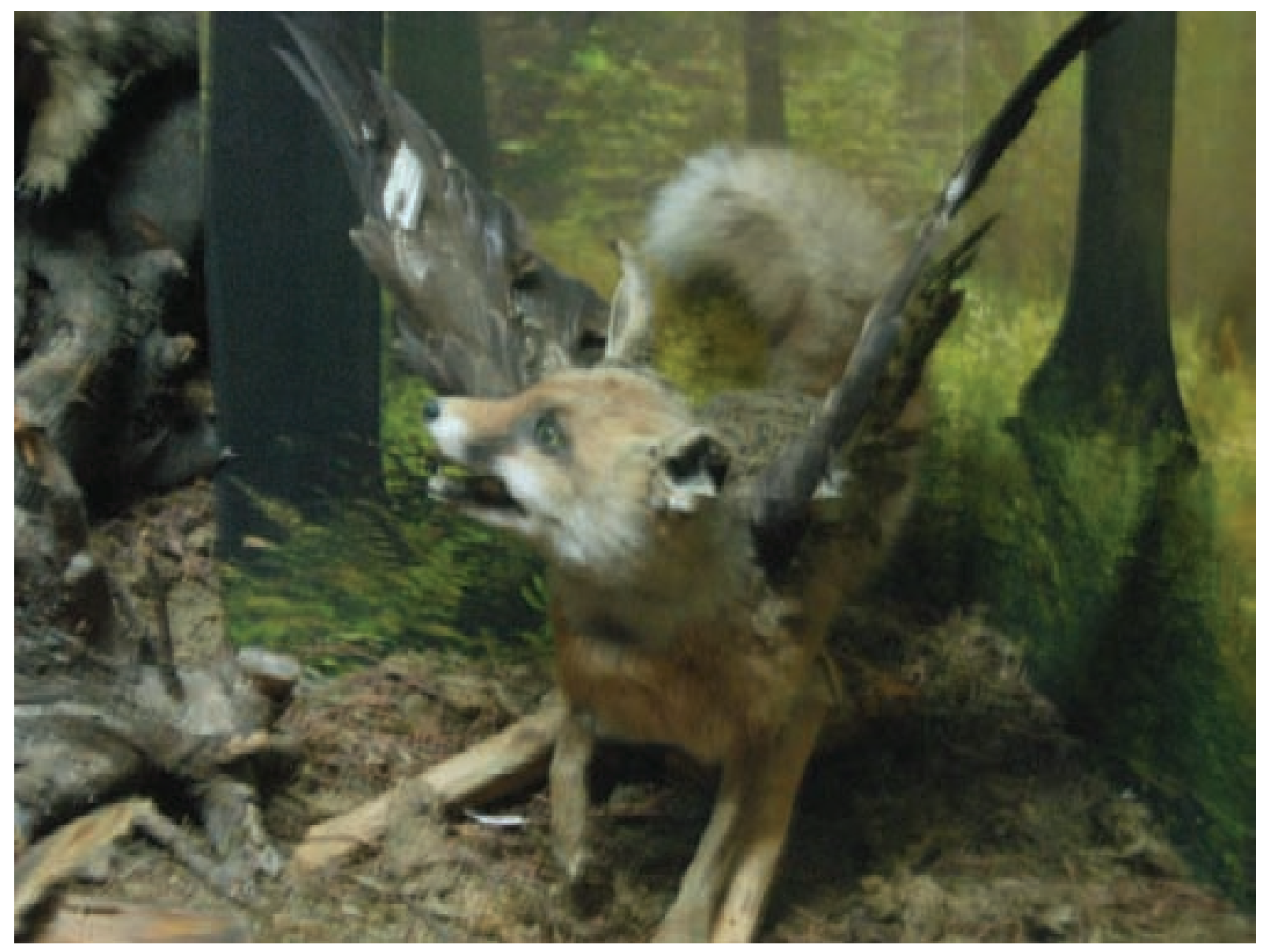

Cuerpo de zorro con formación de alas.

Deutsches Jagd- und Fischereimuseum, Munich. Fotografía del autor. 2007 


\section{V}

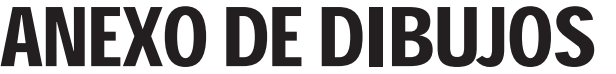

Se ha optado por colocar agrupados y al final de la Tesis todos los dibujos realizados por los Smithson para la Universidad de Sheffield. Se entiende que la lectura de la Tesis se hace más fluida sin las pausas a que obliga un estudio de los planos, y por otra parte, dado que hay variaciones y versiones que difieren de unos planos a otros, parece más cómodo para su comparación reunirlos todos juntos.

El concurso, como se ha explicado en otra parte, constaba de dos planteamientos; por un lado se trataba de un concurso de ideas para la construcción de varios edificios y por otro, se pedía también un plan de desarrollo de los terrenos universitarios. Los planos así lo reflejan.

Por otro lado hay dibujos no presentados al concurso, entre los cuales, por su peso específico, está la axonométrica de 1953, y su variación de 1978. Dedicaré algunos comentarios sobre ello:

Los Smithson tardaron unos años en publicar su proyecto ${ }^{1}$. La 1 a vez que lo hacen es en 1957 en el artículo de "The Aesthetics of Change" ${ }^{2}$, donde, además de incluir dibujos y fotos de Cambridge y Oxford y referencias a Illinois Institute of Tehnology, al ayuntamiento de Säynatsalo, y a la vivienda de los Eames, ilustran su proyecto con el Plano se Situación (ref. 53 00), el Alzado Oeste de la Biblioteca (ref. 53 08) y un dibujo retocado del Alzado General a Western Bank, que tiene el interés de que recoge una estructura a modo de balcón, en un enclave que ellos llaman "The Great Head".

Un segundo texto de Alison y Peter Smithson dedicado al proyecto de Sheffield es una contribución de 1962 al libro "Structure in Arts and Sciences", que recoge artículos de varios autores, compilado

1 Me refiero bajo su propia interpretación, dado que el proyecto fue primeramente publicado por Banham en 1955, en el artículo "The New Brutaliam" (Architectural Review, Diciembre 1955).

2 "The Aesthetics of Change", Architects'Year Book, no 8, 1957, pp. 14-22. Este artículo, retocado en las ilustraciones es aportado a su libro "Ordinaress and Light" de 1970, pp. 154-59 
por Gyorgy Kepes y editado en $1965^{3}$. Es en este artículo donde aparece por primera vez la axonométrica (retocada con una trama que destaca el nivel de concourse), que se convertiría en el plano más relevante de los confeccionados durante el concurso, llegando incluso a servir como imagen de referencia para las nuevas universidades ${ }^{4}$.

Aparece también la perspectiva, no recogida en esta Tesis, dado las dudas que genera su origen. Se atribuye a un dibujante, Robinson, del cual desconozco cualquier referencia acerca de él. Para algunos como Augusto Mazzini ${ }^{5}$ se trata de Ron Simpson, que hubiera estampado su abreviatura "Robinson" en el dibujo de un camión de reparto en la perspectiva. Lo que puedo llegar a descifrar de la firma (en algunas reproducciones con un formato algo mayor se puede entrever una firma) no parece representar el nombre de Ron Simpson. Por otro lado, Peter Smithson parece indicar que es hecha ex profeso para la publicación de Reyner Banham en Architectural Review de Diciembre de 1955: "Architectural Review's perspective done in-house for their publication of the scheme, December 1955, in Banham's New Brutalism"6, aunque no aclara la autoría. Por mi parte no he conseguido ver el original y no sé sigue conservando.

El tercer artículo dedicado monográficamente al proyecto de Sheffield es el que acompaña una exposición celebrada en Roma en 1979 dedicado a los proyectos de Sheffield y Churchill College (1959). En la portada del catálogo se imprime como único dibujo la axonométrica del 53, sin los retoques del libro de Kepes. El artículo recoge aspectos destacados de la memoria del concurso y una amplia muestra de dibujos antiguos así como nuevos: un esquema y el Plano de Situación (ref. 53 00), el Alzado de la Biblioteca (ref. 53 08), el Alzado de la Aulas Generales y el testero de las Salas de Conferencias y del edificio de Administración y Artes (ref. 53 05), y unas axonométricas nuevas de 1978. Hay dos seccionadas por el nivel de concourse (con y sin gente) y dos del conjunto (con y sin árboles), con una modificación del cuerpo de lo Biblioteca respecto del plano original.

A partir de esta tercera publicación ya no conozco más artículos debidos a los Smithson dedicados exclusivamente a Sheffield. Las restantes referencias a este proyecto quedan englobadas dentro del conjunto de su obra.

En esta Tesis, se ha recogido el juego completo de 9 planos del concurso, algunos nunca publicados (ref. 53 02, ref. 53 03, ref. 53 04, ref. 5306 y ref. 53 07). Así mismo se han modificado algunos planos de concurso para recoger variantes propias a la particularidad de éste: como se verá, los planos presentados para la Biblioteca contemplan un desarrollo menor que el indicado para el Plan global de la universidad.

3 Parece ser que al publicarse hubo variaciones tipográficas importantes respecto a lo impreso en el libro definitivo. Véase Jeremy Baker, "Arena. The Architectural Association Journal", Febrero 1966, p. 211

4 Michael Bravne, "The New Universities”, Architectural Review, Abril 1970, pp. 25054 y 283-85

5 Augusto Mazzini "Il Rosso e il Verde", en Marco Vidotto, "A+P Smithson", p. 78

6 Peter Smithson, "Sheffield University 1953. Ilustration to Text. Sketch Plan as prepared for inclusion in Ordinariness and light (i.e. c. 1967)". Texto redactado con motivo de la exposición en Roma de los proyectos de Sheffield y Churchill College. (1979). 
Por otro lado he creído conveniente, incluir algunos planos del proyecto presentado por Skinner, Bayley y Lubetkin. En primer lugar por el interés en sí del proyecto. En segundo lugar, porque algunos dibujos no quedaba recogidos en la monografía sobre Lubetkin de John Allan? $Y$ en tercer lugar y sobre todo por ser exponente de una arquitectura desarrollada por un eje compositivo y por tanto perteneciente a lo que he denominado Principio de Posición y porque, además, es interesante comparar algunas piezas singulares de ambos proyectos, como las Salas de Conferencias, que presentan notables coincidencias.

Otro aspecto, que he incluido en las láminas del proyecto, son las distribuciones de pilares. Creo que muestran muy claramente la diferencia entre una distribución muy particularizada del los soportes, como es el caso del los tres ejemplos recogidos de los Smithson, frente a una neutral, como es el caso de los edificios de IIT de Mies van der Rohe. Se pretende con esto destacar la diferencia entre un espacio absoluto, como es el espacio base de Mies van der Rohe, frente a un espacio circunstancial, como es el espacio de la práctica según lo expuesto en esta Tesis. De la distribución de pilares de los planos de los Smithson es prácticamente inmediato deducir cada proyecto, sea Hunstanton, el Economist o el de Sheffield. En este sentido adquieren una particularidad las posiciones, perfiles y tamaños empleados para los soportes, que los enlazan, en cierto modo, con las contingencias de posición vistas para la columna en la Arquitectura Oblicua.

He confeccionado algunos dibujos como los alzados de Sheffield, Hunstanton y dos edificios de Mies para el IIT con el objeto de comparar los tamaños entre ellos. Queda así de manifiesto la gran escala del proyecto de Sheffield, frente a otros proyectos también de grandes dimensiones.

Se muestran también los planos originales del Firth Court, necesarios como material indispensable para enlazar el proyecto de concurso con el edificio de Gibbs. Se presenta así mismo un plano del estado actual del Firth Court, cedido por los Servicios Técnicos de la Universidad de Sheffield, simplificado de los añadidos posteriores (que en la actualidad vuelven a colmatar el terreno) y sobre el cual se han conectado la versión de los edificios de concurso y la del Plan de Ordenación.

Por último, en otro orden de cosas, se han incluido algunos dibujos en apoyo de la demostración de ciertos pasajes del texto. Es el caso de la lámina dedicada al Teorema de Desargues, y la Razón Armónica, y los dibujos que explican el proceso de transformación del Economist Buildng en número figurado y las consecuencias de ello. Así mismo se incluyen unos dibujos de Sebastián Fernández de Medrano con indicaciones mías con el objeto de exponer en dibujo la variada y compleja nomenclatura del baluarte, tratado en el Capítulo III. 


\section{LÁMINA V.1}

"El tercer artículo dedicado monográficamente al proyecto de Sheffield es el que acompaña una exposición celebrada en Roma en 1979 dedicado a los proyectos de Sheffield y Churchill College..."
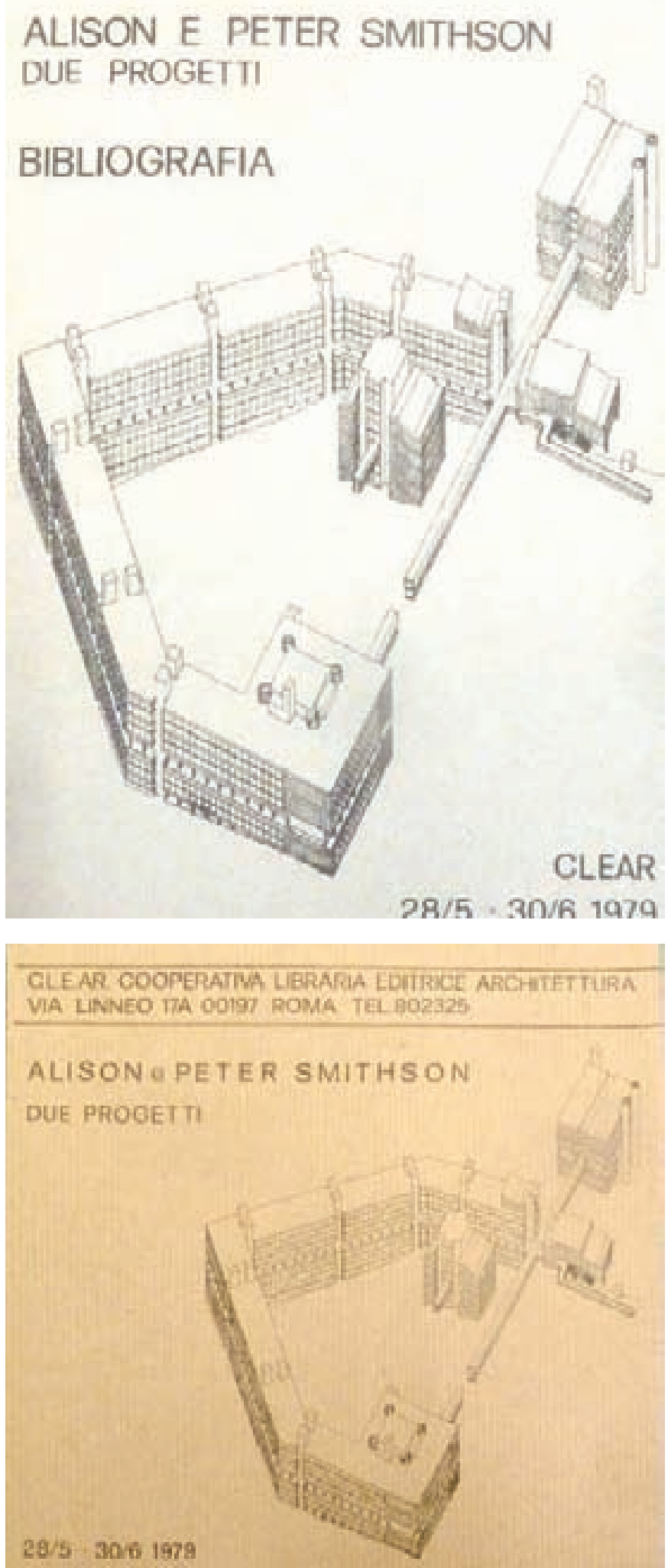


\section{ÍNDICE DE ILUSTRACIONES}

\section{V.I. PROYECTO DE SHEFFIELD}

1. Organización de los bloques. Maqueta

2. Plano de Situación, con inclusión de leyenda y tramas por el autor.

3. Esquema General.

4. Desarrollo del Esquema General. Esquema en Planta

4.1. Alzado y Sección originales del Firth Court

4.2. Salas de Conferencias y Aulas Generales

4.3. Administración y Artes

4.4. Biblioteca y Escuela de Arquitectura. Plantas y Alzados

4.5. Biblioteca. Alzado a concurso y a color

4.6. Alzados

4.7. Plano de Situación

5. La Gran Cabeza. Situación del enclave en el alzado de Architects'Year Book, no 8,1957

6. Axonométricas

7. Axonométrica modificada por el autor, versión "Piezas a Concurso"

8. Salas de Conferencias. Comparación con el proyecto de Skinner, Bayley y Lubetkin:

8.1. Plano de Situación Proyecto de Skinner, Bayley y Lubetkin

8.2. Plantas comparativas

8.3. Alzados comparativos

8.4. Secciones Comparativas

9. Esquemas de distribución de pilares:

9.1. Sheffield

9.2. Escuela en Hunstanton

9.3. Economist Building

9.4. IIT. Ingeniería Química y Metalurgia. Mies van der Rohe

10. Alzados Comparativos (dibujos del autor):

10.1. Sheffield, Hunstanton, IIT Ingeniería Química y Metlurgia y IIT Biblioteca y Administrción (Mies van der Rohe)

10.2. Alzados parciales. Sheffield y Hunstanton

11. Plantas definitivas con la conexión al Firth Court

11.1. Planta General de Ordenación

11.2. Planta con los edificios a concurso

\section{V.II. PITAGORISMO. ECONOMIST BUILDING}

1. Transformación del Economist en número figurado

2. Aplicación de la figura del Banco al número figurado

\section{V.III. DESARGUES}

1. Teorema de Desargues

\section{V.IV. VAUBAN}

1. Nomenclatura de ángulos y líneas de un baluarte 


\section{V.I. PROYECTO DE SHEFFIELD}

1. Organización de los bloques. Maqueta

UNIVERSIDAD DE SHEFFIELD

ALISON Y PETER SMITHSON

ORGANIZACION DE LOS BLOQUES
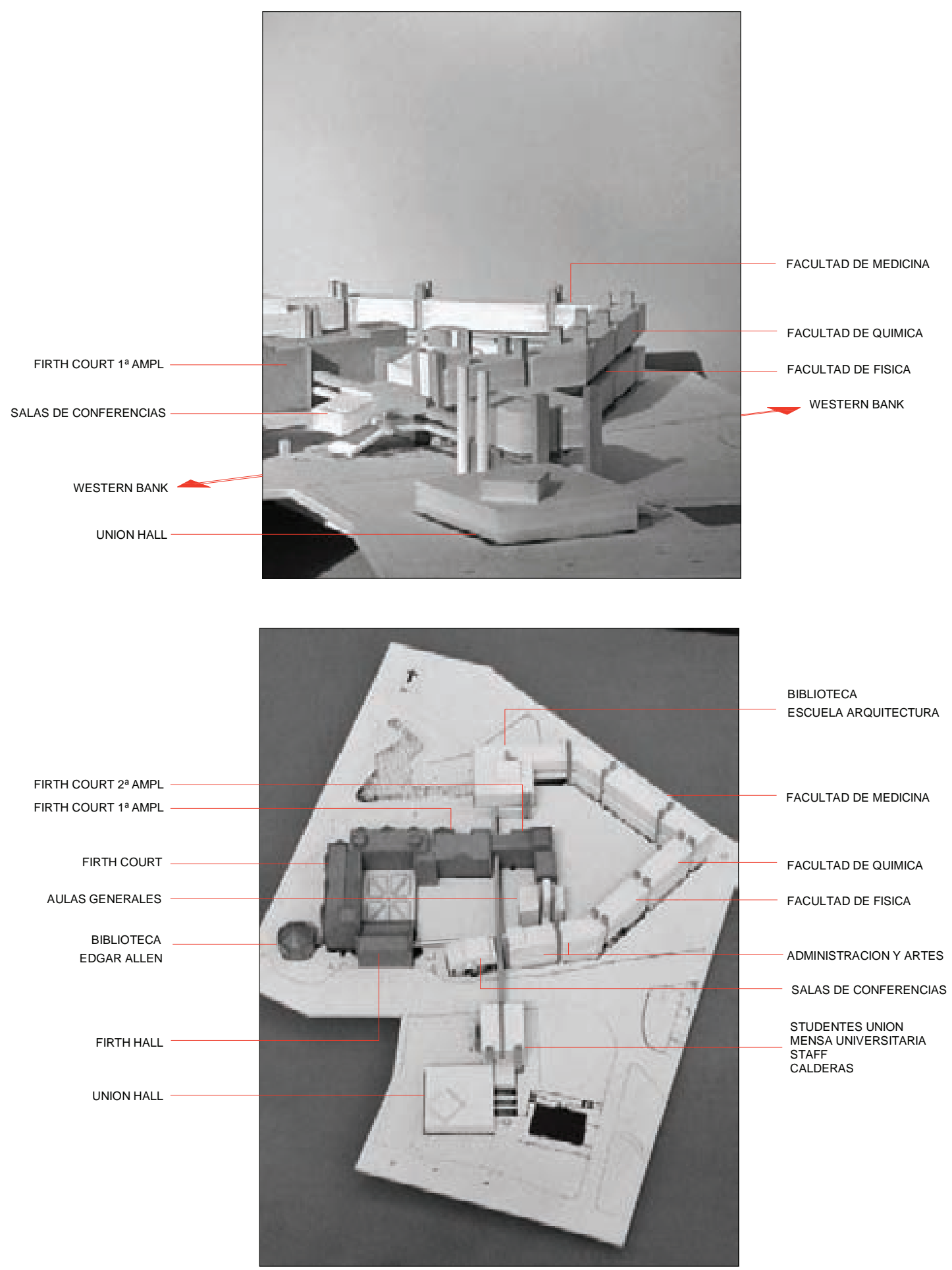

MAQUETA OBSEQUIO DE FELIZ MOYANO ARDID 
2. Plano de Situación, con inclusión de leyenda y tramas por el autor.

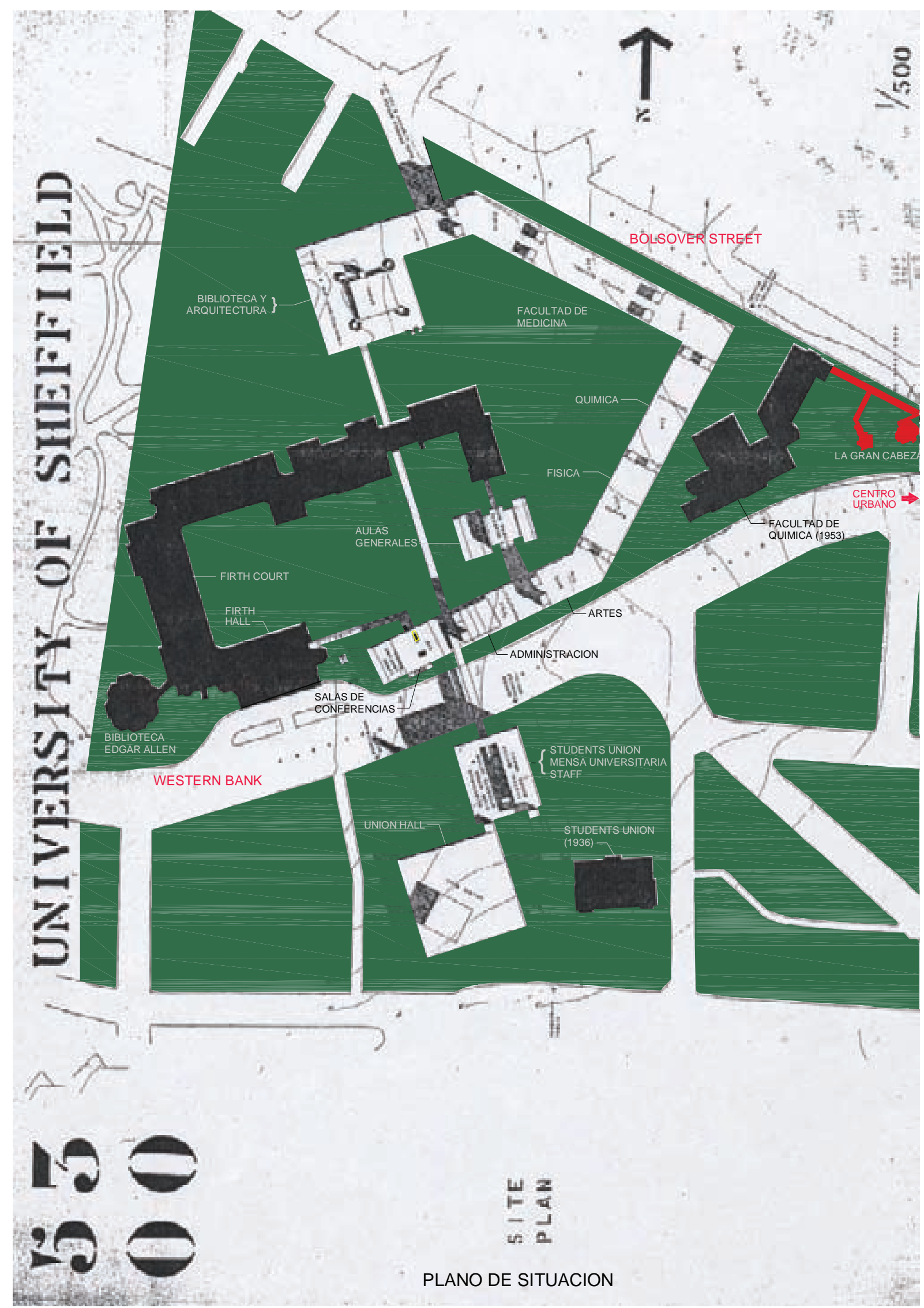




\section{Esquema general}

UNIVERSIDAD DE SHEFFIELD

ALISON Y PETER SMITHSON

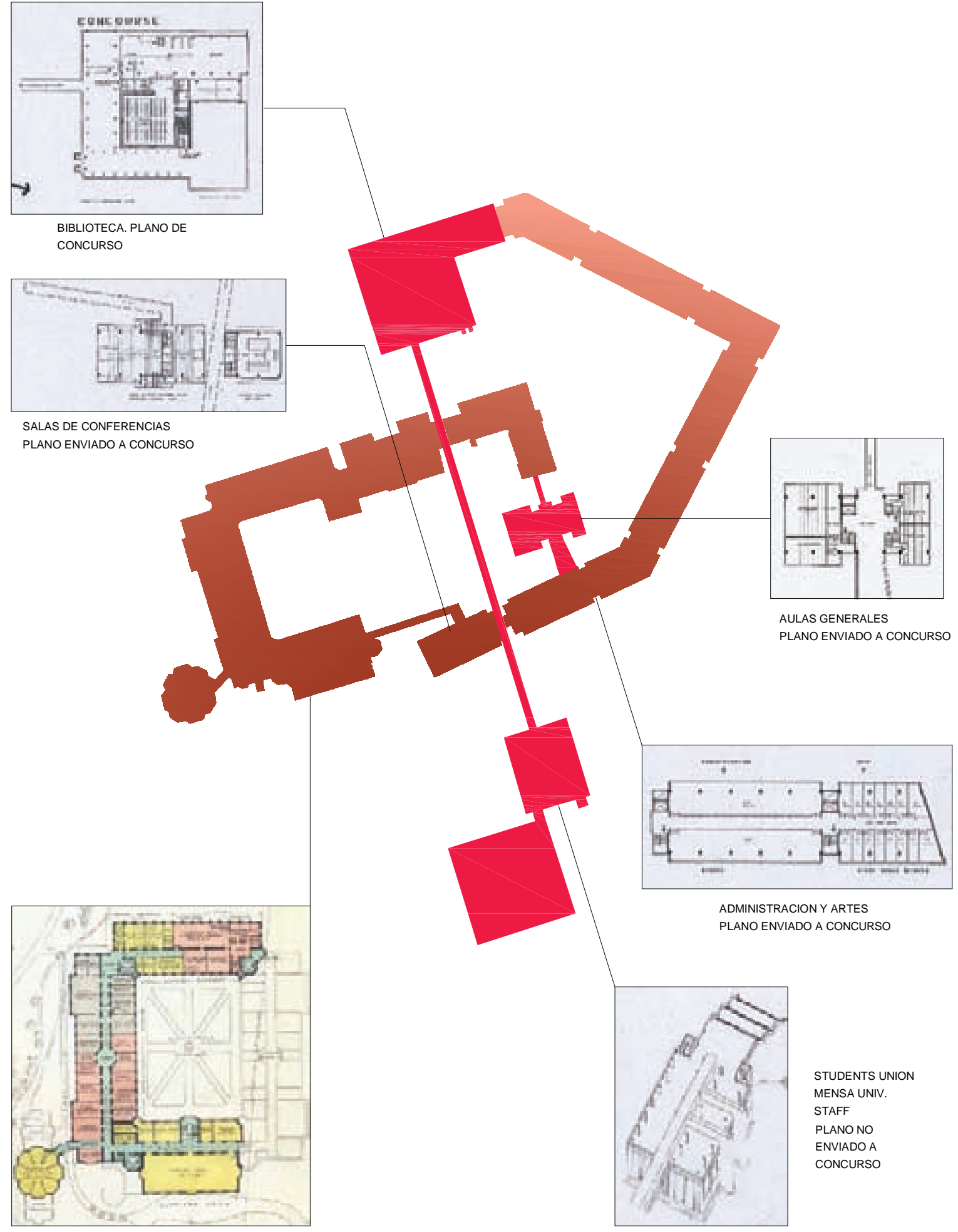

FIRT COURT. ORIGINAL EDWARD GIBBS 
4. Desarrollo del Esquema General. Esquema en Planta

4.1. Alzado y Sección originales del Firth Court

UNIVERSIDAD DE SHEFFIELD

FIRTH COURT

SECCION TRANSVERSAL POR EL FIRT HALL

GIBBS \& FLOCKTON 1903

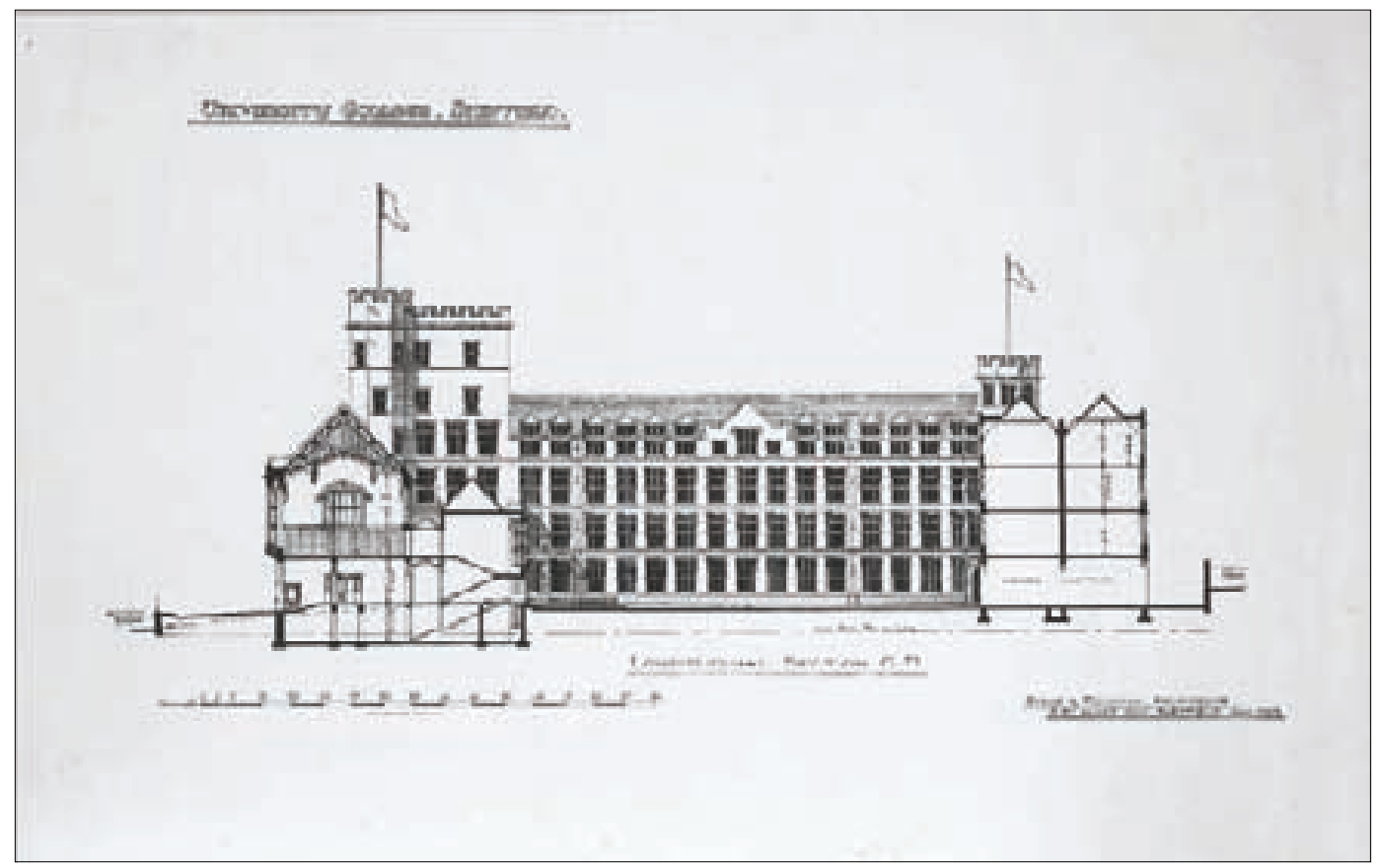

ALZADO NORTE

GIBBS \& FLOCKTON 1903

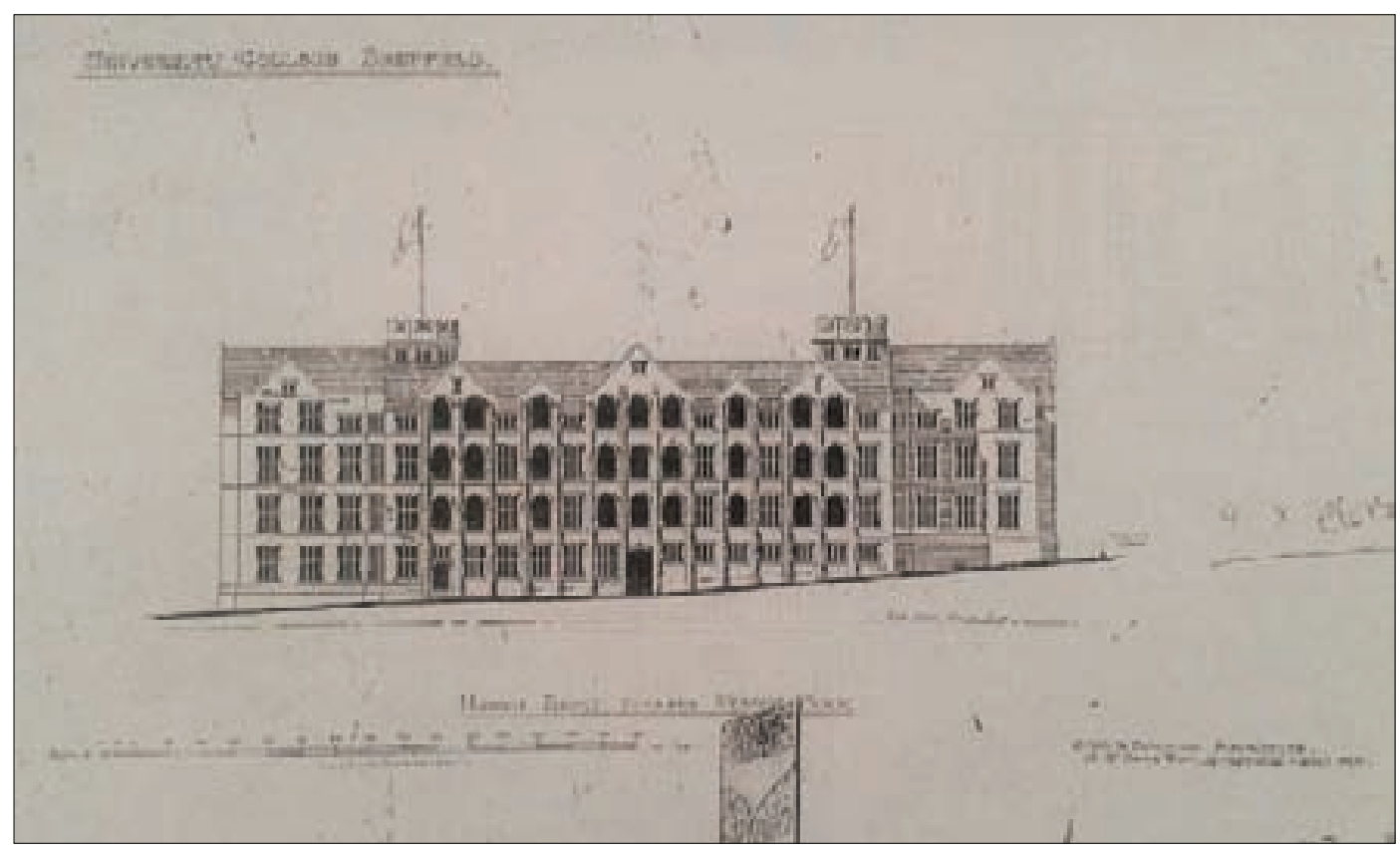

ARCHIVO UNIVERSIDAD DE SHEFFIELD. ENVIADOS POR PETER BLUNDELL JONES 
4.2. Salas de Conferencias y Aulas Generales

UNIVERSIDAD DE SHEFFIELD

ALISON Y PETER SMITHSON

ADMINISTRACION Y ARTES

SALAS DE CONFERENCIAS Y AULAS GENERALES

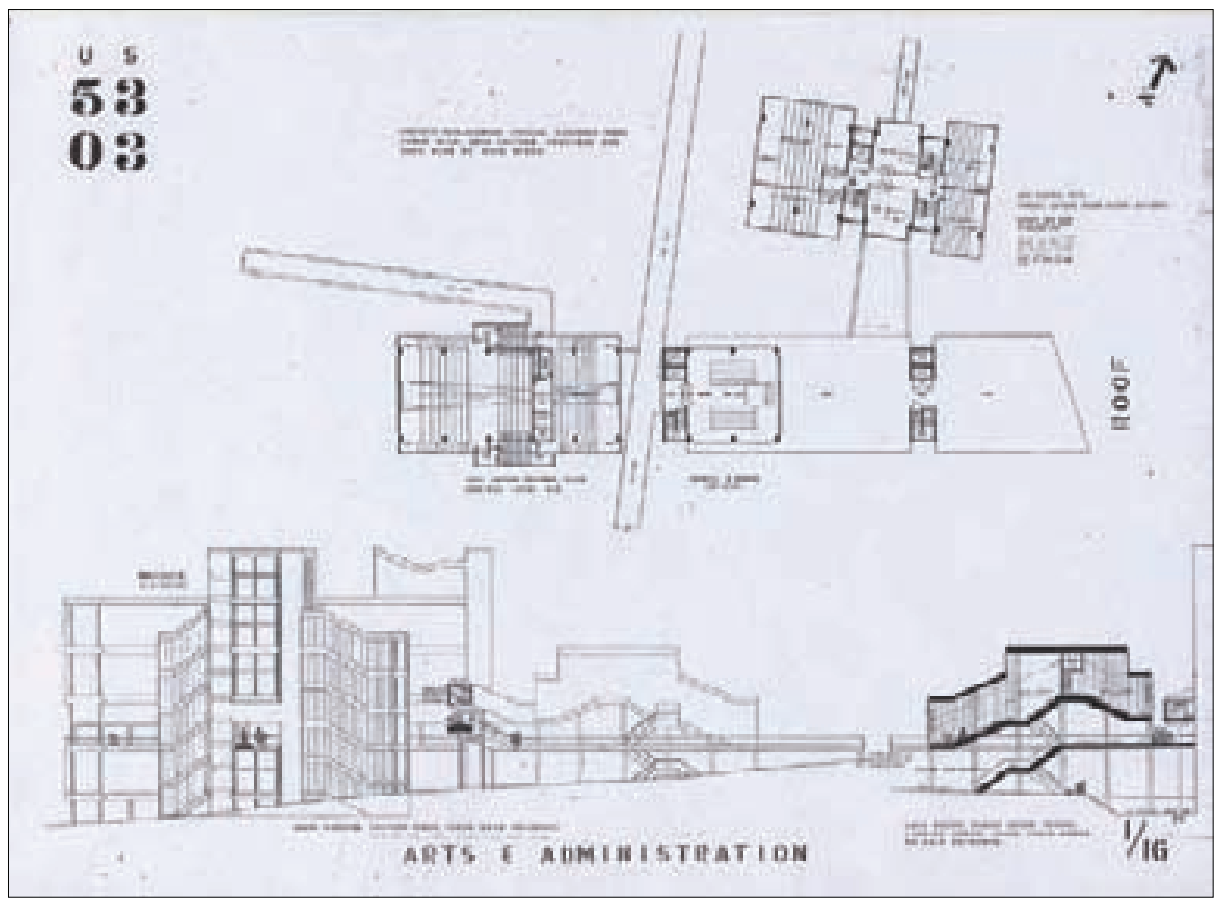

PLANO DE CONCURSO. NIVEL DE CONDUCTO.

FACILITADO POR MARCO VIDOTTO (Mediados años 90)

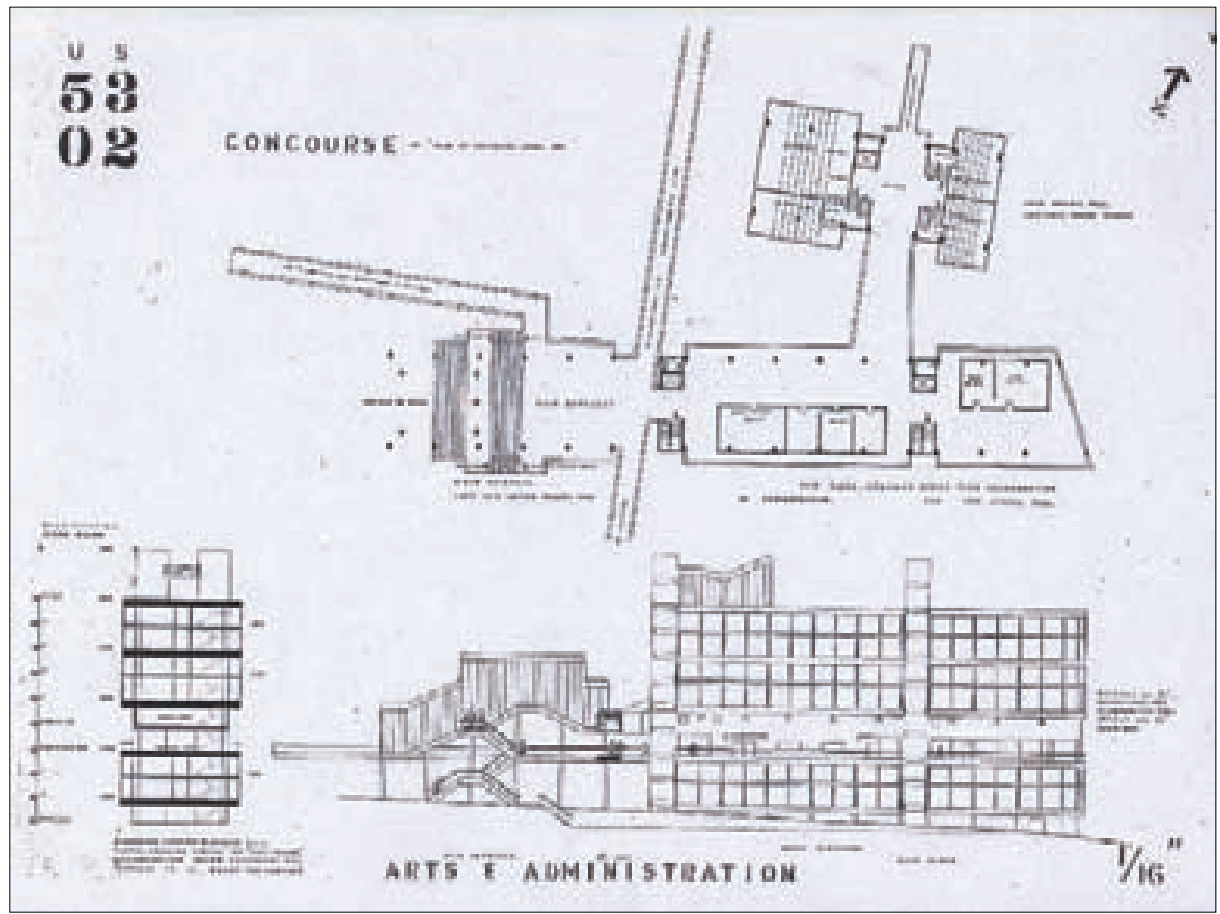

PLANO DE CONCURSO. NIVEL DE CONCOURSE.

FACILITADO POR MARCO VIDOTTO (Mediados años 90) 


\subsection{Administración y Artes}

UNIVERSIDAD DE SHEFFIELD

ALISON Y PETER SMITHSON

ADMINISTRACION Y ARTES

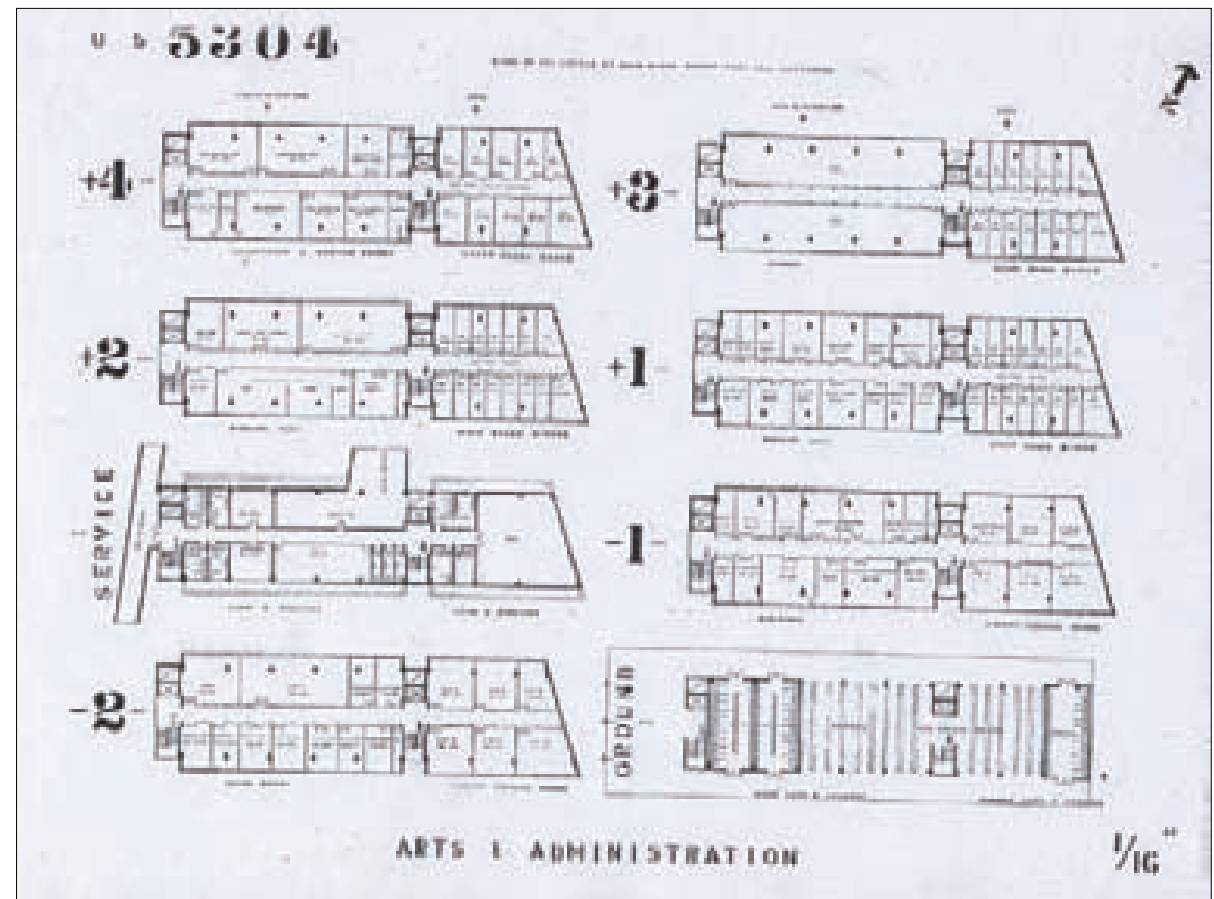

PLANO DE CONCURSO

FACILITADO POR MARCO VIDOTTO (Mediados años 90) 


\section{UNIVERSIDAD DE SHEFFIELD \\ ALISON Y PETER SMITHSON \\ BIBLIOTECA}

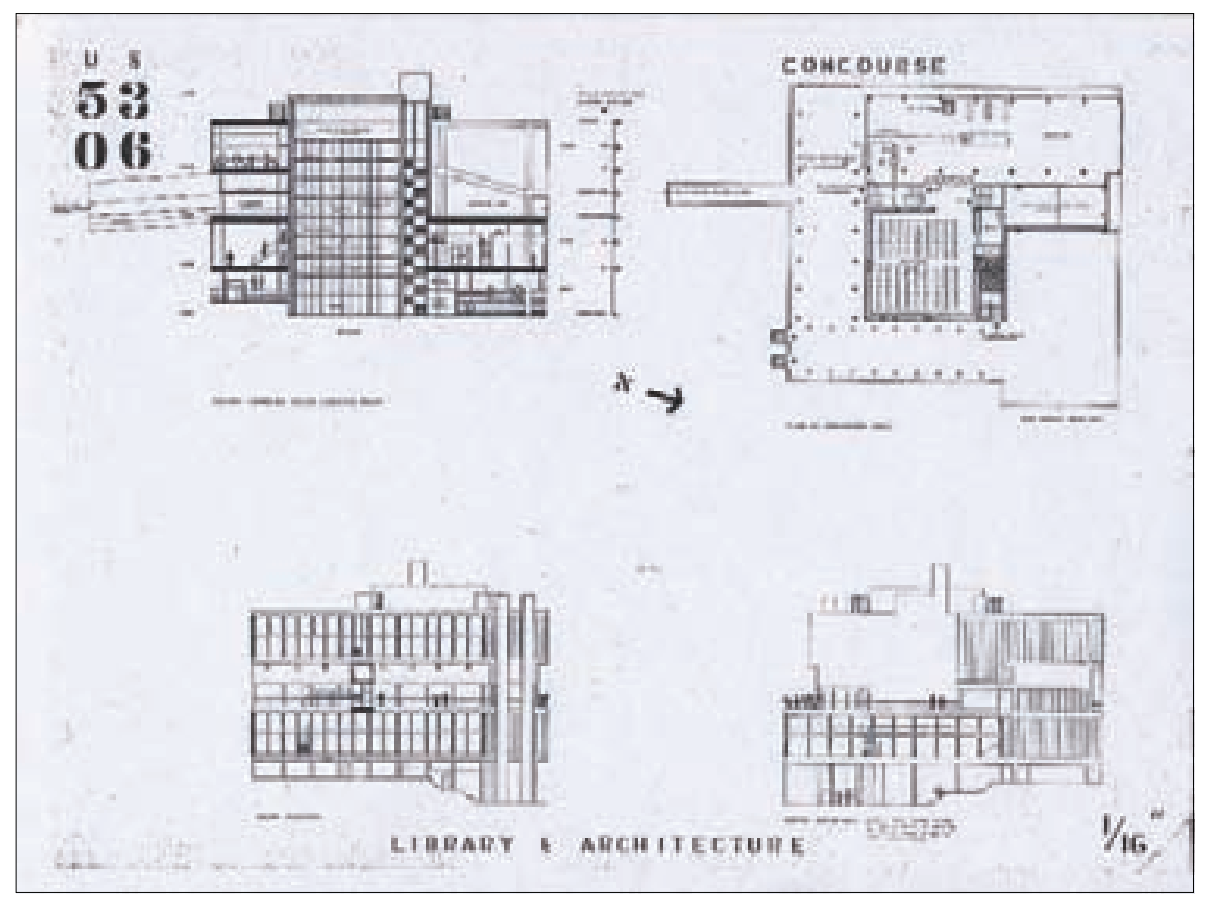

PLANO DE CONCURSO. NIVEL DE CONCOURSE, ACCESO PRINCIPAL BIBLIOTECA FACILITADO POR MARCO VIDOTTO (Mediados años 90)

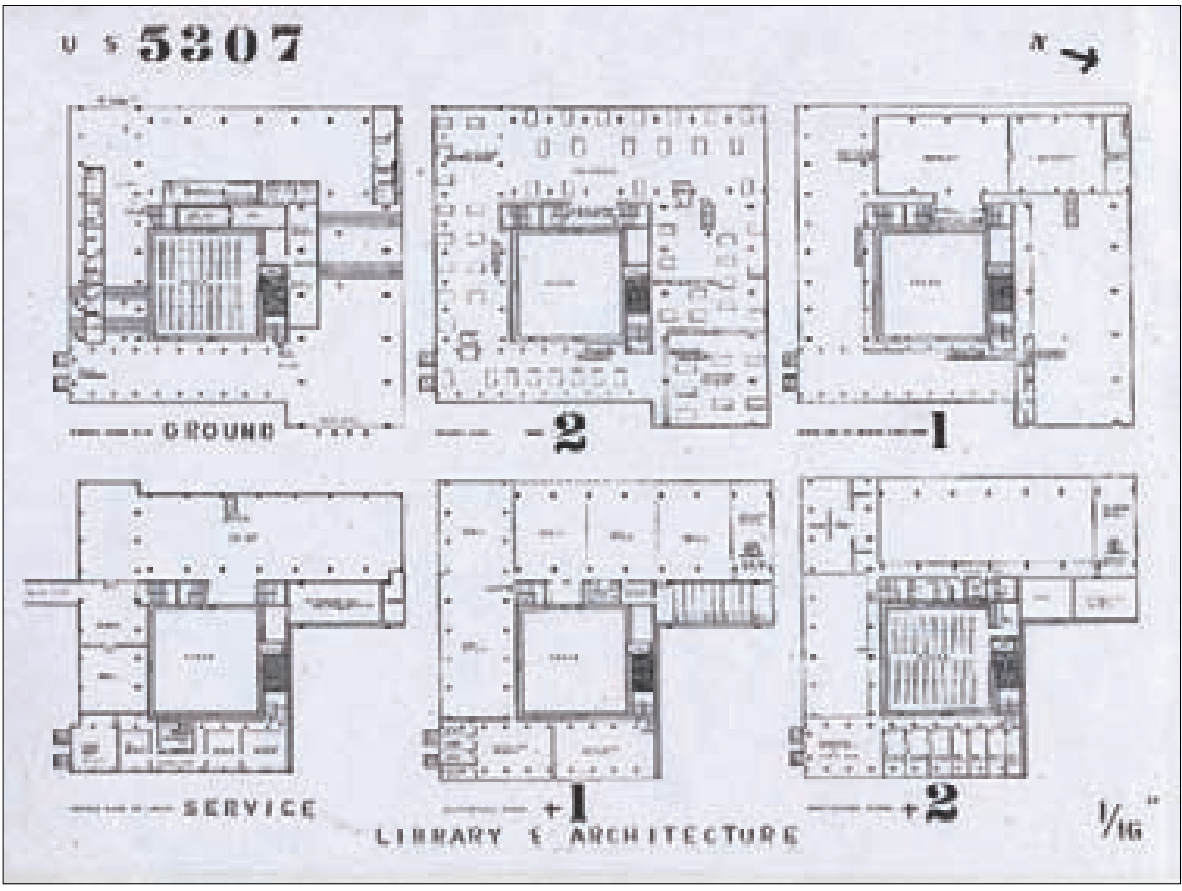

PLANO DE CONCURSO. ESCUELA DE ARQUITECTURA EN NIVELES $+1 Y+2$ FACILITADO POR MARCO VIDOTTO (Mediados años 90) 


\subsection{Biblioteca. Alzado a concurso y a color}

UNIVERSIDAD DE SHEFFIELD

ALISON Y PETER SMITHSON

BIBLIOTECA ALZADO OESTE

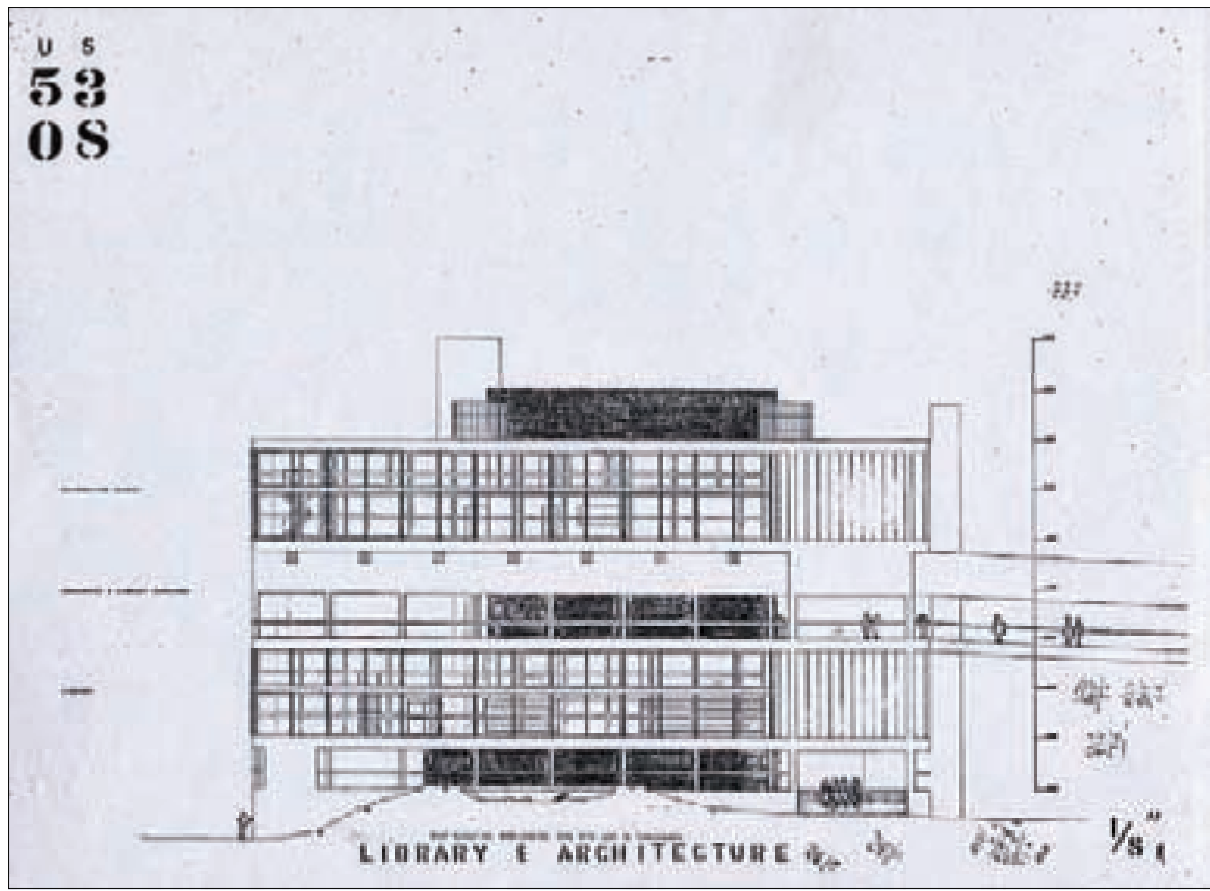

PLANO DE CONCURSO

FACILITADO POR MARCO VIDOTTO (Mediados años 90)

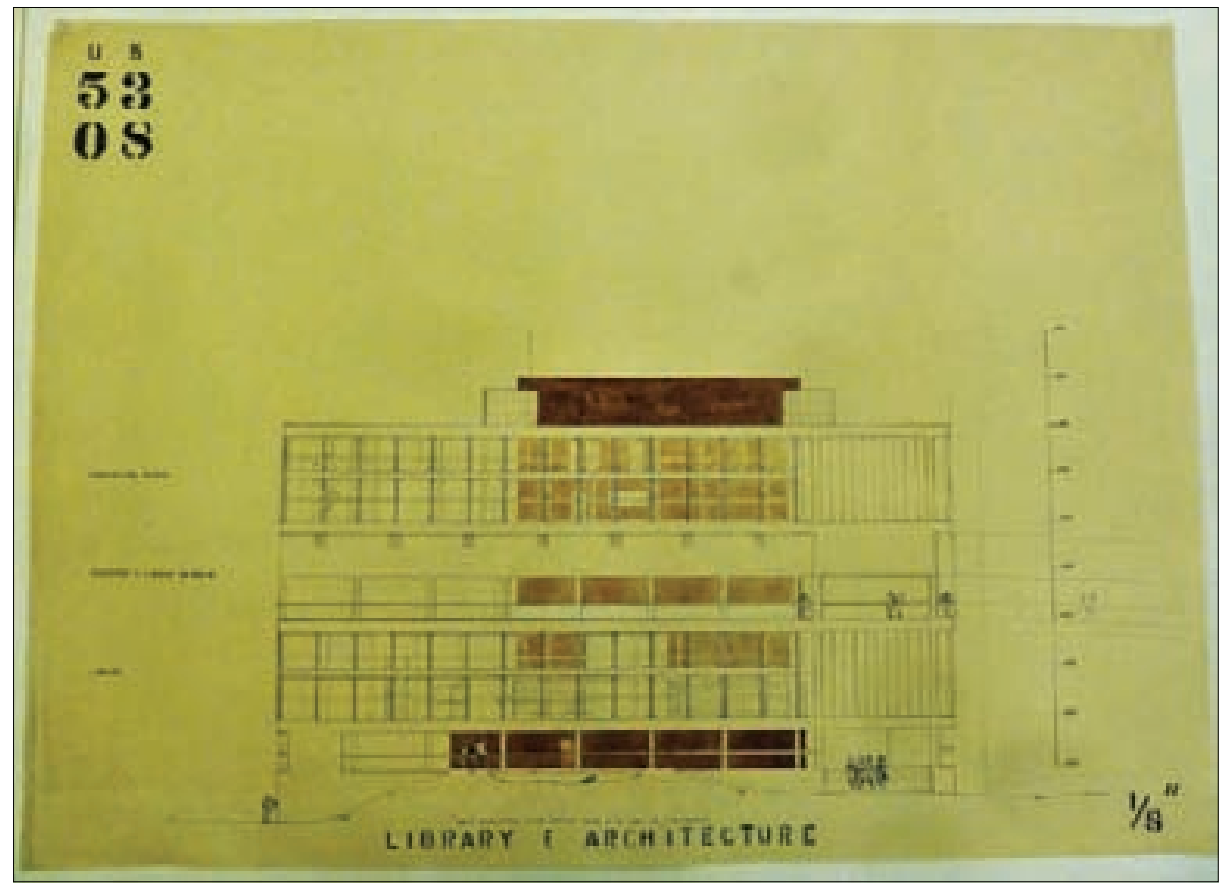

PLANO DE CONCURSO A COLOR

ARCHIVO A + P SMITHSON. LOEB LIBRARY 
UNIVERSIDAD DE SHEFFIELD

ALISON Y PETER SMITHSON

ALZADOS

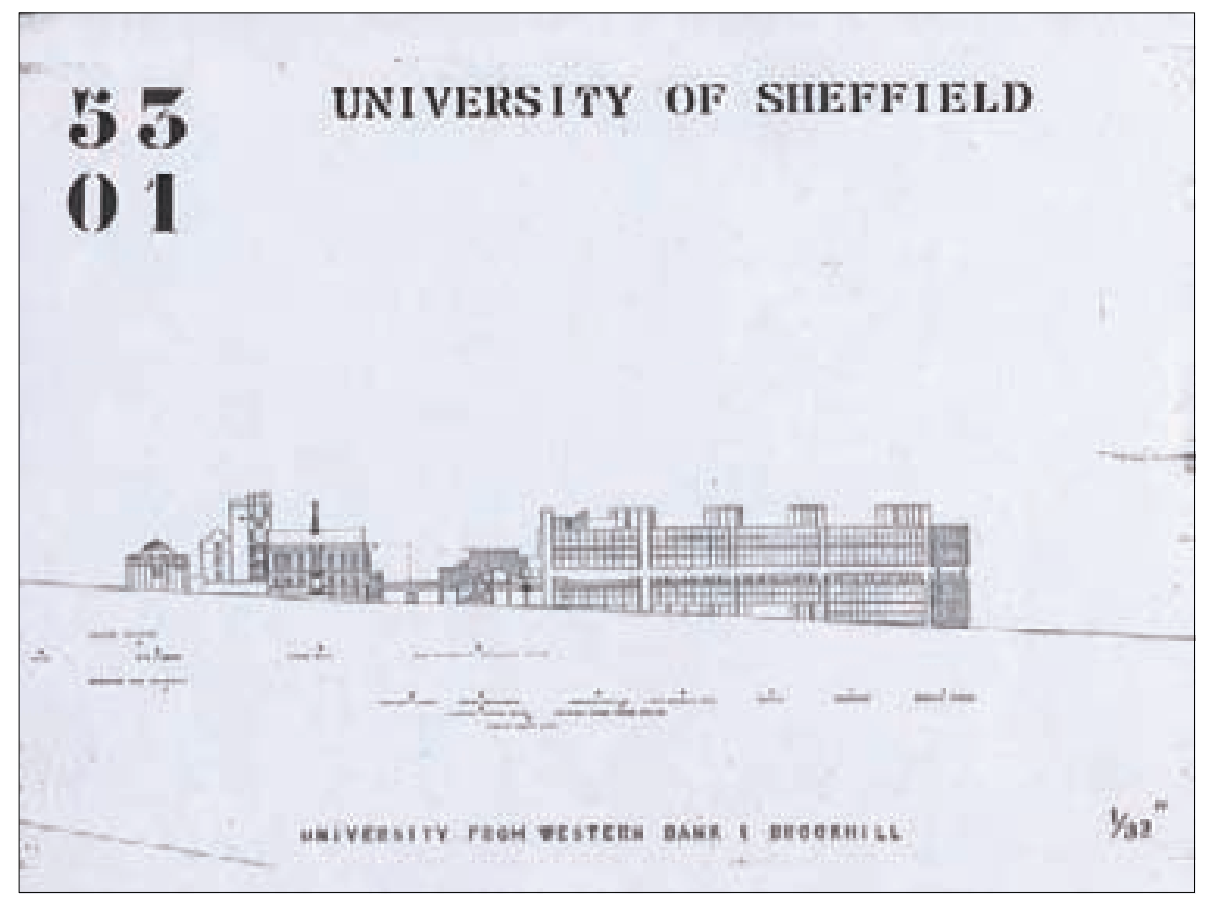

PLANO DE CONCURSO. ALZADO GENERAL A WESTERN BANK

FACILITADO POR MARCO VIDOTTO (Mediados años 90)

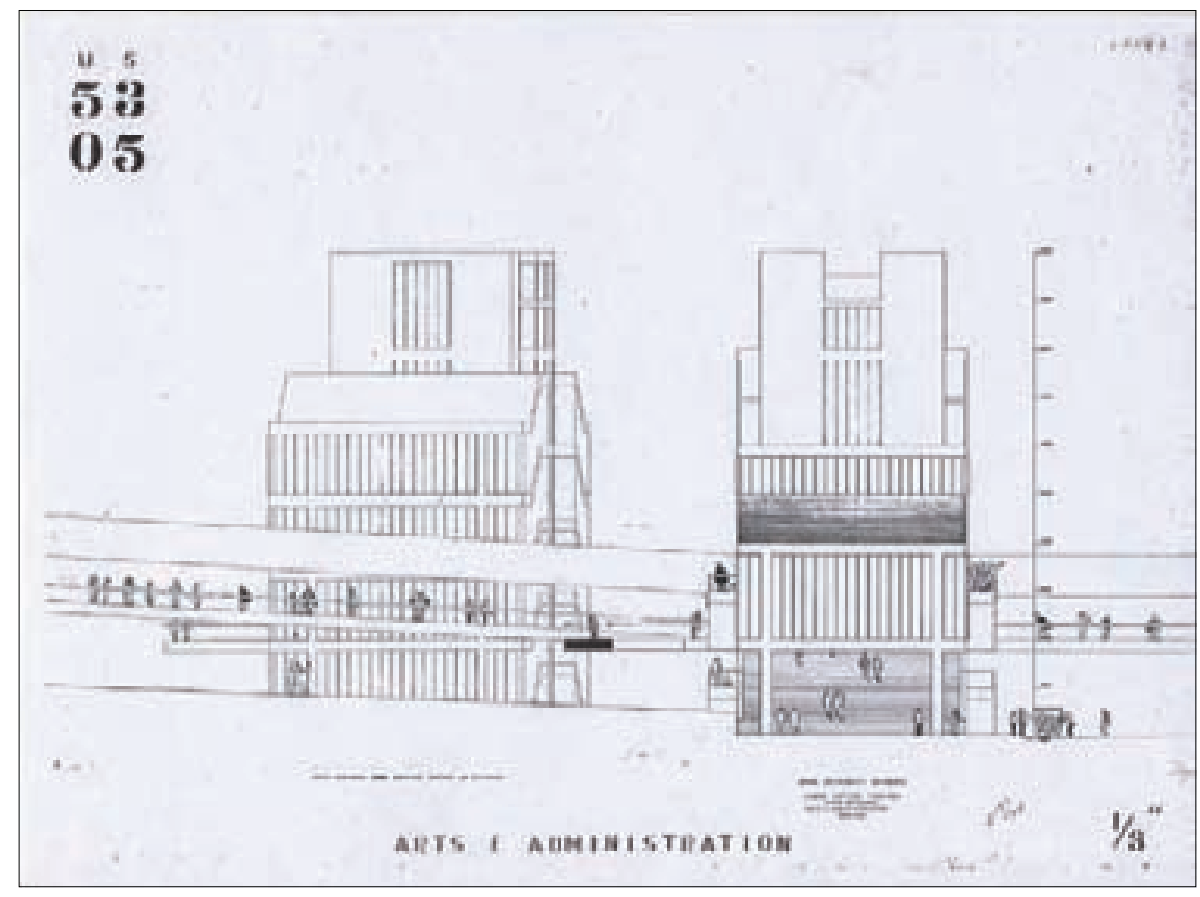

PLANO DE CONCURSO. ALZADO POR EL EJE DE CIRCULACION FACILITADO POR MARCO VIDOTTO (Mediados años 90) 


\subsection{Plano de Situación}

UNIVERSIDAD DE SHEFFIELD

ALISON Y PETER SMITHSON

PLANO DE SITUACION

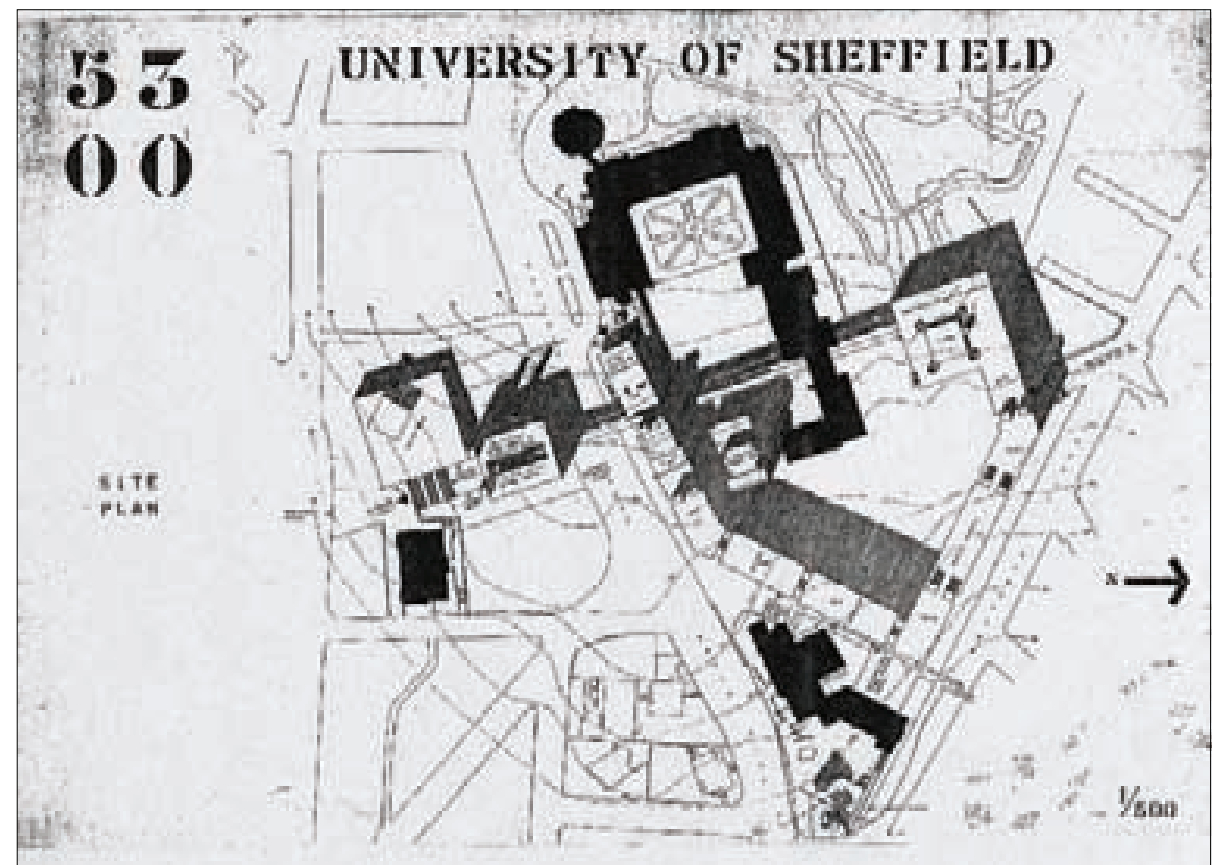

PLANO DE CONCURSO

FACILITADO POR MARCO VIDOTTO (Mediados años 90) 
5. La Gran Cabeza. Situación del enclave en el alzado de Architects’Year Book, no 8, 1957

UNIVERSIDAD DE SHEFFIELD

ALISON Y PETER SMITHSON

LA GRAN CABEZA

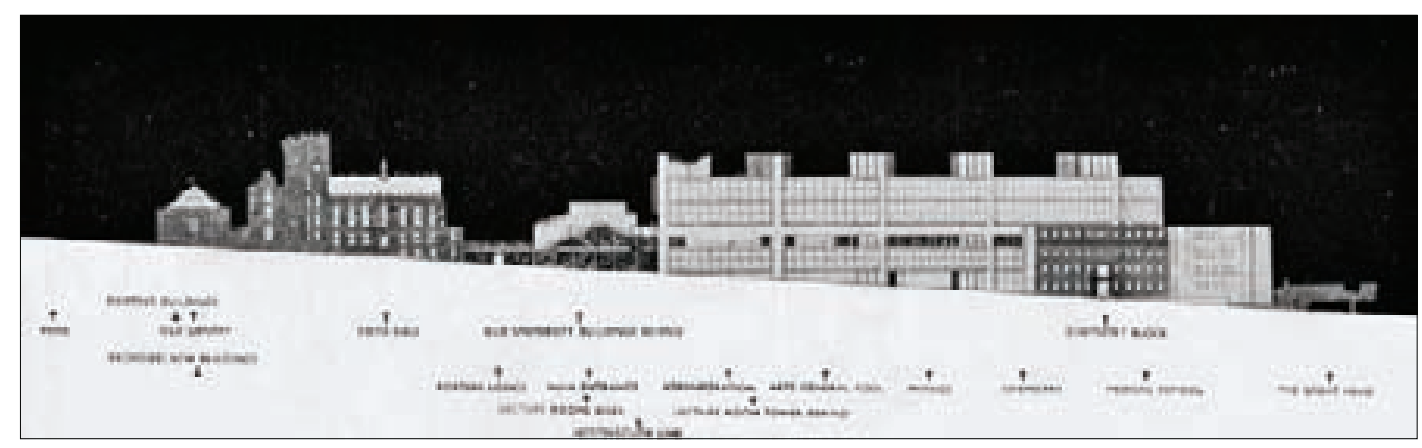

ALZADO PRESENTADO CON EL ARTICULO "THE AESTHETICS OF CHANGE" (ALISON Y PETER SMITHSON)
EN ARCHITECTS'YEAR BOOK, ,No 8, 1957 (p. 19)

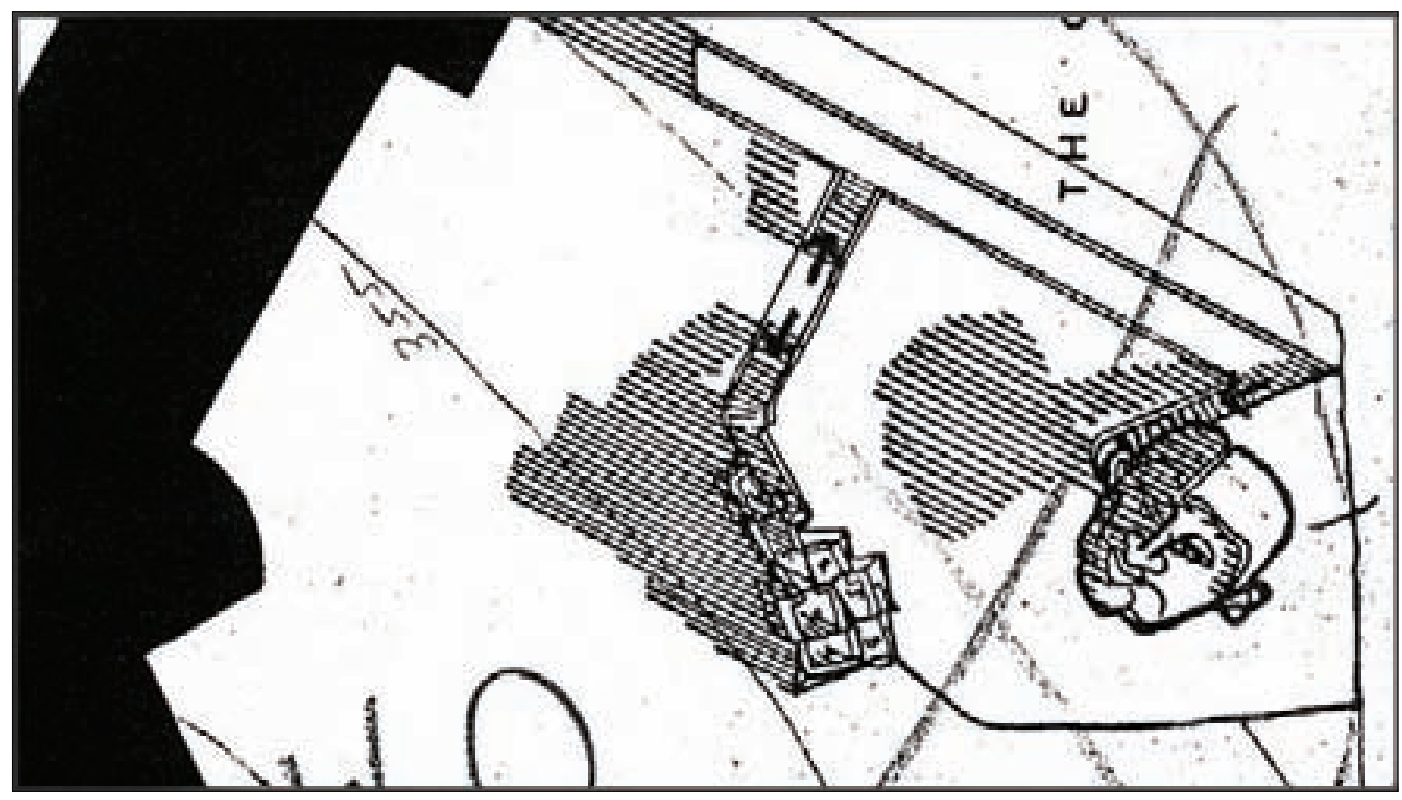

"LA GRAN CABEZA". DETALLE PLANO DE SITUACION (53 00). A LA IZDA. LA SILUETA DEL EDIFICIO DE QUIMICA. EN EL DIBUJO SUPERIOR (ANGULO DERECHO) SE HALLA LA REFERENCIA A LA ESTRUCTURA DE UN MIRADOR CON EL NOMBRE "THE GREAT HEAD". 


\section{Axonométricas}

UNIVERSIDAD DE SHEFFIELD

ALISON Y PETER SMITHSON

AXONOMETRICAS

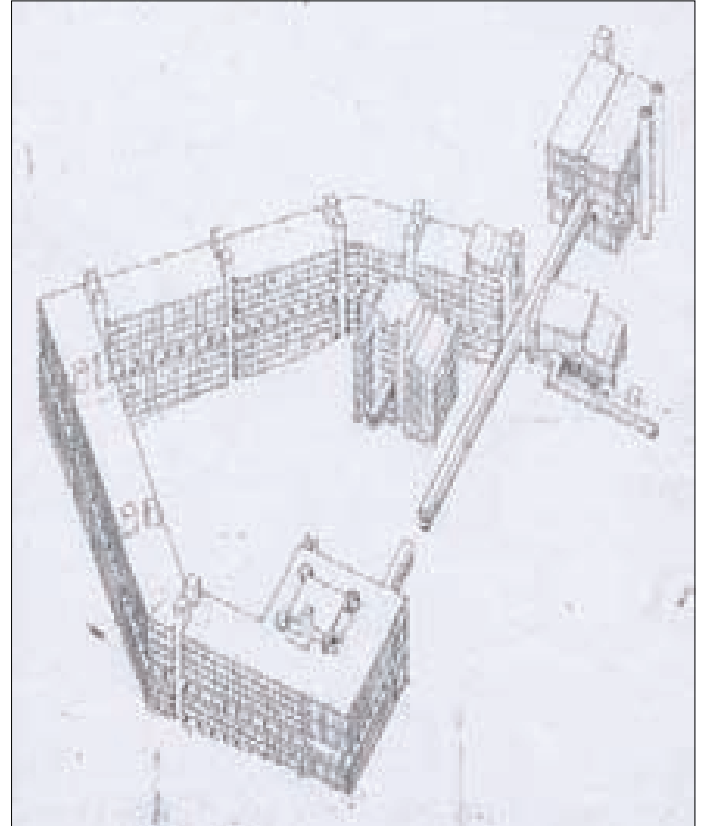

VERSION DE 1953. DIBUJO A.M.S

FACILITADO POR MARCO VIDOTTO (mediados años 90)

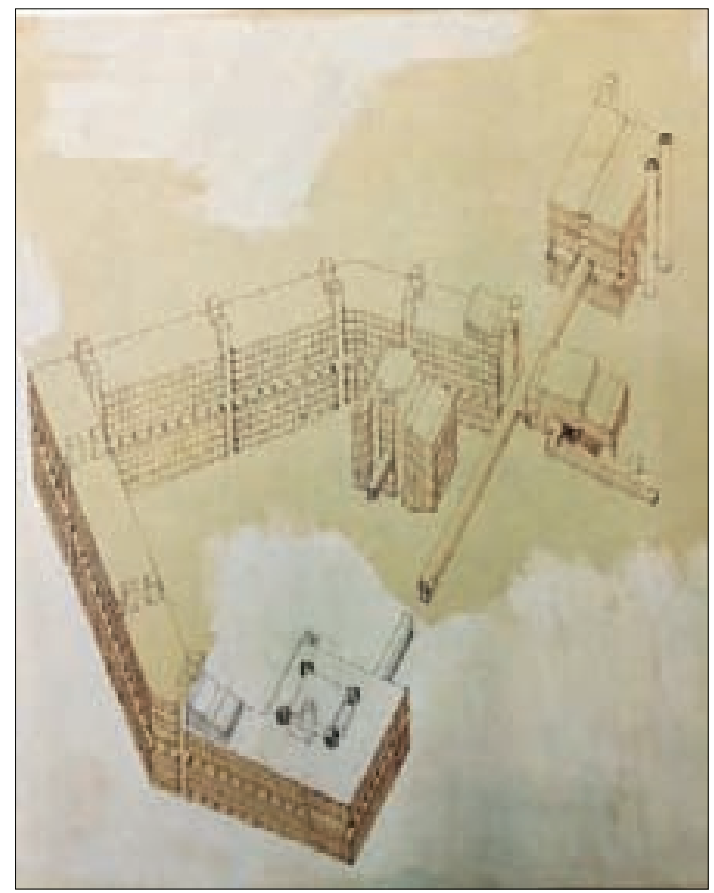

VERSION DE 1978 (sobre copia del original). DIBUJO A.M.S. Y W.R.B. ARCHIVO A\&P SMITHSON. LOEB LIBRARY

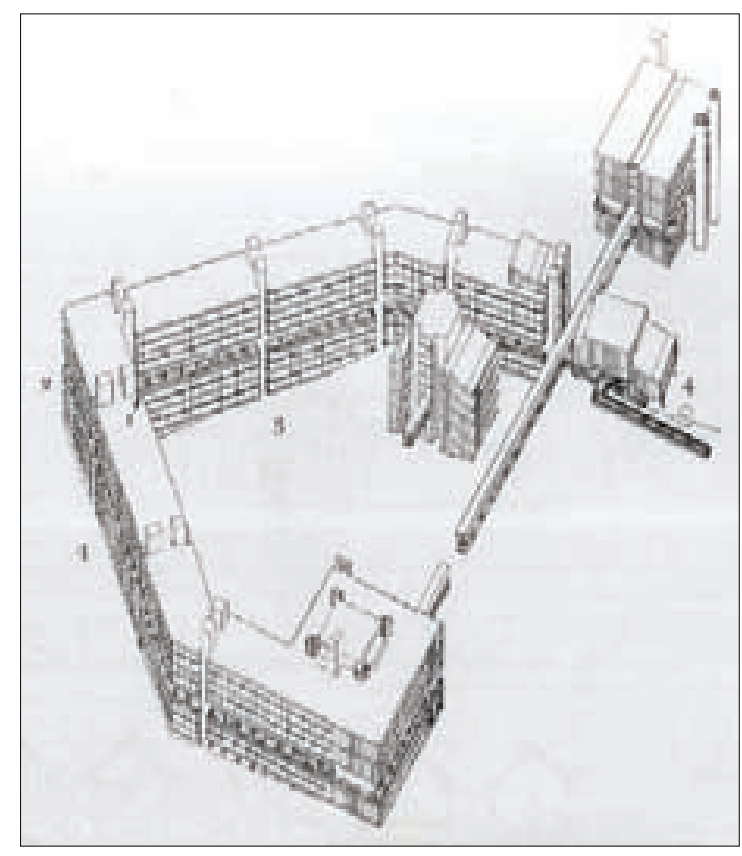

VERSION PRESENTADA AL LIBRO DE GYORGY KEPES "La Structure dans les Arts et dans les Sciences". 1965

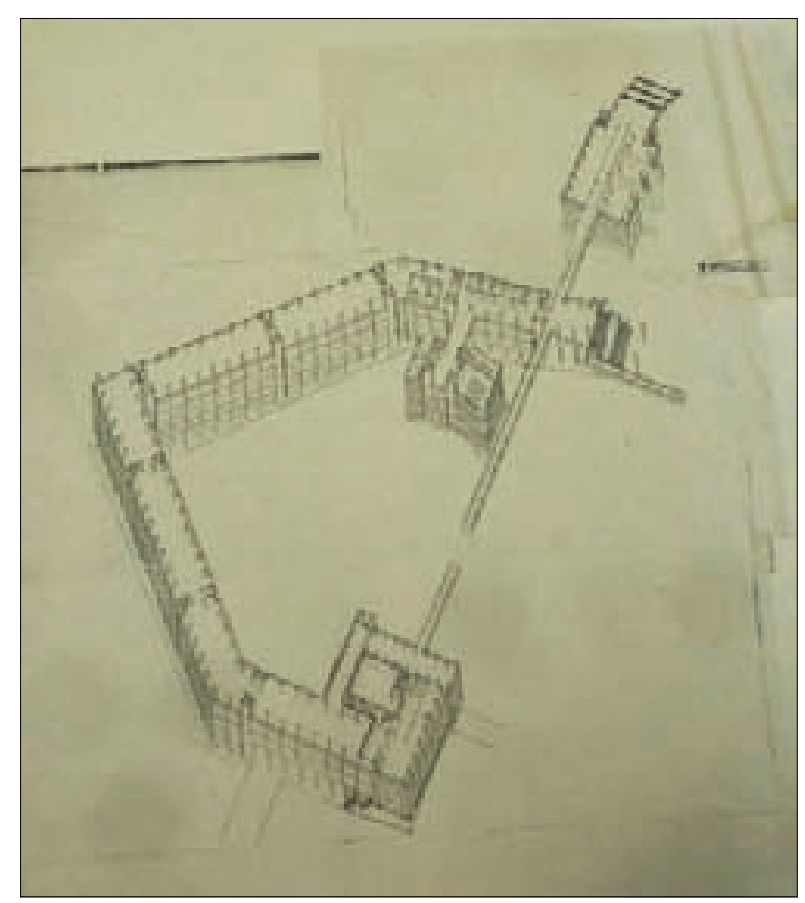

VERSION DE 1978 DIBUJO A.M.S.

Y W.R.B. ARCHIVO A\&P SMITHSON. LOEB LIBRARY 
7. Axonométrica modificada por el autor, versión "Piezas a Concurso"

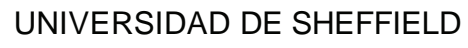

ALISON Y PETER SMITHSON

AXONOMETRICA DE LAS PIEZAS A CONCURSO

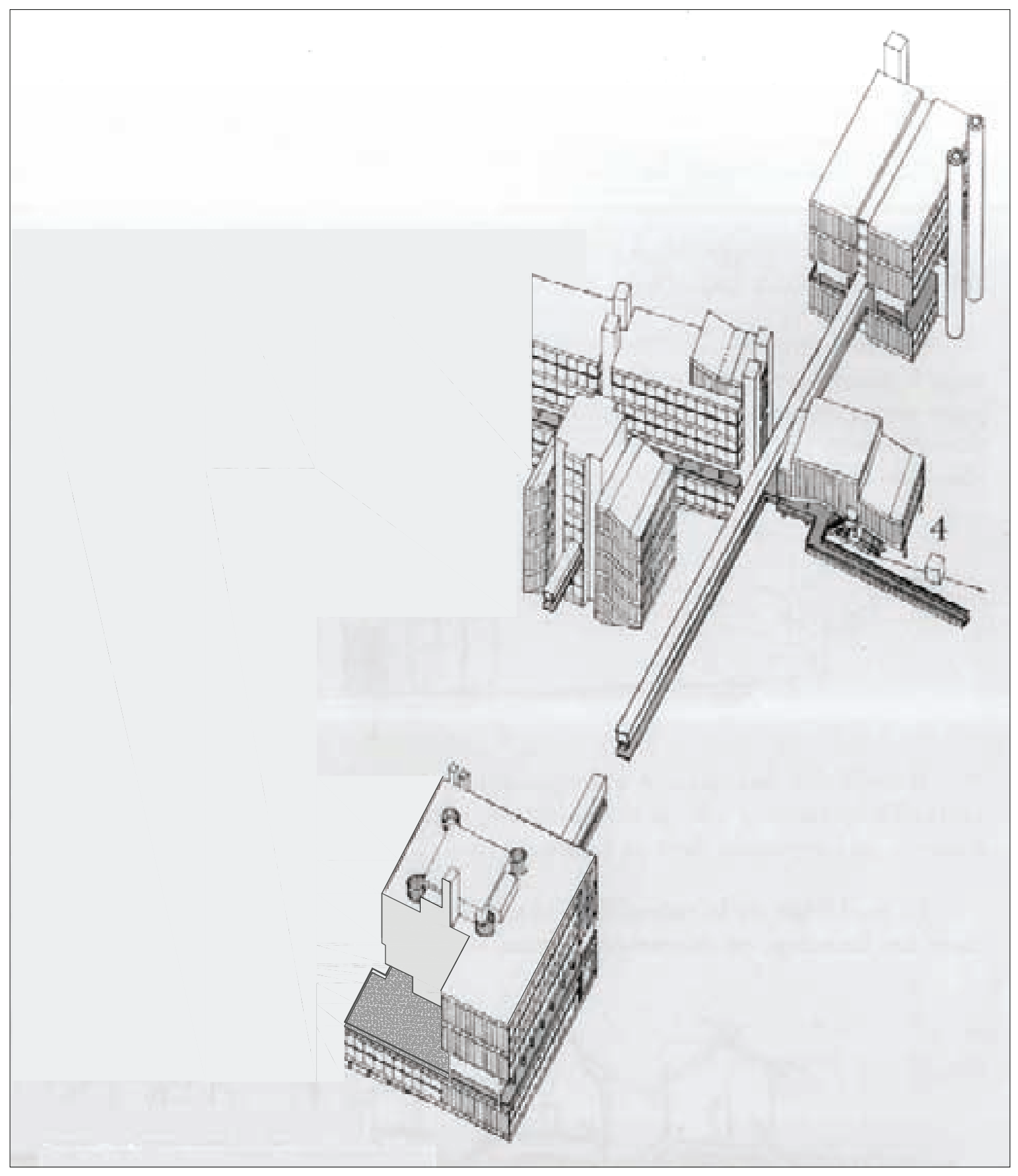

MODIFICACION DEL AUTOR SOBRE PLANO PUBLICADO EN GYORGY KEPES 
8. Salas de Conferencias. Comparación con el proyecto de Skinner, Bayley y Lubetkin:

8.1. Plano de Situación Proyecto de Skinner, Bayley y Lubetkin

UNIVERSIDAD DE SHEFFIELD

SKINNER, BAYLEY y LUBETKIN

PLANO DE SITUACION

COMPARACION ENTRE SALAS DE CONFERENCIAS

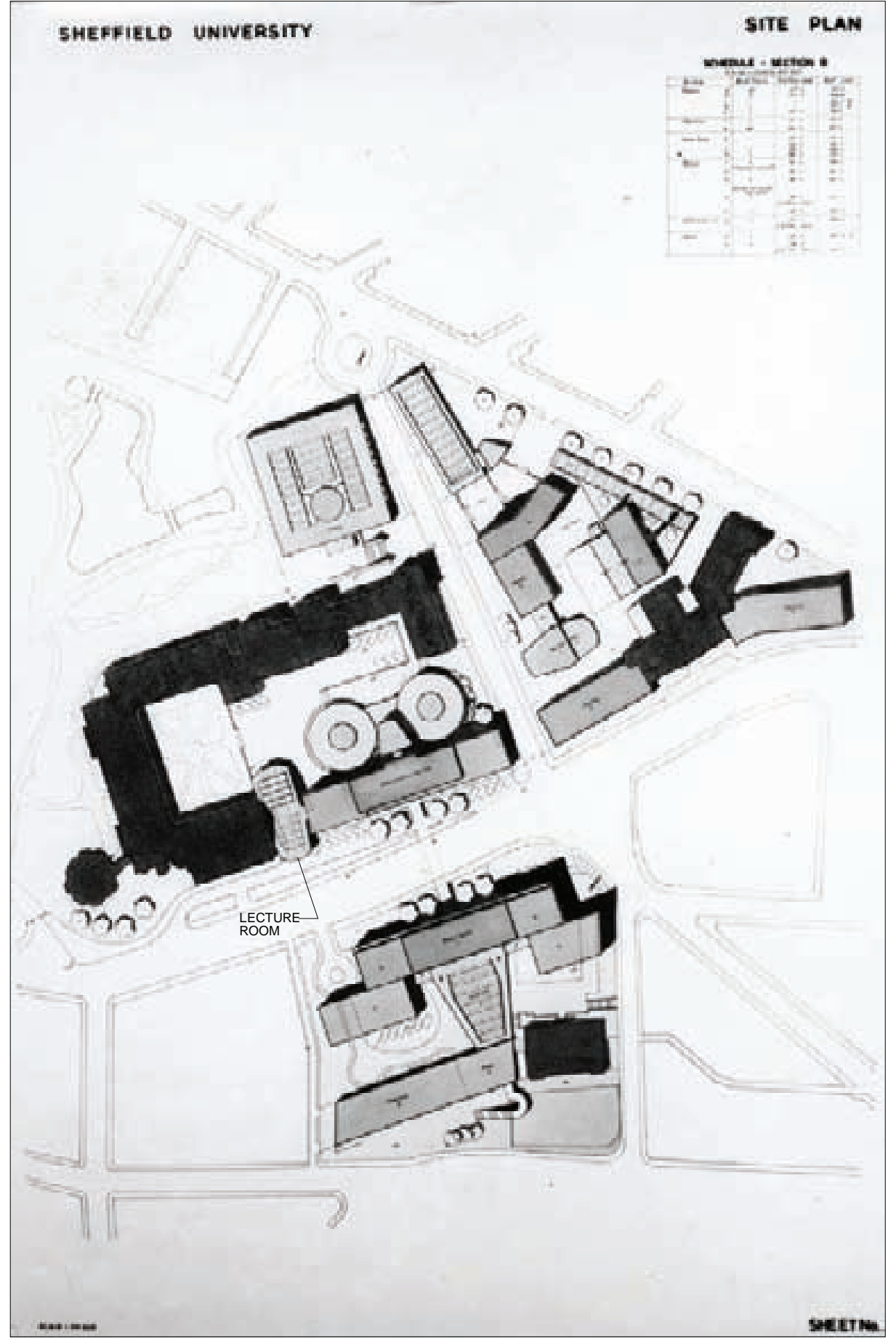

DOCUMENTACION FACILITADA POR JUSTINE SAMBROOK. RIBA Library Photographs Collection 


\title{
8.2. Plantas comparativas
}

\author{
UNIVERSIDAD DE SHEFFIELD \\ SKINNER, BAYLEY y LUBETKIN \\ PLANTA ADMINISTRACION Y ARTES
}

COMPARACION ENTRE SALAS DE CONFERENCIAS

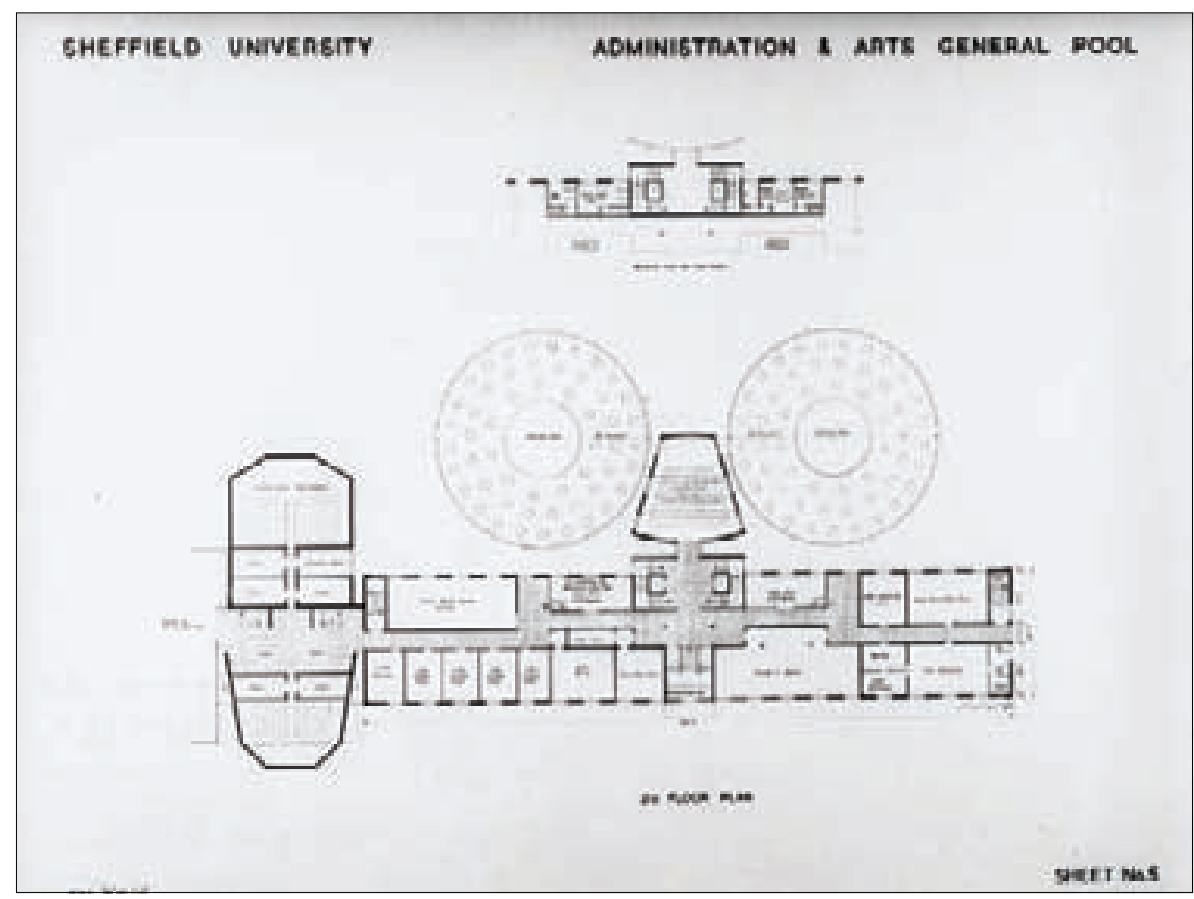

PLANO DE CONCURSO. PLANTA ADMINISTRACION Y ARTES, NIVEL $2^{\mathrm{a}}$ PLANTA

DOCUMENTACION FACILITADA POR JUSTINE SAMBROOK. RIBA Library Photographs Collection

ALISON Y PETER SMITHSON

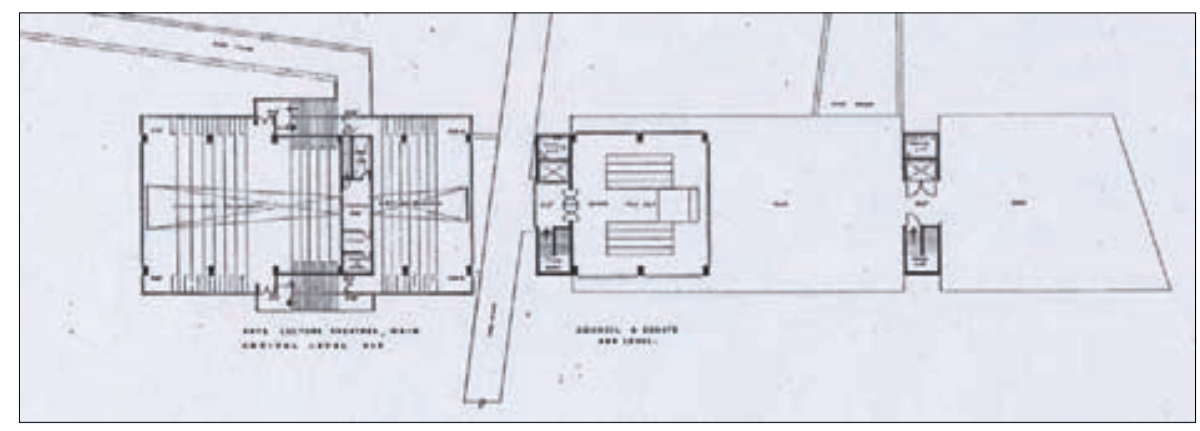

PLANO DE CONCURSO. PLANTA SALAS DE CONFERENCIA, NIVEL DE CONDUCTO (53 03), DETALLE FACILITADO POR MARCO VIDOTTO (Mediados años 90) 


\title{
8.3. Alzados comparativos
}

\author{
UNIVERSIDAD DE SHEFFIELD \\ SKINNER, BAYLEY Y LUBETKIN \\ ALZADOS A WESTERN BANK
}

COMPARACION ENTRE SALAS DE CONFERENCIAS

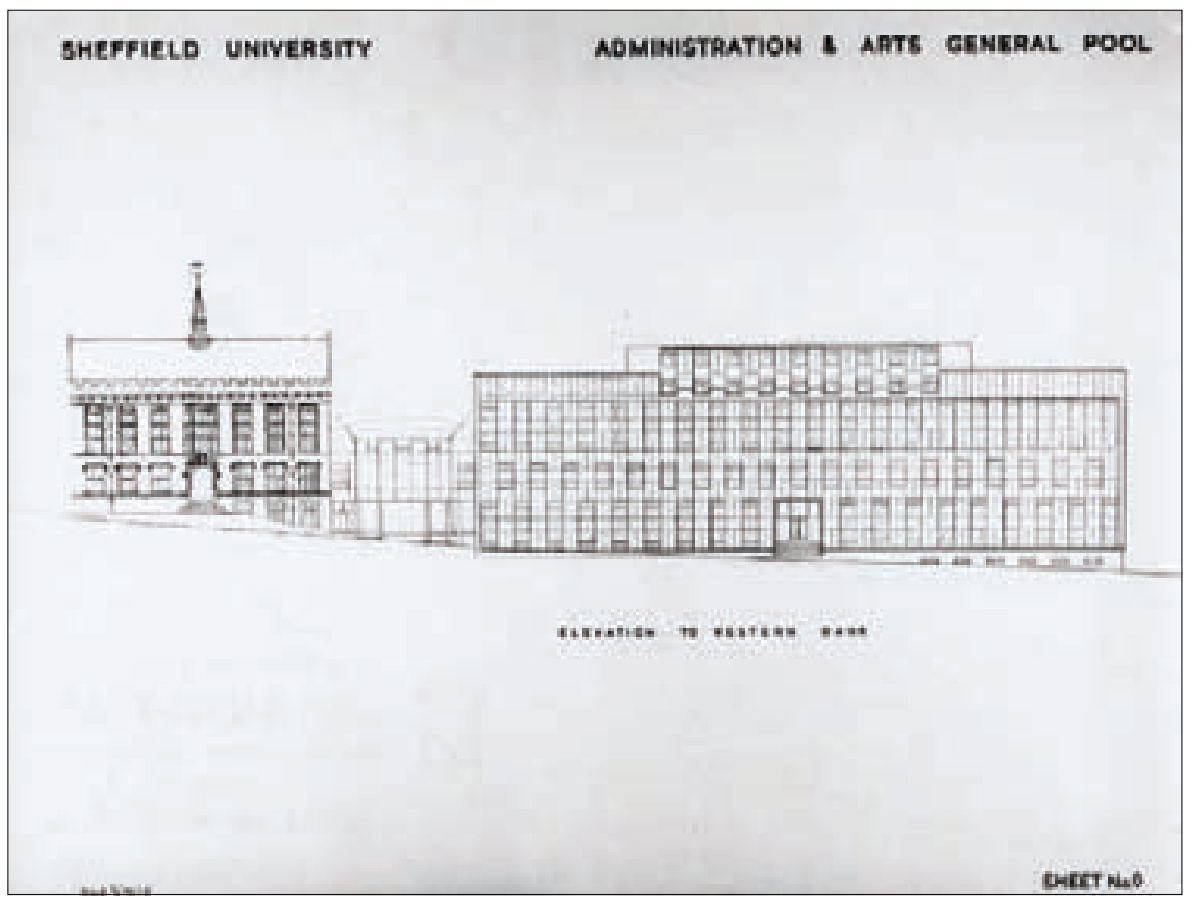

PLANO DE CONCURSO. ALZADO GENERAL A WESTERN BANK

DOCUMENTACION FACILITADA POR JUSTINE SAMBROOK. RIBA Library Photographs Collection

ALISON Y PETER SMITHSON

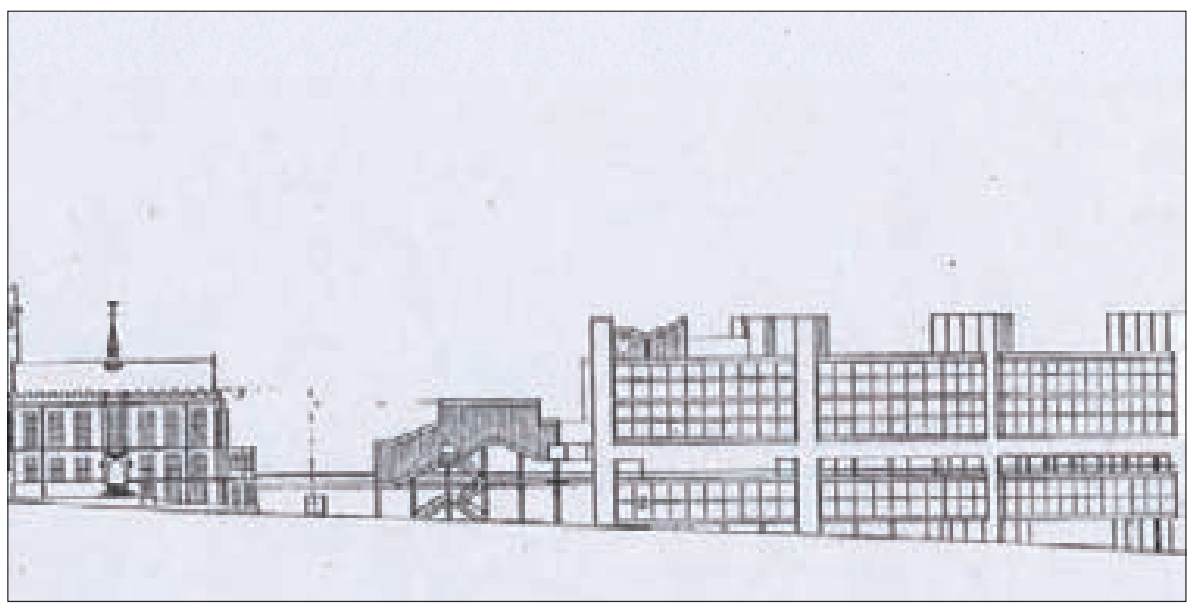

PLANO DE CONCURSO. ALZADO GENERAL A WESTERN BANK (53 01), DETALLE FACILITADO POR MARCO VIDOTTO (Mediados años 90) 


\title{
8.4. Secciones comparativas
}

\author{
UNIVERSIDAD DE SHEFFIELD \\ SKINNER, BAYLEY y LUBETKIN
}

SECCION LONGITUDINAL

\section{COMPARACION ENTRE SALAS DE CONFERENCIAS}

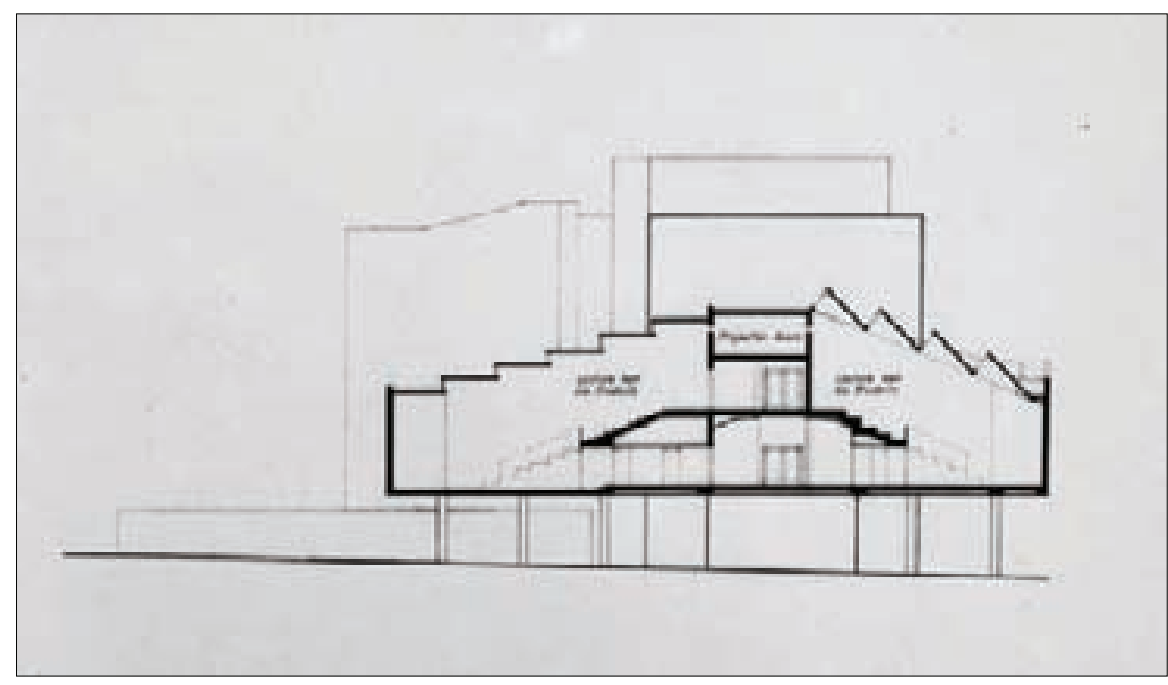

PLANO DE CONCURSO. SECCION POR SALAS DE CONFERENCIAS, PLANO No 8, DETALLE DOCUMENTACION FACILITADA POR JUSTINE SAMBROOK. RIBA Library Photographs Collection

ALISON Y PETER SMITHSON

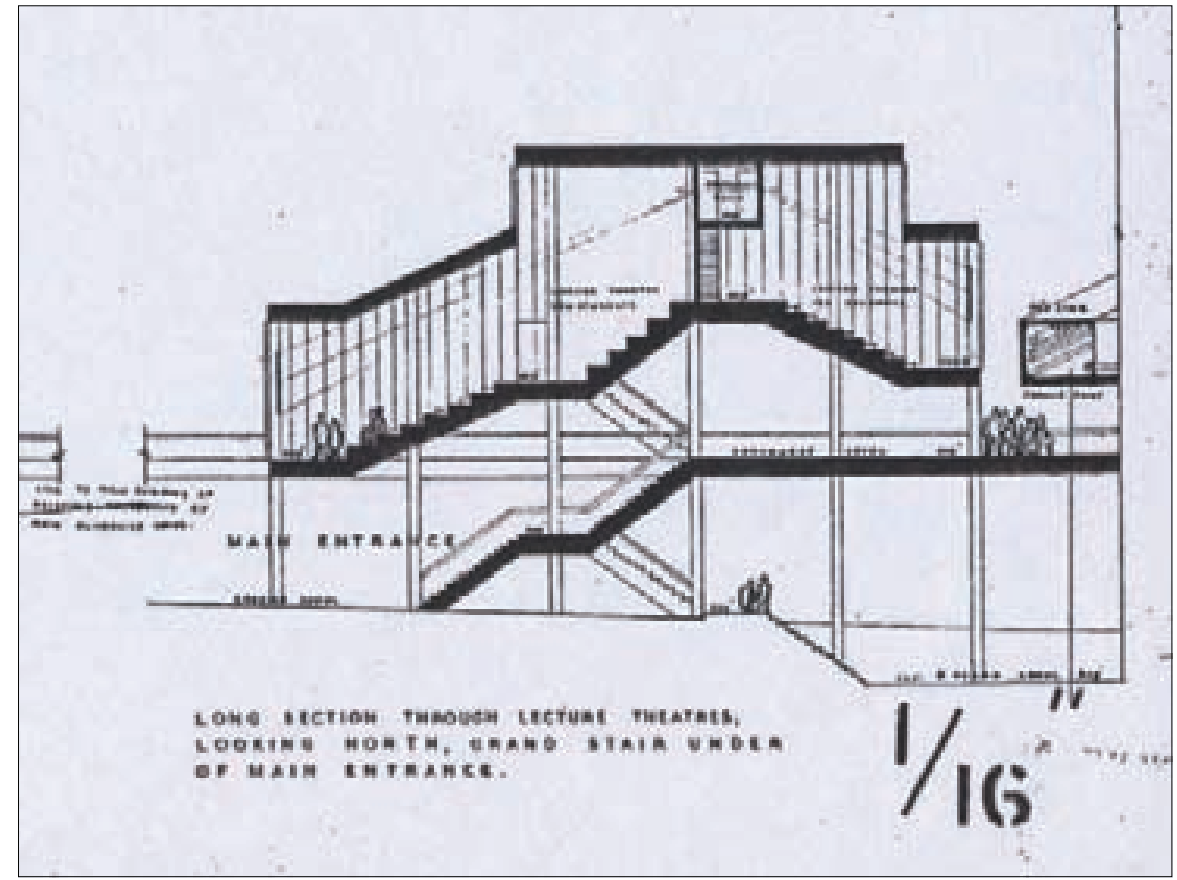

PLANO DE CONCURSO. SECCION LONGITUDINAL POR SALAS DE CONFERENCIA, (53 03), DETALLE FACILITADO POR MARCO VIDOTTO (Mediados años 90)

Obsérvese en ambos proyectos dos soluciones similares; $1^{0}$ : coincidencia de posición, es la pieza de conexión entre el Firth Court y el desarrollo del edificio de Administración y Artes. $2^{\circ}$ : la misma solución escultórica entre los planos escalonados o inclinados de la cubierta que acompañan la inclinación de los graderíos. 
9. Esquemas de distribución de pilares:

9.1. Sheffield

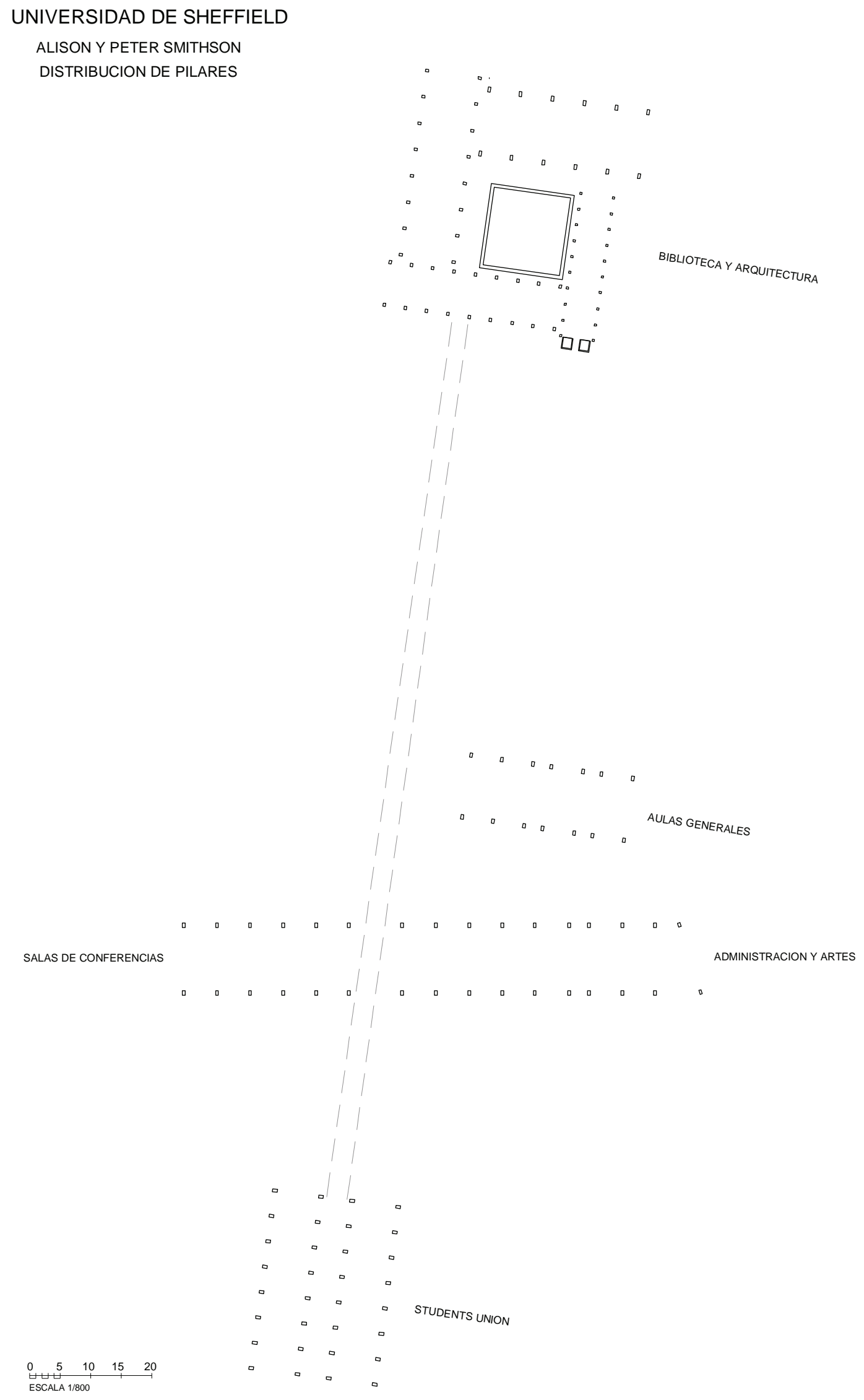


9.2. Escuela en Hunstanton

ESCUELA EN HUNSTANTON

ALISON Y PETER SMITHSON

DISTRIBUCION DE PILARES

MEDIDAS TOMADAS IN SITU POR EL AUTOR

\begin{tabular}{lllll}
0 & 5 & 10 & 15 & 20 \\
$\forall$ & \multicolumn{1}{l|l}{}
\end{tabular} 
9.3. Economist Building

ECONOMIST BUILDING

ALISON Y PETER SMITHSON
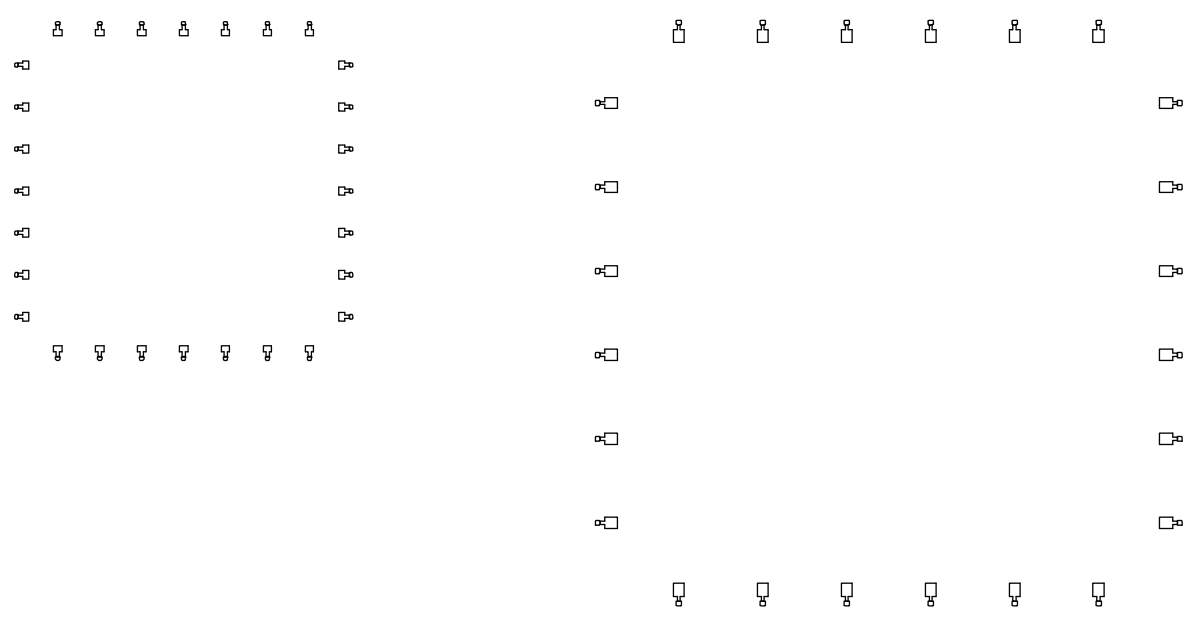

BUCION DE PILARES

MEDIDAS TOMADAS IN SITU POR EL AUTOR $10 \quad 15$

ESCALA 1/300

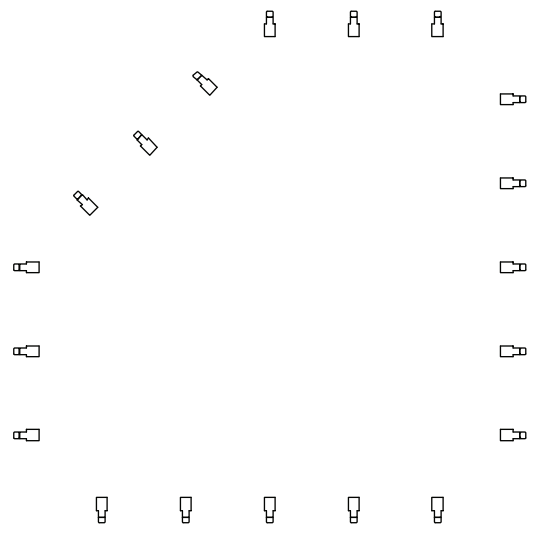


9.4. IIT. Ingeniería Química y Metalurgia. Mies van der Rohe

INGENIERIA QUIMICA Y METALURGICA I.I.T. (1945-6)

MIES van der ROHE 
10. Alzados Comparativos (dibujos del autor):

10.1. Sheffield, Hunstanton, IIT Ingeniería Química y Metlurgia y IIT Biblioteca y Administrción (Mies van der Rohe)

UNIVERSIDAD DE SHEFFIELD

ALISON Y PETER SMITHSON

TAMAÑOS COMPARATIVOS

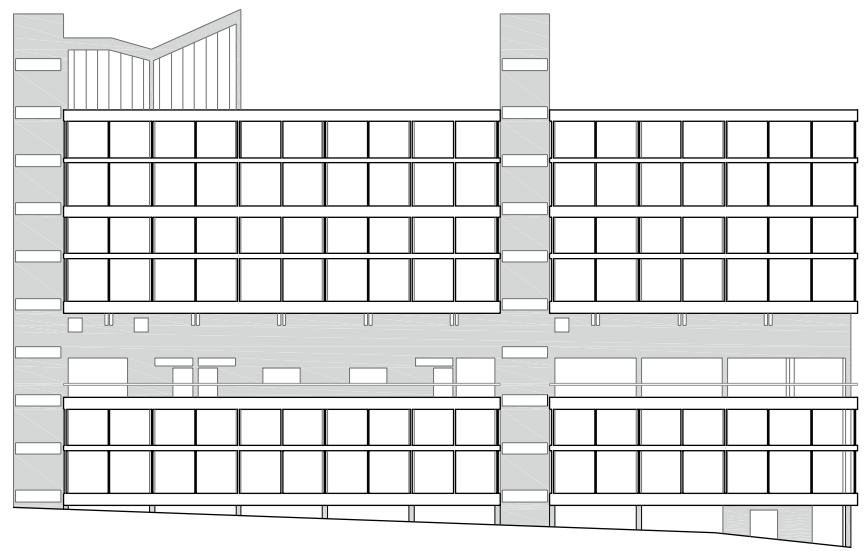

UNIVERSIDAD DE SHEFFIELD (1953). ALZADO A WESTERN BANK

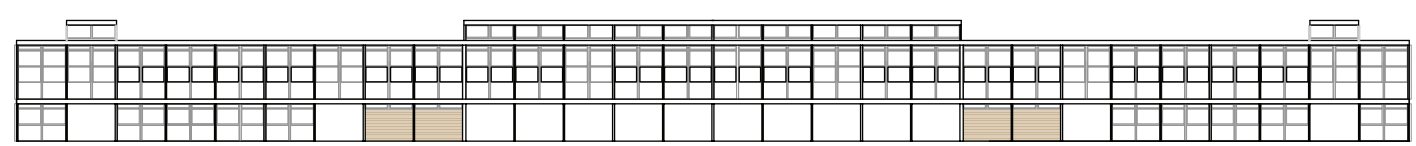

ESCUELA EN HUNSTANTON (1949-54). ALZADO A LA PRADERA

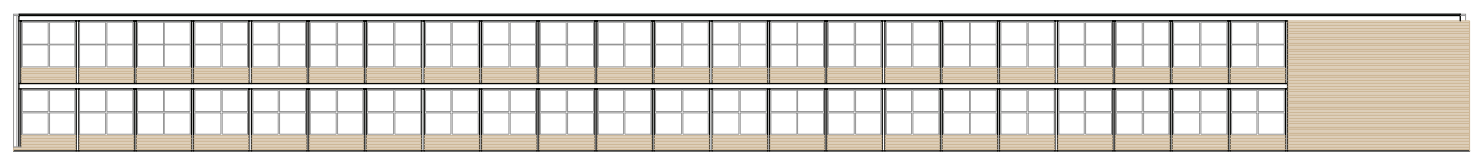

IIT. EDIFICIO DE INGENIERIA Y METALURGIA (1945-46). Mvd Rohe

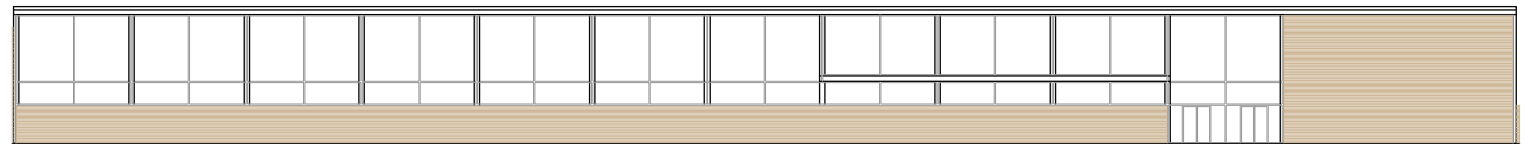

IIT. BIBLIOTECA Y ADMINISTRACION (1944-45). Mvd Rohe

$\stackrel{0}{\forall} \quad \begin{array}{llll}5 & 10 & 15 & 20\end{array}$

ESCALA $1 / 500$ 
10.2. Alzados parciales. Sheffield y Hunstanton

UNIVERSIDAD DE SHEFFIELD

ALISON Y PETER SMITHSON

ALZADOS PARCIALES SHEFFIELD Y HUNSTANTON

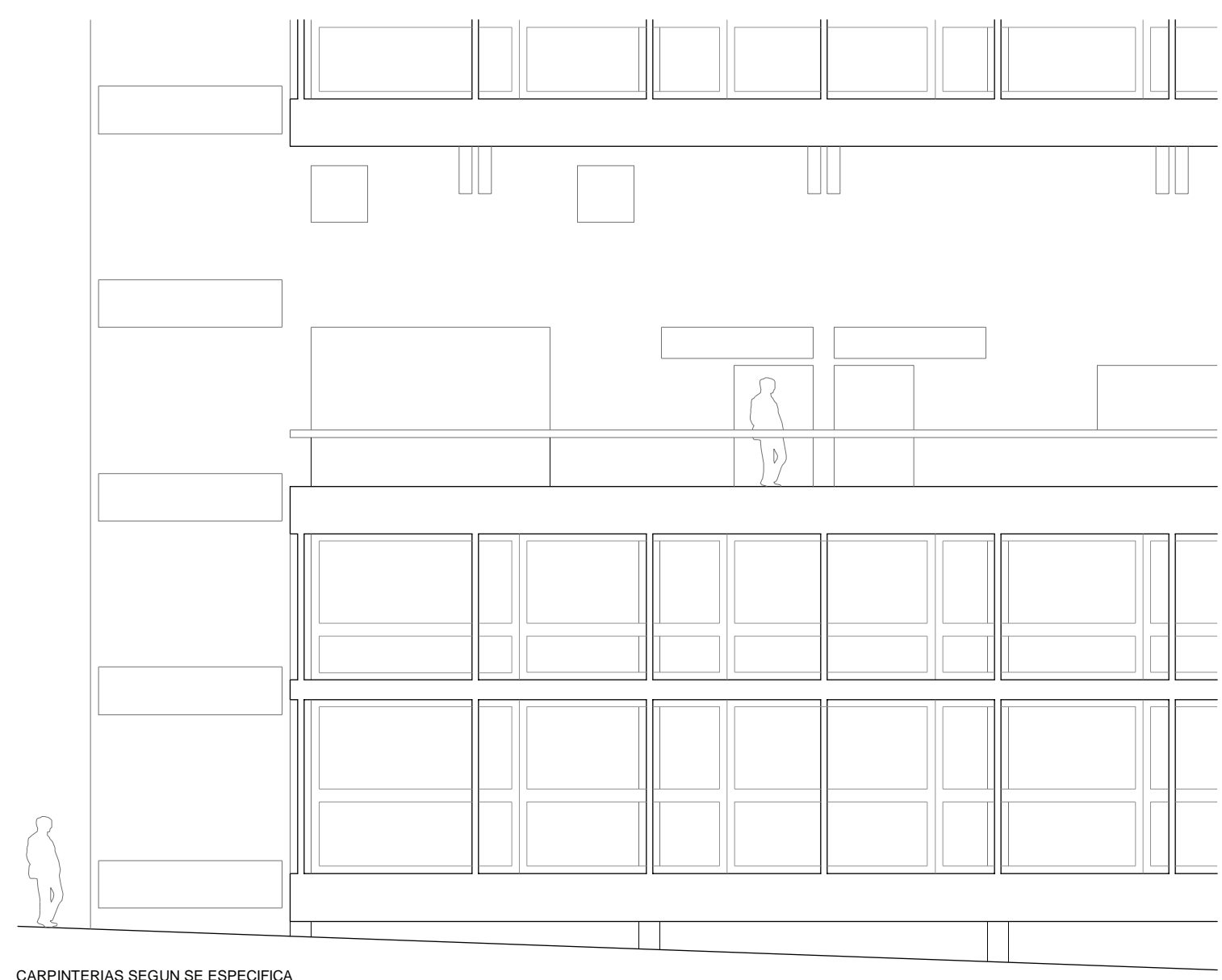

EN EL PLANO 53 08. ESCALA ORIGINAL1/8

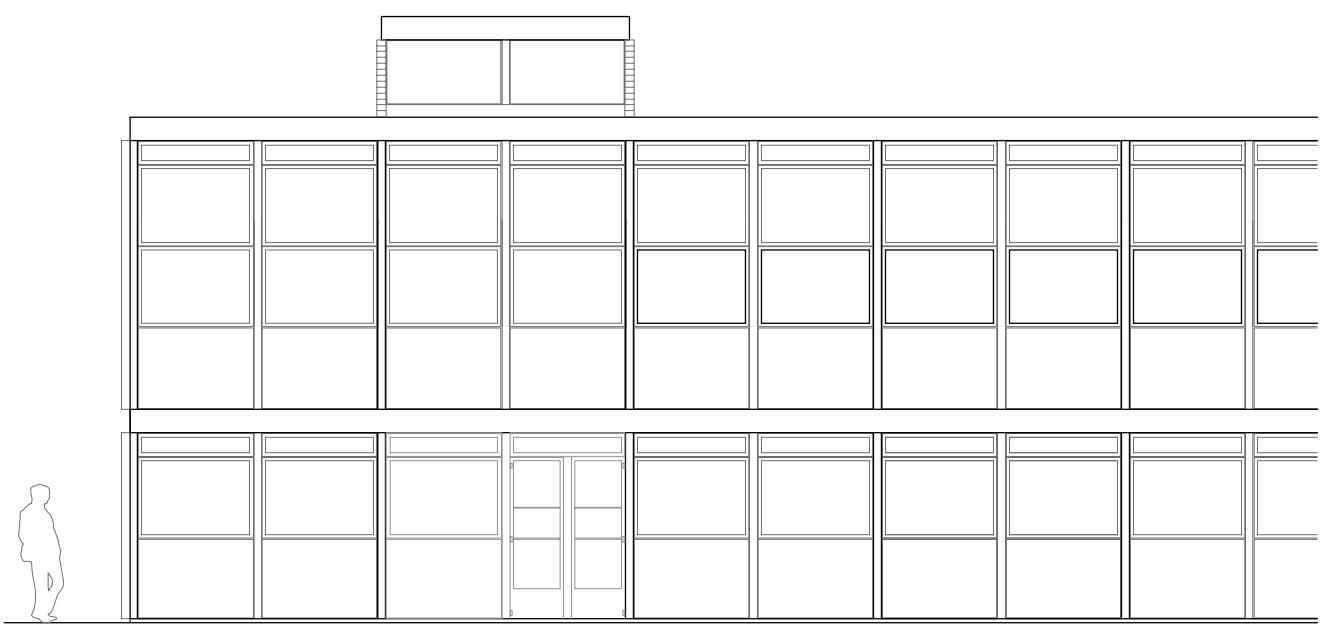

SEGUN MEDIDAS TOMADAS IN SITU

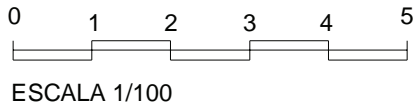


11. Plantas definitivas con la conexión al Firth Court

11.1. Planta General de Ordenación

UNIVERSIDAD DE SHEFFIELD

ALISON Y PETER SMITHSON

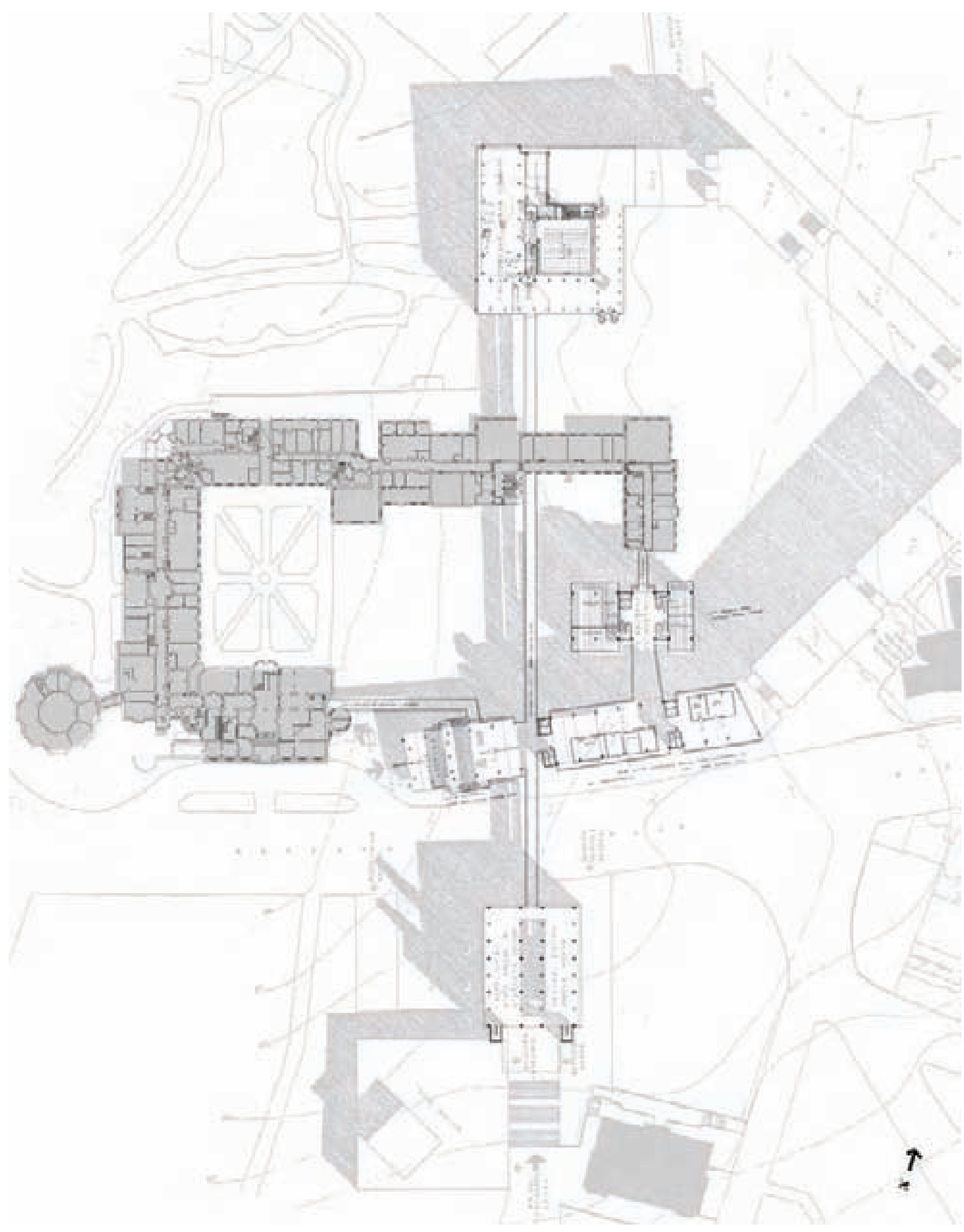

PLANO DEL FIRTH COURT CEDIDO POR LOS SERVICIOS TÉCNICOS DE LA UNIVERSIDAD DE SHEFFIELD

Montaje Pablo Cabrera en colaboración con el autor 
11.2. Planta con los edificios a concurso

UNIVERSIDAD DE SHEFFIELD

ALISON Y PETER SMITHSON

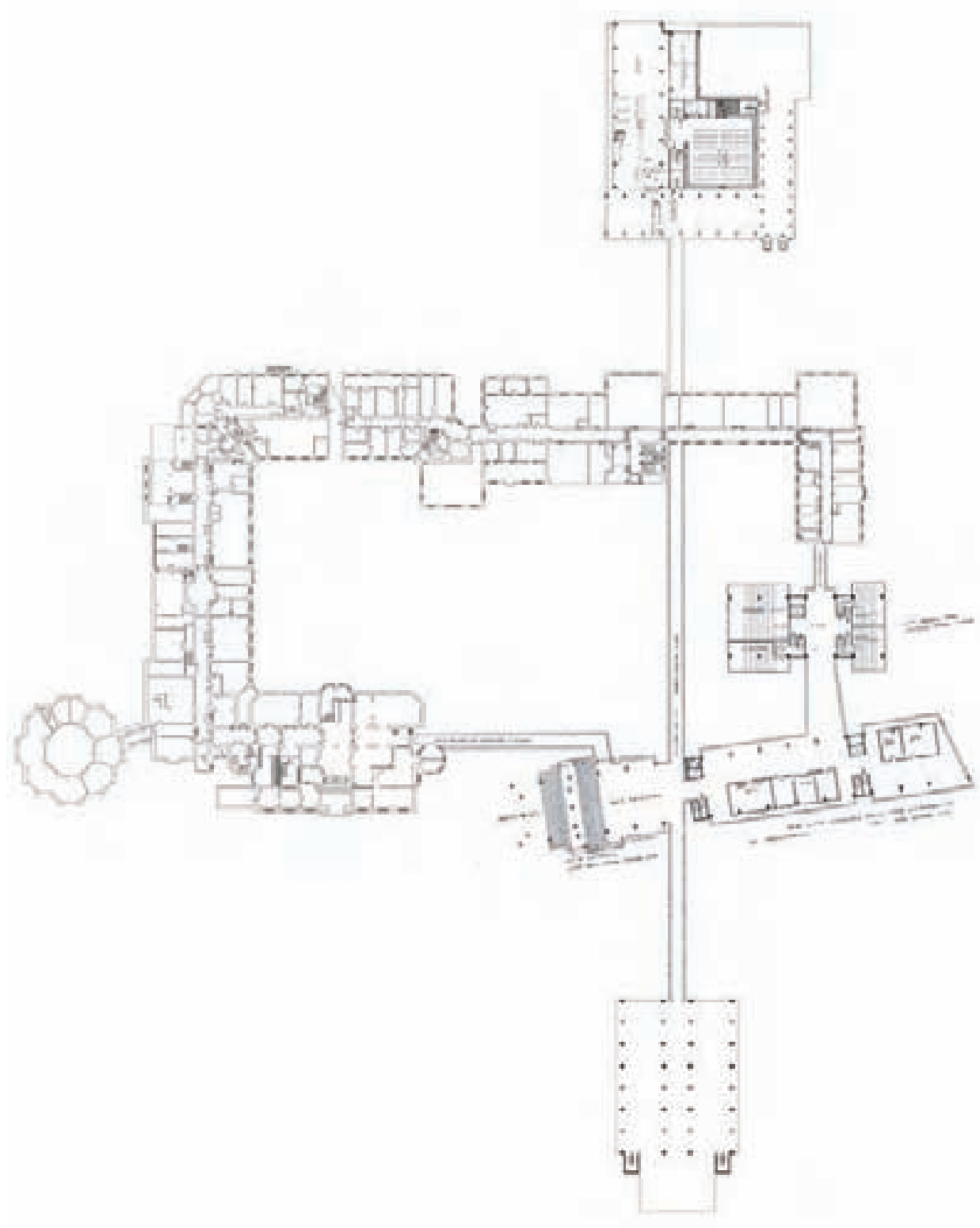

PLANO DEL FIRTH COURT CEDIDO POR LOS SERVICIOS TÉCNICOS DE LA UNIVERSIDAD DE SHEFFIELD Montaje Pablo Cabrera en colaboración con el autor 


\section{V.II. PITAGORISMO. ECONOMIST BUILDING}

1. Transformación del Economist en número figurado

TRANSFORMACION DEL ECONOMIST EN NUMERO FIGURADO

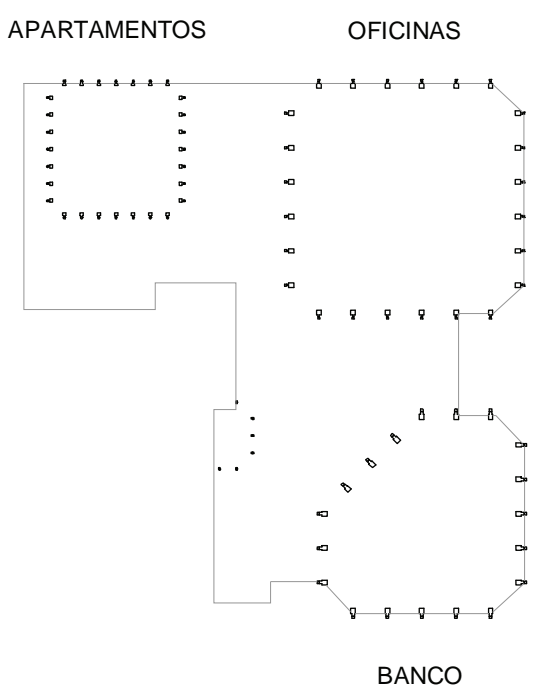

No FIGURADO 9X9

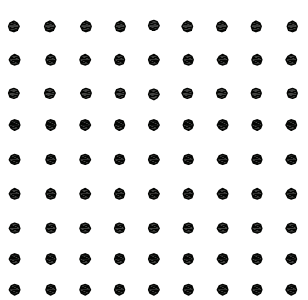

- $\bullet$

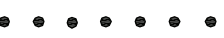

- $\bullet \bullet \bullet$

-

-

$\because \div$

No FIGURADO $7 \times 7$

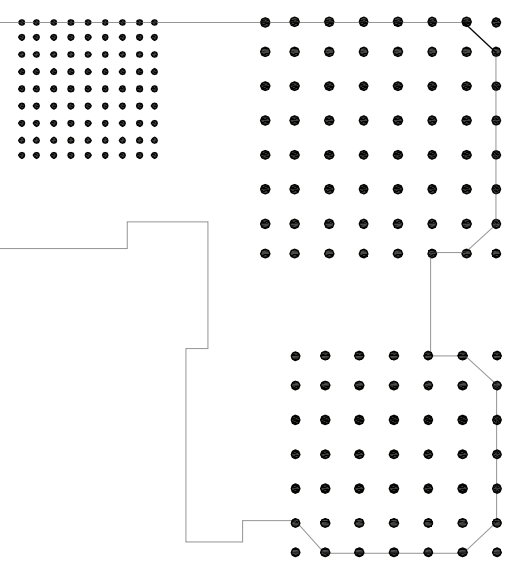

APLICACION DE LA SERIE DE CUADRADOS: $7 \times 7 / 8 \times 8 / 9 \times 9$

APLICACION GNOMÓN DEL 17

APLICACION GNOMÓN DEL 15
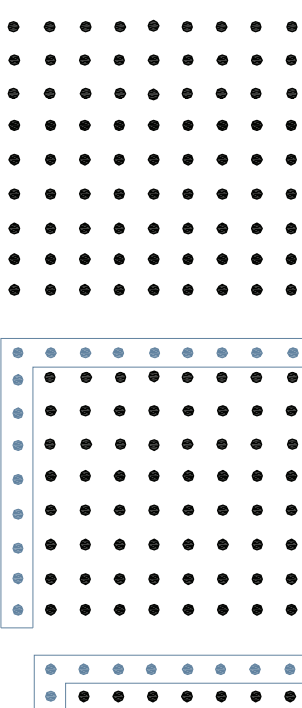

- .0

- .

- . . .

- . . .

-

- 
2. Aplicación de la figura del Banco al número figurado

APROXIMACION DE LA FIGURA DEL BANCO AL NUMERO CUADRADO

$1^{\text {a }}$ SOLUCION
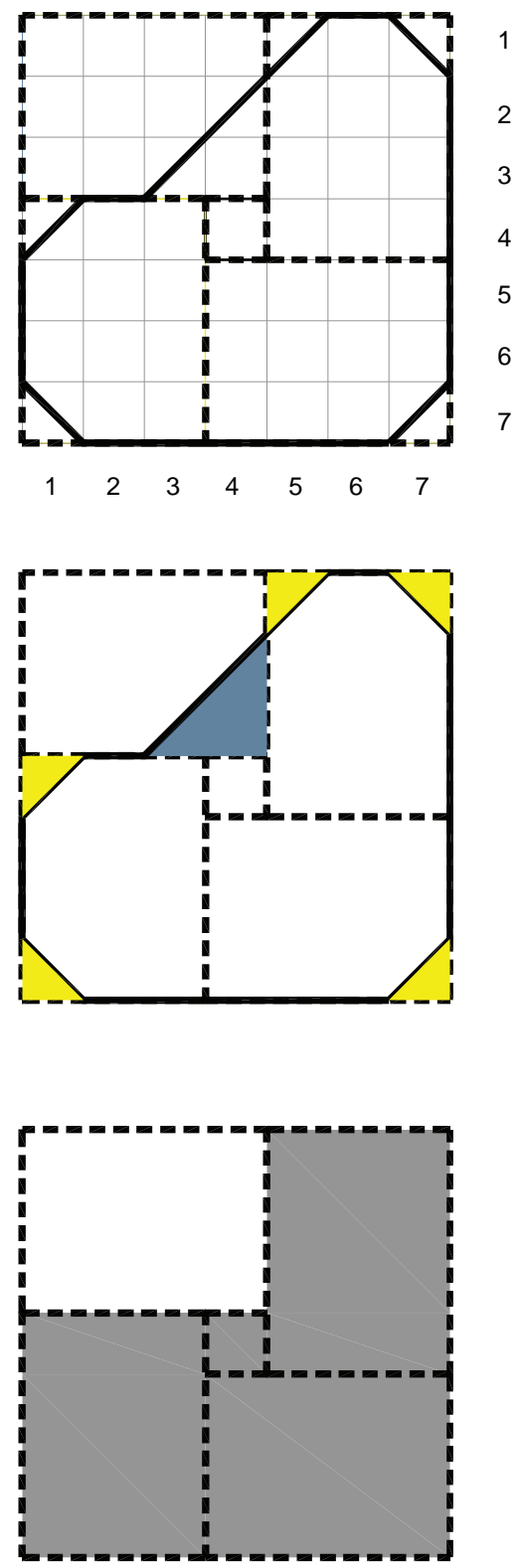

SOLUCION DEFINITIVA
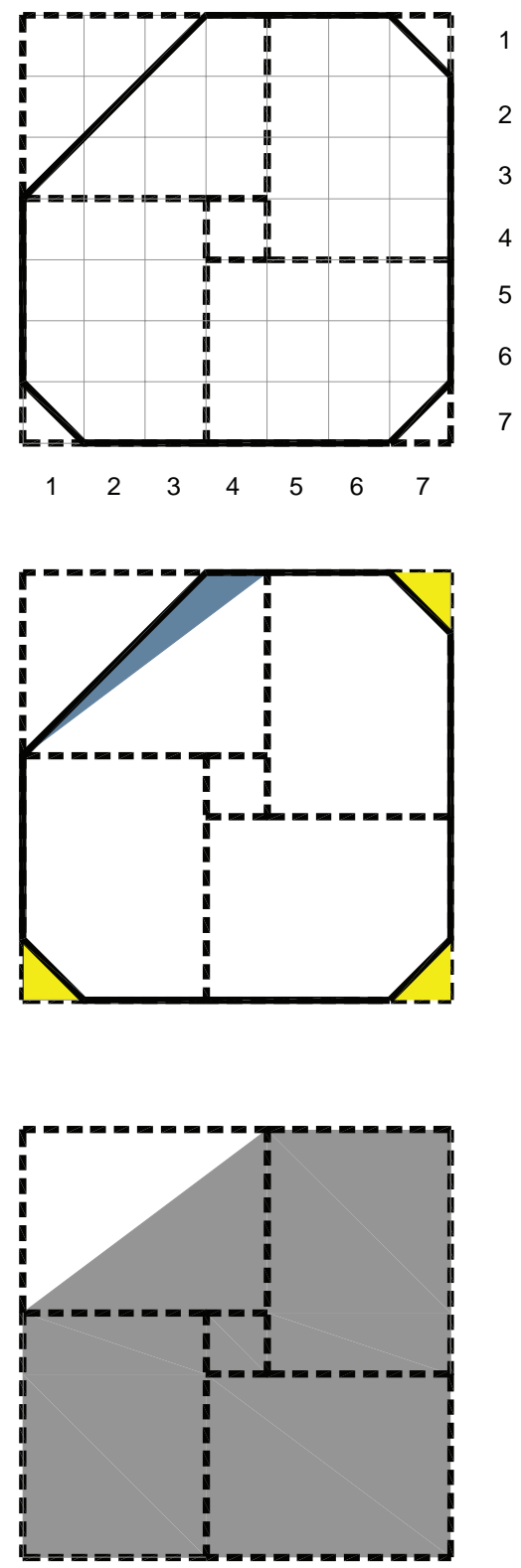

La aplicación de la figuración del cuadrdaro $7 \times 7$ a la figura deñ edificio bancario permite analizar el aprovechamineto de las dos soluciones presentadas. En la tabla de la izquierda aplicada a la solución inicial, se observa un desaprovechamineto de un rectángulo de $4 \times 3$ unidades. La solución definitiva, a la derecha, la perdida de espacio construido en planta es exactamente la mitad, un triángulo de $4 \times 3$ unidades.

Leyenda: en amarillo las perdidas de espacio debidas a los chaflanes. En azul el mismo área concentrada en una única superficie. 


\section{V.III. DESARGUES}

\section{Teorema de Desargues}

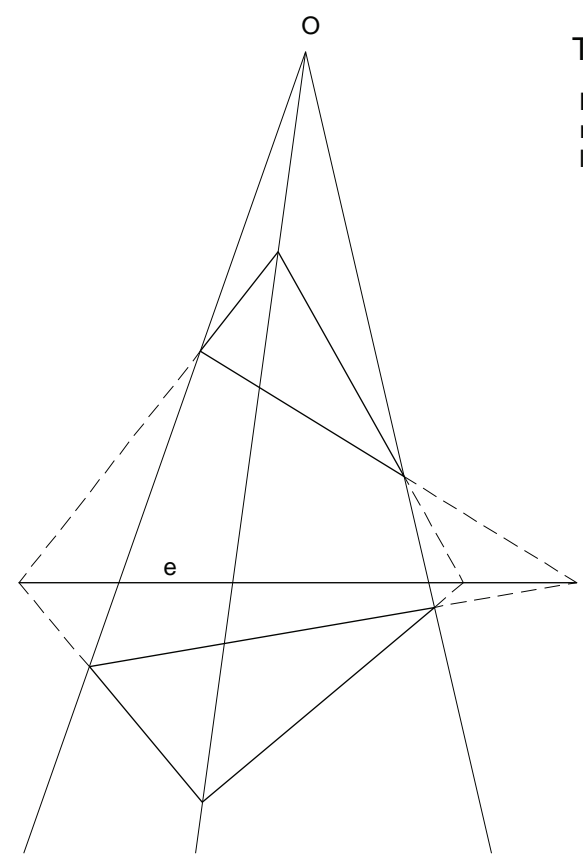

\section{TEOREMA DE DESARGUES}

Los triángulos están en pespectiva respecto a la recta e (serie doble), y lo están repecto del haz O (haz doble)

Dados 2 triángulos sin elementos comunes, si sus lados se cortan dos a dos en puntos alineados, las rectas que unen sus vértices

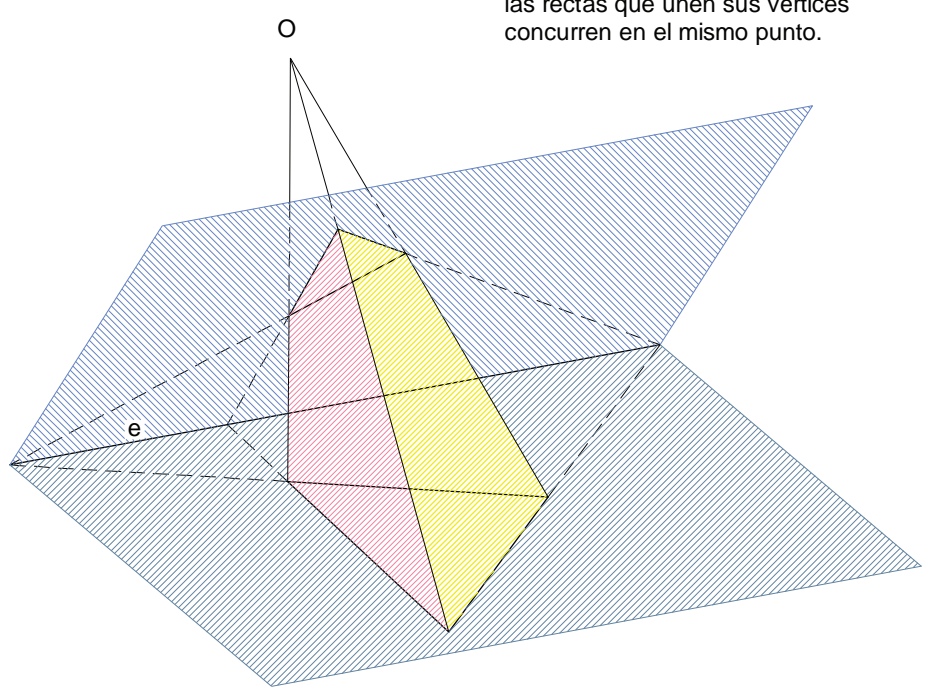

La razón armónica según el teorema de Desargues para hallar el punto $D$
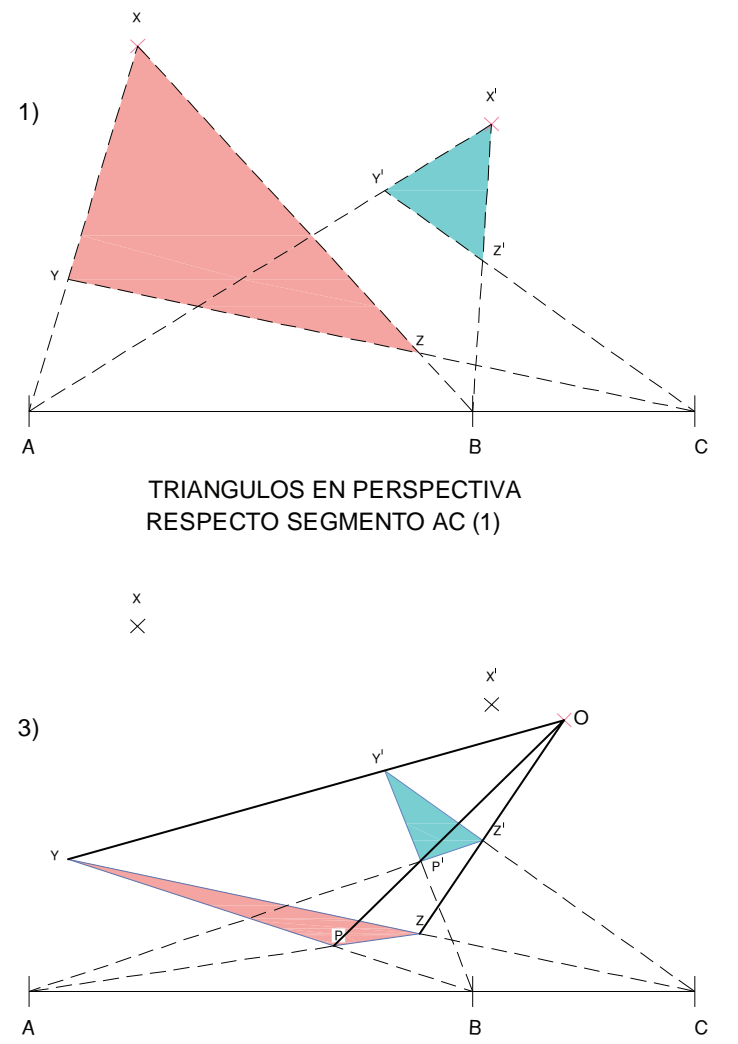

RAZÓN ARMONICA: 6; $8 ; 12$

La diferencia del media a un extremo se expresa por la misma relación que su diferencia co el otro extremo. $(a-b) /(b-c)=a / c:(12-8) /(8-6)=12 / 6$

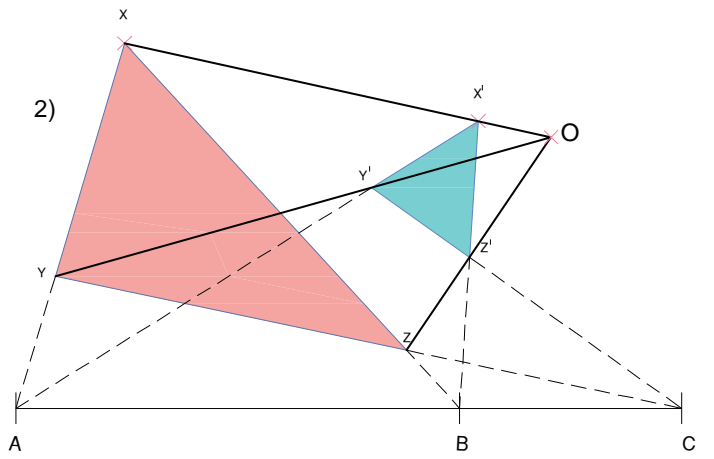

TRIANGULOS EN PERSPECTIVA RESPECTO PUNTO O (2, 3 y 4)

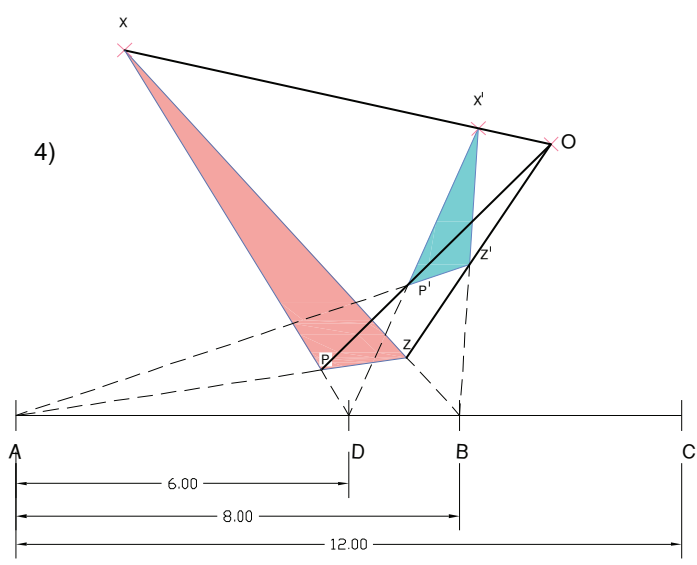




\section{V.IV. VAUBAN}

1. Nomenclatura de ángulos y líneas de un baluarte

\section{BALUARTE}

NOMENCLATURA DE ANGULOS Y LINEAS DE UN BALUARTE

SEBASTIAN FERNANDEZ DE MEDRANO

"EL ARCHITECTO PERFECTO EN EL ARTE MILITAR"
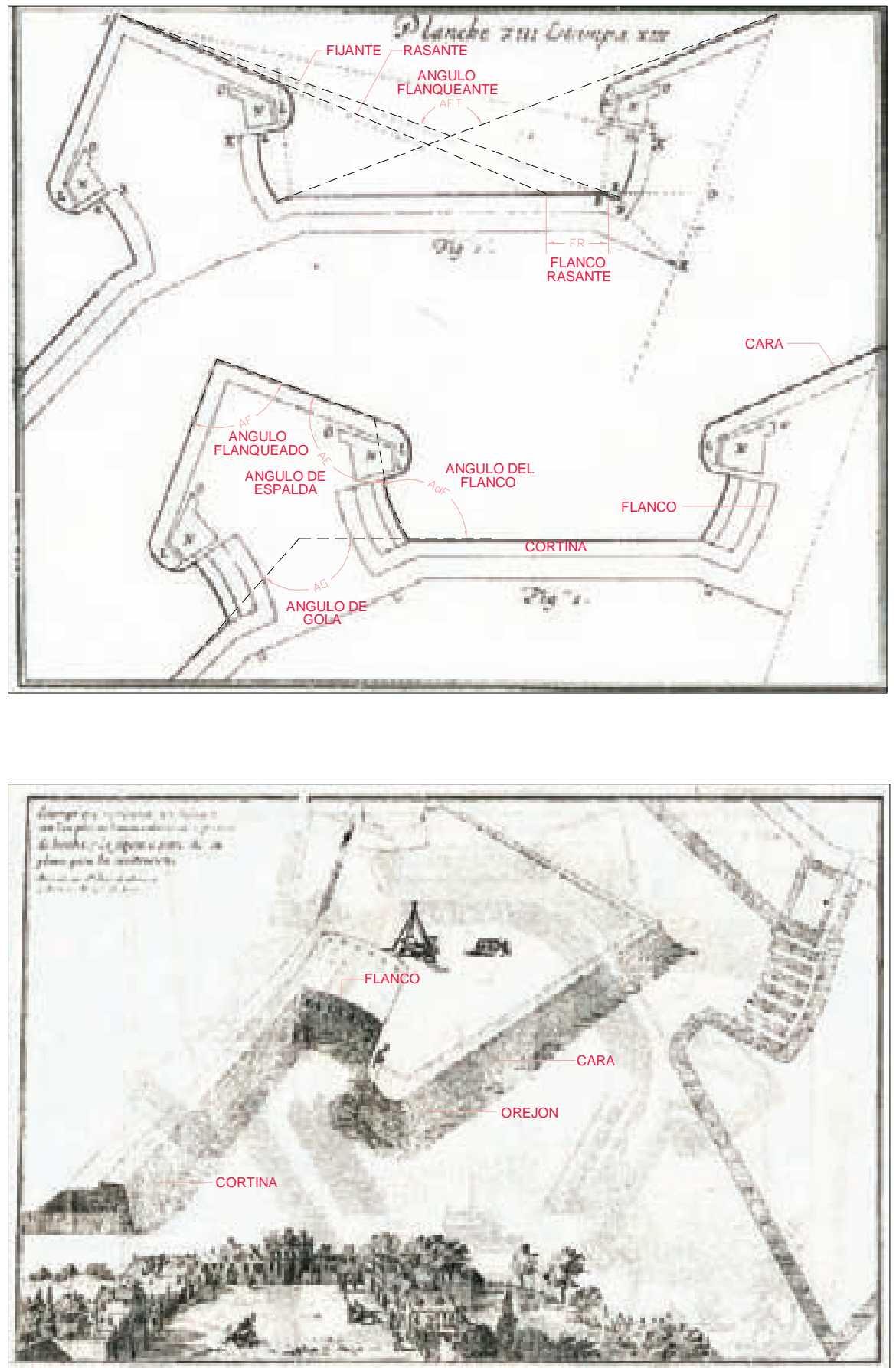


\section{LIBROS}

Abadie, Daniel Dubuffet as architect Éditions Hazan, Paris 2011

Althusser, Louis Maquiavelo y Nosotros Ed. Akal, Madrid 2004

Álvarez Martino, Eva El laberinto de la continuidad en G.W. Leibniz Biblioteca Nueva S.L., Madrid 2011

Banham, Reyner Brutalismus in der Architektur. Ethik oder Ästhetik? Karl Krämer Verlag, Stuttgart, 1966 (original en inglés The New Brutalism Ethic or Aesthetic Architectural Press, London 1966)

Benévolo, Leonardo La Captura del Infinito Celeste Ediciones, Madrid 1994

Bergson, Henri La Evolución Creadora Cactus, Buenos Aires 2007

Bergson, Henri Materia y Memoria. Ensayo sobre la relación del cuerpo con el espíritu Cactus, Buenos Aires 2006

Bergson, Henri Memoria y Vida. Textos escogidos por Gilles Deleuze. Alianza Editorial, S.A., Madrid 2004

Blundell Jones, Peter University of Sheffield School of Architecture BDR Publications The School of Architecture University of Sheffield, Sheffield, 2008

Borie, Alain, Micheloni, Pierre y Pinon, Pierre Forma y Deformación Editorial Reverté , S.A., Barcelona 2008

Borsi, Franco Bernini Architetto Electa, Milán 1980

Bourbaki, Nicolas Elementos de Historia de las Matemáticas Alianza Editorial S.A., Madrid 1976

Braunfels, Wolfgang, Urbanismo Occidental Alianza Editorial. Madrid 1983

Brunschvicg, Leon Las Edades de la Inteligencia Hachette, S.A. Argentina 
Brunschvicg, Leon Las Etapas de la Filosofía Matemática Lautaro Buenos Aires 1945

Bruschi, Arnaldo Bramante Editori Laterza Roma 1985

Camón Aznar, José La Idea del Tiempo en Bergson y el Impresionismo S. Aguirre, Impresor, Madrid 1956

Cañón Loyes, Camino La Matemática, creación y descubrimiento Publicaciones de la Universidad Pontificia Comillas, Madrid 1993

Carnap, Rudolf El Espacio (Der Raum) en Yates, Steve (ed.) Poéticas del espacio Editorial Gustavo Gili, S.A., Barcelona 2002

Carroll, Rutter Ryder and Yeats RIBA Publishing Londres 2009

Cassirer, Ersnt El Problema del Conocimiento Tomos I-IV, Fondo de Cultura Económica, México 1979

Cassirer, Ersnt Filosofía de las Formas Simbólicas Tomas I-III, Fondo de Cultura Económica, México 1976

Colomina, Beatriz Doble Exposición. Arquitectura a través del Arte Ediciones Akal S.A. Madrid 2006

Collins, Judith Eduardo Paolozzi Lund Humphries Farnham, Surrey 2014

Cornford, Francis Macdonald Platón y Parménides Visor Dis., S.A. Madrid 1989

Darwin, Charles El origen de las Especies Espasa Calpe, Madrid 1988

Darwin, Charles La Expresión de las emociones en los animales y en el hombre Alianza Editorial, S. A. Madrid 1984

Deleuze, Gilles El pliegue. Leibniz y el Barroco Ediciones Paidós Ibérica S.A., Barcelona 1989

Dhombres, Jean y Sakarovitch, Joel Desargues en son Temps Éditions Albert Blanchard Paris 1994

Echeverría Exponda, Javier La Intuición en Matemáticas. Las Figuras y el Lugar Tesis Doctoral Inédita, Facultad de Filosofía y Letras Sección Filosofía Pura, Abril 1975

Echeverría Ezponda, Javier Leibniz Barcanova, Barcelona 1981

Echeverría Ezponda, Javier La Geometría Leibniciana: de la Perspectiva al Analysis Situs Actas del III Congreso de la Sociedad Española de Historia de las Ciencias Editorial Guipuzcoana San Sebastián 1984

Echeverría Ezponda, Javier La Identidad de las Figuras Geométricas Teoría. Revista de Teoría, Historia y Fundamento de la Ciencia, Año I, Número I, San Sebastián 1985

Echeverría Ezponda, Javier Cálculos Geométricos en Leibniz Teoría. Revista de Teoría, Historia y Fundamento de la Ciencia, Año VI, Número 


\section{4-15, San Sebastián 1991}

Echeverría Ezponda, Javier Ciencia y valores Ediciones Destino, S.A. Barcelona 2002

El Vizconde de Güel Espacio, Relación y Posición. Ensayo sobre los Fundamentos de la Geometría Edición Calpe, Madrid 1924

Euclides Elementos Libros I-IV Editorial Gredos, S.A., Madrid 1991

Ferreirós Domínguez, José Bernhard Riemann. Riemannana Selecta Consejo Superior de Investigaciones Científicas, Madrid, 2000

Frege, Gottlob Ensayos de Semántica y Filosofía de la Lógica Luis M. Valdés Villanueva (ed.) Editorial Tecnos S.A., Madrid, 2013

Freudenthal, Hans Las Matemáticas en la vida cotidiana Ediciones Guadarrama S.A. Madrid 1967

Freudenthal, Hans Leibniz und die Analysis Situs Separata facticia del Homenaje a Millás-Vallicrosa. Tomo I. Barcelona 1954

Galileo Galilei Diálogo sobre los dos máximos sistemas del mundo Ptolemaico y Copernicano Edición a cargo de Antonio Beltrán Marí, Alianza Editorial Madrid 1994

Giedion, Sigfried Espacio, Tiempo y Arquitectura, Editorial Dossat, S.A., Madrid 1982

Granon-Lafont, Jeanne La Topología Básica de Jacques Lacan Ediciones Nueva Visión Buenos Aires, Edición 3a 1999

Gruen, Victor The Heart of our Cities: diagnosis and cure Thames and Hudson, London, 1965

Gutierrez Ramón y Esteras, Cristina Territorio y Fortificación. Vauban, Fernández de Medrano, Ignacio Sala y Félix Prósperi Influencia en España y América Ediciones Tuero, S.A., Madrid 1991

Harman, Ruth y Minnis, John Pevsner Architectural Guides. Sheffield Yale University Press, London, 2004

Hocquenhem, Guy y Schérer, René El Alma Atómica. Para una estética de la era nuclear Editorial Gedisa Barcelona 1987

Jaeger, Werner Paideia Fondo de Cultura Económica España S.A. Madrid 1982

Jacobus, John Twentieth-Century Architecture.The Middle Years 194065 Frederick A. Praeger, Publishers, New York, 1966

Jencks, Charles Movimientos Modernos en Arquitectura Hermann Blume Ediciones, Madrid, 1983

Gyorgy Kepes La Structure dans les Arts et dans les Sciences Editions de la Connaissance, S.A., Bruxelles, 1967

Kline, Morris El Pensamiento matemático de la Antigüedad a nuestros días Volúmenes I, II y III Alianza Editorial 1992 
Koyré, Alexandre Del Mundo Cerrado al Universo Infinito Siglo XXI de España Editores, S.A. Madrid 1979

Le Corbusier Hacia una arquitectura Ediciones Apóstrofe Barcelona 1998

Lefebvre, Henri La Revolución Urbana Alianza Editorial S.A. Madrid 1983

Leibniz, Gottfried Wilhelm Filosofía para Princesas Alianza Editorial, Madrid 1989

Leibniz, Gottfried Wilhelm Monadología. Principios de Filosofía. Edición de Julián Velarde Editorial Biblioteca Nueva S.L. Madrid 2012

Leibniz, Gottfried Wilhelm Nuevos Ensayos sobre el Entendimiento Humano Alianza Editorial, S.A. Madrid 1992

León Tello, Francisco José y Sanz Sanz, Ma Virginia Estética y Teoría de la Arquitectura en los Tratados Españoles del Siglo XVIII Consejo Superior de Investigaciones Científicas, Madrid 1994

Lotz, Wolfgang La Arquitectura del Renacimiento en Italia Hermann Blume, Madrid 1985

Martin, Thierry y Virol Michèle Vauban, Architecte de la Modernité? Presses Universitaires de France-Comté, Paris 2008

Mathers, Helen Steel City Scholars. The Centenary History of the University of Sheffield James \& James (Publishers) Ltd, London, 2005

Miller, Arthur I. Einstein y Picasso Tusquets Editores, Barcelona 2007

Nazzaro, Barbara y Villa, Guglielmo Francesco Di Giorgio Martíni. Roche, Città, Paesaggi Edizioni Kappa, Roma 2004

Newman, Oscar CIAM'59 in Otterlo Karl Krämer Verlag Stuttgart 1961

Ortega y Gasset, José La Idea de Principio en Leibniz Alianza Editorial, S.A. Madrid 1992

Ortega y Gasset, José Meditación de la Técnica y otros Ensayos sobre Ciencia y Filosofía Alianza Editorial, S.A. Madrid 2004

Panofsky, Erwin La Perspectiva como Forma Simbólica Tusquets Editores, Barcelona 1980

Pérez-Gómez, Alberto L'Architecture et la Crise de la Science Moderne Pierre Mardaga, éditeur, Bruselas 1987

Pérouse de Montclos, Jean Marie L'Architecture a la Française. XVI, XVII, XVIII Siècles Picard, Paris 1982

Rada, Eloy La Polémica Leibniz - Clarke Taurus Ediciones, Madrid 1980

Read, Herbert Wonder and Horror of the Human Head Lund Humphries, Londres 1953 
Rey, Abel La Juventud de la Ciencia Griega Unión Tipográfica Editorial Hispano-Americana, México D.F., 1961

Rey Pastor, Julio y Babini, José, Historia de la Matemática. De la Antigüedad a la Baja Edad Media Gedisa Editorial, Barcelona 2000

Rey Pastor, Julio y Babini, José, Historia de la Matemática. Del Renacimiento a la Actualidad Gedisa Editorial, Barcelona 2000

Robertson, Donald Struan Arquitectura Griega y Romana Ediciones Cátedra, Madrid 1981

Rowe, Colin Manierismo y Arquitectura Moderna y Otros Ensayos Editorial Gustavo Gili, S.A., Barcelona 1999

Russell, Bertrand Breve Historia de la Metageometría Ediciones de la Biblioteca, Universidad Central de Venezuela, Caracas, 1982

Russell, Bertrand Exposición Crítica de la Filosofía de Leibniz Ediciones Siglo Veinte, Buenos Aires 1977

Santaló, L.A. Geometrías no Euclidianas Editorial Universitaria de Buenos Aires, Buenos Aires 1963

Scalbert, Irénée Architecture is not made with the Brain: The Smithsons and the Economist Building Architectural Association 2005

Schneider, Tatjana This Building should have some Sort of Distinctive Shape. The Story of The Arts Tower in Sheffield

PAR -Praxis for Architectural Research-, Sheffield, 2008

Smithson, Alison y Smithson, Peter Urban Structuring Studio Vista Ltd Londres 1967

Smithson, Alison y Smithson, Peter Ordinariness and Light. Urban theories 1952-60, and their application in a building project 1963-70 The M.I.T Press Cambridge, Massachusetts, 1970

Smithson, Alison y Smithson, Peter Without Rhetoric. An Architectural Aesthetic 1955-1972 The M.I.T. Press Cambridge 1974

Smithson, Alison y Smithson, Peter Due Progetti Cooperativa Libraria Editrice Architettura, Roma 1979

Smithson, Alison y Smithson, The Charged Void: Architecture The Monacelli Press, Inc., New York, 2001

Smithson, Alison y Smithson, Peter The Charged Void: Urbanism The Monacelli Press, Inc., New York, 2005

Smithson, Alison y Smithson, Peter Italienische Gedanken, weitergedacht Birkhäuser, Basilea 2001

Stein, Clarence Toward New Towns for America The University Press of Liverpool, Liverpool, 1951

Stirling, James "The Black Notebook" en Mark Crinson (ed.)

James Stirling. Early Unpublished Writings on Architecture, Routledge, 
Stonehouse, Roger Colin St John Wilson: buildings and projects

Black Dog Publishing, London, 2007

Tapié, Michel Un Art Autre Gabriel Giraud et Fils, Paris 1952

Teresa, Enrique de Tránsitos de la Forma: Presencia de Le Corbusier en la Obra de Stirling y Siza Fundación Caja de Arquitectos, Madrid 2007

Tezanos Tortajada, José Félix La explicación sociológica: una Introducción a la Sociología UNED, Madrid 2009

Thom, René Estabilidad estructural y Morfogénesis Editorial Gedisa S.A. Barcelona 2008

Thompson, D'Arcy Sobre el Crecimiento y la Forma Cambridge University Press, Madrid 2003

Tucker, Albert y Bayley, Herbert, Topología en AA.VV. Matemáticas en el Mundo Moderno, Editorial Blume, Madrid 1974

Unwin, Raymond La Práctica del Urbanismo: una introducción al arte de proyectar ciudades y barrios Editorial Gustavo Gili, S.A., Barcelona, 1984

Van den Heuvel, Dirk Alison and Peter Smithson A Brutalist Story Engels 2013

Van den Heuvel, Dirk y Risselada, Max De la Casa del Futuro a la Casa de Hoy COAC/Ediciones Polígrafa, Barcelona 2007

Vicens, Francesc Prolégomênes á une Esthétique Autre de Michel Tapié Centre International de Recherches Esthétiques, Barcelona 1960

Vidler, Anthony Historias del Presente Inmediato. La Invención del Movimiento Moderno arquitectónico Editorial Gustavo Gili, S.A. Barcelona 2011

Vidotto, Marco A+P Smithson. Pensieri, progetti e frammenti fino al 1990 Sagep Editrice, Genova, 1991

Warmoes, Isabelle y Sanger, Victoria Vauban, bâtisseur du Roi-Soleil Somogy éditions d'art, Paris 2007

Wiebenson, Dora Los Tratados de Arquitectura: de Alberti a Ledoux Hermann Blume, Madrid 1988

Wittkower, Rudolf Los Fundamentos de la Arquitectura en la Edad del Humanismo Alianza Editorial, S.A., Madrid 1995

Wittkower, Rudolf Sobre la Arquitectura en la Edad del Humanismo. Ensayos y Escritos Editorial Gustavo Gili, S.A. Barcelona 1979

Zubiri, Xavier Cinco lecciones de Filosofía Alianza Editorial, S.A., Madrid 2002 


\section{REVISTAS}

INFORMACION SOBRE EL CONCURSO DE LA UNIVERSIDAD DE SHEFFIELD

THE ARCHITECT and Building News 19 de Febrero 1953 THE ARCHITECT and Building News 23 de Abril 1953 THE ARCHITECT and Building News 26 de Noviembre 1953 THE ARCHITECTS'JOURNAL 26 de Noviembre 1953 THE BUILDER 27 de Noviembre 1953

THE ARCHITECT and Building News 3 de Diciembre 1953

\section{EN GENERAL}

L'ARCHITECTURE D'AUJOURD'HUI, Diciembre 1954

ARCHITECTURAL REVIEW, Octubre 1961

THE ARCHITECTURAL FORUM, Enero 1962

THE ARCHITECTS'JOURNAL INFORMATION LIBRARY, 16

Diciembre 1964

BAUMEISTER Septiembre 1965

ARCHITECTURAL REVIEW, Abril 1970

NÚMEROS MONOGRÁFICOS

CUADERNOS SUMMA-NUEVA VISION, Noviembre 1968 CUADERNOS SUMMA-NUEVA VISION, Mayo 1969 OASE № 51

\section{ARTÍCULOS}

Alloway, Lawrence This is Tomorrow. An exhibition at the Witechapel Gallery ARCHITECTURAL DESIGN, Septiembre 1956

Banham, Reyner Parallel of Life and Art THE ARCHITECTURAL REVIEW, Octubre 1953

Banham, Reyner The New Brutalism THE ARCHITECTURAL REVIEW, Diciembre 1955

Banham, Reyner This is Tomorrow Exhibitions THE ARCHITECTURAL REVIEW, Septiembre 1956

Banham, Reyner Balance 1961 R.N..ARQUITECTURA 1961

Bloomfield, Julia A Bibliography of Alison and Peter Smithson OPPOSITIONS № 2, Enero1974

Borchers, Juan La Medición como Substrato del Fenómeno Arquitectural Hogar y Arquitectura, Marzo-Abril 1970

Butler, A.S.G. Book Review Architectural Principles in the age of Humanism RIBA JOURNAL, Diciembre 1951

Casino, David Estrategias de enraizamiento en Alison y Peter Smithson REVISTA EUROPEA DE INVESTIGACIÓN EN ARQUITECTURA, nำ2, 2013

Carolin, Peter y Smithson, Peter Reflections on Hunstanton ARQ ARCHITCTURAL RESEARCH QUARTERLY, no 32, 1997 
Carolin, Peter John Voelcker: Team 10 founder member: a view from the practice ARQ ARCHITCTURAL RESEARCH QUARTERLY, n ㄴ, 2012

Colomina, Beatriz Couplings OASE № 51

Crosby, Theo This is Tomorrow ARCHITECTURAL DESIGN, Octubre 1956

Crosby, Theo Thoughts in progress ARCHITECTURAL DESIGN, Abril 1957 Frank, Suzanne John Voelcker: redefining his place in Team 10 and post-war British architectural culture ARQ ARCHITCTURAL RESEARCH QUARTERLY, no 1, 2012

Gruen, Victor Mammoth Shopping Center ARCHITECTURAL FORUM, Julio 1950

Gruen, Victor Suburban Retail Districts ARCHITECTURAL FORUM, Agosto 1950

Herrero, Esteban La fase exenta de medida REVISTA EUROPEA DE INVESTIGACIÓN EN ARQUITECTURA, nำ, 2015

Jeremy Baker A Smithson File THE ARCHIECTURAL ASSOCIATION JOURNAL. ARENA, Febrero 1966

Lynn, Greg La Forma Animada QUADERNS D'ARQUITECTURA I URBANISME no 2191998

Llewelyn Davies, Richard Endless Architecture ARCHITECTURAL ASSOCIATION JOURNAL, Noviembre1951

Melville, Robert, This is Tomorrow Exhibitions THE ARCHITECTURAL REVIEW. Noviembre 1956

Olitsky, Ruth y Voelcker John Form and Mathematics ARCHITECTURAL DESIGN, Octubre 1954

Pevsner, Nikolaus y Brett, Lionel, Universities THE ARCHITECTURAL REVIEW, Octubre 1957

Scott, Kenneth House in Soho THE ARCHITECTURAL REVIEW, Abril 1954

Smithson, Alison y Smithson, Peter Correspondence Architectural Principles in the age of Humanism RIBA JOURNAL, Febrero 1952

Smithson, Alison y Smithson, House in Soho, London ARCHITECTURAL DESIGN, Diciembre 1953

Smithson, Alison y Smithson, Peter The New Brutalism (statement) THE ARCHITECTURAL REVIEW, Abril 1954

Smithson, Alison y Smithson, Peter The New Brutalism ARCHITECTURAL DESIGN, Enero 1955

Smithson, Alison y Smithson, Peter The built World: Urban Reidentification ARCHITECTURAL DESIGN, Junio 1955

Smithson, Alison y Smithson, Peter An Alternative to the Garden City Idea ARCHITECTURAL DESIGN, Julio 1956 
Smithson, Alison y Smithson, Peter New Brutalism, answer the criticism on the opposite page ARCHITECTURAL DESIGN, Abril 1957

Smithson, Alison y Smithson, Peter The Aesthetics of Change

Trevor Dannat (ed.) Architects' Year Book no 8, Elek Books Limited, London, 1957

Smithson, Alison y Smithson, Peter Cluster City. A New Shape for the Community THE ARCHITECTURAL REVIEW, Noviembre 1957

Smithson, Alison y Smithson, Peter Mobility: Road System ARCHITECTURAL DESIGN, Octubre 1958

Smithson, Alison y Smithson, Peter London Road Study ARCHITECTURAL DESIGN, Mayo 1960

Smithson Alison Ruminations on Foubders Court ARCHITECTURAL DESIGN, Agosto 1973

Smithson, Peter Three Generations ILA\&UDAnnual Repport1980-1981, 1981

Smithson, Peter Fortifications ILA\&UDAnnual Repport1998-1999, 1999

Stalder, Laurent New Brutalism, Topology and Image: some remarks on the architectural debates in England around 1950 The Journal of Architecture Volumen 13, Número 3, 2008

Voelcker, John Correspondence Architectural Principles in the age of Humanism RIBA JOURNAL, Febrero 1952

Tentori, Francesco Phoenix Brutalism ZODIAC, Noviembre 1968

\section{MANUSCRITOS}

(Archivo Alison \& Peter Smithson, Loeb Library, Graduate School of Design, Harvard University)

Smithson, Alison y Smithson, Peter University of Sheffield: 1959 Extracts from the Original Report, 1953, 1959

Smithson, Alison y Smithson, Peter Aesthetics of Change: 1969 Extract from Ordinariness and Light, 1969

Smithson, Alison y Smithson, Peter Sheffield University 1953 Ilustrations to Text. Sketch as prepared for inclusion in Ordinariness and Light (sin fecha, 1978 o posterior)

Smithson, Alison y Smithson, Peter Sheffield University and Churchill College: 1953 and 1959, 14 de Febrero 1979 